\title{
EVOLUTION OF QUARTZ AND CALCITE MICROSTRUCTURES EXHUMED FROM DEEP BRITTLE- DUCTILE SHEAR ZONES IN THE SOUTHERN ALPS OF NEW ZEALAND
}

\author{
Matthew P. Hill
}

\author{
A thesis \\ submitted to the Victoria University of Wellington \\ in partial fulfilment of the requirements for \\ the degree of \\ Master of Science \\ in Geology
}

Victoria University of Wellington

2005 


\section{Frontispiece}

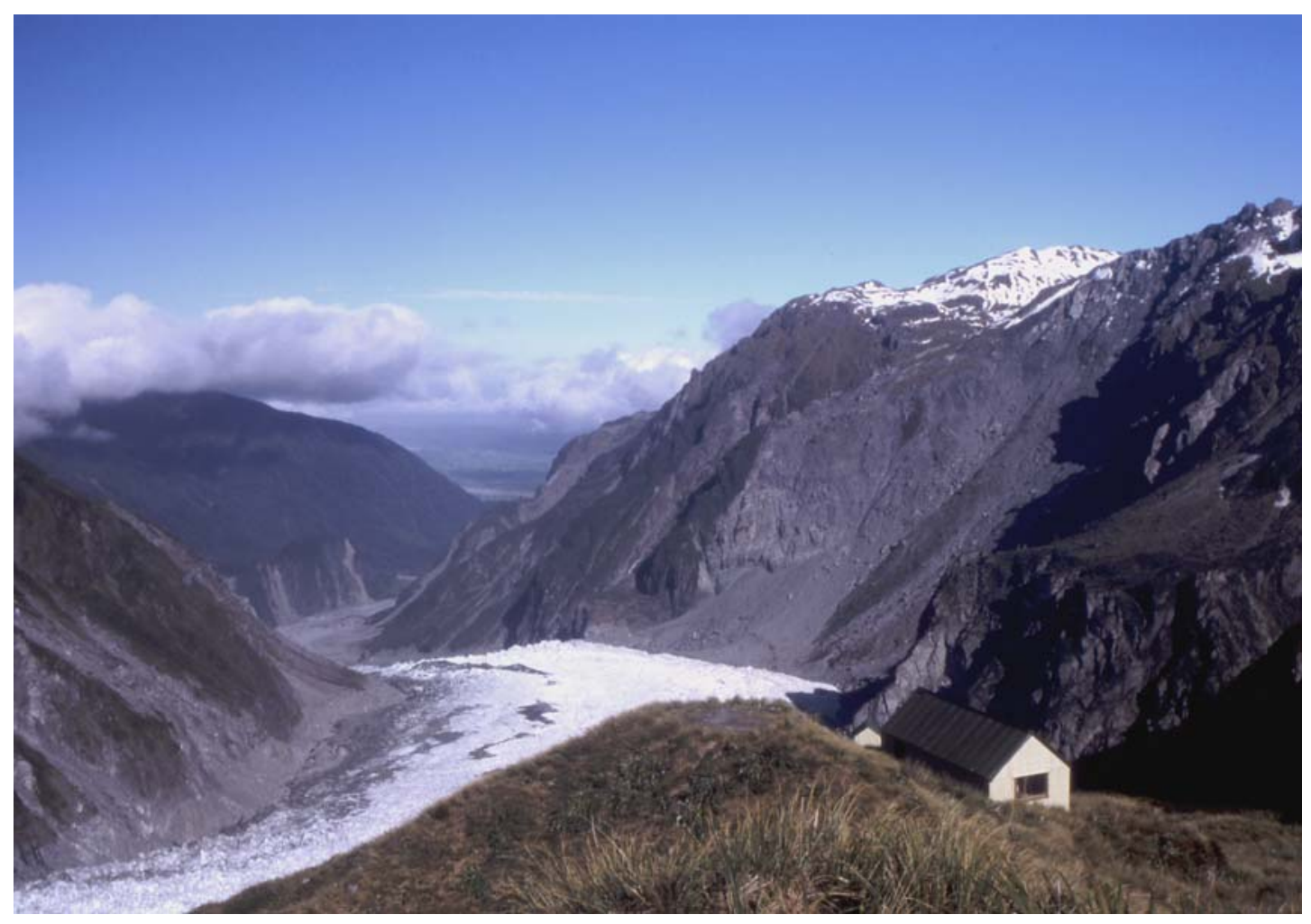

The historic Chancellor Hut and the Fox Glacier from Chancellor Ridge looking out towards the West Coast in the South Island of New Zealand. 


\section{Abstract}

Arrays of brittle-ductile shears exposed in the Southern Alps of New Zealand, have provided a superb natural laboratory for insight into the microstructural evolution of lower crustal shear zones during exhumation. Shears are exposed in the central section of the Southern Alps at Sam Peak, Chancellor Ridge, and Baumann Glacier in a zone $\sim 2 \mathrm{~km}$ wide that is located $6-8 \mathrm{~km}$ structurally above the Alpine Fault. An array of systematically spaced shear zones that formed by embrittlement and faulting of quartzofeldspathic schist took place at the same time as ductile shearing of quartzcarbonate veins embedded within the schist. This study has used field-based structural mapping along with optical microscopy and universal stage measurements of crystallographic preferred orientations (CPO) to resolve the shear zone kinematics and rheology. On the basis of these data, the strain path can be reconstructed for the sheared veins during their progressive deformation. This began with their incidence as backshears at the base of the Alpine Fault ramp and ended with their subsequent recrystallisation, uplift, and exhumation.

The near-vertical shear planes have mean orientation of 221@89 NW $\pm 1^{\circ}(\mathrm{n}=$ 780). They are inferred to have formed as backshears accommodating uplift of the Pacific Plate as it was translated onto the oblique footwall ramp of the Alpine Fault during late Cenozoic oblique convergence. Detailed fault offset transect surveys across the shears at Chancellor Ridge and Baumann Glacier reveal a mean spacing between the shear zones of $25 \pm 5 \mathrm{~cm}(\mathrm{n}=410)$. Quartz-carbonate marker veins are displaced in a dextral west-sideup shear sense. Fault offset geometry and a consistent arrangement of mineral fibre lineations that decorate fault surfaces, indicate that the mean displacement vector pitches $35^{\circ} \mathrm{SW}$ in the shear plane (trend and plunge of: $262,35 \pm 7^{\circ}$ ). Ductilely deformed marker veins have been subject to a mean displacement of $9.9 \pm 1.4 \mathrm{~cm}(\mathrm{n}=344)$ and a mean finite ductile shear strain of $4.8 \pm 0.3(n=219)$. A strain-rate for the ductile deformation of the veins is estimated at $3 \times 10^{-11} \mathrm{sec}^{-1}$ based on the observed finite ductile shear strain, an escalator kinematic model, and assumptions about the width of the deforming zone.

Five deformation phases have affected the sheared veins during their transport up the fault ramp: 1) initial brittle faulting and ductile shearing; 2) grain boundary sliding of mylonitic quartz in response to a post-ramping differential stress drop; 3) recrystallisation and grain growth; 4) renewed late-stage dislocation creep; and 5) semibrittle deformation and exhumation. 
In the schist, the shears initiated as planar brittle faults at lower crustal depths of $\sim 21 \mathrm{~km}$ at a temperature of $450 \pm 50^{\circ} \mathrm{C}$. They developed in a zone of transiently high shear strain-rates near the base of the Alpine Fault ramp. Dislocation creep caused a CPO of quartz and calcite to develop in sheared veins. Using the flow law of Hirth et al. (2001) and the estimated strain-rate, a differential stress of $\sim 165 \mathrm{MPa}$ is inferred for ductile deformation of the veins. Near-lithostatic $(\lambda=0.85)$ fluid pressures would have caused the rocks to undergo brittle failure, a situation that is confirmed by a late component of brittle deformation that over prints the ductilely sheared veins. Syntectonic quartz-calcite veins infill the shear fractures, and these themselves have been sheared. The deformation of the veins was not a simple shear process but one with triclinic flow symmetry. This is inferred from discordance between the shear direction and the near-vertical principle extension direction that is revealed by the pattern and symmetry of quartz and calcite CPO fabrics.

After the shears move away from the ramp-step, grain boundary sliding (GBS) accommodated by solid-state diffusion creep is inferred to have affected quartz veins. This deformation mechanism takes place because of 1) the small $8 \mu \mathrm{m}$ grain size inherited from Phase 1 ; 2) the presence of fluid in the shear zone; and 3) a stress drop to $22 \mathrm{MPa}$ that followed the initial up-ramping. Quartz CPO fabrics in the sheared veins are remarkably weak considering their large shear strains. GBS is inferred to have been a chief deformation mechanism that caused the weakening of quartz CPO fabrics in the highly sheared sections of deformed veins. Calcite has also affected the quartz fabric strength as those veins containing $>5 \%$ calcite have very weak quartz $\mathrm{CPO}$ fabrics. In contrast to quartz, the $\mathrm{CPO}$ fabrics for the co-existing calcite remained strong and continued to develop by dislocation creep.

The third phase of deformation, a process that may have contributed to subsequent weakening of quartz CPO fabrics, was recrystallisation and grain growth to $126 \mu \mathrm{m}$ and an equigranular-polygonal grain shape fabric. This fabric was overprinted by late-stage dislocation creep microstructures in the fourth deformation phase in response increased differential stress encountered by the rocks at lower temperatures in the upper crust. The final phase of deformation to affect the sheared veins was semibrittle deformation at differential stresses of $<189 \mathrm{MPa}$ and temperatures of $200-280^{\circ} \mathrm{C}$ as the rocks passed through the steady-state brittle-ductile transition zone at depths of $8-10 \mathrm{~km}$ before being exhumed at the surface. 


\section{Acknowledgments}

I would like to thank the following people that have assisted me throughout this research, without them this project would not have been possible:

My greatest thanks go to my supervisor, Tim Little, who's wealth of knowledge, guidance and enthusiasm continuously kept me interested in this research and looking for new ideas. Thank you for taking the time to apply a critical eye to my research and read my draft chapters (even while on holiday with your family). Thanks also to Julie Vry for her assistance with the mineralogical aspects of this study, for teaching me the art of 'garnet hunting', and for always popping in to ensure that there was still 'a sign of life' in the optical darkroom during the time I spent in there looking down the microscope.

A huge thank you goes to Ruth Wightman who has shared this journey with me since our first geology lecture back some $8 \frac{1}{2}$ years ago. From frozen socks in the Southern Alps to flow law solutions in the office; your boundless energy, enthusiasm and expertise related to this research have been invaluable. Thank you for casting a critical eye over my draft chapters in these past few months and your support, understanding and friendship throughout all the brittle-ductile shear madness.

Thanks go out to all my field assistants during my numerous expeditions to Chancellor Ridge. Doug, Kate, Rebekah and Ruth; without your help carrying rocks, time behind the wheel of the Hilux, enduring my one-pot hut meals and humour (even after hours endured on frozen rock outcrops) this research would not have been possible. Thanks also to Warren Dickinson for carrying out a huge sample of mylonite from Hare Mare Creek on probably the wettest day in recent history on the West Coast.

This research could not have accomplished with out the assistance from the many technicians and staff in the School of Earth Sciences. Thanks especially to Stewart Bush for making hundreds of oriented thin-sections and enjoying the challenge of ultra-thin calcite slides; John Patterson for ensuring that the u-stage microscope was always in good shape and for his photographic skills; and Euan 
Smith and Cliff Atkins for your help with some of the mathematics and an introduction to eigenvectors.

Thank you to Dave Prior, Richard Norris, Simon Cox and Richard Law for discussions about this research during its various stages. Thank you also to FranzFox Heli Services, Klaus and the rest of team from the Alpine Guides in Fox Glacier, and South Westland DOC offices for your logistical support and guidance during my field work throughout the Southern Alps over the years.

I am also grateful for financial support from the Geological Society of New Zealand who awarded me the S. J. Hastie Scholarship in 2002 and to Victoria University of Wellington for the John Gamble Award in Geology in 2004.

A special thanks to Doug Mason who over the years as my office mate, and more recently my flatmate, has kept my laughing in the office, on my toes during hallway cricket, and endured many field seasons with me throughout the country from the heat of the Awatere Valley to snow storms on Chancellor Ridge. Cheers mate. Thanks also to my flatmate Natalie, who always has the fire going when I come home, isn't afraid of making pumpkin soup the ol' fashioned way, and has put up with me coming home at all hours of the night.

To my fellow graduate students here at the School of Earth Sciences, Nora, Dan, Natalie, Katie, Jodi, Claire and more recently Nadine and Susanne; thank you for the good times, enduring my sense of humour and odd cornflake diet, and sharing countless cups of coffee you could stand a spoon in. Thanks also to Rory Little for his critical eye over my optical microscopy chapter and Eric and Biro for your company during the late nights of the final stages of this thesis.

Finally I would like to thank my family: Mum, Dad and Rebekah for all your assistance and interest throughout my time and university. I really appreciate your understanding and unconditional support throughout the course of this research

Thanks to everyone acknowledged here and anyone I may have inadvertently forgotten. Without all your help I would have never been able to put this puzzle together. 


\section{Contents}

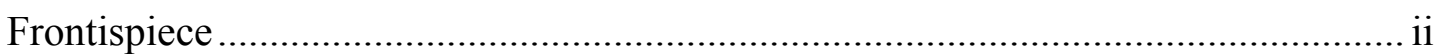

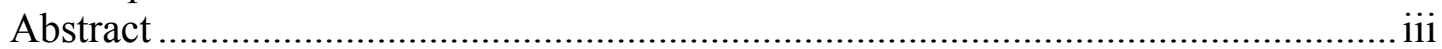

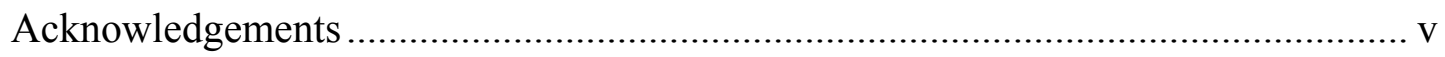

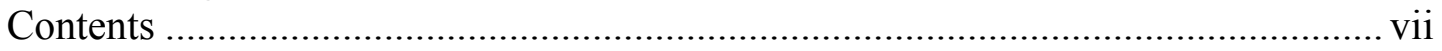

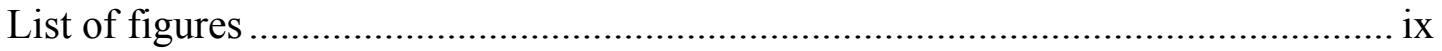

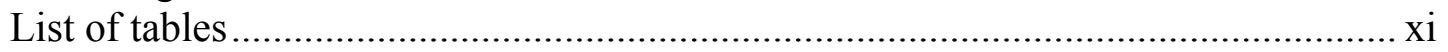

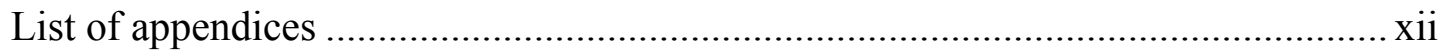

Chapter 1: Introduction ......................................................................................... 1

Chapter 2: Tectonic setting and geology of the Southern Alps of NZ.................. 6

2.1 Tectonics of the South Island of New Zealand ........................................ 6

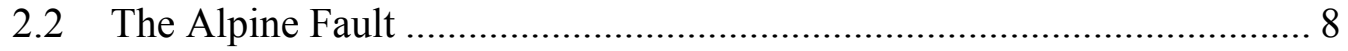

2.3 Geology of the central Southern Alps ............................................... 10

2.4 The Alpine Fault ramp ......................................................................... 12

Chapter 3: Field-based structural geology of the brittle-ductile shear zones .... 18

3.1 Structural mapping of the field areas ................................................... 19

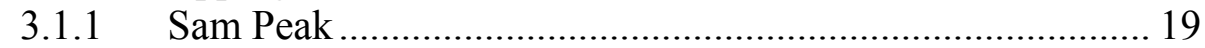

3.1.2 Chancellor Ridge ............................................................ 23

3.1.3 Baumann Glacier.............................................................. 26

3.1.4 Variation in foliation and lineation between field areas ...... 29

3.1.5 Waiho River and Hare Mare Creek..................................... 32

3.2 Observations of deformation in the BDSZ's........................................ 32

3.2.1 Brittle-ductile shear arrays ............................................. 32

3.2.2 Brittle-ductile sheared veins............................................. 37

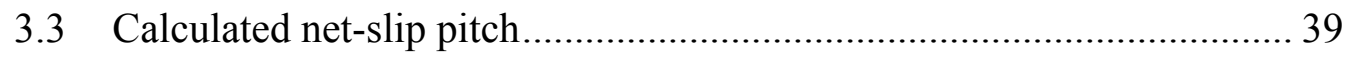

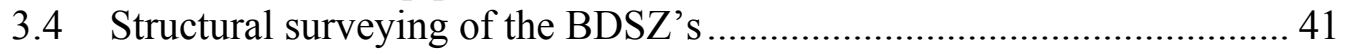

3.4.1 Structural surveying methods and field locations ............... 42

3.4.2 Calculation of the shear displacement............................... 48

3.4.3 Calculation of the finite ductile shear strain.......................... 48

3.4.4 Shear spacing and ductile deformation of the veins.............. 51

3.4.5 Calculation of maximum strain-rate.................................... 53

3.5 Proposed field-based deformation sequence ....................................... 55

Chapter 4: Optical microscopy of the BDSZ's ............................................................. 58

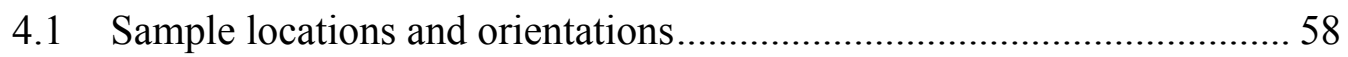

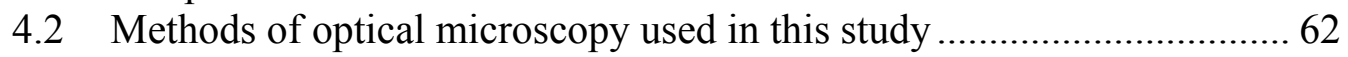

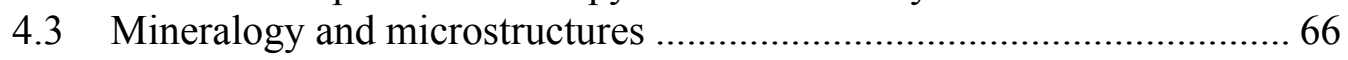

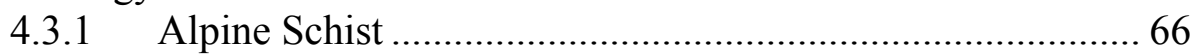

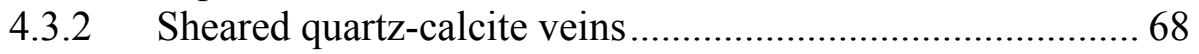

4.3.3 Shear infilling veins ....................................................... 71

4.4 Grain shape fabric based estimates of finite ductile shear strain in the

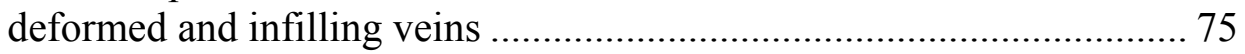

4.5 Active crystallographic slip systems in quartz and calcite.................... 79

4.5.1 Quartz slip systems......................................................... 79 
4.5.2 Calcite twinning deformation and slip systems.................. 84

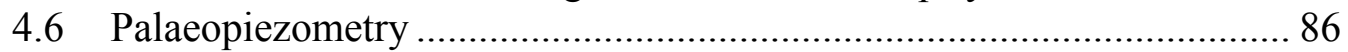

4.6.1 Palaeostress from calcite twinning ..................................... 86

4.6.2 Palaeostress from recrystallised grain size.......................... 90

4.6.3 Maximum differential stress before brittle failure .............. 93

4.6.4 Estimated maximum differential stress ............................... 96

4.7 Changes in deformation conditions up the Alpine Fault ramp................. 99

Chapter 5: Crystallographic preferred orientation of quartz c-axes................ 101

5.1 Measurement of quartz c-axes and presentation of fabric plots........... 102

5.1.1 Measurement of quartz c-axes using a universal stage ...... 102

5.1.2 Quartz c-axis CPO fabric and CPO pattern plots............... 104

5.2 Quartz CPO-derived stretching directions ........................................ 109

5.3 CPO fabrics and patterns found across the BDSZ's ........................... 112

5.3.1 Measured quartz c-axis CPO fabrics ................................ 112

5.3.2 Strain path and kinematics for deformation from CPO's... 118

5.4 Shear sense from CPO fabrics................................................... 120

5.5 Slip systems and approximate deformation temperature from CPO's.. 123

5.6 Strength of quartz c-axis CPO fabrics............................................ 125

5.6.1 Measuring the strength of CPO fabrics ........................... 125

5.6.2 Comparison of CPO fabrics with existing fabrics............. 127

5.6.3 Quartz CPO fabric strength in polymineralic and

5.6.4 Possible reasons for weak CPO fabrics.............................. 132

Chapter 6: Crystallographic preferred orientation of calcite c-axes ................ 136

6.1 Measuring the orientation of calcite c-axes...................................... 137

6.2 Rotation of calcite CPO fabrics..................................................... 138

6.3 Calcite c-axis CPO fabrics in the brittle-ductile shear zones ................ 141

Chapter 7: Discussion and conclusions ........................................................... 149

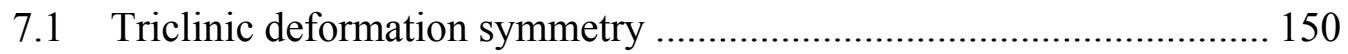

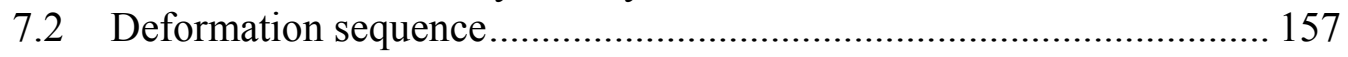

7.2.1 Phase A: Brittle-ductile shearing...................................... 157

7.2.2 Phase B: Differential stress drop ......................................... 161

7.2.3 Phase C: Static recrystallisation and grain growth............. 166

7.2.4 Phase D: Final increment of ductile strain during uplift .... 167

7.2.5 Phase E: Semibrittle faulting.............................................. 169

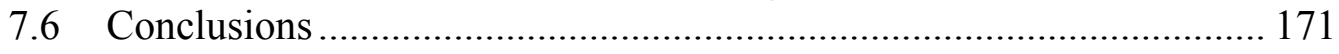

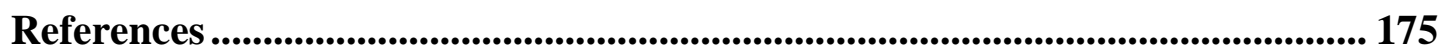




\section{List of Figures}

\section{Chapter 1: Introduction}

Fig. 1.1: Southern Alps field area location map .................................................. 2

Fig. 1.2: Brittle-ductile sheared veins................................................................. 2

\section{Chapter 2: Tectonic setting and geology of the Southern Alps of NZ}

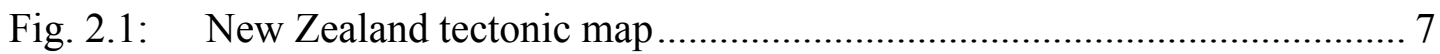

Fig. 2.2: Central Southern Alps location and geological map............................... 11

Fig. 2.3: Cross-section through the Southern Alps............................................... 14

Fig. 2.4: Schematic backshearing models of the Pacific Plate .............................. 14

\section{Chapter 3: Field-based structural geology of the brittle-ductile shear zones}

Fig. 3.1: Structural geology map of Sam Peak ..................................................... 20

Fig. 3.2: Photographs of the Alpine Schist at Sam Peak ...................................... 21

Fig. 3.3: Structural geology map of Chancellor Ridge ......................................... 24

Fig. 3.4: Photographs of the Alpine Schist at Chancellor Ridge ......................... 25

Fig. 3.5: Structural geology map of Baumann Glacier........................................ 27

Fig. 3.6: Stereonets of foliations and lineations across the field areas .................. 30

Fig. 3.7: Orientation of the shear planes and lineations ....................................... 31

Fig. 3.8: Aerial photographs of Chancellor Ridge and Baumann Glacier............. 34

Fig. 3.9: Photographs of vertical cliff outcrops of BDSZ .................................. 35

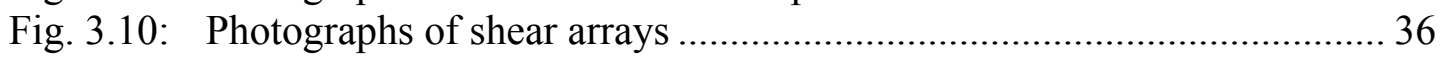

Fig. 3.11: Photographs of individual brittle-ductile shears .................................. 38

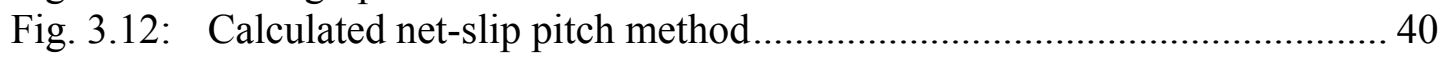

Fig. 3.13: Survey calculation of shear displacement ........................................... 43

Fig. 3.14: Calculation of finite ductile shear strains and maximum strain-rates ..... 44

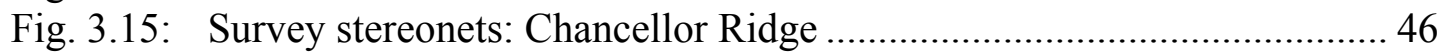

Fig. 3.16: Survey stereonets: Baumann Glacier ................................................. 47

Fig. 3.17: Shear displacement, shear strain and ductile ratio graphs......................5 50

Fig. 3.18: Ductile deformation graphs................................................................. 51

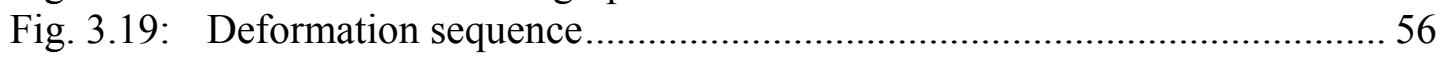

\section{Chapter 4: Optical microscopy of the BDSZ's}

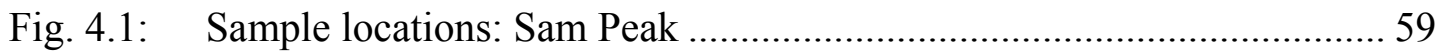

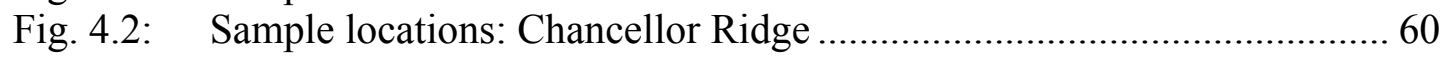

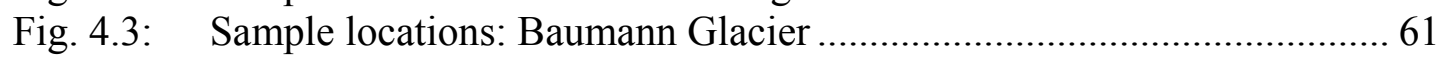

Fig. 4.4: Sample locations: Hare Mare Creek and Waiho River ........................... 63

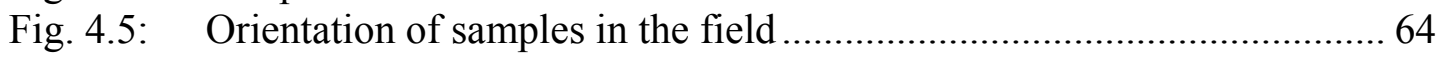

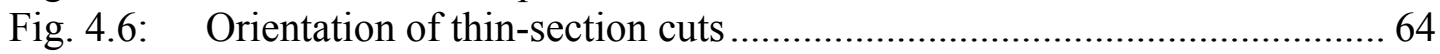

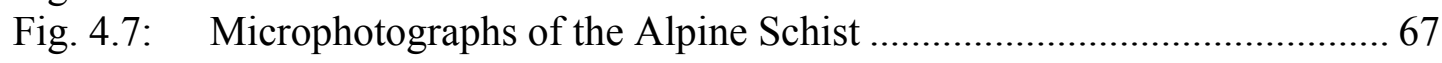

Fig. 4.8: Microphotographs of sheared quartz-calcite veins ..............................69 69

Fig. 4.9: Microphotographs of quartz microstructures ..................................... 72

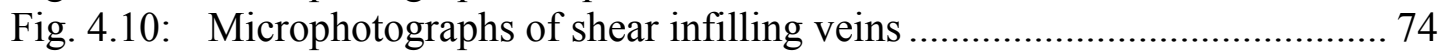

Fig. 4.11: Microphotographs of calcite deformation twinning ............................. 76

Fig. 4.12: Microphotographs of calcite microstructures......................................... 77

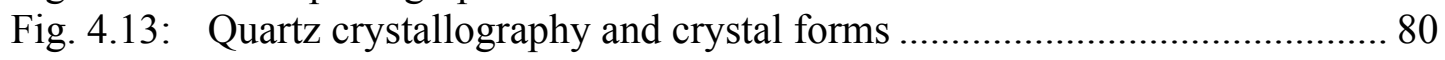




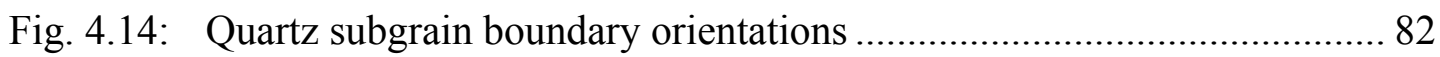

Fig. 4.15: Quartz subgrain boundary orientation measurements.......................... 83

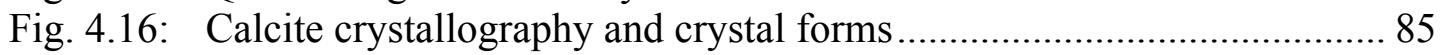

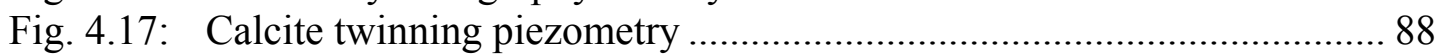

Fig. 4.18: Recrystallised grain size palaeopiezometer for quartz and calcite......... 92

Fig. 4.19: Mohr circle for brittle Coulomb failure................................................... 95

Fig. 4.20: Differential stress from estimated strain-rates using flow laws .............. 98

\section{Chapter 5: Crystallographic preferred orientation of quartz c-axes}

Fig. 5.1: The universal stage microscope and shear zone sections..................... 103

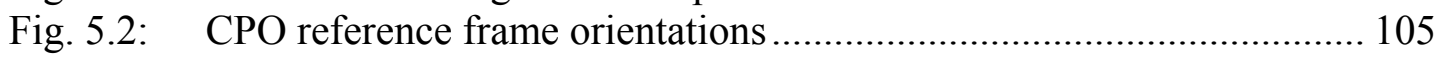

Fig. 5.3: CPO patterns and inferred stretching directions ................................ 106

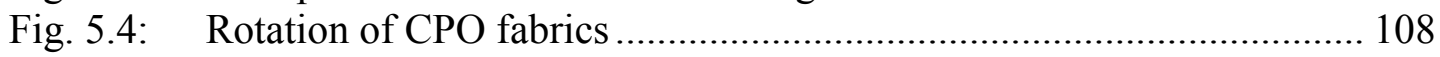

Fig. 5.5: Quartz c-axis CPO-derived stretching directions............................... 108

Fig. 5.6: Schematic illustration of sheared veins and quartz CPO patterns......... 113

Fig. 5.7: Quartz c-axis fabrics ...................................................................... 114

Fig. 5.8: Graphs of quartz CPO fabric strengths ............................................ 128

Fig. 5.9: Monomineralic and polymineralic vein CPO fabrics........................... 131

\section{Chapter 6: Crystallographic preferred orientation of calcite c-axes}

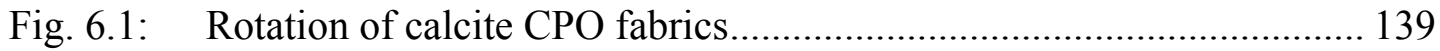

Fig. 6.2: Calcite c-axis CPO-derived stretching directions .............................. 142

Fig. 6.3: Schematic illustration of sheared veins and calcite CPO patterns ........ 143

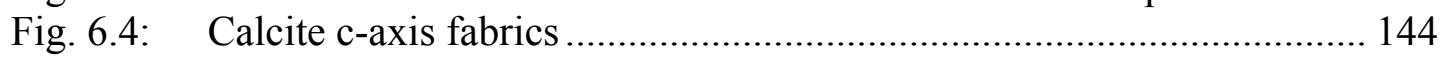

Fig. 6.5: Deformation map for calcite deformation........................................ 147

\section{Chapter 7: Discussion and Conclusions}

Fig. 7.1: Models of deformation and predicted CPO patterns............................ 151

Fig. 7.2: Orientation of extension directions and symmetry poles ..................... 152

Fig. 7.3: Schematic illustration of triclinic symmetry deformation...................... 156

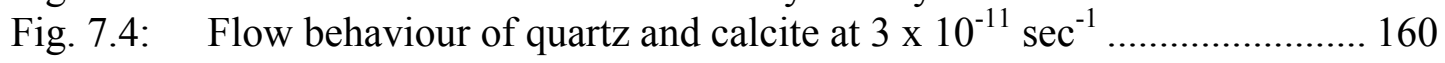

Fig. 7.5: Deformation map for quartz deformation ........................................ 162

Fig. 7.6: Deformation map for quartz with Deformation Phases A-C................. 162

Fig. 7.7: Flow behaviour of quartz and calcite at $1 \times 10^{-11} \mathrm{sec}^{-1} \ldots \ldots \ldots \ldots \ldots \ldots \ldots \ldots . . . . . . . . . . .168$ 


\section{List of Tables}

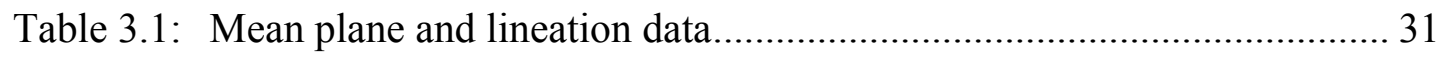

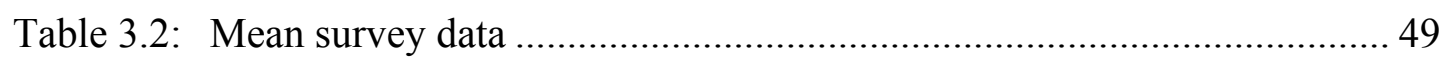

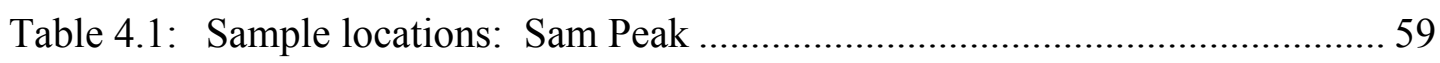

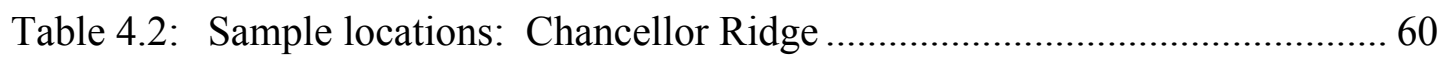

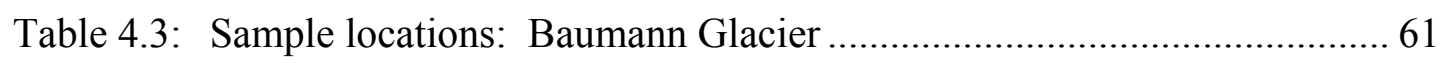

Table 4.4: Sample locations: Hare Mare Creek and Waiho River ........................... 63

Table 4.5: Calcite palaeopiezometry results........................................................ 88

Table 4.6: Quartz palaeopiezometer results ........................................................ 92

Table 4.7: Estimated maximum strain-rates and differential stress ........................ 98

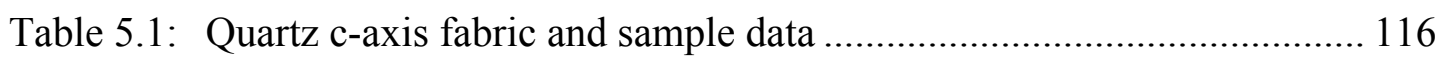

Table 5.2: Monomineralic and polymineralic vein samples and CPO fabrics....... 131

Table 6.1: Calcite c-axis fabric and sample data................................................... 142

Table 6.2: Flow law parameters used in the calcite deformation map .................. 147

Table 7.1: Parameters for experimentally derived flow law equations .................. 160 


\section{List of appendices}

Appendix A: $\quad$ Structural field data............................................................. A-1

Appendix B: $\quad$ Brittle-ductile shear survey data ......................................... A-15

Appendix C: $\quad$ Data collected from optical microscopy ................................. A-35

Appendix D: Quartz CPO fabric plots of sheared brittle-ductile veins........... A-39

Appendix E: Quartz CPO fabric plots measured throughout the BDSZ......... A-56

Appendix F: $\quad$ Hare Mare Creek Alpine Schist mylonite................................ A-65

Appendix G: $\quad$ CPO of euhedral quartz crystals .......................................... A-66

Appendix H: $\quad$ Quartz and calcite CPO fabric data ..................................... A-67

Appendix I: $\quad$ Calcite CPO fabric plots of sheared brittle-ductile veins .......... A-72

Appendix J: Calcite CPO fabric plots measured throughout the BDSZ ........ A-75 


\section{CHAPTER 1: Introduction}

Microstructures and the crystallographic preferred orientation (CPO) of rocks which have undergone ductile deformation have been used to determine many different aspects of the rheology of naturally deformed rocks. For example, combined with sound structural mapping, microstructural and CPO studies can be used to determine the kinematics of ductile deformation in exhumed crustal rocks. Quartz and calcite are among the most useful minerals for these fabric studies as they are abundant in crustal rocks and easily deform in the solid state by plastic intracrystalline deformation. In many studies it possible to reconstruct aspects of the three-dimensional flow kinematics and deformation mechanisms of a rock from microstructures and crystallographic orientation fabrics generated from this plastic deformation. This is especially useful in transpressive tectonic regimes where complex three-dimensional flow fields are known to occur and where complex strain histories are to be expected. This study examines the conditions and deformation mechanisms that occurred during shearing of quartz-carbonate veins in the lower crust of the Southern Alps and the subsequent fabric evolution in these veins during their exhumation to the surface. The investigation of natural deformation processes in the crust, especially neotectonically deforming regions, is essential for understanding orogenic processes and for the calibration of experimental and field descriptions of crustal rheology.

The natural laboratory from which this study is based is located on the exhumed hanging wall of the Pacific Plate in the South Island of New Zealand. Uplift and exhumation of Pacific Plate rocks is occurring east of the plate boundary expressed on the surface as the Alpine Fault trace (Fig. 1.1). The Pacific Plate east of this boundary is undergoing oblique collision with the Australian Plate to the west and experiencing uplift and transpression as it is displaced in a dextral reverse sense up the southeast dipping Alpine Fault. Three main field sites have been selected for this research: Sam Peak, Chancellor Ridge and Baumann Glacier, located in the central part of the Southern Alps in the South Island, New Zealand (Fig. 1.1). These sites are situated 6-8 km structurally above the Alpine Fault in a zone where brittleductile shearing of Pacific Plate rocks, including quartz-carbonate veins, has occurred deep in the crust during the late Cenozoic. At these field sites glaciated platforms of schist provide superb exposure of exhumed arrays of shear zones. 


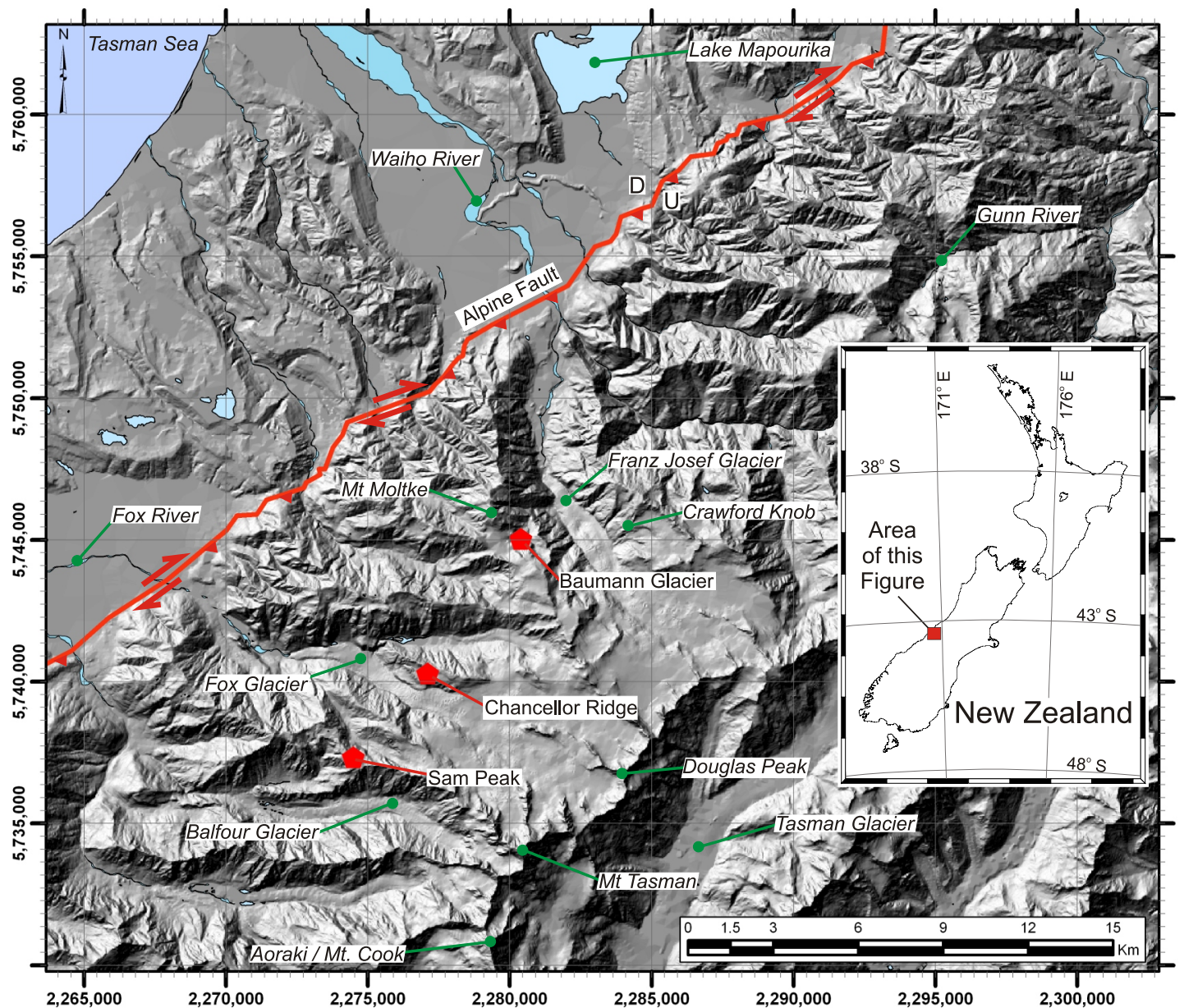

Fig. 1.1. Southern Alps and field area location map. Digital elevation model map of the central Southern Alps of New Zealand generated from the LINZ digital 1:50,000 data set. Map grid (metres) are in New Zealand map grid coordinates. Red markers are the three main research field sites in this study; Sam Peak, Chancellor Ridge and Baumann Glacier. Green labelled markers are major glaciers, peaks, rivers and lakes. The Alpine Fault trace is marked for reference and is from Norris and Cooper (1995). Inset map of New Zealand shows the location of this figure in the South Island of New Zealand.

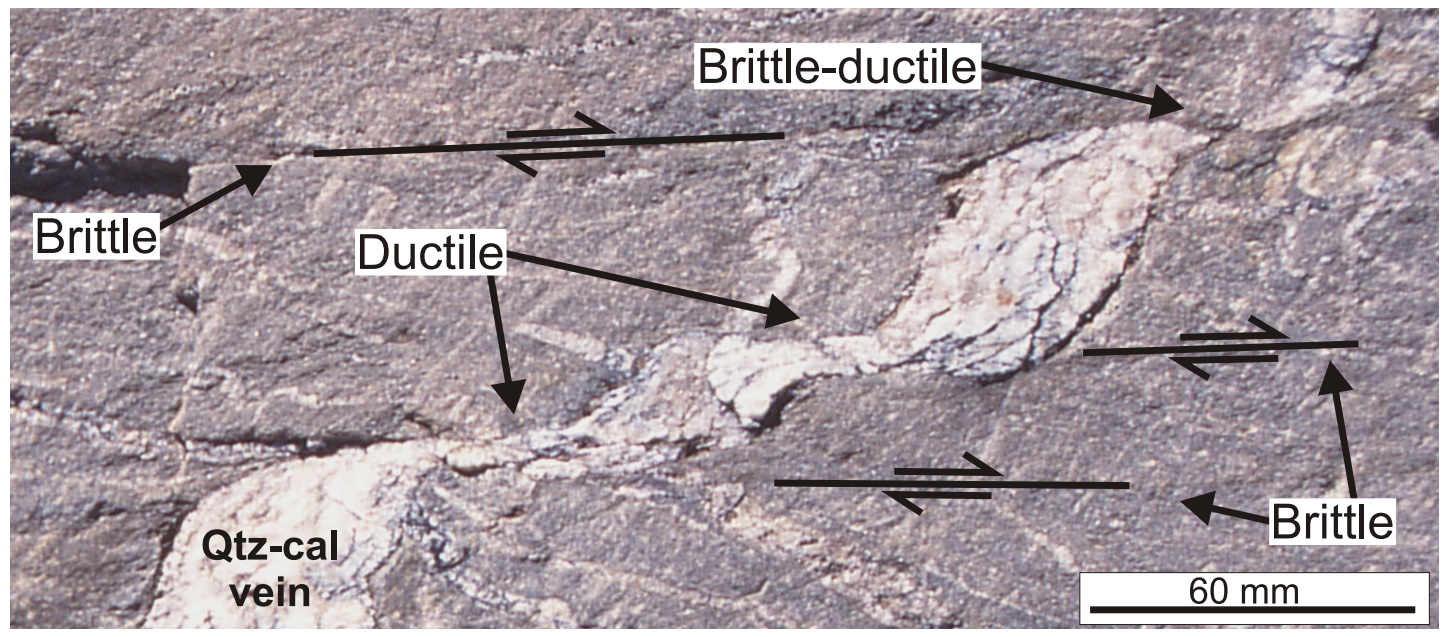

Fig. 1.2. Photograph of brittle-ducitle shear zones in the Alpine Schist. The host schist has been displaced by brittle faults and quartz-carbonate vein has been deformed by ductile shearing. The vein has crossed three shear zones with ductile deformation in the lower two and brittle-ductile deformation in the upper shear. Photograph was taken on a flat glaciated exposure above Baumann Glacier and preferentially shows the strike-slip component of slip on a near vertically dipping vein. 
Quartz-carbonate veins within the host schist rocks are found deformed in these shear zones and have undergone aspects of both brittle and ductile deformation (Fig. 1.2) at lower-crustal depths before their exhumation and subsequent exposure at the surface (Little et al., 2002b; Wightman, 2005). These shear zones provide a rare opportunity to study the natural ductile deformation of quartz and calcite in the crust in a young deforming orogen where the tectonic kinematics are well known.

This study builds on the initial recognition of these exhumed shear zones by Little et al. (2002a), and takes advantage of the opportunity to study processes of deep embrittlement and ductile deformation in naturally deformed crustal rocks. There are few case studies in the existing literature of the deformation of crustal material, such as quartz veins, where the kinematics and geodynamics is independently well constrained on an almost neotectonic time scale. Because of the superb exposure of the shears zones, their context in a modern orogen, the simplicity of their offset and measurable nature of their finite strain, we are able to estimate strain-rates and deformation mechanisms active during deformation and evaluated experimental flow laws. This study provides rare comparisons between the rheology of natural rocks and those deformed in laboratory experiments. Research from this study is able to directly contribute to the knowledge about the brittle-ductile deformation which may be active today several kilometres below the Southern Alps of New Zealand near a major continental plate boundary.

In this study I will analyse deformation processes affecting the quartzcarbonate veins deformed in the shear zones by a combination of detailed structural surveying, optical microscopy and crystallographic studies with a universal stage microscope. These results are discussed in terms the kinematics and deformation mechanisms affecting the Pacific Plate during its ramping and uplift on the Alpine Fault. The techniques employed in this research enable me to study aspects of the shear zone deformation from a broad tectonic scale of the deforming plate down to the crystallographic scale. Broad structural mapping has been undertaken across the $\sim 2 \mathrm{~km}$ wide field areas as well as detailed structural surveys along 30-50 m long transects of the shear zone array. With this mapping we hope to quantify magnitudes and rates of both brittle and ductile bulk deformation, to calculate the shear displacement, shear strain and (maximum) strain-rate in the individual shear zones. 
Optical microscopic techniques in this study will be used to document deformation microstructures and to decipher the deformation mechanisms that accommodated the ductile strain. Observations of the microstructures in the sheared sections of quartz-carbonate veins, the sections of the vein external to the shear zone and the host schist will be compared and contrasted to determine key temperature and spatial relationships between fabrics and to determine the strain and deformation paths. Specific methods such as grain size piezometry, subgrain orientation and calcite twin density will be used to constrain the approximate pressure and temperature conditions at which the deformation occurred. Grain shape analysis will be used to identify the sense of shear from oblique fabrics in the sheared sections of deformed veins and shed insight into the final increments of strain prior to the freezing in of microstructures. These last increments will be compared with the field-based observations of finite ductile shear strain in the deformed veins.

CPO fabrics imprinted during ductile deformation are useful in determining the flow sense of sheared rock (e.g. Lister, 1977; Schimd and Casey, 1986; Law, 1990; Bestmann et al., 2000). This study has measured quartz and calcite c-axis crystallographic fabrics for over 100 sample sections using a universal stage on a polarising microscope. The crystallographic fabrics defined by these c-axis pole measurements are used to constrain the nature of the three-dimensional deformation, and as a tool to compare natural with experimental crystallographic studies of deformed quartz veins. In this study, the crystallographic fabrics will shed new insight into the deformation mechanisms active during the shearing and subsequent ductile deformation. The CPO fabrics will be used to determine the slip systems that the crystals were using to accommodate the intracrystalline plastic deformation and these inferences will add / support to the deformation temperature approximations made from the microstructural observations. This field to crystallographic scale geological research will aid in the understanding of complex transpressional tectonics and provide a sound dataset that will allow conclusions to drawn about the applicability of experimental flow laws to natural crustal deformation.

Experimental determination of flow laws that describe the deformation of quartz and calcite (e.g. Rutter and Brodie, 2004a; Schmid et al., 1977) are found to extrapolate poorly from experimental high temperatures and fast strain-rates to natural geological conditions (Stipp et al., 2002a). This study aims to deduce the 
deformation mechanisms active at calculated strain-rates and temperatures during natural deformation in the mid-crust to assist in better correlation of experimental results to natural conditions in wet polymineralic rocks. It has been shown that the alignment of crystallographic axes during ductile deformation of quartz and calcite is associated with the last increment of strain (e.g. Brunel, 1980). This study aims to determine if the last increment of strain during exhumation has overprinted older shearing-related crystallographic fabrics or whether there is still a remnant of the $\mathrm{CPO}$ in the shear zone that may represent earlier deformation increments that occurred at deep crustal levels. The ductile shear direction in the shear zones has been assumed to be coincident with the fault surface lineations on the brittle-ductile shears and has not been resolved because of poor microstructural preservation and very weak or randomised crystallographic fabrics (e.g. Little et al., 2002b; Little, 2004; Wightman, 2005). This study aims to use extensive CPO measurements from large sample sets to ascertain the ductile extension and shear directions during deformation in the shear zone and the microstructural evolution of fabrics during uplift.

This thesis is comprised of seven chapters which cover the tectonic and geological setting in the Southern Alps of New Zealand, the field-based structural mapping, optical microscopy and crystallographic orientation studies. Detailed appendices are found in the back of this thesis and document the structural field measurements, structural survey data, mineralogical and microstructural observations and a complete archive of all stereographic plots made for the crystallographic measurements obtained for this study. 


\section{CHAPTER 2: Tectonic setting and geology of the Southern Alps of New Zealand}

\subsection{Tectonics of the South Island of New Zealand}

New Zealand straddles the plate boundary between the Australian (AUS) and the Pacific (PAC) plates (Fig. 2.1a). The plate boundary changes southward from a west dipping subduction zone beneath which oceanic lithosphere of the Pacific Plate is subducted off the east coast of the North Island, to an oblique collision zone between continental parts of both plates in the central South Island. This oblique collision zone is most obviously expressed on the surface by the Alpine Fault. Farther south, west of Fiordland, oceanic lithosphere of the Australian Plate is subducted beneath continental rocks of the Pacific Plate (Walcott, 1998; Sutherland et al., 2000; Barnes et al., 2005). Deformation across the plate boundary initiated at ca. $45 \mathrm{Ma}$ in the South Island when PAC-AUS deformation was diffusely distributed and transtensional (Sutherland, 1995; Sutherland et al., 2000). An increase in strikeslip along the plate boundary took place at $\sim 25 \mathrm{Ma}$ (Sutherland, 1995). After this time the Alpine Fault has played a major role in accommodation of plate motion, today accommodating as much as $70 \%$ of the margin parallel component of motion (Cooper and Norris, 1994; Beavan et al., 1999; Sutherland, 1999a). The remaining $30 \%$ of the current motion distributed over a $\sim 200 \mathrm{~km}$ wide zone to the east of the Alpine Fault (Walcott, 1979; Norris et al., 1990; Beavan et al., 1999). Since 6.4 Ma the Alpine Fault has become an oblique-slip structure due to increased convergence across the PAC-AUS boundary (Walcott, 1998; Vry et al., 2004). Reverse slip on this fault allows uplift of the Southern Alps mountain range to the west of the southeast dipping Alpine Fault.

The contemporary plate motion direction of PAC relative to AUS is $071 \pm 2^{\circ}$ near Fox Glacier (NUVEL-1A solution of DeMets et al., 1994; Fig. 2.1b). This vector's velocity of $37 \mathrm{~mm} / \mathrm{yr}$ can be divided into a $35.5 \mathrm{~mm} / \mathrm{yr}$ component parallel to the Alpine Fault and $10.2 \mathrm{~mm} / \mathrm{yr}$ component normal to that fault. Uplift rates in the central section of the Southern Alps determined from lacustrine sedimentation, uplifted marine terraces and direct geodetic measurements from GPS stations are as high as 8-10 mm/yr (Wellman, 1979; Bull and Cooper, 1986; Beavan et al., 2002) and are higher than other parts of the Southern Alps (Little et al., 2005). South of 
a

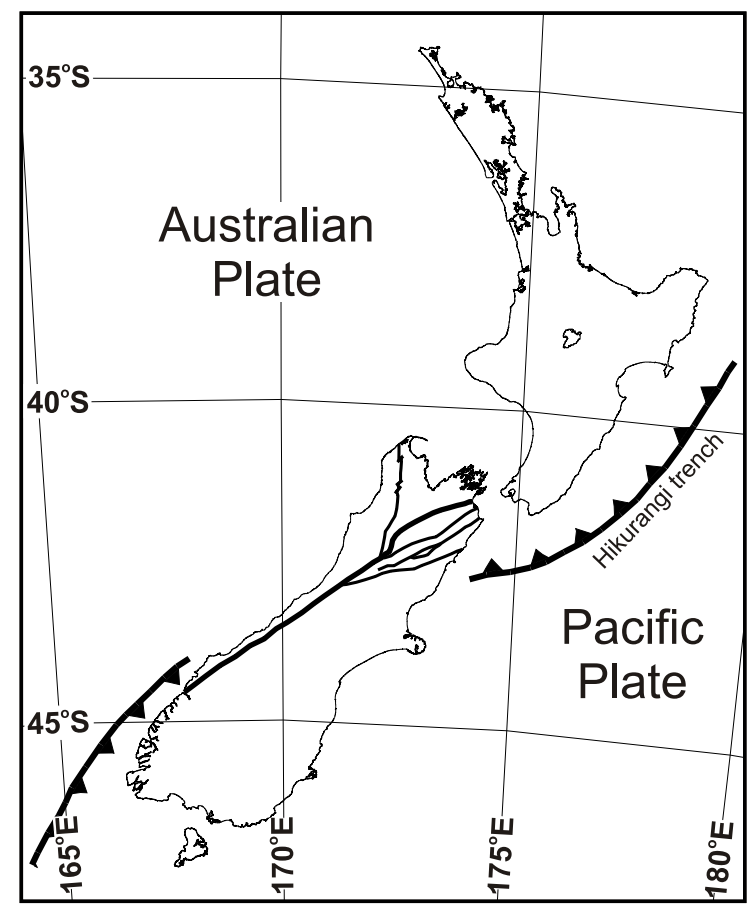

b

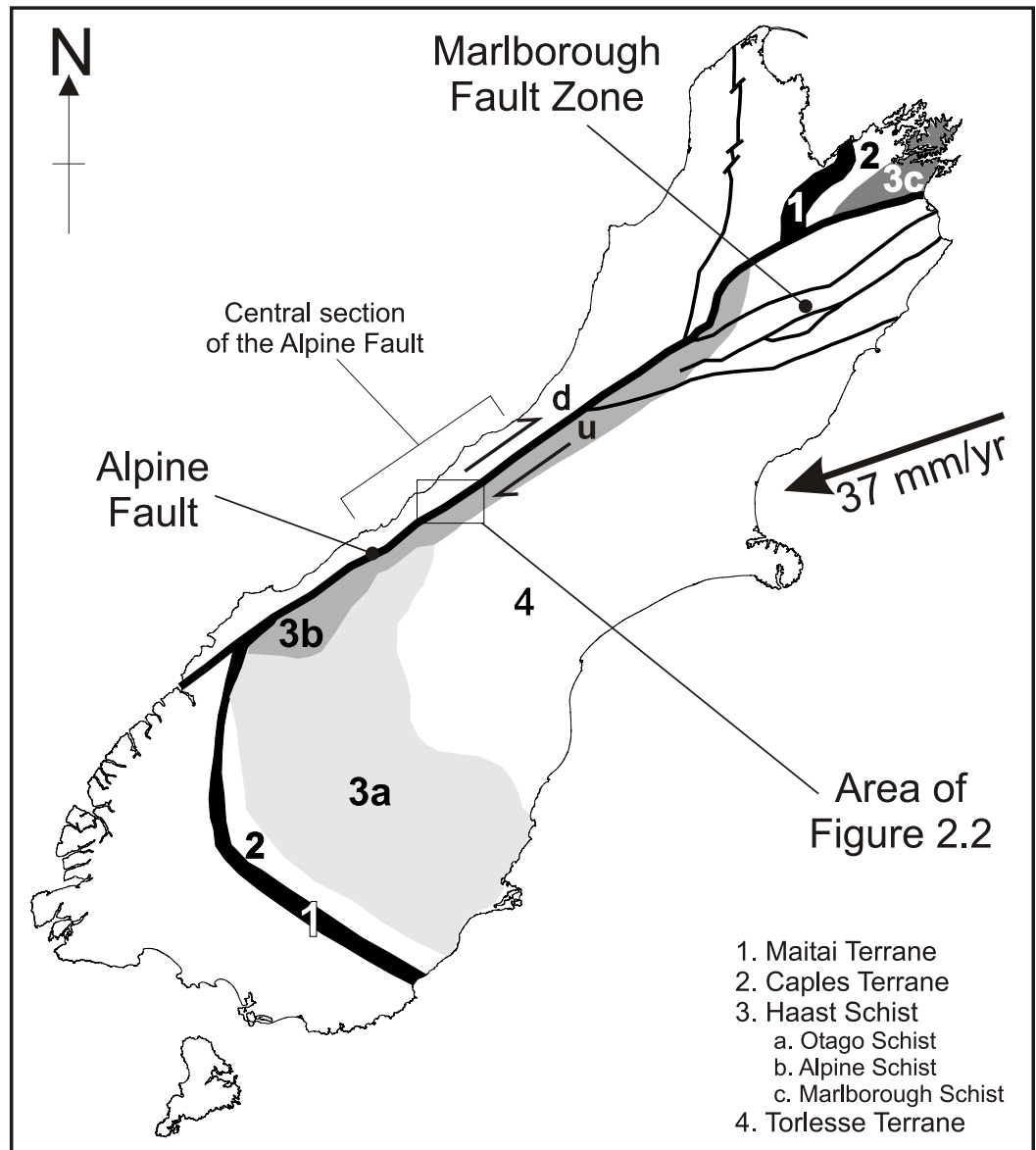

Fig. 2.1. a. Large scale tectonic overview of New Zealand. Pacific and Australian plates shown for reference with northern and southern subduction zones. Traces of major faults in the South Island of New Zealand shown for reference. b. Terrane map of the South Island of New Zealand (after Sutherland et al., 2000) with the Alpine Fault and other major faults in the Marlborough Fault Zone. Major basement terranes of New Zealand are indicated and the three domains of schist found in the South Island including the Alpine Schist sampled in this study. Study area (area of Fig. 2.2) shown for reference as well as the central section of the Alpine Fault. Plate motion vector (DeMets et al., 1994) relative to fixed Australian Plate for position at Fox and Franz Josef glaciers. 
Haast, in the southern section of the Southern Alps, uplift rates of the PAC plate rocks on the Alpine Fault are as low as 0.1-1.4 mm/yr (Sutherland and Norris, 1995; Sutherland et al., 1995). The topography of the Main Divide of the Southern Alps near the central section of the plate boundary reflects the high uplift rate and is where New Zealand's only peaks higher than $3000 \mathrm{~m}$ are located.

The Main Divide in the central part of the Southern Alps separates the Tasman Glacier from the Fox and Franz Josef glacier névés and includes the highest mountains in the South Island such as Aoraki / Mt Cook, Mt Tasman and Douglas Peak (Fig. 1.1). These mountains all exceed $3 \mathrm{~km}$ in height and are just $15 \mathrm{~km}$ from the Alpine Fault whereas the Main Divide outside this section is as far as $25 \mathrm{~km}$ from the fault (Little et al., 2005). The central Southern Alps may be uplifting more rapidly than other parts of the range to the north and south because the Alpine Fault is slightly more steeply dipping there on average (Little et al., 2005). High local uplift rates in the central Southern Alps are causing a rapid exhumation of crust because this uplift is balanced by an equally high erosion rate (Wellman, 1979). A result of this rapid exhumation on the east side of the Alpine Fault is a locally high geothermal gradient, perhaps as high as $60^{\circ} / \mathrm{km}$ in the upper crust (Allis and Shi, 1995), a situation that is reflected by an unually shallow seismogenic zone of 10$12 \mathrm{~km}$ (Leitner et al., 2001).

\subsection{The Alpine Fault}

The Alpine Fault (Fig. 2.1b) is located west of the Southern Alps mountain range and is continuous for $\sim 850 \mathrm{~km}$ across the South Island (Barnes et al., 2005) and has had up to $460 \mathrm{~km}$ of dextral strike-slip displacement since $45 \mathrm{Ma}$ (Sutherland et al., 2000). The fault is expressed both as a fault trace offsetting Quaternary deposits (e.g. Cooper and Norris, 1994; Sutherland, 1994; Norris and Cooper, 1995; Norris and Cooper, 1997) and as a major boundary offsetting basement rocks of the Maitai and Caples terranes and the Haast Schist (Sutherland, 1999a; Fig 2.1b). The Alpine Fault plane has a mean strike of 055 (Norris and Cooper, 1995) and dips southeast at 30-50 (Sibson et al., 1981; Norris et al., 1990; Kleffmann et al., 1998). The Australian Plate footwall block is considered to be a relatively rigid indentor for the Pacific Plate. The base of the Pacific Plate hanging wall of the Alpine Fault consists of amphibolite grade schist and fault related mylonite rocks that have been 
exhumed from depths of 22-25 km (Grapes, 1995; Walcott, 1998). To the east and structurally above these lower crustal metamorphic rocks are biotite grade schists that grade further eastwards into the protolith sedimentary Torlesse Terrane.

Offset Quaternary markers indicate a strike-slip rate of $26-28 \mathrm{~mm} / \mathrm{yr}$ in the southern section of the Alpine Fault, a place where dip-slip displacement is as low as 0-2.5 mm/yr (Sutherland et al., 1995; Sutherland and Norris, 1995; Norris and Cooper, 2001). The central section of the Alpine Fault has similarly high late Quaternary strike-slip rates of 22-27 mm/yr (Cooper and Norris, 1994; Norris and Cooper, 1997) but has a dip-slip rate of $8-12 \mathrm{~mm} / \mathrm{yr}$ that is much higher than those to the north and south (Norris and Cooper, 2001). The slip direction on the obliquereverse Alpine Fault pitches northeast at $14-35^{\circ}$ as inferred from striations on the fault surface (e.g. Norris and Cooper, 1997). This direction is essentially parallel to the predicted slip direction $\left(10^{\circ}\right.$ pitch to the northeast) calculated from the PAC plate motion resolved onto the mean fault plane. Stretching directions from lineations in the mylonite exhumed along the Alpine Fault however are more scattered pitching $\sim 30-70^{\circ}$ in the fault plane (Sibson et al., 1981; Wightman, 2000; Little et al., 2002b; this study Appendix F).

No fault creep at the surface has occurred on the Alpine Fault during the past 25 years and no earthquakes have ruptured that structure historically in the last 170 years suggesting that the Alpine Fault fails in large or great earthquakes (Sutherland, 1994; Beavan et al., 1999; Wells, 1999). Although the upper crust is accumulating elastic strain today (Sutherland, 1994; Beavan et al., 1999, 2002), dislocation modelling from GPS data suggests that ongoing slip could be accommodated by aseismic ductile creep processes on the down dip extension of the Alpine Fault ramp at depths greater than 5-8 km (Beavan et al., 1999). Although the PAC-AUS plates in map view are obliquely converging, the three dimensional deformation of the Pacific Plate is likely to be transpressive and deviate from simple shear by including a component of pure shear shortening perpendicular to the plate boundary (Sibson et al, 1979; Koons et al., 1998; Beavan et al., 1999; Jiang et al., 2001; Wightman 2000; Little et al., 2002a; Little, 2004; Norris and Cooper, 2003). 


\subsection{Geology of the central Southern Alps}

The crust exhumed on the Alpine Fault ramp is a segment of metamorphic rock that represents a vertical section through the crust after tilting and uplift on the Alpine Fault ramp (Grapes and Watanabe, 1992). This exhumed section shows a complete progressive prograde metamorphic sequence from the protolith sedimentary rocks in the southeast through to garnet-oligoclase amphibolite facies Alpine Schist in the northwest adjacent to the Alpine Fault (Grapes, 1995; Fig. 2.2). The predominant quartzofeldspathic Alpine Schist has been metamorphosed from a protolith Torlesse Terrane greywacke; however in structurally deeper sections of the Alpine Schist, the rocks are dominantly pelitic with metabasite and metachert horizons, interpreted to have originated from the Aspiring Terrane (Craw, 1984; Norris and Craw, 1987; Grapes et al., 1998). The Alpine Schist was subject to a period of sustained deep burial and ductile deformation during its residence in the lower crust of the Pacific Plate and during its late Cenozoic passage through the PAC-AUS deformation zone east of the Alpine Fault. The ductile fabrics in the Alpine Schist become progressively more ductile and complex from southeast to northwest with increasing metamorphic grade, and were initially imprinted into these rocks in the Mesozoic before the modern phase of oblique convergence and uplift. Within 1-2 km to the east of the Alpine Fault the hanging wall consists of mylonitic and protomylonitic ("curly schist") rocks (Fig 2.2) formed from the changes related to late Cenozoic shearing along the Alpine Fault structure. These mylonite rocks over thrust the late Quaternary outwash and glacial sediments found on the western side of the Alpine Fault (e.g. Cooper and Norris, 1994; Norris and Cooper, 1997).

The Alpine Schist in the Southern Alps has undergone four deformational events ( $D_{1}$ to $D_{4}$ from Little et al., 2002a) with $D_{4}$ being the last event during the late Cenozoic and related to Southern Alps deformation and related ramping and uplift on the Alpine Fault. Field observations of the Alpine Schist in this study largely concern the foliations generated during the $\mathrm{D}_{2}$ and $\mathrm{D}_{3}$ events as well as the mylonitic foliation generated during the $\mathrm{D}_{4}$ event. The subvertical $\mathrm{S}_{3}$ or "Alpine" foliation is a crenulation or cleavage foliation generated from the folding of the older $\mathrm{S}_{2}$ fabric during the $\mathrm{D}_{3}$ deformation event in the late Cretaceous (ca. $86 \mathrm{Ma}$ ). These Alpine fabrics were later reactivated and strengthened during the late Cenozoic $\mathrm{D}_{4}$ transpression (Little et al., 2002a; Little, 2004; Vry et al., 2004). During the $\mathrm{D}_{2}$ and 


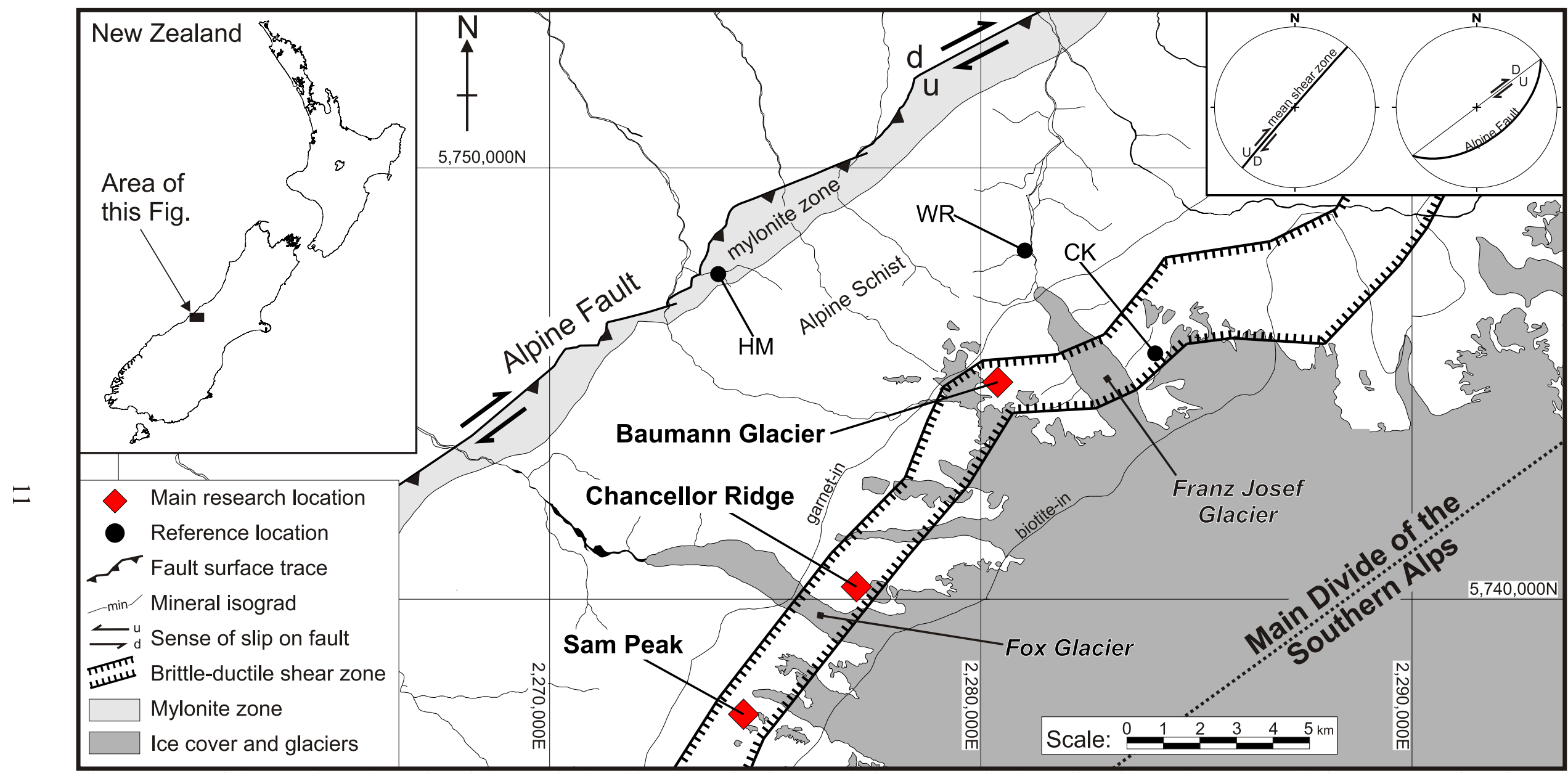

Fig. 2.2. Map of the central Southern Alps of New Zealand and locations of main research sites Sam Peak, Chancellor Ridge and Baumann Glacier. Inset map for reference location of this Figure within New Zealand. Coordinates are in NZ Map Grid (m) with the Alpine Fault trace from Norris and Cooper (1995), isograds from this study and QMap unpublished data (courtesy Simon Cox IGNS), Alpine Fault mylonite zone from Little et al. (2002a) and brittle-ductile shear zone from Wightman (2005) and this study. Reference locations for Crawford Knob (CK), Waiho River (WR) and Hare Mare Creek (HM) are also shown. Permanent ice and snow shaded dark grey and only the major rivers have been plotted. Stereographic, equal area, lower hemisphere projections of the mean Alpine Fault plane and the mean brittle-ducitle shear plane are inset. 
$\mathrm{D}_{3}$ events quartz-carbonate veins were emplaced in the Alpine Schist. The veins have been variably deformed during the subsequent $\mathrm{D}_{3}$ and $\mathrm{D}_{4}$ events by folding, boudinage and (importantly here) brittle-ductile shearing. The $\mathrm{S}_{2}$ and $\mathrm{S}_{3}$ foliations generally lie at an angle to each other with folding of the older fabric $\left(\mathrm{S}_{2}\right)$ folded by the steep axial planar $S_{3}$. Little et al. (2002a) have shown that on the steep or overturned limbs of large Alpine $\left(\mathrm{F}_{3}\right)$ folds, termed the planar fabric zones, the two foliations are near parallel and difficult to distinguish in the field.

Arrays of brittle-ductile shears in the Alpine Schist (Fig. 1.2) have been mapped 6-8 km southeast of the Alpine Fault (Little et al., 2002a; Little et al., 2002b; Little 2004; Little et al., 2005; Wightman, 2005; Fig. 2.2). These shears crosscut and displace the quartzofeldspathic Alpine Schist brittlely, but displace quartz veins embedded in this quartzofeldspathic schist in a variably ductile to brittle manner. This shearing is the youngest ductile deformation to have affected the non-mylonitic Alpine Schist (Little et al., 2002a). The brittle-ductile shears are found in a $\sim 2 \mathrm{~km}$ wide brittle-ductile shear zone (BDSZ) that lies in biotite grade Alpine Schist (Fig. 2.2). This schist is mostly psammitic, but includes pelitic interbeds, with a phyllitic cleavage in the central and upper sections of the zone. Deeper parts of the zone to the west have a distinct schistosity $\left(\mathrm{S}_{3}\right)$. The brittle-ductile shears are not found in garnet grade schist or are they well developed in the pelitic dominated Alpine Schist from the Aspiring Terrane protolith. The BDSZ has been traced along strike, subparallel to the Alpine Fault (Fig. 2.2) from the most northern known occurrence at Gunn River (Fig. 1.1) to Sam Peak in the south (Fig. 2.2; Wightman, 2005). These shears have been interpreted as forming during a short-lived period of deep embrittlement in the otherwise ductilely deforming lower crust during upward bending of the Pacific Plate onto the Alpine Fault ramp in the last 3-4 Ma (Little et al, 2004; Wightman, 2005). In this study, the brittle-ductile shears themselves are referred to in abbreviated form as " $\mathrm{S}_{4}$ " (equivalent of $\mathrm{S}_{\mathrm{bds}}$ in Little et al., 2002a) because of their discrete cleavage-like appearance, regular systematic spacing and their development during the $\mathrm{D}_{4}$ deformation.

\subsection{The Alpine Fault ramp}

The collision of the Australian and Pacific plates has exhumed deformed midcrustal rock from the Pacific Plate up the Alpine Fault to expose amphibolite schist 
adjacent to the Alpine Fault mylonites (Grapes, 1995; Walcott, 1998). This exhumation of crustal rock that does not include any deeper lower crustal material has been used as evidence for a possible décollement in the Pacific Plate between the middle and lower crust (Grapes, 1995). Geophysical reflection, seismic velocity and gravity studies (e.g. Woodward, 1979; Davey et al., 1998; Kleffmann et al., 1998; Stern et al., 2001) support the basic model of a décollement at depth. They also delineate Moho depths of $\sim 25 \mathrm{~km}$ to the southeast of the Southern Alps outside of the deforming orogen, and 40 to $50 \mathrm{~km}$ in the root zone below the Southern Alps (Fig. 2.3). Modelled seismic velocity contrasts within the crust (Davey et al., 1998) confirm this crust thickening under the Southern Alps, with the lower crust forming a crustal root while the middle and upper crust velocity contours are deflected upwards onto the Alpine Fault (Fig. 2.3). This geophysical evidence supports the earlier hypothesis of Wellman (1979) who noted that the need for a décollement in the midcrust and the accommodation of the lower crust by thickening and formation of a crustal root.

The down-dip projection of Alpine Fault is imaged as a reflection that dips southeast at $40 \pm 5^{\circ}$ (Davey et al., 1995; Davey et al., 1998; Kleffmann et al., 1998) from seismic velocity contrasts (Davey et al., 1998; Stern et al., 2001). The Alpine Fault zone (Davey et al., 1995; Fig. 2.3) is inferred from seismic reflections located at depths of 25-35 km to intercept the crustal Pacific Plate décollement at depths of 30-40 km (Kleffmann et al., 1998). Above the downward projections of the Alpine Fault at depths of $10-35 \mathrm{~km}$ a low seismic velocity zone of $5.5-5.8 \mathrm{~km} / \mathrm{s}$ (Fig. 2.3) has been imaged (Davey et al., 1998) as well as a zone of decreased resistivity (Wannamaker et al., 2002). These two features have both been interpreted as reflected a interconnected body fluid under lithostatic pressure which could reduce the work required for deformation in the lower crust (Stern et al., 2001).

Due to the fast exhumation rates in the central Southern Alps, high geothermal gradients and a shallow brittle-ductile transition zone have been inferred (Holm et al., 1989; Shi et al., 1996). A high near surface geothermal gradient of $\sim 60^{\circ} \mathrm{C} / \mathrm{km}$ has been calculated from heat flow data from a single drill hole in the Waima River (Fig. 1.1) and from thermal modelling of the central Southern Alps (Allis and Shi, 1995). Isotherms that have been advected upward on the inboard 


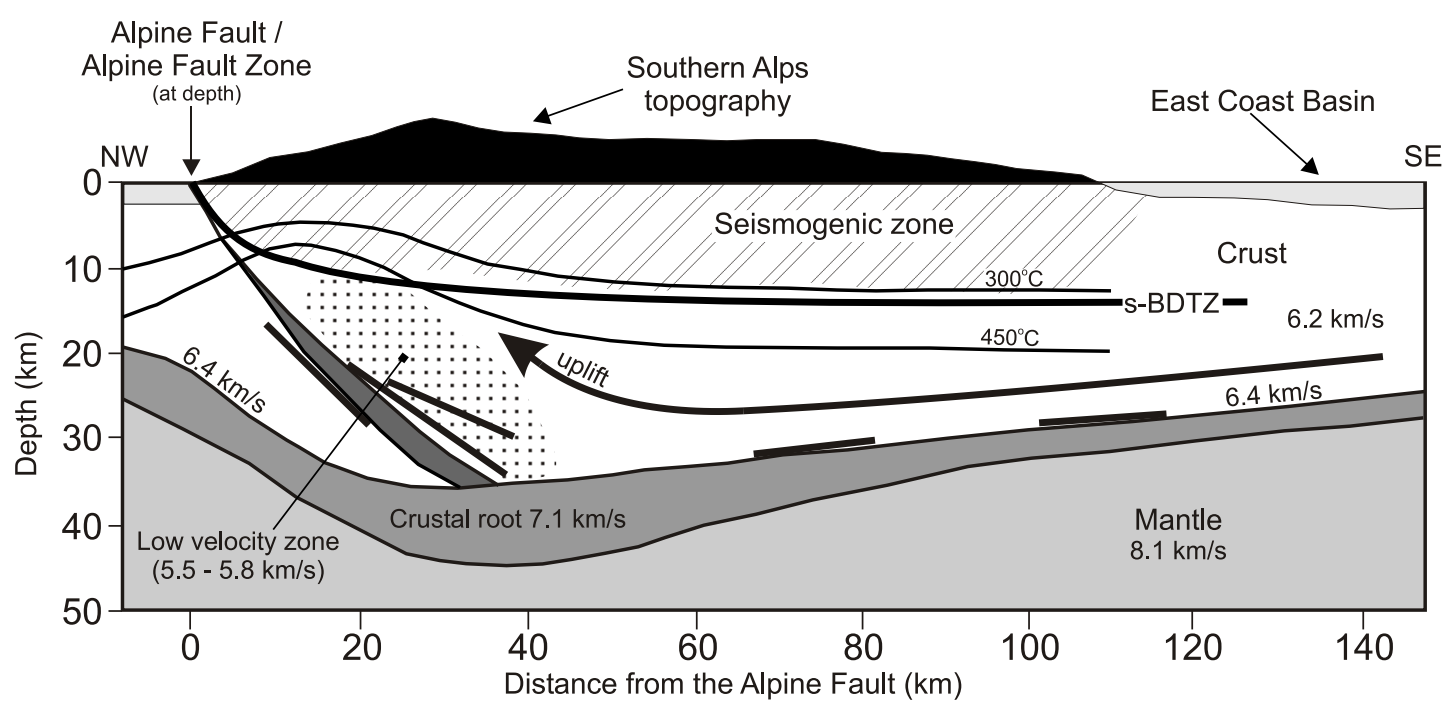

Fig. 2.3. Cross section through the Southern Alps with wave speed $(\mathrm{km} / \mathrm{s})$ contours from Davey et al. (1998) and Stern et al. (2001), Alpine Fault seismic reflectors from Stern et al. (2001), decollement seismic reflectors from Kleffmann et al. (1998) and the seismogenic zone (after Leitner et al., 2001). Modelled isotherms from Batt and Braun (1999). Seismically defined brittle-ductile transition zone (sBDTZ) illustrated at base of seismogenic zone at 10-12 km depth.
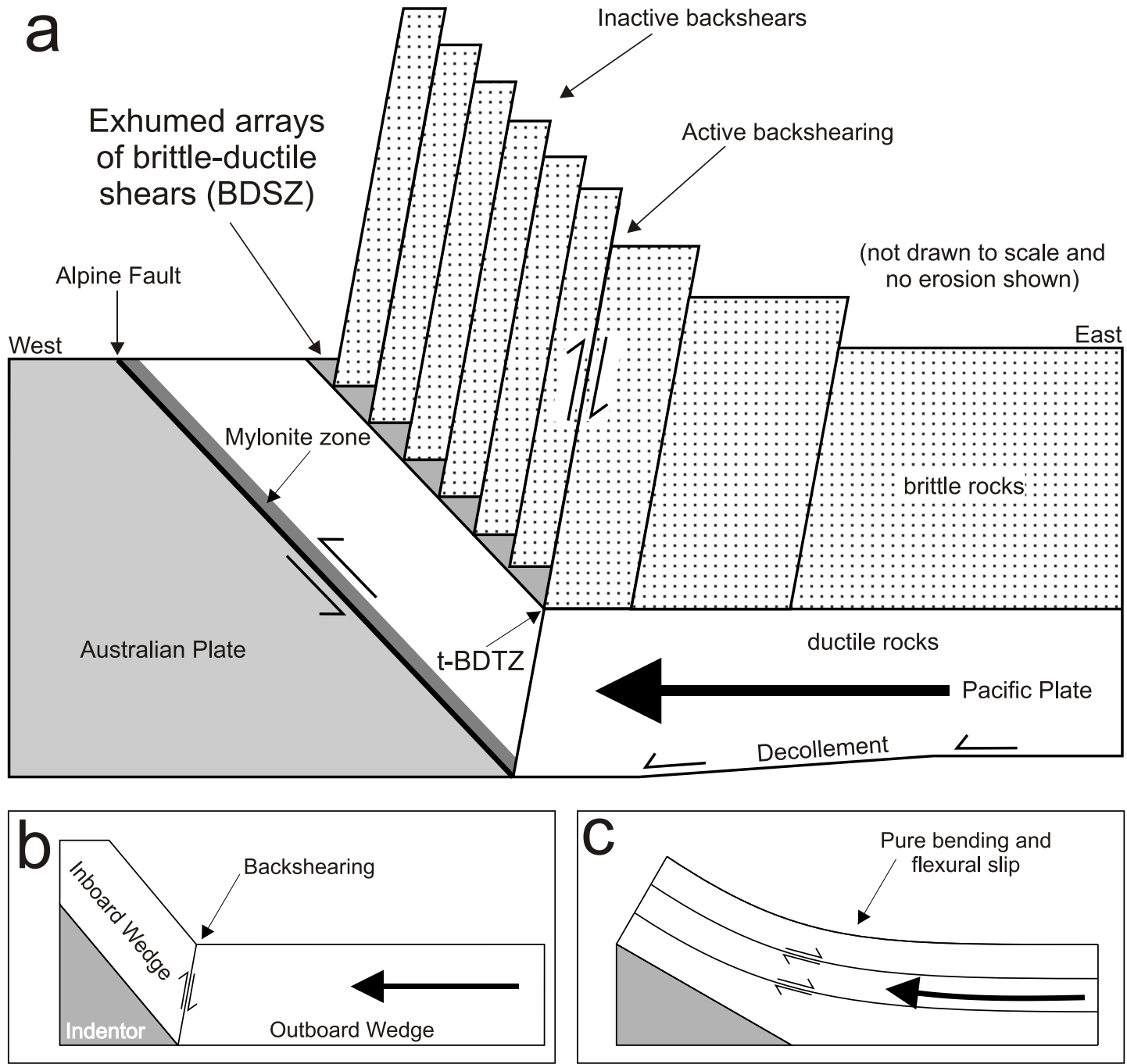

Fig. 2.4. Schematic cross sections through the Southern Alps of New Zealand. a. Cartoon simplification of backshearing model of Little et al. (2002b) showing the transient brittle-ductile transition zone (tBDTZ) and the exhumed brittle-ductile shear zone (BDSZ). b. Cartoon illustration of backshearing model after Sanderson (1982) and Little et al. (2002b) with labels for two-sided orogen model used in Koons (1990) and location of backshearing zone. c. Cartoon model of flexural bending after Sanderson (1982). 
wedge during convergence have been modelled using the finite element method for two-sided orogens like the Southern Alps by Batt and Braun (1999). This advection of the isotherms (Fig. 2.3) is due to the inability of the rapidly exhumed hanging wall of the Alpine Fault to dissipate heat as it is uplifted and is inferred to thermally weaken the hanging wall block (Koons, 1987; Batt and Braun, 1999). Crustal temperatures within $2 \mathrm{~km}$ of the surface are inferred to range between $140^{\circ}$ and $350^{\circ} \mathrm{C}$ and are consistent with hot springs found in the central Southern Alps and the mixing between meteoric and metamorphic fluid within this shallow depth range (Allis et al., 1979). A brittle-ductile transition zone 6-8 $\mathrm{km}$ below the surface found from modelling of fluid inclusion analyses was suggested by Holm et al. (1989) and a transition at 10-12 $\mathrm{km}$ was inferred from a shallow seismogenic zone by Leitner et al. (2001). This depth is shallower than other brittle-ductile transitions in the continental crust, which commonly occur at depths of 10-15 km (Stöckhert et al., 1999).

The uplift and exhumation of the Pacific Plate can be described in the context of a two-sided orogen, for example Koons (1990). An outboard wedge (the Pacific Plate) transported west across a basal décollement. Ultimately, the Pacific Plate rocks collide with a less deformable or "rigid" indentor (the Australian Plate and Alpine Fault foot wall), which causes the outboard wedge to ramp upward as the inboard wedge. This ramped crust forms the western flank of the resultant Southern Alps mountain range and undergoes rapid erosion due to the prevailing westerly airflow and its associated orographic climate regime.

The work of Little et al., (2002a) on the brittle-ductile shears indicate that structural deformation of the Pacific Plate in the central Southern Alps during its uplift onto the Alpine Fault ramp is best described by a backshearing process (Fig. 2.4a; e.g. Sanderson, 1982; Bonini et al., 2000). Pacific Plate rocks that encounter the Alpine Fault ramp are cut by a zone of shearing that is up-to-the-west and which tilts material up onto the dipping fault ramp (Fig. 2.4b; e.g. Beaumont et al., 1996; Batt and Braun, 1999; Little et al., 2002b; Little, 2004). Today these backshears are exposed at the surface as brittle-ductile shears in the BDSZ's, 6-8 km structurally above the Alpine Fault. These exhumed shear zones have near vertical shear planes and a dextral, west-side-up sense of shear that is antithetic to dip-slip on the Alpine Fault (Little et al., 2002a). Little et al. (2002b) have argued that these arrays of shear 
zones have been produced from a sequential activation of shears required for rock particles to move across the step at the base of the ramp. Once a shear has accomplished the tilting on the fault ramp it is translated away from the base of the ramp it, and eventually abandoned in favour of formation of a new shear at the base of the ramp. The inactive shears are passively translated up the Alpine Fault ramp where they are eventually exposed at the surface (Fig. 2.4a). Little et al. (2005) have argued that the slightly steeper dip of the Alpine Fault in the central Southern Alps causes backshearing to occur as the accommodation mechanism for deformation at the fault ramp bend rather than flexural bending processes that might accommodate a more gentle change in dip at the base of the ramp (Fig. 2.4c).

One can define two different types of brittle-ductile transition zones (BDTZ's) in the Southern Alps. The first is the contemporary seismically defined BDTZ (s-BDTZ) as expressed by the base of the seismogenic zone at 10-12 km (Leitner et al., 2001). Presumably this marks the base of brittle deformation in the crust at the prevailing strain-rates and temperature structure. The s-BDTZ is to a large degree thermally controlled and fixed relative to the topographic surface. Rock particles flux though the s-BDTZ as they are transported upward along the Alpine Fault (Holm et al., 1989).

A second type of BDTZ can be defined in the Southern Alps, a palaeo-BDTZ. This BDTZ coincides with the BDSZ in the biotite zone Alpine Schist. Wightman (2005) has shown that these shears were formed during a transient deep embrittlement of the mid-crust at $21 \pm 5 \mathrm{~km}$ beneath the Southern Alps, during shearing of the Pacific Plate rocks as they negotiated the step onto the Alpine Fault ramp (Fig. 2.4a). This palaeo-BDTZ in the mid-crust formed due to transiently elevated strain-rates and fluid pressures associated with the ramp bend that allowed deep embrittlement of crust that otherwise would be deforming ductilely. We refer to this transient palaeo-BDTZ, which is represented by specific structures in the rocks, as the t-BDTZ.

Some predictions have been made about the conditions during deformation in t-BDSZ of this study from experimental modelling, mineral thermometry and thermochronology. High strain-rates and differential stresses have been modelled at the base of indentor fault ramps from thermally coupled modelling and numerical 
mechanical models (e.g. Batt and Braun, 1999; Erickson et al., 2001). These models can explain the formation of a deep t-BDSZ as rock particles move through the backshearing zone. There, conditions of high differential stress and strain-rate are inferred to occur above the base of the ramp. These conditions, as well as high pore fluid pressures (Wightman, 2005), triggered transient brittle deformation of the Pacific Plate crust in the t-BDTZ significantly deeper than the modern s-BDTZ. Wightman (2005) has estimated deformation temperatures in this t-BDTZ from stable oxygen isotope thermometry and chlorite thermometry of quartz-calcite veins that infill the brittle-ductile shear and from ${ }^{40} \mathrm{Ar}-{ }^{39} \mathrm{Ar}$ thermochronology of muscovite in schist surrounding the BDSZ. These analyses indicate temperatures and of shear zone deformation of $450 \pm 50^{\circ} \mathrm{C}$ and at depths of $21 \pm 5 \mathrm{~km}$. Because the brittle-ductile shears formed at greater depths and higher temperatures than the sBDTZ they may have undergone further ductile deformation as they were translated upwards through the mid to upper crust, presumably under slower strain-rate conditions than the fast transient strain-rates that initiated deep embrittlement and formation of the brittle-ductile shears. 


\section{CHAPTER 3: Field based structural geology of the brittle-ductile shear zones}

Field studies involving collection of detailed structural data and sampling of brittle-ductile shears has been undertaken at Sam Peak, Chancellor Ridge and Baumann Glacier (Fig. 1.1). These field areas all have superb exposures of Alpine Schist on smooth glaciated outcrops that provide excellent continuous outcrop for more than $100 \mathrm{~m}$ in some locations. The field areas are situated $6-8 \mathrm{~km}$ structurally above the Alpine Fault and are in biotite zone schist (Fig. 2.2). Field studies of the exposed brittle-ductile shear zones in these areas included mapping, sampling, measurement of structural data and detailed structural surveys of spacing and slip of individual shears within the exposed brittle-ductile shear zones (BDSZ's). This field work aimed to define the structural extent of the BDSZ, to quantify the amount brittle-ductile slip across the shear zones, and to calculate the finite strain accumulated in deformed veins offset by individual shear zones.

Structural mapping techniques were used to measure the attitude of foliation planes, lineation directions and offset veins in the BDSZ. The orientation of $\mathrm{S}_{2}$ and $\mathrm{S}_{3}$ foliation planes were measured as well as shear planes $\left(\mathrm{S}_{4}\right)$ and displaced marker veins within the individual shear zones. $\mathrm{L}_{2 \times 3}$ intersection lineations were calculated from the intersection of the two foliations $\left(\mathrm{S}_{2}\right.$ and $\left.\mathrm{S}_{3}\right)$ and also measured directly as crenulation lineations. The intersection lineations and the changing vergence between the two foliations were used to map the position and attitude of large kilometre-scale $\mathrm{F}_{3}$ fold structures in the Alpine Schist. Detailed measurements were made on individual $\mathrm{S}_{4}$ shear zones of the orientation of the shear planes, fabric elements in the Alpine Schist, and the displaced quartz vein markers. In addition, separations of the veins across the shears were recorded and the pitch of any fault surface lineations. Detailed structural surveys were conducted at four sites within the BDSZ to quantify the amount of offset and deformation accommodated across the array; three surveys were undertaken on Chancellor Ridge and on at Baumann Glacier. This chapter discusses the results from the structural mapping and detailed shear zone surveys and proposes a deformation sequence to explain the brittle-ductile deformation observed in the shear zones. 


\subsection{Structural mapping of the field sites}

\subsubsection{Sam Peak}

Sam Peak is located to the southwest of Fox Glacier, $\sim 8 \mathrm{~km}$ southeast of the Alpine Fault, and was the southern-most field area examined in this study. The 3 km-wide field area (Fig. 3.1) can be divided into two sections: the western section consists of patchy outcrop of dominantly pelitic schist; and the eastern section where a $\sim 1 \mathrm{~km}$-wide shear array is superbly exposed on glaciated rock platforms in dominantly psammitic schist. The schist in the western section is comprised of $\mathrm{F}_{3^{-}}$ crenulated sections of psammite within $>100 \mathrm{~m}$ thick dark grey pelitic schist sequences (e.g. Figs. 3.2a and 3.2b). This schist has been identified as part of the Aspiring Terrane based on this dominantly pelitic composition. In the eastern section thick-bedded sequences of psammitic schist with a phyllitic cleavage are found with only minor 1-10 m sequences of pelite. This section has been identified as part of the Torlesse Terrane (Fig. 3.1a) based on the absence of thick pelitic schist sequences. Textural zone (TZ) boundaries, defined after Turnbull et al. (2001), have been mapped from field observations of the rock textures and by optical microscopy. The eastern section contains TZ's $2 b$ and 3 and the western section contains TZ's 3 and 4. The location of the boundaries between these TZ's is shown in Fig. 3.1a.

The Alpine Schist exposed in the Sam Peak area contains both the $S_{2}$ and $S_{3}$ foliations. The mean orientation of $\mathrm{S}_{3}$ is 200@89 NW $\pm 7^{\circ}$ (95\% elliptical confidence cone about the planes pole), with variable $S_{2}$ orientations due to $F_{3}$ folding. The changing vergence between these two foliation planes indicates an $F_{3}$ antiform in the middle of the western section with a fold hinge orientation of 211, $26^{\circ}$ (Figs. 3.1a and 3.1b). This large km-scale folding was accompanied by cm-scale crenulation of the $S_{2}$ foliation with $S_{3}$ seen parallel to the axial plane of these crenulations (Fig. 3.2a). Where $\mathrm{S}_{3}$ was observed as a crenulation foliation, the intersection of the two foliation planes (Fig. 3.2b) defines a fold hinge lineation, $\mathrm{L}_{2-3}$ (Fig 3.2c). The mean $\mathrm{L}_{2-3}$ lineation measured in the field of $215,27^{\circ} \pm 3^{\circ}(95 \%$ elliptical confidence cone) matches well with the pole to the $S_{2} \pi$-girdle (Fig. 3.1c). Extensional features in the schist such as necked and boudinaged quartz veins were also observed near the $F_{3}$ fold hinge (Fig. 3.2b). Quartz veins, found commonly 

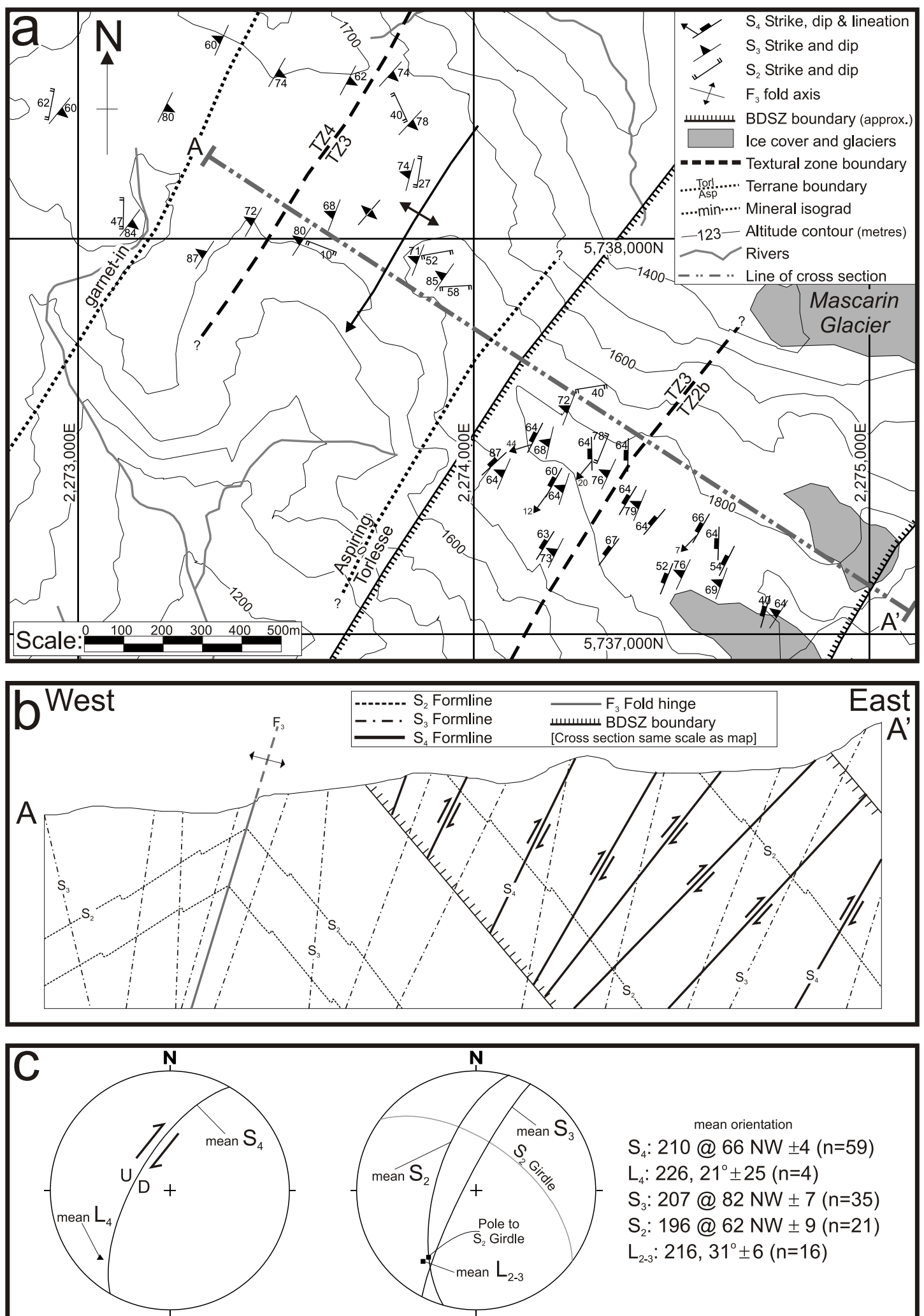

mean orientation

$\mathrm{S}_{4}: 210 @ 66 \mathrm{NW} \pm 4(\mathrm{n}=59)$

$\mathrm{L}_{4}: 226,21^{\circ} \pm 25(\mathrm{n}=4)$

$\mathrm{S}_{3}: 207 @ 82 \mathrm{NW} \pm 7(\mathrm{n}=35)$

$\mathrm{S}_{2}: 196 @ 62 \mathrm{NW} \pm 9(\mathrm{n}=21)$

$\mathrm{L}_{2-3}: 216,31^{\circ} \pm 6(n=16)$

Fig. 3.1. Structural geology of Sam Peak in the Southern Alps of New Zealand. a. Structural map of the Sam Peak field area with mapped mineral isograds, textural zones (after Turnbull et al., 2001), terrane boundaries and brittle ductile shear zone (BDSZ) boundaries. Alpine Schist foliations of $\mathrm{S}_{2}$ and $\mathrm{S}_{3}$, brittleductile shear planes $\left(\mathrm{S}_{4}\right)$ and major $\mathrm{F}_{3}$ folds are plotted. Altitude contours are spaced at $100 \mathrm{~m}$ intervals, taken from the LINZ 1:50,000 topographic digital data set. Projected grid system is New Zealand Map Grid with units in metres. b. Cross section through line A-A' at the same scale as (a) with schematic formlines of major structures and foliations. c. Stereographic, lower hemisphere, equal area projections of mean foliation planes and lineations calculated from measured structural field data. Full stereographic scatter plots available in Fig. 3.6 with data listed in Appendix A. Uncertainties represent a 95\% confidence ellipse about the line or pole to the plane. 



Fig. 3.2. Alpine Schist in the Sam Peak field area. a. Pelitic schist with crenulated $\mathrm{S}_{2}$ foliation with $\mathrm{S}_{3}$ foliation visible as axial planes to the folding. b. Pelitic schist with $\mathrm{S}_{2}$ and $\mathrm{S}_{3}$ foliations visible and a necked quartz-carbonate vein. c. Crenulated psammitic schist with crenulated lineation clearly visible. All photographs taken with $58 \mathrm{~mm}$ lens cap for scale. d. Glaciated platform covered with some snow near Crozet Peak with Sam Peak and Craig Peak silhouetted by the cloud in the distance to the west. 
throughout the field area, are often discordant to the $\mathrm{S}_{3}$ foliation in the Alpine Schist and have been folded by $F_{3}$ about axial planes parallel to $S_{3}$.

Brittle-ductile shears occur in the eastern section of the Sam Peak field area (Fig. 3.1a). The brittle-ductile shears are located in a zone $\sim 1 \mathrm{~km}$-wide but are not found in the adjacent Aspiring Terrane schist to the west. The base of the BDSZ must therefore lie to the west of the mapped $\mathrm{S}_{4}$ shears but east of the terrane boundary (Fig. 3.1a and 3.1b), but was not actually observed in outcrop. BDSZ boundary in the west is defined passed on where the $\mathrm{S}_{4}$ shears are no longer present. The flat glaciated surfaces in this eastern section of Sam Peak (Fig. 3.2d) provide excellent exposure for the detailed study of these features. The brittle-ductile shears crosscut both foliations in the Alpine Schist and have displaced quartz-carbonate veins in the schist that act as markers of brittle-ductile deformation with variable components of ductile shearing and brittle slip. The shear planes $\left(\mathrm{S}_{4}\right)$ have a mean orientation of $210 @ 66 \mathrm{NW} \pm 4^{\circ}$. Mineral fibre lineations were observed on the surface of some 1-10 mm-thick quartz-carbonate veins that infill brittle fractures along the shear zone. These lineations are defined by aligned fibrous calcite or chlorite grains and have a mean orientation of $226,21^{\circ} \pm 25^{\circ}$. They are referred to here as $\mathrm{L}_{4}$. Markers of brittle-ductile deformation include quartz-carbonate veins in the schist as well as the foliation and other and layering (e.g. bedding) all indicating a consistent west-side-up sense of dip-slip and dextral sense of strike-slip motions along the shears. Structural data for the Sam Peak field area is documented in Appendix A.

Open cavity veins that infilling the brittle fractures were also found in the Sam Peak area and had a distinctly different texture to the thinner, fibrous veins that commonly infill the brittle-ductile shears. The thick open cavity veins were up to $100 \mathrm{~mm}$ wide, consisting of large (some greater than $5 \mathrm{~mm}$ in diameter) quartz and calcite crystals, that are often euhedral in form, are texturally distinct from the more typically fine-grained and commonly fibrous veins that infill the shears. Similar open-cavity veins have been described by Craw et al. (1987) and Teagle et al. (1998) from the Callery River headwaters and Almer Ridge in the central Southern Alps, and interpreted as hydrothermally deposited veins. These open cavity veins also occur at Chancellor Ridge and Baumann Glacier field areas but are not as abundant 
as at Sam Peak field. These veins, where they infill the brittle-ductile shears, probably represent shallow subsurface reactivation of the $S_{4}$ shears, resulting in precipitation of the coarse grained hydrothermal veins at a much later time than the brittle-ductile deformation that initiated the shear zones (Wightman, 2005).

\subsubsection{Chancellor Ridge}

Chancellor Ridge is located next to Fox Glacier, $\sim 7 \mathrm{~km}$ east of the Alpine Fault (Fig. 1.1). This field site has been divided into three sections based on the textural grade of the schist. The eastern section is comprised of psammitic schist classified as TZ 2b (Fig. 3.3a) with a phyllitic cleavage (Fig. 3.4a). This section is comprised of biotite zone schist that is psammite-dominated in composition and is here attributed to a Torlesse Terrane protolith. The middle section consists of TZ 3 Alpine Schist (Fig. 3.3a). This section has the same composition psammitic Alpine Schist as in the eastern section however the foliation is more developed and is defined by the macroscopically visible biotite and muscovite minerals. The western section is structurally deeper than the other two and closest to the Alpine Fault (Fig. 3.3b) and is comprised of TZ 4 psammitic schist (Fig. 3.4b) attributed to the Torlesse Terrane and pelitic schist attributed to the Aspiring Terrane. The Torlesse Terrane schist is biotite grade like the other two sections, but has a visibly layered schistosity defined by mica and quartzite domains. The transition to Aspiring Terrane schist is defined by a sharp contact between TZ 4 psammitic schist and pelitic schist with metabasite and metachert units 10-20 m thick.

The Alpine Schist exposed throughout the Chancellor Ridge field area includes both the $S_{2}$ and $S_{3}$ foliations. In the western section the two foliations are typically at an angle of $\sim 15^{\circ}$ to each other (Fig. 3.4b) and define a vergence direction which indicates an antiform to the northwest (Fig. 3.3b). In the central section the $S_{3}$ foliation is near parallel to the weakly crenulated $S_{2}$ foliation, but in the eastern section only a single phyllitic $\mathrm{S}_{2}$ cleavage is present (Fig. 3.4a). The mean orientation of the $\mathrm{S}_{2}$ and $\mathrm{S}_{3}$ foliations is 036@71 SE $\pm 17^{\circ}$ and 033@77 SE $\pm 3^{\circ}$ respectively (Fig. 3.3c). Intersection and crenulation lineations $\left(\mathrm{L}_{2-3}\right)$ measured in the field area have a mean direction of $214,29^{\circ} \pm 7^{\circ}$ (Fig. 3.3c). Quartz-carbonate veins that are 5-20 $\mathrm{mm}$ were found in the Alpine Schist where they are folded and 

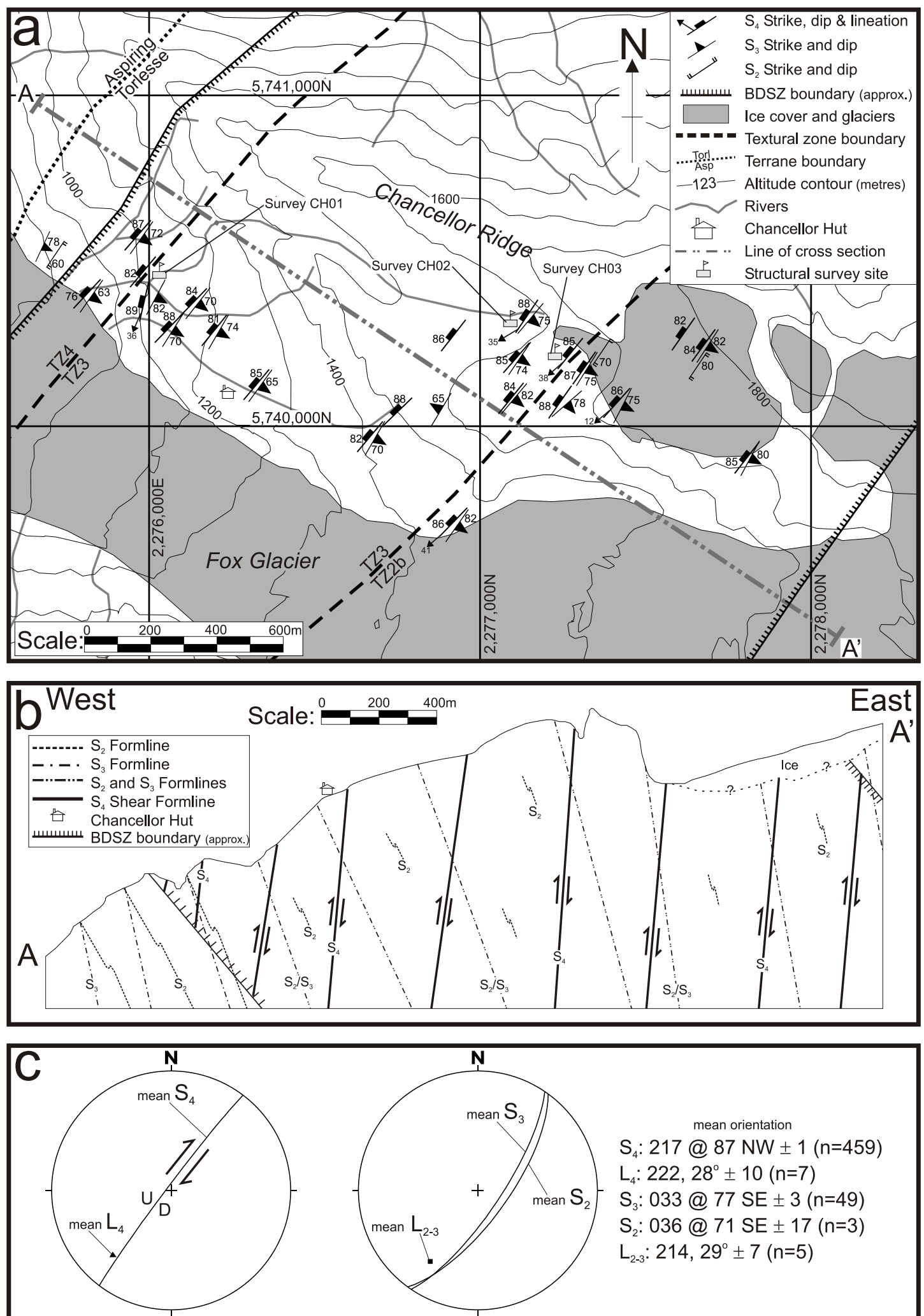

mean orientation

$\mathrm{S}_{4}: 217 @ 87 \mathrm{NW} \pm 1(\mathrm{n}=459)$

$L_{4}: 222,28^{\circ} \pm 10(n=7)$

$\mathrm{S}_{3}: 033 @ 77 \mathrm{SE} \pm 3(\mathrm{n}=49)$

$\mathrm{S}_{2}: 036 @ 71 \mathrm{SE} \pm 17(\mathrm{n}=3)$

$\mathrm{L}_{2-3}: 214,29^{\circ} \pm 7(n=5)$

Fig. 3.3. Structural geology of Chancellor Ridge in the Southern Alps of New Zealand. a. Structural map of the Chancellor Ridge area with mapped, textural zones (after Turnbull et al., 2001), terrane boundaries and brittle ductile shear zone (BDSZ) boundaries. Alpine Schist foliations $\mathrm{S}_{2}$ and $\mathrm{S}_{3}$, and brittle-ductile shear planes $\left(\mathrm{S}_{4}\right)$ are plotted. Altitude contours are spaced at $100 \mathrm{~m}$ intervals, taken from the LINZ 1:50,000 topographic digital data set. Projected grid system is New Zealand Map Grid with units in metres. b. Cross section through line A-A' with formlines for major structures, foliations and Chancellor Hut for reference. c. Stereographic, lower hemisphere, equal area projections of mean planes calculated from measured structural field data. Full stereographic scatter plots available in Fig. 3.6 with data listed in Appendices A and B. Uncertainties represent a 95\% confidence ellipse about the line or pole to the plane. 

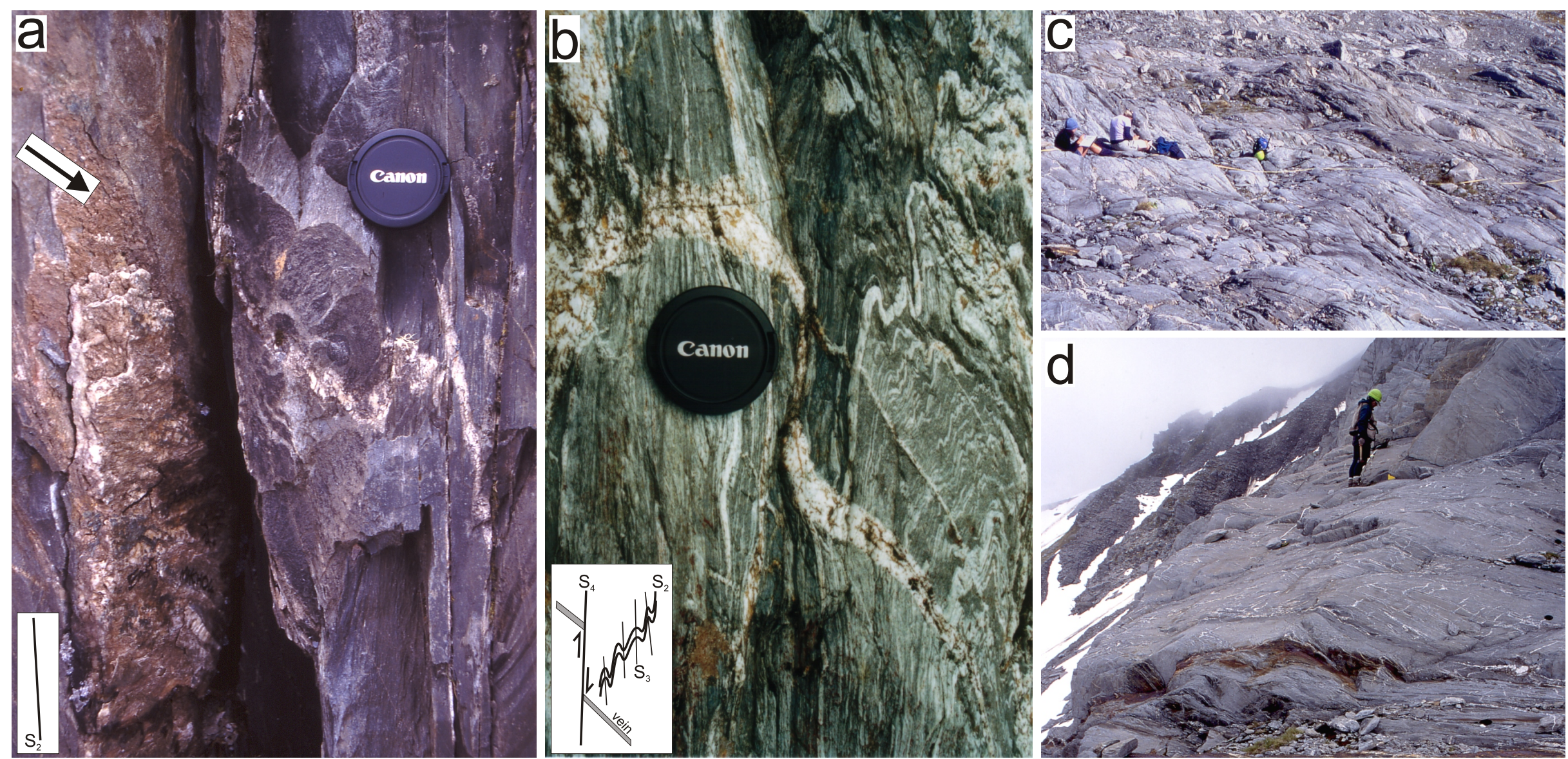

Fig. 3.4. Alpine Schist on Chancellor Ridge and structural surveys on Chancellor Ridge and Sam Peak. a. Psammitic schist in textural zone $2 \mathrm{~b}$ with a millimeter scale phyllitic cleavage. $\mathrm{S}_{2}$ foliation is visible with quartz-carbonate vein that infills a brittle shear $\left(\mathrm{S}_{4}\right)$ that has a mineral fibre lineation on the surface (marked with arrow). b. Alpine Schist from textural zone 4 with well defined $\mathrm{S}_{2}$ schistosity. Schistosity is folded with $\mathrm{S}_{3}$ cleavage visible parallel to the fold hinges. Quartz-carbonate vein is displaced by brittle-ductile shear $\left(\mathrm{S}_{4}\right)$ that crosscuts all foliations. Glaciated platform with geologists R. H. Wightman and K. J. Wilson working on structural survey CH03 on Chancellor Ridge. d. Glaciated platform at Baumann Glacier with geologist A/Prof. T. A. Little working on structural survey BM01. 
crenulated across folds that are axial planar to the $S_{3}$ foliation. These veins are typically $<5 \mathrm{~m}$ in length.

Brittle-ductile shears were observed in all three sections on Chancellor Ridge with the best exposures of the arrays occurring in the eastern section on glacially eroded platforms (Fig. 3.4c). The shear arrays in the central and western sections crop out between tussock fields and in incised river channels leading down toward Fox Glacier. The eastern BDSZ boundary was not seen in the field because of excessive seasonal snow and ice, but can be approximately located using aerial photographs (see section 3.2.1). The western structurally lower BDSZ boundary was located in the western section along the margin of Fox Glacier where brittle-ductile deformation was no longer seen in the Alpine Schist on distinct shear planes.

The shear planes $\left(\mathrm{S}_{4}\right)$ at Chancellor Ridge have a mean orientation of $217 @ 87 \mathrm{NW} \pm 1^{\circ}$ with mean spacing between the shears varying from $\sim 2 \mathrm{~m}$ in the western section to $\sim 10 \mathrm{~mm}$ in the eastern section. Like the shear arrays found at Sam Peak, the Chancellor Ridge shear arrays offset quartz-carbonate veins in the host rocks and the Alpine Schist foliation by a variable combination of ductile shearing and brittle slip. Displaced veins and foliations consistently indicate west-side-up dip-slip and dextral strike-slip shear senses throughout the BDSZ. The shear planes are commonly filled with quartz-carbonate veins $1-10 \mathrm{~mm}$ thick preserve a mineral fibre lineation $\left(\mathrm{L}_{4}\right)$ defined by fibrous calcite and chlorite on the vein margin, that has a mean orientation of $222,28^{\circ} \pm 10^{\circ}$. All structural data for the Chancellor Ridge field area is listed in Appendix A.

\subsubsection{Baumann Glacier}

The Baumann Glacier field area is located around the Baumann, Fritz and Andermatten Glaciers (Fig. 3.5a) and is the northernmost field area in this study, situated $1.5 \mathrm{~km}$ south of Franz Josef Glacier (Fig. 1.1). This field area is located $\sim 6$ $\mathrm{km}$ east of the Alpine Fault and field mapping was limited to outcrops exposed through unseasonably extensive snow and ice. There the Alpine Schist is biotite grade and consists dominantly of psammite with an inferred Torlesse Terrane protolith. Outcrops of Aspiring Terrane metabasites were seen to the northwest from a distance across the Baumann Glacier. There green and red coloured outcrops occur near the boundary between TZ 4 and TZ 3 outcropping on the steep southeast slope 

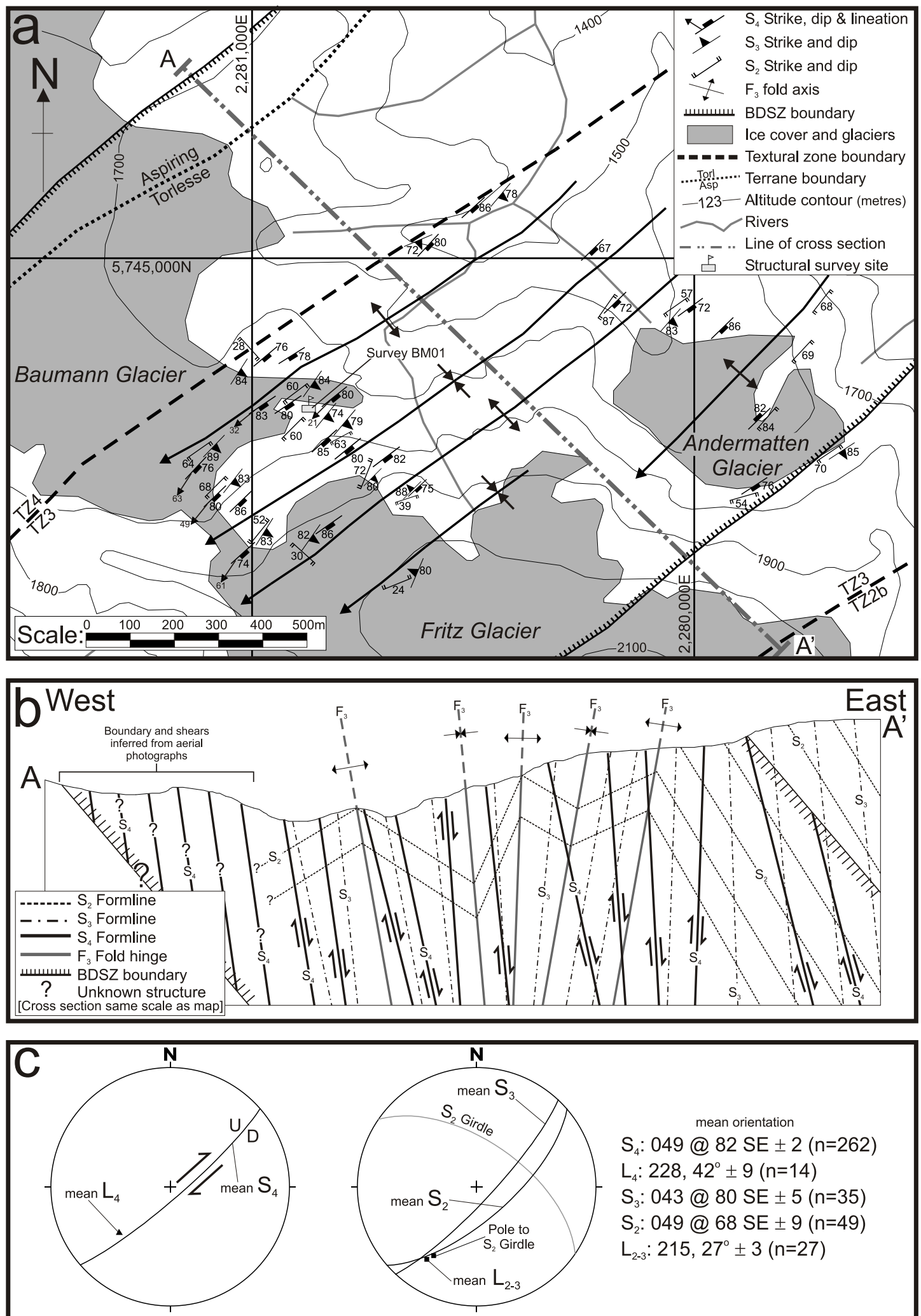

mean orientation

$\mathrm{S}_{4}: 049 @ 82 \mathrm{SE} \pm 2(\mathrm{n}=262)$

$L_{4}: 228,42^{\circ} \pm 9(n=14)$

$\mathrm{S}_{3}: 043 @ 80 \mathrm{SE} \pm 5(\mathrm{n}=35)$

$\mathrm{S}_{2}: 049 @ 68 \mathrm{SE} \pm 9(\mathrm{n}=49)$

$L_{2-3}: 215,27^{\circ} \pm 3(n=27)$

Fig. 3.5. Structural geology of the Baumann Glacier region in the Southern Alps of New Zealand. a. Structural map of the Baumann Glacier area with mapped textural zones (after Turnbull et al., 2001), terrane boundaries and brittle ductile shear zone (BDSZ) boundaries. Alpine Schist foliations, $\mathrm{S}_{2}$ and $\mathrm{S}_{3}$, brittle-ductile shear planes $\left(\mathrm{S}_{4}\right)$, and major $\mathrm{F}_{3}$ folds are plotted. Altitude contours are spaced at $100 \mathrm{~m}$ intervals, taken from the LINZ 1:50,000 topographic digital data set. Projected grid system is New Zealand Map Grid with units in metres. b. Cross section through line A-A' at the same scale as (a) shows schematic formlines for major structures and foliations. Area of unmapped BDSZ has structure interpreted from aerial photographs. c. Stereographic, lower hemisphere, equal area projections of mean planes calculated from measured structural field data. Full stereographic scatter plots available in Fig. 3.6 with data listed in Appendices A and B. Uncertainties represent a 95\% confidence ellipse about the line or pole to the plane. 
of Mt Moltke (Fig. 1.1) to the northwest of Baumann Glacier. This approximate location of the Torlesse-Aspiring terrane boundary (Fig. 3.5a) matches unpublished maps of T. A. Little and B. R. Ilg who identified a fault which juxtaposes the Torlesse and Aspiring terrane lithologies. Two TZ boundaries are identified in this field area (Fig. 3.5a). The TZ $2 \mathrm{~b}$ to TZ 3 boundary was mapped based on field observations from this study and from unpublished maps of T. A. Little and B. R. Ilg. The TZ 3 to TZ 4 boundary was located based on field textural observations of the schistosity at the northwest extent of the outcrops observed in this study.

Most outcrops of Alpine Schist throughout the Baumann Glacier area have the $S_{2}$ and $S_{3}$ foliations. The mean orientation of $S_{3}$ is $043 @ 80 \mathrm{SE} \pm 5^{\circ}$ with the orientation of $\mathrm{S}_{2}$ varying throughout the field area (Fig. 3.5c). The location of $\mathrm{F}_{3}$ fold structures (three antiforms and two associated synforms) were mapped (Figs. $3.5 \mathrm{a}$ and $3.5 \mathrm{~b}$ ) on the basis of the changing vergence between these two foliations. Hinges of the $\mathrm{F}_{3}$ folds a have mean orientation of $215,31^{\circ}$. This large kilometrescale folding is accompanied by centimetre-scale crenulation of the $\mathrm{S}_{2}$ foliation with $\mathrm{S}_{3}$ axially planar to these crenulation folds. Intersection and crenulation lineations are parallel to the fold hinges with a mean orientation of $215,27^{\circ} \pm 3^{\circ}$. Quartzcarbonate veins in the Alpine Schist are generally $<5 \mathrm{~m}$ long. Some outcrops contained $30 \mathrm{~cm}$-long gash veins in arrays of 10 veins or more, spaced $\sim 20 \mathrm{~cm}$ apart. These gash veins are folded and crenulated with axial planes parallel to the $S_{3}$ foliation. Extensive ice and snow cover during the field season prevented study of the region to the northwest of the TZ 3 to TZ 4 boundary.

Arrays of brittle-ductile shears have been mapped from the southeast cirque walls of the Andermatten Glacier to the northwest side of the Baumann Glacier and both the upper and lower boundaries of the BDSZ can be approximately located (Fig 3.5a). Brittle-ductile shears occur as discrete fault-like planes that are spaced $\sim 15$ $\mathrm{cm}$ apart. They offset quartz-carbonate veins and the Alpine Schist foliations by variable components of ductile shearing and brittle slip. Shear planes $\left(\mathrm{S}_{4}\right)$ exposed on glaciated surfaces (Fig. 3.4d) have a mean orientation of 046@82 SE $\pm 2^{\circ}$ (Fig. 3.5c) and consistent west-side-up dip-slip and dextral strike-slip shear senses. Shears were not seen in the snow-covered northwest section of the field area, however, aerial photographs confirm their presence in these regions (see section 3.2.1). As at 
Sam Peak and Chancellor Ridge, some shear planes are filled by quartz-carbonate veins that are 1-10 mm thick. These infilling veins have mineral fibre lineations $\left(\mathrm{L}_{4}\right)$ composed of calcite and chlorite visible on the surface of the veins, with a mean orientation of $228,42^{\circ} \pm 9^{\circ}$; however, some infilling veins had more than one orientation of lineation on their surface or had a lineation which curved from a steep to shallow pitch within the same shear plane. All structural data collected from the Baumann Glacier field area in this study can be found in Appendix A.

\subsubsection{Variation in foliation and lineation orientations between the field areas}

The structural attitudes of the shear planes, schist foliations, and lineations are plotted in Fig. 3.6 and illustrate the changing orientation of the shear planes and the foliations from Sam Peak in the south to Baumann Glacier in the north. The Alpine folded $S_{2}$ foliation at Sam Peak (Fig. 3.6a) and Baumann Glacier (Fig. 3.6c) has a mean northeast strike and varies in dip from near horizontal to near vertical. The $\mathrm{S}_{2}$ foliations at Chancellor Ridge are consistently steeply dipping to the southeast with a northeast strike (Fig. 3.6b). The southwest plunging pole to the $\pi$ girdle is similar at both Sam Peak and Baumann Glacier, and matches well with the measured intersection lineations $\left(\mathrm{L}_{2-3}\right)$ and the plotted intersection of the $\mathrm{S}_{2}$ and $\mathrm{S}_{3}$ foliations in all three field areas (Fig. 3.6). The attitude of $S_{3}$ is similar across all the field areas with a common northeast strike and dip that is within $15^{\circ}$ of vertical. Mean structural attitudes for the field areas can be found in Table 3.1.

The brittle-ductile shear planes change their strike from NNE in the south at Sam Peak to NE strike in the north at Baumann Glacier (Fig. 3.6; Table 3.1; Fig. 3.7). This clockwise rotation of strike continues further north at Crawford Knob (Fig. 1.1; Table 3.1) where an ENE strike was measured by Wightman (2005). The average dip of $66^{\circ}$ northwest for the Sam Peak shear planes to the south is shallower than the Chancellor Ridge and Baumann Glacier shear planes that, on average, dip within $10^{\circ}$ of vertical (Fig. 3.7). This changing attitude of the shear planes has been related to the changing dip of the Alpine Fault ramp at depth by Little et al. (2005). The mineral fibre lineations found on quartz-carbonate veins infilling the shear zones vary in pitch from $80^{\circ}$ to $7^{\circ}$ southwest (Fig. 3.7). They have a mean trend and plunge of $226,35^{\circ} \pm 6.9^{\circ}$ as calculated for the combined data from Sam Peak, Baumann Glacier and Chancellor Ridge (Table 3.1). The lineations $\left(\mathrm{L}_{4}\right)$ appear to be slightly 

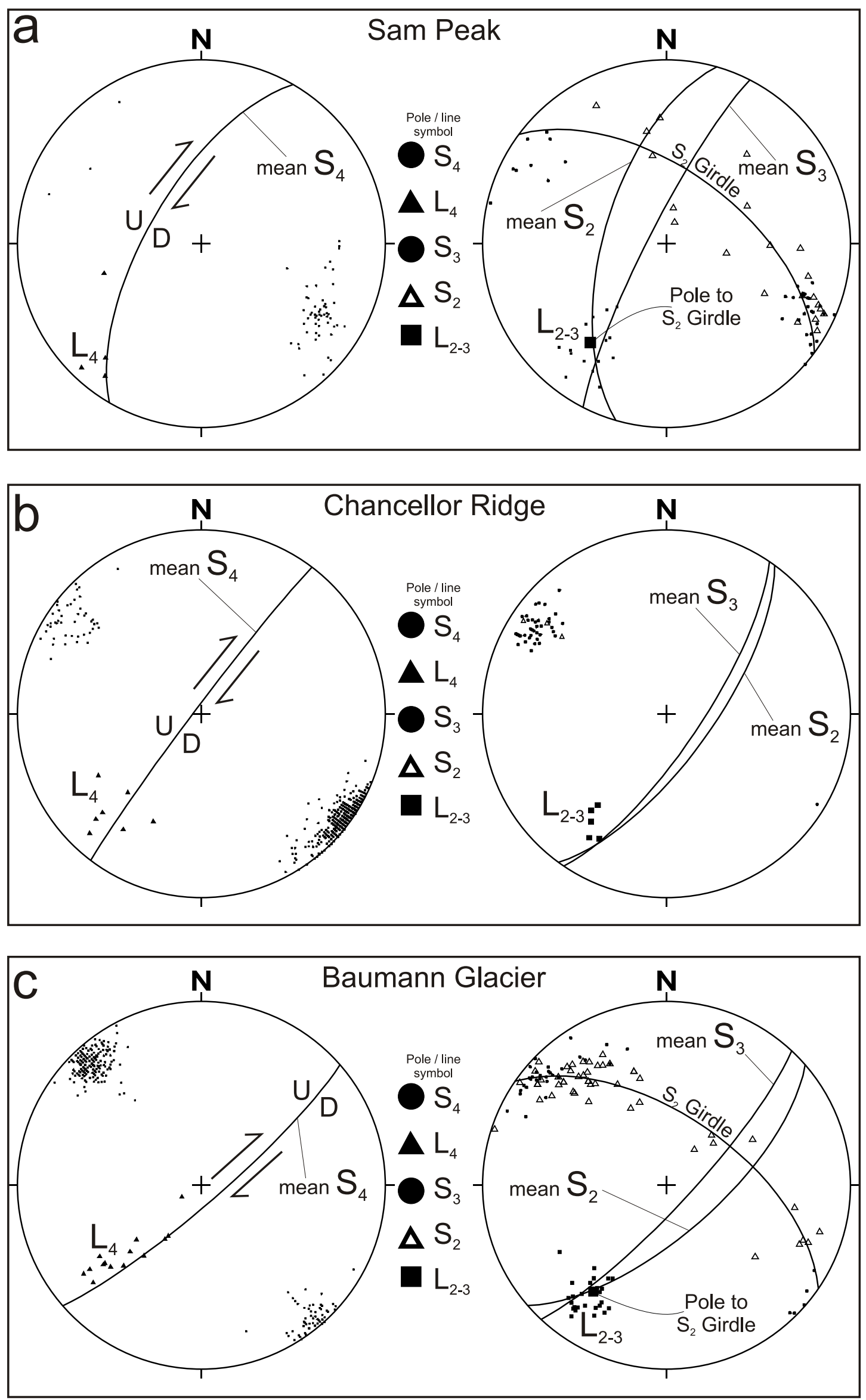

Fig. 3.6. Stereographic, lower hemisphere, equal area projections of foliation and shear planes and lineation lines for Sam Peak (a), Chancellor Ridge (b) and Baumann Glacier (c). Orientations are listed in Table 3.1 with data used to generate plots in Appendices A and B. 


\begin{tabular}{|c|c|c|c|c|c|c|c|c|c|c|c|c|}
\hline & \multicolumn{3}{|c|}{ Chancellor Ridge } & \multicolumn{3}{c|}{ Sam Peak } & \multicolumn{3}{c|}{ Baumann Glacier } & \multicolumn{3}{c|}{ Combined } \\
Plane / Line & mean & \pm & $\mathrm{n}$ & mean & \pm & $\mathrm{n}$ & mean & \pm & $\mathrm{n}$ & mean & \pm & $\mathrm{n}$ \\
\hline $\mathrm{S}_{4}$ & $217 @ 87 \mathrm{NW}$ & 0.8 & 459 & $210 @ 66 \mathrm{NW}$ & 4 & 59 & $049 @ 82 \mathrm{SE}$ & 1.5 & 262 & $221 @ 89 \mathrm{NW}$ & 1.1 & 780 \\
$\mathrm{~L}_{4}$ & $222,28^{\circ}$ & 10.3 & 7 & $226,21^{\circ}$ & 25.4 & 4 & $228,42^{\circ}$ & 8.9 & 14 & $226,35^{\circ}$ & 6.9 & 25 \\
$\mathrm{~S}_{3}$ & $033 @ 77 \mathrm{SE}$ & 2.9 & 49 & $207 @ 82 \mathrm{NW}$ & 6.7 & 35 & $043 @ 80 \mathrm{SE}$ & 4.7 & 35 & $034 @ 84 \mathrm{SE}$ & 3.4 & 119 \\
$\mathrm{~S}_{2}$ & $036 @ 71 \mathrm{SE}$ & 17.3 & 3 & $196 @ 62 \mathrm{NW}$ & 9.4 & 21 & $049 @ 68 \mathrm{SE}$ & 9.4 & 49 & $045 @ 73 \mathrm{SE}$ & 13.3 & 73 \\
Pole to $\mathrm{S}_{2}$ girdle & $213,08^{\circ}$ & 7.9 & 3 & $216,33^{\circ}$ & 6.9 & 21 & $215,31^{\circ}$ & 6.9 & 49 & $214,31^{\circ}$ & 7.5 & 73 \\
$\mathrm{~L}_{2-3}$ & $214,29^{\circ}$ & 7.2 & 5 & $216,31^{\circ}$ & 6.4 & 16 & $215,27^{\circ}$ & 3.7 & 27 & $216,28^{\circ}$ & 2.8 & 48 \\
\hline
\end{tabular}

[Crawford Knob: $\mathrm{S}_{4}: 240 @ 89 \mathrm{NW}(\mathrm{n}=1074)$ and $\left.\mathrm{L}_{4}: 241,39^{\circ}(\mathrm{n}=81)\right]$

Table 3.1. Mean values for planes and poles plotted in Fig. 3.6 calculated from data in Appendices A and B. Uncertainties in degrees for $95 \%$ elliptical confidence cone about a mean line or pole to plane. Crawford Knob data courtesy of Wightman (2005). Combined column represents an augmented data set from Chancellor Ridge, Sam Peak and Baumann Glacier data sets for measured planes and poles.

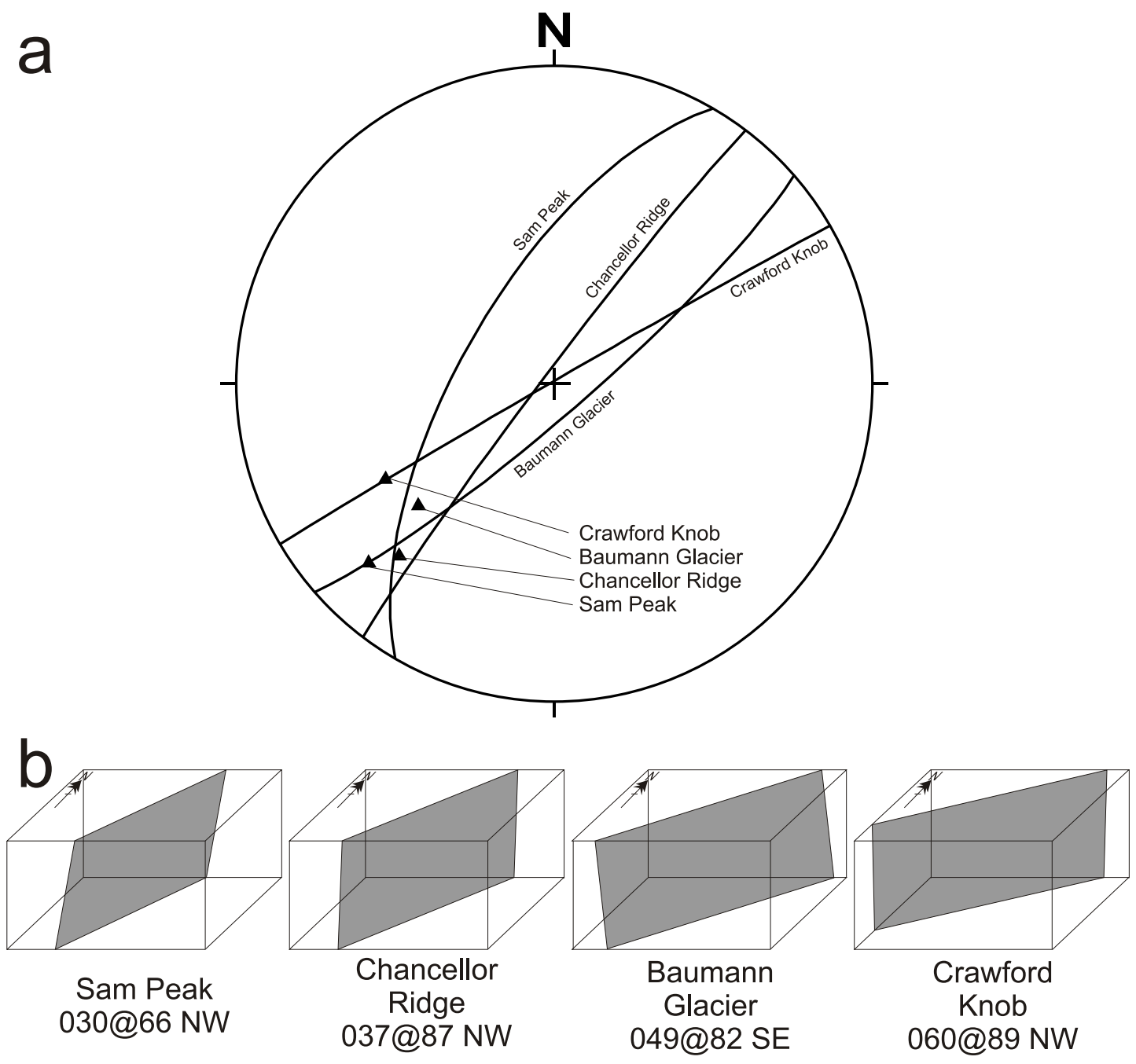

Fig. 3.7. Mean orientation of brittle-ductile shear planes from the main field areas and Crawford Knob. a. Stereographic, lower hemisphere, equal area projection of mean brittle-ductile shear planes and mineral fibre lineations for the main field areas. b. 3-dimensional block diagrams of the shear planes with the mean orientation listed with strike values all for the northeast end of the plane. 
steeper plunging in the northern field areas than the southern ones (Fig. 3.7a), but these differences are not statistically significant.

\subsubsection{Waiho River and Hare Mare Creek}

The Waiho River and Hare Mare Creek locations (Fig. 2.2) were chosen in order to compare the $\mathrm{CPO}$ behaviour of quartz in the higher grade non-mylonitic and mylonitic schist with the deformed veins in the BDSZ. These two field sites are located structurally below the BDSZ, closer to the Alpine Fault. The Waiho River site is located $\sim 4.5 \mathrm{~km}$ east of the Alpine Fault in the garnet zone non-mylonitic schist and Hare Mare Creek site is located $\sim 100$ m east of the Alpine Fault in amphibolite facies mylonitic rocks (Fig. 2.2). The Waiho River sample site occurs on the overturned limb of a large $\mathrm{F}_{3}$ antiform, referred to as a planar zone by Little et al., (2002a). There, $S_{2}$ and $S_{3}$ are a single parallel cleavage and lineations plunge moderately southwest and include crenulation lineations, intersection lineations and stretching lineations. Foliation and lineation data are listed in Appendix A and have mean orientations of $040 @ 79 \mathrm{SE} \pm 2.1^{\circ}$ and $206,50^{\circ} \pm 5.2^{\circ}$ respectively.

The Hare Mare Creek sample site is located in the Alpine Fault mylonite zone (Fig. 2.2) and is comprised of fine-grained micaceous mylonitic fault rocks which are well foliated and laminated into cleavage and microlithon domains. These domains are $<5 \mathrm{~mm}$ thick and defined by mica-dominated layers and quartzofeldspathic dominated layers. Locally, 5-15 $\mathrm{mm}$ chert bands lie parallel to this mylonitic foliation. S-C' shears, necked quartz bands, boudinaged hornblende porphyroblasts and rotated garnet porphyroblasts are observed in hand sample as well a northeast plunging mineral stretching lineation defined by the elongated quartz and hornblende porphyroclasts. Orientation for the mylonitic foliation $\left(\mathrm{S}_{\mathrm{m}}\right)$ and the mineral stretching lineation $\left(\mathrm{L}_{\mathrm{m}}\right)$ are in Appendix A and Appendix F. This foliation and lineation have mean orientations of $048 @ 30 \mathrm{SE} \pm 3^{\circ}$ and 105, 28 $\pm 7^{\circ}$ respectively.

\subsection{Observations of deformation in the BDSZ's}

\subsubsection{Brittle-ductile shear arrays}

Brittle-ductile shear arrays have been observed in aerial photographs in each of the three main field areas (not including the Waiho River and Hare Mare Creek sample sites), as well as in $\sim 100 \mathrm{~m}$ high cliff outcrops and directly on flat glaciated 
platforms at the scale of an individual shear zones spaced at $20 \mathrm{~cm}$. Aerial photographs of Chancellor Ridge and Baumann Glacier in Fig. 3.8 show the entire 2 $\mathrm{km}$-wide BDSZ and some of the individual shear zones. These shear zones are seen as distinct lineaments parallel to the strike of the brittle-ductile shears $\left(\mathrm{S}_{4}\right)$ and have allowed the upper and lower boundaries of the BDSZ to be mapped beyond the areas where foot access was possible. The lineaments seen on the aerial photographs are defined by the $\mathrm{S}_{4}$ fault planes in the schist along which differential erosion has caused the rock to weather and partition into slabs in preference to the more NNE striking Alpine Schist foliation. Wightman (2005) mapped the upper and lower boundaries from aerial photographs to define a 1-2 km wide zone of brittle-ductile shear arrays, located 6-8 km southeast of the Alpine Fault, that extend along strike from Sam Peak in the south to the Price Range above the Gunn River in the north (Fig. 2.2).

Distant views of cliff outcrops, in some cases greater than $100 \mathrm{~m}$ high, have been used to obtain a better understanding of the three-dimensional extent of the shear zones and their orientation with respect to the Alpine Foliation (Fig. 3.9). These exposures clearly revealed the brittle-ductile shear planes $\left(\mathrm{S}_{4}\right)$ cross cutting both the $S_{2}$ and $S_{3}$ foliations at an acute angle (Fig. 3.9a). The shears are more steeply dipping than $S_{3}$ at Chancellor Ridge (Fig. 3.9b) but shallower in dip than $S_{3}$ at Sam Peak (Fig. 3.9c). An approximately consistent $<10 \mathrm{~m}$ spacing and orientation of shear planes can be seen throughout all of these cliff exposures.

Outcrops of brittle-ductile shear arrays on glaciated surfaces of the Alpine Schist (Fig. 3.10) have been studied in detail with respect to their spacing, shear sense and separation or offset of displaced marker veins. Fig. 3.10a illustrates the superb glaciated exposure of Alpine Schist and the parallel fractures that represent shear zones with brittle-ductile offset. The fractures are spaced $\sim 20 \mathrm{~cm}$ apart (Figs. $3.10 \mathrm{~b}$ and 3.10c) and offset markers such as quartz-carbonate veins in the schist in both a dextral (Fig. 3.10d) and a west-side-up (3.10e) shear sense. These quartzcarbonate veins are commonly serially displaced across a series of adjacent shear zones (Fig. 3.10d), and make excellent markers for analysis of shear-related deformation caused by repeated slip across faults in the array. 

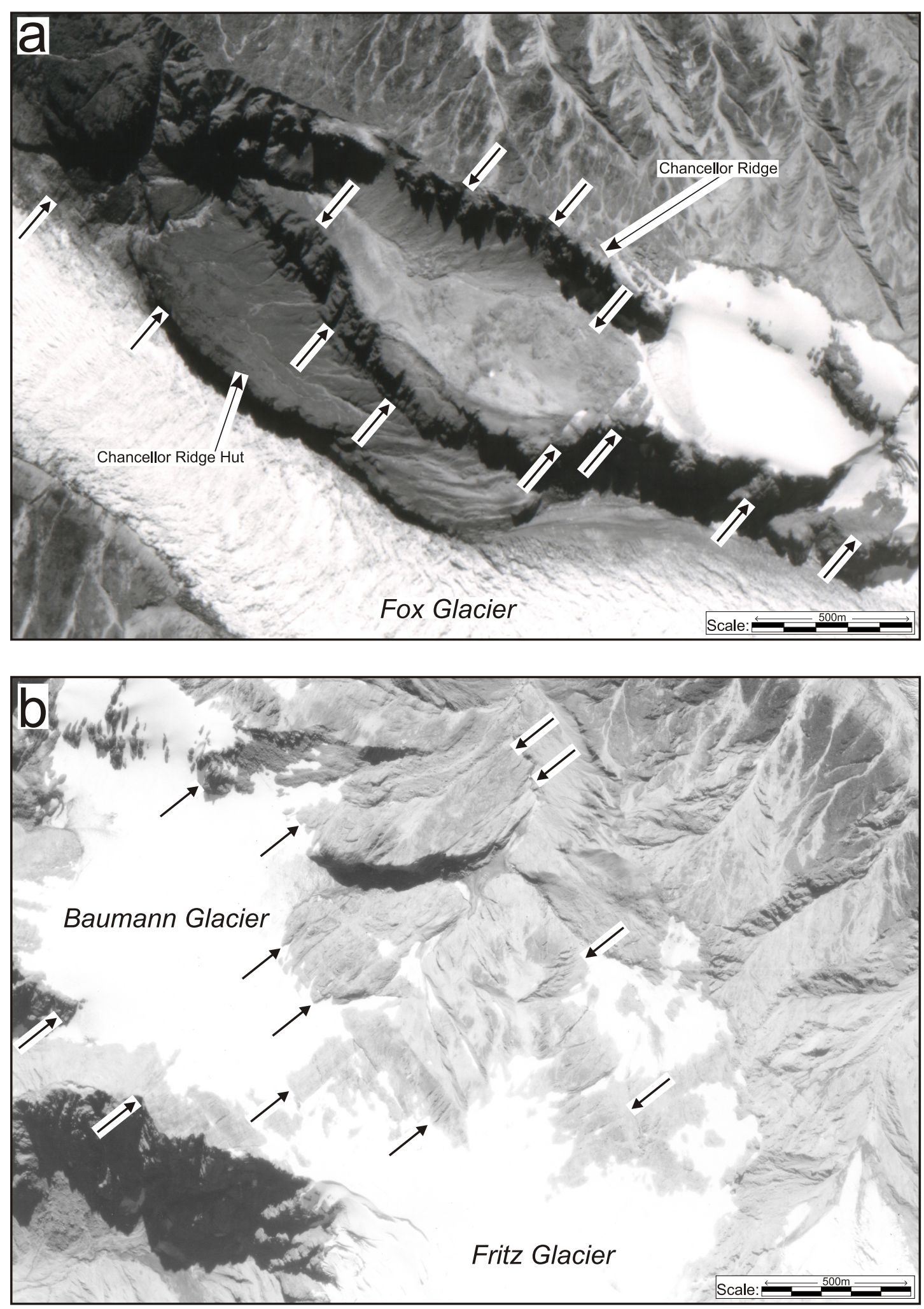

Fig. 3.8. Aerial photographs of Chancellor Ridge and Baumann Glacier field areas. a. Chancellor Ridge and Fox Glacier aerial photograph with shear planes visible as discrete lineaments and fractures in the Alpine Schist. Arrows indicate and are parallel to some selected fracture locations. b. Baumann Glacier and Fritz Glacier aerial photograph with shear planes visible as discrete lineaments and fractures as at Chancellor Ridge. Arrows indicated shears as in Chancellor Ridge photograph in Fig. 3.8a. 

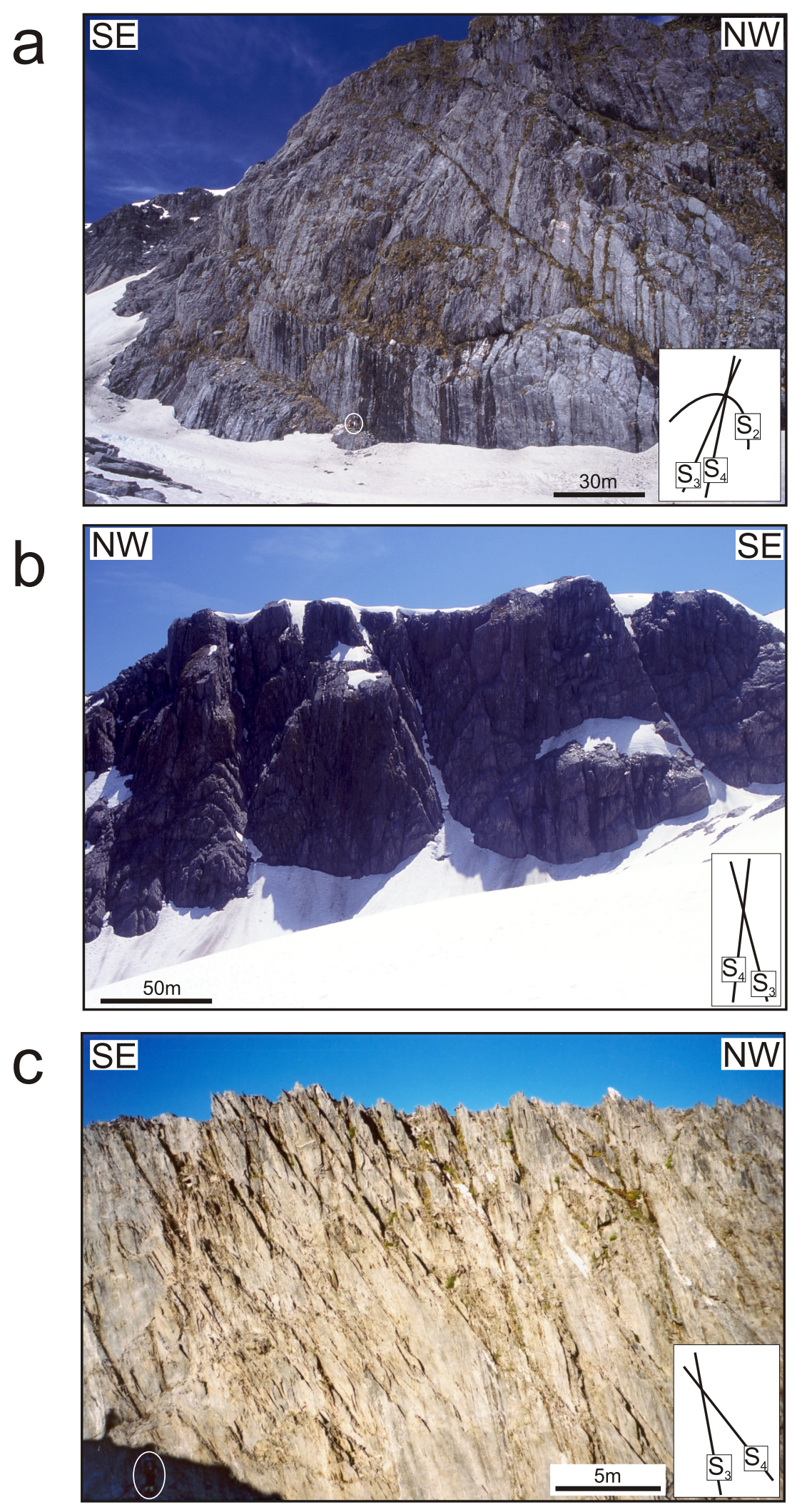

Fig. 3.9. Vertical cliff outcrops at the three main field areas with brittle-ductile shears visible. a. SW side of Andermatten Glacier (from the Baumann Glacier field area); NW-SE striking glacially eroded exposure showing steep SE-dipping $\mathrm{S}_{4}$ shears, $\mathrm{S}_{3}$ foliation, $\mathrm{S}_{2}$ foliation and $\mathrm{F}_{3}$ fold. Geologists for scale on rock, circled, bottom, centre. b. Chancellor Ridge; exposure of steep NW-dipping $\mathrm{S}_{4}$ shears and $\mathrm{S}_{3}$ foliation. c. Sam Peak; exposure of moderate NW-dipping $\mathrm{S}_{4}$ shears. Sam Peak photograph by T. A. Little. Author for scale in bottom left corner (circled). 

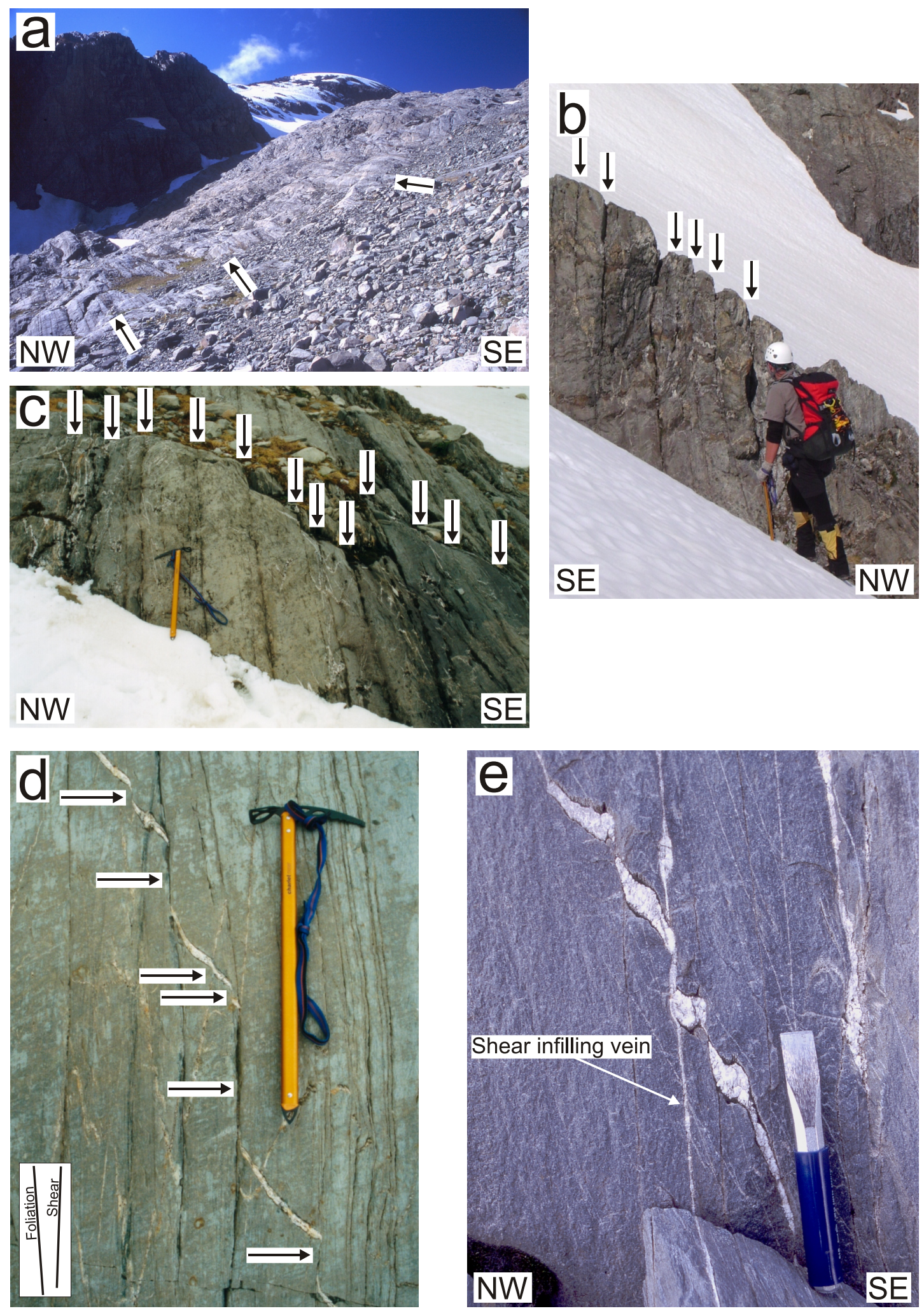

Fig. 3.10. Arrays of brittle-ductile shears on Chancellor Ridge and Baumann Glacier. a. Glaciated platform on Chancellor Ridge with discrete crack features running horizontally across the exposed Alpine Schist. b. Vertical section of brittle-ductile shears seen as cracks crosscutting the Alpine Schist at Baumann Glacier (author for scale). c. Arrays of brittle-ductile shears with west-side-up sense of shear at Chancellor Ridge. Shear planes arrowed. d. Horizontal surface outcrop showing displaced quartzcarbonate vein in Alpine Schist at Chancellor Ridge separated by multiple shear planes showing dextral shear sense. e. Vertical outcrop surface at Chancellor Ridge showing west-side-up sense of shear and brittle-ductile deformation of quartz-carbonate veins. Shear infilling vein 2-3 mm thick also seen precipitated along central shear plane. Cold chisel for scale is $150 \mathrm{~mm}$ long. 


\subsubsection{Brittle-ductile sheared veins}

Deformation within individual shear zones is accommodated by brittle offset of the quartzofeldspathic Alpine Schist with contemporaneous ductile deformation of quartz-carbonate veins embedded within that schist (Fig. 3.11). These veins are observed to have variably undergone ductile, brittle-ductile or totally brittle deformation. Veins that have undergone ductile shearing only (e.g. Fig. 3.11a) have the same displacement as markers in the schist that are offset by brittle fracturing, however, the brittle cracks in those cases terminated into the ductilely deformed vein and did not propagate through across it. Brittle faults displace the quartzofeldspathic schist as far as the margins of the vein where they are blunted into the edge of the vein, and later potentially propagate along the margin of the already ductilely sheared vein.

Some sheared veins have undergone both brittle and ductile deformation (e.g. Fig. 3.11b). In these veins ductile shearing accommodated a proportion of the offset and brittle slip accommodated the rest. Younger, shear-parallel, veins infill some of the brittle fractures cross-cutting the quartzofeldspathic schist. These syntectonic shear infilling veins are found in the shear zone where the quartz-carbonate marker veins have deformed by brittle offset (e.g. Fig. 3.11c). Some quartz-carbonate veins have undergone solely brittle offset in the shear zone and the faults are seen to displace the veins without any accompanying ductile shearing (e.g. Fig. 3.11d).

Deformation in a series of individual shear zones and across different marker veins is variably brittle to ductile with inconsistent marker separations, largely because of the different dips of these veins. The proportion of brittle to ductile shear strain in a given vein is rarely the same as an adjacent offset on the same or and adjoining shear. It is not uncommon for deformation of a single vein to be accommodated by different proportions of brittle and ductile styles where it is intersected by a series of shears (Fig. 3.11d). Marker offsets are rarely exactly the same between adjacent shears because of changing vein attitude and outcrop orientations. Most outcrop separations are in the range of 25-100 mm (e.g. Fig. 3.11d and Fig. 311e) with the largest separation measured at $720 \mathrm{~mm}$.

The Alpine Schist foliation $\left(\mathrm{S}_{3}\right)$ is cut at an acute angle by the younger shear planes (Fig. 3.11e). Where the schist is pelitic, shear planes commonly either 


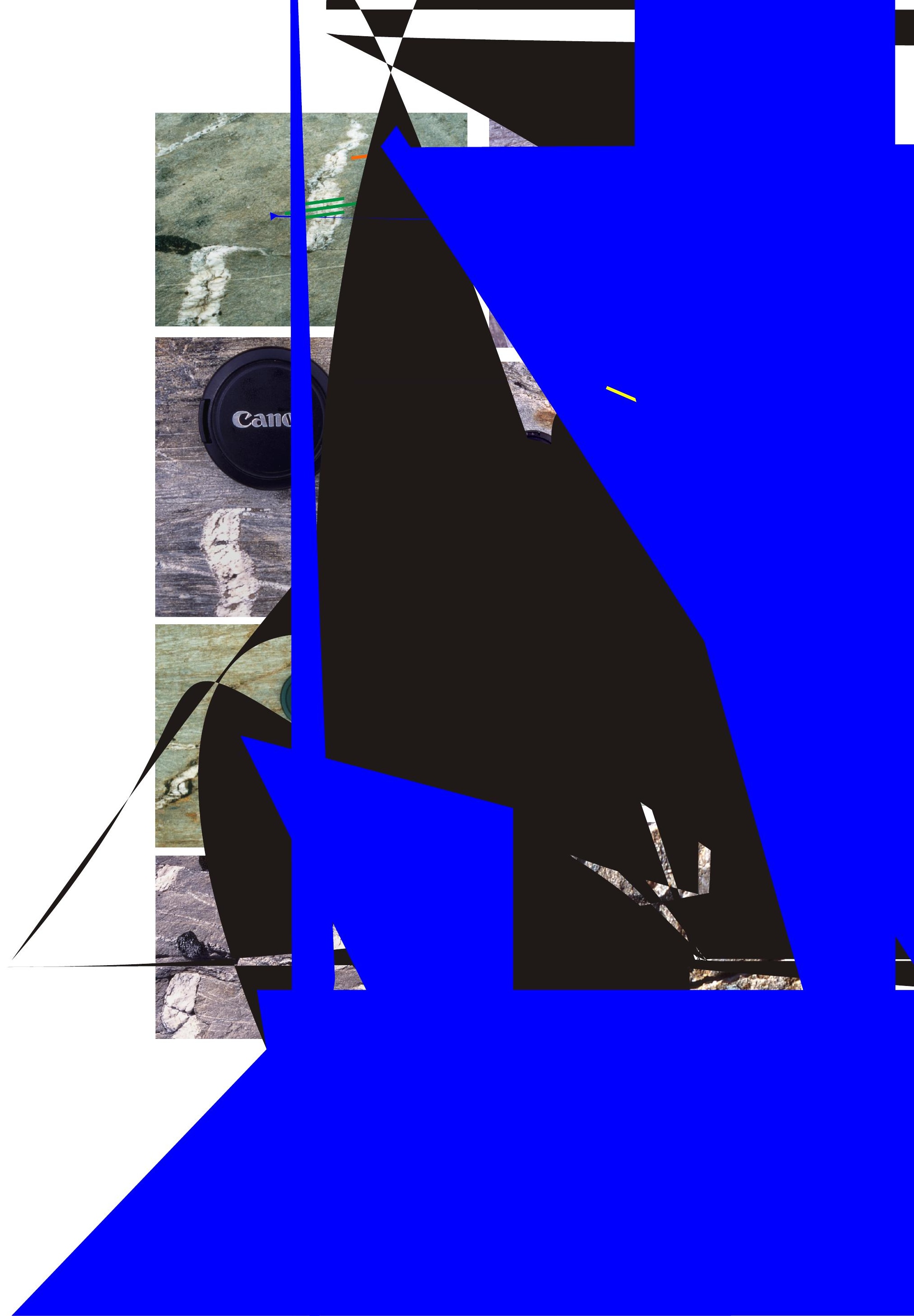


crosscut or merge into parallelism with the Alpine foliation. Such merging does not occur in the psammitic schist which is crosscut everywhere by the shears at an acute angle. Between the shears, folding and buckling of the deformed veins accompanied development of the older foliations and has generated a cleavage parallel to $S_{3}$ in some veins (e.g. Fig. 3.11a). The mean orientation of the marker veins measured in this study was 029@77 SE $\pm 4^{\circ}(\mathrm{n}=425)$. Where markers for the shear zone deformation were folded, the enveloping surface was measured as the mean marker orientation. Some shear planes did not crosscut quartz-carbonate veins and alternative features such as the $\mathrm{S}_{2}$ or $\mathrm{S}_{3}$ foliation layering defined by graphitic or pelitic rich layers were used as offset markers (Fig. 3.11f).

The veins infilling the brittle fractures in the shear zone vary from 1-20 mm in thickness and often have a mineral fibre lineation $\left(\mathrm{L}_{4}\right)$ on the vein surface (Fig. $3.11 \mathrm{~g}$ ). Occurring in calcite and chlorite selvages on the outside of the vein wall, the mineral fibre lineations give the vein surface a grooved texture and striate the fault plane. Chlorite books and single crystals observed on the vein surface in the field (Fig. 3.11h) are dimensionally aligned to define a surface lineation on the vein surface. The lineations plunge moderately to the southwest at a mean pitch of $35^{\circ} \pm$ $7(n=25)$ with a range from $8-80^{\circ}$. Lineations are typically well preserved in shear zones with infilling veins but are found on some shear planes as a thin mineral layer on the fault surface.

\subsection{Calculated net-slip pitch}

The pitch of the three-dimensional displacement vector (net-slip pitch) in the shear plane has been calculated from multiple non-parallel veins in cross section (Fig. 3.12). Measurements were made of the outcrop surface orientation, vein orientations, shear attitude, and the separation of the veins on the outcrop surface. The planar data are plotted on a stereographic projection to find the marker vein intersections on the fault surfaces and then a fault-parallel orthographic plot of these cut-offs and the outcrop trace was constructed. When the non-parallel traces of the sheared veins are plotted on the fault surface, piercing points in the shear plane can be determined from the two differently intersecting marker traces. Piercing points are identified from this orthographic projection and line connecting these points is the inferred pitch of the displacement vector (Fig. 3.12). 

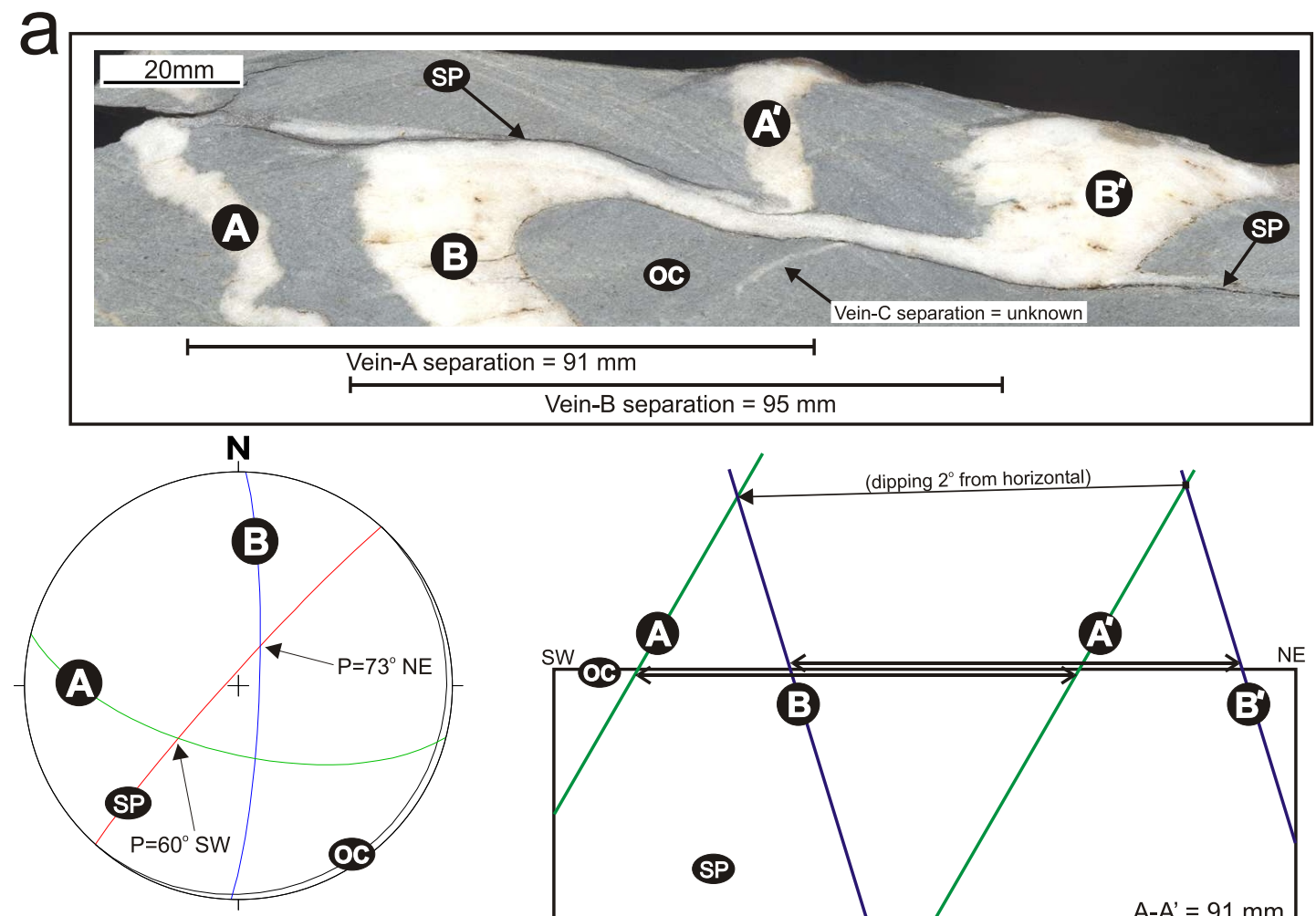

Vein A (A) - 104@64 S

Vein B (B) - 002@82 E

Shear plane (SP) - 222@86 NW

Outcrop surface (OC) - 042@04 SE
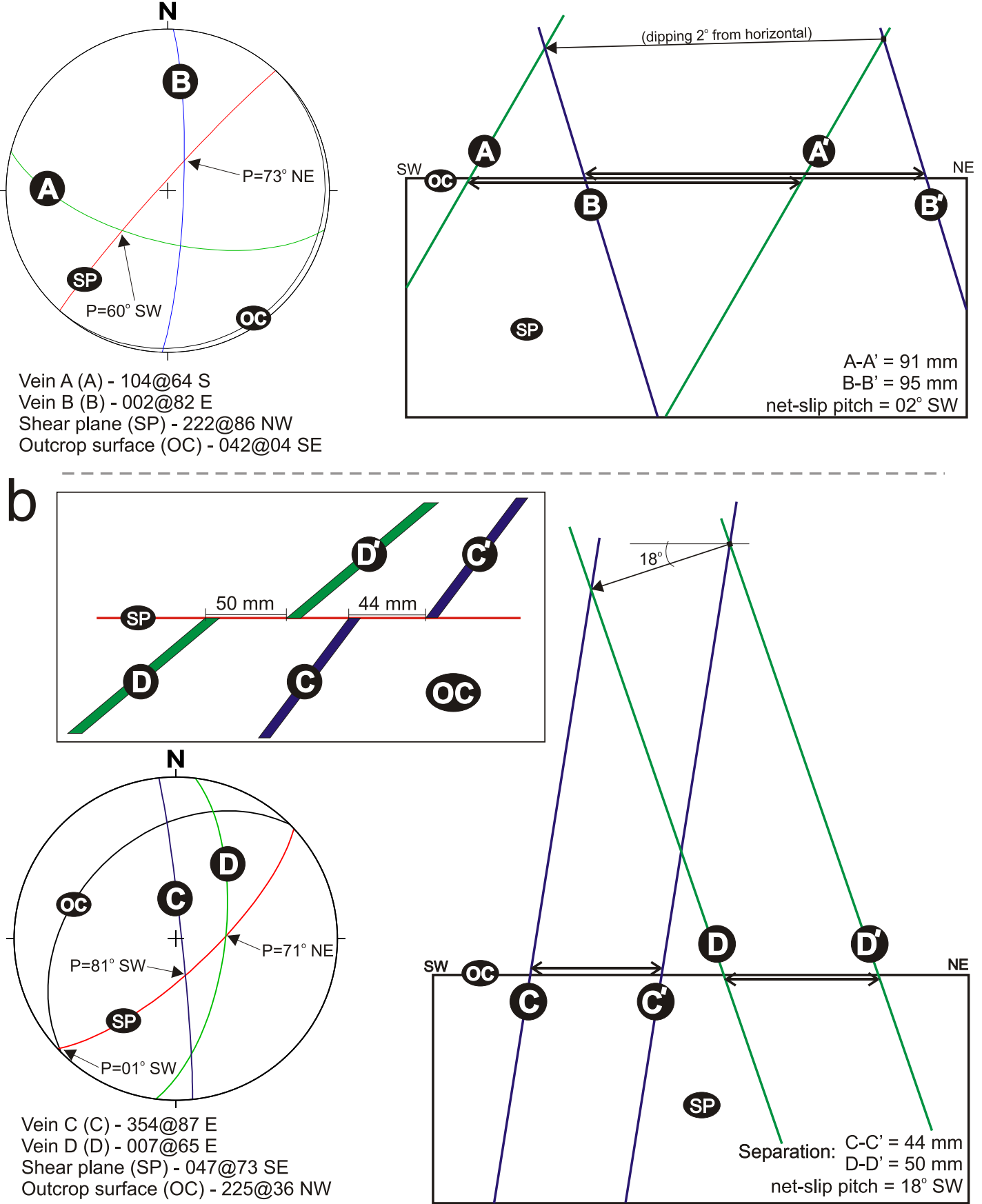

Fig. 3.12. Net-slip vector pitch calculations using the piercing point method for samples MHCH20 (a) and BM22 that contain multiple non-parallel marker veins (b). Photograph or cartoon of outcrop surface, stereographic projections of marker, shear and outcrop surface planes, and orthographic projection of the fault plane where the net-slip pitch and shear displacement (net-slip) are calculated. White labels in black circle are constant for the planes in the different diagrams for each sample and defined in text below stereographic projection. See text for further details. 
More typically, the shear zones offset only one visible displaced marker visible on a given outcrop exposure or multiple markers that are sub-parallel in their orientation and calculation of the net-slip vector is not possible. However, two pairs of non-parallel marker vein offsets have been used to calculate the net-slip vector from a site at Chancellor Ridge (Fig. 3.12a) and another at Baumann Glacier (Fig. $3.12 b$ ). Shallow southwest net-slip pitches of $2^{\circ}$ and $18^{\circ}$ for these two sites have been calculated. Unfortunately neither of these samples had a mineral fibre lineation present on the shear plane for direct comparison to the calculated net-slip pitch. Given the uncertainties, in this calculation the resulting displacement vectors are similar to the observed mean mineral lineation pitches at these localities (Table 3.1) and confirm that the fault surface lineations are at least sub-parallel to the net-slip vector.

Fault offset analysis and numerical modelling by Wightman (2005) from data collected from a linear transect survey undertaken in the BDSZ at Crawford Knob (Fig. 2.2) has shown that a mean southwest net-slip pitch of $20-45^{\circ}$ is likely for the brittle-ductile shears. Wightman (2005) also concluded that the mineral fibre lineations, although having a broad range, represent the displacement vector at some point within the deformation phase and that the mineral fibres grew throughout the displacement. Results from this study agree well with these arguments and the displacement vector for the shears can therefore be inferred as a pitch of $\sim 30^{\circ}$ from the southwest.

The mineral lineation and calculated net-slip directions have a broad range of southwest pitches from $2^{\circ}$ to $80^{\circ}$. During transpressive deformation, this range is not unusual and lineations may have a wide range of orientations (Robin and Cruden, 1994), or even rotate along strike or across the shear zone due to strain gradients (Tikoff and Greene, 1997). Mineral lineations that curve and have variable pitches are found on some exposed shear planes at Baumann Glacier. These variations are therefore most likely due to transpressive deformation in the shear zones.

\subsection{Structural surveying of the BDSZ's}

Detailed structural surveys were carried out within the BDSZ along linear transects at Chancellor Ridge and Baumann Glacier. Surveying was undertaken along a survey transect line approximately perpendicular to the strike of the Alpine 
Fault on glaciated exposures of schist with continuous outcrop, along which we endeavoured to measure every shear zone offset. These surveys involved measuring structural data to calculate the shear displacement, shear spacing and finite ductile shear strain. These calculations made for the individual surveys (e.g. Figs. 3.13 and 3.14) have been used to approximate the bulk deformation and kinematics of the shear zone arrays as a whole.

\subsubsection{Structural survey methods and field locations}

The survey transects involved measuring the orientation of 1) the shear plane, 2) a separated marker plane, and 3) the outcrop surface in addition to the offset or separation of the marker on that surface. Each shear zone intercepted by the transect was allocated a node number for reference in the survey and the distance between the shears in the direction parallel to the transect line was noted. The computer software (in Microsoft Excel) from Little (1996) was used to calculate the shear normal spacing and the shear displacement from the data measured in the field for each node (Fig. 3.13). A three-dimensional slip vector for each offset observation (1 per node) was assigned. The mineral lineations were used as this slip direction for the six nodes ( $1 \%$ of the surveyed nodes) where they were measured on the shear plane. For the remaining nodes where a lineation was not observed on a given shear a mean value was assigned instead. The assigned mean value has a southwest pitch of $30^{\circ}$ in the shear plane and was based on an average of the mineral fibre lineations measured across the field areas and the calculated net-slip pitch from piercing point analyses (see section 3.3).

Surveys were made at different structural levels within the BDSZ on sections where continuous outcrop exposed more than fifty shear zones for measurement. Measurement of the ductile deformation width, the deformed vein thickness and the ductile separation of the marker was also made. This data will be used to compare the ductile deformation in the shear zones with shear spacing and Alpine Schist lithology at different structural levels within the BDSZ.

Structural transect data were collected on Chancellor Ridge at three survey locations; one at the structural base of the BDSZ, one in the middle, and one near the top of the BDSZ (see Fig. 3.3a for mapped locations). Survey Chancellor 01 (CH01) was made at a site of dominantly pelitic schist located $\sim 220 \mathrm{~m}$ structurally above the 


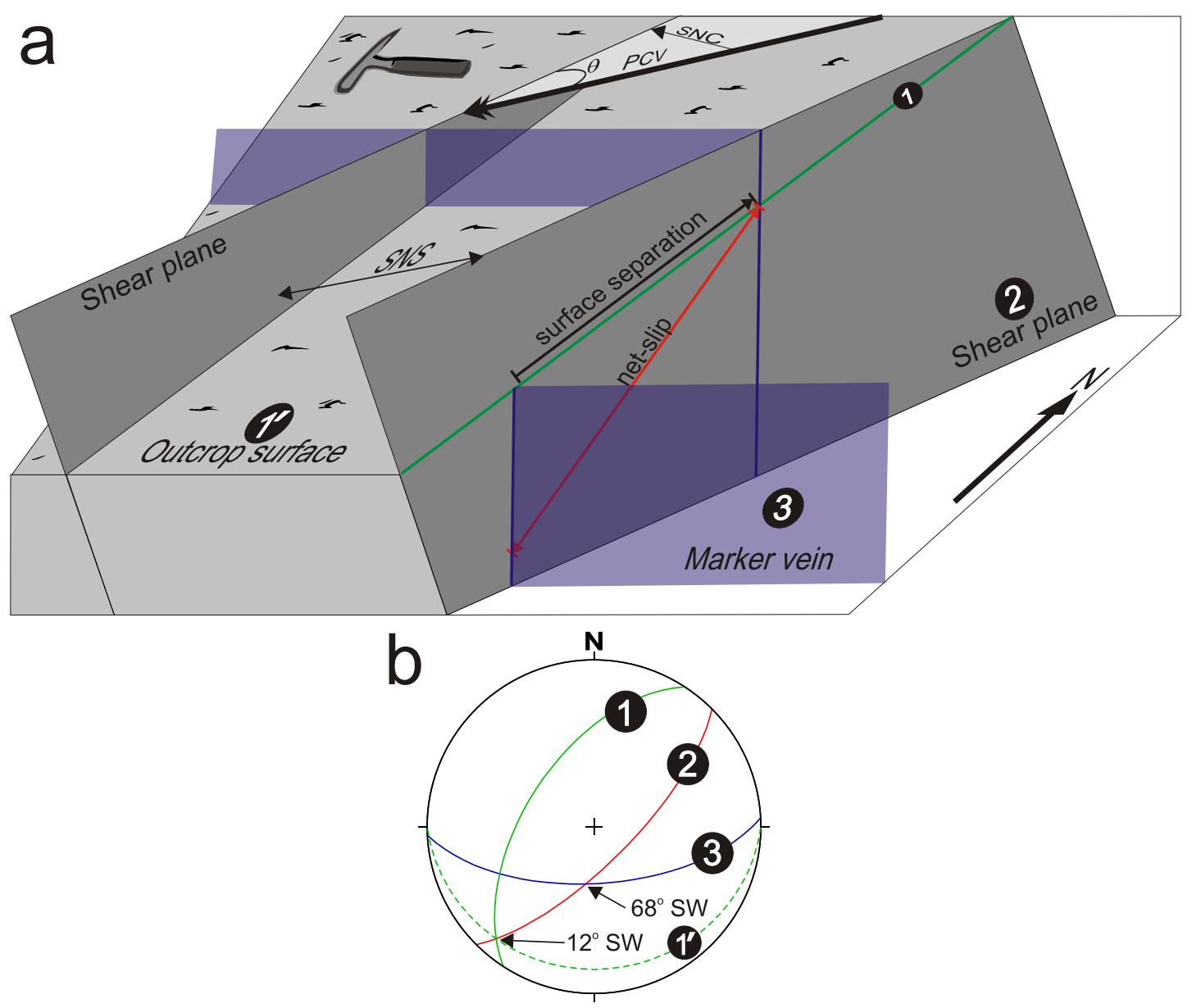

1. Outcrop surface: 213@56 NW

2. Shear plane: 045@72 SE

3. Marker vein: 087@62 S

1'. Outcrop surface for Fig. (a) above

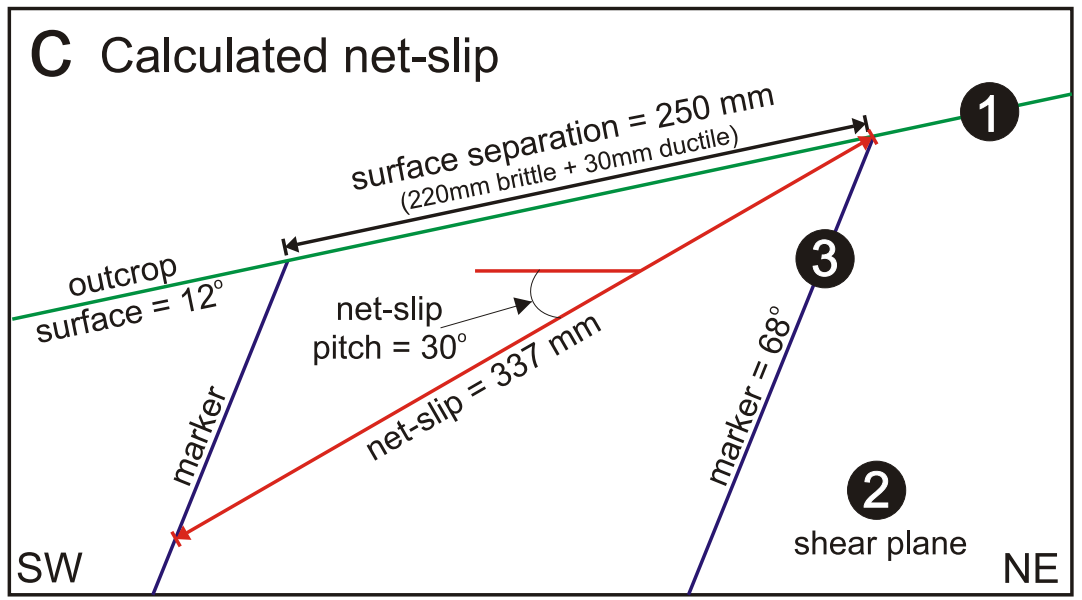

Fig. 3.13. Method of calculation for shear displacement (net-slip) from data in survey transects of fault offsets. Node 34 in survey BM01 (Appendix B) used as example. Black numbered circles represent planes measured and are consistent across all three sections of figure. a. 3-dimensional block diagram illustrating calculated net-slip from measured surface displacement and given SW net-slip pitch of $30^{\circ}$. Shear normal spacing (SNS) calculated as distance to structurally lower shear. Shear normal convergence (SNC) calculated from plate convergence vector (PCV) of $071^{\circ}$ at $37 \mathrm{~mm} / \mathrm{yr}$ and angle $\theta$ (PCV - shear plane strike). Surface ( $\left.1^{\prime}\right)$ is a representative outcrop plane for this Fig. with the same shear intersection as the actual surface. Net-slip of $250 \mathrm{~mm}$, net-slip SW pitch of $30^{\circ}$, and marker vein are scaled and oriented as in Figs. b and c. Cartoon geological hammer approximate scale for figure. b. Lower hemisphere, equal area, stereographic projection of outcrop surface (1), shear plane (2), marker vein (3) and representative outcrop surface in Fig. a (1'). Pitch of intersections with shear plane are labeled. c. Calculated net-slip from displaced marker in projected view of the shear plane. Pitches of marker vein and outcrop surface from Fig. b. See Fig. 3.14a for displacement measurement. 


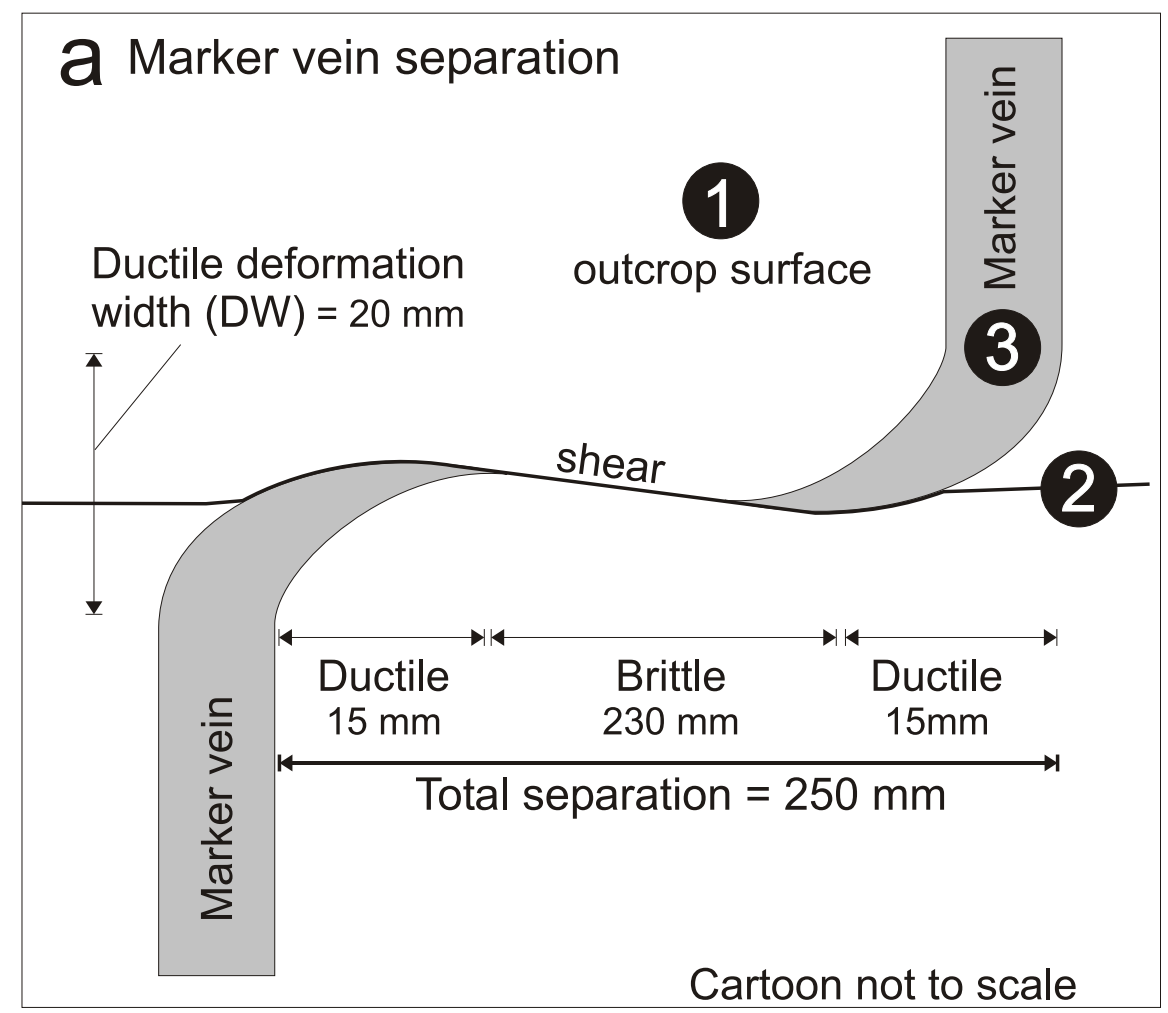

b Calculated $\lambda_{\mathrm{d}}$ and $\varepsilon_{\mathrm{m}}$

$\gamma_{d}=\frac{(\text { netslip } \times D T R)}{D W}=\frac{337 \times 0.12}{20}=2$

where:

$$
\begin{gathered}
\text { DTR }=\frac{\text { ductile_sep. }}{\text { total_sep. }}=\frac{30}{250}=0.12 \\
\varepsilon_{m}=\frac{\gamma_{d}}{\text { time }}=\frac{2}{2.45 y r}=2.6 \times 10^{-8} \mathrm{sec}^{-1}
\end{gathered}
$$

where:

$$
\begin{aligned}
& \text { time }=\frac{S N S}{S N C}=\frac{40}{16.2}=2.45 y r \\
& S N C=\sin \theta \times P C V=\sin (26) \times 37=16.2 \mathrm{~mm} / y r
\end{aligned}
$$

Fig. 3.14. Calculation of finite ductile shear strain $\left(\gamma_{\mathrm{d}}\right)$ and maximum strain-rate $\left(\varepsilon_{\mathrm{m}}\right)$ from survey data. Node 34 in survey BM01 (Appendix 2) used as example. a. Cartoon shear zone illustrating the measured brittle and ductile separation and ductile deformation width (DW) of a displaced vein. Black labeled circles represent planes in Fig. 3.13. b. Formula used for calculating $\gamma_{\mathrm{d}}$ and $\varepsilon_{\mathrm{m}}$ for Node 34. Formula for shear normal convergence rate (SNC) using the plate convergence vector (PCV) (Fig. 3.13) and the time between sequential shear activation using the shear normal spacing (SNS) and the SNC. Ductile to total separation ratio (DTR). Angle between the shear plane and the PCV $(\theta)$. 
western and basal BDSZ boundary. This transect consisted of 47 nodes measured along a $61.01 \mathrm{~m}$ long survey line. Survey Chancellor 02 (CH02) was made southeast of $\mathrm{CH} 01$ in psammitic schist located $\sim 1150 \mathrm{~m}$ structurally above the western and basal BDSZ boundary. This transect consisted of 100 nodes measured along a $5.1 \mathrm{~m}$ survey line. Survey Chancellor 03 (CH03) was made southeast of $\mathrm{CHO}$ in psammitic schist at a site located $\sim 1420 \mathrm{~m}$ structurally above the western and basal BDSZ boundary (Fig. 3.4c). This transect consisted of 155 nodes along a $27.11 \mathrm{~m}$ survey line.

At Baumann Glacier, another transect was measured (see Fig. 3.5a for location) and individual shear array measurements collected across the field area were additionally compiled into a second data set that was not rigorously measured along a continuous transect. Survey Baumann 01 (BM01) was made in psammitic schist located $\sim 515 \mathrm{~m}$ structurally above the western and basal BDSZ boundary (Fig. 3.4d). This transect consisted of 111 nodes measured along a $19.54 \mathrm{~m}$ survey line. The non-transect line survey (BM-f) consisted of 22 shear observations measured throughout the BDSZ near Baumann Glacier (mapped area of Fig. 3.5). The survey BM-f was compiled to test whether the small survey lines measured in the transect surveys (CH01, CH02, CH03 and BM01) are biased towards particular localised deformation conditions within the BDSZ or representative of the whole $2 \mathrm{~km}$ wide zone. Grid references, survey line bearing directions and data measured for all of the transect surveys in the Baumann Glacier and Chancellor Ridge field areas can be found in Appendix B.

Mean planar orientations of the shear planes and markers were calculated from the data compiled from the five surveys, including cut-offs of the marker veins against the shear planes (Figs. 3.15 and 3.16). The mean shear plane for the aggregated the Chancellor Ridge data (compiled from all three surveys) is steeply dipping to the northwest whereas the mean shear plane from the Baumann Glacier data has a steep southeast dip. The northeast strike of the shear planes in both survey areas is similar. The marker veins in the Baumann Glacier surveys have near vertical dips and strike close to the north whereas the Chancellor Ridge marker veins have a northeast strike and a moderate southeast dip. Unfortunately, this southeast-dipping mean vein orientation at Chancellor Ridge results in a southwest pitching cut off for these markers on the shear planes. Typically the southwest cut-off pitch of $17-26^{\circ}$ is 

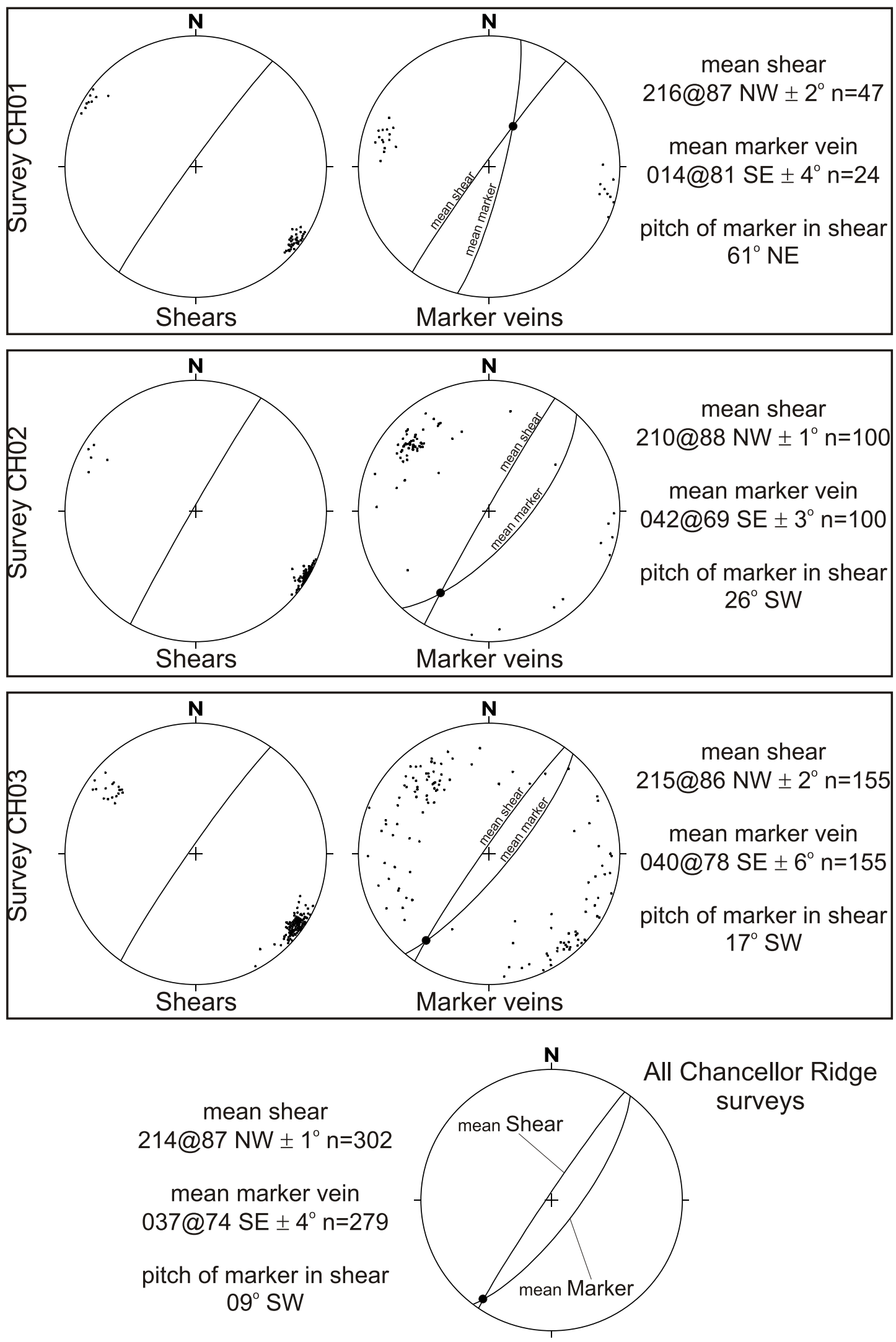

Fig. 3.15. Orientations of shear planes and marker veins from the three surveys on Chancellor Ridge. Combined results are also shown for all plane and marker veins measured in Chancellor Ridge surveys. Mean shear plane has been shown on the marker vein projections for reference in graphical representation of intersection pitch. Projections are on lower hemisphere, equal area, stereographic plots and uncertainties are in degrees for a $95 \%$ confidence ellipse about the mean line or pole to the plane. 

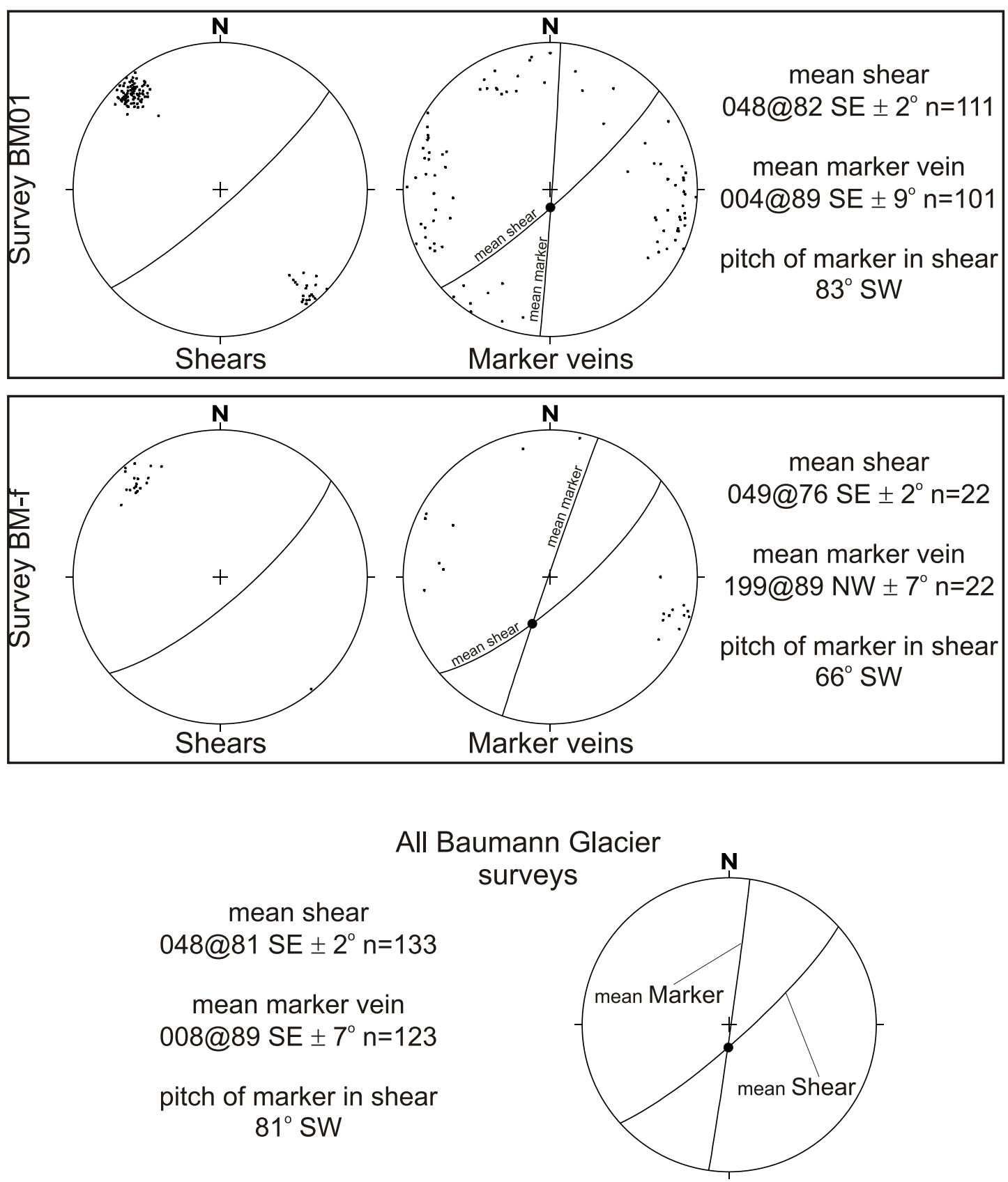

Fig. 3.16. Orientations of shear planes and marker veins from the two surveys at Baumann Glacier. Combined results are also shown for all plane and marker veins measured in Baumann Glacier surveys. Mean shear plane has been shown on the marker vein projections for reference in graphical representation of intersection pitch. Projections are on lower hemisphere, equal area, stereographic plots and uncertainties are in degrees for a $95 \%$ confidence ellipse about the mean line or pole to the plane. 
sub-parallel to the pitch of the mineral fibre lineation or the assigned net-slip pitch in the shear plane. This results in a trigonometrically unstable cut-off geometry that hinders reliable calculation of shear displacement from the outcrop separation of the veins. Nodes where the cut-off pitch of these marker veins was within five degrees of the net-slip vector pitch were filtered from the survey to avoid these trigonometrically unstable shear displacements. Typically, $\sim 14 \%$ of the data was eliminated by this filtering (Table 3.2d); however, up to $60 \%$ of the data was removed in survey $\mathrm{CH} 01$, as many of the marker veins had a moderate pitching southwest cut-off (Table 3.2d). The pitch of the marker vein in the shear plane for each survey node can be found in Appendix B.

\subsubsection{Calculation of shear displacement}

The shear displacement (net-slip) calculated by the computer software of Little (1996) required planar measurements of the shear plane, the separated marker and the outcrop surfaces as well as the observed separation of the markers in the outcrop. The net-slip calculation process made by the computer software is illustrated graphically in Fig. 3.13 using a shear zone from the Baumann Glacier survey as an example. The shear displacement calculations have been carried out on the data for the preferred assigned net-slip pitch of $30^{\circ}$ (Table 3.2; Fig. 3.17a) as well as net-slip pitches of $20^{\circ}$ and $40^{\circ}$ (Fig. 3.17a). These two additional net-slip calculations illustrate that the data is sensitive to net-slip pitch variations with steeper pitches in most surveys resulting in higher shear displacements. The mean shear displacement calculated from all the survey nodes is $9.9 \pm 1.4 \mathrm{~cm}(\mathrm{n}=380$ of 435 nodes; Table 3.2c). The mean shear displacement in both of the Baumann Glacier surveys was higher than that at Chancellor Ridge with survey CH01 having the lowest displacement of $5.5 \pm 1.9 \mathrm{~cm}$ and BM-01 having a higher displacement of $11.3 \pm 2.8 \mathrm{~cm}$ (Table 3.2; Fig. 3.17a).

\subsubsection{Calculation of finite ductile shear strain}

During surveying the total and the ductile component of separation were both measured during the surveying (Fig. 3.14a) and the ratio of ductile to total slip (DTR) has been calculated. This ratio has been used to calculate the ductile component of the net-slip, which when divided by the ductile deformation width 


\begin{tabular}{|c|c|c|c|c|c|c|c|c|c|}
\hline \multirow[t]{2}{*}{ (for net-slip pitch of $30^{\circ}$ ) } & \multicolumn{3}{|c|}{$\mathrm{CH} 01$} & \multicolumn{3}{|c|}{$\mathrm{CH} 02$} & \multicolumn{3}{|c|}{$\mathrm{CHO} 3$} \\
\hline & mean & $2 \sigma$ & $\mathrm{n}$ & mean & $2 \sigma$ & $\mathrm{n}$ & mean & $2 \sigma$ & $\mathrm{n}$ \\
\hline Total shear displacement $(\mathrm{cm})$ & 5.48 & 1.87 & 19 & 15.20 & 8.24 & 82 & 8.93 & 2.83 & 131 \\
\hline Finite ductile shear strain & 2.01 & 0.75 & 18 & 7.6 & 3.7 & 27 & 3.9 & 1.2 & 78 \\
\hline Shear spacing $(\mathrm{m})$ & 1.27 & 0.27 & 47 & 0.05 & 0.01 & 100 & 0.15 & 0.03 & 155 \\
\hline Marker vein thickness (mm) & 9.5 & 2.9 & 24 & 5.5 & 1.2 & 38 & 6.3 & 1.0 & 129 \\
\hline Infilling vein thickness (mm) & 2.4 & 0.5 & 24 & 1.6 & 0.7 & 100 & 2.3 & 0.8 & 155 \\
\hline Ductile deformation width $(\mathrm{cm})$ & 0.64 & 0.19 & 24 & 0.09 & 0.04 & 98 & 0.43 & 0.11 & 155 \\
\hline Displacement / spacing ratio & 0.43 & - & - & 31.19 & - & - & 5.92 & - & - \\
\hline Ductile / total separation ratio & 0.24 & 0.08 & 24 & 0.14 & 0.06 & 98 & 0.30 & 0.06 & 150 \\
\hline
\end{tabular}

O
\begin{tabular}{|l|c|c|c|c|c|c|}
\hline (for net-slip pitch of $30^{\circ}$ ) Survey: & \multicolumn{3}{c|}{ BM01 } & \multicolumn{4}{c|}{ BM-f } \\
& mean & $2 \sigma$ & $\mathrm{n}$ & mean & $2 \sigma$ & $\mathrm{n}$ \\
\hline Total shear displacement (cm) & $\mathbf{1 1 . 2 8}$ & 2.80 & 91 & $\mathbf{1 3 . 4 7}$ & 4.42 & 21 \\
Finite ductile shear strain & $\mathbf{5 . 5}$ & 1.1 & 75 & $\mathbf{4 . 9}$ & 1.4 & 21 \\
Shear spacing (m) & $\mathbf{0 . 1 4}$ & 0.03 & 111 & $\mathbf{0 . 1 1}$ & 0.04 & 4 \\
Marker vein thickness (mm) & $\mathbf{1 0 . 5}$ & 1.3 & 101 & $\mathbf{8 . 7}$ & 1.4 & 22 \\
Infilling vein thickness (mm) & $\mathbf{1 . 7}$ & 0.5 & 61 & $\mathbf{2 . 1}$ & 1.3 & 7 \\
Ductile deformation width (cm) & $\mathbf{0 . 9 7}$ & 0.21 & 101 & $\mathbf{1 . 2 4}$ & 0.32 & 22 \\
Displacement / spacing ratio & $\mathbf{7 . 8 0}$ & - & - & $\mathbf{1 2 . 7 3}$ & - & - \\
Ductile / total separation ratio & $\mathbf{0 . 4 8}$ & 0.08 & 101 & $\mathbf{0 . 5 4}$ & 0.14 & 22 \\
\hline
\end{tabular}

C
\begin{tabular}{|l|c|c|c|}
\hline (for net-slip pitch of $\left.30^{\circ}\right)$ & \multicolumn{3}{|c|}{ All Surveys } \\
& mean & $2 \sigma$ & $\mathrm{n}$ \\
\hline Total shear displacement $(\mathrm{cm})$ & $\mathbf{9 . 9}$ & 1.4 & 344 \\
Finite ductile shear strain & $\mathbf{4 . 8}$ & 0.7 & 219 \\
Shear spacing $(\mathrm{m})$ & $\mathbf{0 . 2 5}$ & 0.05 & 410 \\
Marker vein thickness $(\mathrm{mm})$ & $\mathbf{8 . 0}$ & 0.7 & 314 \\
Infilling vein thickness $(\mathrm{mm})$ & $\mathbf{2 . 0}$ & 0.4 & 347 \\
Ductile deformation width $(\mathrm{cm})$ & $\mathbf{0 . 5 3}$ & 0.08 & 395 \\
Ductile / total separation ratio & $\mathbf{0 . 3 1}$ & 0.04 & 395 \\
Shear normal convergence rate & $\mathbf{1 9 . 7}$ & 0.4 & 435 \\
Mean maximum strain-rate $\left(\mathrm{sec}^{-1}\right)$ & $\mathbf{8 . 6 E}-\mathbf{0 8}$ & $3.1 \mathrm{E}-08$ & 224 \\
\hline
\end{tabular}

Q
\begin{tabular}{|c|c|c|c|c|c|c|c|c|c|c|c|c|c|c|c|}
\hline Survey: & \multicolumn{3}{|c|}{ CH01 } & \multicolumn{3}{c|}{ CH02 } & \multicolumn{3}{c|}{ CH03 } & \multicolumn{3}{c|}{ BM01 } & \multicolumn{3}{c|}{ BM-f } \\
& Total & Filtered & $\%$ & Total & Filtered & $\%$ & Total & Filtered & $\%$ & Total & Filtered & $\%$ & Total & Filtered & $\%$ \\
\hline $\mathrm{P}=40$ & 47 & 30 & 63.8 & 100 & 15 & 15.0 & 155 & 29 & 18.7 & 111 & 24 & 21.6 & 22 & 2 & 9.1 \\
$\mathrm{P}=30$ & 47 & 28 & 59.6 & 100 & 18 & 18.0 & 155 & 24 & 15.5 & 111 & 20 & 18.0 & 22 & 1 & 4.5 \\
$\mathrm{P}=20$ & 47 & 26 & 55.3 & 100 & 34 & 34.0 & 155 & 30 & 19.4 & 111 & 19 & 17.1 & 22 & 0 & 0.0 \\
\hline
\end{tabular}

Table 3.2. Results for structural surveys $\mathrm{CH} 01, \mathrm{CH} 02$, and $\mathrm{CH} 03$ at Chancellor Ridge (a) and BM01 and BM-f at Baumann Glacier (b). Survey results combined for all surveys, with the addition of the calculated mean shear normal convergence and calculated mean maximum strain-rate, are listed in Table (d). Nodes from the survey which had an intersection of the marker and shear plane $\pm 5^{\circ}$ from the net-slip pitch have been filtered from the survey data sets. Table (d) contains the statistics for the total number of survey nodes measured, the number of nodes removed and the fraction of the nodes removed from filtering. These are listed for each of the surveys and at different net-slip pitches from the southwest. 

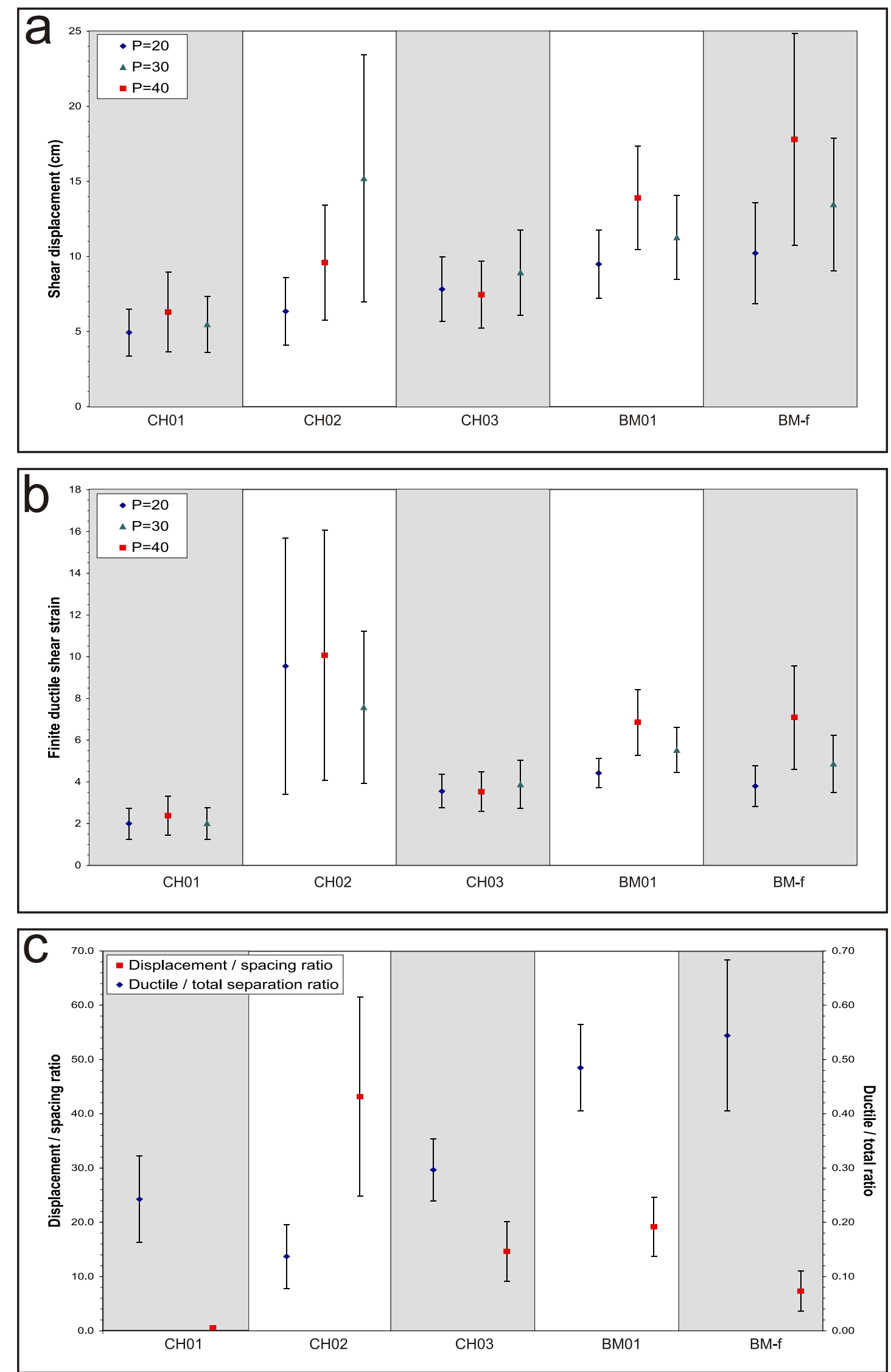

Fig. 3.17. Graphed results for survey data in Table 3.2 for different net-slip pitches $(\mathrm{P}=\mathrm{SW}$ net-slip pitch: $20^{\circ}$-blue, $30^{\circ}$-green and $40^{\circ}$-red) and survey sites. a. Shear displacement (net-slip) for different surveys and SW net-slip pitches. b. Finite ductile shear strain for each survey and different net-slip pitches. c. Total shear displacement / shear normal spacing ratio and ductile / total separation ratio for each survey. Uncertainty bars $\pm 2 \sigma$ for plots. 
(DW) affecting the marker, allows the finite ductile shear strain $\left(\gamma_{d}\right)$ for individual ductilely sheared quartz veins to be calculated (Fig. 3.14b) using the equation:

$$
\begin{gathered}
\gamma_{d}=\frac{(\text { netslip } \times \text { DTR })}{D W} \\
\text { where } D T R=\frac{\text { ductile_separation }}{\text { total_separation }}
\end{gathered}
$$

The mean finite ductile shear strain calculated from all the survey nodes is $4.8 \pm 0.7(\mathrm{n}=241)$. Chancellor Ridge surveys CH01 and CH02 showed the lowest and highest finite ductile shear strains with values of $2 \pm 0.8$ and $7.6 \pm 3.7$, respectively (Fig. 3.17b). The other three surveys were all closer to the mean shear strain.

\subsubsection{Shear spacing and ductile deformation of the veins}

The difference in finite ductile shear strains between individual shears and in the surveys, may be related to ductile deformation width, the amount of ductile deformation that the marker veins have undergone, or the lithology of the Alpine Schist. The mean ductile deformation width for the surveys was $0.53 \pm 0.08 \mathrm{~m}$, but ranged from $0.09 \pm 0.04 \mathrm{~cm}$ in survey $\mathrm{CH02}$ to the largest width recorded in survey BM-f of $1.24 \pm 0.32 \mathrm{~cm}$ (Fig. 3.17c; Table 3.2). The amount of ductile deformation was compared between the surveys using the ratio of ductile separation to total separation, averaging 0.31 across all the survey data but as low as 0.14 at survey $\mathrm{CH02}$. Although survey $\mathrm{CHO2}$ had the lowest proportion of ductile deformation, it also had a narrow ductile deformation width, resulting in the highest finite ductile shear strain of all the surveys.

The large ductile deformation width and proportion of ductile deformation for survey BM-f is most likely due to a bias in the data collection. Because survey BM-f is a combination of shear zones measured at individual field sites, there exists a bias towards sheared veins which had undergone large proportions of ductile deformation and / or had thick deformed marker veins as these shear zones were more obvious in the field and preferentially studied. The proportion of ductile to brittle deformation 
in this study does show an obvious increase with the structural depth of the survey throughout the BDSZ.

Shear normal spacing (see Fig. 3.13) was calculated from the survey data, yielding a mean shear spacing of $0.25 \pm 0.5 \mathrm{~m}$. The spacing at survey $\mathrm{CH} 01$, taken on pelitic schist, has a larger mean spacing of $1.27 \pm 0.3 \mathrm{~m}$ compared to the spacing in the psammite schist dominated survey $\mathrm{CH} 02$ with a mean spacing of $0.05 \pm 0.01$ $\mathrm{m}$. The proportion of ductile deformation or the ductile deformation width does not explain the lower shear displacement or finite ductile shear strain at survey $\mathrm{CH} 01$ so the ratio of shear displacement to shear normal spacing was compared to the lithology of the schist in each transect. A very low displacement to spacing ratio was calculated for survey $\mathrm{CH} 01$ that was predominantly in pelitic schist, compared with much higher ratios for the remaining surveys undertaken on psammitic schist (Fig. 3.17c; Table 3.2).

Assuming that bulk ramping-related strain has been distributed evenly across the BDSZ, I infer that the pelitic schist must be accommodating strain within the schist and in a non-discrete distributed way rather than by discrete slip on the shears. In some instances, shear planes in psammite are observed to merge into a foliation plane in pelite along strike. Shear zones in psammitic schist, such as $\mathrm{CHO2}$ and $\mathrm{CH} 03$, have a smaller shear normal spacing and shear planes invariably crosscut the Alpine foliation at an acute angle (e.g. Fig. 3.11e). Again, assuming that the strain is distributed evenly across the BDSZ, the higher strain and displacement / spacing measurements in the psammitic sections of the BDSZ suggest that the discrete brittle-ductile shears are accommodating a higher proportion of the bulk strain than the shears in the pelitic sections of schist, where deformation is apparently more distributed (Little et al., 2002a). The spacing of the shears does not appear to be controlled by structural depth but primarily by the composition of the Alpine Schist.

The thickness of marker and infilling veins thicknesses were similar in all three surveys (Tables 3.2). The thickness of the deformed marker veins ranged from 1 to $35 \mathrm{~mm}$ with a mean thickness of $8 \pm 0.7 \mathrm{~mm}$ for data collected from all the surveys. The thickness of infilling veins varied between nodes (shears) with a mean of $2 \pm 0.4 \mathrm{~mm}$. These infilling veins occurred in $80 \%$ of shear zones surveyed and showed no preference towards precipitation in psammitic or pelitic schist. 
Thick marker veins are observed to undergo a greater fraction of ductile deformation than thin marker veins. However, plots of marker vein width vs. ductile deformation proportion reveal that marker veins as thick as $30 \mathrm{~mm}$ can be brittlely displaced and those as thin as $1 \mathrm{~mm}$ can be totally ductilely sheared (Fig. 3.18a). Overall the data shows an increase in the proportion of ductile deformation with increasing marker vein width (Fig. 3.18a) and fewer veins with widths $>10 \mathrm{~mm}$ underwent brittle deformation compared with the thinner veins which generally underwent brittle-ductile or brittle deformation. Plots of marker vein width against ductile deformation width (Fig. 3.18b) show a dispersed correlation between these quantities, although there is a weak correlation that shows an increase in deformation width with marker thickness. The plots of ductile deformation width against the ductile / total slip ratio also show this weak correlation between the deformation width and the proportion of ductile deformation (Fig. 3.18a). Vein thickness data for the infilling and marker veins for each node can be found in Appendix B.

\subsubsection{Calculation of maximum strain-rate}

Maximum ductile strain-rates have been estimated from measurements of finite ductile shear strain $\left(\gamma_{d}\right)$ and an estimate of the time over which the deformation occurred (e.g. Fig. 3.14b). Based on an escalator-like kinematic model for the formation of brittle-ductile shears, the time period between each shear zone's activation can be calculated. Assuming each shear zone is sequentially activated and all deformation is accommodated on that shear prior to the formation of the next shear zone, then it activation life can be estimate by dividing the average shear normal spacing (SNS) by the shear normal plate convergence rate (SNC) (i.e. the time to translate the Pacific Plate the distance between the shears). The SNC has been calculated from the velocity of the plate convergence vector (PCV) (NUVEL1A solution of DeMets et al., 1994) and the acute angle $(\theta)$ between the PCV and the shear plane (e.g. Fig. 3.13). The maximum strain-rate is calculated from these properties for each node in transects where a marker vein has been ductilely deformed. The maximum strain-rate $\left(\varepsilon_{\mathrm{m}}\right)$ for the ductile deformation is calculated from the equations:

$$
\varepsilon_{m}=\frac{\gamma_{d}}{\text { time }}
$$



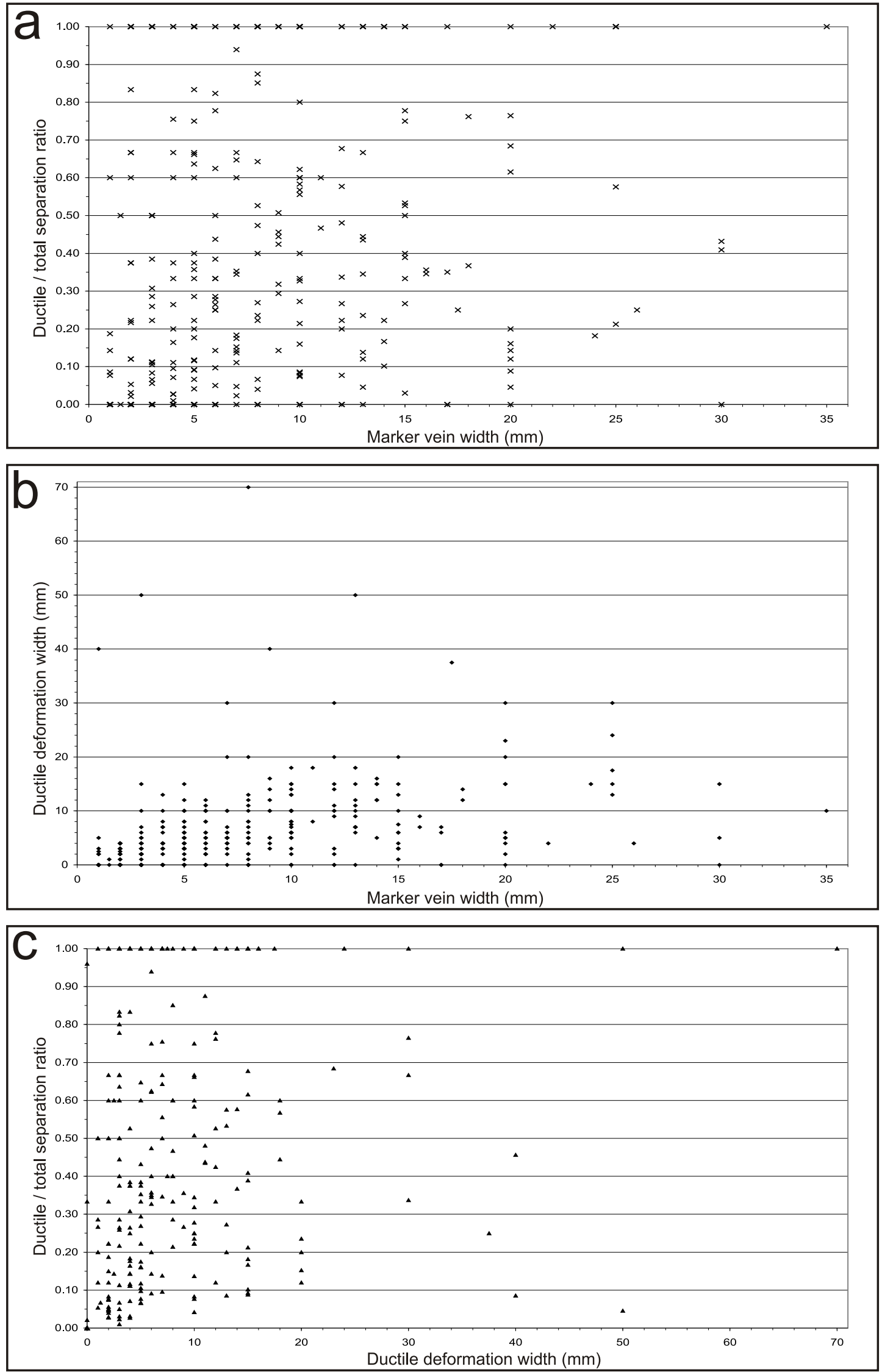

Fig. 3.18. Plots of ductile deformation of marker veins in the shear zones. a. Ratio of ductile separation / total separations vs. marker vein width. b. Ductile deformation width against original marker vein width. c. Ratio of ductile separation to total separation against ductile deformation width. 


$$
\begin{gathered}
\text { where time }=\frac{S N S}{S N C} \\
\text { and where } S N C=\sin \theta \times P C V
\end{gathered}
$$

The calculation of strain-rate from this data assumes that only one shear was active at a time and that the current plate convergence rate was similar to the rate at the time of deformation. The maximum strain-rates calculated from the transect data range from $5 \times 10^{-10}$ to $2 \times 10^{-7} \mathrm{sec}^{-1}$ with a mean rate of $8.6 \times 10^{-8} \pm 3.1 \times 10^{-8} \mathrm{sec}^{-1}$. The fast and slow end members of the maximum strain-rate range reflect the difference in spacing in surveys $\mathrm{CH01}$ and $\mathrm{CH} 02$. These strain-rates are fast compared to expected natural strain-rates of $1 \times 10^{-12}$ to $1 \times 10^{-14} \mathrm{sec}^{-1}$ in continental crust (Mercier et al., 1977; Pfiffner and Ramsay, 1982; Twiss and Moores, 1992). Maximum strain-rates from this study may be faster than the expected natural rates because of the underlying assumption in the escalator model that only one shear is active at a time. Calculated strain-rates would reduce to $1.5 \times 10^{-12} \mathrm{sec}^{-1}$ if the entire $2 \mathrm{~km}$ wide zone of the BDSZ was actively accommodating the strain or reduce to 3.0 $\mathrm{x} 10^{-11} \mathrm{sec}^{-1}$ if a $100 \mathrm{~m}$ wide zone of shears was accommodating the bulk rampingrelated shear strain.

\subsection{Proposed field-based deformation sequence}

Based on the field observations and transect data, I propose a deformation path for the shearing of quartz-calcite veins and the brittle-ductile shear zones. This deformation sequence is illustrated in Fig. 3.19 which shows eight steps in the development of a single shear zone that displaces several marker veins of different thickness and orientation. Steps (a) and (b) show initial brittle fracturing of the Alpine Schist; at this time the two thinnest veins (blue and yellow) were transected by the fault (Fig. 3.19c inset magnification); the two thicker veins (green and white) are not but underwent ductile deformation. In stages (c) and (d) the ductile deformation of these thicker veins continued as the tips of the brittle crack was unable to propagate across. Eventually the crack tips propagated along the already deflected vein-schist boundary (Fig. 3.19f inset magnification; e.g. Fig. 3.11a). With increased shear strain in stage (e), the thinner of the two ductilely deforming veins (green) was finally penetrated by the crack tips and began to undergo a late increment of brittle slip (Fig. 3.19e inset magnification; e.g. Fig. 3.11b). The thicker 
a
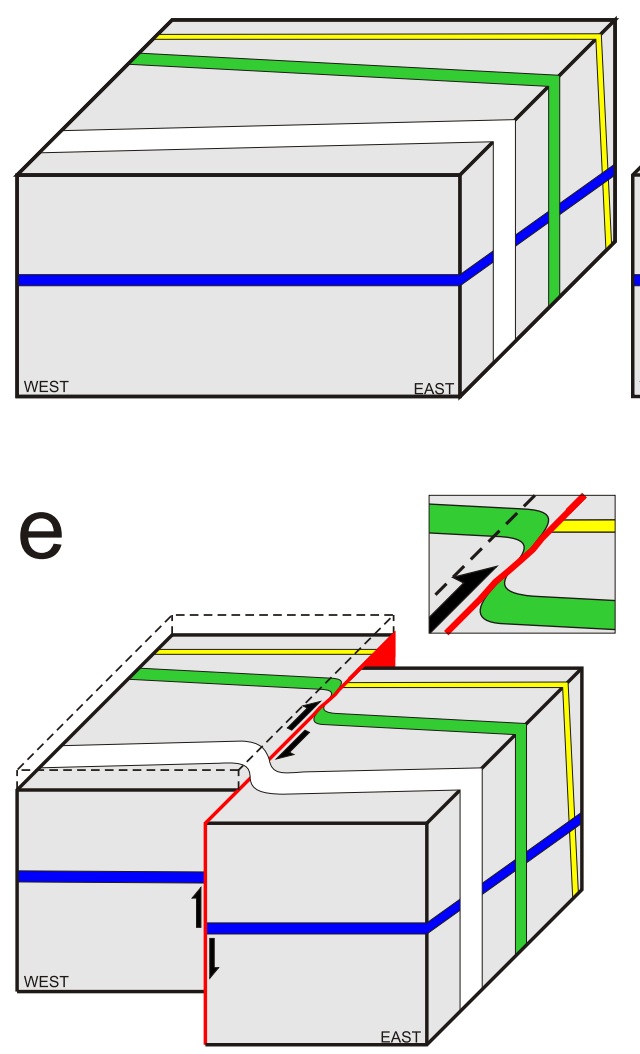

b
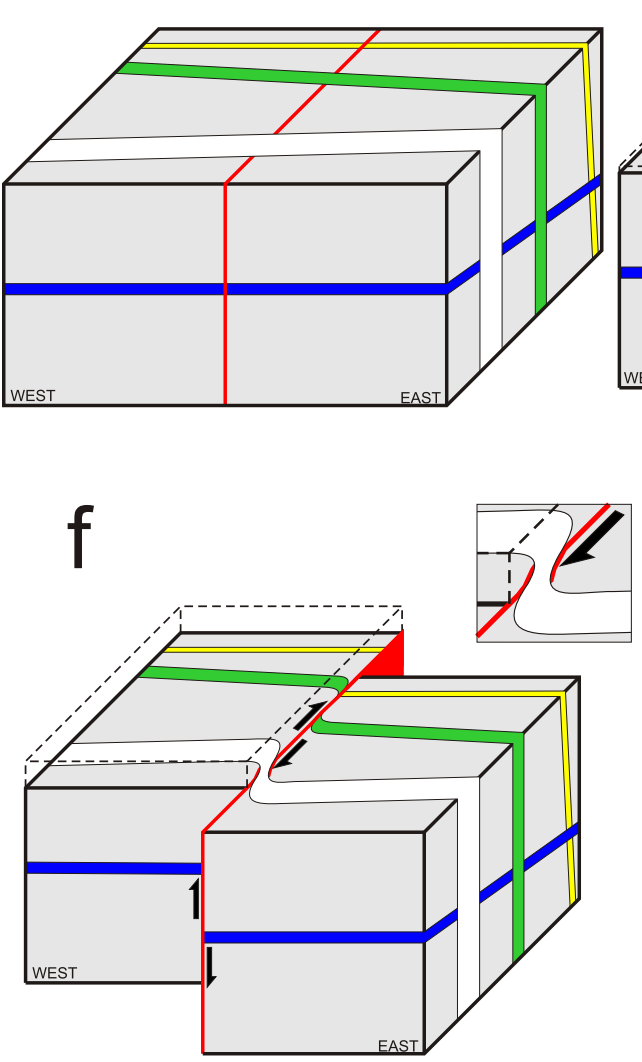

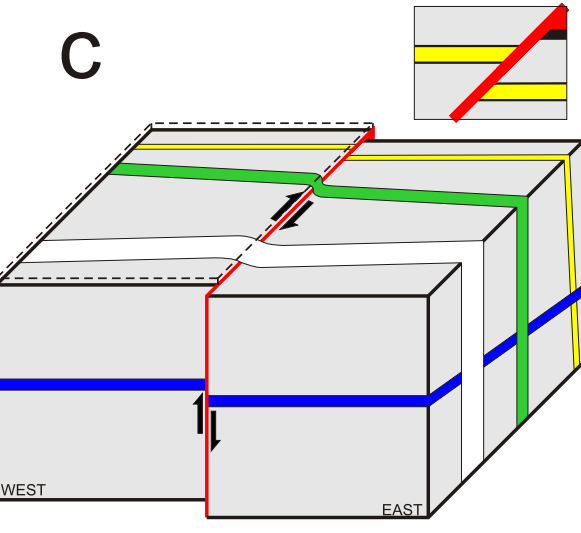

9

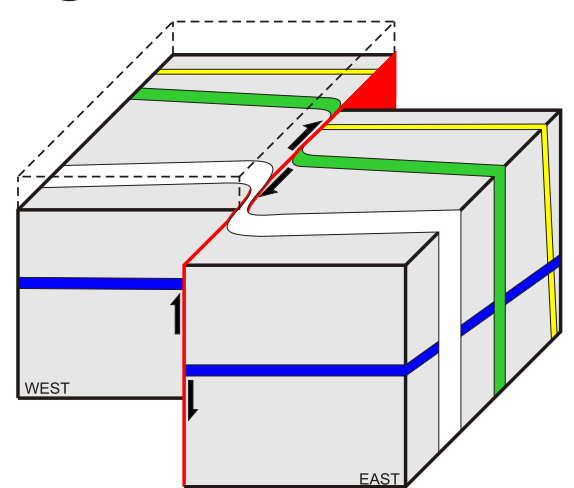

$\mathrm{d}$
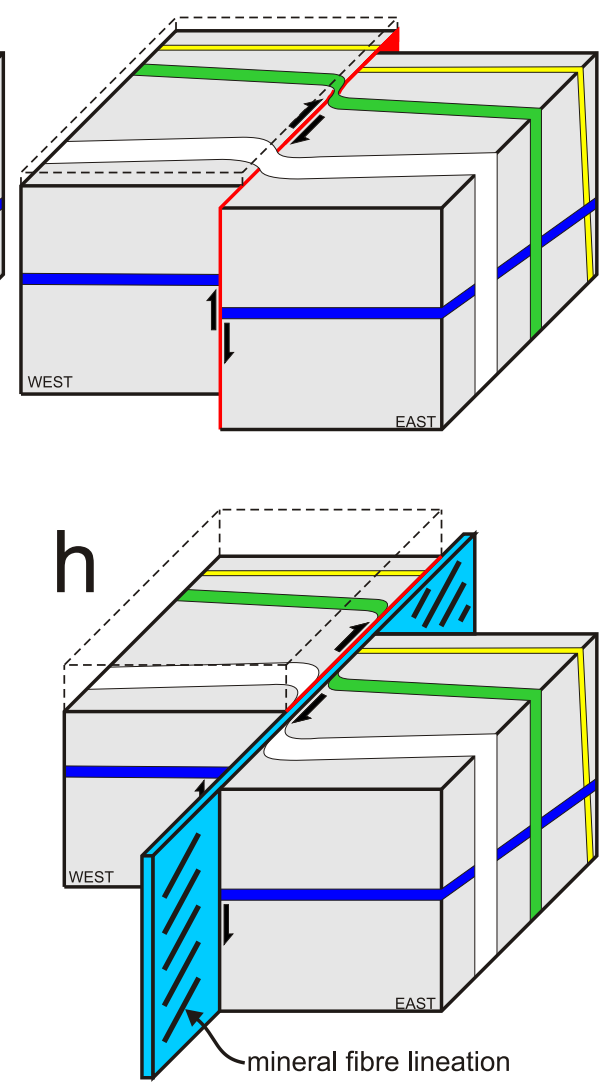

Fig. 3.19. Schematic deformation sequence (a-h) proposed for brittle-ductile deformation in shear zones. Four hypothetical veins of different thickness undergo shear deformation with a displacement vector pitching $30^{\circ} \mathrm{SW}$ in the shear plane. Veins undergo different brittle-ductile deformation (explained further in the text) while Alpine Schist undergoes brittle deformation. Final figure (h) shows precipitation of infilling vein and mineral fibre lineations. All block diagrams are eroded down to a flat surface after each deformation and a wire frame represents the eroded material. Note: no erosion is implied during actual brittle-ductile shearing. Inset figure are enlarged images of a section in the deforming blocks for the associated stages. 
white vein continued to deform ductilely in stages (f)-(g) until the vein has been sufficiently attenuated to allow the brittle crack tips link up across the narrowest part of the sheared vein (h). In stage (h) the infilling vein was precipitated into the brittle fracture and deformation continued by ductile deformation of the infilling vein material and by brittle slip along the crack.

This deformation sequence seems applicable to most of the shear zones but the behaviour of individual veins and propagating crack tips can vary. For example, some shear zones have thick veins that undergo only brittle deformation, and in others the crack tips never penetrate them completely or no infilling vein is precipitated. 


\section{CHAPTER 4: Optical microscopy of the brittle-ductile shear zones}

Results obtained using optical microscopy techniques can provide insights into rock fabric development and rheology that would be unobtainable from fieldbased structural studies alone. In the present study, petrographic (polarised transmitted light) microscopy and universal stage methods have been used to examine the deformation microstructures and determine the temperature and differential stress conditions when fabrics were imprinted in the late Cenozoic during deformation of the Pacific Plate across the Alpine Fault ramp. Quartz-calcite veins, and the Alpine Schist rock hosting them, that have been deformed by brittle-ductile shearing (along individual shear zones) within the brittle-ductile shear zone (BDSZ), have been sampled and used to undertake this petrographic research.

Samples from the sheared veins have been used to identify the microstructures which have been used to determine the types of active deformation mechanisms and the shear sense during deformation. Further analysis of these veins yielded estimated final increments of strain using grain shape fabrics, the approximate deformation temperature using quartz and calcite slip systems and the differential stress that may have dominated during phases of the deformation using recrystallised grain size and calcite twins. From these microscopic analyses an approximate microstructural evolution of the sheared and shear infilling veins has been determined.

\subsection{Sample locations and orientations}

Samples were collected from rocks in (or in some cases below) the BDSZ at Sam Peak (Fig. 4.1; Table 4.1), Chancellor Ridge (Fig. 4.2; Table 4.2) and Baumann Glacier (Fig. 4.3; Table 4.3) field areas. These samples were of quartz-calcite veins deformed by the brittle-ductile shears, the shear infilling veins and the Alpine Schist that hosts these veins. Sample numbers, grid references, and orientations for samples from the BDSZ are listed in Table 4.1-4.3. For descriptive purposes, samples are divided into four types for description: the Alpine Schist host rock; the strongly sheared and most attenuated parts of deformed veins (internal vein sections); the less deformed part of the vein external to the shear zones (external vein sections); and the syntectonic vein material that infills the shears (shear infilling vein sections). 


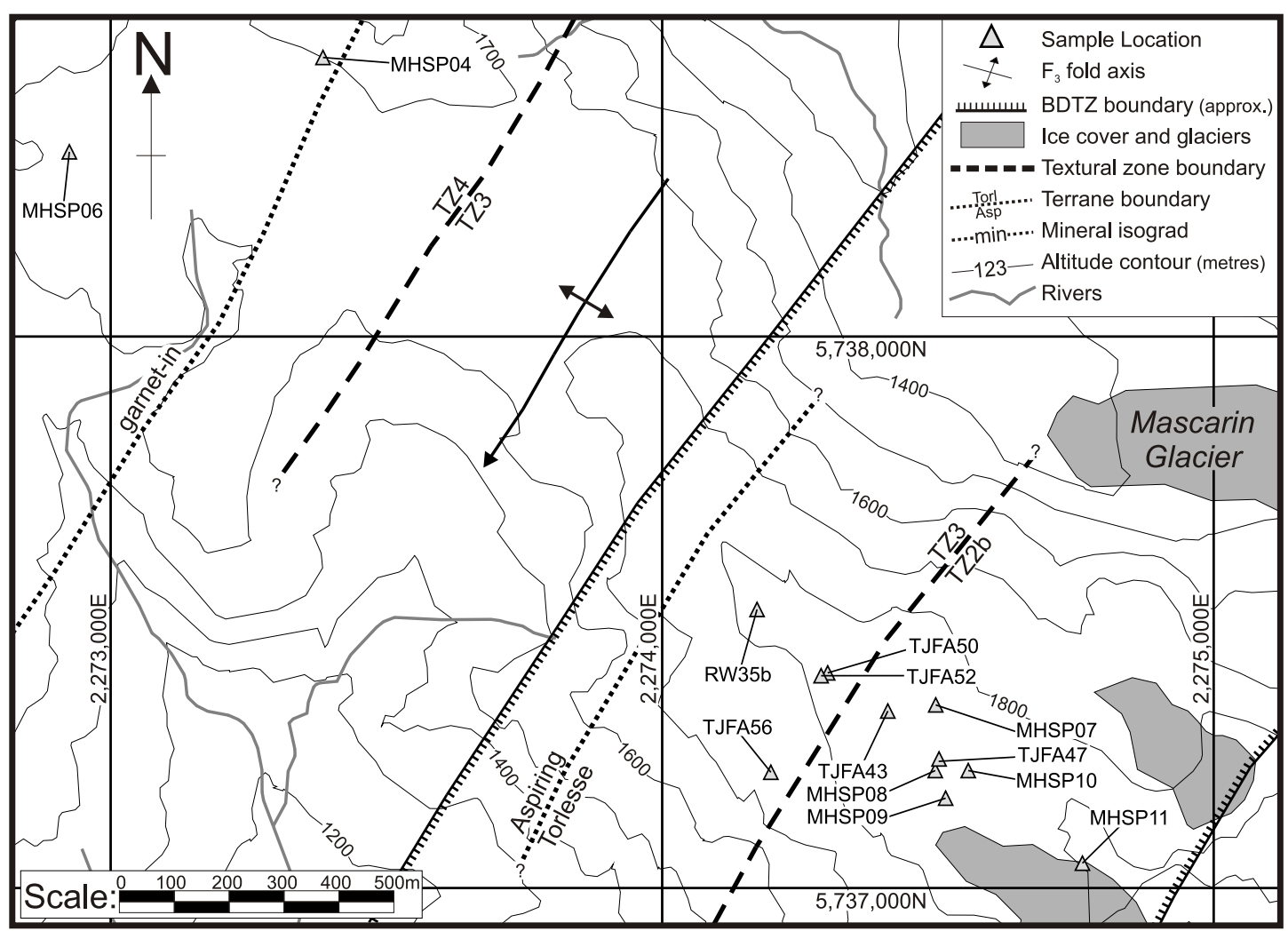

Fig. 4.1. Location map for samples collected in the Sam Peak field area. Maps are as in Chapter 3 with $100 \mathrm{~m}$ contours from the LINZ 1:50,000 digital data set, grid in metres for the New Zealand Map Grid projection system. Major geological structures are shown for reference.

\begin{tabular}{cccccccccc}
\hline $\begin{array}{c}\text { Field } \\
\text { Number }\end{array}$ & Vollection $\#$ & Easting & Northing & Elevation & Sample Type & \multicolumn{3}{c}{ Orientation of reference surface } \\
Coch & $(\mathrm{Y})$ & $\mathrm{m}$ & & Strike & Dip & Side & Surface \\
\hline MHSP04 & 39410 & 2273385 & 5738506 & 1,700 & Schist & 210 & 56 & $\mathrm{~T}$ & $\mathrm{O}$ \\
MHSP06 & 39411 & 2272925 & 5738335 & 1,680 & Schist & 182 & 62 & $\mathrm{U}$ & $\mathrm{O}$ \\
MHSP07 & 39412 & 2274496 & 5737332 & 1,860 & Schist & 208 & 72 & $\mathrm{~T}$ & $\mathrm{O}$ \\
MHSP08 & 39413 & 2274495 & 5737213 & 1,865 & Schist & 212 & 64 & $\mathrm{~T}$ & $\mathrm{O}$ \\
MHSP09 & 39414 & 2274514 & 5737163 & 1,865 & Infilling vein & 216 & 46 & $\mathrm{~T}$ & $\mathrm{O}$ \\
MHSP10 & 39415 & 2274555 & 5737213 & 1,875 & Schist & 204 & 64 & $\mathrm{~T}$ & $\mathrm{O}$ \\
MHSP11 & 39416 & 2274762 & 5737045 & 1,900 & Infilling vein & 206 & 48 & $\mathrm{~T}$ & $\mathrm{~S} 4$ \\
RW35b & 39431 & 2274172 & 5737505 & 1,820 & Infilling vein & 193 & 68 & $\mathrm{~T}$ & $\mathrm{O}$ \\
TJFA43 & 39432 & 2274409 & 5737321 & 1,824 & Infilling vein & 216 & 62 & $\mathrm{~T}$ & $\mathrm{O}$ \\
TJFA47 & 39433 & 2274502 & 5737234 & 1,865 & Infilling vein & 212 & 60 & $\mathrm{~T}$ & $\mathrm{O}$ \\
TJFA50 & 39434 & 2274300 & 5737390 & 1,815 & Schist & 206 & 65 & $\mathrm{U}$ & $\mathrm{S} 4$ \\
TJFA52 & 39435 & 2274288 & 5737385 & 1,797 & Infilling vein & 200 & 65 & $\mathrm{~T}$ & $\mathrm{~S} 4$ \\
TJFA56 & 39436 & 2274197 & 5737210 & 1,741 & Sheared vein & 207 & 73 & $\mathrm{~T}$ & AF \\
\hline
\end{tabular}

Table 4.1. Locations and orientations for samples collected in the Sam Peak field area. Field numbers are those displayed in Fig. 4.1 and VUW Collection number refers to the Victoria University of Wellington rock collection. Grid references are in metres for the New Zealand Map Grid projection system and elevations are above mean sea level. Sample type refers to either shear infilling vein or sheared quartz carbonate-vein. Orientation is listed for the marked surface on the sample with the side referring to either the top or bottom of the sample and the surface type for which the orientation markings are on; AF - Alpine Foliation plane, S4 - infilling vein plane or brittle-ductile shear plane and O - other surface. Strikes are all listed in right-hand-rule. 


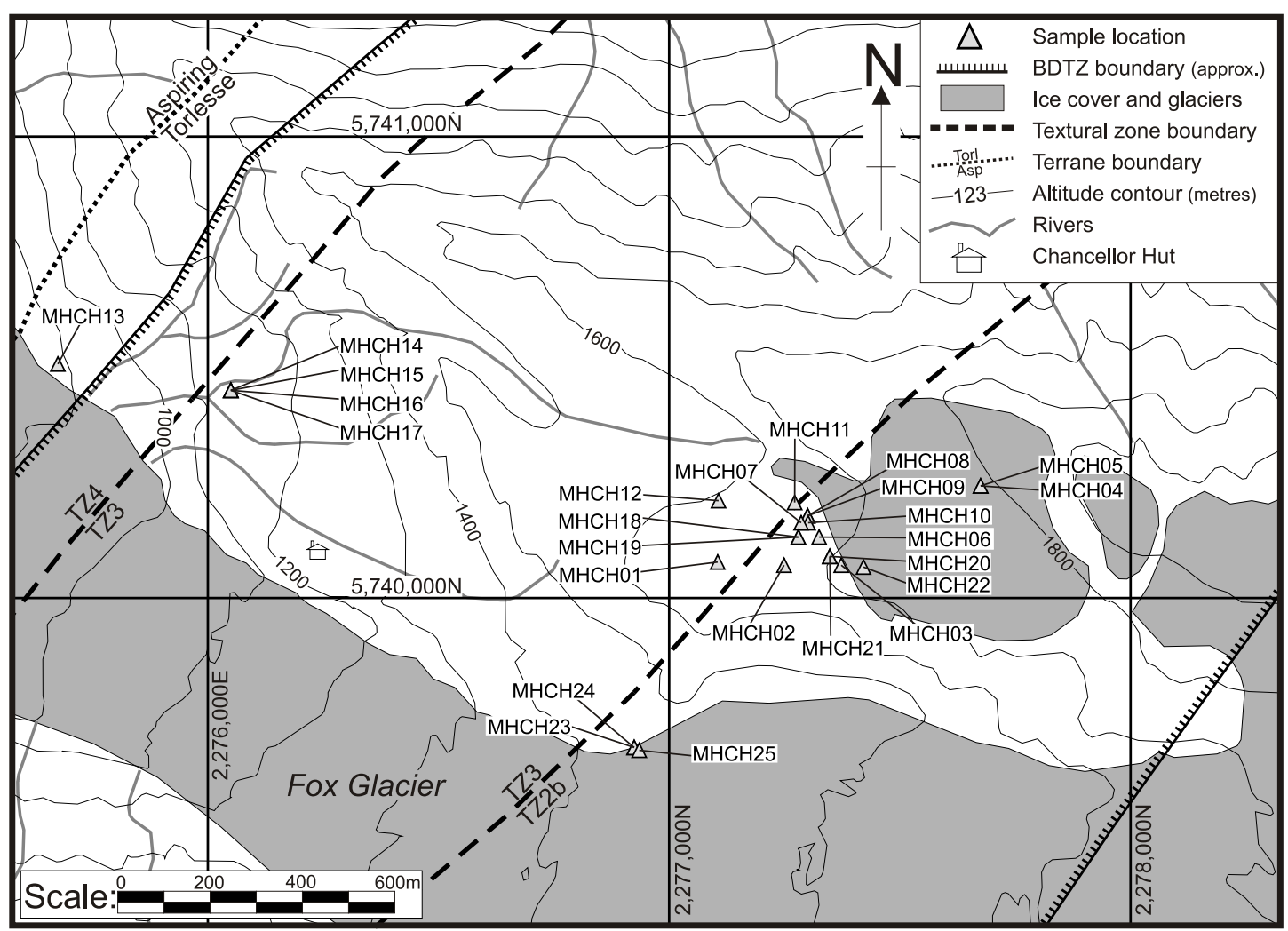

Fig. 4.2. Location map for samples collected in the Chancellor Ridge field area. Maps are as in Chapter 3 with 100 m contours from the LINZ 1:50,000 digital data set. Grid in metres for the New Zealand Map Grid projection system. Major geological structures are shown for reference.

\begin{tabular}{|c|c|c|c|c|c|c|c|c|c|}
\hline \multirow{2}{*}{$\begin{array}{c}\text { Field } \\
\text { Number }\end{array}$} & \multirow{2}{*}{$\begin{array}{c}\text { VUW } \\
\text { Collection \# }\end{array}$} & \multirow{2}{*}{$\begin{array}{l}\text { Easting } \\
(\mathrm{X})\end{array}$} & \multirow{2}{*}{$\begin{array}{l}\text { Northing } \\
(Y)\end{array}$} & \multirow{2}{*}{$\begin{array}{c}\text { Elevation } \\
\mathrm{m}\end{array}$} & \multirow[t]{2}{*}{ Sample Type } & \multicolumn{4}{|c|}{ Orientation of reference surface } \\
\hline & & & & & & Strike & Dip & Side & Surface \\
\hline $\mathrm{MHCH} 01$ & 39380 & 2277105 & 5740078 & 1,671 & Sheared vein & 205 & 90 & $U$ & $\mathrm{O}$ \\
\hline $\mathrm{MHCH} 02$ & 39381 & 2277249 & 5740071 & 1,685 & Infilling vein & 215 & 87 & $\mathrm{~T}$ & S4 \\
\hline $\mathrm{MHCH} 03$ & 39382 & 2277373 & 5740071 & 1,710 & Schist & 215 & 84 & $\mathrm{~T}$ & $\mathrm{O}$ \\
\hline $\mathrm{MHCHO4}$ & 39383 & 2277675 & 5740243 & 1,771 & Infilling vein & 039 & 88 & $\mathrm{~T}$ & S4 \\
\hline $\mathrm{MHCH} 05$ & 39384 & 2277675 & 5740243 & 1,771 & Schist & 033 & 82 & $\mathrm{~T}$ & $\mathrm{AF}$ \\
\hline $\mathrm{MHCHO6}$ & 39385 & 2277325 & 5740132 & 1,710 & Infilling vein & 218 & 84 & $\mathrm{~T}$ & S4 \\
\hline $\mathrm{MHCH} 07$ & 39386 & 2277286 & 5740163 & 1,689 & Infilling vein & 217 & 88 & $\mathrm{~T}$ & S4 \\
\hline $\mathrm{MHCH} 08$ & 39387 & 2277300 & 5740178 & 1,689 & Infilling vein & 215 & 87 & $\mathrm{~T}$ & S4 \\
\hline MHCH09 & 39388 & 2277300 & 5740178 & 1,689 & Schist & 214 & 84 & $\mathrm{~T}$ & $\mathrm{O}$ \\
\hline $\mathrm{MHCH} 10$ & 39389 & 2277301 & 5740163 & 1,695 & Infilling vein & 217 & 86 & $\mathrm{~T}$ & S4 \\
\hline MHCH11 & 39390 & 2277272 & 5740207 & 1,665 & Sheared vein & 217 & 82 & $U$ & S4 \\
\hline $\mathrm{MHCH} 12$ & 39391 & 2277107 & 5740211 & 1,618 & Infilling vein & 221 & 85 & $\mathrm{~T}$ & S4 \\
\hline $\mathrm{MHCH} 13$ & 39392 & 2275675 & 5740507 & 878 & Schist & 034 & 60 & $\mathrm{~T}$ & $\mathrm{AF}$ \\
\hline $\mathrm{MHCH} 14$ & 39394 & 2276050 & 5740450 & 1,183 & Infilling vein & 218 & 88 & $\mathrm{~T}$ & S4 \\
\hline $\mathrm{MHCH} 15$ & 39395 & 2276050 & 5740450 & 1,183 & Infilling vein & 208 & 81 & $\mathrm{~T}$ & S4 \\
\hline $\mathrm{MHCH} 16$ & 39396 & 2276050 & 5740450 & 1,183 & Schist & 040 & 82 & $\mathrm{~T}$ & S4 \\
\hline $\mathrm{MHCH} 17$ & 39397 & 2276050 & 5740450 & 1,183 & Sheared vein & 038 & 88 & $\mathrm{~T}$ & S4 \\
\hline $\mathrm{MHCH} 18$ & 39398 & 2277280 & 5740132 & 1,666 & Sheared vein & 213 & 85 & $\mathrm{~T}$ & S4 \\
\hline $\mathrm{MHCH} 19$ & 39399 & 2277280 & 5740132 & 1,666 & Sheared vein & 219 & 84 & $\mathrm{~T}$ & S4 \\
\hline $\mathrm{MHCH} 20$ & 39400 & 2277348 & 5740090 & 1,704 & Sheared vein & 222 & 88 & $\mathrm{~T}$ & S4 \\
\hline $\mathrm{MHCH} 21$ & 39401 & 2277348 & 5740090 & 1,704 & Sheared vein & 218 & 89 & $U$ & S4 \\
\hline $\mathrm{MHCH} 22$ & 39402 & 2277421 & 5740067 & 1,698 & Sheared vein & 219 & 89 & $\mathrm{~T}$ & S4 \\
\hline $\mathrm{MHCH} 23$ & 39403 & 2276926 & 5739676 & 1,452 & Infilling vein & 218 & 84 & $\mathrm{~T}$ & S4 \\
\hline $\mathrm{MHCH} 24$ & 39404 & 2276924 & 5739671 & 1,441 & Sheared vein & 035 & 82 & $\mathrm{~T}$ & $\mathrm{AF}$ \\
\hline $\mathrm{MHCH} 25$ & 39405 & 2276935 & 5739670 & 1,450 & Sheared vein & 216 & 80 & $\mathrm{~T}$ & S4 \\
\hline
\end{tabular}

Table 4.2. Locations and orientations for samples collected in the Chancellor Ridge field area. Field numbers are those displayed in Fig. 4.2. Sample type listing of schist refers to a sample of Alpine Schist. All other table definitions are as in Table 4.1. Strikes are all listed in right-hand-rule. 


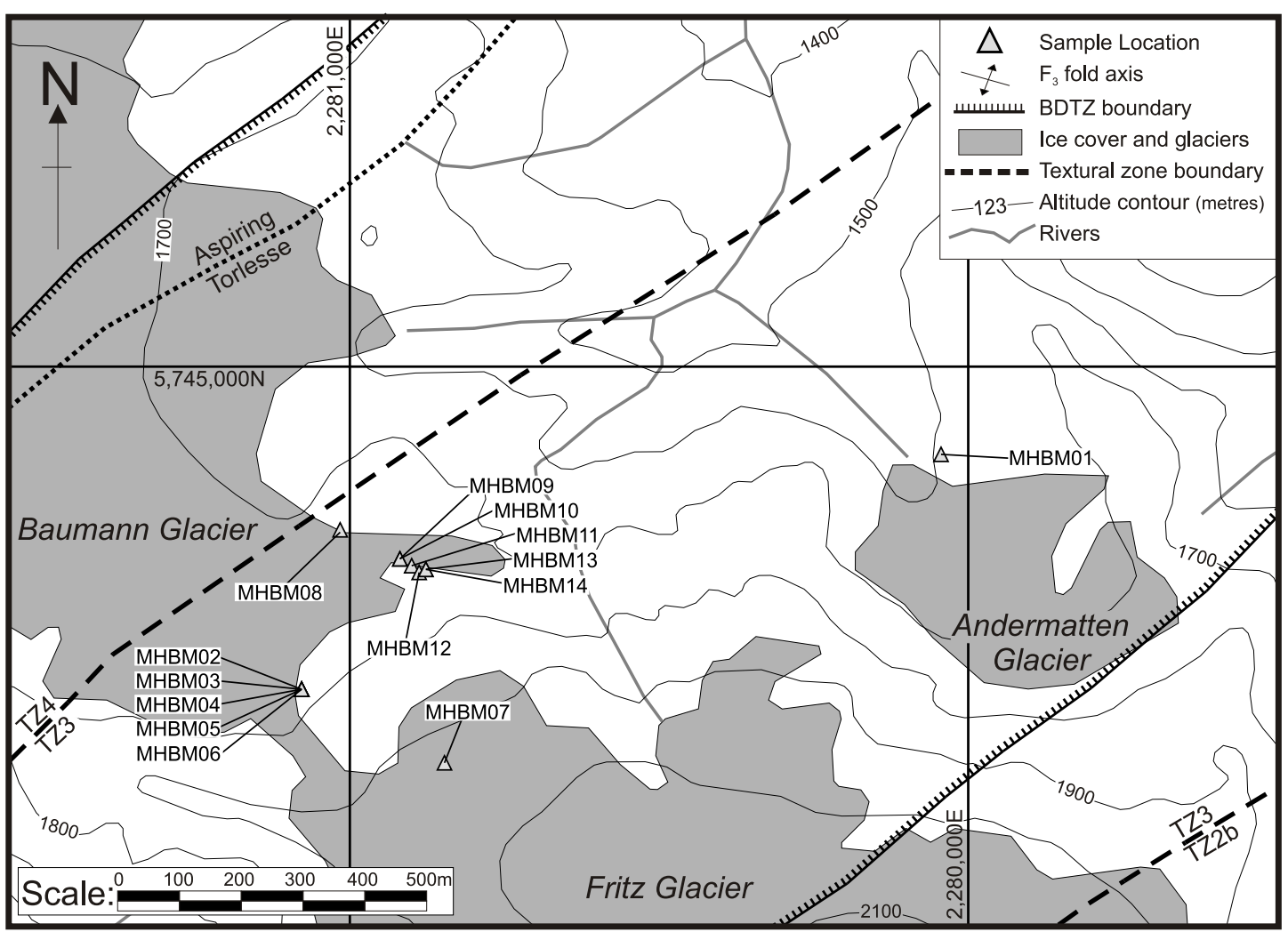

Fig. 4.3. Location map for samples collected in the Baumann Glacier field area. Maps are as in Chapter 3 with 100 m contours from the LINZ 1:50,000 digital data set. Grid in metres for the New Zealand Map Grid projection system. Major geological structures are shown for reference.

\begin{tabular}{|c|c|c|c|c|c|c|c|c|c|}
\hline \multirow{2}{*}{$\begin{array}{c}\text { Field } \\
\text { Number }\end{array}$} & \multirow{2}{*}{$\begin{array}{c}\text { VUW } \\
\text { Collection \# }\end{array}$} & \multirow{2}{*}{$\begin{array}{c}\text { Easting } \\
(\mathrm{X})\end{array}$} & \multirow{2}{*}{$\begin{array}{l}\text { Northing } \\
(Y)\end{array}$} & \multirow{2}{*}{$\begin{array}{c}\text { Elevation } \\
\mathrm{m}\end{array}$} & \multirow[t]{2}{*}{ Sample Type } & \multicolumn{4}{|c|}{ Orientation of reference surface } \\
\hline & & & & & & Strike & Dip & Side & Surface \\
\hline MHBM01 & 39417 & 2280956 & 5744858 & 1,613 & Infilling vein & 048 & 74 & $\mathrm{~T}$ & $\mathrm{AF}$ \\
\hline MHBM02 & 39418 & 2279922 & 5744478 & 1,780 & Infilling vein & 045 & 82 & $U$ & S4 \\
\hline MHBM03 & 39419 & 2279922 & 5744478 & 1,780 & Sheared vein & 050 & 70 & $\mathrm{~T}$ & 0 \\
\hline MHBM04 & 39420 & 2279922 & 5744478 & 1,780 & Sheared vein & 041 & 86 & $u$ & 0 \\
\hline MHBM05 & 39421 & 2279922 & 5744478 & 1,780 & Sheared vein & 184 & 84 & $T$ & $\mathrm{O}$ \\
\hline MHBM06 & 39422 & 2279922 & 5744478 & 1,780 & Infilling vein & 046 & 80 & U & S4 \\
\hline MHBM07 & 39423 & 2280153 & 5744359 & 1,940 & Infilling vein & 040 & 72 & $U$ & S4 \\
\hline MHBM08 & 39424 & 2279994 & 5744738 & 1,744 & Infilling vein & 044 & 88 & $U$ & S4 \\
\hline MHBM09 & 39425 & 2280081 & 5744689 & 1,737 & Sheared vein & 152 & 20 & $T$ & 0 \\
\hline MHBM10 & 39426 & 2280081 & 5744689 & 1,737 & Sheared vein & 197 & 65 & $\mathrm{~T}$ & $\mathrm{O}$ \\
\hline MHBM11 & 39427 & 2280100 & 5744678 & 1,750 & Sheared vein & 221 & 89 & $\mathrm{~T}$ & $\mathrm{AF}$ \\
\hline MHBM12 & 39428 & 2280112 & 5744667 & 1,759 & Sheared vein & 042 & 88 & $U$ & 0 \\
\hline MHBM13 & 39429 & 2280123 & 5744672 & 1,764 & Sheared vein & 056 & 80 & $U$ & S4 \\
\hline MHBM14 & 39430 & 2280123 & 5744672 & 1,764 & Infilling vein & 225 & 82 & $\mathrm{~T}$ & S4 \\
\hline
\end{tabular}

Table 4.3. Locations and orientations for samples collected in the Baumann Glacier field area. Field numbers are those displayed in Fig. 4.3. Definitions for all terms in this table can be found in Tables 4.1 and 4.2. Strikes are all listed in right-hand-rule. 
Analysis of the different types of sample sections will allow us to make conclusions about the deformation path during brittle-ductile shearing of the veins.

Additional samples were also collected from Alpine Fault mylonitic chert at Hare Mare Creek (Fig. 4.4a) and from non-mylonitic Alpine Schist metacherts outcropping along the Waiho River (Fig. 4.4b). Grid references and sample orientations for these samples are listed in Table 4.4. These additional, structurally deeper, samples have been used for microstructural and crystallographic comparisons with the sheared quartz vein samples from the BDSZ's at Sam Peak, Chancellor Ridge and Baumann Glacier.

Every sample was marked using a standard orientation marking on one of the planar surfaces (usually on the dominant foliation or shear plane). This marking is a line parallel to the strike of the plane in situ with a half arrow on the more northern end of the strike line. Samples marked on the top side of the rock have a single tick label in the down dip direction. Samples marked on the bottom side of the rock have dip labels with a loop in the up-dip direction and a tick symbol in the down-dip direction. These symbols are illustrated in Fig. 4.5.

\subsection{Methods of optical microscopy used in this study}

A petrographic (polarising transmitted light) microscope was used for mineral identification, the observation and measurement of microstructural fabrics, and the determination of mineral proportions. A similar microscope fitted with a 5-axis universal stage was used for measurement of crystallographic orientations of quartz and calcite c-axes, as well as the angle between this axis and microstructural features such as quartz subgrain boundaries and calcite twins.

Thin-sections suitable for standard optical microscopy and crystallographic orientation measurements of quartz and calcite have been made for the samples collected in this study. For the microstructural and quartz crystallographic thin sections were made $30 \mu \mathrm{m}$ thick, but were reduced to $15 \mu \mathrm{m}$ for the crystallographic measurements of calcite to reduce interference due to the high birefringence of that mineral. Thin-sections were cut perpendicular to the shear plane and parallel to one of three orientations: the shear plane's strike direction (-st cuts), the dip direction (-d cuts) or the mineral fibre lineation (-p cuts) direction (Fig. 4.6). For shear infilling 

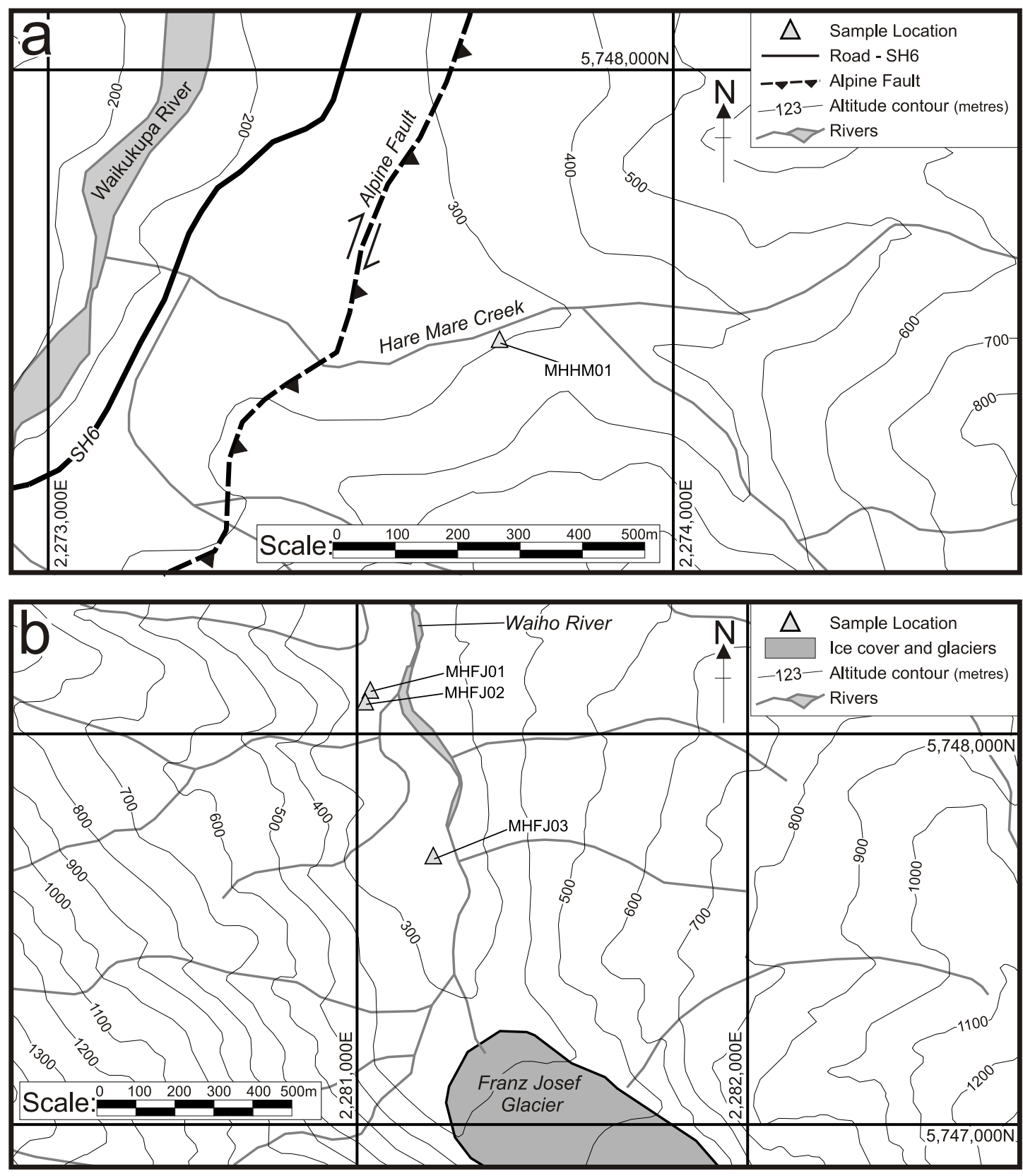

Fig. 4.4. Location map for samples collected in the Hare Mare Creek (a) and Waiho River (b) field areas. Contours are shown at $100 \mathrm{~m}$ intervals and are from the LINZ 1:50,000 digital data set. The grid is in metres for the New Zealand Map Grid projection system. Major geological structures shown for reference. SH6 refers to State Highway 6 on the west coast of the South Island in New Zealand.

\begin{tabular}{cccccccccc}
\hline $\begin{array}{c}\text { Field } \\
\text { Number }\end{array}$ & Vollection $\#$ & Easting & Northing & Elevation & Sample Type & \multicolumn{3}{c}{ Orientation of reference surface } \\
& C & $(\mathrm{Y})$ & $\mathrm{m}$ & & Strike & Dip & Side & Surface \\
\hline MHFJ01 & 39406 & 2281034 & 5748112 & 261 & Chert & 048 & 75 & $\mathrm{~T}$ & $\mathrm{AF}$ \\
MHFJ02 & 39407 & 2281021 & 5748082 & 274 & Chert & 037 & 75 & $\mathrm{~T}$ & $\mathrm{AF}$ \\
MHFJ03 & 39408 & 2281195 & 5747688 & 279 & Chert & 035 & 75 & $\mathrm{~T}$ & $\mathrm{AF}$ \\
MHHM01 & 39409 & 2273722 & 5747569 & 275 & Mylonitic chert & 061 & 32 & $\mathrm{U}$ & MF \\
\hline
\end{tabular}

Table 4.4. Locations and orientations for samples collected in the Baumann Glacier field area. Field numbers are those displayed in Fig. 4.4. Definitions for all terms in this table can be found in Tables 4.1 and 4.2 with the addition of sample types of chert and mylonitic chert which refer to chert rich section of the non-mylonitic Alpine Schist and Alpine Fault mylonite rocks and the MF orientation surface which refers to the mylonitic foliation. Strikes are all listed in right-hand-rule. 


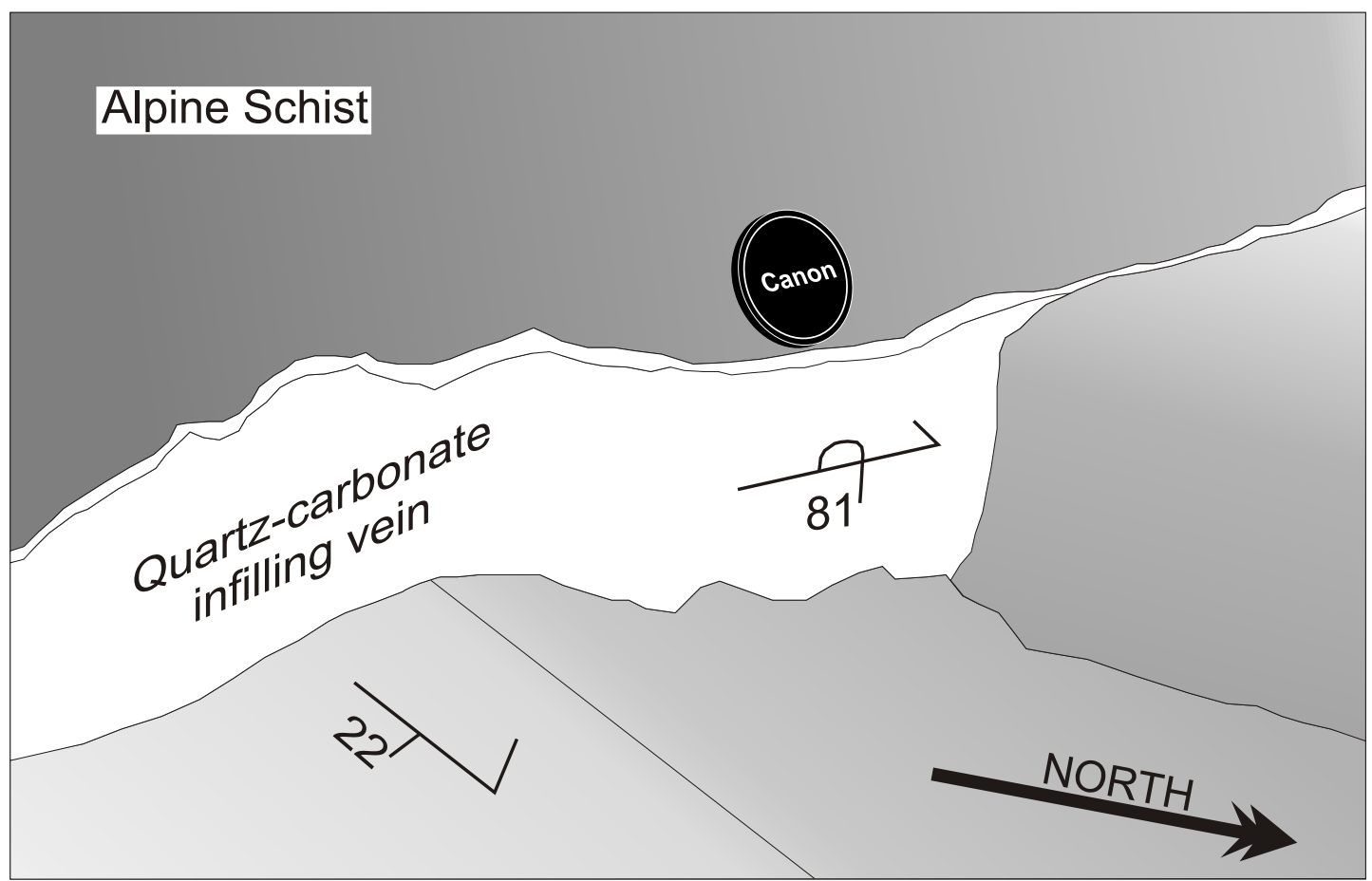

Fig. 4.5. Cartoon showing the orientation marking system used on samples. One marking is on a plane in the Alpine Schist that is dipping $22^{\circ}$ to the southeast. This marking is on the top of the sample and has a long line parallel to strike with a half arrow tick on north end and a short tick in the down dip direction. The second example is on the quartz-carbonate infilling vein. This marking is on the bottom of the steeply dipping vein and has a long line parallel to the veins strike and a half arrow tick on the north end. As the sample has the marking on the bottom the down- dip tick is annotated with a loop in the up-dip direction.

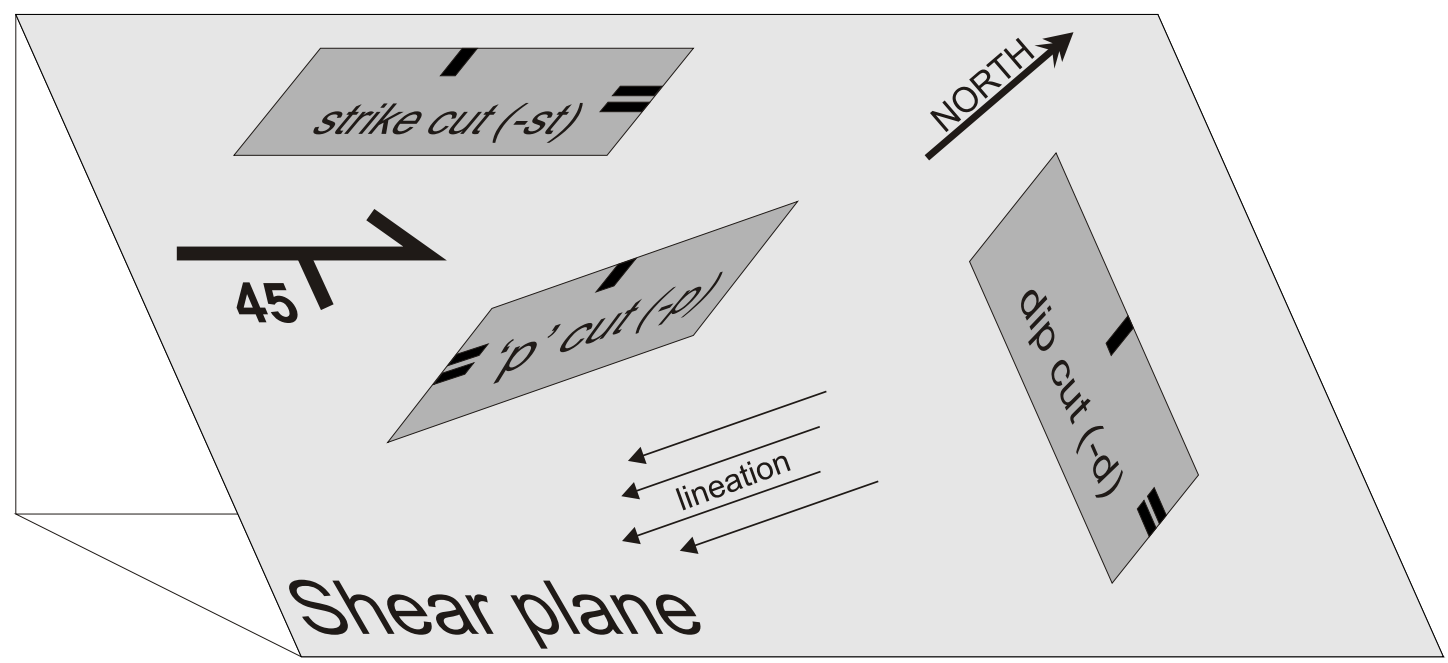

Fig. 4.6. Cartoon showing the orientation and notching system used on thin sections relative to the $\mathrm{S}_{4}$ shear plane and $\mathrm{L}_{4}$ lineations. The strike cut (-st) is parallel to the strike of the shear plane and perpendicular to the shear plane. This thin section cut contains the pole to the shear plane and the shear plane strike. The dip cut (-d) is parallel to the dip of the shear plane and perpendicular to the shear plane. This thin section cut contains the pole to the shear plane and the line pitching $90^{\circ}$ in the shear plane. The lineation parallel ' $p$ ' cut $(-p)$ is parallel to the lineation and perpendicular to the shear plane. This thin section cut contains the pole to the shear plane, and pitches parallel to the lineation. 
vein samples, thin sections were generally cut in all three directions (-st, $-\mathrm{d}$ and $-\mathrm{p})$. Sheared vein samples, however, were only cut parallel to the strike direction (-st) as the small volume of sample typically only allowed for one thin section to be made. Multiple thin-sections were often required to cover the extent of a single shear zone sample. Outside of the BDSZ (in the Alpine Schist), samples were cut perpendicular to the dominant foliation $\left(S_{2}\right.$ or $\left.S_{3}\right)$ and parallel to both the strike and dip (-st and $\left.-d\right)$.

Quartz grain diameters were measured in two orthogonal directions using the intercept method (Christie and Ord, 1980; Stipp et al., 2002a). Grain boundaries were counted that intercepted a line of known length (usually $1.2 \mathrm{~mm}$ ), from which a mean grain diameter was calculated for that line. The representative length of the long axis of the grains (a) was calculated from the average of counts along five lines parallel to the grain shape fabric, and the representative length of the short axis $(b)$ was calculated from the average of counts along five lines orthogonal to the grain shape fabric. The 2-D grain diameter $(D)$ was measured (as in Stipp et al., 2002a; Appendix C) from the equation:

$$
D=\sqrt{a \cdot b}
$$

Because three mutually perpendicular thin-sections were not cut from many samples, three-dimensional grain diameters (Smith and Guttman, 1953; Christie and Ord, 1980) were not calculated in this study. The intercept method for grain diameter measurement was only applied to quartz grains as other minerals did not occur in concentrations large enough for statistically significant numbers of grains to fall on a single intercept line.

Sizes of individual features such as large grains, micas and calcite twin widths were measured using a graduated reticle in the eyepiece of the petrographic microscope. This reticle was calibrated using a stage micrometer. The angular orientations of oblique grain shape fabrics, subgrain boundaries and calcite twins were measured by reading the vernier scale after rotation of the microscope stage. 


\subsection{Mineralogy and microstructures}

\subsubsection{Alpine Schist}

The Alpine Schist at Sam Peak, Chancellor Ridge and Baumann Glacier typically consists of biotite grade metagreywacke that ranges in chemistry from relatively psammitic to relatively more pelitic bulk compositions (Fig. 4.7a, b, c and d). The dominant foliation in the Alpine Schist was generated during the $D_{3}$ deformation in the late Cretaceous (Vry et al., 2004) and reinforced during the late Cenozoic (Little et al., 2002a). Porphyroblasts of biotite, that include the earlier $\mathrm{S}_{2}$ foliation, occur locally in Aspiring Terrane schist at Sam Peak (e.g. Fig. 4.7e) and record an earlier deformation that formed the $S_{3}$ foliation. A phyllitic cleavage is typically dominant structurally above the base of the BDSZ where minerals are not separated into obvious domains. Occasionally, quartz grains in these rocks are observed to have undergone brittle deformation where fractures are in-filled by micas (e.g. Fig. 4.7d). Structurally below the BDSZ, a well-developed schistosity occurs (Fig. 4.7c) defined by separate microlithon (quartzite-rich) and cleavage domain (mica and chlorite-rich) layering.

Minerals in the schist typically include quartz $(\mathrm{Qtz})+$ biotite $(\mathrm{Bt}) \pm$ white mica $(\mathrm{Ms}) \pm$ titanite $(\mathrm{Ttn}) \pm$ epidote $(\mathrm{Ep}) \pm$ calcite $(\mathrm{Cal}) \pm$ plagioclase $(\mathrm{Pl}) \pm$ chlorite (Chl) \pm graphite $(\mathrm{Gr}) \pm$ illmenite (Ilm). Abbreviations used here are after Kretz (1983). In structurally lower regions of Sam Peak, the Alpine Schist contained garnet porphyroblasts, the first appearance of which defined the garnet-in (Grt) isograd plotted in Figs. 3.1 and 4.1. Alpine Schist from Sam Peak in the Aspiring Terrane samples contained up to $\sim 30 \%$ graphite (Fig. $4.7 \mathrm{f}$ ). The metachert samples from the Waiho River consist mostly of Qtz $+\mathrm{Ms} \pm \mathrm{Bt}$ (Fig. 4.7g). The mylonitic metachert sample from Hare Mare Creek consists of Qtz + Grt + Bt + Ms (Fig. 4.7h) with potassium feldspar $(\mathrm{Kfs})+$ hornblende $(\mathrm{Hbl})$ also present in the surrounding mylonitic schist. Quartz grain sizes in the schist typically vary from 20 to $100 \mu \mathrm{m}$ for small recrystallised grains and may reach up to $250 \mu \mathrm{m}$ in relict detrital or porphyroclastic sand grains (e.g. Fig. 4.7a).

The mapping of the textural zones (TZ's), after Turnbull et al. (2001), has been used to define an increase in metamorphic textural grade westwards in all of the field areas. These TZ's were initially based on field observations (see Chapter 3, this 

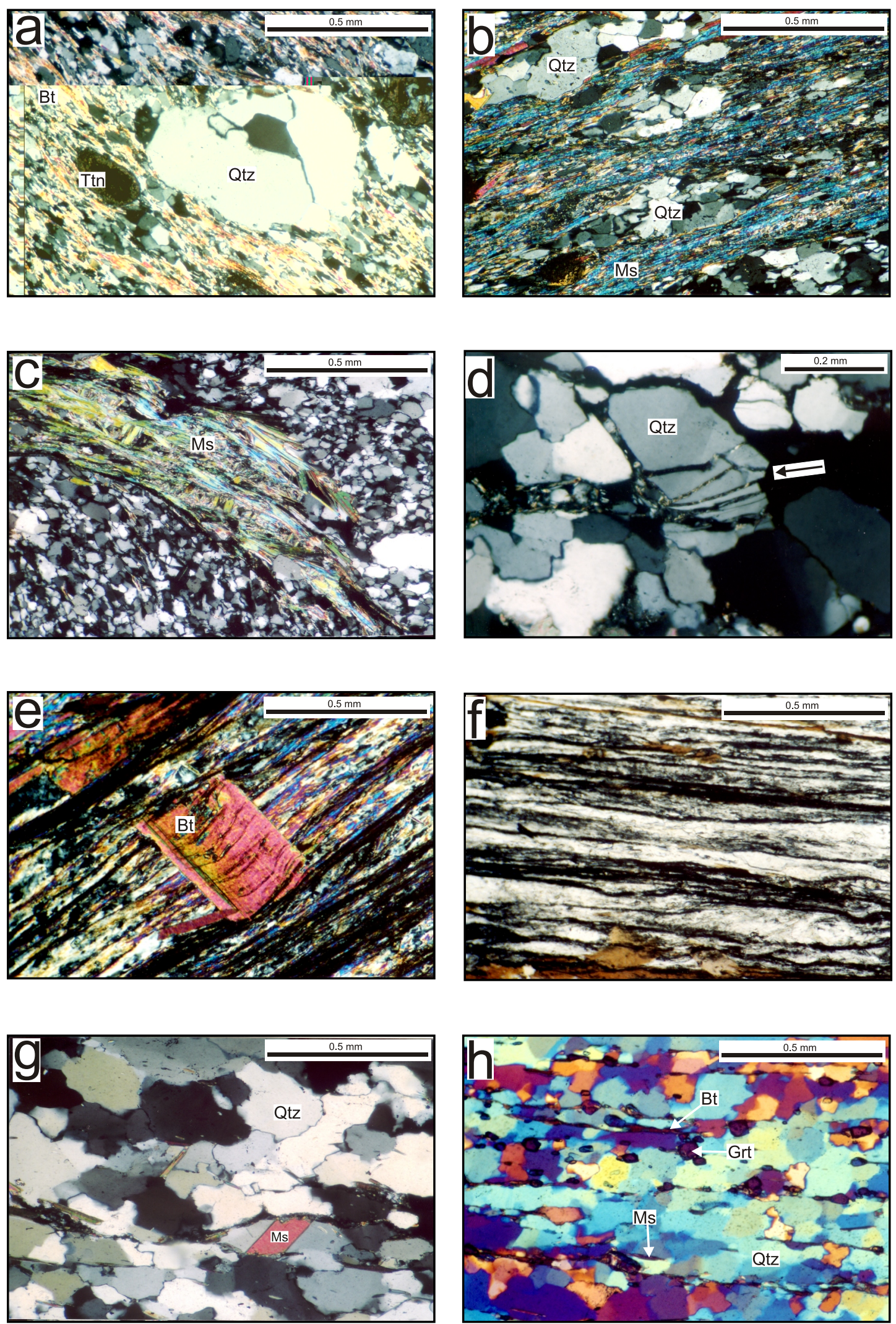

Fig. 4.7. Photomicrographs of Alpine Schist fabrics and the Alpine Fault mylonite. For all photomicrographs (herein and subsequent figures) PPL is plane polarised light and CPL is cross-polarised light. a. Textural zone (TZ) 2B Alpine Schist with a relict quartz grain that has undergone subgrain rotation recrystallistion (CPL). b. TZ 3 Alpine Schist with muscovite and foliation parallel quartz (CPL). c. TZ 4 Alpine Schist (CPL). d. Brittle fracturing of a quartz crystal in the Alpine Schist (arrowed) (CPL). e. Biotite porphyroblast with graphite inclusion trails of the $S_{2}$ foliation (CPL). f. Graphite rich schist from the Aspiring Terrane on Sam Peak (PPL). g. Alpine Schist from a Waiho River chert sample (CPL). h. Alpine Fault mylonite sample taken with gypsum plate inserted (CPL). 
study) and refined here on the basis of muscovite grain size and recrystallised quartz grains as observed in thin-section. The textural zones defined in this study are plotted in Figs. 4.1, 4.2 and 4.3 and their petrographic features are described below. Microfabrics from TZ 2B are distinguished typically by a fine grained schist (quartz grains $20-50 \mu \mathrm{m}$ and white micas $<75 \mu \mathrm{m}$ long and $<5 \mathrm{~mm}$ thick) with detrital sand grains that have undergone subgrain rotation recrystallisation (e.g. Fig. 4.7a). In TZ 3 these detrital sand grains have been recrystallised into elongated quartz-rich layers that no longer preserve the relict grain shape and are frequently pinned by mica layers. In addition, TZ 3 shows an increase in length and width of muscovite crystals to $75-125 \mu \mathrm{m}$ long and 5-15 $\mu \mathrm{m}$ wide (Fig. $4.7 \mathrm{~b}$ ). TZ 4 has a schistosity defined by segregated domains of micas and quartz; also the muscovite crystals are further enlarged to $125-200 \mu \mathrm{m}$ long and $25-50 \mu \mathrm{m}$ wide (Fig. $4.7 \mathrm{c}$ ).

\subsubsection{Sheared quartz-calcite veins}

The sheared veins were variably emplaced into the Alpine Schist during the mid Cretaceous to the early Miocene $\mathrm{D}_{3}$ deformation (Little et al., 2002a). Some of the sheared veins have undergone $\mathrm{D}_{3}$ folding to develop a grain shape foliation in dynamic recrystallised grains and a macroscopically distinct axial planar foliation in the fold hinges (Fig. 3.11a). These veins have been sheared during the late Cenozoic and displaced by brittle-ductile deformation in shear zones within the BDSZ (Little, 2002b; Little et al., 2004; Wightman, 2005; also see Chapter 3 of this study). Petrographic study of these sheared veins has been divided into sections of the shear zone: the most strongly deformed internal section where ductile shearing has occurred and the external area where the veins are not deformed in the shear zone. This division has been made to differentiate between microstructures that may be related to the late Cenozoic shearing and those external to the deformation. The samples of sheared veins in this study have a mean finite ductile shear strain of $5.5 \pm$ $1.3(n=17)$ and are within the uncertainties of the mean ductile shear strain calculated for the BDSZ which is $4.8 \pm 0.7$ (see Chapter 3).

The veins include Qtz \pm Cal \pm Ms \pm Chl (Fig. 4.8). Commonly chlorite, white mica and calcite concentrations are found along the vein boundaries with quartz and calcite the dominant vein forming minerals. Quartz makes up a minimum composition of $70 \%$ and micas (mostly white mica) and chlorite not more than $5 \%$ of 

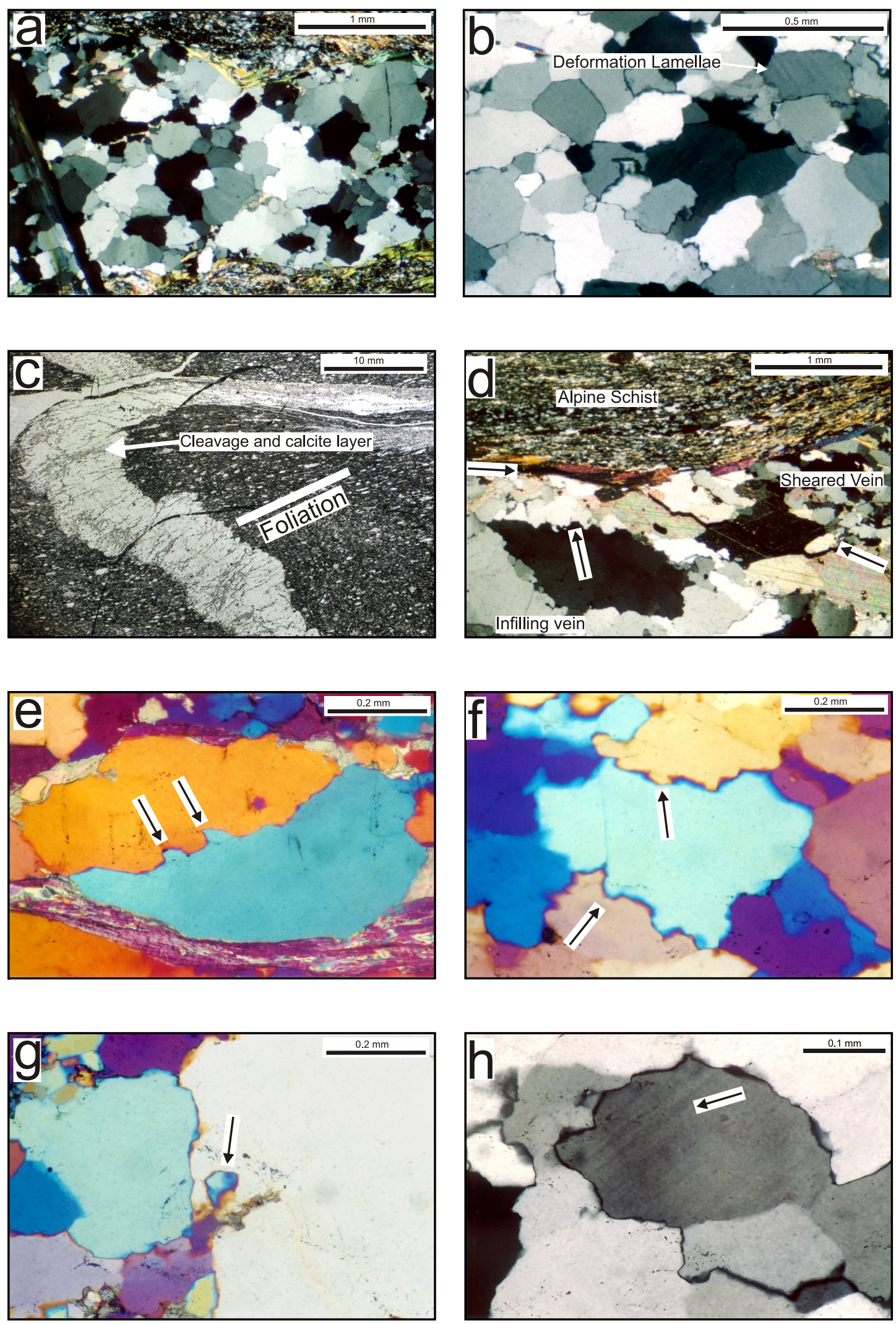

Fig. 4.8. Photomicrographs of microstructures in sheared quartz veins and infilling veins. a. View of internal section of sheared vein showing polygonal grain shape fabric (GSF) (CPL). b. Enlargement of polygonal GSF in (a) (CPL). c. Sheared quartz vein in Alpine schist showing attenuation of strongly deformed and deflected vein material and local development of a distinct Alpine Foliation in the vein external to the shear zone (PPL). d. Internal section of a sheared vein and adjacent infilling vein. Brittle fracture seen between the two shear zone sections indicated by arrow (CPL). e and f. Grain boundary migration clearly seen between two quartz grains (arrows) as enhanced with a gypsum plate (CPL). g. An island grain (arrowed) formed from grain boundary migration clearly visible when using a gypsum plate (CPL). h. Deformation lamallae (arrowed) in a quartz grain (CPL). 
the veins composition. Calcite varies in abundance (not more than $30 \%$ of the bulk composition) and is commonly found in concentrated layers parallel to the vein boundaries with local concentrations exceeding 50\%. A mean quartz grain size of $126 \pm 16 \mu \mathrm{m}$ is characteristic of the internal sections and a relatively coarser $171 \pm$ $14 \mu \mathrm{m}$ characteristic of the external veins sections.

Microstructures between different sections of the sheared veins are very similar, and although present, the quartz grains have few subgrain boundaries and only show minor grain boundary bulging. More common across the sheared veins are quartz grains with undulose extinction and deformation lamellae (Fig. 4.8a and b) and calcite grains with mostly thin planar $(2-5 \mu \mathrm{m})$ twins. Small dynamically recrystallised quartz grains $(<50 \mu \mathrm{m})$ are not found in abundance and the quartz grain size is typically homogeneous throughout the veins indicating that little recrystallisation has occurred. Microstructures fit Regime 1 of Hirth and Tullis (1992), as conditions do not appear to have been met to allow significant dislocation climb and subsequent recrystallisation to occur. Intracrystalline deformation however, has occurred in the veins.

A grain shape fabric (GSF) defined by elongated grains was found in approximately half of the sheared veins. The internal sections had these quartz and calcite GSF's elongated parallel to the vein wall (parallel to the shear plane) and were not found oblique to the shear plane in any of samples. The GSF's in the external sections were either parallel to the vein wall (at an angle to the shear zone in these sections) or parallel to the foliation in the Alpine Schist hosting the veins (Fig. 4.8c). Polygonal GSF's and uniformly sized quartz grains occurred in the internal sections of the remaining samples (e.g. Figs. 4.8a and 4.8b).

Microstructures such as the polygonal GSF's, the homogeneous grain size and similar internal and external microstructures reflect the strongly recovered nature of the veins and indicate that static recrystallisation may have occurred after deformation. This is confirmed by the absence of dynamic recrystallisation fabrics such as a progressive reduction to a small grain size $(<20 \mu \mathrm{m})$ with increased shear strain (as in White et al., 1980) by grain boundary migration and subgrain rotation recrystallisation and microstructures such as oblique GSF's, deformation lamellae, and undulose extinction (Passchier and Trouw, 1998). After the high shear strains 
that have apparently affected these veins (mean $5.5 \pm 1.3$ ), recrystallisation mechanisms such as grain boundary area reduction and static recrystallisation, may have removed many of the microstructures that were acquired during the shearing.

\subsubsection{Shear infilling veins}

The syntectonic shear infilling veins are 1-15 mm wide and composed of Qtz $\pm \mathrm{Cal} \pm \mathrm{Chl} \pm \mathrm{Ms} \pm \mathrm{Bt}$. The dominant mineral is quartz (abundances $>60 \%$ ) with white mica (Ms) and chlorite (the most common phyllosilicate) occurring in smaller concentrations $(<10 \%)$. Calcite is not proportionally more than $40 \%$ but a vein is rarely found without this mineral present. In the veins, chlorite and muscovite are typically aligned with their cleavage surfaces parallel to the shear zone boundary and chlorite is sometimes also concentrated along the edges of some veins in thick 100$500 \mu \mathrm{m}$ mica books near the contact with the Alpine Schist wall rock. Biotite occurs only as xenolithic inclusions in the veins which have become incorporated into the infilling vein from the schist. Quartz in the infilling veins has a mean grain diameter of $141 \pm 21 \mu \mathrm{m}$ and commonly there are large grains up to $1000 \mu \mathrm{m}$ in diameter. The shear infilling veins can be distinguished from the sheared veins by the commonly coarser and heterogeneous grain size (e.g. Fig. 4.8d).

Evidence for intracrystalline deformation and dynamic recrystallisation are common in the shear infilling veins. Grain boundary bulging and grain boundary migration fabrics in quartz are found in most samples (Figs. 4.8e and 4.8f); some include recrystallised island grains (Fig. 4.8g). Deformation lamellae and undulose extinction are common (e.g. Fig. 4.8h) and subgrain boundaries are especially common in the coarser $(>200 \mu \mathrm{m})$ sub-population of grains (Fig. 4.9a), with some rare examples including core and mantle textures (Fig. 4.9b). Quartz crystals that have similar optical interference colours after insertion of a gypsum (440 nm retardation) accessory plate into the light path have a similar orientation. The use of this technique shows that for some samples there is no crystallographic preferred orientation (e.g. Fig. 4.9c). In others, a preferred orientation in large domains was caused by subgrain rotation recrystallisation, causing a mosaic of smaller grains to have a similar crystallographic orientation to an originally much larger host grain (Fig. 4.9f). There are no textures in the veins that suggest that the vein ever had a 

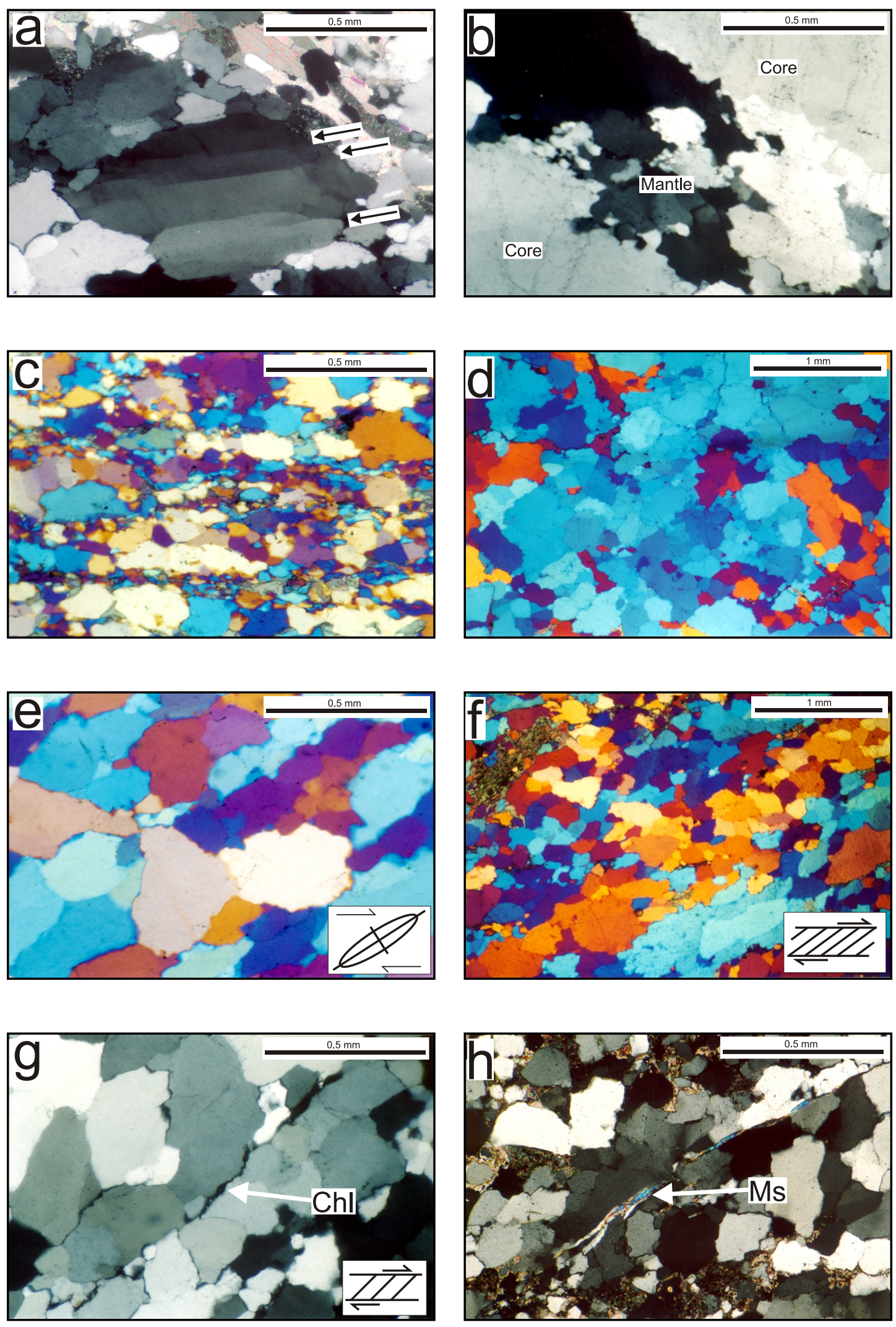

Fig. 4.9. Photomicrographs of infilling vein microstructures. a. Quartz grain showing subgrain boundaries (arrowed) (CPL). b. Core and mantle (subgrain rotation) recrystallisation microstructure (CPL). c. Little crystallographic preferred orientation (CPO) of quartz as seen under gypsum plate (CPL). d. Domainal CPO seen under a gypsum plate (CPL). e. Weak oblique grain-shape fabric (GSF) (CPL and gypsum plate). f. GSF and CPO seen from orientation of quartz grains under gypsum plate (CPL). g. Oblique GSF enhanced by chlorite pinning (CPL). h. Muscovite crystal in shear infilling vein causing quartz grain pinning and at an oblique angle to the shear zone (CPL). 
comb structure of originally euhedral quartz crystals that had grown inward from the vein walls into an open cavity.

Oblique grain shape fabrics were commonly observed in the infilling veins with varied intensities from weak (e.g. Fig. 4.9e) to strong (e.g. Fig. 4.9f), with long axes of the grains that making an angle of $<45^{\circ}$ to the shear plane. Elongated quartz and calcite grains commonly define the oblique fabric, however, in some veins pinning of quartz by micas oblique to the shear zone defines the GSF (e.g. Figs. $4.9 \mathrm{~g}$ and $4.9 \mathrm{~h}$ ). The shear senses inferred from these fabrics are invariably dextral in the strike-parallel thin section cuts, west-side-up in the dip-parallel cuts, and dextral west-side-up in the lineation-parallel cuts. The oblique GSF angle in the lineationparallel thin section cuts averages $27 \pm 4^{\circ}(n=7)$, and was always lower than that seen in the strike- or dip-parallel cuts. Grain boundary pinning has caused shear parallel GSF's in some veins where micas or calcite abut quartz crystals (Fig. 4.10a and 4.10b). This GSF is from pinning related grain growth anisotropies and not from high shear strains where the angle between the shear plane and the GSF approaches zero.

Brittle fractures are not uncommon along the margin of the infilling veins (Fig. 4.10c and 4.10d). Although these fractures have accumulated a proportion of brittle slip in the shear zone (see Chapter 3 ) there is no gouge or cataclasite along their margin. The only evidence for wall rock deformation during the brittle slip is from xenolithic inclusions of schist along the crack boundaries and their incorporation into the shear infilling veins. Incorporation of this material suggests that antitaxial vein growth was occurring in the shear zones, potentially as a crackseal mechanism (e.g. Cox and Etheridge, 1983).

In the shear infilling veins, secondary two-phase (vapour-liquid) fluid inclusions (Fig. 4.10e) are sometimes found in single trails across quartz crystals (Fig. 4.10f). The single fluid inclusion trials may cross grain boundaries (Fig. 4.10b) or occur along subgrain boundaries. Veins from some Sam Peak samples contain large quartz grains that have multiple trails in them (Fig. 4.10c). The multiple fluid inclusion trails are inferred to be healed microcracks whereas the single fluid inclusion trails are may have been either a healed grain or subgrain boundary (Roedder, 1984; pers. comm. T. Takeshita, 2004). The inclusion trails that cross the 

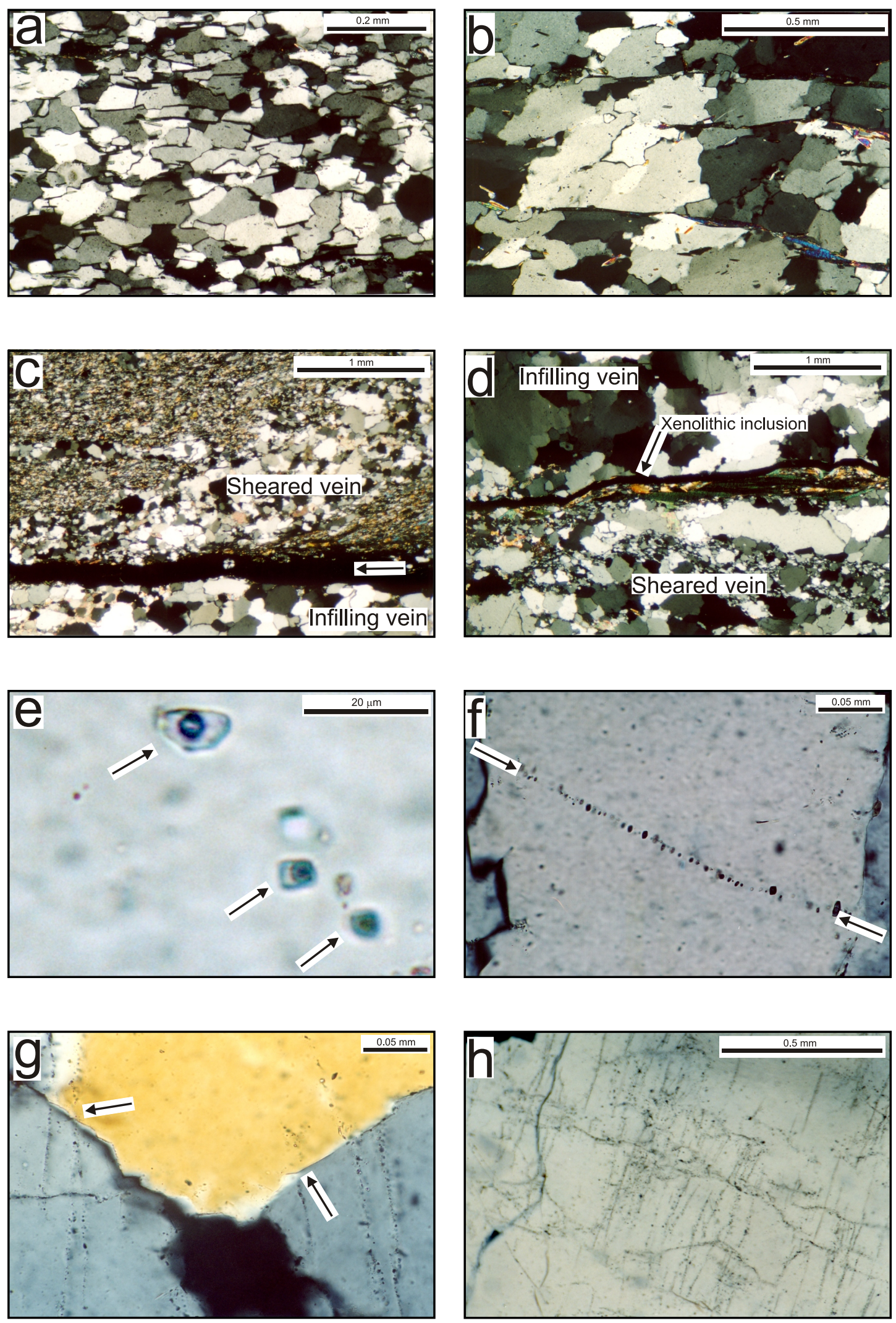

Fig. 4.10. Photomicrographs of fluid inclusions and other microstructures in infilling vein samples. a. Chlorite pinning quartz crystals in an infilling vein sample (CPL). b. Chlorite and muscovite pinning quartz crystals (CPL). c. Sheared vein and infilling vein separated by fracture (arrowed) (CPL). d. Sheared and infilling vein samples with brittle fracture between them and incorporated wall rock (xenolithic inclusion) (arrowed) (CPL). e. Two phase fluid inclusions (PPL). f. Single fluid inclusion trail (arrowed) (PPL). g. Single fluid inclusion trails crossing grain boundaries (arrowed) (CPL). $h$. Multiple parallel fluid inclusion trails (PPL). 
grain boundaries must have occurred prior to the grain boundaries or developed in the semibrittle faulting regime of Hirth and Tullis (1994) where microcracks can crosscut several grains. Cracks that do not crosscut the grain boundaries are more likely to occur in the semibrittle flow regime where dislocation glide accommodates some of the crack stress at the grain boundary (Hirth and Tullis, 1994). The semibrittle faulting and semibrittle flow regimes are inferred to be at lower temperatures and / or higher differential stresses than the Regime 1 microstructures that they crosscut, which deform by plastic rather than brittle creep mechanisms. Primary fluid inclusions are also found in quartz grains throughout the shear infilling veins. Their occurrence suggests that vein precipitation was from the conversion of amorphous silica to quartz, rather than from the growth of euhedral crystals from the fracture walls (Herrington and Wilkinson, 1993).

Calcite crystals in the infilling veins are mostly twinned (e.g. Fig. 4.11a). Some of the twins are curved and show evidence for twin boundary migration (sutured edges along the twin boundary); however, most are thin $(2-10 \mu \mathrm{m})$ and straight (Fig. 4.11b). Some larger calcite grains are volumetrically dominated by twinning (Fig. 4.12a) and where grain boundaries are shared by quartz, twinning is frequently more intense (Fig. 4.12b). These larger grains on occasion had several sets of twins at different angles (Fig. 4.12c) potentially caused by multiple deformations. Calcite is found either in concentrated bands (Fig. 4.12d) or as isolated grains within the quartz (Fig. 4.12e) and is commonly enriched along the boundaries of the infilling veins (Fig. 4.12f). Thin twin sets commonly intersect on another at an angle of $128^{\circ}$ (Fig. 4.12g). The curved and oblate grain boundaries between quartz and calcite (Fig. 4.12h) in some samples are inferred to have been formed from solid-state diffusion creep (as in Gower and Simpson, 1992; Passchier and Trouw, 1998).

\subsection{Grain shape fabric based estimates of finite incremental ductile shear strain in deformed and infilling veins}

Calculations for a late increment of strain have been made from the oblique grain shape fabrics and from the aspect ratios of elliptical recrystallised quartz grains from the shear infilling veins. These strain calculations have provided information about the proportion of strain that the microfabrics represent compared with the total strain that deflection and offset of the sheared veins represent. Oblique angles of 

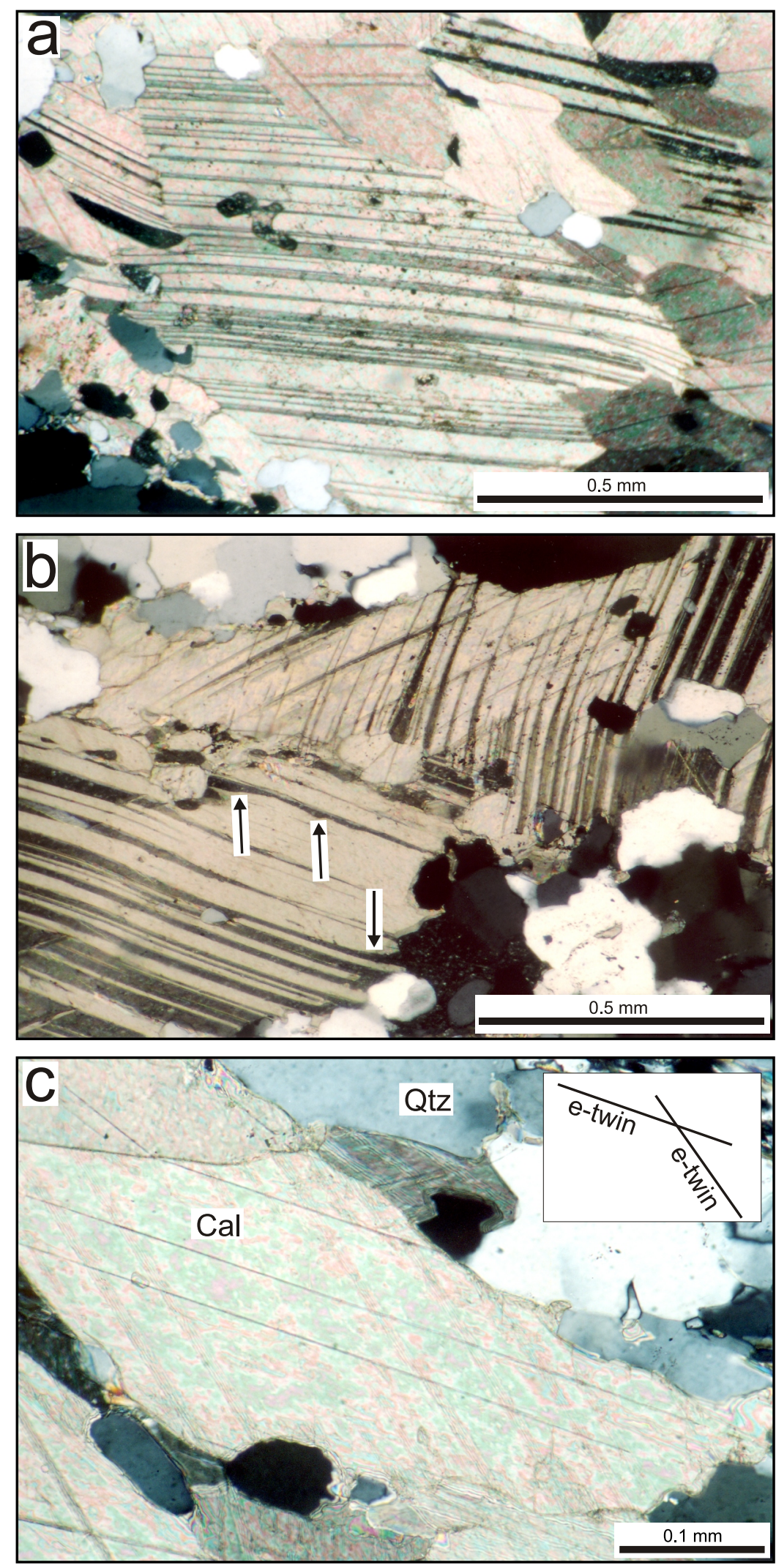

Fig. 4.11. Photomicrographs of deformation twinning in calcite crystals. a. Type I and II twinned calcite crystals in an infilling vein (CPL). b. Type III calcite twins (Burkhard, 1993) with thick, curved twins that have undergone twin boundary migration (arrowed) (CPL). c. Type I calcite e-twins which are thin and straight (CPL). Calcite grain boundary migration is seen in all photomicrographs along calcite-calcite grain boundaries. 

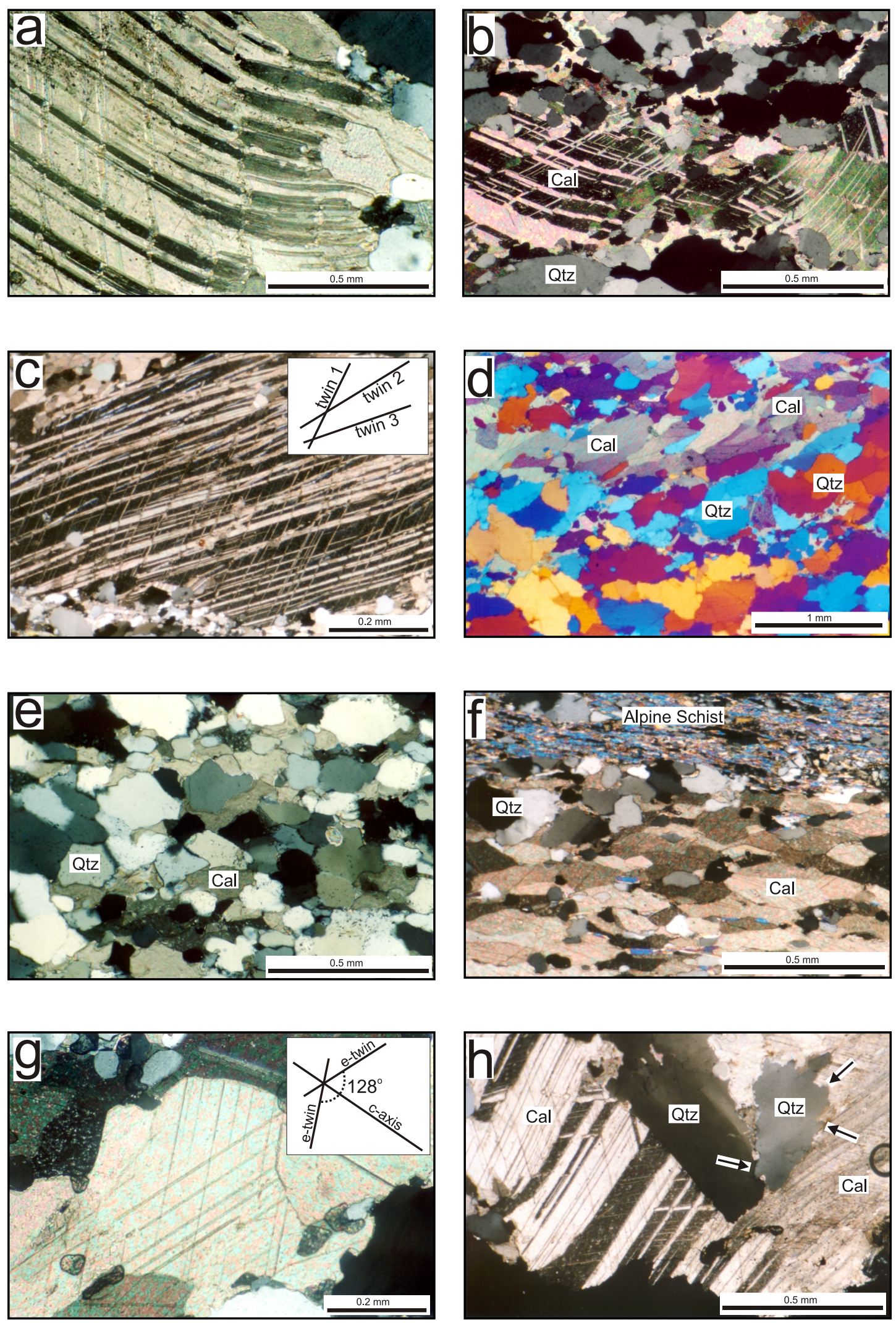

Fig. 4.12. Photomicrographs of calcite in infilling veins. a. Type III twinned calcite grain showing curved twins and twin boundary migration (CPL). b. Type IV twinned calcite showing thick curved twins and quartz intergrown (CPL). c. Multiple twin orientations in the same calcite crystal (CPL). d. Calcite layer in quartz vein parallel to the shear zone (CPL and gypsum plate). e. Intergrown calcite and quartz crystals of equal grain size without layering in a shear infilling vein (CPL). f. Calcite concentration on the edge of infilling vein in contact with wall rock Alpine Schist (CPL). g. Calcite e-twins evident from the angle of the twins from the crystallographic c-axis of the grain (CPL). h. Sutured grain boundaries of quartz and calcite (arrowed) indicating solid-state diffusion creep (CPL). 
grain shape fabric long axes to the shear zone boundary ( $\left.\theta^{\prime}\right)$ were measured and converted to shear strains $(\gamma)$ assuming a simple shear deformation and using the equation of Ramsay and Huber (1983):

$$
\tan 2 \theta^{\prime}=-\frac{2}{\gamma}
$$

Aspect ratios $(R)$ were calculated from grain long axis $(a)$ and the grain short axis (b) measurements (see section 4.5.1) using the equation:

$$
R=\frac{a}{b}
$$

Aspect ratios were then converted into extensional strains $\left(1+\mathrm{e}_{1}\right)$ assuming that there was no volume change out of the shear plane $(\Delta \mathrm{A}=0)$ using the equation:

$$
\left(1+e_{1}\right)=\sqrt{R}(\text { Assumes that } \Delta \mathrm{A}=0)
$$

The extensional strain calculations were then converted into shear strains for infilling veins using the equation of Ramsay (1967):

$$
\begin{gathered}
\left(1+e_{1}\right)^{2}=\frac{\gamma^{2}+2+\gamma \sqrt{\left(\gamma^{2}+4\right)}}{2} \\
\gamma=\frac{\left(1+e_{1}\right)^{2}-1}{\left(1+e_{1}\right)}(\text { Rearranged to solve for } \gamma)
\end{gathered}
$$

In the shear infilling veins, oblique grain shape fabric measurements were made in all three thin sections cuts; however, the p-cuts parallel to the lineation invariably had the lowest angle between the long axis and the shear zone boundary, and the strongest GSF fabrics. Aspect ratios were also higher in the mineral fibre lineation-parallel cuts than in the strike- or dip-parallel cuts. Shear strains have only been calculated for these lineation-parallel cuts. In the infilling veins, calculations from oblique GSF's yield moderate shear strains of $1.51 \pm 0.46$, but the results of calculations based on aspect ratios from the same samples yielded shear strains of 0.8 
\pm 0.1 . The two measurements should have been very similar for simple shear deformation and the difference between them suggests that a component of pure shear may have been involved or that grain growth may have occurred after the development of the oblique GSF. These shear strains are much lower than the mean finite ductile shear strain for the sampled shear zones that the shear infilling veins were in which is $5.5 \pm 1.3$. This difference shows that the microstructures in the infilling veins were formed during a late incremental stage of the shear deformation.

In the sheared veins, mean aspect ratio $(R)$ calculations yielded estimates of $1.5 \pm 0.19$ in the internal sections and $1.7 \pm 0.2$ in the external sections. GSF fabrics in the internal sections of the sheared veins were parallel to the shear plane. These fabrics therefore represented either very large shear strains $(<10)$ where the long axis would have approached the shear plane, a pure shear deformation where the veins were flattened but not sheared, or where a growth anisotropy controlled by mineral impurities controlled the grain shape. None of these possibilities could be confirmed, although grain growth anisotropies are possible adjacent to the calciterich layers and in mica-rich layers parallel to the shear plane because of pinning of quartz grains. There is very little difference between the aspect ratios calculated for the external and internal vein sections. This suggests that since their recrystallisation the entire shear zone has undergone a similar increment of strain that was not related to displacement on the brittle-ductile shear plane.

\subsection{Active crystallographic slip systems in quartz and calcite minerals}

\subsubsection{Quartz slip systems}

Subgrain boundaries and grain boundary bulging microstructures in quartz can be used to determine the active slip systems (Fig. 4.13) and temperature conditions during deformation. In this study the angle between a quartz subgrain boundary and the c-axis was measured with a universal stage to determine the direction of glide on quartz prism planes. Quartz subgrain boundaries are commonly near parallel to either the basal plane or the prism planes because of prism glide in the $[\mathrm{c}]$ or $<\mathrm{a}>$ directions respectively (Kruhl, 1996). Intracrystalline slip can occur by either edge dislocations or screw dislocations; however, subgrains are dominantly formed from edge dislocations joining during dislocation climb and slip on the prism planes (Twiss and Moores, 1992). Therefore, prismatic subgrains typically form 


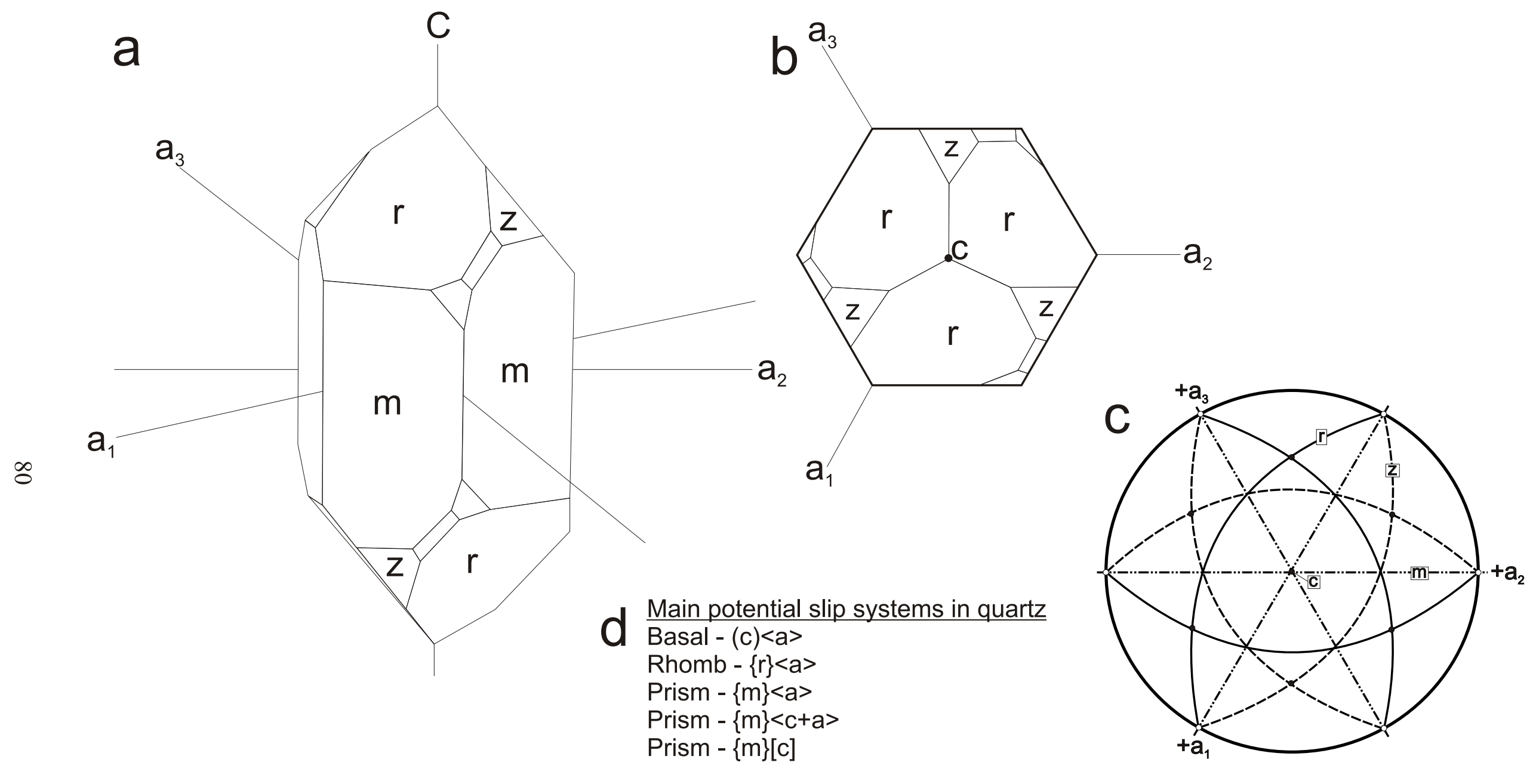

Fig. 4.13. a. Simplified 3D view of quartz crystal and the slip planes used for deformation. b. Plan view of quartz crystal and the slip systems used for deformation. (a) and (b) are redrawn from Twiss and Moores (1992). Stereographic, upper hemisphere, equal angle projection of crystallographic planes and poles of quartz. d. Main potential slip systems for deformation of quartz (from Lister et al., 1978). 
parallel to the $<\mathrm{a}>$ direction during prism [c] slip and parallel to the [c] direction during prism $<\mathrm{a}>$ slip with both perpendicular to the slip plane (Fig. 4.14). Subgrain boundaries can form during basal <a> slip (Kruhl, 1996) but are usually not formed by edge dislocations during this deformation. Therefore, in this study the method has been restricted to the determination of slip directions on the prism planes only.

For the Southern Alps samples the mean angle between subgrain boundaries and the c-axis was measured using a universal stage on a polarising microscope. Using the method outlined in Passchier and Trouw (1998), the quartz c-axis was rotated parallel to the A4 stage axis on the microscope in grains that have visible subgrain boundaries. The angle between the c-axis and subgrain boundary was measured on the microscope stage after a rotation about the A5 stage axis that brought the subgrain boundary parallel to the A4 stage axis. These angles were measured in five samples resulting in a total of 100 measured grains. These angles are plotted in Fig. 4.15a and have a mean of $4.2 \pm 0.7^{\circ}$. Several subgrain boundaries were parallel to the c-axes (angle $=0^{\circ}$ ), the maximum angular difference was $13^{\circ}$, and no significant variation was seen between samples. Four of these measured grains are displayed in Fig. 4.15b. The low mean angle measured between the c-axes and subgrain boundaries indicates that glide took place on the prism or basal planes in the $<\mathrm{a}>$ direction and rules out significant glide in the [c] direction (after Kruhl, 1996; Morgan and Law, 2004).

A temperature range for prism $<\mathrm{a}>$ slip has been estimated from the minimum temperature required for dislocation climb (formation of edge dislocations) and the maximum before prism [c] slip occurs. Basal subgrains commonly occur with prism subgrains at high temperatures of $\sim 650^{\circ} \mathrm{C}$ and form chessboard patterns (Mainprice et al, 1986; Kruhl, 1996) whereas prismatic subgrains will form as soon as conditions for dislocation climb and subgrain formation are met at $\sim 400^{\circ} \mathrm{C}$ (Stipp et al., 2002b). A temperature range estimate for the subgrain rotation deformation is therefore between 400 and $650^{\circ} \mathrm{C}$.

Grain boundary bulging and grain boundary migration in quartz occurs at lower temperatures than subgrain boundary formation (Hirth and Tullis 1992; Stipp et al, 2002b). The presence of these microstructures in the BDSZ samples (Fig. 4.8) suggest that temperatures may be less than the $400^{\circ} \mathrm{C}$ minimum for prism $<\mathrm{a}>$ slip 


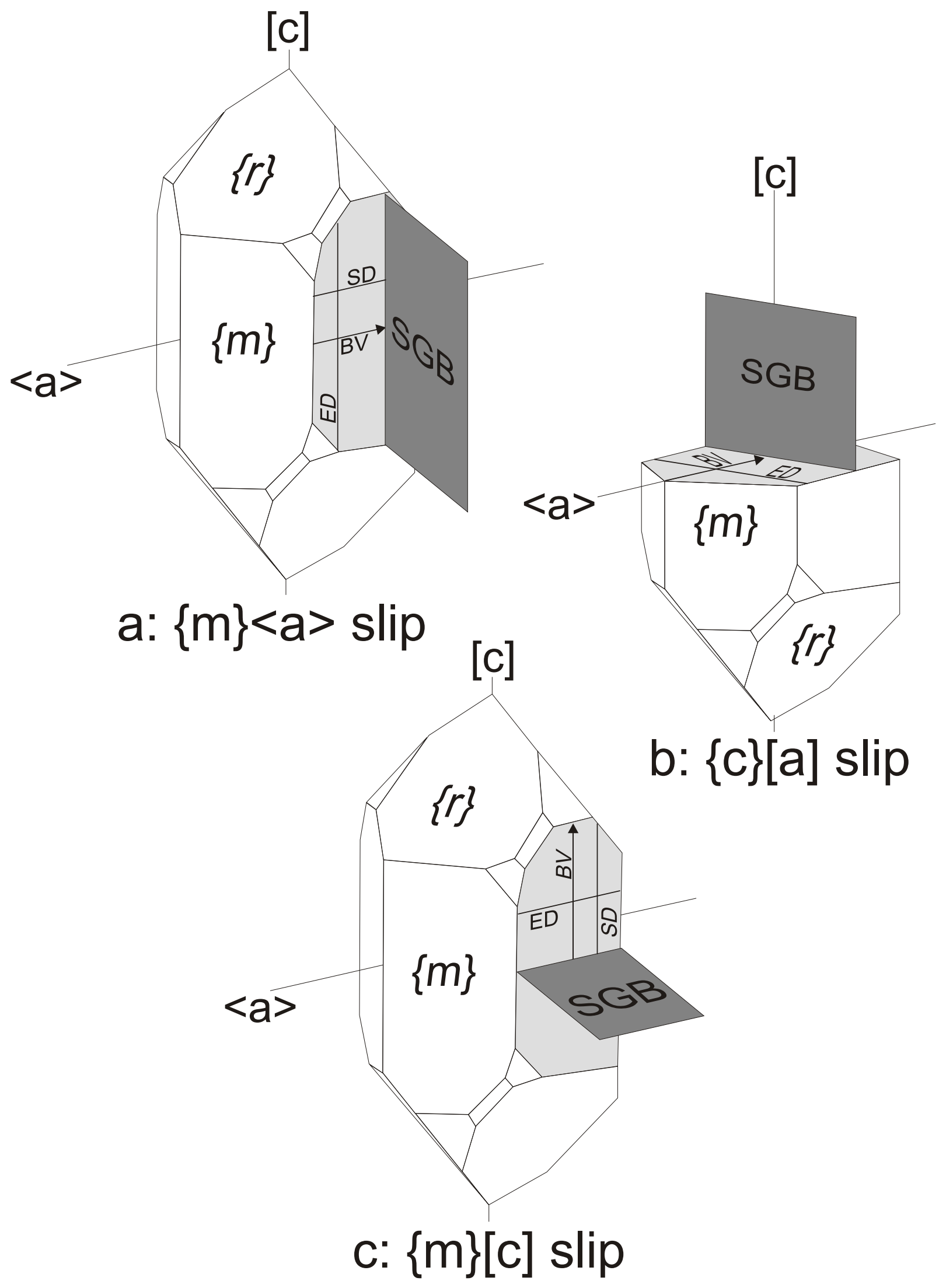

Fig. 4.14. Orientation of common quartz subgrain boundaries to the main slip planes of the crystal. Crystal faces are those from Fig. 4.13a. a. Slip on the prism $\{\mathrm{m}\}$ plane in a Burgers vector (BV) of $<\mathrm{a}>$ where a subgrain boundary is forming perpendicular to the slip plane and parallel to the edge dislocation (ED). $b$. Slip on the basal $\{c\}$ plane in a Burgers vector (BV) of $<a>$ where a subgrain boundary is forming perpendicular to the slip plane and parallel to the edge dislocation (ED). c. Slip on the prism plane $\{\mathrm{m}\}$ in the Burgers vector (BV) of [c] where a subgrain boundary is forming perpendicular to the slip plane and parallel to the edge dislocation (ED). Screw dislocations (SD) are shown for reference on the prism planes. 

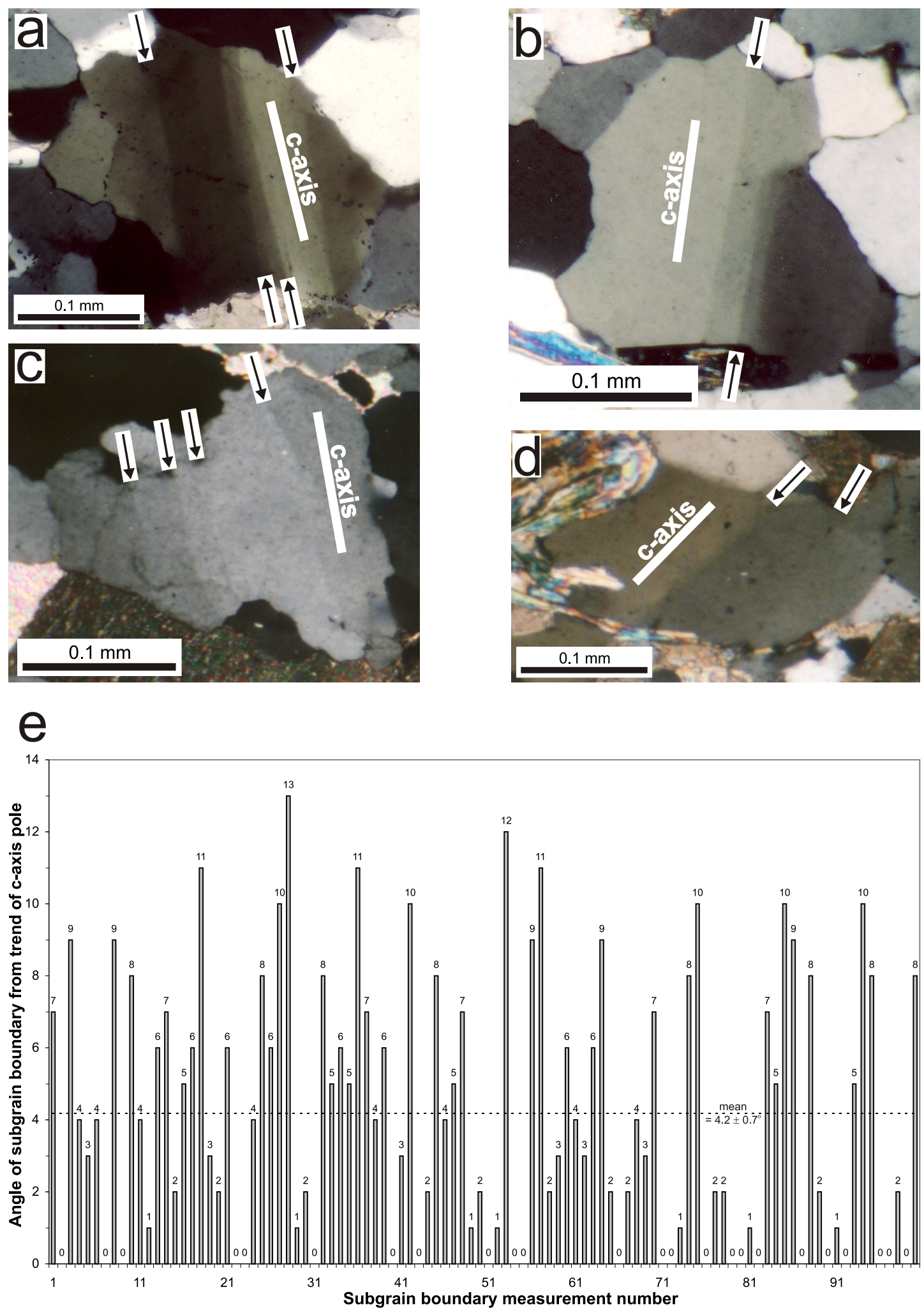

Fig. 4.15. Quartz subgrain boundary angles from the c-axis. a-d. Photomicrographs of quartz crystals with visible subgrain boundaries. c-Axis pole trend orientations are found using a universal stage microscope and marked for comparison with the subgrain boundary orientations (some have been marked with arrows). All c-axis poles marked are horizontal in the plane of the photomicrograph and near parallel to the subgrain boundaries within the quartz crystals. e. Graph of 100 measured angles between the subgrain boundaries and the trend of the c-axis pole in quartz crystals. Angle is noted at the top of each column with the mean angle for the data set plotted as the dashed line across the columns. 
and that basal and rhomb slip systems may have been active. A minimum temperature for deformation is therefore estimated to be as low as $280^{\circ} \mathrm{C}$, a temperature that has been associated with the frictional-viscous transition in natural rocks and the beginning of grain boundary bulging recrystallisation (Stipp et al. 2002b).

\subsubsection{Calcite twinning deformation and slip systems}

Calcite crystals in the sheared and shear infilling veins have been deformed by intracrystalline plastic deformation that has been accommodated by twinning and dislocation creep. By determining the style of twin deformation and which calcite slip systems (Fig. 4.16) were active during deformation, an approximate temperature can be estimated for the deformation. Calcite c-axes were measured (same method as for quartz in Section 4.51) and compared with the twin plane orientations. As illustrated in Fig. 4.12g, the twinning planes occur in pairs at $128^{\circ}$ about the c-axes, which make a $26^{\circ}$ angle to the basal planes. Crystallographic twin planes in calcite with these angles are e-twins (Fig. 4.16). This is the most common type of deformation twinning in calcite (Wenk, 1985c). Deformation on the e-twin planes can occur at temperatures from 25 to $500^{\circ} \mathrm{C}$ and can take place as a result of critical resolved shear stress (CRSS) of less than $10 \mathrm{MPa}$ (De Bresser and Spiers, 1997).

Evidence for slip systems other than e-twinning are found from grain boundary migration and twin boundary migration microstructures of some calcite crystals from the shear zones (sheared and infilling veins). For this type of deformation to occur, intracrystalline deformation by slip on the $\{r\}$ and $\{\mathrm{f}\}$ planes is required (De Bresser and Speirs, 1990; Burkhard, 1993). Use of these planes could be from one, or a combination, of the following three conditions: 1) a higher CRSS and temperature where $\{r\}$ and $\{\mathrm{f}\}$ slip become dominant (De Bresser and Speirs, 1997), 2) the grain is unable to twin because of a poor crystallographic orientation (Turner and Weiss, 1963; Schmid et al., 1987; Barhoon et al., 2004), or 3) the maximum shear strain (0.68) that a calcite grain can accommodate by twinning (without causing recrystallisation) has been reached (Wenk, 1985c).

Temperature estimates can be made for deformation of calcite based on the style and appearance of twin deformation. Calcite twins can fall into one of the four classifications of twin appearance defined by Burkhard (1993). Type I twins are 
a
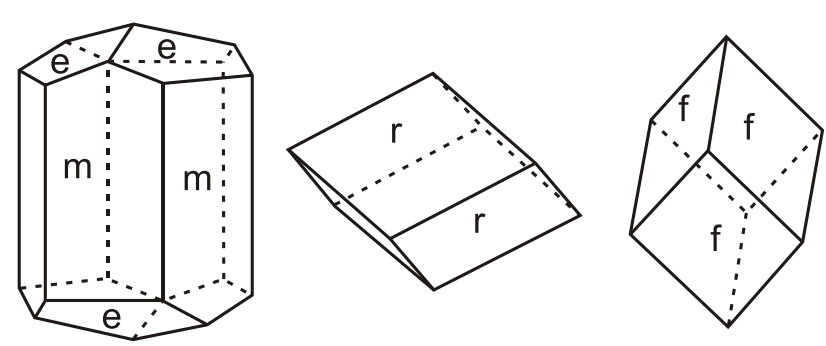

$\stackrel{\infty}{\leftrightarrow}$
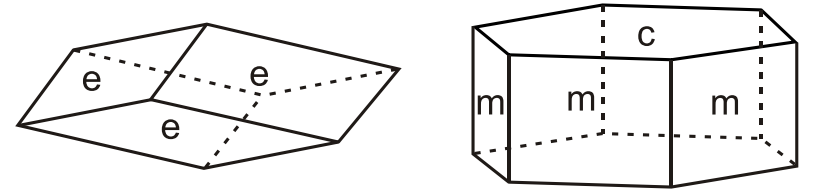

b

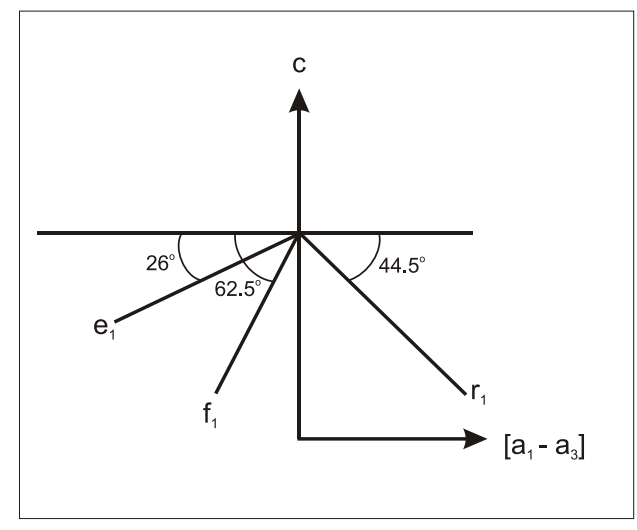

C

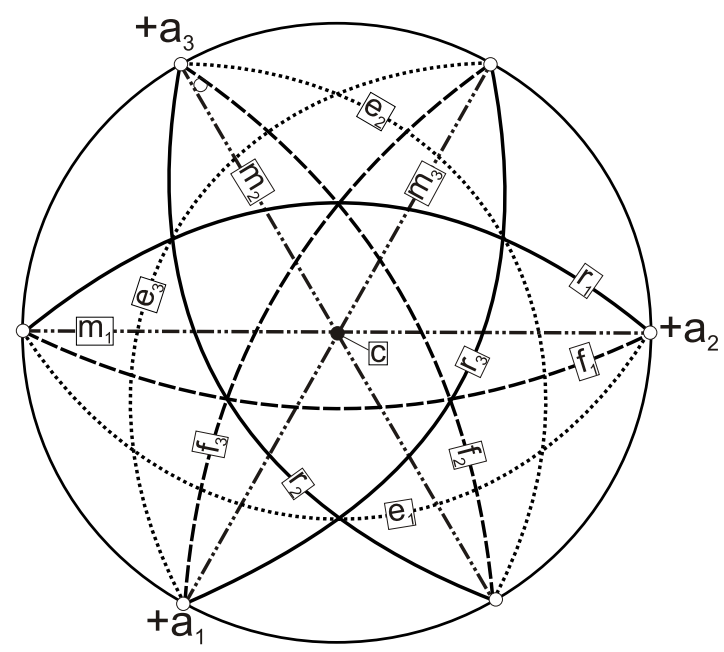

Fig. 4.16. a. Selected crystallographic forms of calcite that show the main slip planes (e, $r, \mathrm{f}, \mathrm{m}$ and c) used for the deformation of calcite. 3D models redrawn from Hurlbut (1971). b. Angles of crystallographic planes in calcite from the basal (c) plane. Redrawn from de Bresser and Spiers (1990). Angles from basal plane to e-twin and $\mathrm{r}$ and $\mathrm{f}$ rhombs from Turner and Weiss (1963) c. Stereographic, upper hemisphere, equal angle projection of calcite planes and crystallographic poles. 
thin, straight (e.g. Fig. 4.11c) and occur at low temperatures $\left(<200^{\circ} \mathrm{C}\right)$. Type II twins are thicker $(>1 \mu \mathrm{m})$, possibly slightly lens shaped (e.g. Fig. 4.11b) and occur at temperatures between 150 and $300^{\circ} \mathrm{C}$. Type III and IV twins have undergone twin boundary migration, are curved and thick (e.g. Fig. 4.12a, b and c), and form from at temperatures of $>200^{\circ} \mathrm{C}$. At these higher temperatures $\left(>200^{\circ} \mathrm{C}\right),\{\mathrm{r}\}$ and $\{\mathrm{f}\}$ slip systems are more dominant and existing twin boundaries grow by twin boundary migration and twins become distorted and curved during intracrystalline deformation of grains (Burkhard, 1993; Ferrill et al., 2004). At lower temperatures, however, the twins are not able undergo this deformation and remain thin and straight (Ferrill, 1991).

Calcite twins in the sheared and infilling veins in this study are dominantly Type I twins and cut across the grains without distortion. Type II-IV twins are much less common and only occur in large grains which have not undergone complete grain recrystallisation. The small Type I twins therefore represent late stage deformation at low temperatures after recrystallisation whereas the Type II-IV twins record a snapshot of the earlier deformation higher temperatures.

\subsection{Palaeopiezometry}

\subsubsection{Palaeopiezometry from calcite twinning}

A technique for determining differential stress from calcite twin characteristics is based on deformation experiments on marble by Rowe and Rutter (1990). Temperatures of $200-800^{\circ} \mathrm{C}$, strain-rates of $10^{-3}$ to $10^{-7} \mathrm{sec}^{-1}$ and confining pressures of 100-200 $\mathrm{MPa}$ were used in these experiments up to a strain of $30 \%$ shortening. Although these are not the same deformation conditions as those argued by Wightman (2005) to have prevailed in the transient brittle-ductile shear zones (tBDSZ's), the resulting formula for calculating differential stress can still be used to determine a reasonable approximation of stress during the development of the calcite twins in this study.

The differential stress can be determined from three different methods by Rowe and Rutter (1990): volume percent of twinning, twin density, and twinning incidence. The volume percent method uses the characteristic that calcite undergoes a higher volume of twinning with increased differential stress. This increased 
volume could be in the form of many thin twins (low temperature) or just a few thick twins at higher temperatures (Burkhard, 1993). The twin density (number of twins per millimetre) method is based on the assumption that at higher differential stresses the number of twins in a grain will increase. Twinning incidence (percent of grains that are twinned for a particular grain size) method uses the differential stress threshold that must be reached to twin a grain of a particular size. Smaller grains require higher differential stresses to undergo twinning compared with larger grains that twin easily (Rowe and Rutter, 1990). These three methods have been used with caution in this study as none of the formula for the differential stress determinations take into account the deformation temperature or the amount of strain that the grain has undergone, both of which have been shown to affect the twin density and the volume percent of a grain that is twinned (e.g. Burkhard, 1993; Newman, 1994; Ferrill, 1998).

The volume percent of twinning was calculated in this study from the number of twins in the grain, the mean twin width and the diameter of the grain. The twin width was measured using a stage micrometer and was multiplied by the number of twins to give a total width of twinned calcite in the grain. All the twins measured maintained a constant thickness and cut all the way across the grain (Type III and IV twins are uncommon and were not found in any of the grains analysed here) which allowed the total width of twinned calcite divided by the grain diameter to approximate the fraction of the grain volume that has undergone twinning (V). The grain diameter was measured the length of the grains long axis $\left(D_{L}\right)$ to ensure that calculated differential stresses were not over estimated. The differential stress was calculated from all the grains out of the 300 examined for each sample that had twins. The method yielded a mean differential stress ( $\left.{ }_{D} \sigma\right)$ of $128 \pm 10 \mathrm{MPa}$ (Fig. 4.17a; Table 4.5) with results calculated from the following equation determined by Rowe and Rutter (1990):

$$
{ }_{D} \sigma=2.72+0.40\left(\log V-\log D_{L}\right) \mathrm{MPa}
$$

Twin density was calculated from the same data as that used to measure the volume percent of twinning. The diameter of the twinned calcite grain was divided by the number of twins to obtain the density of twins per millimetre (d). The differential stress was calculated for all measured grains in which twins occurred. 

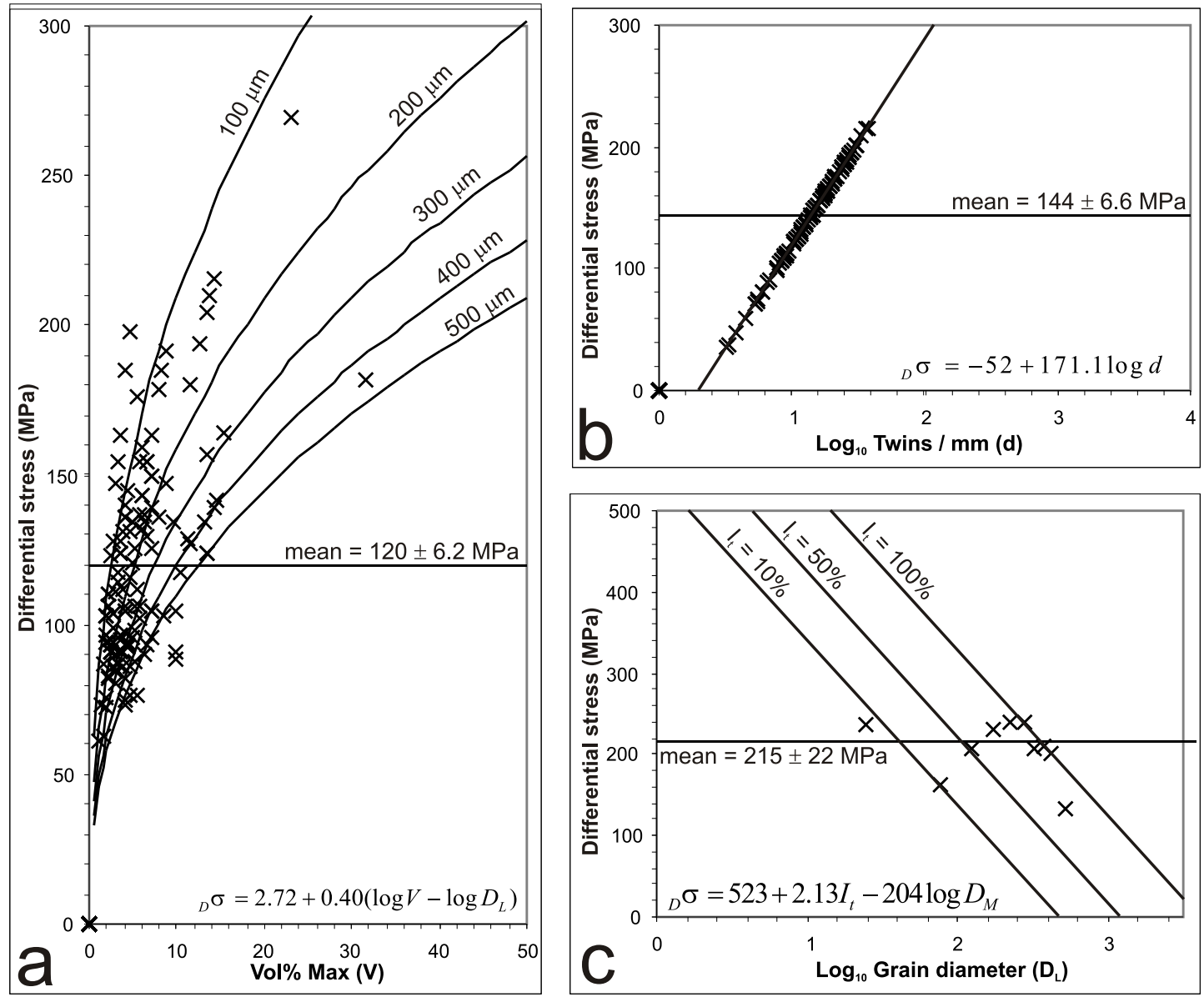

Fig. 4.17. Differential stress $\left({ }_{\mathrm{D}} \sigma\right)$ calculated from calcite twins. An example from sample TJFA47-p from an infilling shear vein. Calculated using the technique of Rowe and Rutter (1990) from the volume \% twinning (a), the twin density (b), and the twinning incidence (c). Formula for differential stress calculations are inset into each graph where $D_{L}$ is the diameter of the calcite crystals long axis, $D_{m}$ is the median grain diameter for each grain size class, $\mathrm{d}$ is the twin density, $I_{t}$ is the incidence of twinning for a given grain size class and $V$ is the volume percent of a grain that is twinned. Graph (a) is contoured for grain diameter and graph (c) is contoured for percent of twinned grains in the sample.

\begin{tabular}{cccccc}
\hline \multicolumn{2}{c}{ Sample } & & \multicolumn{3}{c}{ Calculated differential stress } \\
\cline { 1 - 2 } \cline { 4 - 5 } $\begin{array}{c}\text { Field stn. } \\
\text { number }\end{array}$ & $\begin{array}{c}\text { Type of } \\
\text { vein }\end{array}$ & & Twin Incidence & Twin density & Vol\% \\
\hline MHCH17 & Infilling & & MPa & MPa \\
MHCH17 & Internal & 185 & 143 & 129 \\
MHCH17 & External & 198 & 140 & 142 \\
MHCH20 & Internal & 189 & 134 & 146 \\
MHCH20 & External & 208 & 133 & 135 \\
MHCH20 & Internal & 197 & 145 & 150 \\
MHCH12b & Infilling & 187 & 134 & 134 \\
MHCH12b & Infilling & 145 & 129 & 116 \\
MHCH14 & Infilling & 178 & 120 & 107 \\
TJFA47 & Infilling & 215 & 129 & 103 \\
\hline & mean: & 189 & 144 & 120 \\
\hline & $2 \sigma:$ & 12 & 135 & 128 \\
\hline
\end{tabular}

Table 4.5. Differential stress calculated from calcite twinning using the Rowe and Rutter (1990) technique for samples from Chancellor Ridge and Sam Peak. Calculations made from formula in Fig. 4.17 with mean values for all of the values in the sample plotted for each sample in this table. Differential stress calculated for each sample is divided into the three different calculation methods; twin incidence, twin density and volume $\%$ of twinning with mean values for each method across the samples listed at the bottom of the table. Type of vein listed to identify the location of the calcite being measured in the shear zone. 
This method yielded a mean differential stress of $135 \pm 5 \mathrm{MPa}$ (Fig. 4.17b; Table 4.5) with results calculated from the following equation determined by Rowe and Rutter (1990):

$$
{ }_{D} \sigma=-52.0+171.1 \log d \mathrm{MPa}
$$

The incidence of twinning differential stress calculation was made from the median grain diameter $\left(D_{M}\right)$ of the class range (e.g. grain diameter $\left(D_{L}\right)$ size class of 50-100 $\mu \mathrm{m}$ had a $\mathrm{D}_{\mathrm{M}}$ of $75 \mu \mathrm{m}$ ) and the percent of grains in that size class that had undergone deformation by twinning $\left(\mathrm{I}_{\mathrm{t}}\right)$. The data set of measured grain diameters $\left(D_{L}\right)$ was divided into 10 class sizes with a range of 50 or $100 \mu \mathrm{m}$ (as in Rowe and Rutter, 1990) depending on the maximum grain diameter measured. All of the 300 measured grains in each of the 10 samples analysed were used in the calculation. Differential stress was calculated for each grain diameter class (e.g. Fig. 4.17c; Table 4.5). This method yielded a mean differential stress of $189 \pm 12 \mathrm{MPa}$ and results were calculated from the following equation determined by Rowe and Rutter (1990):

$$
{ }_{D} \sigma=523+2.13 I_{t}-204 \log D_{M} \mathrm{MPa}
$$

The volume percent of twins and the twin density calculations are treated with some scepticism in this study. Both the twin thickness and the number of twins are affected by temperature (Ferrill, 1991; Ferrill, 1998) and the amount of strain that the grain has undergone (Burkhard, 1993). The thin and low density twinning style of calcite in this study, associated with low temperatures and small strains, (Burkhard, 1993; Ferrill et al., 2004) is reflected in the lower calculated differential stresses for these methods. As in Newman (1994), the incidence of twinning calculation of differential stress is considered a more reliable indicator of differential stress during twin formation. The incidence of twinning is not dependant on the amount of strain, and temperature is not considered to be as dominating a factor as stress and grain diameter for this method. However, because of the polymineralic samples used in this study (as in Newman, 1994), the differential stress calculated from twinning incidence probably represents a maximum. Impurities around the calcite grain boundaries (quartz and micas) may cause stress concentrations where twins may nucleate at lower differential stresses than in the monomineralic marble used in the experimental study of Rowe and Rutter (1990). The differential stress for 
the twinning deformation in calcite is therefore considered to represent a maximum value of $189 \pm 12 \mathrm{MPa}$.

\subsubsection{Palaeostress from recrystallised grain size}

Palaeostress can be calculated from the grain diameter of recrystallised minerals such as calcite and quartz. Using results from experimental deformation and grain growth studies, formulae have been empirically developed to estimate the differential stress required to recrystallise a grain to a particular steady-state grain size during deformation. Care must be taken with these types of palaeostress calculations if grain growth or grain boundary pinning has occurred. Microfabrics such as grain boundary migration, polygonal grain shape fabrics, fluid inclusion planes and twin boundary migration all suggest that grain growth has occurred in the deformed samples studied here. Therefore the palaeostress calculated will at best represent a minimum differential stress for the ductile deformation of the veins. Grain boundary pinning microstructures are also seen in some samples. In these cases the calculated differential stress may be greater than the actual one during ductile shearing of the quartz veins. Quartz and calcite minerals have been used to determine minimum differential stresses during ductile shearing of the quartz-calcite veins.

The quartz palaeopiezometer of Twiss (1977) and revised by Twiss (1980) has been used to determine the differential stress for the finite recrystallisation of quartz in the external, internal and infilling veins. The Twiss (1980) palaeopiezometer, although criticised because of its assumptions of equilibrium thermodynamics, is regarded as the most applicable to wet quartz in natural settings (Stipp et al., 2002a). Many authors prefer the Twiss (1980) piezometer as it is based on sound experimental constraints, uses easily measured recrystallised quartz grain sizes and it does not give unrealistically high differential stress results for naturally deformed quartz samples (Ord and Christie, 1984; Zulauf, 2001; Stipp et al., 2002a). The Twiss (1980) piezometer uses the grain diameter (D) calculated from the intercept method (as in Twiss, 1977 and Stipp et al., 2002a) to calculate the differential stress $\left({ }_{D} \sigma\right)$ in the equation:

$$
{ }_{D} \sigma=6.03 D^{-0.68} \mathrm{MPa}
$$


The calcite palaeopiezometer of Rutter (1995) was used in this study (after Brodie and Rutter, 2000) and allows a minimum differential stress for recrystallised calcite to be calculated. This technique has been applied to the same external, internal and infilling veins as for the quartz piezometer above. The Rutter (1995) piezometer has been used with grain long axis diameters $\left(D_{L}\right)$ and approximated mean grain diameters (D), assuming an elliptical grain with an $\mathrm{R}$ value of 2 (see section 4.4; Ramsay and Huber, 1983). The ellipticity value (R) was assigned based on the maximum measured ellipticity in shear infilling veins of $2.1 \pm 0.2$ and was calculated an approximate minimum mean grain size. These two diameters allow the minimum (when using $\mathrm{D}_{\mathrm{L}}$ ) and maximum (when using $\mathrm{D}$ ) differential stress for calcite grains to be estimated. The constants for migration recrystallisation piezometry from Rutter (1995) have been used instead of those for rotational recrystallisation, because of the evidence for migration recrystallisation in the calcite microstructures. The following formula has been used to calculate a minimum differential stress for deformation of calcite:

$$
\begin{gathered}
{ }_{D} \sigma=2691.5 D^{-0.89} \mathrm{MPa} \\
\text { where } D=\sqrt{D_{L} \times \frac{D_{L}}{R}} \mu \mathrm{m} \text { for maximum stress estimates }
\end{gathered}
$$

The differential stress estimates from the quartz and calcite grain sizes in the external, internal and infilling veins are listed in Table 4.6 and displayed graphically in Fig. 4.18. The mean quartz differential stress estimates are between 16 and 65 $\mathrm{MPa}$ and there is no significant difference between the three vein sections. The small quartz grain sizes preserved in the pinned microstructures from MHCH20 and MHCH22 record higher differential stress values than the mean values as expected. The average calcite maximum differential stresses (calculated from D like the quartz mean) are higher than the mean quartz values; however considering the assigned high $\mathrm{R}$ value of 2 and the experimental uncertainties of the two piezometers, they broadly agree well. These palaeostress calculations from grain size for the sheared and shear infilling veins are lower than those expected for dynamic recrystallisation of quartz (e.g. 50-100 MPa from Hirth and Tullis, 2002). This is not unexpected as the quartz and calcite grains are known to have undergone grain growth after dynamic recrystallisation during shearing of the veins (Wightman, 2005), as 

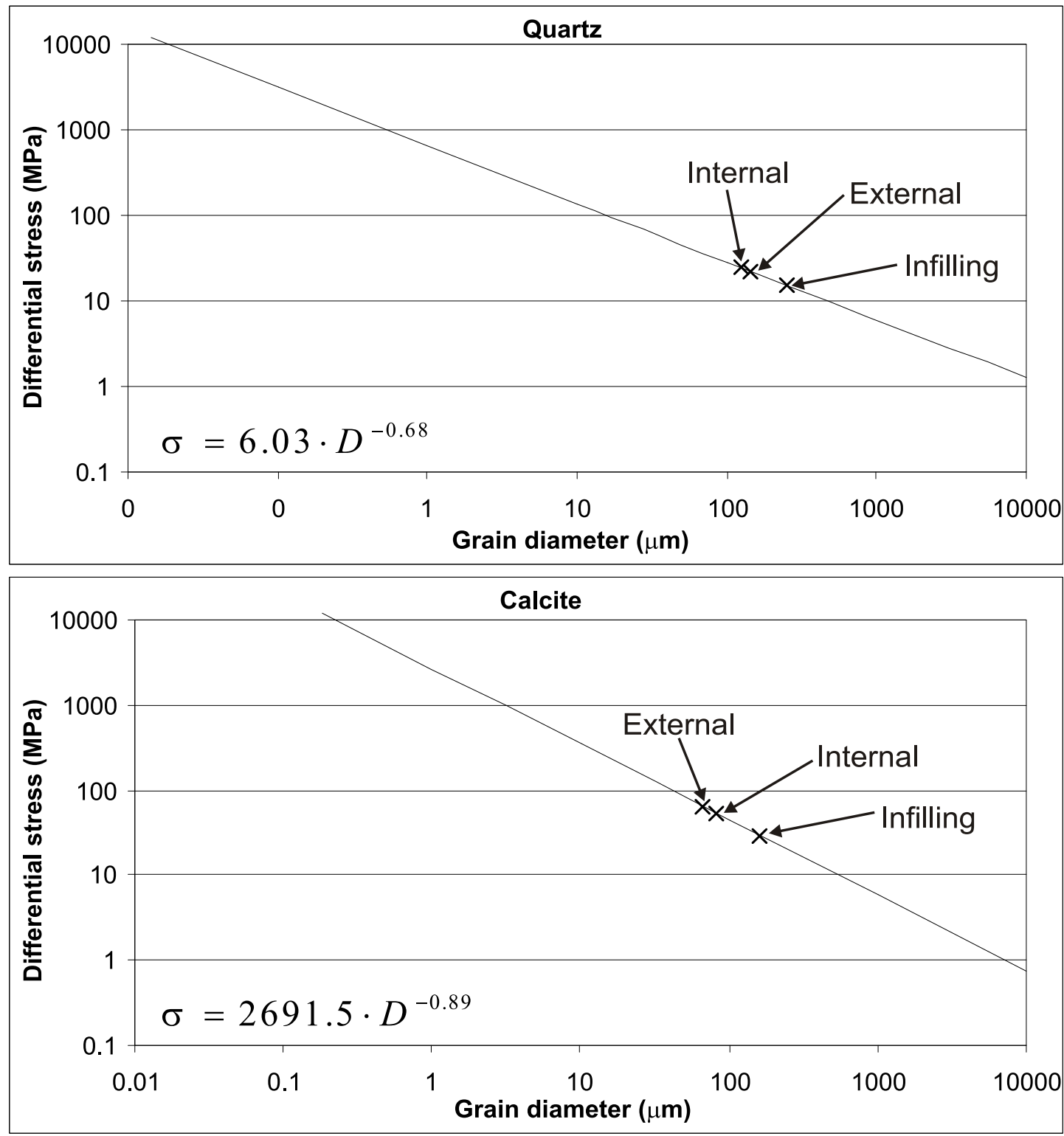

Fig. 4.18. Graphs of differential stress for recrystallised grain diameters from Twiss (1980) for quartz and Rutter (1995) for calcite. Quartz graph is labeled with mean recrystallised grain diameters (D) for each of the vein sections. Calcite graph is also label for each of the vein sections with mean recrystallised grain diameters (D) for the maximum differential stress. Formulae for the recrystallised grain size piezometers are plotted in the lower left hand corner of each graph.

\begin{tabular}{|c|c|c|c|c|c|c|c|c|}
\hline \multirow{2}{*}{$\begin{array}{l}\text { Section } \\
\text { of shear } \\
\text { measured }\end{array}$} & \multicolumn{4}{|c|}{ Mean grain diameter } & \multicolumn{3}{|c|}{ Differential stress } & \multirow{2}{*}{$\begin{array}{c}\text { Piezometer } \\
\text { used for } \\
\text { calculation }\end{array}$} \\
\hline & $\begin{array}{c}\text { mean }^{a} \\
(\mu \mathrm{m})\end{array}$ & $2 \sigma$ & $\begin{array}{l}\min \\
(\mu \mathrm{m})\end{array}$ & $\begin{array}{l}\max \\
(\mu \mathrm{m})\end{array}$ & $\begin{array}{c}\operatorname{mean}^{\mathrm{b}} \\
(\mathrm{MPa})\end{array}$ & $\begin{array}{l}\min ^{\mathrm{c}} \\
(\mathrm{MPa})\end{array}$ & $\begin{array}{l}\max ^{d} \\
(\mathrm{MPa})\end{array}$ & \\
\hline Internal & 126 & 16 & 52 & 200 & 25 & - & 45 & Twiss (1980) \\
\hline NExternal & 145 & 14 & 90 & 208 & 22 & - & 31 & Twiss (1980) \\
\hline Infilling & 248 & 123 & 38 & 1504 & 16 & - & 56 & Twiss (1980) \\
\hline Internal & 116 & 5 & 14 & 1420 & - & 39 & 53 & Rutter (1995) \\
\hline ত্তু External & 93 & 6 & 5 & 448 & - & 47 & 65 & Rutter (1995) \\
\hline Infilling & 225 & 12 & 24 & 3731 & - & 22 & 30 & Rutter (1995) \\
\hline
\end{tabular}

Table 4.6. Grain size palaeopiezometry of recrystallised quartz and calcite. Quartz differential stress calculated from Twiss (1980) and calcite differential stress calculated from Rutter (1995) assuming grain boundary migration recrystallisation. a - For quartz: mean recrystallised grain size calculated from intercept method (D). For calcite: mean length of crystal long axis diameters $\left(D_{L}\right) . \quad b$ - calculated from the mean grain diameter of quartz crystals for each section. $c$ - calculated from $D_{L}$ for calcite crystals. $d$ - For calcite: calculated assuming a maximum $\mathrm{R}$ value (ellipticity) of 2 where grain diameter (D) was calculated from $\mathrm{D}=\left(\mathrm{D}_{\mathrm{L}} \times\left(\mathrm{D}_{\mathrm{L}} \times 0.5\right)\right)^{0.5}$. For quartz: calculated from the minimum grain size measured. 
observed in the vein microstructures. At these low differential stresses the grain growth is most likely to have occurred by grain boundary area reduction (GBAR) in quartz and calcite which can occur at near static conditions.

\subsubsection{Maximum differential stress from Coulomb failure criteria}

In addition to the palaeopieziometric techniques above, the differential stress during shearing in the transient brittle-ductile transition zone (t-BDTZ), $\sim 21 \mathrm{~km}$ below the Southern Alps, can be estimated from the stress required to achieve brittle failure and ductile flow in quartz and calcite at that depth. The maximum differential stress possible would be that required to achieve shear failure of the rocks at a near hydrostatic fluid pressure, an underestimated fluid pressure which likely did not in general, prevail (Sibson et al., 1988; Twiss and Moores,1992; Wightman, 2005) in the t-BDSZ. The differential stress active during ductile shear must have been lower than this maximum differential stress estimate, and can be approximated using the field-based strain-rates and determined from experimental flow laws for the intracrystalline plastic creep of quartz and calcite.

A maximum differential stress can be calculated for ductile deformation of the quartz by considering the differential stress that would place the rock in conditions where brittle Coulomb failure would occur, thus preventing ductile flow. The vertical stress component $\left(\sigma_{\mathrm{v}}\right)$ acting on the shear zone is calculated from an average rock density $\left(\rho_{\mathrm{r}}\right)$ of $2.67 \mathrm{~g} / \mathrm{cm}^{3}$ and the rock overburden thickness (h) of 21 $\mathrm{km}$ (depth of the t-BDSZ below the Southern Alps estimated by Wightman, 2005), yielding an overburden pressure of $550 \mathrm{MPa}$. For a vertical strike-slip fault, Anderson's theory of faulting predicts that the mean intermediate stress $\left(\sigma_{2}\right)$ is vertical. We here, assume that the intermediate stress $\left(\sigma_{2}\right)$ direction of the near vertical fault planes is approximately equal to the vertical stress component $\left(\sigma_{2}\right)$. Assuming that the intermediate stress $\left(\sigma_{2}\right)$ is approximately equal to the mean lithostatic normal stress $\left({ }^{\mathrm{L}} \sigma_{\mathrm{n}}\right)$, then ${ }^{\mathrm{L}} \sigma_{\mathrm{n}}=550 \mathrm{MPa}$ by the following equation:

$$
{ }^{L} \sigma_{n}=\sigma_{2} \approx \sigma_{V}=\rho_{r} \cdot g \cdot h
$$

Microstructures indicate that fluid was present during deformation (e.g. fluid inclusions) and needs to be taken into consideration as fluid pressure $\left(\mathrm{P}_{\mathrm{f}}\right)$ reduces the 
mean lithostatic normal stress $\left({ }^{\mathrm{L}} \sigma_{\mathrm{n}}\right)$ affecting the rocks by an amount equal to the fluid pressure, resulting an effective normal stress $\left({ }^{\mathrm{e}} \sigma_{\mathrm{n}}\right)$. The vertical hydrostatic fluid pressure created by a connected column of water down to the depth of the t$\operatorname{BDSZ}(21 \mathrm{~km})$ can be calculated using the mean density of water, $\rho_{\mathrm{w}}\left(1.0 \mathrm{~g} / \mathrm{cm}^{3}\right)$ and the height of the water column (h) of $21 \mathrm{~km}$. The hydrostatic fluid pressure $\left(\mathrm{P}_{\mathrm{H}}\right)$ at $21 \mathrm{~km}$ depth (open column of fluid) is $210 \mathrm{MPa}$, resulting in an effective normal stress of $340 \mathrm{MPa}$ and a fluid pressure ratio $(\lambda)$ of $\sim 0.4$, calculated using the equations below:

$$
\begin{gathered}
P_{H}=\rho_{w} \cdot g \cdot h \\
{ }^{e} \sigma_{n}={ }^{L} \sigma_{n}-P_{f} \\
\lambda=\frac{P_{f}}{{ }^{L} \sigma_{n}} \text { or } \lambda=\frac{{ }^{L} \sigma_{n}-{ }^{e} \sigma_{n}}{{ }^{L} \sigma_{n}}
\end{gathered}
$$

The maximum possible differential stress $\left({ }_{D} \sigma\right)$ during shearing at a given effective normal stress $\left({ }^{\mathrm{e}} \sigma_{\mathrm{n}}\right)$ can be determined from the shear stress required to achieve brittle Coulomb failure $\left({ }^{*} \sigma_{\mathrm{s}}\right)$. Assuming a cohesive shear strength (c) of 40 MPa (Sibson, 2000; Lockner, 1995) and a coefficient of internal friction ( $\mu$ ) of 0.75 (Byerlee, 1978), a differential stress $\left({ }_{D} \sigma\right)$ of $472 \mathrm{MPa}$ was required to achieve brittle failure as an effective normal stress $\left({ }^{\mathrm{e}} \sigma_{\mathrm{n}}\right)$ of $340 \mathrm{MPa}$ (Fig. 4.19), using the equations:

$$
\begin{gathered}
\frac{{ }_{D} \sigma}{2}=\cos \phi \cdot * \sigma_{s} \\
\text { where }{ }^{*} \sigma_{s}=c+\mu \cdot{ }^{e} \sigma_{n} \\
\text { and } \mu=\tan \phi
\end{gathered}
$$

It is unlikely the fluid pressure was hydrostatic $(\lambda=4)$ at a depth of $21 \mathrm{~km}$, and may, in fact, have been approaching lithostatic $(\lambda=1)$ (Twiss and Moores, 1992). The differential stress calculated above for shear failure under hydrostatic conditions would therefore be a maximum. A fluid pressure at the time of shear infilling vein precipitation of $310 \pm 90(\lambda=0.6)$, recorded in fluid inclusions trapped 


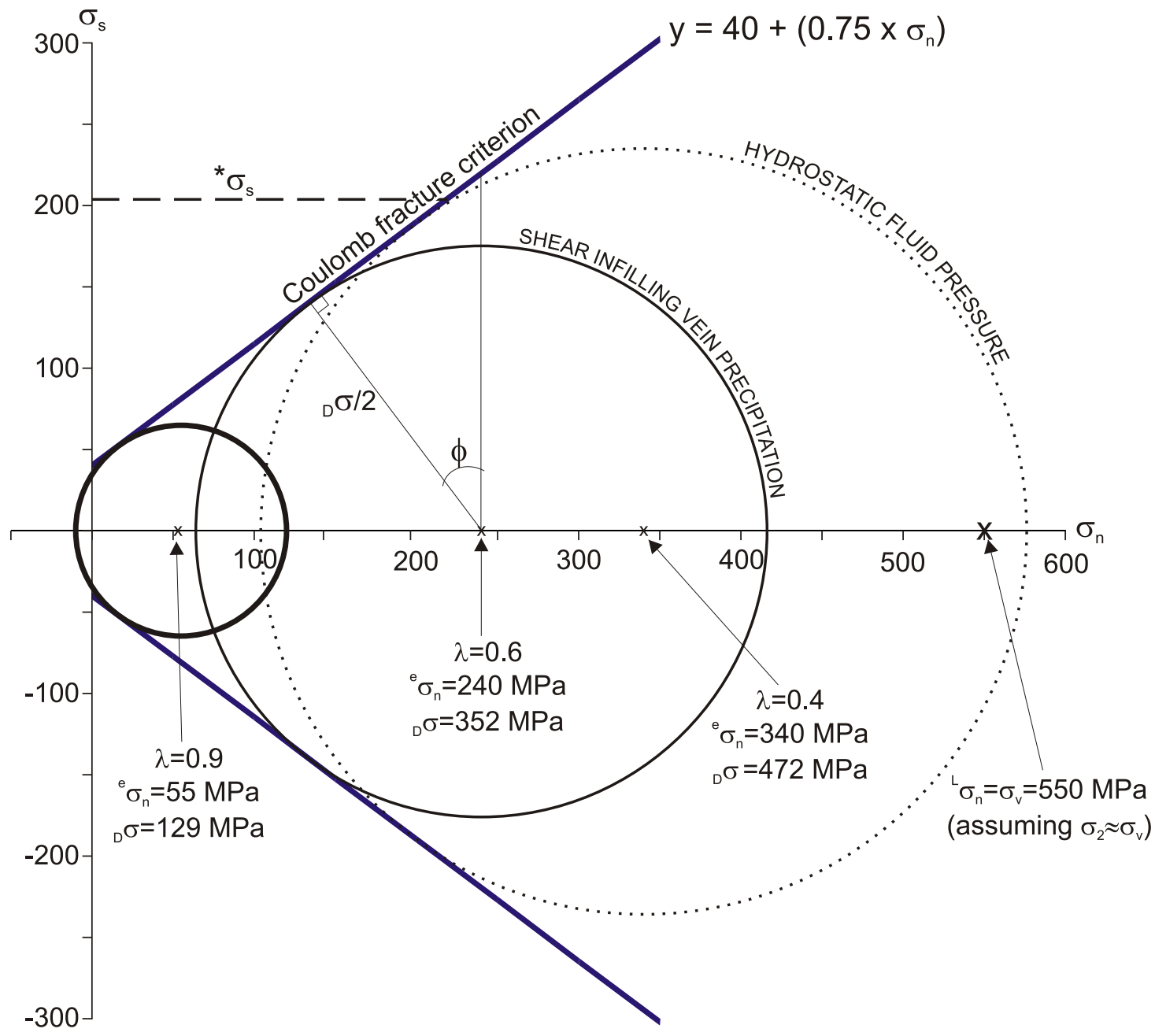

Fig. 4.19. Mohr circle diagram for brittle coulomb failure. Coulomb fracture criterion $\left({ }^{*} \sigma_{s}\right)$ calculated from the normal stress $\left(\sigma_{n}\right)$, the cohesive shear strength $(c)$, the coefficent of internal friction $(\mu)$, the tensile strength $(\mathrm{T})$ and the angle of internal friction $(\phi)$. The coulomb fracture criterion is calculated from the formula $* \sigma_{\mathrm{s}}=\mathrm{c}+\mu . \sigma_{\mathrm{n}}$ where $\mathrm{c}=2 \mathrm{~T}, \mathrm{~T}=20 \mathrm{MPa}$ (Lockner, 1995), $\mu=\tan (\phi)=0.75$ (Byerlee, 1978). Lithostatic normal stress ( $\left({ }^{\mathrm{L}} \sigma_{\mathrm{n}}\right)$ is calculated as $550 \mathrm{MPa}$ for $21 \mathrm{~km}$ under the Southern Alps. Here it is assumed that the mean lithostatic normal stress $\left({ }^{\mathrm{L}} \sigma_{\mathrm{n}}\right)$ is equal to the vertical stress $\left(\sigma_{v}\right)$ as for a near-vertical fault plane, where the intermediate principle stress direction $\left(\sigma_{2}\right)$ is approximately vertical $\left(\sigma_{2} \approx \sigma_{v}\right)$. Differential stresses required for brittle Coulomb failure have been calculated at $\lambda=0.4, \lambda=0.6$ and $\lambda=0.9$ for hydrostatic, shear infilling vein precipitation, and near-lithostatic fluid pressures respectively. These are represented by the circles shown with differential stress calculated from formula ${ }_{\mathrm{D}} \sigma / 2=* \sigma_{\mathrm{s}} \cdot \cos \phi$. 
in the shear infilling veins after initial brittle fracturing (Wightman and Little, 2003; Wightman, 2005), has been used to calculate a more realistic maximum limit for differential stresses expected for ductile deformation in the t-BDTZ before Coulomb shear failure of $353 \mathrm{MPa}$ (Fig. 4.19). In detail however, fluid pressures may have cycled between this post-failure value and near lithostatic fluid pressures $(\lambda=\sim 0.9)$ before Coulomb failure of the rock (Sibson et al., 1988; Wightman, 2005). The differential stresses required for shear failure at these elevated fluid pressures $(\lambda=$ 0.9 ) could have been as small as $129 \mathrm{MPa}$ (e.g. Fig. 4.19) or $100 \mathrm{MPa}$ for hybrid extensional failure (Wightman and Little, 2003).

\subsubsection{Estimated maximum differential stress during brittle-ductile shearing}

Experimental flow laws for intracrystalline plastic creep can be used to calculate an approximate differential stress for ductile deformation in the t-BDSZ. The flow law parameters of Hirth et al. (2001) for quartz and Schmid et al. (1980) for calcite were used here. This approximation assumes that the quartz and calcite flow laws can be extrapolated to low temperatures in order to calculate realistic differential stresses for natural ductile deformation in the crust $(<500 \mathrm{MPa})$. The flow law equation given below has a standard power law creep form (with an additional factor for water fugacity in quartz) from which differential stress $\left({ }_{D} \sigma\right)$ can be calculated:

$$
\varepsilon=A_{{ }_{D}} \sigma^{n} \cdot f_{\mathrm{H}_{2} \mathrm{O}}{ }^{w} \cdot \exp \left(\frac{-Q}{R T}\right) \sec ^{-1}
$$

Where the ideal gas constant (R) of $8.31451 \mathrm{~J} \cdot \mathrm{mol}^{-1} \cdot \mathrm{K}^{-1}$ and the temperature (T) of $723.15^{\circ} \mathrm{K}\left(450^{\circ} \mathrm{C}\right.$ as in Wightman, 2005) are constant for both quartz and calcite in the calculation for this study. The strain-rate $(\varepsilon)$ was estimated from the field-based transect data. The flow law for quartz from Hirth et al. (2001) uses a material parameter $(A)$ of $10^{-11.2}$, a stress exponent $(n)$ of 4 , a water fugacity $(f)$ of $35 \mathrm{MPa}$, a water fugacity exponent (w) of 1, and an activation energy (Q) of 135 $\mathrm{kJ} \mathrm{mol}^{-1}$. The water fugacity in this study was not able to be calculated, so the 37 MPa fugacity of Hirth et al. (2001) was used as a minimum as their deformation temperatures and lithostatic pressures were lower than those used in this study. The flow law parameters for calcite from Schmid et al. (1980) are $A=10^{-3.1}, \mathrm{n}=7.6$ and $\mathrm{Q}=418 \mathrm{~kJ} \cdot \mathrm{mol}^{-1}$. 
As derived in Chapter 3, maximum strain-rates can be calculated using the escalator model for shear zone formation, the mean finite ductile shear strain, the shear spacing, and the convergence rate (see Fig. 3.14). This maximum strain-rate of $8.6 \times 10^{-8} \mathrm{sec}^{-1}$, when used in the quartz and calcite flow laws above, yields differential stresses for dislocation creep of $1208 \mathrm{MPa}$ in quartz and $436 \mathrm{MPa}$ in calcite. These stresses are greater than the maximum threshold calculated for ductile vein deformation without brittle failure (353 $\mathrm{MPa}$ for $\lambda=0.6$ ). Assuming that the experimental flow laws adequately predict natural ductile deformation, this result suggests that the estimated strain-rates are too fast for ductile deformation to occur.

Additional strain-rates have been used in this study to investigate variations in the escalator model to a more realistic scenario where more than one shear could be accommodating strain at a time. This involved deforming a wider block of rock, allowing individual shears to be accumulating deformation simultaneously, resulting in a longer period of time over which the deformation is achieved. This time period variation was made by using different deformation widths that ranged from $10 \mathrm{~cm}$ to $2 \mathrm{~km}$ (Table 4.7; Fig. 4.20). Of these variations, a $100 \mathrm{~m}$ wide deformation width is used as the best approximation. This deformation width is based on results of fault ramp numerical modelling by Erickson et al. (2001) that showed zones of deformation between successive backshears 100-200 m thick. Deformation widths $<10 \mathrm{~m}$ are considered unlikely based on the flow law parameters, given the calculated differential stresses for these smaller deformation widths are high enough to undergo brittle failure ( $>353 \mathrm{MPa})$ and not ductile flow at near-hydrostatic fluid pressures (Table 4.7; Fig. 4.20). A maximum deformation width of $2 \mathrm{~km}$, where the entire array of shear zones would be active simultaneously, is not realistic, based on modelling of recrystallisation times by Wightman (2005), as the time taken to accumulate deformation in $2 \mathrm{~km}$ wide block does not leave sufficient time for quartz annealing and grain growth to occur before exhumation of the Alpine Fault hanging wall.

The preferred $100 \mathrm{~m}$ deformation width yielded an estimated maximum strain-rate of $3.0 \times 10^{-11} \mathrm{sec}^{-1}$. This rate is an approximate differential stress for ductile deformation in the sheared veins from the flow laws of $165 \mathrm{MPa}$ for quartz and $153 \mathrm{MPa}$ for calcite. Brittle failure at these differential stresses would require 

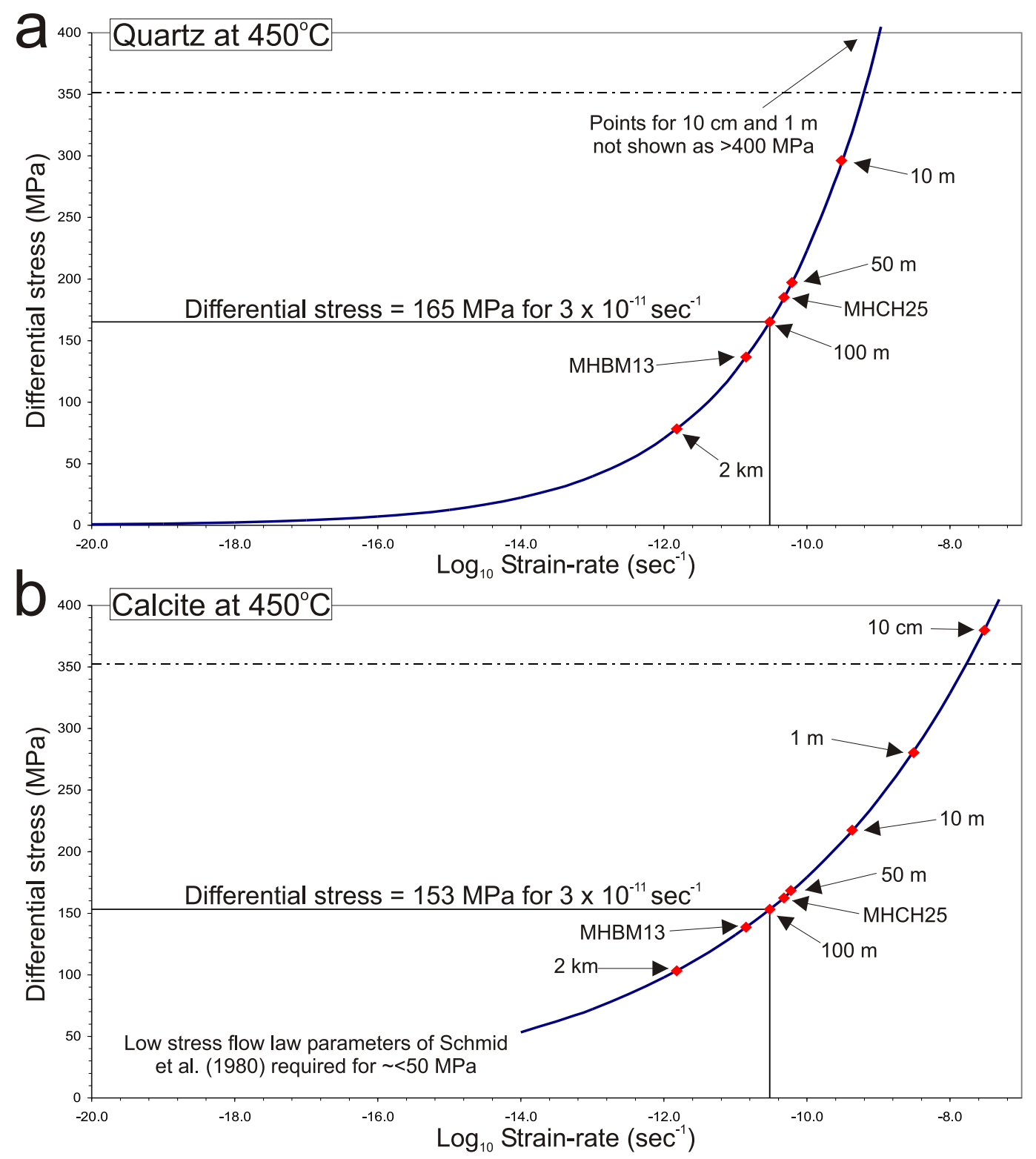

Fig. 4.20. Graphs of strain-rate against differential stress from power law creep equations for quartz (a) and calcite (b) showing calculated differential stress results for estimated strain-rates in Table. 4.7. a. Flow behaviour of quartz for the flow law parameters of Hirth et al. (2001). b. Flow behaviour of calcite for estimated strain-rates calculated from the flow law parameters of Schmid et al. (1980). Points are labeled from 'Sample or width' column in Table 4.7 for different widths of deforming rock. Differential stress threshold for brittle coulomb failure (at $\lambda=0.6$ ) shown as dash-dotted line at $353 \mathrm{MPa}$ in both graphs.

\begin{tabular}{|c|c|c|c|c|c|c|c|}
\hline \multirow{2}{*}{$\begin{array}{c}\text { Sample } \\
\text { or } \\
\text { width }\end{array}$} & \multirow{2}{*}{$\begin{array}{l}\text { Width of } \\
\text { def. rock } \\
(\mathrm{mm})\end{array}$} & \multirow{2}{*}{$\begin{array}{c}\text { Convergence } \\
\text { rate } \\
(\mathrm{mm} / \mathrm{yr})\end{array}$} & \multirow{2}{*}{$\begin{array}{c}\text { Time } \\
\text { (years) }\end{array}$} & \multirow{2}{*}{$\begin{array}{l}\text { Shear } \\
\text { strain }\end{array}$} & \multirow{2}{*}{$\begin{array}{c}\text { Strain-rate } \\
\left(\sec ^{-1}\right)\end{array}$} & \multicolumn{2}{|c|}{ Differential stress } \\
\hline & & & & & & $\begin{array}{l}\text { Quartz } \\
\text { (MPa) }\end{array}$ & $\begin{array}{c}\text { Cal } \\
(\mathrm{MPa})\end{array}$ \\
\hline $10 \mathrm{~cm}$ & 100 & 19.7 & 5.08 & 4.8 & $3.0 \mathrm{E}-08$ & 929 & 380 \\
\hline $1 \mathrm{~m}$ & 1000 & 19.7 & 50.8 & 4.8 & 3.0E-09 & 519 & 281 \\
\hline $10 \mathrm{~m}$ & 10000 & 19.7 & 507.8 & 4.8 & $3.0 \mathrm{E}-10$ & 294 & 207 \\
\hline $50 \mathrm{~m}$ & 50000 & 19.7 & 2538 & 4.8 & $6.0 \mathrm{E}-11$ & 197 & 168 \\
\hline $100 \mathrm{~m}$ & 100000 & 19.7 & 5076 & 4.8 & 3.0E-11 & 165 & 153 \\
\hline $2 \mathrm{~km}$ & 2000000 & 19.7 & 101,523 & 4.8 & $1.5 \mathrm{E}-12$ & 78 & 103 \\
\hline $\mathrm{MHCH} 25$ & 100000 & 22.2 & 4505 & 6.7 & 4.7E-11 & 185 & 163 \\
\hline MHBM13 & 100000 & 14.3 & 6993 & 3.1 & 1.4E-11 & 137 & 139 \\
\hline
\end{tabular}

Table 4.7. Data used to calculate the estimated maximum strain-rates and differential stresses for ductile deformation in the brittle-ductile shears for varied width of deforming rock and from 2 samples. Shear strain is the mean finite ductile shear strain for the BDSZ and the convergence rate is shear normal plate convergence rate and varies depending on field area (mean for all field areas $=19.7 \mathrm{~mm} / \mathrm{yr}$ ). Strain-rates calculated as in Section 3.4.5 and Fig. 3.14b. Differential stress calculated for quartz from the flow law parameters of Hirth et al. (2001) and for calcite from the flow law parameters of Schmid et al. (1980) for power law creep. 
near lithostatic fluid pressures of $\lambda=0.85$, with ductile flow potentially occurring at lower fluid pressures after the initial failure event.

\subsection{Changes in deformation conditions up the Alpine Fault ramp}

From the palaeopiezometry of the brittle-ductile shears and microstructural observations, three periods of deformation for the quartz-calcite veins are proposed: 1) shearing, 2) stress drop with grain growth and dislocation creep and partial exhumation followed by 3 ) semibrittle faulting and calcite e-twin deformation. These occur in order of decreasing inferred temperature.

Brittle-ductile deformation of the quartz-calcite veins is estimated to have taken place at $450 \pm 50{ }^{\circ} \mathrm{C}$ (Wightman, 2005). At this temperature and an estimated maximum strain-rate of $3.0 \times 10^{-11} \mathrm{sec}^{-1}$ (100 m wide deformation width), power law creep flow laws for quartz and calcite estimate differential stresses of $\sim 160 \mathrm{MPa}$ during ductile deformation. During the brittle-ductile shearing a maximum differential stress of $353 \mathrm{MPa}$ is estimated based on brittle Coulomb failure of the rocks at a fluid pressure of $310 \mathrm{MPa}(\lambda=0.6)$. However, the fluid pressure is likely to have been closer to lithostatic prior to failure. If $\lambda=0.85$, brittle failure would occur at the estimated differential stress for ductile deformation of $160 \mathrm{MPa}$. Microstructures preserved in the veins are not related to this period of ductile shearing and veins may have had a smaller grain size generated from dynamic recrystallisation and an oblique grain shape fabrics generated from the shearing.

After dynamic recrystallisation, grain growth occurred at an estimated minimum, near-static, differential stress of 16-65 MPa. This was calculated using recrystallised grain size piezometers and is a significant decrease in differential stress from the initial period of ductile shearing in the veins. With the low differential stress, GBAR may have been the active recovery mechanism overprinting any existing rock fabrics generated during shearing. After, or synchronously, with this GBAR, veins underwent intracrystalline deformation that produced Regime 1 (of Hirth and Tullis, 1992) microstructures (e.g. grain boundary bulging, deformation lamellae and some subgrain boundaries) that are found preserved in the veins across the shear zone. Oblique grain shape fabrics indicate that a late stage shearing occurred in the shear infilling veins with a minimum shear strain of $\sim 1.5$. Based on microstructures in the sheared and infilling veins a temperature of range of 280- 
$650^{\circ} \mathrm{C}$ was estimated; however, this temperature is more likely closer to the cooler end of the range based on the Regime 1 microstructures. The homogeneous grain size, Regime 1 microstructures, moderate temperatures and near-static differential stress across all parts of the veins in the shear zone suggests that this deformation occurred after the main ductile shearing event and further up the Alpine Fault ramp.

Calcite grains that have been recrystallised and undergone grain growth typically have e-twin deformation lamellae which are estimated to occur at temperatures $<200^{\circ} \mathrm{C}$. Grain growth does not appear to have occurred after this twinning as they are in most cases straight, and intercept the grain boundaries. Fluid inclusion trails found in all vein sections, inferred to be healed microcracks, are also inferred to be at lower temperatures when plastic creep is not easily accommodated. From calcite twin incidence palaeopiezometry, the differential stress for this deformation is estimated to be $<189 \mathrm{MPa}$. Even though this stress is a maximum, it is more than triple that of the previous static grain growth and plastic deformation period. The third deformation period is proposed to occur at a higher differential stress due to the rocks proximity to the contemporary seismically defined brittleductile transition zone (s-BDTZ; see Chapter 2 and Fig. 2.3) where elevated differential stress occurs (Twiss and Moores, 1992). Under these higher differential stress and lower temperature conditions strain is accommodated by semibrittle faulting in quartz and by e-twinning in calcite. 


\section{CHAPTER 5: Crystallographic preferred orientation of quartz c-axes}

During crystal-plastic deformation a preferred orientation of quartz crystallographic axes can occur from intracrystalline deformation and dynamic recrystallisation (Lister and Williams, 1979; Wenk, 1985a; Passchier and Trouw, 1998; Bons and den Brok, 2000). Pole diagrams of quartz crystallographic c-axis orientations can be used to infer the aspects of deformation conditions and mechanisms that accompanied shearing, as crystals will align differently depending on the differential stress, temperature, strain and slip systems that are active (e.g. Tullis, 1977; Lister et al., 1978; Lister and Hobbs, 1980; Hobbs, 1985; Schmid and Casey, 1986; Law, 1990). In this study crystallographic orientations were measured using a universal stage microscope to obtain more information about the kinematics and rheology of the brittle-ductile shear zone (BDSZ).

A data set of 30,800 quartz c-axis orientations has been measured from samples collected within the BDSZ at Sam Peak, Chancellor Ridge and Baumann Glacier. Measurements have been made for sheared quartz-calcite veins, both inside and outside of the discrete shear zones, as well as for the syntectonic shear infilling veins to provide a complete crystallographic overview. c-Axes have been plotted on stereographic projections for each of the 102 selected areas within shear zone samples collected across the BDSZ. In some cases measurements from up to seven of these selected areas were analysed across a single shear zone (e.g. MHCH20, Appendix D). Crystallographic measurements were also made on metacherts in the non-mylonitic Alpine Schist at Waiho River and in the Alpine Fault mylonite at Hare Mare Creek in order to compare the crystallographic preferred orientation (CPO) fabrics in these structurally lower samples to those veins in the BDSZ.

The CPO fabrics have been used as a tool to determine the stretching direction, whether the flow was coaxial or non-coaxial, to approximate temperature during deformation, and to infer aspects of the strain path in the shear zones. The kinematic interpretations are unfortunately limited in this study because of the unexpectedly weak and diffuse nature of the CPO fabrics. The cause for this fabric weakness or weakening is a major concern for this study, and will be explained using a combination of CPO fabrics and microstructural observations. 


\subsection{Measurement of quartz c-axes and presentation of fabric plots}

\subsubsection{Measurement of a quartz c-axis using a universal stage microscope}

Quartz c-axis orientation measurements were made using a 5-axis universal stage fitted to a Leitz polarising microscope (Fig. 5.1a). Marked and orientated thinsections (30 $\mu \mathrm{m}$ thick) were mounted between glass hemispheres, using a mounting fluid with a refractive index of 1.56 to avoid refraction effects (as in Turner and Weiss, 1963). Rotation of the universal stage was made following the technique in Passchier and Trouw (1998) to find the c-axis orientations. These were converted to pole orientations suitable for display on stereographic, lower hemisphere, equal area projection (CPO fabric plots) using methods outlined in Wenk (1985b) and Phillips (1971). Typical errors on angular measurements for c-axes of quartz crystals are $\pm 5^{\circ}$ with the smallest size crystal able to be measured typically between 30 and $50 \mu \mathrm{m}$ (Mainprice et al., 1993; Ullemeyer et al., 2000).

A minimum c-axis pole sample size of 300 was measured for each CPO fabric. 300 c-axes are determined as a statistically representative sample size, as incremental increases of 100 measurements from 300 to 900 resulted in no significant change in the generated CPO fabric. Slides were moved on the stage parallel to the shear plane pole (parallel to the $\mathrm{c}+$ direction in Turner and Weiss, 1963) and every grain which fell under the crosshairs of the microscope was measured (Fig. 5.1b). Multiple runs were made parallel in this direction and spaced $\sim 0.5 \mathrm{~mm}$ apart to ensure that grains were not measured twice and that a representative area of slide was covered without possible bias towards domains present within the samples. Typically, the orientation measurements were made in an area $\sim 10 \mathrm{~mm}^{2}$.

Thin-sections of vein segments that lie in the external and internal areas of the most attenuated vein sections and of shear infilling veins (Fig. 5.1c) were all cut perpendicular to the shear plane and parallel to the strike of the shear zone. This was the only orientation of thin-section made for the external and internal vein sections due to the limited sample size. However, some shear infilling veins had sufficient sample volume for additional cuts to be made perpendicular to the shear plane and parallel to the dip direction; and / or perpendicular to the shear plane and parallel to the fault surface mineral fibre lineation. Mutually perpendicular sections normal to 


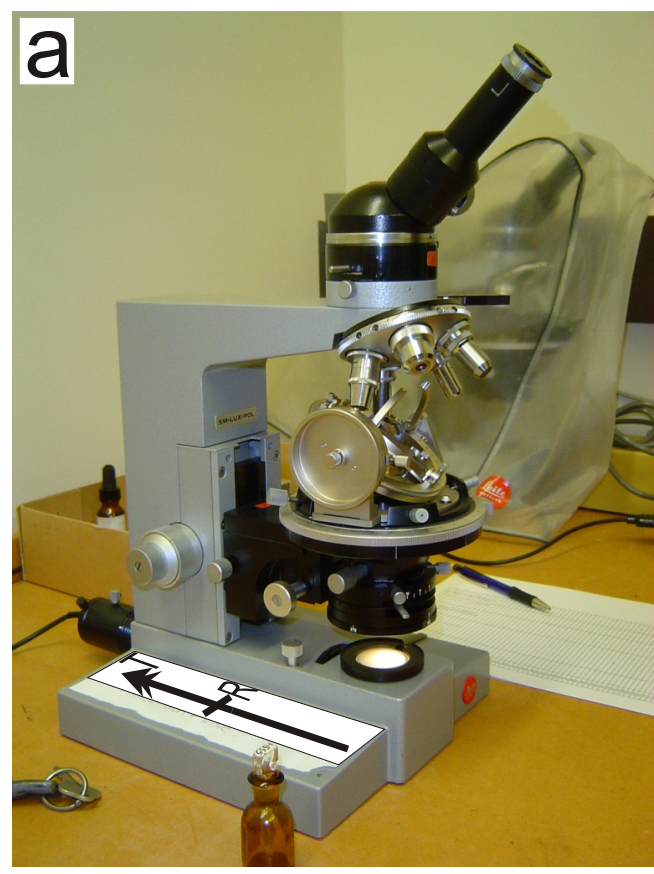

\section{b}

Pole normal to shear plane and top side of sample.

Equivalent of c+ direction of Turner and Weiss (1963).

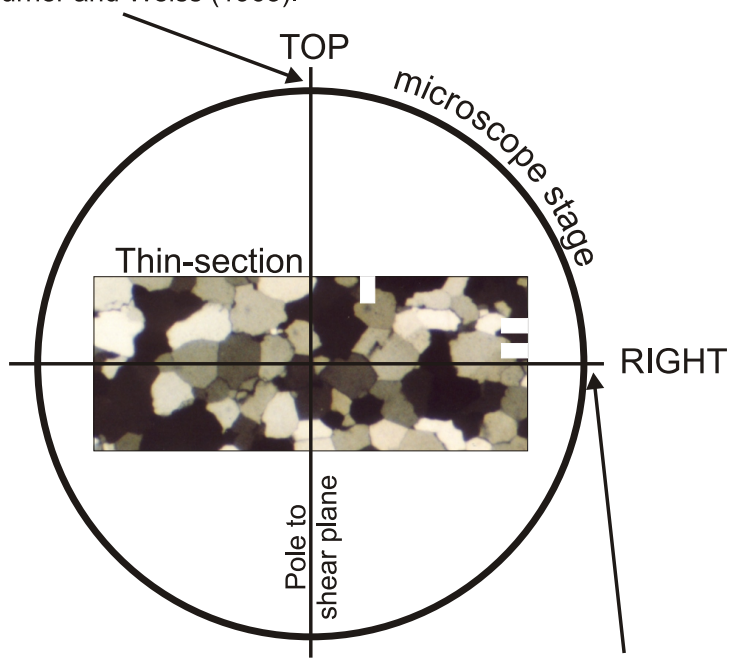

Pole parallel to the shear plane and either the north end of strike or the down direction of dip or lineation parallel cuts.

Equivalent of $b+$ direction of Turner and Weiss (1963)

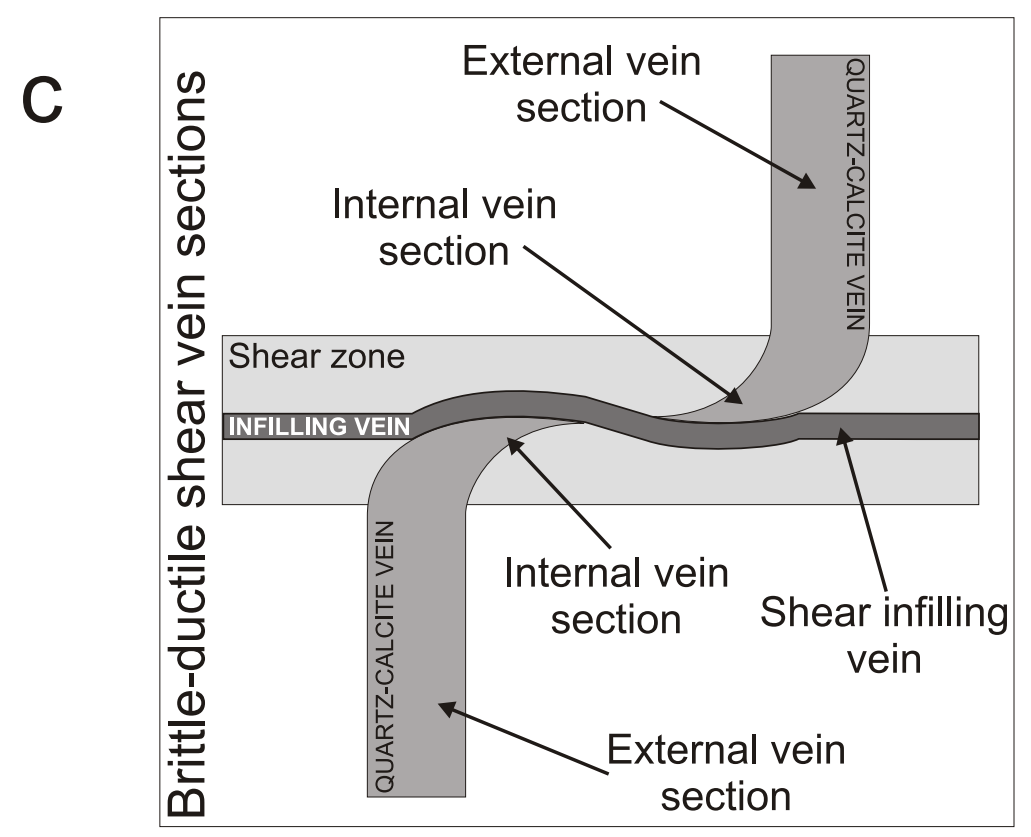

Fig. 5.1. Slide orientations on the universal stage microscope and locations of sections in the shear zones. a. Photograph of the 5-axis universal stage mounted on a polarising microscope that was used in this study. Top (T) and right (R) directions annotated on the side of the microscope for reference with (b). b. Schematic plan view of the universal stage microscope stage with a mounted thin section. North and east relate to directions on the microscope (a). c. Cartoon of a shear zone with brittle-ductile marker vein and a shear infilling vein. The vein sections used to differentiate between the different parts of the shear zone are labelled. External vein section - part of vein that has not been sheared by the brittle-ductile deformation. Internal vein section - the attenuated section of the vein that has been sheared by the brittleductile deformation. Shear infilling vein - the infilling vein material precipitated along the shear plane. 
the shear plane made in some samples were rotated into a common orientation to ensure that a bias in c-axis measurements was not being created as a result of thinsection orientation. In addition, serial thin-sections were often required to cover a large enough lateral extent of the veins in the shear zones and be representative. All the analysed samples of deformed veins had a cut in the external section and one or more cuts in the more strongly deformed, internal vein section. Thin-sections for infilling veins were made where material was available and taken from several areas along the vein length to ensure that there was not a bias was toward any particular fabric domains. Thin-sections were positioned in the microscope with the top of the shear plane and its pole pointed upward in the "top" position, and the more northern end of the strike (or the down-plunge or down-dip direction of the side) pointing towards the "right" position of the microscope stage $(\mathrm{c}+$ and $\mathrm{b}+$ directions, respectively of Turner and Weiss, 1963; Fig. 5.1b).

\subsubsection{Quartz c-axis CPO fabric and CPO pattern plots}

CPO fabrics are plotted with reference to a vertically positioned shear plane that strikes east-west on the lower hemisphere stereogram, and with the top of the sample in the north position (as in Lister and Hobbs, 1980; Figs. 5.2 and 5.3). These CPO fabric plots differ from the conventional orientation used by Llana-Fúnez (2002) and Law et al. (2004) for example, in that it is the shear plane rather the foliation that is the reference plane. As no obvious foliation occurs in the quartz veins examined in this study, the shear plane has been used as the planar reference for the CPO fabric plots. This means that the minimum and maximum principle strain axes would be anticipated to lie at an oblique angle to this reference plane in the case of a non-coaxial deformation involving ductile shear, unless that deformation involved a very large strain (i.e. $\gamma=10$ for simple shear).

CPO fabric plots have been produced using the computer software StereoNet for Windows (Geological-Software, 1995). A scatter plot and a contour plot were generated for each set of CPO fabric data. These are displayed side-by-side, in accordance with the method recommended by Marshak and Mitra (1988). Contour plots were generated using the Kamb contouring method (Kamb, 1959) and plotted with shading in either a greyscale or a colour spectrum according to the point density (percent of total points). The Kamb contouring method was used as it takes into 


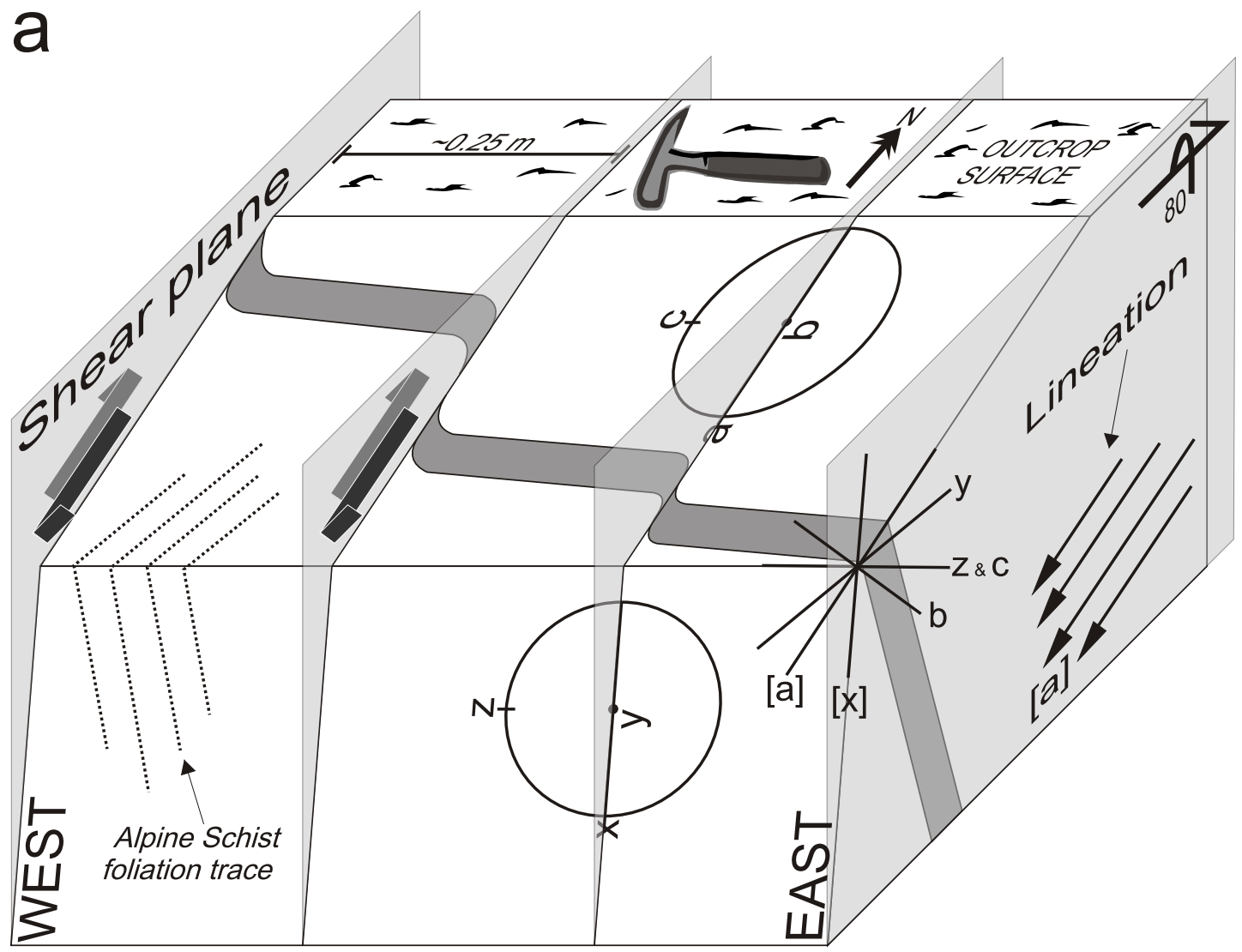

b

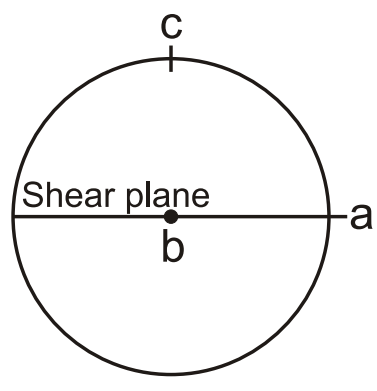

C

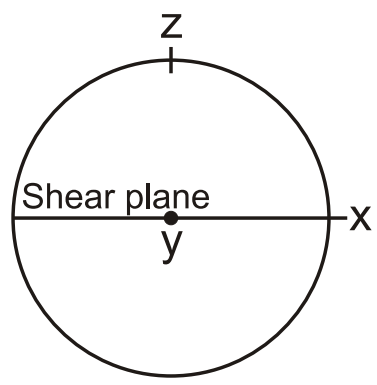

\section{Initial CPO fabric plot reference frame}

a - parallel to mineral lineation on shear plane.

Labelled end is in down plunge direction and [a].

$\mathrm{b}$ - perpendicular to mineral lineation in shear plane

c - pole shear plane (same as [z] below).

Labelled end indicates the top of the sample.

All plots are stereographic, lower hemisphere, equal area projections.

\section{Rotated CPO fabric plot reference frame}

$\mathrm{x}$ - CPO-derived stretching pole.

Labelled end is in down plunge direction and $[\mathrm{x}]$.

$y$ - perpendicular to the $x$-pole in the shear plane

$z$ - pole to shear plane (same as [c] above).

Labelled end indicates the top of the sample.

All plots are stereographic, lower hemisphere, equal area projections.

Fig 5.2. a. 3-D schematic illustration of shear zone features. a-b-c reference frame for initial CPO data collection with the mineral fibre lineation [a] plotted parallel to the east-west direction on the stereogram. $x-y-z$ reference frame for rotated CPO fabrics with stretching direction $[x]$. Stereographic reference frames for CPO fabric plots are shown in 3-D positions for both $a-b-c$ and $x-y-z$ positions. Shear plane (and shear sense), mineral fibre lineations and Alpine Schist foliation are illustrated as well as a sheared vein. Rock hammer used for approximate scale and a mean shear normal spacing of $\sim 0.25 \mathrm{~m}$ shown on schematic outcrop surface. b. Initial stereographic reference frame used for collecting CPO data. c. Rotated stereographic reference frame with CPO fabric symmetry axes alligned relative to $[\mathrm{x}]$. [x] is the inferred elongation direction. 

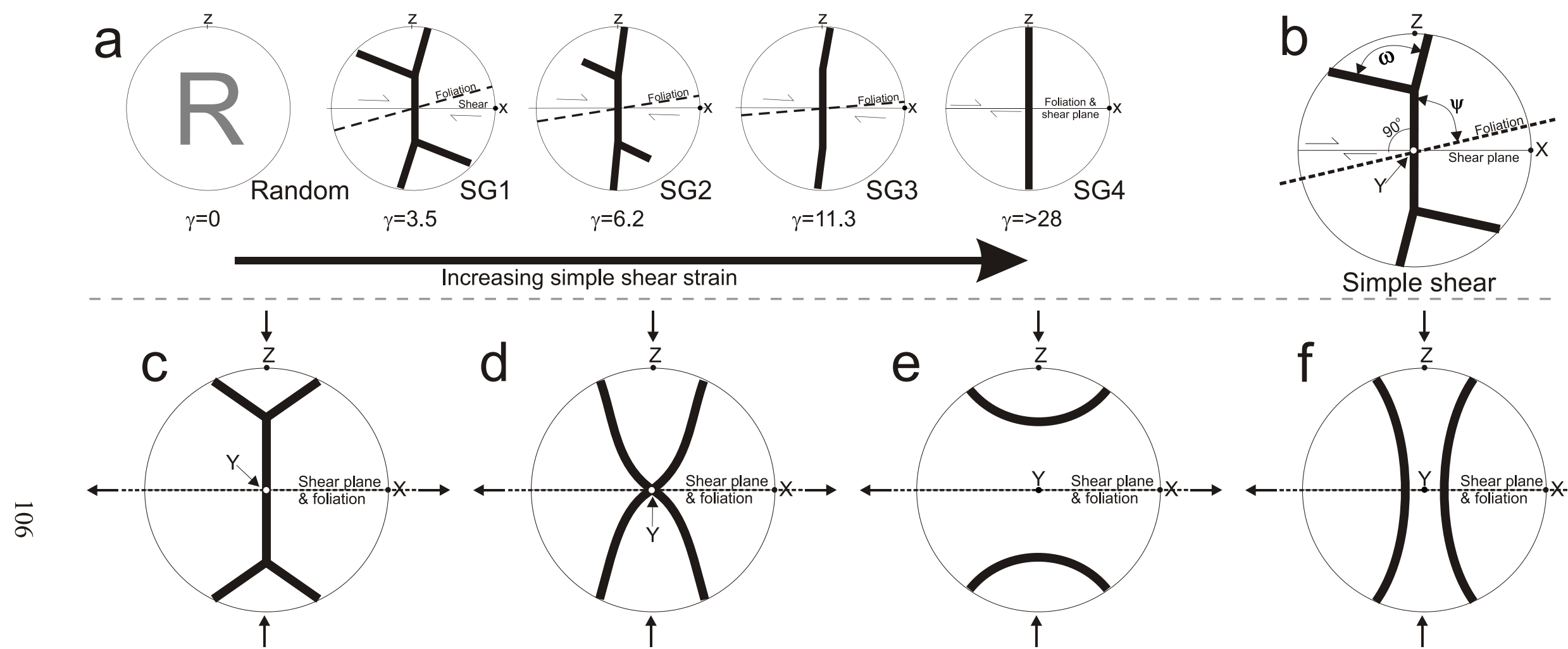

ncreasing simple shear strain

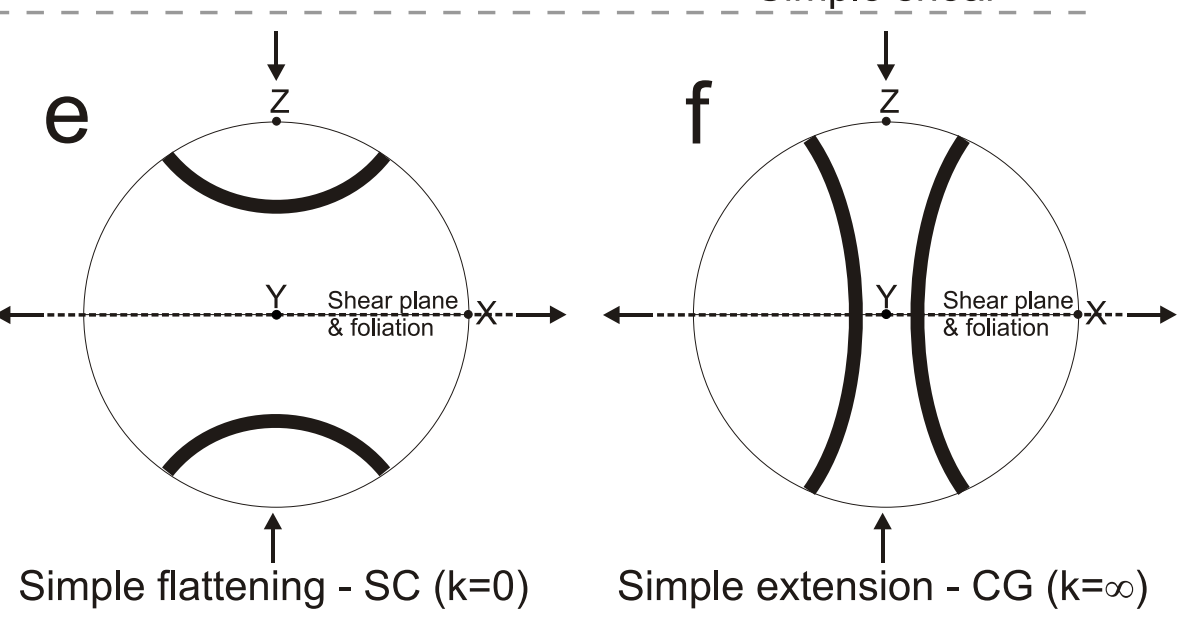

Simple shear

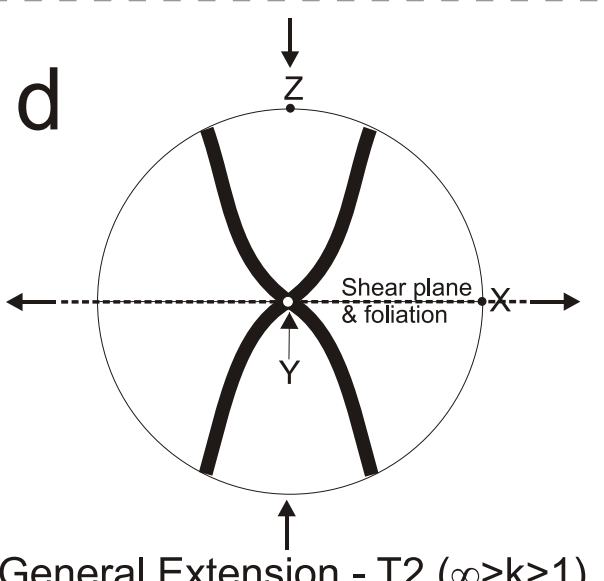

Fig. 5.3. CPO patterns (skeletal outlines) of non-coaxial ( $a$ and b) and coaxial (c, d, e and f) strain. Dashed line represents the foliation, half arrows indicated the shear sense, and full arrows represent the stretching directions. a. Progressive changes in the CPO pattern with increasing simple shear strain adapted from Schmid \& Casey (1986). CPO pattern on the left has an initial random fabric. With a small increase in simple shear a Type I girdle develops an internal and external asymmetry with the dominant girdle section perpendicular to the shear zone. With increased strain a single girdle is developed perpendicular to the shear zone and the angle between the foliation and the shear plane $(90-\psi)$ approaches $0^{\circ}$ (as in Lister and Hobbs, 1980). Strain calculated from (90- $\psi$ ) for simple shear as in Platt \& Behrmann (1984) using formula in Ramsay (1983). b. Type I girdle with labels indicating $\omega$ - the girdle opening angle, $\psi$ - the angle from the dominant girdle to the foliation, $\mathrm{x}, \mathrm{y} \& \mathrm{z}$ - pole orientation, and the shear sense (half arrows) observed from the external and internal asymmetry. c. Type I crossed girdle CPO pattern generated from plane strain. d. Type II crossed girdle CPO pattern generated from general extension e. Small-circle girdle CPO pattern generated from simple flattening. f. Cleft girdle CPO pattern generated from simple extension. CPO patterns $\mathrm{c}, \mathrm{d}$, e and f have the foliation parallel to the shear plane. $\mathrm{k}$ values calculated from ratio of extension axes (from Twiss and Moores, 1992). 
account the statistical significance of the number of c-axes measured (Kamb, 1959). Counting circles of $1 \sigma$ were used to generate most contour plots (e.g. Sample 03 in Fig. 5.4a), instead of the standard $3 \sigma$ (Kamb, 1959) as the weak CPO fabrics measured in this study required increased fabric detail (reduction of $\sigma$ as in Miller and Christie, 1981). Contour plots for stronger fabrics (e.g. Sample 10 in Fig. 5.4b) were made using a $3 \sigma$ counting circle to reduce the detail and produce a clearer contour plot.

CPO patterns (skeletal outlines of Lister and Williams, 1979) have been overlain on each CPO fabric plot to delineate the concentration of c-axes in the stereogram. The term 'CPO pattern' is used here for the interpretation of a skeletal outline and the inferred kinematics associated with that pattern, whereas the term 'CPO fabric' is reserved for reference to a c-axis pole diagram or contour plot (as in Schmid and Casey, 1986). The types of CPO patterns recognised in this study are outlined in Fig. 5.3. Fig. 5.3a shows an idealized progressive pattern development by simple shear; Fig. 5.3b show angular relationships used here for asymmetrical CPO patterns; and Fig. 5.3c-f show other types of symmetrical CPO patterns referred to in this study and their generally interpreted stretching and compression directions.

CPO patterns were plotted 'by eye' from CPO fabrics in this study. However, eigenvalue ratios have also proven useful for describing some patterns (e.g. girdled, domainal, or random CPO patterns) using the Woodcock (1977) method and calculated eigenvalues from the computer software Stereonet for Windows (Allmendinger, 2003). The eigenvalue ratio of $\mathrm{S}_{2}: \mathrm{S}_{3}$ has been used as a guide for girdle strength (ratios $<1.4$ define a weak girdle), whereas the ratio of $\mathrm{S}_{1}: \mathrm{S}_{2}$ measures the strength of a fabric cluster (a significant cluster has a ratio $>1.4$ ). The $\mathrm{S}_{1}: \mathrm{S}_{3}$ ratio can be used as a guide for randomness (ratio $<1.44$ is random; also see Section 5.6.1). However, these ratios are limited in their application, as some CPO patterns are not well described by orthorhombic eigenvalues. As noted by Woodcock (1977), caution should be exercised when interpreting fabrics that are multimodal or have small-circle patterns. Eigenvalue ratios are used here in conjunction with the visual interpretation of a contour and scatter plot, where CPO patterns are assigned to fabrics based on contour densities. 

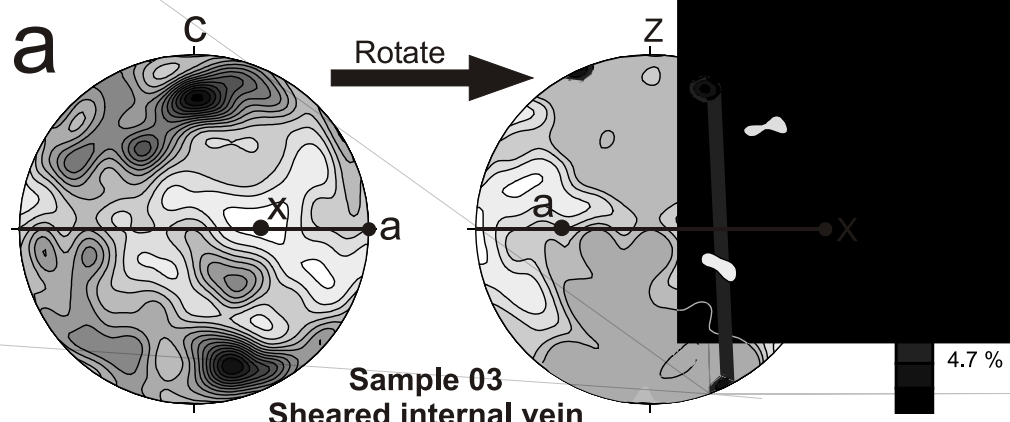

b

Fig. 5.4. a. Rotation method used to find the CPO-derived stretching direction. Rotation of the CPO fabric about the c-pole is made from the mineral lineation direction [a] to the stretching direction $[\mathrm{x}]$ as defined by the Type II quartz CPO pattern measured in Sample 3. SP= shear plane. b. Sample 10 is used to test the rotation method with a known stretching direction $[\mathrm{x}+\mathrm{a}]$ on a strong $\mathrm{CPO}$ pattern. Rotation occurs from down-dip to the position where the single girdle CPO pattern crosses the $y$-axis. Measured direction of mineral stretching lineation $[\mathrm{x}+\mathrm{a}]$ rotates into east-west direction when girdle crosses the $\mathrm{y}$ axis. Kamb contouring method used with a $1 \sigma$ counting circle for Sample 3 and a $3 \sigma$ counting circle for Sample 18. Both samples have a sample population of $300 \mathrm{c}$-axis measurements and are contoured by percent and shaded according to illustrated scale. Specific down plunge or top of sample directions represented by pole labels in square brackets (e.g. [x] - down plunge; [z]- top of sample). Brackets are not used in CPO fabric plots, instead, labelled ends of the poles represent these specific directions.

Fig. 5.5. Stereographic projection of 19 measured quartz CPO-derived stretching poles from internal and infilling vein sections and 25 mineral fibre lineation directions from field-based measurements. Stretching poles derived from rotated quartz CPO fabrics are divided into those with a west-side-up shear sense (filled triangles) and stretching poles with no shear sense (stars). The west-side-up shear sense is inferred from internal asymmetries from fabrics with Type I CPO patterns. Uncertainties represent a $95 \%$ confidence ellipse surrounding the mean lineation or pole-to-plane orientation. 


\subsection{Quartz CPO-derived stretching directions}

The quartz CPO fabrics were initially viewed in the a-b-c reference frame (Fig. 5.2) with the a-pole parallel to the displacement vector (assumed to be represented by the mineral lineation measured in the field). If the CPO patterns when viewed in this reference frame were not centred about the b-pole (e.g. Fig. 5.4a) one might infer that the stretching or shear direction was not parallel to the observed lineation and finite displacement vector (a-pole). In these cases the CPO fabrics were rotated about the c-pole to bring CPO pattern into alignment as best as possible with the b-pole (as in Klaper, 1988; MacCready, 1996; e.g. Fig. 5.4). Based on this rotation, a CPO symmetric reference frame (x-y-z) was defined (Fig. 5.2). A stretching direction, referred to here as the quartz CPO-derived stretching direction, has been found from the direction of the x-pole in the shear plane. All CPO fabrics in this study are plotted in Appendix E and presented in the rotated $x-y-z$ reference frame. Shear plane orientations, with pitches of x-pole from the southwest (as derived from rotations of the CPO data) for each plot, are listed in Appendix $\mathrm{H}$.

A rotation about the b-pole was not required for the CPO fabrics measured from deformed internal vein sections and shear infilling veins, as once rotated about the c-pole these patterns were in mirror symmetry across the $y-z$ plane. This symmetry indicates that the shear plane measured in the field (the $x-y$ plane) was indeed the shear plane of the ductile deformation that generated the CPO fabrics. The CPO fabrics measured from the external sections of the veins did not show mirror symmetry about the $y-z$ or the $x-y$ planes after rotation. This implies that the deformation which produced these CPO patterns was unrelated to the shearing.

To avoid confusion, a CPO fabric pole label inside square brackets represents a specific direction or pole end (in all cases the down-plunge end when viewed in a geographic projection such as Fig. 5.5). For example the symbol [x] refers to the down-plunge end of the x-pole. For simplicity, the square brackets are only used in the text and not in CPO fabric plots. In the fabric plots the labelled ends of the poles represent the down plunge directions for $[\mathrm{a}]$ or $[\mathrm{x}]$ and the top of the sample for $[\mathrm{z}]$.

The method of rotating fabrics to find the stretching direction is based on replicating the CPO patterns produced from numerical modelling and experimental deformation of quartz where the stretching directions for the deformation are known 
(e.g. Tullis, 1977; Lister, 1978; Lister and Williams, 1979; Schmid and Casey, 1986). A CPO pattern, Type II for example (Fig. 5.3d), is generally in mirror symmetry about the shear plane (also the foliation for coaxial CPO patterns in Fig. 5.3, and a-b or $x-y$ planes in Fig. 5.2) and the plane perpendicular to the shear plane (the b-c or the y-z plane in Fig. 5.2). This symmetry only occurs when the shear plane is plotted in the east-west vertical orientation in the CPO fabric plots and the finite stretching lineation is aligned east-west and horizontal (e.g. a- and x-poles in Fig. 5.2). An example of this rotation is shown in Fig. 5.4a, where a CPO pattern has been plotted with the a-pole (parallel to the mineral fibre lineation) in the east-west direction but the pattern is not in mirror symmetry about the shear plane. Therefore the stretching direction is not aligned parallel to the a-pole and a rotation of the fabric is required. A rotation about the c-pole was made until the CPO pattern aligned symmetrically about the shear plane (Fig. 5.4a). The x-pole, which is inferred to be parallel to the stretching direction during CPO fabric development, now lies in the east-west [x] direction of the stereogram. The a-pole (parallel to the mineral lineation) still lies in the shear plane but is no longer plotted parallel to the east-west direction and has been rotated about the c-pole away from that position (Fig. 5.4a).

The rotation of the CPO fabrics was made using Stereonet for Windows (Allmendinger, 2003) and rotated according to visual and statistical methods. For the visual method rotations were made until the CPO pattern was determined visually 'by eye' to be symmetrical about the y-pole or shear plane. The statistical method utilised the eigenvector statistics of the CPO fabric to find the centre of the CPO pattern that should have intercepted the y-pole in the $x-y$ plane. The plane containing both the $S_{1}$ and $S_{2}$ eigenvectors was used to define the girdle patterns or the centres of Type I, Type II or Cleft girdle CPO patterns (Fig. 5.3). Once this centre or girdle was established, a rotation of the fabric in the shear plane (about the c-pole) was made until it was centred symmetrically about the b-pole. By knowing how many degrees, and in which direction the rotation was made, the new $\mathrm{x}$-pole and $[\mathrm{x}]$ orientation was established.

This rotation method for finding the apparent fabric stretching direction was confirmed by two tests. The first test involved measuring CPO fabrics from two slides cut perpendicular to each other from the same sample and rotating them to find the stretching direction. Although each required a different rotation about the c-pole 
due to the difference in the original orientation, the rotations resulted in both slides having the same final $x$-pole orientation and coincident $x-y-z$ reference frames. This exercise confirmed that the rotation method for determining the $[x]$ direction was robust.

The second test was employed to ensure that rotations were determining a stretching direction from a CPO fabric. The CPO fabric from a metachert in the Alpine Fault mylonite zone was used to perform this test as a mineral stretching direction (elongated quartz porphyroclasts, aligned micas, and boudinaged hornblende and feldspar crystals) is measured and interpreted here to represent ductile stretching in the rocks which have undergone an estimated shear strain of $>120$ (Norris and Cooper, 2003). The CPO fabric in this rock, with an asymmetric, single girdle CPO pattern, was measured in a slide that was cut in the dip direction and subsequently rotated giving a stretching direction pitch $34^{\circ}$ from the northeast in the shear plane (Fig. 5.4b). This quartz CPO-derived stretching direction $[\mathrm{x}]$ is only $4^{\circ}$ steeper than the actual mineral stretching lineation [a] measured in the field and their near-coincidence confirms that the fabric rotation method provides reasonable results. The shear sense measured from the internal asymmetry of this CPO pattern girdle (method of Law, 1990) was found to be dextral-reverse and is consistent with many other microfabric and field-based estimates of shear sense in this rock (see Sibson et al., 1979; Wightman, 2000; Little et al. 2002a; Appendix F this study). These two tests confirm that with a known shear plane and a CPO pattern the ductile stretching direction for quartz can be reliably determined after a rotation about the cpole.

From this study, CPO patterns from the most deformed, internal, vein sections and shear infilling veins used to infer a stretching direction (excludes small circle, domainal and random CPO patterns which did not have determinable or reliable stretching directions) were rotated to find the quartz CPO-derived stretching direction. These are plotted in Fig. 5.5 along with the orientations of the mineral fibre lineations observed on the shear planes in the field for comparison. The quartz CPO-derived stretching directions pitch steeply towards the down dip direction in the shear plane with a mean orientation of $239,79^{\circ} \pm 11$ (uncertainty represents a $95 \%$ confidence ellipse surrounding the mean orientation). These are clearly not 
coincident with outcrop measured mineral fibre lineations that decorated the shear planes in the field and pitch moderately at $35^{\circ}$ from the southwest (Fig. 5.5). A notable exception to the general trend of quartz CPO-derived stretching directions is in Sample 7 (an infilling vein section). This sample has a stretching direction that pitches $18^{\circ}$ from the southwest, which is coincident with the mineral fibre lineation measured on the outcrop for that sample (Fig. 5.5). The steeply pitching quartz CPO-derived stretching directions from most deformed internal and shear infilling vein sections of the remaining samples, suggest that the ductile elongation of the quartz recorded in the $\mathrm{CPO}$ fabrics was not coincident with displacement vector (interpreted as parallel to the mineral fibre lineations) on the adjacent brittle faults cutting the quartzofeldspathic wall rocks.

\subsection{CPO fabrics and CPO patterns found across the brittle-ductile shear zones}

\subsubsection{Measured quartz c-axis CPO fabrics}

Crystallographic preferred orientations for quartz c-axes have been measured in sixteen hand-samples of sheared quartz-carbonate veins: one from Sam Peak, seven from Chancellor Ridge and eight from Baumann Glacier (Appendix D). A representative sample of four of these are illustrated as cartoons in Fig. 5.6 which represent the main types of vein deformation and CPO patterns across the BDSZ. The finite ductile shear strain of the deformed veins in Samples 1-3 was calculated using a lineation parallel slip vector pitching southwest at $30^{\circ}$. In Sample 4, which lacked a lineation, a slip vector was calculated from a piercing point construction and yielded a southwest pitch of $2^{\circ}$ (see Fig. 3.12 for this calculation). CPO patterns are shown in Fig. 5.6 for each location in the shear zone where quartz c-axes were measured and illustrate progressive changes taking place across individual shear zones. CPO fabrics for each of the patterns are plotted in Fig. 5.7. Interpreted shear senses, interpreted CPO patterns, and the trace of the external Alpine Schist foliation are plotted on each of these fabrics as appropriate. All CPO fabrics have been rotated into the $x-y-z$ reference frame (see Table 5.1 for $[\mathrm{x}]$ direction in the shear plane). An exception to this was Sample 7 where no rotation was required as the [a] and $[\mathrm{x}]$ directions were coincident.

The CPO patterns found in the strongly deformed internal vein sections were variable. These include small circles (e.g. Fig. 5.6b), cleft girdles (Fig. 5.6f), Type II 

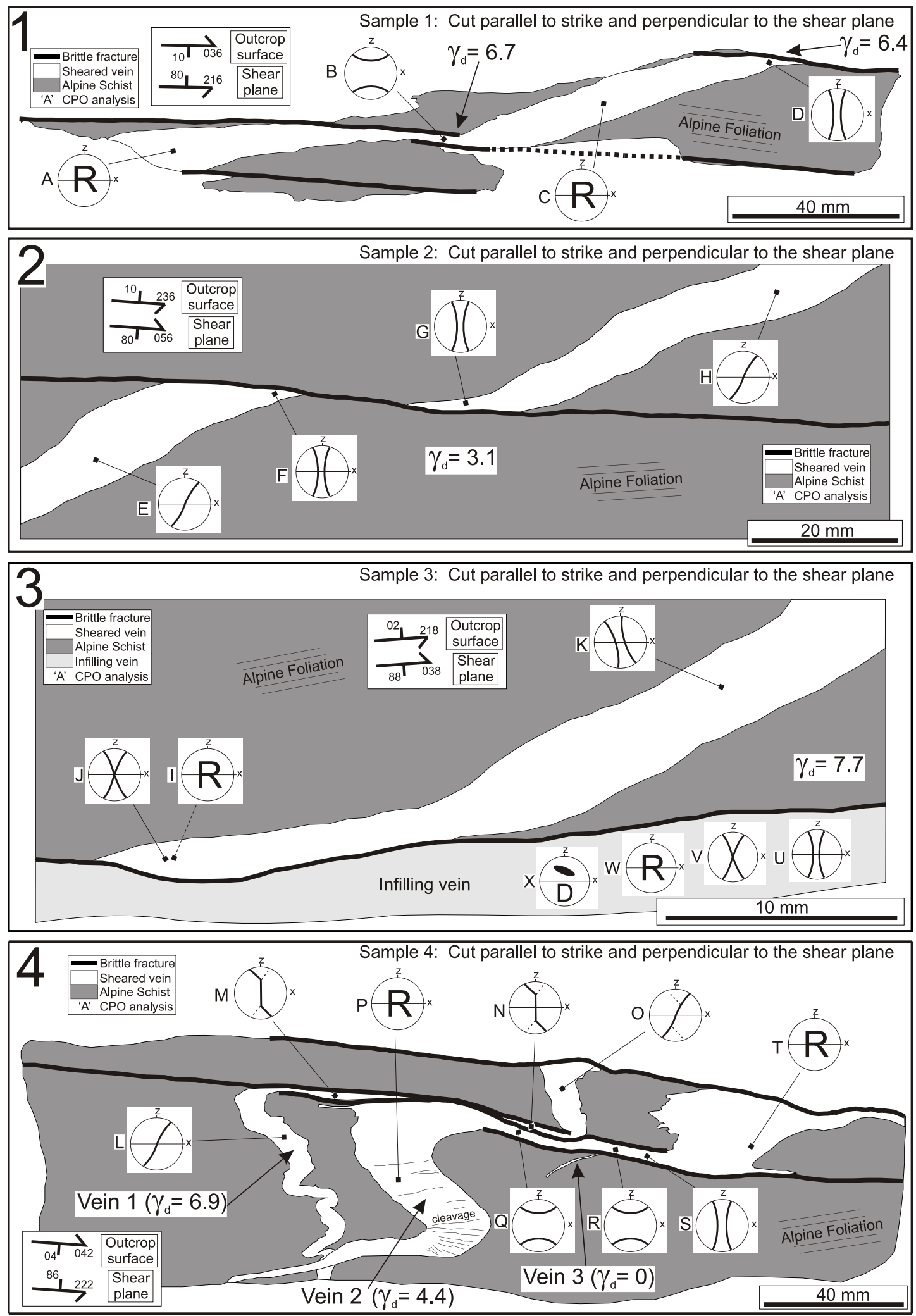

Fig. 5.6. Sheared quartz-carbonate veins with finite ductile shear strains $\left(\gamma_{d}\right)$ ranging from $3.1-7.7$ with interpreted CPO patterns. Complete CPO fabric plots for CPO patterns A to X can be found in Fig. 5.7 with orientation and fabric strength data in Table 5.1. Samples $1 \& 4$ dip west, and $2 \& 3$ dip east. 1. Sample 1 showing two shear zones, one with a small circle and the other a cleft girdle CPO pattern. 2. Sample 2 showing shear zone with cleft girdles in the ductile sheared sections of the vein. 3 . Sample 3 showing shear zone with internal, external and infilling vein sections. CPO pattern J from Sample 3 (shown) and I from Sample 5 (not shown, but has the same shear strain and scale of offset as Sample 3). Sample 3 infilling CPO pattern W and representative infilling CPO patterns from Samples 6-10. 4. Sample 4 showing two sheared veins; one with asymmetric girdles and the other with cleft and small circle girdles. 



Fig. 5.7. Quartz c-axis fabrics and patterns for veins deformed by shears in Fig. 5.6. Quartz c-axis poles plotted on equal area, lower hemisphere, stereographic projections. Contours were calculated using a counting circle of $1 \sigma$ and plotted as lines of equal concentration percentage. Contours are shaded for concentration and scaled according to the graduated scale bars. Contour and scatter plots are paired for complete and objective fabric interpretations. Pitch of $[\mathrm{x}]$ in the shear plane can be found in Table 5.1. CPO fabric analysis I is from the internal vein section in Sample 5 which is very similar in strain and scale to Sample 3 (Fig. 5.6c). Great circles, drawn on external vein section CPO fabrics, represent the Alpine Schist foliation. CPO patterns illustrated on scatter plots as in Fig. 5.3. 

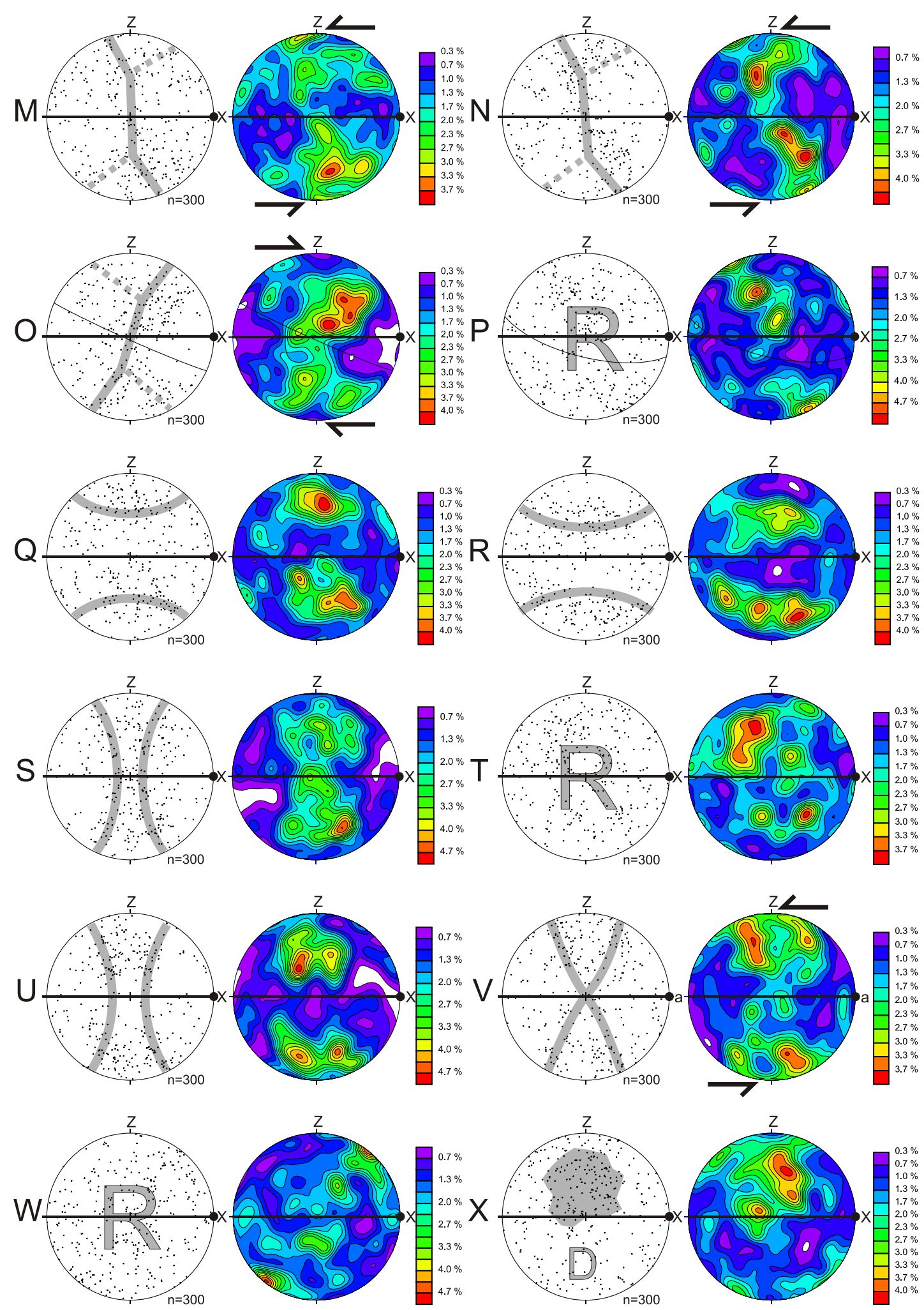

Fig. 5.7 continued... Quartz c-axis CPO fabrics and patterns for veins deformed by shears in Fig. 5.6. Details as in caption on previous page. CPO patterns marked on scatter plots as in Fig. 5.3 with the addition of a domainal CPO pattern in CPO fabric X. All fabrics have been rotated in the $\mathrm{x}-\mathrm{y}-\mathrm{z}$ reference frame with the exception of CPO fabric V (Sample 7) which is in the a-b-c reference frame. 


\begin{tabular}{|c|c|c|c|c|c|c|c|c|c|c|c|c|c|c|c|c|c|}
\hline \multirow{2}{*}{$\begin{array}{c}\text { CPO } \\
\text { fabric Fig. } \\
\text { number }\end{array}$} & \multirow{2}{*}{$\begin{array}{l}\text { Vein } \\
\text { sect. }\end{array}$} & \multicolumn{3}{|c|}{ Sample number } & \multirow{2}{*}{\multicolumn{2}{|c|}{$\begin{array}{c}\text { Grid Reference } \\
\text { (New Zealand Grid) }\end{array}$}} & \multirow{2}{*}{$\begin{array}{c}\text { Shear plane } \\
\text { orientation } \\
\text { (x-y plane) }\end{array}$} & \multirow{2}{*}{$\begin{array}{l}\text { Sheared } \\
\text { vein } \\
\text { orientation }\end{array}$} & \multirow{2}{*}{$\begin{array}{l}\text { Alpine Schist / } \\
\text { mylonitic }\left(S_{m}\right) \\
\text { fol. orientation }\end{array}$} & \multirow{2}{*}{$\begin{array}{r}\text { Calculated } \\
\text { finite ductile } \\
\text { shear strain }\end{array}$} & \multirow{2}{*}{$\begin{array}{l}\text { Pitch of CPO } \\
\text { derived }[x] \text { in } \\
\text { shear plane }\end{array}$} & \multicolumn{3}{|c|}{ Eigenvalue ratios } & \multirow{2}{*}{\begin{tabular}{|l} 
Visual \\
fabric \\
strength
\end{tabular}} & \multirow{2}{*}{$\begin{array}{c}\text { CPO } \\
\text { pattern } \\
\text { code }\end{array}$} & \multirow{2}{*}{$\begin{array}{c}\text { Mean } \\
\text { grain dia. } \\
(\mu \mathrm{m})\end{array}$} \\
\hline & & $\begin{array}{l}\text { This } \\
\text { study }\end{array}$ & \begin{tabular}{|l} 
VUW \\
Collect.
\end{tabular} & $\begin{array}{c}\text { Field } \\
\text { number }\end{array}$ & $\begin{array}{l}\text { (New Zea } \\
\text { Easting }\end{array}$ & & & & & & & & $\mathrm{S} 1 / \mathrm{S} 2$ & $\mathrm{~S} 2 / \mathrm{S} 3$ & & & \\
\hline Fig. 5.7 A & $E$ & \multirow{4}{*}{1} & \multirow{4}{*}{39405} & \multirow{4}{*}{$\mathrm{MHCH} 25$} & \multirow{4}{*}{$2,276,935$} & \multirow{4}{*}{$5,739,670$} & \multirow{4}{*}{ 216@80 W } & \multirow{4}{*}{ 017@80 E } & \multirow{4}{*}{ 042@78 SE } & \multirow{2}{*}{6.7} & \multirow[t]{4}{*}{90} & 1.41 & 1.22 & 1.15 & 1 & $\mathrm{R}$ & 130 \\
\hline Fig. 5.7 B & I & & & & & & & & & & & 1.85 & 1.65 & 1.12 & 4 & SC & 120 \\
\hline Fig. $5.7 \mathrm{C}$ & I & & & & & & & & & \multirow{2}{*}{6.4} & & 1.50 & 1.11 & 1.35 & 0 & $\mathrm{R}$ & 124 \\
\hline Fig. $5.7 \mathrm{D}$ & $\mathrm{E}$ & & & & & & & & & & & 2.04 & 1.51 & 1.35 & 3 & CG & 144 \\
\hline Fig. 5.7 E & $E$ & \multirow{4}{*}{2} & \multirow{4}{*}{39429} & \multirow{4}{*}{ MHBM13 } & & & & & & & 68 & 2.08 & 1.32 & 1.57 & 3 & SG3-f & 145 \\
\hline Fig. $5.7 \mathrm{~F}$ & I & & & & 2280123 & 5744672 & 056ค80 F & 014ค80 F & $215 \cap 84 \mathrm{NH}$ & 31 & 86 & 2.03 & 1.34 & 1.51 & 4 & CG & 109 \\
\hline Fig. $5.7 \mathrm{G}$ & I & & & & $2, \angle 80,1<3$ & $5,144,6 / 2$ & $050 @ 80$ E & 14@80 E & 215@84 NVV & 3.1 & 80 & 1.66 & 1.35 & 1.23 & 3 & CG & 106 \\
\hline Fig. $5.7 \mathrm{H}$ & $\mathrm{E}$ & & & & & & & & & & 73 & 2.12 & 1.44 & 1.47 & 3 & SG3-f & 208 \\
\hline \begin{tabular}{|l|} 
Fig. 5.7 I \\
\end{tabular} & $\mathrm{T}$ & 5 & 39404 & $\mathrm{MHCH} 24 \mathrm{c}$ & $2,276,924$ & $5,739,671$ & $218 @ 82 \mathrm{~W}$ & $020 @ 76 \mathrm{E}$ & 035@82 SE & 6.8 & - & 1.44 & 1.23 & 1.17 & 0 & $\mathrm{R}$ & 108 \\
\hline \begin{tabular}{|l|} 
Fig. $5.7 \mathrm{~J}$ \\
\end{tabular} & $\mathrm{~T}$ & 3 & 30307 & $\mathrm{MHCH} 17$ & 2076050 & 5710150 & 038ค8८ F & $016 \curvearrowright 87 \mathrm{NE}$ & $036 \curvearrowright 70 \mathrm{SC}$ & 77 & 82 & 2.08 & 1.41 & 1.47 & 3 & T2 & 178 \\
\hline Fig. $5.7 \mathrm{~K}$ & $\mathrm{E}$ & 3 & 39391 & 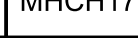 & $2,210,050$ & $0,140,450$ & 030@00 [ & O $10 @ 0$. TNE & USO@ & 1.1 & 82 & 1.61 & 1.01 & 1.59 & 3 & CG & 208 \\
\hline Fig. 5.7 L & $\mathrm{E}$ & & & & & & & & & & 70 & 1.96 & 1.15 & 1.71 & 4 & SG2-f & 118 \\
\hline Fig. $5.7 \mathrm{M}$ & I & & & & & & & $104 \mathrm{~A} 64 \mathrm{~s}$ & & 68 & 70 & 1.62 & 1.29 & 1.26 & 3 & SG2 & 149 \\
\hline Fig. $5.7 \mathrm{~N}$ & I & & & & & & & $104 @ 045$ & & 0.8 & 70 & 1.73 & 1.10 & 1.58 & 4 & SG2 & 76 \\
\hline Fig. $5.7 \mathrm{O}$ & $\mathrm{E}$ & & & & & & & & & & 60 & 2.14 & 1.23 & 1.74 & 4 & $S G 2-f$ & 90 \\
\hline Fig. 5.7 P & $E$ & 4 & 39400 & $\mathrm{MHCH} 20$ & $2,277,348$ & $5,740,090$ & 222@86 W & & 027@75 SE & & - & 1.52 & 1.26 & 1.21 & 0 & $\mathrm{R}$ & 116 \\
\hline Fig. 5.7 Q & I & & & & & & & & & & - & 1.52 & 1.10 & 1.38 & 3 & SC & 135 \\
\hline Fig. $5.7 \mathrm{R}$ & I & & & & & & & 002@82 E & & 4.4 & - & 1.35 & 1.17 & 1.16 & 4 & SC & 122 \\
\hline Fig. $5.7 \mathrm{~S}$ & I & & & & & & & & & & 80 & 2.31 & 1.11 & 2.08 & 4 & CG & 52 \\
\hline Fig. 5.7 T & $\mathrm{E}$ & & & & & & & & & & - & 1.55 & 1.32 & 1.18 & 1 & $\mathrm{R}$ & 142 \\
\hline Fig. $5.7 \mathrm{U}$ & $\ln$ & 6 & 39402 & $\mathrm{MHCH} 22$ & $2,277,421$ & $5,740,067$ & 219@85 W & - & - & - & 105 & 2.35 & 1.31 & 1.79 & 4 & CG & 38 \\
\hline Fig. $5.7 \mathrm{~V}$ & In & 7 & 39391 & $\mathrm{MHCH} 12$ & $2,277,107$ & $5,740,211$ & 221@85 W & - & - & - & 18 & 1.97 & 1.44 & 1.37 & 3 & $\mathrm{~T} 2$ & 143 \\
\hline Fig. $5.7 \mathrm{~W}$ & In & 8 & 39397 & $\mathrm{MHCH} 17$ & $2,276,050$ & $5,740,450$ & 038@88 E & - & - & - & - & 1.50 & 1.13 & 1.33 & 0 & $\mathrm{R}$ & 150 \\
\hline Fig. $5.7 \mathrm{X}$ & In & 9 & 39385 & $\mathrm{MHCHO6}$ & $2,277,325$ & $5,740,132$ & 218@84 W & - & - & - & - & 1.82 & 1.67 & 1.09 & 4.0 & $\mathrm{D}$ & 140 \\
\hline Fig. 5.4 B & - & 10 & 39409 & MHHM01 & $2,273,722$ & $5,747,569$ & foliation & - & 061@32 SE $\left(\mathrm{S}_{\mathrm{m}}\right)$ & $>120^{*}$ & 146 & 21.09 & 2.48 & 8.50 & 5 & SG3 & 76 \\
\hline
\end{tabular}

Table 5.1. CPO fabric and pattern data for each of the sheared veins in Fig. 5.6 and CPO fabric plots in Figs. 5.4 and 5.7. Sample numbers are given for those used in this chapter (this study), Victoria University Collection numbers and for the field collection numbers. Orientation of the shear planes in the sample and CPO fabrics, the Alpine Schist or mylonitic $\left(\mathrm{S}_{\mathrm{m}}\right)$ foliation are given, as well as the finite ductile shear strain calculated for each sample. Finite ductile shear strain calculated from displacement vectors (using net-slip pitch of $30^{\circ}$ for all samples other than Sample 4 where a pitch of $2^{\circ}$ is used). Ductile strain for Sample 10 is from Norris and Cooper (2003). Vein sections are noted for each of the samples where ' $E$ ' is the external vein section, ' $I$ ' is the internal veins section and 'In' is the infilling vein section. Vein sections are illustrated in Fig. 5.1c. The pitch of [x] (down plunge end of $\mathrm{x}$-pole in CPO fabric plots) and is from the southwest in the shear plane. Eigenvalue ratios used for CPO fabric strength $\left(\mathrm{S}_{1} / \mathrm{S}_{3}\right)$, domainal strength $\left(\mathrm{S}_{1} / \mathrm{S}_{2}\right)$ and girdle strength $\left(\mathrm{S}_{2} / \mathrm{S}_{3}\right)$ are given as well as the fabric strength ranking. CPO pattern codes are from Fig. 5.3 with the addition of D for a domainal pattern. Mean grain diameters have been calculated from the intercept method for each vein section. The symbol '-' denotes where data was not applicable to a sample. 
cross girdles (Fig. 5.6j), Type I cross girdles (Fig. 5.6m) and random patterns (Fig. 5.6i). All the CPO patterns found in the internal vein sections are in mirror symmetry about the shear plane and are different from the patterns in the less deformed external vein sections (Fig. 5.6). Some veins show the generation of a CPO pattern from random crystallographic orientations in the external section (e.g. Sample 1, in Fig. 5.6), whereas other veins show the generation of a new fabric overprinting an already existing external fabric (e.g. Sample 2, Fig. 5.6). Some veins with the same external pattern and have undergone similar deformation and have different internal patterns. For example, Sample 3 (Fig. 5.6), which has two internal CPO patterns plotted (one for each of the two deformed veins that the cartoon represents); a Type II for one vein and a random CPO pattern for the other. Sample 4 illustrates two sheared veins in the same shear zone. These have the same slip but different shear strains because of deformation zone width differences. Their resultant CPO patterns are different (Fig. 5.6); the thin vein (Vein 1) has Type I whereas the thick vein (Vein 2) has small circle and cleft girdle CPO patterns. Overall, random and types of coaxial CPO patterns are most common in the internal vein sections. The progressive development of a single girdle CPO pattern with the stretching direction $[\mathrm{x}]$ sub-parallel to the known displacement vector (a-pole) (Fig. 5.3a after Schmid and Casey, 1986 and Lister and Hobbs, 1980) was not observed in any samples.

The CPO patterns found in the less deformed, external parts of the veins were variable like the internal vein sections. The patterns however, were not symmetrical about the shear plane and instead often had mirror symmetry about the external Alpine Schist foliation plane. E.g. CPO patterns E, K and L in Fig. 5.7 show this where the foliation has been plotted on CPO fabrics from external sections. As expected, these external CPO patterns are similar on both sides of the shear zone, but are different from the CPO patterns found in the strongly deformed internal parts of these veins.

Quartz samples from 32 shear infilling veins (Appendix E) also yielded diverse and generally weak CPO fabrics and patterns. Unlike the sheared veins, domainal CPO patterns were found from some infilling samples (e.g. CPO fabric X from Fig. 5.6 and 5.7). All domainal concentrations were located in regions away from the z-poles and were typically in samples where the microstructures included 
many large quartz grains $(200-1000 \mu \mathrm{m})$ containing a subgrain substructure, and in some cases, a core-and-mantle microstructure. For example, CPO fabric X (Fig. 5.7) is from an infilling vein (shown in micrograph Fig. 4.9f) that contains large grains $(\sim 1000 \mu \mathrm{m})$ with subgrain boundaries, and small recrystallised grains $(\sim 100 \mu \mathrm{m})$. The range of CPO patterns from shear infilling veins is illustrated on Sample 3 (Fig. 5.6c). Type I CPO patterns were not found in any of these veins and random patterns were more common than in the internal or external vein sections.

For comparison three quartz c-axis CPO fabrics were measured in samples below the BDSZ to investigate the CPO patterns and stretching directions in structurally lower sections of the Pacific Place crust. These non-mylonitic Alpine Schist samples from the Waiho River area were taken from metachert layers to ensure an abundant monomineralic composition of quartz grains. They had Type I CPO patterns in a mirror symmetry about the Alpine foliation $\left(\mathrm{S}_{3}\right)$ and yielded quartz CPO-derived stretching directions pitching southwest at 25-60 (Appendix E).

\subsubsection{Strain path and kinematics for deformation recorded in CPO's}

Quartz c-axis CPO fabric measurements made across the sheared veins have revealed a significant variation of CPO patterns between, and in some cases, within individual shear zones, showing that the deformation of quartz was not homogenous. CPO patterns in the more strongly deformed, internal sections of the sheared veins all show a reorganisation of the CPO pattern relative to the external parts of those veins. These internal CPO patterns are in mirror symmetry about the shear plane and are therefore related to the ductile shearing of the deformed vein in the shear zones (Fig. 5.7). $60 \%$ of the measured internal CPO patterns, somewhat unexpectedly, yielded CPO patterns that suggest irrotational strain deformation, such as plane strain, pure shear flattening or constriction rather than a rotational strain such as simple shear (e.g. Fig. 5.3). These irrotational CPO patterns suggest that the steep quartz CPO-derived [x] direction represents a finite extension direction associated with irrotational deformation rather than one associated with simple shearing in the vorticity plane.

The highly variable nature of the CPO patterns found across adjacent shear zones and in different veins within the same shear zone may reflect local variations in deformation conditions. This has been documented in studies such as White et al. 
(1980) and Hippertt and Tohver (1999) where CPO patterns and measured shear senses change between adjacent shear zones and even between layers in multilayered rock. Variations in CPO patterns between shear zones may also be caused by a partitioning of strain from the quartz into different sections of the shear zone such as the shear infilling veins, the brittle fracture, or even calcite enriched layers within the veins.

The external CPO patterns are frequently in mirror symmetry about the Alpine Schist foliation plane (Fig. 5.7) suggesting that their generation is related to deformation that generated this foliation and not from late Cenozoic brittle-ductile shearing. The Alpine foliation, in many cases, is axial planar to the cleavage observed in fold hinges of the veins external to the shear zone (e.g. Vein 2 from Sample 4 in Fig. 5.6) indicating involvement of the veins in the older schistosity formation, so these fabrics are not unexpected. It is inferred that these CPO patterns are indeed proto-fabrics to the internal shear fabrics and were generated during earlier deformation of the Alpine Schist before brittle-ductile shearing.

The external vein CPO fabrics have similar patterns with mirror symmetry about the foliation and variable quartz CPO-derived stretching directions (southwest pitches of $37-110^{\circ}$ ) to those measured from the Waiho River metachert samples further supporting the interpretation that the external fabrics are related to vein deformation during development or strengthening of the Alpine Schist foliation. Wightman (2005), Little et al. (2002a) and Little (2004) have argued that the brittleductile shears did not accommodate all of the strain related to tilting onto the Alpine Fault ramp at depth, and infer that some late Cenozoic strain must have been accommodated by microscale ductile deformation in the schist between successive shears. Therefore, the external fabrics may not be entirely inherited in the sense that they may include an effect of the late Cenozoic shearing overprint. The foliation parallel CPO patterns are therefore interpreted as strengthening or reinforcement of existing fabrics by the microscale shear along the foliation planes during uplift.

CPO fabrics measured from the shear infilling veins have a broad variety of CPO patterns, like the internal sections, but include more random and domainal CPO patterns (Appendix E). The domainal CPO patterns found in the infilling vein sections are most likely due to a primary crystallographic anisotropy that was 
inherited from the original growth of the veins by precipitation. This anisotropy was not generated by euhedral quartz grains growing inward from the fracture wall as the CPO fabrics do not show domains of intense c-axis concentration about the z-axis as expected for this type of vein precipitation (Fournier, 1985; Appendix G, this study). Instead, the inclined domains of intense c-axis concentration (e.g. Fabric X, Fig. 5.7) could have been generated from subgrain rotation recrystallisation of an original mosaic of very coarse grains, with their recrystallised grains retaining similar orientations to the original host grain, thus yielding a domainal fabric.

Random CPO patterns found in some infilling veins could have been preserved from primary crystallographic orientations that were similarly random and which have not undergone significant further deformation and fabric development. This is likely as the large and broad range of grain sizes in these veins (mean of 248 $\mu \mathrm{m}$ with a maximum of $1500 \mu \mathrm{m}$ ) does not resemble the equigranular polycrystalline texture typically of a dynamically recrystallised quartzite aggregate (Passchier and Trouw, 1998). Randomisation by a deformation processes cannot be ruled out completely though, as several infilling veins had a weak alignment of crystallographic c-axes (e.g. Fig. 5.7u and v) consistent with at least some dislocation creep (Wenk, 1985, Knipe, 1989; Bons and den Brok, 2000). The CPO patterns were symmetrical about the shear plane in these samples and therefore are likely to be related to dislocation creep during shearing.

\subsection{Shear sense from $\mathrm{CPO}$ fabrics}

CPO patterns generated from plane strain, such as a Type I or single girdle patterns, are often used to determine the shear sense if they had an asymmetric CPO fabric (e.g. Lister, 1977; Lister and Williams, 1979; Schmid and Casey, 1986; Dell'Angelo and Tullis, 1989; Law et al., 1990). In particular the, 'external asymmetry', or obliquity between the shear plane and the foliation reflects the shear sense. This method is method works best when the foliation is distinct, when the shear plane is easily determined from CPO patterns, and when the two fabric elements are not too similar or sub-parallel in their attitude (e.g. Schmid and Casey, 1986). Unfortunately, external asymmetries could not be resolved in this study because the strongly recrystallised sheared veins lack a macroscopically distinct foliation. However, an internal asymmetry of the Type I girdles in the CPO fabrics, 
where present, does provide a potential measure of shear sense. This internal symmetry is defined by recrystallised grains that have c-axis orientations which form a concentration on one limb of the girdle during rotational shear (as in Fig. 5.3b).

Shear senses for four CPO fabrics in the strongly deformed, internal sections of the sheared veins measured in this study have been determined from internal asymmetries (after Law, 1990). In addition, five were measured from external sections of these veins, and one from a shear infilling vein. Two of the CPO fabrics from internal sections of the vein have a sense of shear that is top-away-from-[x] and are plotted in Figs. 5.6 and 5.7 (fabrics $M$ and N). As [x] in this sample has a steep southwest pitch that lies in a west dipping shear plane (Table 5.1), the indicated shear sense is interpreted to be dextral and west-side-up. The same shear sense was also measured in the three other samples of strongly deformed internal vein sections (Appendix D) and for the shear infilling vein sample (CPO fabric V, Fig. 5.7). By contrast, the less deformed (inherited) CPO fabrics in external parts of deformed veins can have a reverse shear sense (e.g. Fig. $5.7 \mathrm{l}$ and o) and is presumable related to the earlier deformation and unrelated to the brittle-ductile shears. The shear senses for the internal and shear infilling CPO patterns are plotted in Fig. 5.5, and are all dextral with a west-side-up shear sense.

Shear senses for deformed internal sections were only observed in the $x-y-z$ reference frame (after fabric rotation) and not in the vorticity plane (a-b-c reference frame) where shear related fabrics would be expected during simple shear deformation. Considering the large shear strain that all the sampled veins had undergone (mean $\gamma=5.5 \pm 1.3$ ), the oblique grain shape fabrics (see Chapter 4) and the well known displacement vector it was expected to find strong fabric asymmetries in the vorticity plane. It was however surprising to find rotational CPO fabrics with a shear sense in the plane parallel to the CPO-derived stretching direction ( $\sim 50^{\circ}$ away from the vorticity plane).

Measured shear senses from quartz CPO patterns are not considered as reliable when based solely on internal asymmetries (Passchier, 1983; Law, 1990; Hippertt and Tohver, 1999). This is because reorientation and concentration of caxes may not be related to shearing, but may also reflect an inherited CPO fabric from an earlier phase of deformation (Lister and Hobbs, 1980; Shelley, 1982). An 
asymmetry can be enhanced by a late stage coaxial overprint where one limb that is already slightly asymmetric can develop a stronger asymmetry from a deformation that is not rotational (Lister and Williams, 1979) or from later grain growth (Shelley, 1989). From this study external CPO fabrics, presumably related to the older Alpine Schist deformation, contain asymmetric concentrations of c-axes which may have influenced the asymmetries in the more deformed, internal vein sections.

The shear sense using variable rotation of biotite porphyroblasts related to the Alpine Schist foliation (Holcombe and Little, 2001), grain shape fabrics (Little, 2004), and mineral lineations (Little et al., 2002a) is west-side-up and dextral, with a steep moderate to down-dip direction of maximum finite stretch in the non-mylonitic schist. This ductile elongation direction matches those in this study found from quartz CPO-derived stretching directions in the CPO fabrics from vein sections external to the shearing. Asymmetries in these external CPO fabrics (near where Type I limbs would develop in the internal fabrics, e.g. Fig. 5.7 CPO fabrics E and H) could have been inherited from earlier Alpine Schist deformation and strengthened further during shear in the internal sections. All shear senses measured from internal asymmetries are therefore used with discretion as they may be inherited in part from an earlier deformation.

For a reliable shear sense measurement, other shear sense indicators such as external asymmetries and field observations should be used in conjunction with the internal asymmetry method and inferred from asymmetric features in the vorticity plane (Passchier, 1983; Law, 1990; Passchier and Trouw, 1998). For example, Sample 7 (a shear infilling vein), has a dextral-reverse shear sense measured from an internal asymmetry in the vorticity plane (Fig. $5.7 \mathrm{v}$ in the a-b-c reference frame), matches the oblique quartz grain-shape fabric (GSF) microstructure (see Fig. 4.9e) and is parallel to the fault surface mineral lineation (the displacement vector; Fig. 5.5). This sample's shear sense inferred from the internal asymmetry is therefore considered reliable. Unfortunately, such a shear sense comparison could not be made for the internal vein sections as no oblique GSF's were observed and stretching directions were not parallel to the displacement vector. 


\subsection{Slip systems and approximate deformation temperature from CPO fabrics}

Aspects of the CPO fabrics can be used to interpret the operative slip systems that accommodate the crystal-plastic deformation in the quartz grains from the location of c-axis concentrations in the fabric plots (e.g. Law, 1990). Concentrations about the z-poles, y-pole and x-poles are commonly used as evidence of basal $<\mathrm{a}>$, prism $<\mathrm{a}>$ and prism [c] slip respectively. Orientations of c-axes that are inclined away from these poles may reflect slip on the rhomb planes in the $<\mathrm{a}>$ direction or on the rhomb and prism planes in the $<\mathrm{c}+\mathrm{a}>$ direction (Schimd and Casey, 1986; Law, 1990). The interpretation of active slip systems from CPO fabrics in natural quartz CPO fabrics by Law (1990) illustrates the reliability of this method. Experimental deformation modelling by Tullis (1977) also supports these with results showing that small circle patterns are a result of slip on the basal and rhomb planes and for a connecting girdle to occur slip must be starting to occur on the prism planes.

Concentrations of c-axes between the z- and y-poles are seen in the CPO fabric plots presented here (e.g. CPO fabrics Q, S, and X in Fig. 5.7) and show that rhomb planes are important in accommodating deformation. For example, CPO fabric Q (Fig. 5.7q) shows c-axis concentrations approximately halfway between the z-pole ends and y-pole, suggesting that the crystals have aligned for 'easy glide' on the rhomb planes. Some fabrics show stronger concentrations about the y-pole suggesting that both prism and rhomb slip occurred (e.g. CPO fabric S in Fig. 5.7). Very few samples have strong concentrations about z-pole ends suggesting that basal $<$ a $>$ slip was not dominantly accommodating the deformation. The complete absence of c-axes about the x-poles in many samples suggests that prism [c] slip was not occurring in any samples.

During shearing, dynamic recrystallisation will generate grains oriented for slip on the crystallographic plane that is easiest to activate, a process which is known as geometric softening (White et al., 1980; Fliervoet and White, 1995). During simple shear deformation the crystallographic slip plane most favourable for slip will typically align parallel to the shear plane in an orientation for 'easy glide' (Wenk and Christie, 1991). To activate slip on these planes, the critical resolved shear stress (CRSS), which is dependant on differential stress, strain-rate and temperature, must 
be exceeded by the shear stress resolved on that particular slip plane (Wenk and Christie, 1991). More than one slip system can be used simultaneously to accommodate deformation, so more than one ideal orientation of crystal for 'easy glide' may exist.

Lister et al. (1978) showed that different quartz slip systems (Fig. 4.13) became dominant as the CRSS was exceeded on the slip planes. Generally in greenschist facies deformation, slip occurs in the $<\mathrm{a}>$ directions on basal planes (Schimd and Casey, 1986). Basal slip is not as temperature or shear stress sensitive as some other slip systems in quartz (Hobbs, 1985; Lister et al., 1978). With increased temperature and differential stress, slip on the rhomb and prism planes in the $<\mathrm{a}>$ and $<\mathrm{c}+\mathrm{a}>$ directions are favoured or activated (Lister and Williams, 1979; Linker et al., 1984). Granulite facies conditions $\left(>650^{\circ} \mathrm{C}\right)$ are needed for slip to occur in the [c] direction on the prism planes (Mainprice et al., 1986; Okudaira et al., 1995).

Using microstructural observations to determine which slip systems are active at known temperatures in naturally deformation rocks (e.g. Stipp et al., 2002b), a CPO fabric showing a dominant slip system can be used as a thermometer. This method is somewhat limited as the precise temperature and CRSS required to activate a slip system in quartz are difficult to determine because of water content in the crystal lattice, and the fact that multiple slip systems are generally active simultaneously. A minimum estimate of $\sim 280^{\circ} \mathrm{C}$ for the Southern Alps sample here can be inferred from the temperature required for the frictional-viscous transition (Stipp et al., 2002b) to activate basal $<$ a $>$ slip. A more likely temperature of $\sim 400^{\circ} \mathrm{C}$ is proposed here, as the sheared quartz veins contain subgrains and thus must have been deformed at temperatures allowing subgrain boundary rotation (Regime 2 of Hirth and Tullis, 1992), which is a result of slip on the prism planes (Kruhl, 1996; Stipp et al., 2002b). Activation of rhomb and prism plane slip systems in the Southern Alps samples also indicate that a more moderate temperature above the minimum must be required (e.g. Lister et al., 1978; Price, 1985; Schmid and Casey, 1986). The temperature could not have been greater than $\sim 650^{\circ} \mathrm{C}$ as there is no evidence for slip on the prism planes in the [c] direction. This estimated temperature compares well with that measured by Wightman (2005) of $450 \pm 50{ }^{\circ} \mathrm{C}$ from stable 
oxygen isotope thermometry and chlorite thermometry of quartz-calcite veins that infill the brittle-ductile shear and from ${ }^{40} \mathrm{Ar}-{ }^{39} \mathrm{Ar}$ thermochronology of muscovite in schist surrounding the BDSZ.

\subsection{Strength of quartz c-axis CPO fabrics}

The most remarkable aspect of the CPO fabrics observed from the BDSZ in this study, is their weak intensity despite the high finite shear strain known to exist in these veins. The strength of the quartz CPO fabrics are not as strong as expected considering the amount of ductile shear strain the veins have undergone, based on comparison with other previous quartz deformation studies (e.g. Schmid and Casey, 1986; Law, 1987; Joy and Saha, 1998; Bestmann et al., 2004). In this section I will compare measured fabrics from the BDSZ samples with those measured in other studies of sheared quartz veins, including numerical, experimental and field-based research of naturally deformed veins. These fabric strength comparisons, combined with the microstructural relationships, will lead to interpretations as to why the quartz CPO fabrics in the New Zealand samples are so weak.

\subsubsection{Measuring the strength of CPO fabrics}

The strengths of the CPO fabrics have been measured using the eigenvalue ratio method of Woodcock and Naylor (1983), the fabric intensity method of Lisle (1985), and from a visual estimation method of the contoured CPO fabric plots. These methods provide a basis for determining whether the interpreted CPO pattern is significant and the strength of the CPO fabric.

Eigenvalue ratios have been used to determine the strength of CPO fabrics and have been particularly useful in defining a random fabric, the strength of a girdle CPO pattern and the existence of a c-axis cluster. Normalised eigenvalues (Woodcock, 1977) used in each of the methods below have been calculated using Stereonet for Windows (Allmendinger, 2003) and are listed for each CPO fabric in Table 5.1 and Appendix H. The uniformity, or randomness of the CPO fabrics, has been measured using the ratio of the $S_{1}$ to $S_{3}$ eigenvalues (Woodcock and Naylor, 1983). A random fabric for 300 measured points (at a $99 \%$ confidence) has a $\mathrm{S}_{1}: \mathrm{S}_{3}$ ratio below 1.44 (ratios of 1.32 and 1.23 are for 500 and 900 measured points respectively). This fabric randomness test has been criticised by Lisle (1985) and 
Benn (1994) for small data sets $(<200)$ but is used in this study as all the CPO fabrics are generated from $300 \mathrm{c}$-axes or more. The mean $\mathrm{S}_{1}: \mathrm{S}_{3}$ ratios for the shear zones were $1.75 \pm 0.1(n=26), 1.79 \pm 0.14(n=26)$, and $1.65 \pm 0.1(n=33)$ for the internal, external and shear infilling vein sections respectively. The strongest fabric ratio was 2.6 , in an external vein section, with the weakest fabric ratio of 1.02 , in a shear infilling vein. The shear infilling veins clearly having weaker fabrics with a lower mean ratio and 11 fabrics with a ratio $<1.5$ compared with only 3 for more deformed internal vein sections.

The Lisle (1985) method of measuring fabric intensity by was also used here as a measure of fabric strength. This method uses the eigenvalues, $\mathrm{S}_{i}$ (where: $i=1,2$, $3)$, to calculate the fabric intensity $(I)$ of $\mathrm{CPO}$ fabrics using the equation:

$$
I=\frac{15}{2} \sum_{i=1}^{3}\left(S_{i}-\frac{1}{3}\right)^{2}
$$

Values of $I$ vary from 0 for random orientations to a maximum of 3.5 for very strong planar fabrics. Using Equation 5.1, I values for internal and external sections in this study had a mean of $0.14 \pm 0.03$ and the shear infilling veins had a mean $I$ value of $0.11 \pm 0.02$. Sample 18 , the Alpine Fault mylonite, had an $I$ value of 1.65 which was the highest value for a CPO fabric in this study. Fabric strength calculations from the Woodcock and Naylor and Lisle method were plotted against each other revealing a positive linear correlation between the two. This indicates that both methods provide comparable results.

Some visually "strong" CPO patterns yielded a random result using the uniformity test of Woodcock and Naylor (1983) and the intensity method of Lisle (1985). Type I, Type II, small circle and cleft girdle CPO patterns can have an eigenvalue ratio that suggests that the fabric is random when it is in fact a significant pattern due to the non-orthorhombic symmetries of these fabrics. Therefore, visual measurements of point density along the contour plot ridges that define a CPO pattern have been made to determine the fabric strength. CPO fabrics were allocated a fabric strength ranking from 0 (as a random fabric, e.g. Fig. $5.7 \mathrm{w}$ ) to 5 (as a very strong CPO fabric, e.g. Sample 10, Fig. 5.4b) based on the relative concentration percents of the ridges in contour plots. A fabric strength ranking of 5 needed to have 
a ridge concentration of more than $5 \%$ (fraction of poles in a $1 \sigma$ counting circle from the total measured in the sample), with ridge concentrations of $4 \%, 3 \%, 2.5 \%$ and $1.5 \%$ for fabric strengths of $4,3,2$, and 1 respectively. A fabric strength ranking of 0 had no preferred orientation of c-axes (apparently random CPO pattern) and an eigenvalue ratio $\left(\mathrm{S}_{1}: \mathrm{S}_{3}\right)$ of $<1.5$. Visually non-random $\mathrm{CPO}$ patterns required the contour ridges defining the pattern to have a point concentration $>2 \%$. Although this fabric strength ranking method may not be mathematically exact, it is sufficient for the comparisons that are made in this study. Fabric strength rankings when plotted against intensity $(I)$ and uniformity $\left(\mathrm{S}_{1}: \mathrm{S}_{3}\right.$ ratio) show a positive linear correlation indicating that this scheme is a robust way of qualitatively ranking fabric strengths.

The mean fabric strength ranking of 26 strongly deformed, internal CPO fabrics was $2.8 \pm 0.5$. This is very similar to the $2.5 \pm 0.5$ for the external CPO fabrics. The 33 shear infilling veins had a mean fabric strength ranking of just $1.4 \pm$ 0.5. The distribution of fabric strengths between different sections in the shear zones are illustrated in Fig. 5.8a. Statistically the shear infilling veins have a much weaker fabric than the sheared veins with more than $50 \%$ of the infilling samples producing a random or very weak CPO fabric. The garnet-zone Alpine Schist metachert and mylonite samples have much stronger CPO fabrics that the sheared veins in the BDSZ, and have a mean fabric strength ranking of $3.8 \pm 0.9$. These fabric strengths have also been compared to the measured finite ductile shear strain (from Chapter 3) and to quartz grain shape ellipticities (from Chapter 4) in the vein microstructures (Fig. 5.8b). There appears to no correlation between CPO fabric strength and finite ductile shear strain or the strain represented by grain shape ellipticity in these recrystallised veins. Fig. $5.8 \mathrm{~b}$ shows a broad scatter of finite shear strains for each CPO fabric strength ranking and importantly some random CPO fabrics are found in samples with high finite ductile shear strains and grain shape ellipticities. This shows that not only are the CPO fabrics weak, but they do no strengthen with increased ductile deformation or shear strain.

\subsubsection{Comparison of quartz CPO fabric strengths to existing measured fabrics}

The CPO fabric strengths measured in this study have been compared to those deformed in other quartzite aggregates that have similarly been subjected to a large finite ductile shear strain. These examples come from numerical modelling, 
a

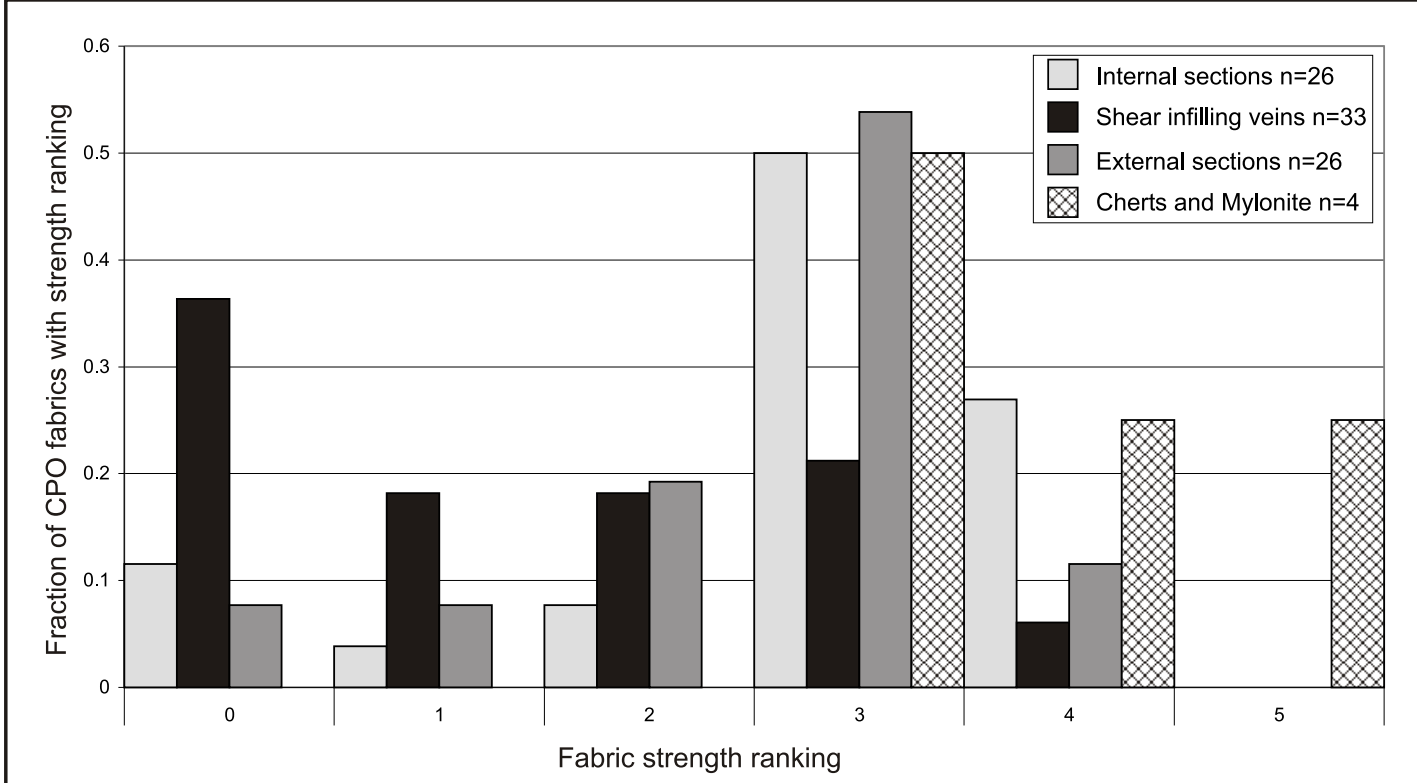

b

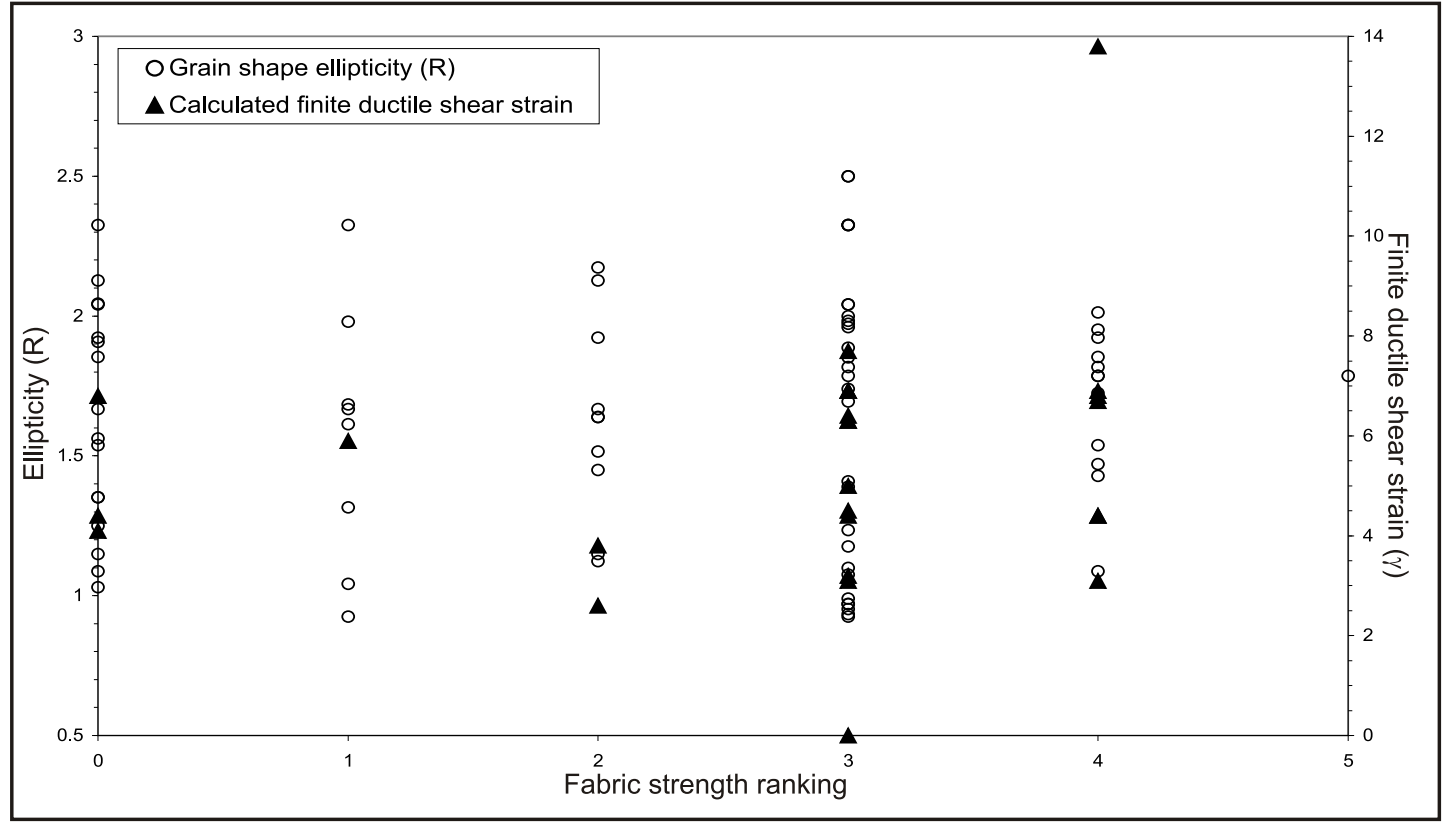

Fig. 5.8. Graphs of fabric strengths measured from CPO fabrics in the brittle-ductile shears. a. Graph showing the fraction of CPO fabrics from different vein sections with a given fabric strength ranking. $b$. Graph showing fabric strength ranking against recrystallised grain shape ellipticity (R) and field-based calculations of finite ductile shear strain $(\gamma)$. The Waiho River and Hare Mare Creek CPO fabrics are not included in this data set. Raw data for both of these plots can be found in Appendix $\mathrm{H}$. 
experimental and natural field studies of ductile shear zones in those rocks. The sheared quartz veins in this study had a mean finite ductile shear strain of $5.5 \pm 1.3$ $(n=17)$. By comparison with the other studies, the natural Southern Alps samples all have remarkably weak CPO fabrics in relation to their known shear strain.

Lister et al. (1978) showed that a shear strain of just 1.6 was enough to significantly change a pre-existing quartz CPO fabric. Their numerical modelling predicts that any inherited CPO pattern that may have existed before the shearing would have been destroyed and replaced in the strongly deformed internal parts of the veins. Later numerical modelling by Lister and Hobbs (1980), showed that strongly asymmetric single girdle CPO patterns could be found in sheared veins after shear strains of $\sim 4$. Deformation of halite and ice were used by Etchecopar and Vasseur (1987) to approximate quartz deformation. They found that single girdle CPO patterns were visible after shear strains of $\sim 2.5$. CPO fabrics in this study, however, despite their high finite shear strains, do not show such strong asymmetric Type 1 or single girdle CPO patterns.

The increase in CPO fabric strength as a function of shear strain was numerically modelled for sheared quartz veins by Lister and Williams (1979) and experimentally investigated by Etchecopar and Vasseur (1987). Both studies showed that an increase in strain resulted in a corresponding increase in fabric strength. The experimental study showed that CPO fabrics strengthened with an increase in shear strain from 1 to 5 yielding pole density contours (a fraction of c-axis poles from the total measured) between 5 and 11\% for the CPO pattern ridges. By comparison, the density contours of the BDSZ samples are only as high as $2-3 \%$ on the CPO pattern ridges and they do not increase as a function of finite ductile shear strain (e.g. Fig. $5.8 b)$.

Deformation of quartzites in laboratory experiments also have a consistently stronger CPO fabric than those found the BDSZ samples. Laboratory deformation of quartz by Tullis (1977) showed strong CPO fabrics were created after coaxial compression of $50 \%$ (equivalent to an approximate shear strain of 1.5). Laboratory studies by Heilbronner and Tullis (2002) showed that quartz which had undergone either coaxial or non-coaxial strain still maintained strong CPO patterns with density point maximums of $\sim 5 \%$ and well defined ridges despite having undergone 
subsequent static recrystallisation. These studies indicate that fabrics formed by coaxial strain as easily as non-coaxial strain and that static recrystallisation alone is not a likely cause for the weak strengths of the CPO fabrics in quartz from the natural shear zones in this study.

CPO fabric strengths of sheared quartz veins from other natural shear zones are much stronger than those measured in this study. For example, a sheared vein from Cap de Creus, Spain (Schmid and Casey, 1986), which is of a similar in size, displacement, mineral composition and shear strain as the sheared veins in this study, shows a CPO fabric with concentrations up to 6 times the normal distribution $(\sim 10 \%$ point density equivalent for contoured fabrics in this study) and has an asymmetric single girdle CPO pattern observed after a ductile shear strain of 3.2-6.2. A sample from the Tauren window, Eastern Alps that has been subject to a shear strain of $\sim 2.5$ had density concentrations of 5-10\% (Brunel, 1980). Tagami and Takeshita (1998) in a buckled quartz vein from the Sambagawa metamorphic belt, central Shikoku, Japan measured a mean intensity $(I)$ of 1.05 for a vein that had been subject to a minimum shear strain of 1.1 (minimum estimate derived from grain aspect ratios). By comparison, a finite ductile shear strain of 4.4 that yielded a mean intensity $(I)$ of 0.25 in this study (Sample 4, CPO fabric S, Fig. 5.7), is much weaker. Also shear infilling veins with a shear strain of 0.8 (minimum estimate derived from grain aspect ratios as in Tagami and Takeshita, 1998) had an intensity (I) of 0.11, which again is much weaker than those from Japan. Miller and Christie (1981) showed that as the strain increased in the Elba Quartzite, the CPO fabric also strengthened in the naturally deformed quartz clasts, a correlation not seen in this study (Fig. 5.8b).

\subsubsection{Quartz CPO fabric strength in polymineralic and monomineralic veins}

The relationship of quartz CPO fabric strength to mineral impurities in the veins has been investigated by comparing fabric strengths of monomineralic $(\leq 5 \%$ calcite \pm chlorite) shear infilling veins to that of polymineralic ones (quartz and calcite). The quartz c-axis CPO fabric strengths (fabric strength rankings and eigenvalue $\mathrm{S}_{1}: \mathrm{S}_{3}$ ratios), quartz CPO patterns and the fraction of calcite or chlorite in the vein and show considerable differences between veins that contain $>5 \%$ calcite and those that are almost 100\% quartz (Table 5.2). Of the quartz CPO fabrics in Fig. 5.9, monomineralic quartz veins have a mean $\mathrm{S}_{1}: \mathrm{S}_{3}$ ratio of 2.0 whereas 

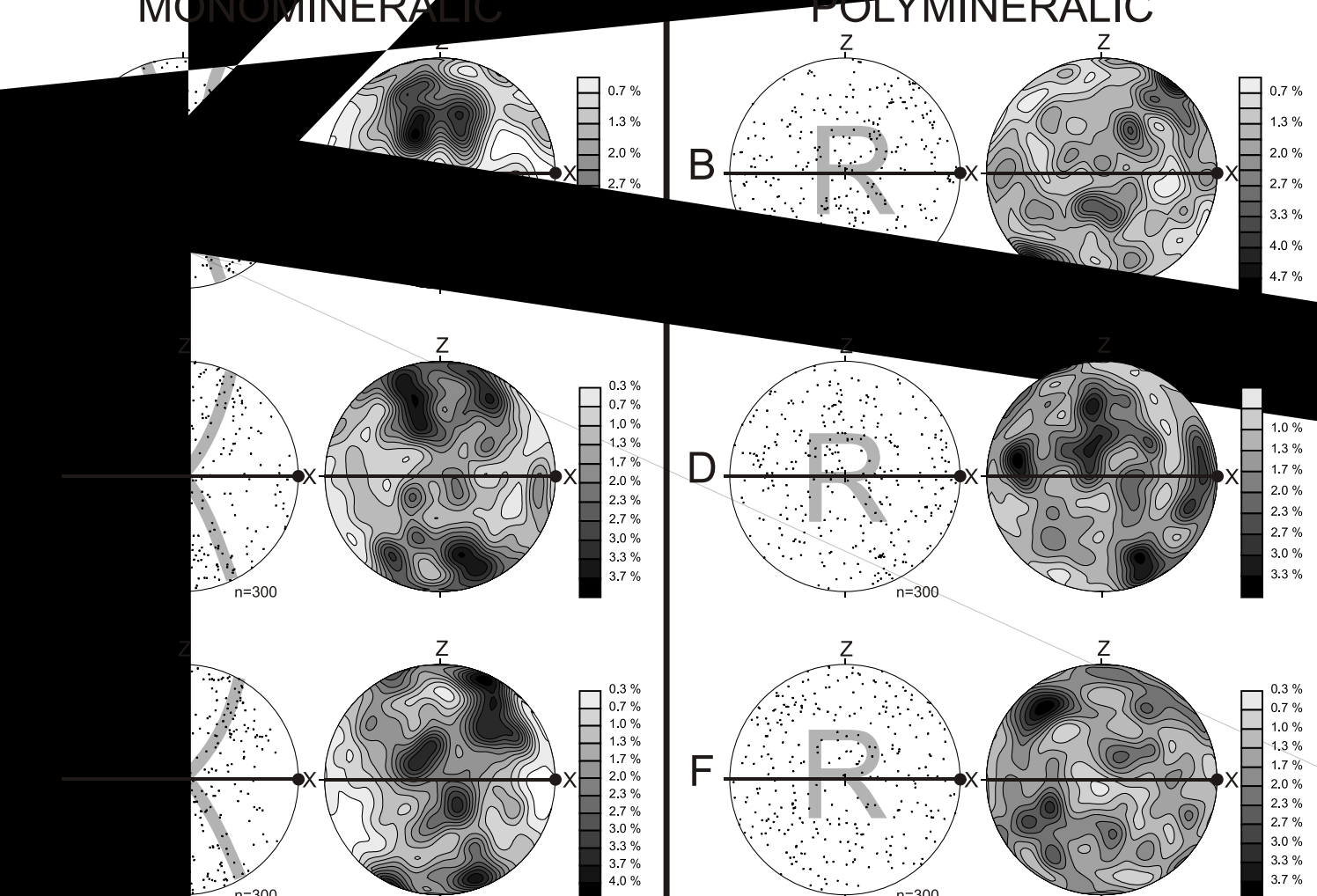

G

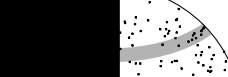

$\mathrm{H}$
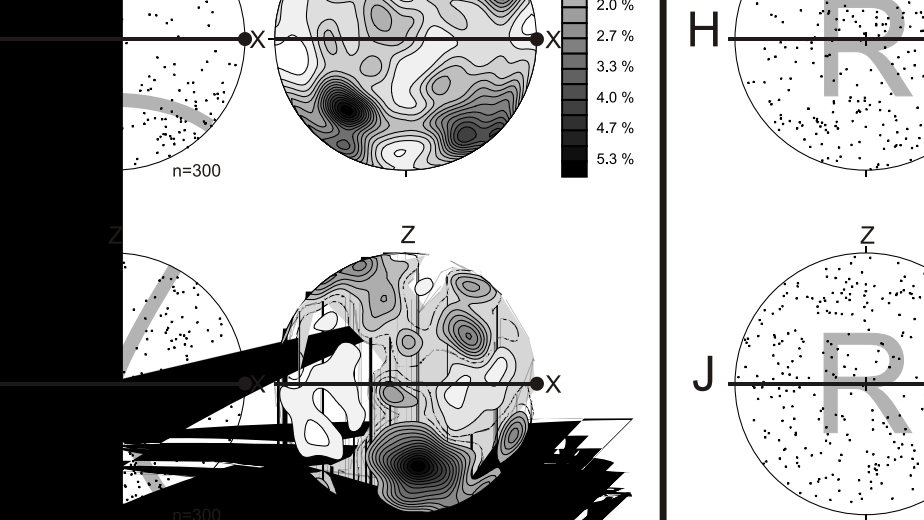

Fig. 5.9. Quartz c-axis plots for infilling veins with (polymineralic) and without (monomineralic) calcite grains. Quartz c-axis poles plotted on equal area, lower hemisphere, stereographic projections. Contours were calculated using a counting circle of $1 \sigma$ and are plotted as lines of equal concentration percentage. Light shades represent low concentration and dark shades represent high concentrations of c-axes. Percent measurements are shown on the graduated scale bar. Fabric information is listed in Table 5.2. Monomineralic samples have $\leq 5 \%$ calcite.

Table 5.2. Fabric strengths for samples with and without calcite. Sample numbers, eigenvalue ratios, pattern codes, fabric strength rankings and grain sizes are given as in Table 5.1. Percent of calcite and chlorite in the samples visually estimated from area of thin-section slide containing calcite. 
polymineralic quartz-calcite veins have a ratio of only 1.2. Monomineralic quartz veins typically have an identifiable pattern and polymineralic quartz-calcite veins have a random or very weak one (Fig. 5.9). Chlorite is also present in many veins but does not seem to affect the fabric strength (in contrast to research by Joy and Saha, 1998). For example, Sample A (Fig. 5.9, Table 5.2) is $\sim 25 \%$ chlorite but has a relatively strong CPO fabric. The proportion of calcite in the veins therefore needs to be considered as a possible explanation for weaker quartz CPO fabrics in veins that have undergone deformation.

\subsubsection{Possible reasons for weak CPO fabrics}

Compared with examples from the published literature, CPO fabrics obtained from the veins deformed in the shear zones in this study are surprisingly weak considering their high shear strains. The fabric strengths in this study are also not related to the amount of ductile shear strain that the veins have undergone, whether it is the final ductile shear strain or the final increment only. Unfortunately, the weak CPO fabrics measured in this study restricts the structural and kinematic interpretations that can be made, but it does pose the question as to why the fabrics in these ductilely sheared veins are so weak compared to other sheared fabrics in both laboratory studies and other natural shear zones.

The random or domainal CPO patterns in the shear infilling veins may be preserved because most of the finite shear strain may have predated their emplacement into the shear zone (see Fig. 3.19). An initially random orientation of crystals in these veins may still be preserved. This random orientation could have formed from precipitation of amorphous silica in the shear zones in response to a drop in fluid pressure (Herrington and Wilkinson, 1993). The domainal CPO patterns also suggest that the fabrics preserve a primary imprint that was inherited from vein precipitation where crystal orientations reflect the large host grain orientations. On the other hand, a shear infilling vein sample that contains an oblique GSF (Sample D, Fig. 5.9) and has a random CPO pattern shows that dynamic recrystallisation has been occurring in this sample but a CPO fabric hasn't formed. The maximum calculated shear strain required to form the GSF is 2.4, theoretically enough to form a strong CPO pattern (e.g. Brunel, 1980). This evidence suggests that some other processes in the infilling veins must be maintaining a weak CPO 
fabric or weakening the fabric during the dynamic recrystallisation that formed this oblique GSF.

Most of the infilling and sheared veins are polymineralic (quartz and calcite). Such rocks distribute strain differently than monomineralic ones that are commonly imitated by numerical modelling, deformed in laboratory experiments, and measured from many natural shear zones (Herwegh and Burger, 2004). Impurities such as calcite and micas can accommodate strain more easily than quartz during deformation (Joy and Saha, 1998; Brodie and Rutter, 2000); thus their presence in abundance can cause a reduction in development of a quartz fabric. As calcite deforms more easily than quartz (Brodie and Rutter, 2000), it maybe accommodating a high proportion of the ductile strain. In this study calcite is frequently observed in concentrated bands parallel to the shear zone boundary (e.g. Fig. 4.12d) so some strain may have been concentrated into these inherently weaker layers (e.g. Lister and Williams, 1979; Pauli et al., 1996). To support this, quartz CPO fabrics tend to be weaker in BDSZ samples containing $>5 \%$ calcite (e.g. Fig. 5.9). It has also been shown that impurities (such as calcite) can allow for easier slip on the grain boundaries than by intracrystalline plasticity; in these circumstances an existing quartz fabric may randomise by grain boundary sliding (Starkey and Cutforth, 1978). Although impurities may have been affecting the fabric strength in the BDSZ, not all veins are polymineralic, therefore further processes must have been weakening the quartz rich veins.

Static recrystallisation is a process that can potentially weaken or randomise an existing CPO fabric. Although this process can weaken a CPO fabric to create a more diffused CPO pattern, near complete randomisation is not likely (Heilbronner and Tullis, 2002). Static recrystallisation will weaken all sections of a shear zone not just the most attenuated strongly sheared section of a deformed vein and may explain why the external and internal vein sections have similarly weak fabric strengths. This process however doesn't explain why there are relatively strong fabrics in the vein sections external to the deformation and random CPO patterns in the most strongly deformed sections of some samples (e.g. Fig. 5.6i).

Grain boundary sliding, accommodated by solid-state diffusion creep, is a process that might randomise a CPO fabric if a late component of the shearing of the 
veins was accommodated by this deformation mechanism, as has been argued by Wightman (2005). This seems particularly likely in those samples for which there is a relatively strong CPO fabric in the external section and a random CPO pattern in the internal section of the shear zone. For remaining samples, grain boundary sliding may have only been a minor deformation process where veins have the same fabric strength in the external part of the shear zone as well as those in the most deformed parts.

Competitive fabric forming processes resulting from complex threedimensional strain are another possible reason for weak CPO fabrics in the shear zones. In complex deformations where monoclinic or triclinic deformation is occurring, finite extension directions may rotate during deformation and could be competing for crystallographic orientations that would allow for easy slip and strain softening (Fossen and Tikoff, 1998). The difference between the near-vertical quartz stretching directions (from CPO fabric rotations) and the moderate-pitching displacement vector (interpreted from field analyses) are consistent with a general transpressional deformation with horizontal shear and flattening with vertical stretching. The temporal evolution of the stretching direction from horizontal to vertical, and the competition between the horizontal shear and the vertical extension, might cause a complex evolution and overprinting of CPO fabrics and an overall weakening of the resultant fabric.

Quartz CPO fabrics may also weaken, or appear to have been weakened, if polyphase deformation was occurring with different kinematic conditions active at different times (e.g. Shelley, 1989; Law, 1987). Sample 7 is an example of a CPO fabric that can be related to at least the final increment of strain recorded in the rock. This sample has a CPO-derived stretching direction and a shear sense that matches the displacement vector from the field and shear direction in the GSF microstructures. These microstructures that the CPO fabric matches have been interpreted to have developed after brittle-ductile shearing and are late stage (see Chapter 4). Other samples may not have generated this overprinting CPO fabric in its entirety and may have the combination of both initial near vertical irrotational strain and an overprinting, later stage, sub-horizontal shear fabric. This polyphase deformation could result in a weak overall resultant CPO fabric. 
The weak c-axis CPO fabrics and CPO patterns measured in this study are most likely a combination of the fabric randomising and weakening processes that occurred during brittle-ductile shearing and during late-stage recrystallisation. In the most deformed internal vein sections grain boundary sliding is most likely a dominant deformation mechanism for fabric randomising along with overprinting by complex three-dimensional strain. The weak and random CPO patterns in the shear infilling veins are typically due to their primary random crystallographic orientation from precipitation and their late emplacement into the shear zone. Calcite concentrations that can accommodate some of the strain may have allowed for the retention of an existing weak fabric in these shear infilling veins, but also may have allowed for easier grain boundary sliding in the strongly deformed internal vein sections. Fabric weakening has been enhanced further in all parts of the shear zone by static recrystallisation and by a potential polyphase fabric overprinting during a late-stage deformation. 


\section{CHAPTER 6: Crystallographic preferred orientation of calcite c-axes}

Calcite textures and microstructures in deformed carbonate rocks can provide information regarding the kinematics and deformation mechanisms in shear zones (Wenk, 1985c). Calcite c-axes have been measured in sheared quartz-calcite veins from the brittle-ductile shear zones in the Southern Alps using a universal stage microscope and are compared with quartz c-axis orientations measured from the same veins. Like quartz, a calcite crystallographic preferred orientation (CPO) can be generated during ductile shearing and used as an indicator of deformation style, recrystallisation mechanisms and the slip systems used to accommodate the strain (e.g. Busch and van der Pluijm, 1995; Bestmann et al., 2000; Ulrich et al., 2002). As calcite deforms more easily than quartz (Brodie and Rutter, 2000) and by dislocation creep at temperatures as low as $150-250^{\circ} \mathrm{C}$ (Kennedy and White, 2001), it can provide further insight into the shear zone deformation not available from quartz CPO fabrics, especially regarding the lower temperature, later stage parts of the deformation path (see Section 4.7).

Calcite has been found in proportions of up to $40 \%$ in some vein samples and is found concentrated in 1-2 mm wide layers oriented parallel to the shear zone and also as individual grains throughout the quartz aggregate (see Chapter 4). Both the calcite grains concentrated in layers, and the isolated grains outside them that are surrounded by quartz, have grain-shape fabrics. The grain long axis is orientated parallel to the shear zone boundary in the most highly deformed sheared vein sections (probably the result of a grain-growth anisotropy) but is often at an oblique angle to the boundary in the younger shear infilling veins (see Chapter 4). All these calcite grains have undergone recrystallisation, which is evident from the polygonal grain textures, and the grain boundary and twin boundary migration microstructures in many of the deformed veins. This recrystallisation contributed towards a strong CPO fabric by preferential selection of crystals that lie in orientations that are favourable for easy intracrystalline slip in the shear zones.

As presented in Chapter 5 for quartz, I will determine a finite extension direction and the slip systems based on the shape and symmetry of the calcite CPO fabrics that were generated by intracrystalline plasticity and dynamic recrystallisation 
in the sheared veins. Understanding this deformation of calcite will lead to a better understanding of the complexities involved in polymineralic vein deformation compared to the monomineralic samples used in laboratory experiments (e.g. Herwegh and Bereger, 2004); a complexity that this study has already shown strongly affects CPO development in quartz.

\subsection{Measuring the orientation of calcite c-axes}

Calcite c-axis orientations were measured using a 5-axis universal stage fitted to a Leitz polarising microscope (Fig. 5.1a). Oriented thin-sections were cut to 15 $\mu \mathrm{m}$ thick to tone down the interference colours generated by the high birefringence. These slides were mounted on the universal stage as was done for quartz (see Chapter 5). Because of the high birefringence of calcite, a gypsum plate could not be used to determine the crystallographic fast direction required for measuring the caxis orientation. The fast direction for calcite was instead determined from a rotation of the A2 universal stage axis once the calcite grain was placed into an extinct position by rotation about the A1 axis. If the grain moved out of an extinction position during an $\mathrm{A} 2$ rotation it required a $90^{\circ}$ rotation about the $\mathrm{A} 1$ axis for the fast direction to be parallel to the A4 axis. If the grain remained in extinction during this A2 axis rotation then the crystallographic fast direction was aligned parallel to the A4 axis and no further rotation was required. Once the crystallographic fast direction was determined, the calcite c-axis orientation was measured, as for quartz, following the method of Passchier and Trouw (1998).

Calcite c-axes were measured for 300 grains from the same thin-sections of sheared veins as those from which quartz CPO data was gathered (Chapter 5). Thus the CPO fabric diagrams of the two minerals could be compared to one another. As was done for the quartz data, calcite CPO fabrics are plotted as both scatter and contour plots. Because of the strong calcite fabrics (fabric strength rankings of 5 for all samples), a counting circle of $3 \sigma$ was used for contouring for the calcite point density data. Two types of CPO patterns (skeletal outlines) were assigned to the calcite fabrics based on these contour plots. The first type of pattern is a double girdle (similar to a cleft girdle of quartz) which defines a concentration of c-axes along a planar distribution in the plot. The second type is a cluster outline, which defines the approximate boundaries of a c-axis cluster. There were no asymmetric 
calcite CPO fabrics observed in this study. This was no surprise, as domainal calcite CPO patterns typically found in the sheared veins here generally cannot be used as a shear sense indicator (see Lafrance et al., 1994).

\subsection{Rotation of calcite CPO fabrics}

Although the calcite CPO fabrics in the sheared veins were strong, the CPO patterns did not match the patterns observed in previous studies of calcite deformed by shear zones when the fabric plots were orientated in the a-b-c reference frame. This reference frame has the a-pole parallel to the mineral fibre lineation (displacement vector), the b-pole perpendicular to the mineral lineation in the shear plane, and the c-pole parallel to shear plane normal (see Chapter 5). As a known CPO pattern was observed in this orientation a rotation of the CPO fabrics (as for quartz fabrics in Chapter 5) has been used to determine the calcite CPO-derived stretching direction and the dominant slip systems during calcite deformation. This method rotates the pole data around the normal to the shear plane (z-axis here). A correctly orientated fabric will have the extension direction parallel to the east-west pole (x-pole) of the fabric plots and in this position the fabrics will be in mirror symmetry about the shear plane and intercept the z-y plane. Once a CPO pattern is identified for a fabric, it is rotated so that the inferred symmetry axis and extension direction is aligned parallel to the east-west axis of the CPO fabric plot (x-pole).

The calcite CPO-derived stretching direction $[\mathrm{x}]$ for each CPO fabric was measured precisely by rotating the plane containing the $S_{1}$ and $S_{2}$ eigenvectors about the z-pole until it was sub-parallel to the z-y plane (e.g. eigenvectors shown in Fig. 6.1a). This rotation was made using the stereonet software by Allmendinger (2003). This method works best when the eigenvalues are similar (i.e. when there is a distribution of c-axes along a plane rather than a cluster about the z-pole) and the eigenvalue ratio of $S_{1}: S_{2}$ is $<2.5$. Larger ratios than this were not used to determine the mean CPO-derived stretching direction as the fabric was too clustered about the z-pole to clearly define the extension direction; however, a rotation was still performed on all fabrics to orient them based on their eigenvectors. An example of this rotation is presented in Fig. 6.1a that shows three differently orientated calcite CPO fabric plots for c-axes measured from a sheared vein on Chancellor Ridge. All 

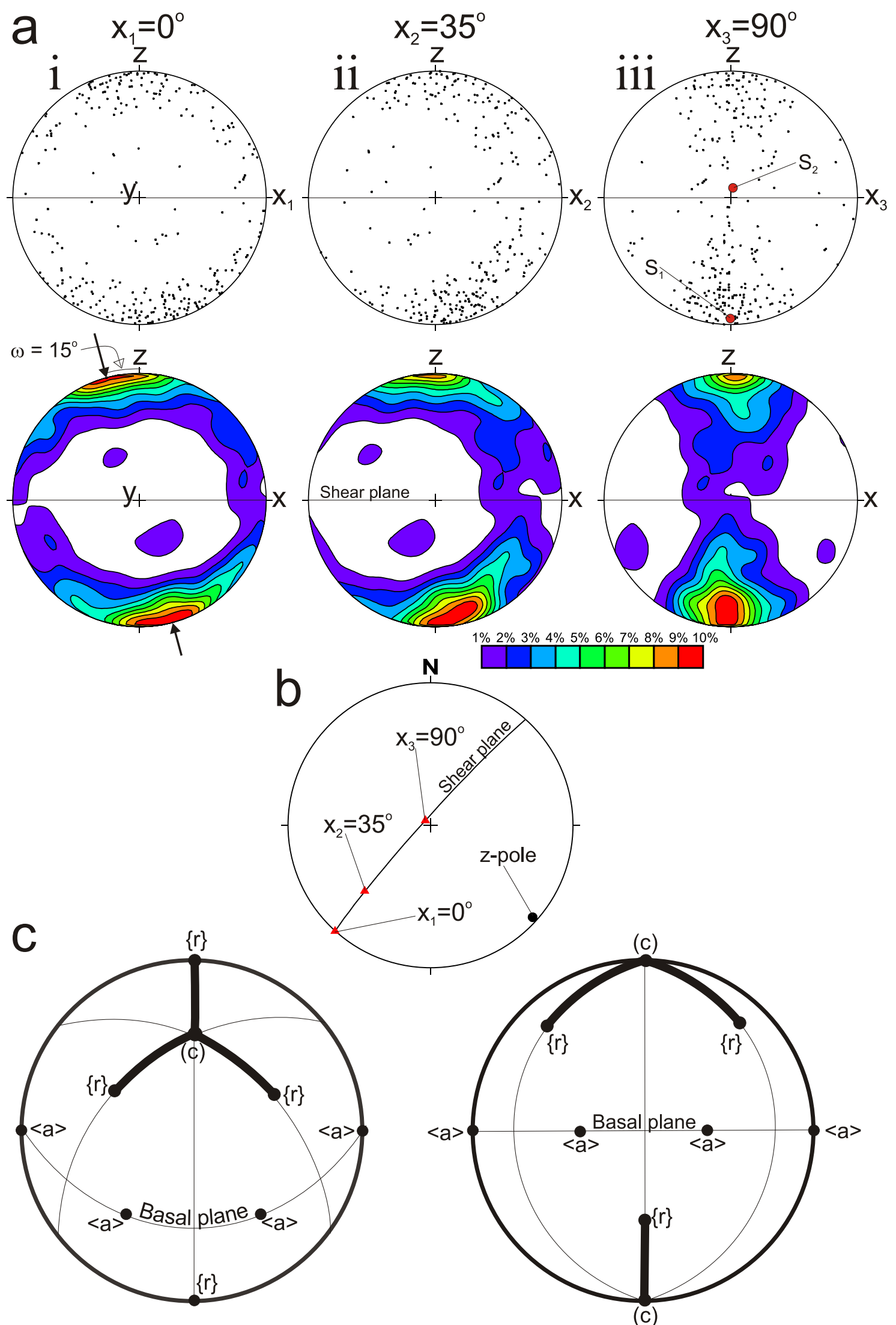

Fig. 6.1. Rotation of calcite CPO fabrics to find the CPO-derived stretching direction and the slip systems being used. a. Three different orientations of the same CPO fabric; i, ii and iii (Sample 4, fabric C, Fig. 6.4). The angle between the shear zone pole and the point maximum $(\omega)$ is shown in the first rotated fabric and the eigenvalues for the $S_{1}$ and $S_{2}$ eigenvectors are marked on the third rotated fabric. Contours of point density are generated using a $3 \sigma$ counting circle. b. Stereogram of the three different $x$-poles for each of the rotated fabrics in (a). c. Orientation of the $\mathrm{c}$ - and a-axes, the poles to the rhomb planes $\{\mathrm{r}\}$ and the basal plane of calcite for two c-axis orientations (after Pieri et al., 2001). All stereographic projections are equal area and lower hemisphere. 
three fabrics are rotated about the z-axis and have different orientations of the x-pole (Fig. 6.1b).

The fabric in Fig. 6.1a(i) has been rotated so that the $\mathrm{x}$-pole $\left(\mathrm{x}_{1}\right)$ has a horizontal pitch in the shear plane (Fig. 6.1a(i) and 6.1b). This fabric shows a strong point maximum at a $15^{\circ}$ angle $(\omega)$ from shear plane normal ( $\mathrm{x}_{1}$-pole). This angle is not large enough for this CPO fabric to have been generated from e-twin glide or $\{\mathrm{r}\}$ $<$ s.d.> slip, where $\omega$ is expected to be closer to $30^{\circ}$ (see Schmid et al., 1987 and Pieri et al., 2001). This horizontal orientation of the x-pole does not, therefore, produce a significant calcite CPO fabric plot and the $\mathrm{x}_{1}$-pole is not parallel to the extension direction. The fabric plot in Fig. 6.1a(ii) has the x-pole $\left(\mathrm{x}_{2}\right)$ pitching $35^{\circ}$ from the southwest (Fig. 6.1b). This reference orientation is equivalent to the a-b-c reference frame where the a-pole ( $\mathrm{x}_{2}$-pole here) is parallel to the mineral fibre lineation (see Chapter 5). There is no CPO pattern observed in this orientation that can be related to any known deformation patterns in calcite, therefore it is assumed the $\mathrm{x}_{2}$-pole and the mineral fibre lineation are not parallel to the finite principle extension direction.

In Fig. 6.1a(iii) the fabric plot has an x-pole that has been rotated to a nearvertical $\left(\mathrm{x}_{3}\right)$ pitch of $90^{\circ}$ in the shear plane (Fig. 6.1b). This fabric plot reference frame shows a significant CPO pattern similar to that found in many other deformed carbonate rocks (e.g. Schmid et al., 1987; Ratschbacher et al., 1991; Lafrance et al., 1994; Pieri et al., 2001; Barnhoorn et al., 2004). This rotated CPO fabric and pattern in Fig. 6.1a(iii) is diagnostic of either irrotational plane strain deformation or from a rotational deformation such as simple shear. In both irrotational and rotational deformation the principle extension direction is oriented parallel to the east-west axis (x-pole) when the CPO fabrics are in position, as shown, with concentrations about the z-pole and towards the y-pole. Fig. 6.1c (after Pieri et al., 2001) shows that the observed orientations of c-axis concentrations could be related either to slip on the basal planes in the $<\mathrm{a}>$ direction (grains oriented with c-axes parallel to the z-pole; e.g. Schmid et al., 1987; Barnhoorn et al., 2004); or to slip on the $\{r\}$ planes in the lesser known $<\mathrm{a}>$ direction (grains oriented with a steeper $\sim 45^{\circ}$ pitch in the $\mathrm{z}-\mathrm{y}$ plane; Pieri et al., 2001). Slip in grains orientated between these two ideal positions in Fig. 6.1c could be accommodated by combinations of multiple slip systems (Barnhoorn et al., 2004). 
Rotations of calcite CPO fabrics measured throughout the brittle-ductile shear zone (BDSZ) have been made to find the mean principle extension direction (calcite CPO-derived stretching direction) generated during the deformation of calcite. Eigenvalue ratios and the southwest pitch of the x-pole determined for all the fabrics measured in this study are listed in Table 6.1. The calcite CPO-derived stretching directions are plotted in Fig. 6.2 for the CPO fabrics obtained from the four deformed internal sections of the sheared veins and one from a shear infilling vein (all with $\mathrm{S}_{1}: \mathrm{S}_{2}$ ratios $<2.5$ ). These patterns yield a mean stretching direction orientation of $201,85 \pm 7^{\circ}$ (uncertainty based on a $95 \%$ confidence cone about the mean pole). Calcite CPO fabrics from the less deformed, external parts of sheared veins were omitted from the mean orientation quoted above, as were any other fabric plots with $\mathrm{S}_{1}: \mathrm{S}_{2}$ ratios $<2.5$. Table 6.1 shows that all calcite CPO fabrics have similar nearvertical x-pole orientations (even those excluded from the mean). This near-vertical CPO-derived stretching direction is not parallel to the finite slip direction [a] (the mineral fibre lineation) but closely parallel to the CPO-derived stretching direction determined from quartz CPO fabrics of 239, $79 \pm 11^{\circ}$ (Fig. 6.2); in the case of Sample 3, the quartz and calcite results are coincident (see Tables 5.1 and 6.1).

\subsection{Calcite c-axis CPO fabrics in the brittle-ductile shear zones}

The calcite CPO fabrics are all very similar across the differently deformed sections of the shear zones (Figs. 6.3 and 6.4), the only variation being minor changes in the distribution of c-axes between the z- and y-poles of the fabric diagrams (distribution measured by $\mathrm{S}_{1}: \mathrm{S}_{2}$ eigenvalue ratio; Table 6.1). All of the CPO fabrics have a mirror symmetry plane coincident with the shear plane, indicating that fabrics developed during deformation of the quartz-calcite veins parallel to the $\mathrm{S}_{4}$ shear planes (as for quartz in Chapter 5). Calcite CPO fabrics from the external vein sections in Fig. 6.4 (fabrics A and D), however, are not in mirror symmetry about the Alpine Schist foliation plane, in contrast to the quartz CPO fabrics presented in Fig. 5.7. CPO patterns from fabrics obtained in the concentrated layers of calcite in the sheared veins (e.g. CPO fabric E in Fig. 6.4) were not significantly different from the patterns of CPO fabrics obtained from calcite grains dispersed amongst a dominantly quartz-rich matrix (e.g. CPO fabric H in Fig. 6.4). All of the calcite CPO fabrics measured in this study are considered to have a very strong fabric strength based on eigenvalue $S_{1}: S_{3}$ ratios that were all greater than 4 


\begin{tabular}{|c|c|c|c|c|c|c|c|c|c|c|c|c|c|}
\hline \multirow{2}{*}{\multicolumn{2}{|c|}{$\begin{array}{l}\text { This } \\
\text { study }\end{array}$}} & \multicolumn{3}{|c|}{ Sample number } & \multirow{2}{*}{\multicolumn{2}{|c|}{$\begin{array}{c}\text { Grid Reference } \\
\text { (New Zealand Grid) }\end{array}$}} & \multirow{2}{*}{$\begin{array}{c}\text { Shear plane } \\
\text { orientation } \\
\text { (x-y plane) }\end{array}$} & \multirow{2}{*}{$\begin{array}{l}\text { Sheared } \\
\text { vein } \\
\text { orientation }\end{array}$} & \multirow[t]{2}{*}{$\gamma_{d}$} & \multirow[t]{2}{*}[x]{} & \multicolumn{3}{|c|}{ Eigenvalue ratios } \\
\hline & & $\begin{array}{l}\text { Vein } \\
\text { sect. }\end{array}$ & $\begin{array}{l}\text { VUW } \\
\text { Collect. }\end{array}$ & $\begin{array}{c}\text { Field } \\
\text { number }\end{array}$ & & & & & & & $\mathrm{S} 1 / \mathrm{S} 3$ & $\mathrm{~s} 1 / \mathrm{S} 2$ & $\mathrm{~S} 2 / \mathrm{S} 3$ \\
\hline \multirow{3}{*}{3} & $A$ & $E$ & & & & & & & & 94 & 6.45 & 1.67 & 3.87 \\
\hline & B & 1 & 39395 & $\mathrm{MHCH} 17$ & $2,276,050$ & $5,740,450$ & 038@88SE & 016@70SE & 7.7 & 82 & 10.17 & 2.26 & 4.51 \\
\hline & C & $\ln$ & & & & & & & & 86 & 10.96 & 2.26 & 4.85 \\
\hline \multirow{3}{*}{4} & $\bar{D}$ & $E$ & \multirow{3}{*}{39400} & \multirow{3}{*}{$\mathrm{MHCH} 20$} & \multirow{3}{*}{$2,277,348$} & \multirow{3}{*}{$5,740,090$} & \multirow{3}{*}{ 222@86NW } & \multirow{2}{*}{ 104@64S } & \multirow{2}{*}{6.8} & 78 & 9.18 & 2.24 & 4.10 \\
\hline & $E$ & I & & & & & & & & 90 & 6.63 & 2.50 & 2.65 \\
\hline & $\mathrm{F}$ & 1 & & & & & & 002@82E & 4.4 & 82 & 8.88 & 2.13 & 4.17 \\
\hline \multirow{2}{*}{11} & G & $\mathrm{I}$ & \multirow{2}{*}{39419} & \multirow{2}{*}{ MHBM03 } & \multirow{2}{*}{$2,279,922$} & \multirow{2}{*}{$5,744,478$} & \multirow{2}{*}{ 048@78SE } & \multirow{2}{*}{ 020@76SE } & \multirow{2}{*}{6.3} & 89 & 8.18 & 2.36 & 3.47 \\
\hline & $\mathrm{H}$ & $\ln$ & & & & & & & & 89 & 6.62 & 4.76 & 1.39 \\
\hline 7 & 1 & $\ln$ & 39389 & $\mathrm{MHCH} 12$ & $2,277,301$ & $5,740,163$ & 221@85NW & - & - & 160 & 4.52 & 2.67 & 1.70 \\
\hline 12 & $\mathrm{~J}$ & In & 39414 & MHSP09 & $2,274,514$ & $5,737,163$ & 202@52NW & - & - & 95 & 11.25 & 4.87 & 2.31 \\
\hline 13 & $\mathrm{~K}$ & In & 39394 & $\mathrm{MHCH} 14$ & $2,276,050$ & $5,740,450$ & 218@68NW & - & - & 19 & 4.40 & 2.74 & 1.61 \\
\hline 14 & $\mathrm{~L}$ & In & 39433 & TJFA47 & $2,274,502$ & $5,737,234$ & 213@60sw & - & . & 139 & 6.02 & 2.77 & 2.17 \\
\hline
\end{tabular}

Table 6.1. CPO fabric data for calcite c-axes in Fig. 6.2 and 6.3. Sample numbers refer to those in Chapters $5 \& 6$ (this study), with the vein section also listed (E - external vein section, I - internal highly deformed vein section, In - shear infilling vein). Finite ductile shear strain $\left(\gamma_{d}\right)$ for sheared veins in Fig. 6.2 and the pitch of the calcite CPO-derived stretching direction $[\mathrm{x}]$ in the shear plane. Eigenvalue ratios listed for fabric strength comparison. Samples 3 and 4 match corresponding sheared veins in Fig. 5.6 for CPO of quartz.

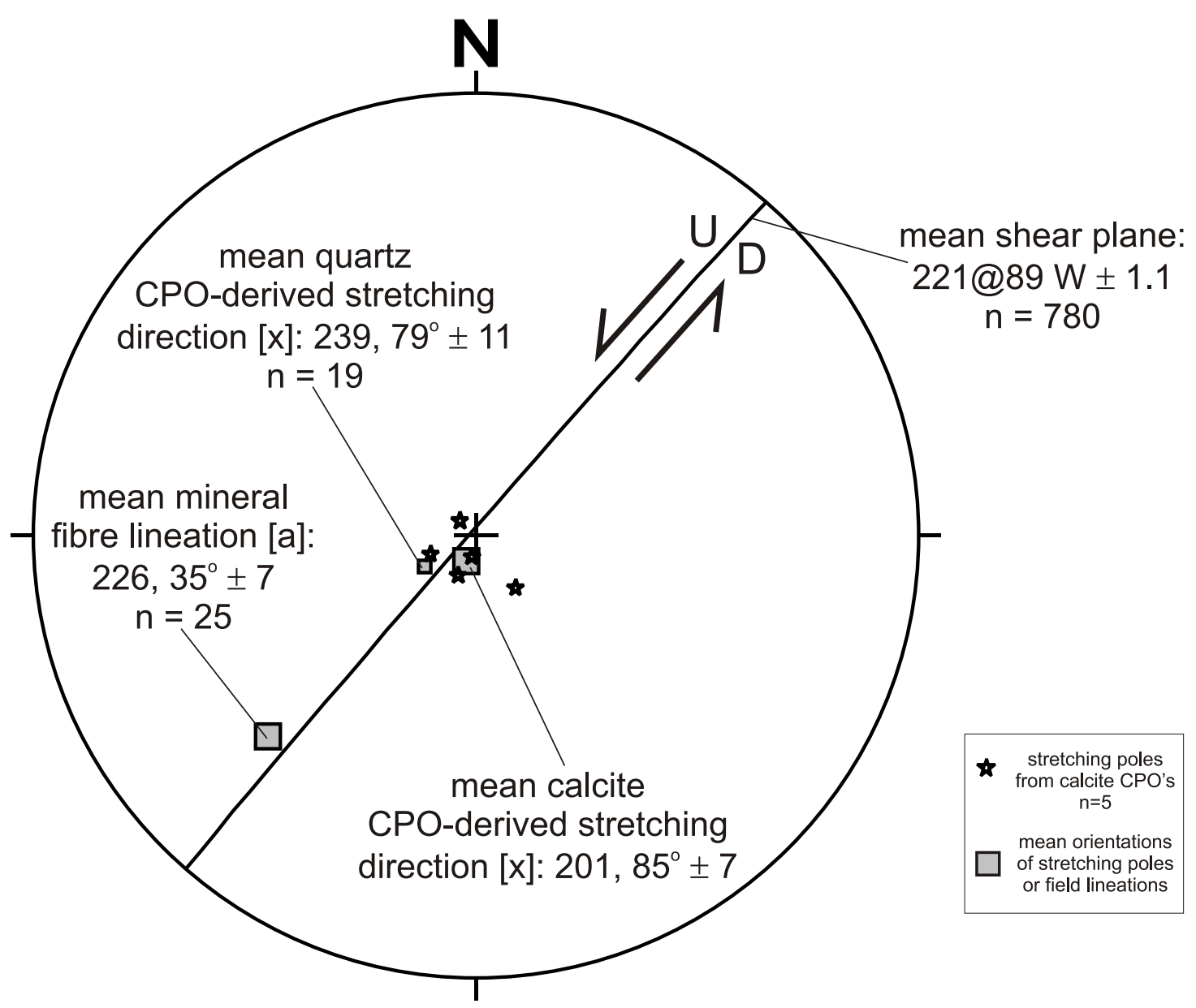

Fig. 6.2. Stereographic projection of 5 measured calcite CPO-derived stretching poles from highly sheared internal vein sections and the sheared infilling veins. Also plotted are mean orientations of the mineral fibre lineation directions from field-based measurements, the quartz CPO-derived stretching direction and the mean shear plane orientation. Uncertainties represent a $95 \%$ confidence ellipse surrounding the mean lineation or pole-to-plane orientation. 

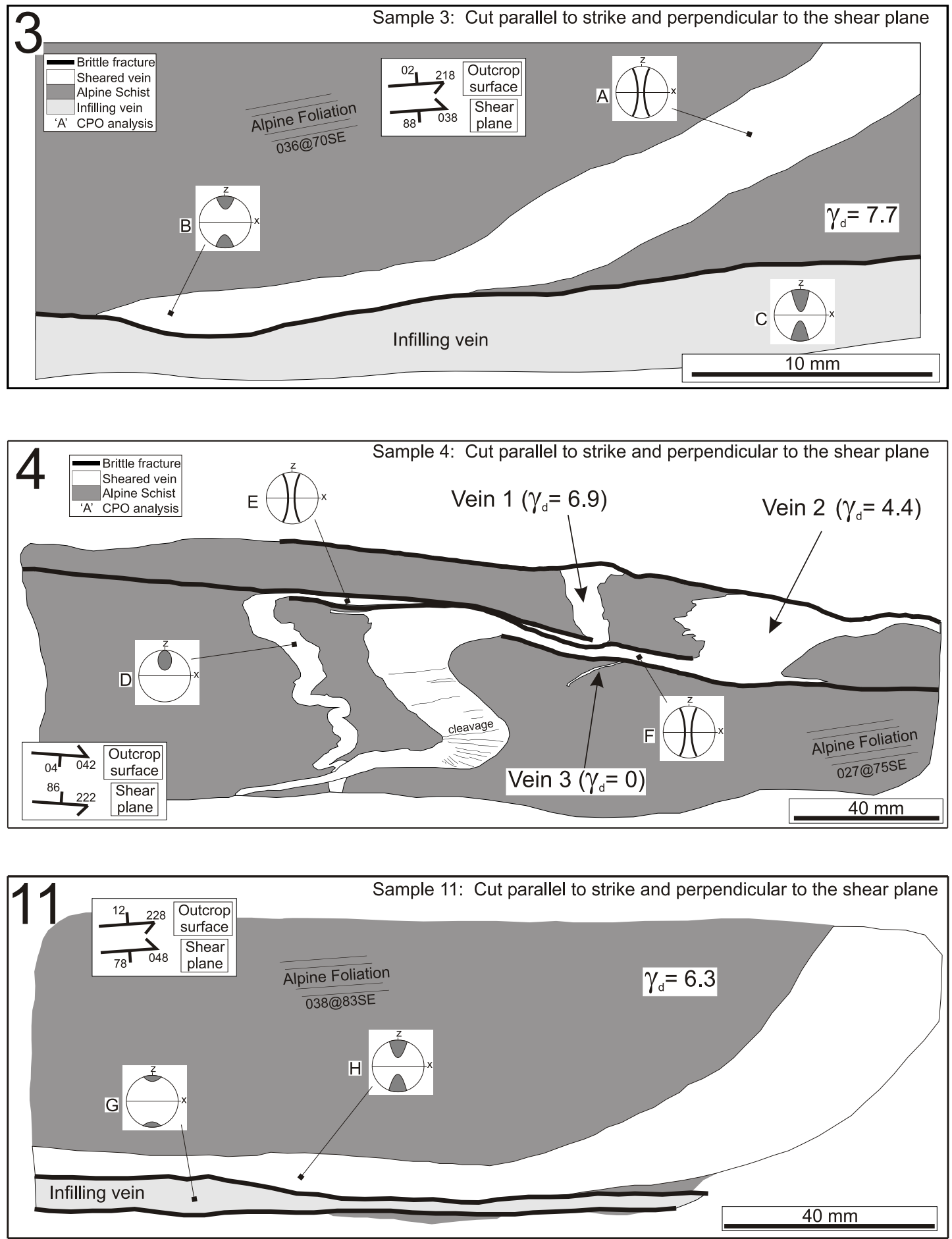

Fig. 6.3. Sheared quartz-carbonate veins with finite ductile shear strains $\left(\gamma_{\mathrm{d}}\right)$ ranging from $4.4-7.7$ with interpreted CPO patterns from calcite c-axis CPO fabric plots. Complete CPO fabric plots for CPO patterns A to $\mathrm{H}$ can be found in Fig. 6.4 with orientation and fabric strength data in Table 6.1. Sample 4 dips west; 3 and 11 dip east. Sample 3 shows a shear zone with CPO fabrics measured from the sheared veins most deformed internal and less deformed external sections and from the shear infilling vein section. Sample 4 shows three sheared veins; a CPO fabric was measured from the most highly deformed section of Veins $1 \& 2$ and from the section external to the deformation in Vein 1. Sample 11 has had two CPO fabrics measured from it, one from the most highly deformed section and one from the shear infilling vein. 

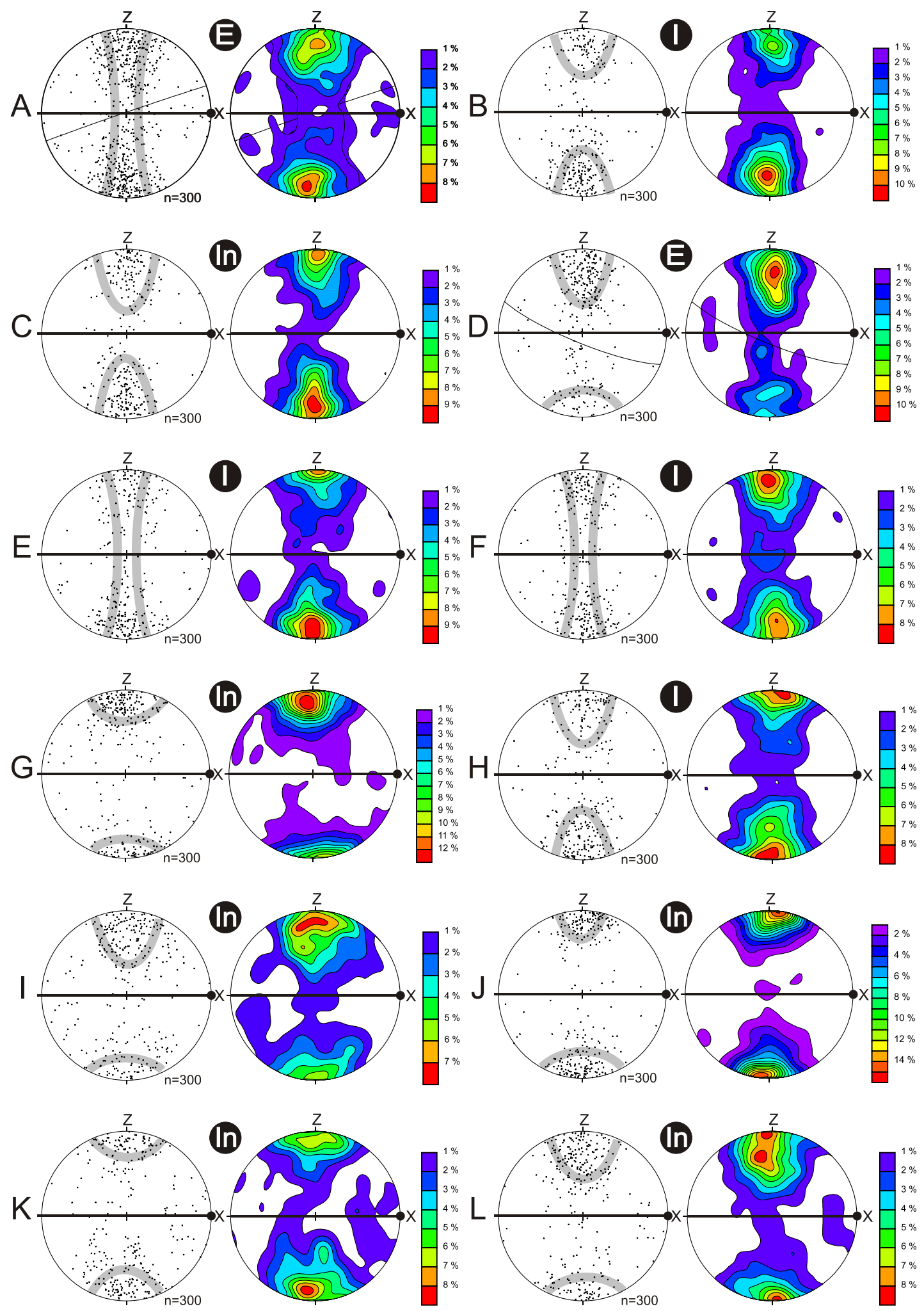

Fig. 6.4. Calcite c-axis fabrics and patterns for sheared and shear infilling veins. Fabric plots A-H are for CPO patterns from sheared veins in Fig. 6.2 and plots I-L are infilling vein samples from various locations. Calcite c-axis poles plotted on equal area, lower hemisphere, stereographic projections. Contours were calculated using a counting circle of $3 \sigma$ and plotted as lines of equal concentration percentage. Contours are shaded for concentration and scaled according to the graduated scale bars. Contour and scatter plots are paired for complete and objective fabric interpretations. Sample names, geographic locations, fabric strengths and the SW pitch of $[\mathrm{x}]$ in the shear plane can be found in Table 6.1. Great circles, drawn on external vein section CPO fabrics, represent the Alpine Schist foliation. CPO patterns illustrated on scatter plots are cleft girdles or outlines of the domainal concentrations. All CPO fabric plots are in the rotated x-y-z reference frame (Figs. 5.2 and 5.3). Black circle with white labels represent internal sections $(I)$ and external sections $(E)$ of sheared veins and shear infilling veins $(I n)$. 
(Table 6.1) and were all given fabric strength rankings (see Chapter 5 for definition) of 5. In contrast to the quartz CPO fabrics in the same veins, the calcite CPO fabrics show no evidence for late-stage fabric weakening and / or randomisation that may be caused by grain boundary sliding or diffusion creep deformation mechanisms (as in Busch and van der Pluijm, 1995).

As briefly mentioned in Section 6.2, the CPO patterns found in the sheared veins could have been formed by an irrotational or a rotational strain. Irrotational deformation with flattening perpendicular to the shear plane could have generated these CPO fabrics, for example during plane strain deformation with the principle extension direction [x] parallel to the x-pole of the CPO fabric (e.g. Wenk and Takeshita, 1987; Ratschbacher et al., 1991). Alternatively, the same CPO pattern could have been generated by rotational deformation (shearing parallel to the shear plane) after shear strains of 3-5, provided that the shear direction was oriented nearvertically and parallel to the x-pole of the CPO fabric (e.g. Schmid et al., 1987; Pieri et al., 2001; Barnhoorn et al., 2004). A full crystallographic orientation of the fabrics that includes the $\{r\}$ pole and a-axis would be required in order to make an exact determination about the rotational nature of the shear zone deformation. However, considering that the quartz CPO fabrics have preferentially accommodated the irrotational component of a general shear deformation (a combination of shear zone flattening with the principle extension direction near-vertical and shearing parallel to the displacement vector), I have inferred that these CPO fabrics have also developed from an irrotational deformation.

Grain boundary migration is typically the main recrystallisation process that generates calcite CPO fabrics like those observed here in the sheared veins (e.g. Schmid et al., 1987; Lafrance et al., 1994; Pieri et al., 2001; Barnhoorn et al., 2004; Herwegh et al., 2005). A preferred crystallographic orientation is reinforced by the preferential growth of grains that are in an orientation for easy slip relative those grains that are misoriented with respect to the shear zone (Pieri et al., 2001). At high shear strains (approximately 3-5) a steady-state fabric can be achieved in calcite due to dynamic recrystallisation (Lafrance et al., 1994; Herwegh et al., 2005). Crystals with a c-axis aligned perpendicular to the shear zone remain in a position for easy slip along crystal planes and will preferentially grow forming a strong CPO with a concentration of c-axes around the z-pole in the fabric plots (Lafrance, 1994). 
Dynamic crystallisation by grain boundary migration is easily achieved in monomineralic carbonate rocks or in calcite-rich vein layers; however, in polymineralic veins (such as those presented in this study) where two different minerals share a grain boundary, such grain boundary migration is impossible. In these situations, the calcite cannot migrate, and it undergoes a twinning process in order to accommodate additional deformation. Twin boundary migration between the host and the twinned crystal domains can then occur, recrystallising a grain into an orientation for easy slip (e.g. Rutter et al., 1994; Bestmann and Prior, 2003). Individual calcite grains that occur surrounded by quartz-rich areas of the sheared veins (e.g. CPO fabric $\mathrm{K}$ ) have $\mathrm{CPO}$ fabrics equally as strong as which are concentrated together into layers (e.g. CPO fabric C). This implies that twin boundary migration has been an effective process in the individual calcite grains, whereas calcite concentrated in layers is likely to have undergone chiefly a grain boundary migration recrystallisation process. Both processes have apparently resulted in the equally strong preserved CPO's in these strongly deformed veins.

CPO fabrics generated from dislocation creep during dynamic recrystallisation (recrystallisation CPO fabrics) occur during deformation at higher temperatures than CPO fabrics generated solely by e-twinning as found in some shear zones (e.g. Schmid et al, 1987; Wenk and Takeshita, 1987). These recrystallisation calcite $\mathrm{CPO}$ fabrics must have been generated at temperatures where slip on the (c), $\{r\}$ and $\{f\}$ planes dominated over glide on the e-twin planes (Burkhard, 1993; De Bresser and Spiers, 1997). With estimated temperatures of 450 $\pm 50^{\circ} \mathrm{C}$ for shear zone deformation in the Southern Alps (Wightman, 2005) and shear strains of $4.7 \pm 0.7$ (see Chapter 3) these CPO fabrics in calcite are not unexpected. The sheared vein microstructures show evidence for grain boundary migration, twin boundary migration and grain boundary area reduction (a process which also favours grains well orientated for growth) supporting the interpretation that these fabrics were generated and strengthened from recrystallisation processes.

From the deformation map constructed in Fig. 6.5 from flow laws in Table 6.2 , it can be seen that calcite never reaches a grain size sensitive (GSS) flow field (of $n=1.7$ ) where grain boundary sliding can occur to weaken or randomise the fabric. Instead, at $450^{\circ} \mathrm{C}$ recrystallised calcite grains form at sizes in equilibrium 


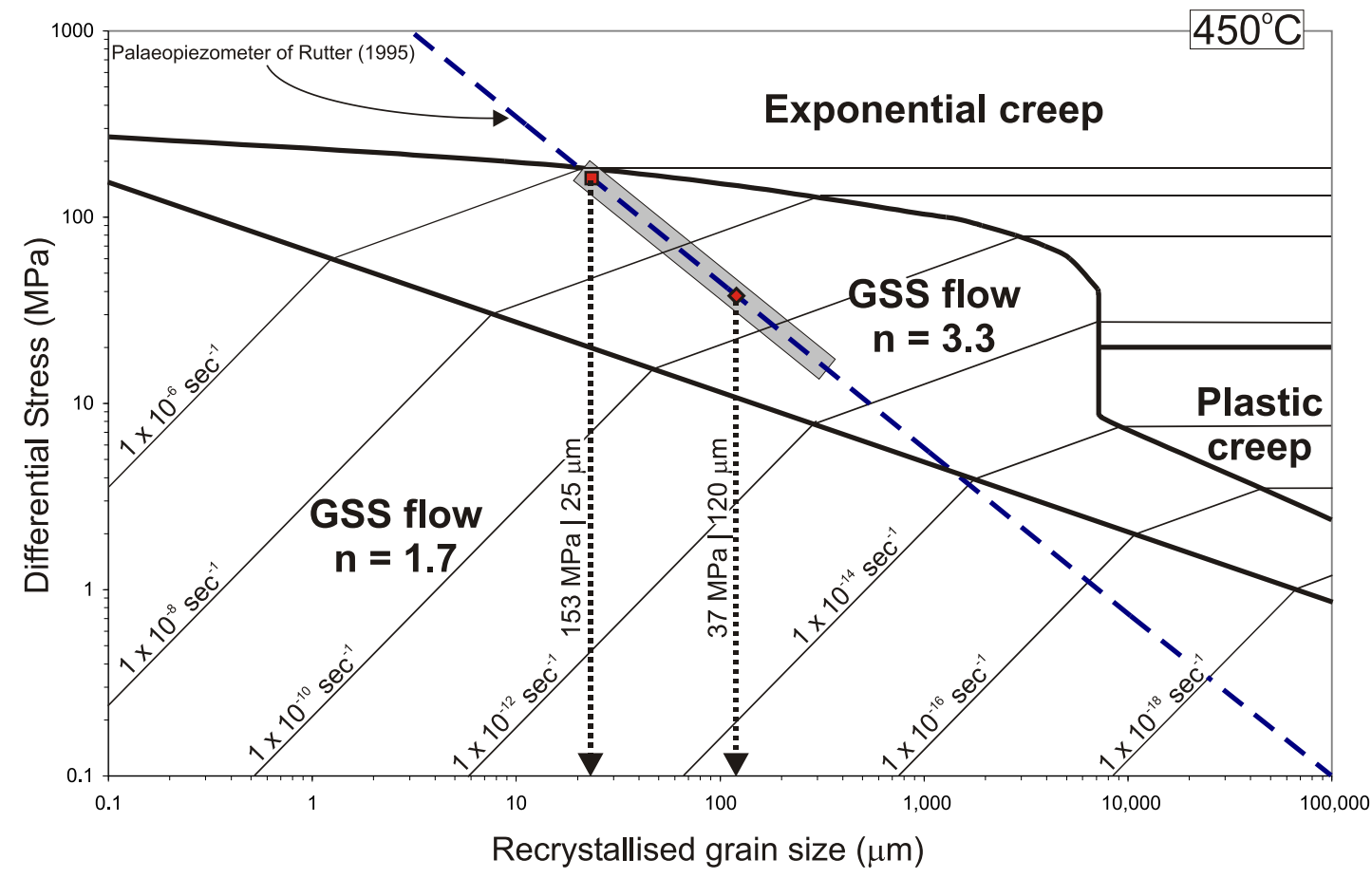

Fig. 6.5. Deformation map for calcite at temperature of $450^{\circ} \mathrm{C}$ and contoured for strain-rate. Flow behaviour of calcite is shown using flow laws for plastic creep (PC), grain size sensitive flow (GSS) and exponential creep (EC) from Table 6.2. PC flow law of the form $\varepsilon=A \cdot \sigma^{\mathrm{n}} \cdot \exp (-\mathrm{Q} / \mathrm{RT})$, GSS flow law of the form $\varepsilon=A \cdot \sigma^{\mathrm{n}} \cdot \mathrm{d}^{\mathrm{m}} \cdot \exp (-\mathrm{Q} / \mathrm{RT})$ and $\mathrm{EC}$ flow law of the form $\varepsilon=\mathrm{A} \cdot \exp (-\mathrm{Q} / \mathrm{RT}) \cdot \exp (\mathrm{C} \cdot \sigma)$ are used for this map. These flow laws have been used to plot fields boundaries (bold lines) for exponential creep (Rutter, 1974), plastic creep (Schmid, 1982) and grain size sensitive (GSS) flow in high and low stress conditions (Walker et al., 1990). The high stress GSS field where $n=3.3$ is where a CPO fabric can strengthen by recrystallisation and the low stress field where $n=1.7$ is where grain boundary sliding and diffusion creep (fabric weakening processes) can occur. Stress dependant recrystallised grain size palaeopiezometer of Rutter (1995) for migration recrystallisation of calcite also shown.. Two differential stress calculation from Chapter 4 are shown and represent the estimated maximum and minimums during ductile deformation of the sheared calcite in the deformed veins. The estimated zone of deformation during the dynamic recrystalliation is indicated by the shaded grey box on the piezometer line that includes these two differential stresses.

\begin{tabular}{lccccc}
\hline Material and deformation mechanism & $\log \mathrm{A}$ & $\mathrm{n}$ & $\mathrm{m}$ & $\mathrm{Q}$ & 1/C Reference \\
\hline Iceland Spar - <25 MPa - GSS flow & 4.9 & 1.7 & -1.9 & 190 & - Walker et al. (1990) \\
Iceland Spar - 25-250 MPa - GSS flow & 2 & 3.3 & -1.3 & 190 & - Walker et al. (1990) \\
Power law creep in calcite & -5.5 & 6 & - & 314 & - Schmid (1982) \\
Carrara Marble - Exponential creep & 5.8 & - & - & 260 & 11 Rutter (1974) \\
Cal recrystallised grain size piezometer & 3.43 & - & 0.89 & - & - Rutter (1995) \\
\hline
\end{tabular}

Table 6.2. Flow laws parameters used to plot the boundaries for the deformation map in Fig. 6.5 for plastic creep (power law creep), exponential law creep and grain size sensitive (GSS) flow. Parameters listed for $\mathrm{A}\left(\mathrm{sec}^{-1} \cdot \mathrm{MPa}^{-\mathrm{n}} \cdot \mu^{-\mathrm{m}}\right), \mathrm{Q}\left(\mathrm{kJ} \cdot \mathrm{mol}^{-1}\right), \mathrm{f}(\mathrm{MPa}), \mathrm{w}, \mathrm{n}, \mathrm{m}$ and c (dimensionless) 
with the differential stress (palaeopiezometer line of Rutter, 1995 in Fig. 6.5) and do not leave the GSS flow field (of $n=3.3$ ) where CPO fabrics can be developed and strengthened (Walker et al., 1990). Fig. 6.5 shows that for the differential stress range of 153-25 MPa calculated in Chapter 4 (when the veins were undergoing deformation at transiently high strain-rates through to low differential stress static recrystallisation) the deformation conditions remain in the field where the CPO fabrics will not be weakened (shaded box along piezometer line in Fig. 6.5). This prediction of the deformation conditions from flow laws shows that calcite CPO fabrics can be strengthened throughout the ductile deformation period estimated in Chapter 4 for the shear zones in the Southern Alps.

In contrast to the quartz CPO fabrics, the calcite fabrics throughout all sections of the shear zones are very similar indicating the strain forming the CPO was, in fact, more distributed throughout the shear zone than the localised strain in the most deformed and shear infilling vein sections suggested by the quartz CPO fabrics. This is not unexpected as the microfabrics show that recrystallisation has occurred away from the highly deformed sections in the sheared veins (Chapter 4). This observation and the very strong calcite CPO fabrics suggest that calcite was able to form a fabric from lower strains and has not been affected by the various fabric weakening processes outlined in Chapter 5. 


\section{CHAPTER 7: Discussion and conclusions}

In this section I will summarise and discuss the deformation path of the brittle-ductile shears from their nucleation at $21 \pm 5 \mathrm{~km}$ below the Southern Alps to the final imprints of ductile deformation affecting them during their upward transport on the Alpine Fault. The shear zones occur in the hanging wall of the Alpine Fault, where they accommodated ramping of the Pacific Plate crust onto the Australian Plate. Uplift of the Pacific Plate is in part accommodated by backshearing at the base of the Alpine Fault ramp, a site where transiently high strain-rates are predicted (e.g. Batt and Braun, 1999; Erickson et al., 2001; Chapter 2). These shears occur as part of a regularly spaced array, and have here been examined by means of fieldbased structural studies and by optical microscopy to gain a better understanding of their deformation path at mid-crustal depths in the Southern Alps of New Zealand.

The microstructures in sheared quartz-calcite veins deformed across the shear zones are recrystallised and have weak crystallographic fabrics which is unusual given that they have undergone a mean finite ductile shear strain of $4.8 \pm 0.7$ (Chapter 3). Preserved microstructures have shown that the veins have undergone three deformation phases during their progression up the Alpine Fault ramp: 1) static recrystallisation, 2) Regime 1 dislocation creep and 3) late stage semibrittle flow (Chapter 4). The crystallographic fabrics of quartz and calcite in the veins distinguish two earlier phases of deformation not observed in the microstructures: 1 ) dynamic recrystallisation, and 2) a period of CPO fabric weakening from grain boundary sliding (Chapter 5). The CPO fabrics in the sheared veins have also shown that the finite ductile extension direction $[\mathrm{x}]$ during shear zone deformation was not always parallel to the independently well known displacement vector for the shears and that the three-dimensional kinematics of flow during the evolution of the shear zones was more complex than previously thought.

In this discussion I will examine the three-dimensional strain that is associated with models of transpressional deformation. I will also suggest a five phase deformation path for the shears that represents a synthesis of all the data collected in this study. This path incorporates constraints that are derived from consideration of the relevant experimental flow law parameters for quartz and calcite. This proposed deformation path will attempt to explain the evolution of the 
shear zones from their generation at the base of the Alpine Fault ramp through to their exhumation and erosion at the surface.

\subsection{Triclinic deformation symmetry}

In obliquely convergent orogens bulk deformation in a parallel-sided zone need not occur by simple shear, or even by a two-dimensional combination of simple shear and plane strain extension (e.g. Fig. 7.1a); but may, for example, occur by three-dimensional flow that includes some combination of irrotational vertical and horizontal extensions together with shear (Dewey et al., 1998; e.g. Figs. 7.1d and 7.1e). A commonly used model of transpression has a monoclinic symmetry and includes an irrotational vertical extension perpendicular to the shear direction together with a horizontal simple shear (e.g. Sanderson and Marchini, 1984; Tikoff and Greene, 1997). Natural transpressive strain maybe more complex than this, for example the flow may instead have a triclinic symmetry (e.g. Robin and Cruden, 1994; Jiang and Williams, 1998; Jiang et al., 2001). As I will argue, the shears in the Southern Alps have deformed internally by a triclinic pattern of general transpression. This triclinic symmetry is where the finite extension direction is neither parallel nor perpendicular to the shear vector, specifically, where the shear related vorticity vector is not parallel to any one principle direction of the symmetric strain tensor (Robin and Cruden, 1994). This flow pattern reveals complex threedimensional strains that might be recognised by a combination of shear offset and finite extension that is oblique to the shear direction (e.g. Passchier, 1998; MacCready, 1996; Jiang et al., 2001).

I recognise triclinic symmetry in the pattern of flow affecting the deformed veins in the Southern Alps from the discordance between their near-vertical ductile extension direction (derived from CPO fabrics) and the moderately pitching finite displacement vector that is consistently recorded by the mineral lineations that decorate the shear planes and displaced planar markers. Within the mean shear plane, the mean displacement vector [a], pitches at $35^{\circ}$ from the southwest and the mean CPO-derived shear direction [x], pitches southwest at $80^{\circ}$ in deformed quartz and at $85^{\circ}$ for deformed calcite (see Chapter 5, Chapter 6, Fig. 7.2). The extension direction is neither parallel nor perpendicular to the independently measured shear 


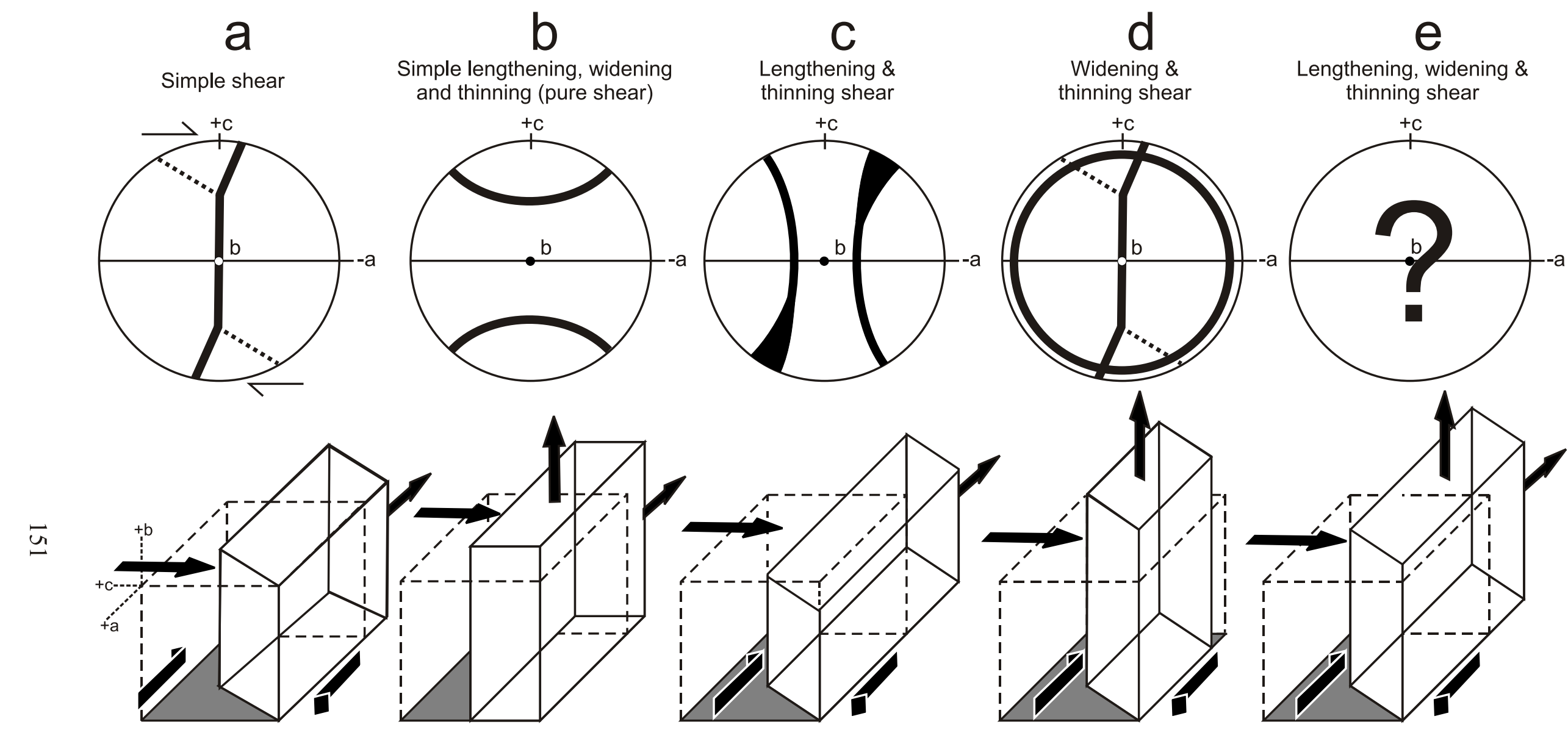

Fig. 7.1. Models of deformation and the inferred crystallographic preferred orientation (CPO) patterns that would be seen in the vorticity plane (a-c plane). Use of the terms widening, lengthening and thinning are based on the strain facies of Tikoff and Fossen (1999) and CPO patterns are based on predictions by Passchier (1998) and this study. a. Model of simple shear and plane strain deformation with a Type I CPO pattern and an internal asymmetry. b. Thinning deformation without any shear which is inferred to yield a small circle CPO pattern. c. Thinning and shearing of a shear zone with principle extension in the shear direction (lengthening) that yields an inferred cleft girdle CPO pattern with an internal asymmetry to reflect the rotational component of the shearing. This could also be a Type I or Type II CPO pattern depending on the ratios of shear extension, vertical compression and thinning strain. d. Thinning and shearing with principle extension in the vertical direction (widening). A Type I CPO pattern centre with an internal asymmetry representing the rotational component of the deformation and a circle around the outside edge representing the finite vertical extension is predicted for this deformation. e. A complex combination of flattening, widening and lengthening shear deformation in a shear zone which may produce a random CPO fabric from the competition between extension directions for a preferred crystallographic preferred orientation. 
a

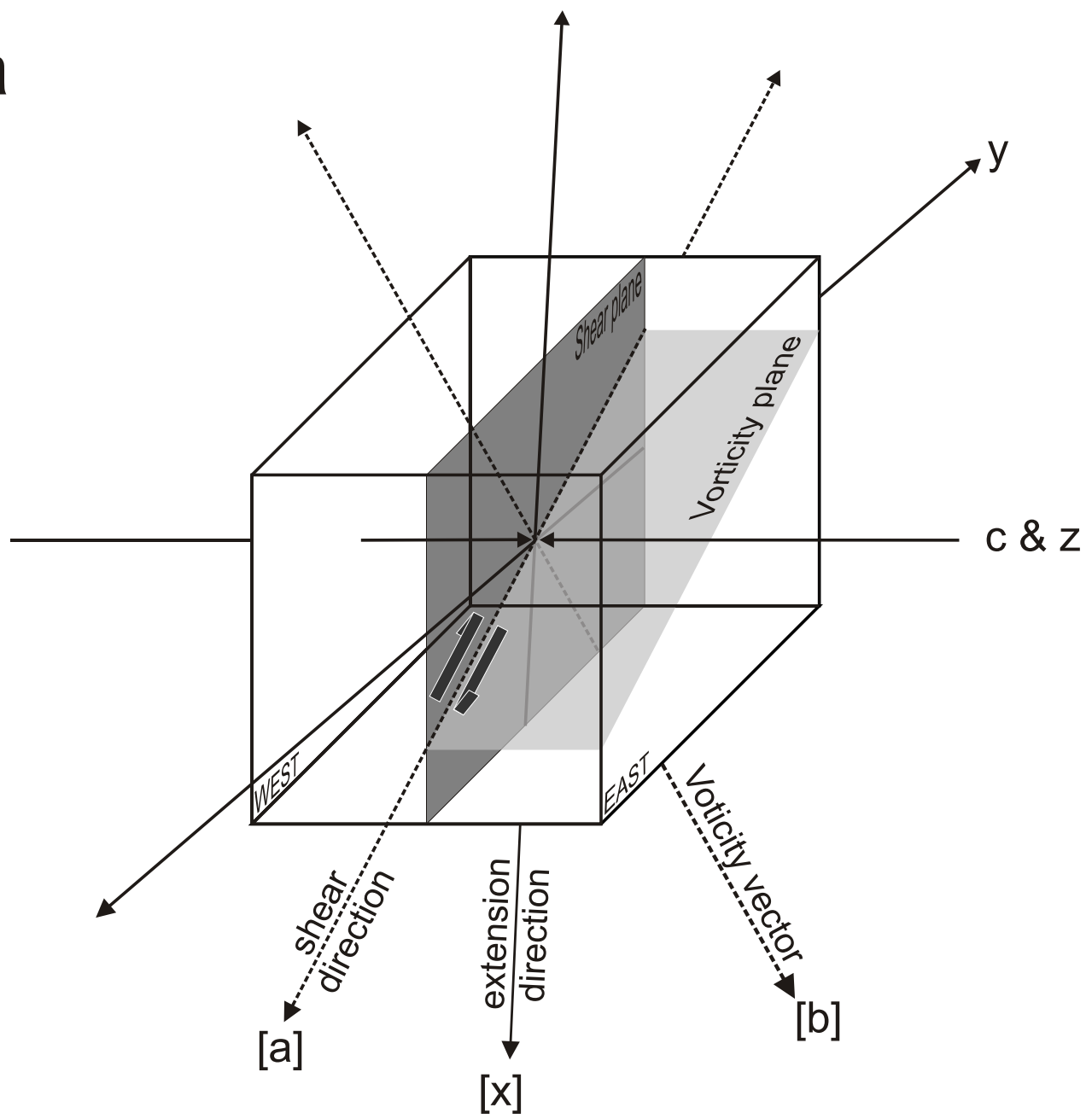

b

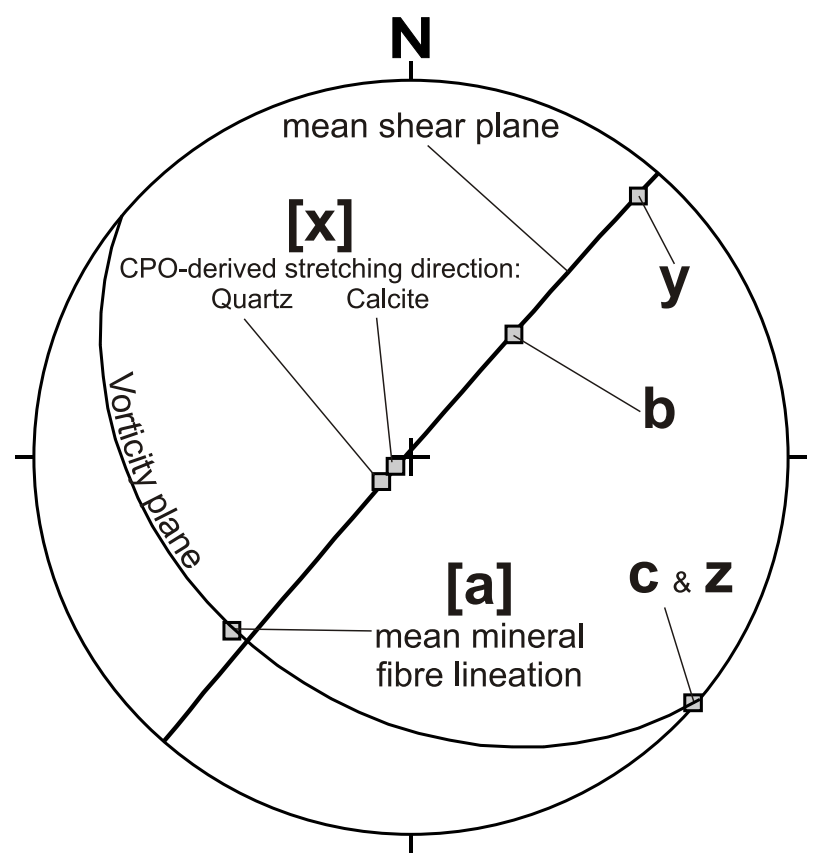

Fig. 7.2. Schematic three-dimensional block diagram of a Southern Alps shear zone (a) and stereogram of extension directions and symmetry poles (b). The quartz CPO-derived stretching direction [x] of 239, 79 $\pm 11^{\circ}$, the calcite CPO-derived stretching direction [x] of $201,85 \pm 7^{\circ}$, and the mineral fibre lineation [a] (shear direction) of $226,35 \pm 6.9^{\circ}$. The attitude of the shear plane is $221 @ 89 \mathrm{~W} \pm 1.1^{\circ}$ and the vorticity plane is perpendicular to the shear plane and contains the shear direction line. The difference between the displacement vector $[\mathrm{a}]$ and the CPO-derived stretching directions $[\mathrm{x}]$ is not $90^{\circ}$ but closer to $\sim 45^{\circ}$. 
vector, indicating that the shear zone has not deformed by simple shear, plane strain or a general transpressive flow of monoclinic symmetry (e.g. Fig. 7.1).

The CPO fabrics that have been used to define the CPO-derived stretching directions $[\mathrm{x}]$ typically that have CPO patterns consistent with an irrotational strain that is either constrictional or plane strain. As I have argued in Chapter 5, these CPO fabrics are recording the finite extension direction resulting from the deformation. Apparently in the Southern Alps the irrotational component of the flow has the predominant affect on the CPO fabric alignment and asymmetry. These irrotational CPO patterns broadly compare with the tentative predictions by Passchier (1998) for CPO fabrics after deformation with a monoclinic symmetry (Fig. 7.1c and Fig. 7.1d). However, unlike Passchier's prediction, where both the irrotational stretching and the shear are represented in the finite CPO (e.g. Fig. 7.1d), the CPO fabrics in this study are dominated by an irrotational CPO that is centred about a near-vertical $[\mathrm{x}]$ extension direction. The CPO fabrics were only recording the near-vertical ductile extension and no CPO patterns (shear or flattening) were related to deformation in the vorticity plane (Fig. 7.2). This was unexpected, as the large finite ductile shear strains $(5.4 \pm 1.4$ for sampled veins) would have been more than sufficient to produce a strong CPO fabric about the vorticity vector in the case of simple shear deformation (see Chapter 5).

The generation of a CPO fabric that is not related to deformation in the primary vorticity plane might be explained by the following strain modelling of Tikoff and Teyssier (1994). In a general flow the strain related to the shearing accumulates less efficiently than that related to the irrotational component. This appears to be reflected in the CPO fabrics of the Southern Alps shears. Numerical strain modelling shows that the maximum extension direction rotates progressively towards the shear zone boundary from and angle of $\leq 45^{\circ}$, and is not coincident with the instantaneous maximum extension direction. However, the intermediate principle strain axis (b-pole for monoclinic flow pattern) does not rotate during shearing so the finite and instantaneous extension directions are coincident. This material line therefore does not rotate during the flow. This coincidence might result in an efficient strengthening of the irrotational CPO fabrics related to the near- 
vertical finite ductile extension direction, whereas CPO fabrics related to the rotational shearing are poorly reflected in the final CPO fabric.

The absence of a CPO fabric as viewed in the vorticity plane might be explained by the numerical strain modelling of Fossen et al. (1994). They show that in a monoclinic transpression the vertical extension direction will quickly become dominant over an initial horizontal maximum finite extension that temporarily is aligned in the vorticity plane at an acute angle to the shear direction. With increased finite shear strain (or initially if the convergence angle to the shear zone is $>20^{\circ}$ ), the maximum principle extension direction that is initially parallel to the shear direction [a] rotates into the vertical extension direction for monoclinic symmetry (Tikoff and Tessier, 1994). This means that the vertical extension undergoes more rapid lengthening than any other line in the deforming body. I infer therefore that the lack of a CPO fabric in the vorticity plane of the Southern Alps samples must be due to the fabric alignment being dominated by the effect of the near-vertical extension direction that is chiefly accommodating the irrotational thinning of the shear zones. The orientations of quartz and calcite c-axes are thus chiefly aligned for easy slip in this direction within the transpressive shear zone. The CPO fabrics might evolve in a complex way as a consequence of the shearing, shear parallel extension and nearvertical extension, but at high finite shear strains dominantly reflect the irrotational component causing the vertical maximum principle extension.

As discussed above, the stable finite extension direction in a monoclinic flow symmetry will be perpendicular to the shear direction (as illustrated in Fig. 7.1); however, in a triclinic flow symmetry the stable finite extension direction at high strain is not necessarily perpendicular to the shear direction by might be disposed at some other angle (Robin and Cruden, 1994; Llana-Funez, 2002). In the Southern Alps samples this angle, measured in the plane of shearing, is $\sim 45^{\circ}$ (Fig. 7.2). This is the pitch of the ductile extension direction, $80^{\circ}$, less that of mineral lineation direction, $35^{\circ}$. Due to the consistency of this angle in all of the shear zone samples measured $(n=17)$ in this study, I infer that the CPO-derived extension direction $[\mathrm{x}]$ represents the steady-state direction of maximum finite extension in a general (triclinic) shear zone flow. 
Asymmetric CPO fabrics were measured in $\sim 2 \%$ of the samples from this study, i.e. those with Type I CPO patterns with an internal fabric asymmetry (e.g. Sample 4 from Fig. 5.6). The apparent vorticity plane related to this asymmetry is not parallel to the vorticity plane of finite shearing, but instead is perpendicular to the shear plane and contains the CPO-derived extension direction [x]. In other words, the only evidence in the CPO fabrics for shearing is near-vertical with a shear direction parallel to the finite extension direction. Jones et al. (2004) has shown that a rotational component to the flow can exist in both the primary shear direction and in a secondary direction that reflects the irrotational stretching. This is likely to be similar to that described by Tikoff and Fossen (1999) for porphyroblasts rotating in the vertical extension direction due to a reduction in the shear parallel extension. This secondary shear can be visualised as a consequence of heterogeneous vertical stretching near the boundary of the deforming zone, a situation which sets up a boundary shearing that is sub-parallel to $[\mathrm{x}]$ and that can be bi-vergent to the bulk shear sense (Fig. 7.3b).

Triclinic deformation symmetry that is inferred to have affected the shear zones in the Southern Alps is illustrated in Fig. 7.3. The block models in Fig. 7.3 represent a highly deformed sheared vein that it is undergoing a primary shear in the direction of the mineral lineations [a], but in which the maximum finite extension is accumulating in a near-vertical direction $[\mathrm{x}]$ as a result of the dominance of the irrotational aspect of the flow on the overall strain. These models show a 'vertical escape' of material from between two non-deformed blocks. This is schematic only as the wall rocks have probably also been extended to some extent parallel to the $[\mathrm{x}]$ direction, in a more realistic case of stretching faults (Means, 1989). With increased strain, the model in Fig. 7.3a with extension both shear parallel and in the nearvertical direction may evolve to a model such as $7.3 \mathrm{~b}$ where the primary extension is in the near-vertical direction.

The observed variation in quartz CPO patterns in the highly deformed internal sections of sheared veins might be explained by variations on a triclinic flow with vertical extension. Varied proportions of thinning and extension in the [a] and the $[\mathrm{x}]$ direction could produce the observed range of CPO dispositions (e.g. Fig. 7.3). Small circle CPO patterns could form from the dominance of irrotational strain in a shear zone with orthorhombic extension symmetry (Fig. 7.3a). A range of CPO 

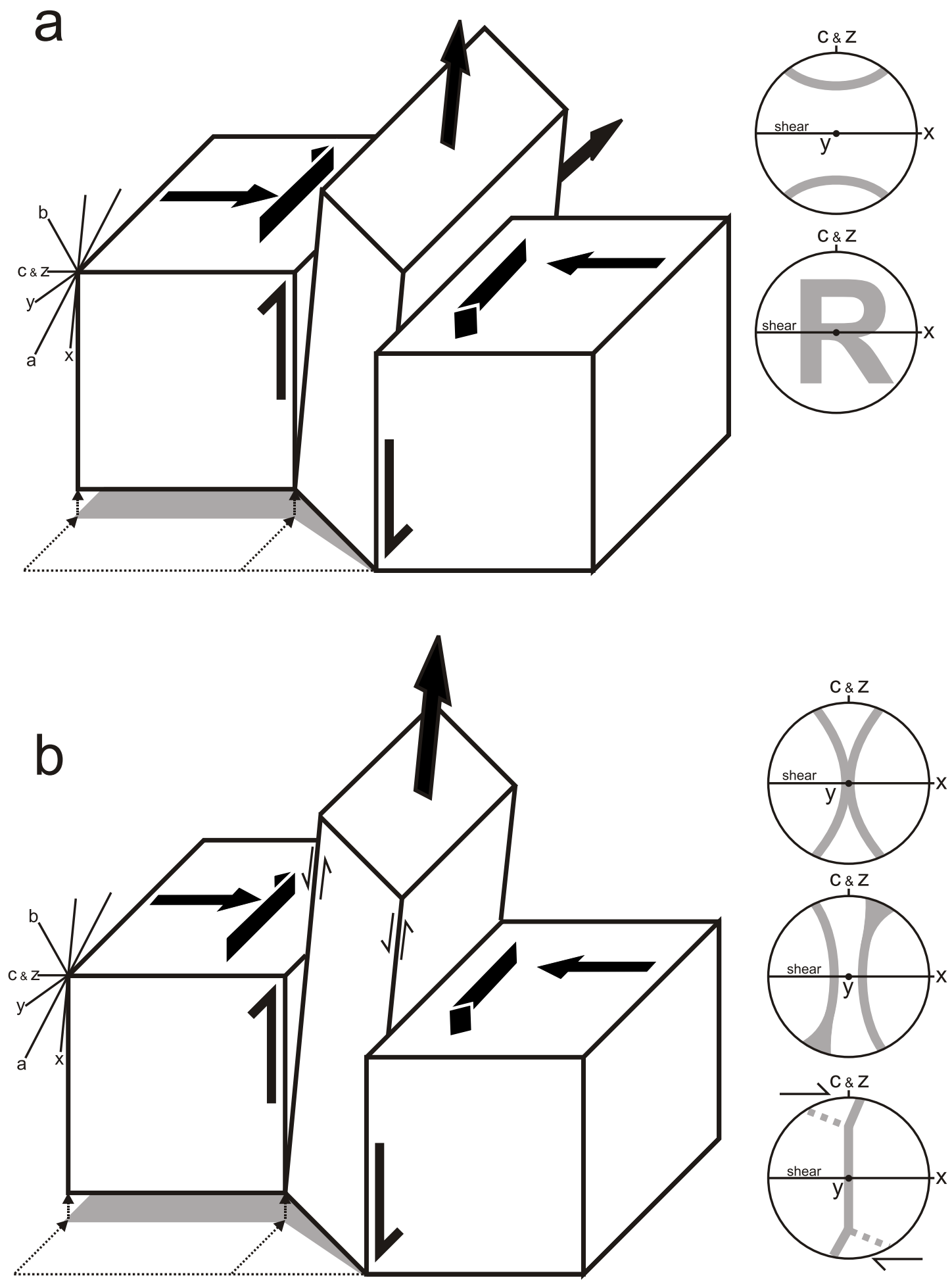

Fig. 7.3. A model of triclinic deformation in a Southern Alps shear zone and some of the CPO patterns that might be anticipated. a. Schematic illustration of shearing with shear displacement and extension parallel to the mineral lineation $[\mathrm{a}]$ and the near-vertical extension $[\mathrm{x}]$. This might generate a flattening CPO pattern (small circles) because of the dominant irrotational and flattening strain or a random CPO pattern from complex overprinting relationships during the deformation. b. Schematic illustration of shearing with the shear displacement parallel to the mineral lineation [a] and the finite extension in the near-vertical [x] direction. An array of CPO patterns (Type II, cleft girdle, or Type I) could be expected during this deformation depending on the ratio of extension between the shear normal compression, the shear parallel extension (or contraction) and the near-vertical principle extension direction. d. The CPO patterns plotted here have an internal asymmetry that represents possible boundary shearing in the $[\mathrm{x}]$ direction as a result of vertical extension and thinning between the two fault blocks (small shear sense arrows shown on the escaping section of rock). 
patterns could be produced from a principle extension in the near-vertical direction (Fig. 7.3b) depending on the amount of constriction in the shear direction. Cleft girdles are anticipated for a more constrictional flow, whereas Type I and Type II CPO patterns would be expected for a more plane strain extension and may have a fabric asymmetry if a vertical shear was occurring as well as extension. The complexity of the flow, its triclinic symmetry, and evolving three-dimensional strain path might be anticipated to produce weak or random CPO fabrics as extension directions compete for easy crystallographic slip (Fig. 7.3a).

\subsection{Deformation Sequence}

A five phase deformation path is suggested here for the Southern Alps brittleductile shear zones. This deformation path reflects decreasing temperatures together with inferred variations in differential stress and strain-rate. These result from activation of the shear zones in the transient brittle-ductile transition zone (t-BDTZ), shearing along them, and finally a cessation of plastic creep as they were exhumed through the long-term (stead-state) brittle-ductile transition zone (s-BDTZ) on their way to the surface.

\subsubsection{Phase A: Brittle-ductile shearing}

The first phase of deformation accompanied initiation of the shears as brittle faults (in quartzofeldspathic schist) and ductile shear zones (embedded quartz veins) at a nucleation depth of $21 \pm 5 \mathrm{~km}$ beneath the Southern Alps. This is the inferred depth of the transient brittle-ductile transition zone (t-BDTZ) related to the ramping of the Pacific Plate onto the Alpine Fault ramp (Little et al., 2002b; Wightman, 2005). Temperature estimates from oxygen isotope thermometry and chlorite thermometry by Wightman (2005) for the primary deformation at $450 \pm 50^{\circ} \mathrm{C}$, compares well with the $\sim 400^{\circ} \mathrm{C}$ estimate in this study based on CPO fabric concentrations and apparent slip systems in quartz (see Chapters 4 and 5). Fieldbased measurements of finite ductile shear strain have allowed for a maximum estimated strain-rate of $3.0 \times 10^{-11} \mathrm{sec}^{-1}$ to be calculated. This assumes that a shear was active for the time period required for a $\sim 100 \mathrm{~m}$ wide block of rock to pass through the backshear zone (see Chapter 4). 
Recrystallisation has removed the original deformation grain-boundary microstructures that were produced during the early phases of the quartz-calcite vein shearing rendering recrystallised grain size and calcite twin piezometers inappropriate. However, using the estimated maximum strain-rate, the deformation temperature, and experimental flow laws a differential stress of $\sim 160 \mathrm{MPa}$ for ductile shearing of quartz and calcite veins has been estimated. These veins and the Alpine Schist are however limited to a maximum differential stress of $353 \mathrm{MPa}$ where brittle Coulomb failure of the rock will occur at a depth of $21 \mathrm{~km}$ with a near-hydrostatic fluid pressure $(\lambda=0.6)$. However, fluid pressure is more likely near-lithostatic $(\lambda=$ 0.9) at these depths and is inferred to have caused the transient deep embrittlement of the schist and veins in the shear zones at the estimated nucleation differential stress of $\sim 160 \mathrm{MPa}$.

From the crystallographic preferred orientation (CPO) of quartz and calcite grains, dislocation creep is inferred to have taken place in quartz during ductile shearing. At the inferred temperature of $\sim 450^{\circ}$, this deformation in quartz would occur in Regime 2 or 3 of Hirth and Tullis (1992). Recovery mechanisms such as grain boundary migration and subgrain rotation recrystallisation during this dynamic recrystallisation would have caused grain size reduction in the quartz-calcite veins. Complex triclinic three-dimensional strain in the shear zones during this deformation phase may have geometrically weakened the CPO fabrics relative to a simple shear situation during the dislocation creep deformation.

The deformation of quartz and calcite to accommodate the shearing might be modelled using a flow law. Examples of these include power-law creep, exponential creep, grain size sensitive (GSS) flow and a grain size piezometer can also be used for grain size modelling. The flow laws used in this study are listed in Table 7.1 and are chiefly derived on the basis of experimental deformation studies. These flow laws take on the following equation forms:

$$
\begin{aligned}
& \text { Power-law creep: } \quad \varepsilon=A \cdot{ }_{D} \sigma^{n} \cdot f_{\mathrm{H}_{2} \mathrm{O}}{ }^{w} \cdot \exp \left(\frac{-Q}{R T}\right) \\
& \text { Grain size sensitive flow: } \quad \varepsilon=A_{{ }_{D}} \sigma^{n} \cdot d^{m} \cdot \exp \left(\frac{-Q}{R T}\right)
\end{aligned}
$$


Exponential creep law: $\quad \varepsilon=A \cdot \exp \left(\frac{-Q}{R T}\right) \cdot \exp \left(C \cdot{ }_{D} \sigma\right)$

Grain size piezometer:

$$
{ }_{D} \sigma=A \cdot D^{-m}
$$

Where: $\varepsilon$ is the strain-rate $\left(\sec ^{-1}\right), A$ is the material parameter, ${ }_{D} \sigma$ is differential stress $(\mathrm{MPa}), \mathrm{n}$ is the stress component, $\mathrm{f}$ is the water fugacity $(\mathrm{MPa}), \mathrm{w}$ is the water fugacity exponent, $\mathrm{Q}$ is the activation energy $\left(\mathrm{J} \cdot \mathrm{mol}^{-1}\right), \mathrm{R}$ is the ideal gas constant $\left(\mathrm{J} \cdot \mathrm{mol}^{-1} \cdot \mathrm{K}^{-1}\right), \mathrm{T}$ is the temperature $(\mathrm{K}), \mathrm{d}$ is the grain size $(\mathrm{mm}), \mathrm{m}$ is the grain size exponent, $\mathrm{C}$ is the stress factor and $\mathrm{D}$ is the recrystallised grain size (mm).

From the estimated maximum strain-rate and $\sim 450^{\circ} \mathrm{C}$ temperature inferred for the Southern Alps shearing a differential stress of $165 \mathrm{MPa}$ has been calculated using the Hirth et al. (2001) flow law for plastic creep. The Hirth et al. (2001) flow law parameters (Fig. 7.4a; Table 7.1) best describe the natural quartz deformation of this study, unlike the Rutter and Brodie (2004a) parameters which extrapolate from experimental conditions to give unrealistically high differential stresses for ductile quartz deformation (Fig. 7.4a; Table 7.1). As seen in Fig. 7.4a, the predicted quartz recrystallised grain sizes of $8 \mu \mathrm{m}$ from the Twiss (1980) piezometer are not small enough for grain size sensitive flow and the differential stress required to do so would exceed the maximum (353 MPa) for ductile flow (i.e. before brittle Coulomb failure; Fig. 7.4a). Calcite, on the other hand, under these conditions is predicted to undergo plastic and exponential creep $\leq 160 \mathrm{MPa}$. At these stresses calcite is predicted from the Rutter (1995) piezometer to recrystallise to a small enough grain size $(23 \mu \mathrm{m})$ to undergo GSS flow (Fig. 7.4b). This reflects that calcite is weaker than quartz (as in Brodie and Rutter, 2000) and can accommodate strain more easily during the conditions estimated here for brittle-ductile shearing.

A prospective quartz deformation map has been constructed for the Southern Alps shears from the flow law parameters of Hirth et al. (2001) and Brodie and Rutter (2000) to show the boundary between power-law creep (e.g. dislocation creep) and GSS flow (e.g. diffusion creep or grain boundary sliding) for varied recrystallised grains sizes of quartz and differential stresses using equations of the form:

$$
A_{g} \cdot{ }_{D} \sigma^{n_{g}} \cdot d^{m} \cdot \exp \left(\frac{-Q_{g}}{R T}\right)=A_{p} \cdot{ }_{D} \sigma^{n_{p}} \cdot f_{H_{2} O}{ }^{w} \cdot \exp \left(\frac{-Q_{p}}{R T}\right)
$$



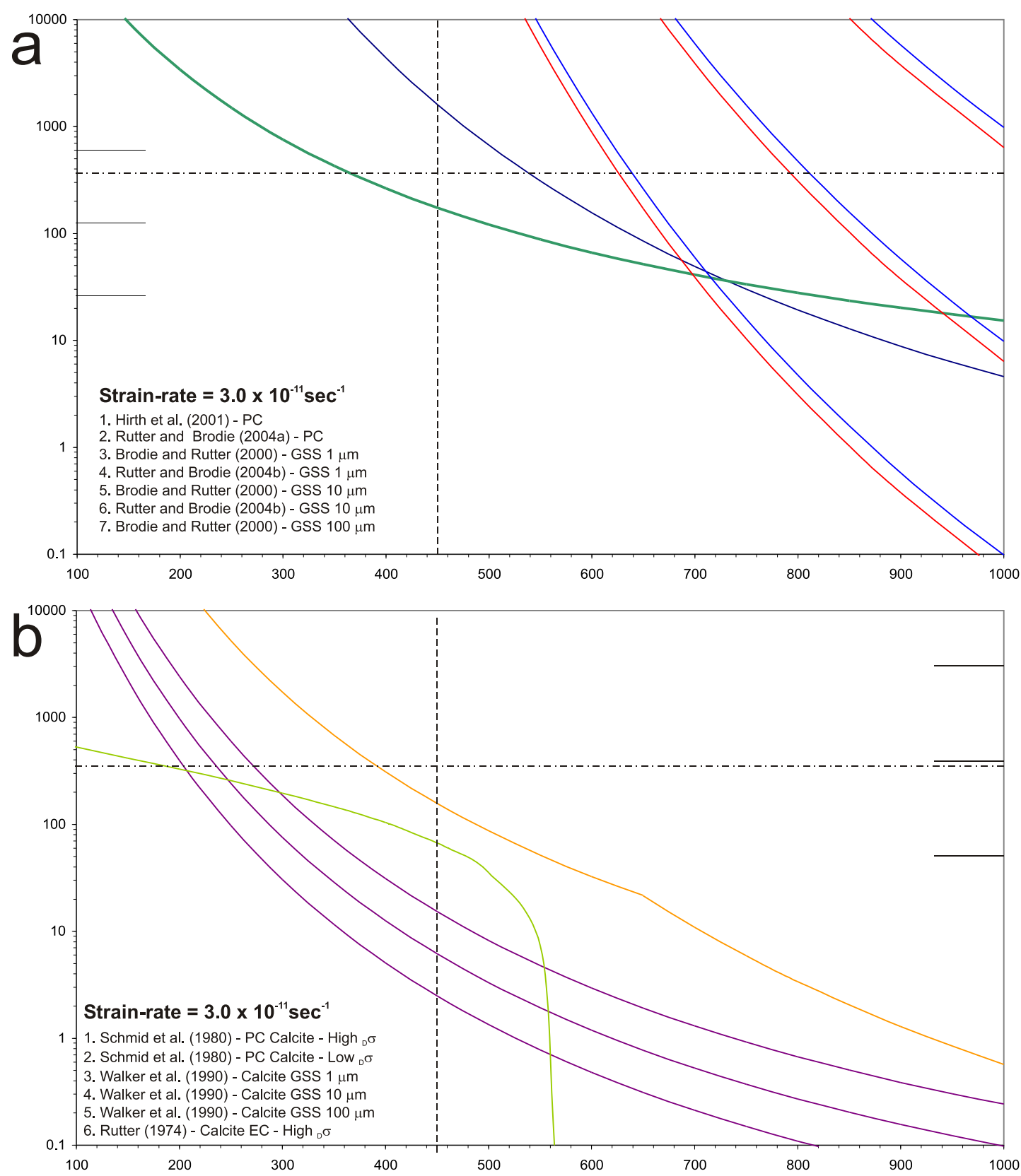

Fig. 7.4. Flow behaviour of qua 
Rearranged to solve for grain size:

$$
\log d=\frac{\left(\log A_{g}-\log A_{p}\right)+\left(n_{g}-n_{p}\right) \log \sigma+\left(\frac{Q_{g}-Q_{d}}{2.3 R T}\right)-w \log f}{m}
$$

It can be seen in Fig. 7.5 that deformation at $450^{\circ} \mathrm{C}$ is predicted to occur solely by dislocation creep for recrystallised grain sizes following the piezometer law of Rutter (1995). Recrystallised grain sizes, strain-rates and differential stresses corresponding to varying widths of backshearing crust (including the preferred approximation of a $100 \mathrm{~m}$ width of deforming shears used for modelling purposes here) are also shown (see Chapter 4 and Table 4.7). These calculated recrystallised grain sizes are all less than the final mean grain size in the sheared veins (Fig. 7.5) which confirms that the microstructures remaining in the veins equilibrated during a lower stress period subsequent to their primary shearing.

A grain size reduction path has been determined for Phase A during early shearing of the quartz veins where grains recrystallise from $\sim 1000-100 \mu \mathrm{m}$ to $8 \mu \mathrm{m}$ as the strain-rate initially builds up to its maximum value (Fig. 7.6). If the maximum strain-rate was faster than $3.0 \times 10^{-11} \mathrm{sec}^{-1}$ or if the fluid pressure was greater than $\lambda$ $=0.85$, then the veins may have undergone brittle failure and the grain size reduction would have been less and only reaching a possible maximum of $16 \mu \mathrm{m}$ for a differential stress of $100 \mathrm{MPa}$ (estimated differential stress required for hybrid extensional failure by Wightman and Little, 2003).

\subsubsection{Phase B: Differential stress drop and grain boundary sliding}

Phase B of the shear zones deformation took place during a period of inferred low strain-rates and shear deactivation as the rocks were transported away from the zone of transiently high strain-rates that resulted in their formation during Phase A. The temperatures at the beginning of this phase were $450 \pm 50^{\circ} \mathrm{C}$, as in Phase A, but might have dropped slowly as the rocks were advected upwards towards the surface. Phase B was marked by a reduction in inferred differential stress to as low as $22 \mathrm{MPa}$ and strain-rate as low as $1 \times 10^{-14} \mathrm{sec}^{-1}$. A pressure and rate determined from the mean finite recrystallised grain size measured in the veins of $126 \mu \mathrm{m}$ (Fig. 7.6) using the Twiss (1980) piezometer and the Hirth et al. (2001) flow law parameters for 


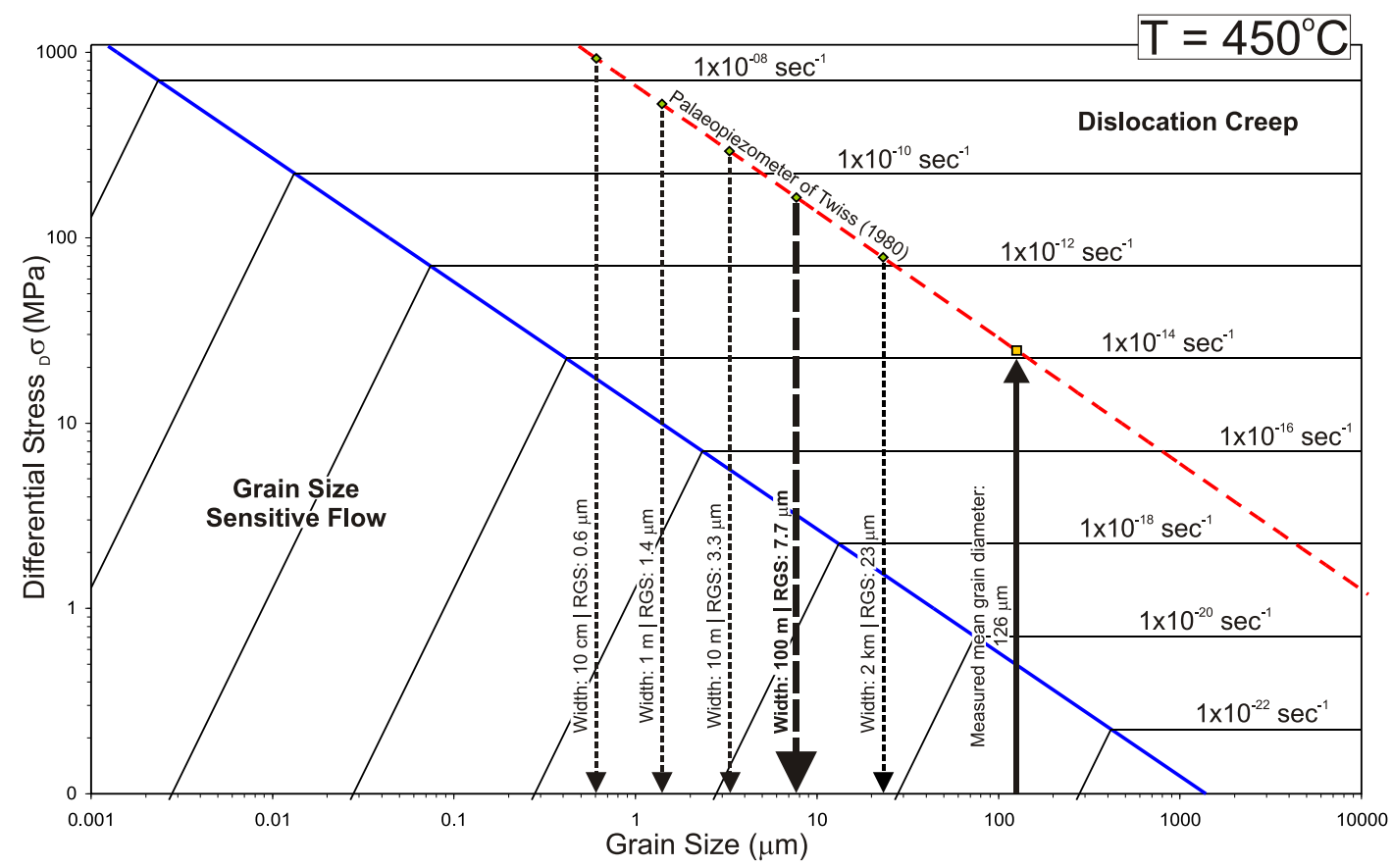

Fig. 7.5. Deformation map for quartz at temperature of $450^{\circ} \mathrm{C}$ and contoured for strain-rate. Produced from the flow law parameters by Hirth el al. (2001) for intracrystalline placticity and Brodie and Rutter (2000) for grain size sensitive flow (GSS) of quartz. Equation for the boundary line can be found in the text and flow law parameters can be found in Table 7.1. Calculated recrystallised grain sizes (RGS) using palaeopiezometer (dash-dotted line) of Twiss (1980) for different widths of deforming rock (dashed and arrowed lines) of $10 \mathrm{~cm}, 1 \mathrm{~m}, 10 \mathrm{~m}, 100 \mathrm{~m}$ and $2 \mathrm{~km}$ (from Table 4.7) with mean finite ductile shear strain of 4.8 and shear normal convergence of $19.7 \mathrm{~mm} / \mathrm{yr}$. Preferred $100 \mathrm{~m}$ width of deforming rock shown in bold. Finite mean grain diameter measured in the highly deformed sheared vein sections from shear zone samples collected in this study (solid arrowed line).

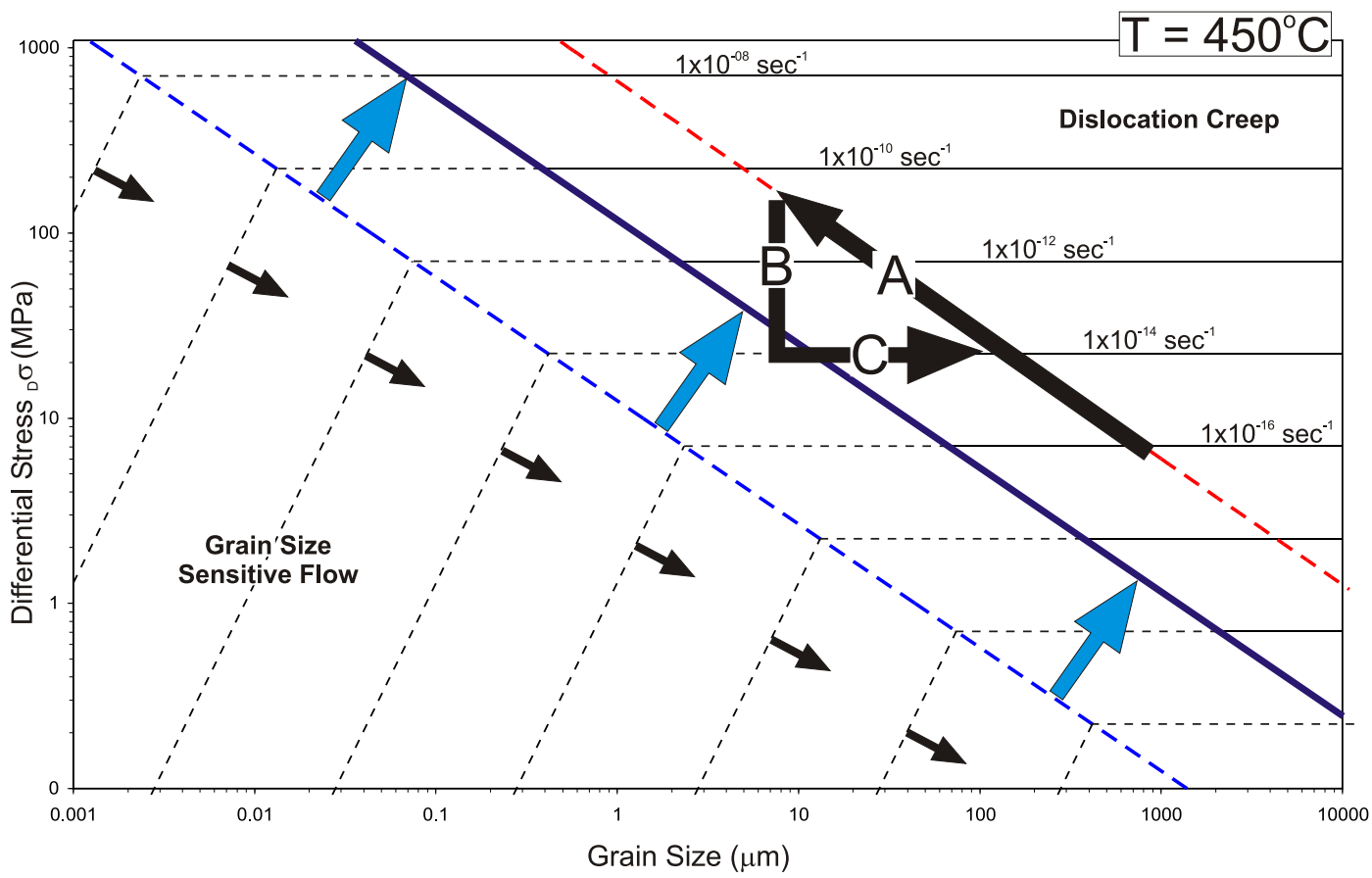

Fig. 7.6. Deformation map for quartz (as in Fig. 7.5 above) at a temperature of $450^{\circ} \mathrm{C}$ and contoured for strain-rate and includes recrystallised grain size piezometer and the boundary line between GSS flow and dislocation creep flow conditions (dashed line). Bold centre line and arrows represent a potential movement of the boundary between the fields from increased water fugacity or easier grain boundary slip for the GSS flow deformation. GSS flow contours with increased water fugacity will move in the direction shown by small arrows. A, B, and C labelled arrows represent the deformation path phases as discussed in the text . 
plastic creep. The decrease in differential stress and strain-rate is shown in Fig. 7.6 (Phase $\mathrm{B}$ deformation path arrow). The differential stress and strain-rate are approximates only and may have been higher or lower as they ignore the effect of post-deformational grain-growth on the palaeopiezometric relationship.

During Phase B, after the drop in differential stress caused by the rocks moving away from the Alpine Fault ramp-step, grain boundary sliding (GBS) is inferred to have been activated as a new deformation mechanism. This process resulted in the partial randomisation of $\mathrm{CPO}$ fabrics in the sheared veins. GBS is a deformation process where grains slide past each other without intracrystalline deformation and this process usually occurs in the presence of fluids which allow potential voids developed during the GBS to be prevented by solid-state diffusion creep (Passchier and Trouw, 1998). This is a grain size sensitive process where the grains need to be small enough and the differential stress low enough, for sliding to occur instead of dislocation creep (White et al, 1980; Lloyd et al, 1992; Brodie and Rutter, 2000).

Largely because of the obliterating affect of later grain growth, direct evidence for GBS, such as small $(<20 \mu \mathrm{m})$ grain sizes in the shears, has not been found in this study. However, very weak to random CPO fabrics in the highly sheared internal parts of quartz veins (see Chapter 5) and microstructural observations of lobate and sutured boundaries between quartz and calcite grains are indirect evidence for GBS. A quartz vein that has a CPO fabric in the section of the vein external to the shear zone and a random CPO pattern in the most highly sheared part of that vein is plausibly attributed to GBS causing a randomisation of the CPO in the most strongly deformed part of the vein (e.g. Behrmann and Mainprice, 1987; Lloyd et al., 1992; Passchier and Trouw, 1998; Wightman, 2005). The lobate and sutured grain boundaries between quartz and calcite grains are evidence for the process of solid-state diffusion creep (Gower and Simpson, 1992; Passchier and Trouw, 1998), required for the accommodation of GBS. From this evidence it is reasonable to assume that GBS occurred at some point during brittle-ductile shearing.

As seen in Fig. 7.5, GBS does not occur while dynamically recrystallised grain sizes are in equilibrium with the differential stress. Rather, a stress drop is 
needed to activate GBS, so long as quartz has a small enough recrystallised grain size, for deformation in the GSS flow field (Fig. 7.5). The differential stress drop required to activate GSS flow and GBS in Phase B for a recrystallised grain size of $\sim 8 \mu \mathrm{m}$ inherited from Phase A, is only $3 \mathrm{MPa}$, much less than $22 \mathrm{MPa}$ (Fig. 7.6). Four possibilities might have allowed GBS to occur despite the $8 \mu \mathrm{m}$ grain size: a) the grain size was smaller than estimated because of a faster strain-rate in Phase A, 2) the stress drop was actually greater than the that inferred from the final measured grain size, 3) the effects of fluids enhancing GBS not accounted for in the GSS flow law, and 4) the effects of calcite and micas aiding the GBS or quartz in polymineralic veins.

If the estimated minimum grain size from dynamic recrystallisation during Phase A was actually smaller than $8 \mu \mathrm{m}$ because the strain-rates had been higher than $3 \times 10^{-11} \mathrm{sec}^{-1}$ (i.e. the deformation width was $<100 \mathrm{~m}$ ) then the dislocation creep induced grain size might have been as low as $\sim 1 \mu \mathrm{m}$, allowing GBS at differential stresses of $10 \mathrm{MPa}$. The drop in differential stress might also have been greater than shown in Fig. 7.6. The finite grain size and the quartz piezometer only give the finite differential stress after grain growth and this may have been lower before grain equilibrated with the lower differential stress.

The two other alternatives invoke a change in the GBS flow law to explain this deformation mechanism taking place in natural conditions in the Southern Alps. White et al. (1980) have shown that after considerable grain size reduction, when there is abundant fluid available, the boundary between GSS flow and dislocation creep will shift in favour of GBS (as shown in Fig. 7.6). For example, grains might undergo solid-state diffusion creep accommodated GBS at higher differential stresses than would be possible in dryer conditions. Such hydrological weakening is a common failure in extrapolated experimental flow laws which are used to predict natural quartz deformation (Farver and Yund, 2000; Tullis, 2002). The infilling veins and their fluid inclusions indicate that fluid was present during the shear zone deformation as well as diffusion creep microstructures (see Chapter 4). The plastic creep flow law parameters used in Fig. 7.5 take this fluid into account using a water fugacity function (equation 7.1), however the GSS flow laws currently available in the literature do not, and the effect of fluid in Equation 7.5 would cause the 
deformation boundary to expand into the dislocation creep field (as approximated in Fig. 7.6).

Starkey and Cutforth (1978) have shown that the roll of impurities (such as micas and calcite) in a sample can enable GBS to occur at higher differential stresses or larger grain sizes. Relatively weaker mica and calcite crystals precipitated between quartz grains can enable quartz to slide more easily along its grain boundaries during deformation than by internal crystallographic slip. As shown in Chapter 5, the presence of calcite is associated with quartz CPO fabric weakening and therefore might have enhanced GBS in the sheared veins. Grain sizes of quartz as large $30 \mu \mathrm{m}$ have been known to undergo GBS at strain-rates of $1 \times 10^{-16} \mathrm{sec}^{-1}$ (pers. comm. Takeshita and Heilbronner; in Wightman, 2005). It appears therefore, that GBS is likely in Phase B, as there are several exceptions that would allow GSS flow during conditions when experimental flow laws predict dislocation creep.

In short, I attribute the weak CPO fabrics in the strongly sheared quartz veins primarily to partial randomisation of those CPO fabrics inherited from Phase A during a Phase $\mathrm{B}$ deformation that included GBS under conditions of reduced differential stress. Completely randomised CPO fabrics only occur in the internal vein sections of 3 of the 17 shear zone samples examined. GBS is the most likely deformation mechanism for the complete fabric randomising; however, the remaining samples that still had a CPO fabric (although weak) may have undergone lesser amounts of GBS during this Phase B deformation. This may have been due to conditions not being met for GSS flow (grain size and strain-rate) or the period of time that conditions were favourable for GSS flow was not maintained for long enough in these shear zones for complete randomisation to occur. Calcite CPO fabrics that are much stronger than the quartz fabrics and do not show microstructural evidence for GBS (Chapters 4 and 6) and from flow laws (Fig. 6.5) are not estimated to have undergone GSS flow (where GBS occurs in calcite) during deformation in Phase B (Chapter 6). From the varied fabric strengths of sheared quartz vein samples it is clear that GBS in Phase B deformation affected individual shear zones and minerals differently. 


\subsubsection{Phase C: Static recrystallisation and grain growth}

Grain growth and static recrystallisation of deformed veins defines Phase C of the shear zone deformation. This recrystallisation was probably driven by grain boundary area reduction (GBAR); a process that increases the mean grain size of a sample and overprints a deformation related grain shape fabric (GSF) with a equigranular-polygonal GSF. The temperature at which the coarsening took place may have been $300-400^{\circ} \mathrm{C}$ and would have decreased as the BDSZ is translated further up the Alpine Fault ramp towards the surface. The strain-rate and differential stress for Phase $\mathrm{C}$ could not have exceeded, $1 \times 10^{-14} \mathrm{sec}^{-1}$ and $22 \mathrm{MPa}$ based on the final $126 \mu \mathrm{m}$ recrystallised grain size, the Hirth et al. (2001) flow law and the palaeopiezometer of Twiss (1980). The coarsening of the equilibrium grain size for Phase $\mathrm{C}$ deformation is illustrated with a horizontal arrow in Fig. 7.6.

Static recrystallisation occurs when the strain-rate is so low (e.g. $1 \times 10^{-15} \mathrm{sec}^{-}$ ${ }^{1}$ ) that significant creep and dynamic recrystallisation does not take place (Pfiffner and Ramsay, 1982; Stipp et al., 2002a). With ample fluid available along grain boundaries and in the crystal structure GBAR would be the main method of recovery during this static recrystallisation. This is a process of grain boundary migration where grain growth and straightening of grain boundaries occurs creating an equigranular-polygonal grain shape fabric (Passchier and Trouw, 1998). During GBAR the internal strain energy of a grain that is deformed during dislocation creep is recovered by preferential overgrowth of large grains that are relatively strain free (van der Pluijm and Marshak, 1997). Reduction of high internal energy grain boundaries between like grains and the increased development of low angle boundaries between unlike grains with lower internal energy boundaries promotes grain shape anisotropies in polymineralic veins during GBAR (Passchier and Trouw, 1998). Grain shape anisotropies observed in the Southern Alps samples between quartz and calcite and equigranular-polygonal grain shape fabrics in the deformed veins (both their internal and external sections, see Chapter 4) are evidence for this static grain growth during Phase $\mathrm{C}$.

During static recrystallisation, CPO fabrics generated during dynamic recrystallisation are largely preserved (Heilbronner and Tullis, 2002) and subgrain and grain misorientation relationships are mostly unaffected by static 
recrystallisation (Bestmann et al., 2005). These two experimental studies illustrate that the CPO patterns are only somewhat weakened, or diffused, during static recrystallisation and not lost completely. This recrystallisation is considered an addition CPO fabric weakening process in the Southern Alps samples. It is most likely responsible for the weakened CPO fabrics and diffused patterns across the entire shear zone, unlike GBS which localised fabric weakening in the most deformed sections of the sheared veins.

\subsubsection{Phase D: Final increment of ductile strain during uplift}

Microstructures preserved in the quartz and calcite microfabrics suggest relatively minor dynamic recrystallisation and dislocation creep took place in sheared quartz veins after the static recrystallisation of Phase C. Subgrain boundaries, grain boundary bulging, deformation lamellae, undulose extinction, fluid inclusion planes and calcite twinning are all evidence for this late stage dislocation creep and are classified as Regime 1 of Hirth and Tullis (1992). Some minor occurrences of core and mantle microstructures suggest that dynamic recrystallisation was able to occur, however it was not dominant. The oblique grain shape fabrics (GSF) observed in the infilling veins also record a deformation increment that was superimposed upon a previously annealed microstructure. These GSF's have a dextral west-side-up shear sense with a shear direction parallel to the moderately southwest pitching finite displacement vector (see Chapter 4).

Phase D deformation occurred in Regime 1 of Hirth and Tullis (1992) between temperatures of 280 and $400^{\circ} \mathrm{C}$ (as in Regime 1 deformation of natural rocks in Stipp et al., 2002b). Subgrain boundaries are uncommon, so temperatures were not as high as those required for Regime 2 of Hirth and Tullis (1992). I infer that the rocks were deforming towards the higher end of Regime 1 in Phase D. As a result of progressive cooing of the rocks, and if the strain-rate was maintained from Phase $\mathrm{C}$, the Hirth et al. (2001) flow law for quartz suggests an increasing differential stress. This is represented by the Phase D arrow in Fig. 7.7a. This increase in differential stress is most likely the cause for these renewed dislocation creep microstructures. As seen in Fig. 7.7b, calcite was not able to undergo plastic creep as easily at these lower strain-rates and temperatures because of the high differential stress required to activate the $\{r\}$ and $\{f\}$ slip planes and would have been deforming dominantly by 

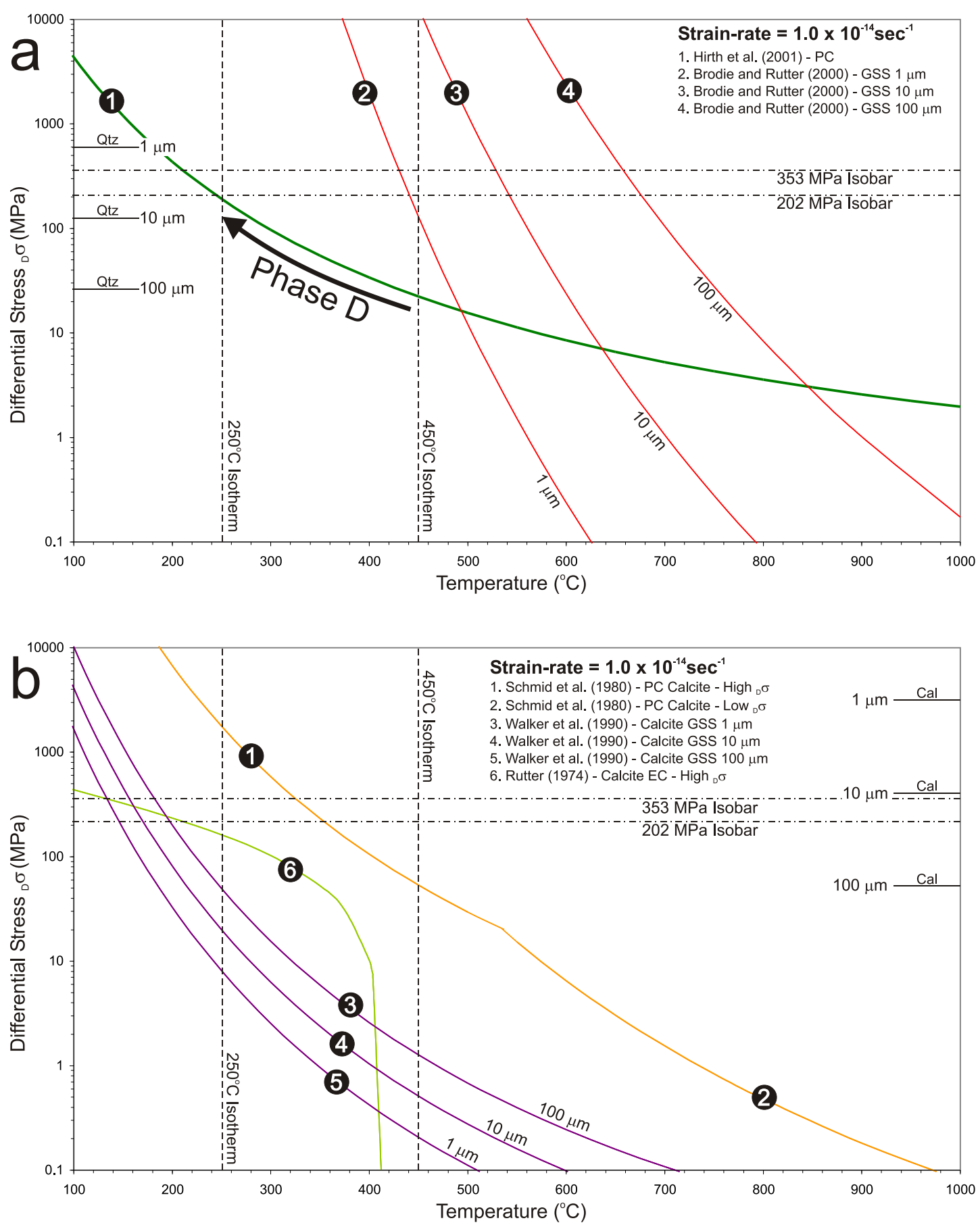

Fig. 7.7. Flow behaviour of quartz (a) and calcite (b) for strain-rate of $1.0 \times 10^{-14} \mathrm{sec}^{-1}$ for plastic creep (PC), grain size sensitive flow (GSS) and exponential creep (EC). PC flow law of the form $\varepsilon=A \cdot \sigma^{\mathrm{n}} \cdot f_{\mathrm{H} 20}{ }^{\mathrm{n}} \cdot \exp (-\mathrm{Q} / \mathrm{RT})$, GSS flow law of the form $\varepsilon=A \cdot \sigma^{\mathrm{n}} \cdot \mathrm{d}^{\mathrm{m}} \cdot \exp (-\mathrm{Q} / \mathrm{RT})$ for grain sizes of $100 \mu \mathrm{m}, 10$ $\mu \mathrm{m}$, and $1 \mu \mathrm{m}$ and EC flow law of the form $\varepsilon=\mathrm{A} \cdot \exp (-\mathrm{Q} / \mathrm{RT}) \cdot \exp (\mathrm{C} . \sigma)$. Stress dependant recrystallised grain sizes of quartz (a) and of calcite from migration recrystallisation (b). Isotherms for $450^{\circ} \mathrm{C}$ and $250^{\circ} \mathrm{C}$ shown for reference. Isobars of $353 \mathrm{MPa}$ and $203 \mathrm{MPa}$ represent maximum differential stress where brittle Coulomb failure occurs (when $\lambda=0.6$ ) at 250 and $450^{\circ} \mathrm{C}$ respectively. Flow law parameters can be found in Table 7.1. Phase $\mathrm{D}$ arrow represents the decreasing temperature during final increment of ductile deformation in the Southern Alps sheared veins. 
twinning and GSS flow as temperatures approached $280^{\circ} \mathrm{C}$ near the end of Phase D deformation.

The microstructures overprinting recrystallised grains in this deformation phase are not restricted to just the most deformed sections but are abundant throughout all parts of the sheared veins. This deformation was not renewed ductile displacement and shear of the veins but a broad deformation of the whole shear zone. However, the microstructures above only form oblique GSF's in the shear infilling veins (see Chapter 4). This implies that some shear deformation was focused into the shear infilling veins and that displacement in the finite shear direction was still occurring to a small extent in the BDSZ on the Alpine Fault ramp.

As dislocation creep is a process that can generate a preferred orientation of grains in a shear zone, the Phase D minimum shear strain estimates of $\sim 1.5$ from oblique GSF's (see Chapter 4) may be responsible for further weakening of quartz CPO fabrics imprinted during Phase A. This is due to this last increment of strain creating a new preferred orientation of quartz for slip in the [a] direction, not the $[\mathrm{x}]$ direction which generated the primary fabrics (see Chapter 5). The strain during this latter Phase D deformation, however, was not large enough to completely overprint the existing CPO fabrics (as in Strine and Wojtal, 2004), but may have been significant enough to weaken an existing CPO fabric.

\subsubsection{Phase E: Semibrittle faulting of quartz and calcite twinning}

The final deformation to affect the shear zones is inferred to have taken place near the s-BDTZ, at the end of the Phase D deformation path line in Fig. 7.7a. At shallower crustal levels and lower temperatures, the rock deformed by semibrittle fracturing rather than by plastic creep. A temperature of $\sim 250-280 \mathrm{MPa}$ is inferred from the transition of ductile to brittle deformation in Stipp et al. (2002b). A maximum differential stress of $202 \mathrm{MPa}$ would have been required for brittle Coulomb failure at this temperature (assuming a $20^{\circ} \mathrm{C} / \mathrm{km}$ geothermal gradient and a minimum pore fluid pressure of $\lambda=0.6$ ). However, if the fluid pressure was closer to lithostatic $(\lambda=0.9)$ then the differential stress required for brittle failure would only be $100 \mathrm{MPa}$. These estimates compare well with the temperature of $\sim 200^{\circ} \mathrm{C}$ and maximum differential stress calculation of $189 \mathrm{MPa}$ I have derived from calcite twin deformation microstructures in the shear zones (see Chapter 4). 
Deformation lamellae and healed microcracks marked by planar alignments of fluid inclusions are consistent with the semibrittle flow and faulting regimes of Hirth and Tullis (1994). Microcracking occurs when internal dislocations rupture at grain boundaries to form brittle cracks and where internal grain dislocations are unable to climb. Recovery by plastic creep is thus hindered at these lower temperatures. Microcracks in the quartz, at the deformation temperature estimated, here would heal instantaneously on a geological time scale (Trepmann and Stöckhert, 2003). Microcracks that propagate across, instead of blunting against, grain boundaries reflect a shift from semibrittle flow to semibrittle fracturing. A decrease in temperature is inferred to have caused such a transition in the Southern Alps rocks (as in Hirth and Tullis, 1994).

Calcite at these temperatures can deform easily by e-twining deformation. In the Southern Alps rocks these deformation microstructures are visible in most calcite grains and similar to the quartz fluid inclusion trails, the e-twins crosscut recrystallised grains and other microstructures formed during Phase $\mathrm{C}$ and $\mathrm{D}$. The crosscutting relationship and the straight and planar aspect of the healed fractures and calcite twins indicate that they formed after the dislocation creep of Phase D. Semibrittle deformation in the shear zones is inferred to have ceased and the final microstructures frozen in when the Southern Alps rocks passed through the s-BDTZ on their way to the surface. 


\subsection{Conclusions}

Exhumed arrays of brittle-ductile shears that have been exposed in the central Southern Alps of New Zealand near the Fox and Franz Josef glaciers have been studied by means of field-based structural mapping and optical microscopy of both microstructures and crystallographic preferred orientations (CPO) of quartz and calcite in sheared veins. The shears are exposed as arrays of systematically spaced shear zones in the host quartzofeldspathic Alpine Schist which has undergone deep embrittlement. By contrast, quartz-calcite veins in the schist have undergone variable brittle to ductile deformation that are the youngest ductile deformation features preserved in the Alpine schist. This study has documented the microstructural evolution of the shears zones from their incidence as backshears at the foot of the Alpine Fault ramp, where rocks of the Pacific Plate were uplifted and subjected to transiently high shear strain-rates, to their recrystallisation during later uplift and exhumation.

Field-based structural mapping of the shear zones at Sam Peak, Chancellor Ridge and Baumann Glacier has been used to determine $2 \mathrm{~km}$ width of the brittleductile shear array and to resolve the kinematics of the shears. The shears have a mean displacement of $9.9 \mathrm{~cm}(\mathrm{n}=344)$ and are spaced on average $25 \mathrm{~cm}$ apart $(\mathrm{n}=$ 410). The shear planes have a mean orientation of $221 @ 89 \mathrm{~W} \pm 1.1^{\circ}(95 \%$ confidence ellipse; $\mathrm{n}=780$ ) and have displaced the Alpine Schist and its veins in a dextral west-side-up sense that is antithetic to the dip-slip sense of the Alpine Fault. The shear displacement vector has been determined from the mineral fibre lineations that decorate the shear plane surfaces and from displaced marker veins, and is 226 , $35 \pm 7^{\circ}(\mathrm{n}=25)$.

The quartz-calcite marker veins have undergone a mean finite ductile shear strain of $4.8 \pm 0.3(n=219 ; 2 \sigma)$. In the host quartzofeldspathic schist the shears occur as brittle fractures that are typically infilled by a syntectonically precipitated quartz-carbonate vein that has also been sheared. Shear spacing is in part controlled by the lithology of the Alpine Schist. Psammitic schist, for example, has more closely spaced shear zones than pelitic schist. While the shear zones in the psammitic schist accommodate much of the ramp related shearing, the pelitic schist 
accommodates a greater proportion of the deformation by microshearing along foliation planes. The variably brittle to ductile expression of deformed marker veins is related in part to the vein thickness; thick veins are observed deform more ductilely and over wider deformation zones than thinner marker veins.

Five deformation phases have affected the sheared veins during their transport up the Alpine Fault ramp which were: 1) primary ductile shearing (triclinic flow with vertical extension); 2) grain boundary sliding accommodated by solid-state diffusion creep of the quartz in response to a drop in stress; 3) recrystallisation and grain growth; 4) renewed late-state dislocation creep; and 5) semibrittle deformation as the rocks pass through the brittle-ductile transition zone on their way to the surface.

Initial shear displacement and deep embrittlement of the schist occurred in the lower crust at temperatures of $450 \pm 50^{\circ} \mathrm{C}$ (Wightman, 2005) at the base of the Alpine Fault ramp in response to up-ramping and transiently high strain-rates. A strain-rate of $3 \times 10^{-11} \mathrm{sec}^{-1}$ has been calculated for this deformation using the mean finite ductile shear strain, a ramping model where a shear is active for a time period estimated from that required for a $100 \mathrm{~m}$ width of rock to translate onto the Alpine Fault ramp and the convergent component of the PAC-AUS plate rotation (19.7 $\mathrm{mm} / \mathrm{yr}$ normal to the mean shear plane from the DeMets et al., 1994 plate convergence vector). Using this strain-rate, and the Hirth et al. (2001) quartz flow law, the differential stress during ductile shearing is estimated to have been $\sim 165$ $\mathrm{MPa}$. This is a differential stress at which the veins can undergo ductile deformation until fluid pressures reach near-lithostatic $(\lambda=0.85)$ and deep embrittlement occurs after Coulomb failure of the rock. Deformation inferred from flow law rheology at this differential stress is expected to occur by dislocation creep (a CPO generating process), and using a palaeopiezometer, the recrystallised grain size is expected to have been $\sim 8 \mu \mathrm{m}$ for quartz and $\sim 25 \mu \mathrm{m}$ for calcite.

Using a universal stage microscope, 89 quartz and 13 calcite crystallographic c-axis data sets were obtained for deformed veins in the shear zones. The c-axis CPO fabrics reveal that dislocation creep accompanied by dynamic recrystallisation was the chief agent of ductile strain during the initial and primary phase of vein deformation. The CPO fabrics for quartz (although weak) typically have CPO 
patterns with a kinematic significance related to irrotational flow during this deformation.

As the shear zones were advected past the base of the Alpine Fault ramp away from the backshearing zone, the transiently high strain-rates are inferred to reduce to a minimum of $1 \times 10^{-14} \mathrm{sec}^{-1}$ and a low differential stress of $\sim 22 \mathrm{MPa}$. These conditions are calculated from the finite recrystallised grain size developed in the subsequent recrystallisation deformation phase which is assumed to represent these low stress conditions. At this low differential stress and inherited fine grain size, together with fluid in the shear zone, grain boundary sliding became a dominant deformation mechanism in some quartz veins. Evidence for this grain boundary sliding is found from some sheared veins from quartz CPO fabrics that were completely randomised in highly sheared parts of veins, probably as the result of this grain boundary sliding that was accompanied by solid-state diffusion creep of the quartz-calcite aggregate. In those same sheared veins, the calcite retains a very strong CPO fabric. Thus the calcite did not undergo significant grain boundary sliding or other fabric weakening processes, unlike the quartz grains surrounding it.

Recrystallisation occurred during the third deformation phase and was driven chiefly by grain boundary area reduction to achieve a finite mean diameter of 126 $\mu \mathrm{m}$ as grains equilibrate with the relatively lower differential stress. This recrystallisation and grain growth generated an equigranular-polygonal grain shape fabric that is retained in many vein samples and caused subsequent weakening of the quartz CPO fabrics across the shear zone. This deformation is inferred to have occurred at similar temperatures and strain-rates at the previous deformation phase.

These recrystallised grains were overprinted by a late-stage increment of dislocation creep accommodated shear and finally by semibrittle deformation during a period of increased differential stress levels experienced by the rocks at lower temperatures in the upper crust. The veins typically have microstructures such as grain boundary bulging, deformation lamellae, and minor subgrain boundaries that overprint the recrystallised fabric from the previous deformation phase. They were formed from a minimum shear strain of $\sim 1.5$ which is recorded by the obliquity of grain shape fabrics in the shear infilling veins. These microstructures are indicative of the low temperature Regime 1 of Hirth and Tullis (1992) and probably took place 
at temperatures of $300-400^{\circ} \mathrm{C}$. Quartz and calcite grain size palaeopiezometry yield low differential stresses of 16-65 MPa during this late-stage deformation.

The final phase of deformation involved micro-cracking of quartz and etwinning of calcite during semibrittle deformation. This deformation occurred at differential stresses of $<189 \mathrm{MPa}$ and temperatures of $200-280^{\circ} \mathrm{C}$ that were determined from calcite twin palaeopiezometry and morphology, as well an assumed temperature for the natural brittle-plastic transition of quartz. The microstructures remnant from the last three phases were then frozen in as the rocks passed through the steady-state brittle-ductile transition zone (t-BDTZ) of the Southern Alps (8-10 $\mathrm{km}$ depth) on their way to being exhumed to the surface.

The CPO patterns in the quartz and calcite reveal that the principle extension direction was not sub-parallel to the southwest pitching shear direction, as would be expected for a case of simple shear. Instead the principal extension direction was consistently near-vertical. This unexpected result for theses demonstrably sheared veins suggests that the deformation involved a three-dimensional transpressive strain and that the irrotational component of this general shear was preferentially imprinted into the resultant CPO pattern. This discordance between the mean CPO-derived finite extension direction of $235,81 \pm 8^{\circ}\left(81^{\circ}\right.$ southwest pitch in the shear plane $)$ and the shear displacement vector consistently recorded by the vein offsets and by the mineral fibre lineations ( $35^{\circ}$ southwest pitch in the shear plane), is evidence for a triclinic symmetry to the flow.

The most remarkable aspect of the quartz CPO fabrics observed from sheared veins in this study is their weak intensity considering the high finite ductile shear strain known to exist in the veins. The complex triclinic strain may have played a role in this fabric weakening; however, grain boundary sliding during the second deformation phase is inferred to have dominantly weakened, and completely randomised some quartz $\mathrm{CPO}$ fabrics during shearing. The quartz fabrics were additionally weakened, although to a lesser degree, by subsequent grain growth recrystallisation and late-stage dislocation creep. Those veins with $>5 \%$ calcite, have on average even weaker quartz CPO's, indicating that calcite may have aided in the grain boundary sliding deformation of quartz, and as indicated by microstructures in the veins, accommodated some of the slip by solid-state diffusion creep. 


\section{References}

Allis, R. G. \& Shi, Y. 1995. New insights to temperature and pressure beneath the central Southern Alps, New Zealand. New Zealand Journal of Geology and Geophysics 38, 585-592.

Allmendinger, R. W. 2003. Stereonet for Windows v. 1.2.

Barnes, P. M., Sutherland, R. \& Delteil, J. 2005. Strike-slip structure and sedimentary basins of the southern Alpine Fault, Fiordland, New Zealand. GSA Bulletin 117(3/4), 411-435; doi: 10.1130/B25458.1.

Barnhoorn, A., Bystricky, M., Burlini, L. \& Kunze, K. 2004. The role of recrystallisation on the deformation behaviour of calcite rocks: large strain torsion experiments on Carrara marble. Journal of Structural Geology 26, 885-903.

Batt, G. E. \& Braun, J. 1999. The tectonic evolution of the Southern Alps, New Zealand: insights from fully thermally coupled dynamical modelling. Geophysical Journal International 136, 403-420.

Beaumont, C., Kamp, P. J. J., Hamilton, J. \& Fullsack, P. 1996. The continental collision zone, South Island, New Zealand: Comparison of geodynamical models and observations. Journal of Geophysical Research 101(B2), 33333359.

Beavan, J., Denham, M., Denys, P., Hager, B., Herring, T., Kurnick, C., Matheson, D., Molnar, P. \& Pearson, C. 2002. A direct geodetic measurement of the uplift rate of the Southern Alps. EOS (Transactions) AGU 83(22).

Beavan, J., Moore, M., Pearson, C., Henderson, M., Parsons, B., Bourne, S., England, P., Walcott, R. I., Blick, G., Darby, D. \& Hodgkinson, K. 1999. Crustal deformation during 1994-1998 due to oblique continental collision in the central Southern Alps, New Zealand, and implications for seismic potential of the Alpine Fault. Journal of Geophysical Research 104(B11), 25,233-25,255.

Behrmann, J. H. \& Mainprice, D. 1987. Deformation mechanisms in a hightemperature quartz-feldspar mylonite: evidence for superplastic flow in the lower continental crust. Tectonophysics 140, 297-305.

Benn, D. I. 1994. Fabric shape and the interpretation of sedimentary fabric data. Journal of Sedimentary Research A64(4), 910-915.

Bestmann, M., Kunze, K. \& Matthews, A. 2000. Evolution of a calcite marble shear zone complex on Thassos Island, Greece: Microstructural and textural fabrics and their kinematic significance. Journal of Structural Geology 22, 1789-1807.

Bestmann, M., Piazolo, S., Spiers, C. J. \& Prior, D. J. 2005. Microstructural evolution during initial stages of static recovery and recrystallization: new insights from in-situ heating experiments combined with electron backscatter diffraction analysis. Journal of Structural Geology 27(3), 447-457.

Bestmann, M. \& Prior, D. J. 2003. Intragranular dynamic recrystallization in naturally deformed calcite marble: diffusion accommodated grain boundary 
sliding as a result of subgrain rotation recrystallization. Journal of Structural Geology 25, 1597-1613.

Bestmann, M., Prior, D. J. \& Veltkamp, K. T. A. 2004. Development of singlecrystal $\sigma$-shaped quartz porphyroclasts by dissolution - precipitation creep in a calcite marble shear zone. Journal of Structural Geology 26(5), 869-883.

Bonini, M., Sokoutis, D., Mulugeta, G. \& Katrivanos, E. 2000. Modelling hanging wall accommodation above rigid thrust ramps. Journal of Structural Geology 22, 1165-1179.

Bons, P. D. \& den Brok, B. 2000. Crystallographic preferred orientation developed by dissolution - precipitation creep. Journal of Structural Geology 22, 17131722.

Brodie, K. H. \& Rutter, E. H. 2000. Deformation mechanisms and rheology: why marble is weaker than quartzite. Journal of the Geological Society of London 157, 1093-1096.

Brunel, M. 1980. Quartz fabrics in shear-zone mylonites: evidence for a major imprint due to late strain increments. Tectonophysics 64, T33-T44.

Bull, W. B. \& Cooper, A. F. 1986. Uplifted marine terraces along the Alpine Fault, New Zealand. Science 234, 1225-1228.

Burkhard, M. 1993. Calcite twins, their geometry, appearance and significance as stress-strain markers and indicators of tectonic regime: A review. Journal of Structural Geology 15(3-5), 351-368.

Busch, J. P. \& Van der Pluijm, B. A. 1995. Calcite textures, microstructures and rheological properties of marble in the Bancroft shear zone, Ontario, Canada. Journal of Structural Geology 17(5), 667-688.

Byerlee, J. D. 1978. Friction of rocks. Pure and Applied Geophysics 116, 615-626.

Christie, J. M. \& Ord, A. 1980. Flow stress from microstructures of mylonites: Example and current assessment. Journal of Geophysical Research 85(B11), 6253-6262.

Cooper, A. F. \& Norris, R. J. 1994. Anatomy, structural evolution, and slip rate of a plate-boundary thrust: The Alpine fault at Gaunt Creek, Westland, New Zealand. Geological Society of America Bulletin 106, 627-633.

Cox, S. F. \& Etheridge, M. A. 1983. Crack-seal fibre growth mechanisms and their significance in the development of oriented layer silicate microstructures. Tectonophysics 92, 147-170.

Craw, D. 1984. Lithologic variations in Otago Schist, Mt Aspiring area, northwest Otago, New Zealand. New Zealand Journal of Geology and Geophysics 27, 151-166.

Craw, D., Rattenbury, M. S. \& Johnstone, R. D. 1987. Structural geology and vein mineralisation in the Callery River headwaters, Southern Alps, New Zealand. New Zealand Journal of Geology and Geophysics 30, 273-286.

Davey, F. J., Henyey, T., Holbrook, W. S., Okaya, D., Stern, T. A., Melhuish, A., Henrys, S., Anderson, H., Eberhart-Phillips, D., McEvilly, T. C., Uhrhammer, R., Wu, F., Jiracek, G. R., Wannamaker, P. E., Caldwell, G. \& Christensen, N. 1998. Preliminary results from a geophysical study across a modern 
continent-continent collisional plate boundary - the Southern Alps, New Zealand. Tectonophysics 288, 211-235.

Davey, F. J., Henyey, T., Kleffmann, S., Melhuish, A., Okaya, D., Stern, T. A., Woodward, D. J. \& SIGHT. 1995. Crustal reflections from the Alpine Fault Zone, South Island, New Zealand. New Zealand Journal of Geology and Geophysics 38, 601-604.

De Bresser, J. H. P. \& Spiers, C. J. 1990. High temperature deformation of calcite single crystals by $\mathrm{r}+$ and $\mathrm{f}+$ slip. In: Deformation Mechanisms, Rheology and Tectonics (edited by Knipe, R. J. \& Rutter, E. H.) 54. Geological Society Special Publication, 285-298.

De Bresser, J. H. P. \& Spiers, C. J. 1997. Strength characteristics of the r, f, and c slip systems in calcite. Tectonophysics 272, 1-23.

Dell'Angelo, L. N. \& Tullis, J. 1989. Fabric development in experimentally sheared quartzites. Tectonophysics 169, 1-21.

DeMets, C., Gordon, R. G., Argus, D. F. \& Stein, S. 1994. Effect of recent revisions to the geomagnetic reversal time scale on estimates of current plate motions. Geophysical Research Letters 21(20), 2191-2194.

Dewey, J. F., Holdsworth, R. E. \& Strachan, R. A. 1998. Transpression and transtension zones. In: Continental Transpressional and Transtensional Tectonics (edited by Holdsworth, R. E., Strachan, R. A. \& Dewey, J. F.) 135. Geological Society, London, Special Publications, 1-14.

Erickson, S. G., Strayer, L. M. \& Suppe, J. 2001. Initiation and reactivation of faults during movement over a thrust-fault ramp: numerical mechanical models. Journal of Structural Geology 23, 11-23.

Etchecopar, A. \& Vasseur, G. 1987. A 3-D kinematic model of fabric development in polycrystalline aggregates: comparisons with experimental and natural examples. Journal of Structural Geology 9(5/6), 705-717.

Farver, J. \& Yund, R. 2000. Silicon diffusion in a natural quartz aggregate: constraints on solution-transfer diffusion creep. Tectonophysics 325, 193-205.

Ferrill, D. A. 1991. Calcite twin widths and intensities as metamorphic indicators in natural low-temperature deformation of limestone. Journal of Structural Geology 13(6), 667-675.

Ferrill, D. A. 1998. Critical re-evaluation of differential stress estimates from calcite twins in coarse-grained limestone. Tectonophysics 285, 77-86.

Ferrill, D. A., Morris, A. P., Evans, M. A., Burkhard, M., Groshong Jr, R. H. \& Onasch, C. M. 2004. Calcite twinning morphology: a low-temperature deformation geothermometer. Journal of Structural Geology 26(8), 15211529.

Fliervoet, T. F. \& White, S. H. 1995. Quartz deformation in a very fine grained quartzo-feldspathic mylontite: a lack of evidence for dominant grain boundary sliding deformation. Journal of Structural Geology 17(8), 10951109.

Fossen, H. \& Tikoff, B. 1998. Extended models of transpression and transtension, and application to tectonic settings. In: Continental transpressional and 
transtensional tectonics. (edited by Holdsworth, R. E., Strachan, R. A. \& Dewey, J. F.) 135. Geological Society, Special Publications, London, 15-33.

Fossen, H., Tikoff, B. \& Teyssier, C. 1994. Strain modelling of transpressional and transtensional deformation. Norsk Geologish Tidsskrift 74, 134-145.

Geological-Software. 1995. StereoNet for Windows. v. 3.03, Norway.

Gower, R. J. W. \& Simpson, C. 1992. Phase boundary mobility in naturally deformed, high-grade quartzofeldspathic rocks: evidence for diffusional creep. Journal of Structural Geology 14(3), 301-313.

Grapes, R. H. 1995. Uplift and exhumation of Alpine Schist, Southern Alps, New Zealand: thermobarometric constraints. New Zealand Journal of Geology and Geophysics 38, 525-533.

Grapes, R. H., Little, T. A. \& Vry, J. 1998. Aspiring lithological association in Alpine Schist, Marlborough Schist and Wellington greywacke. Geological Society of New Zealand Miscellaneous Publication 101A, 101.

Grapes, R. H. \& Watanabe, T. 1992. Metamorphism and uplift of Alpine Schist in the Franz Josef-Fox Glacier area of the Southern Alps, New Zealand. Journal of Metamorphic Geology 10, 171-180.

Heilbronner, R. \& Tullis, J. 2002. The effect of static annealing on microstructures and crystallographic preferred orientations of quartzites experimentally deformed in axial compression and shear. In: Deformation mechanisms, Rheology and Tectonics: Current status and future perspectives. (edited by De Meer, S., Drury, M. R., De Bresser, J. H. P. \& Pennock, G. M.) 200. Geological Society, London, Special Publications, 191-218.

Herrington, R. J. \& Wilkinson, J. J. 1993. Colloidal gold and silica in mesothermal vein systems. Geology 21, 539-542.

Herwegh, M. \& Berger, A. 2004. Deformation mechanisms in second-phase affected microstructures and their energy balance. Journal of Structural Geology 26, 1483-1498.

Herwegh, M., De Bresser, J. H. P. \& ter Heege, J. H. 2005. Combining natural microstructures with composite flow laws: an improved approach for the extrapolation of lab data to nature. Journal of Structural Geology 27(3), 505521.

Hippertt, J. \& Tohver, E. 1999. On the development of zones of reverse shearing in mylonitic rocks. Journal of Structural Geology 21, 1603-1614.

Hirth, G., Teyssier, C. \& Dunlap, W. J. 2001. An evaluation of quartzite flow laws based on comparisons between experimentally and naturally deformed rocks. International Journal of Earth Sciences 90, 77-87.

Hirth, G. \& Tullis, J. 1992. Dislocation creep regimes in quartz aggregates. Journal of Structural Geology 14(2), 145-159.

Hirth, G. \& Tullis, J. 1994. The brittle-plastic transition in experimentally deformed quartz aggregates. Journal of Geophysical Research 99(B6), 11731-11747.

Hobbs, B. E. 1985. The geological significance of microfabric analysis. In: Preferred orientation in deformed metals and rocks: An introduction to modern texture analysis. (edited by Wenk, H.-R.). Academic Press Inc., Sydney, 463-484. 
Holcombe, R. J. \& Little, T. A. 2001. A sensitive vorticity gauge using rotated porphyroblasts, and its application to rocks adjacent to the Alpine Fault, New Zealand. Journal of Structural Geology 23, 979-989.

Holm, D. K., Norris, R. J. \& Craw, D. 1989. Brittle and ductile deformation in a zone of rapid uplift: Central Southern Alps, New Zealand. Tectonics 8(2), 153-168.

Hurlbut, C. S. 1971. Dana's Manual of Mineralogy. John Wiley \& Sons, Inc., New York.

Jiang, D., Lin, S. \& Williams, P. F. 2001. Deformation path in high-strain zones, with reference to slip partitioning in transpressional plate-boundary regions. Journal of Structural Geology 23, 2001.

Jiang, D. \& Williams, P. F. 1998. High-strain zones: a unified model. Journal of structural geology 20(8), 1105-1120.

Jones, R. R., Holdsworth, R. E., Clegg, P., McCaffrey, K. J. W. \& Tavarnelli, E. 2004. Inclined transpression. Journal of Structural Geology 26, 1531-1548.

Joy, S. \& Saha, D. 1998. Influence of micaceous impurity on dynamically recrysallized quartz c-axis fabric in L-S tectonites from the Singhbhum Shear Zone and its footwall, Eastern India. Journal of Structural Geology 20(11), 1509-1520.

Kamb, W. B. 1959. Ice petrofabric observations from Blue Glacier, Washington, in relation to theory and experiment. Journal of Geophysical Research 64(11), 1891-1909.

Kennedy, L. A. \& White, J. W. C. 2001. Low-temperature recyrstallization of calcite: Mechanics and consequences. Geology 29(11), 1027-1030.

Klaper, E. M. 1998. Quartz c-axis fabric development and large-scale post-nappe folding (Wandfluhhorn Fold, Penninic nappes). Journal of Structural Geology 10(8), 795-802.

Kleffmann, S., Davey, F., Melhuish, A., Okaya, D., Stern, T. A. \& SIGHT. 1998. Crustal structure in the central South Island, New Zealand, from the Lake Pukaki seismic experiment. New Zealand Journal of Geology and Geophysics 41, 39-49.

Koons, P. O. 1987. Some thermal and mechanical consequences of rapid uplift: an example from the Southern Alps, New Zealand. Earth and Planetary Science Letters 86, 307-319.

Koons, P. O. 1990. Two-sided orogen: Collision and erosion from the sandbox to the Southern Alps, New Zealand. Geology 18, 679-682.

Koons, P. O., Craw, D., Cox, S. C., Upton, P., Templeton, A. S. \& Chamberlain, C. P. 1998. Fluid flow during active oblique convergence: A Southern Alps model from mechanical and geochemical observations. Geology 26(2), 159162.

Kretz, R. 1983. Symbols for rock-forming minerals. American Mineralogist 68, 277279.

Kruhl, J. H. 1996. Prism- and basal-plane parallel subgrain boundaries in quartz: a microstructural geothermobarometer. Journal of Metamorphic Geology 14, 581-589. 
Lafrance, B., White, J. C. \& Williams, P. F. 1994. Natural calcite c-axis fabrics: an alternative interpretation. Tectonophysics 229, 1-18.

Law, R. D. 1987. Heterogeneous deformation and quartz crystallographic fabric transitions: natural examples from the Moine Thrust zone at the Stack of Glencoul, northern Assynt. Journal of Structural Geology 9(7), 819-833.

Law, R. D. 1990. Crystallographic fabrics: a selective review of their applications to research in structural geology. In: Deformation Mechanisms, Rheology and Tectonics, Geological Society Special Publication (edited by Knipe, R. J. \& Rutter, E. H.) 54, 335-352.

Law, R. D., Schmid, S. M. \& Wheeler, J. 1990. Simple shear deformation and quartz crystallographic fabrics: a possible natural example from the Torridon area of NW Scotland. Journal of Structural Geology 12(1), 29-45.

Law, R. D., Searle, M. P. \& Simpson, R. L. 2004. Strain, deformation temperatures and vorticity of flow at the top of the Greater Himalayan Slab, Everest Massif, Tibet. Journal of the Geological Society of London 161, 305-320.

Leitner, B., Eberhart-Phillips, D., Anderson, H. J. \& Nabelek, J. L. 2001. A focused look at the Alpine Fault, New Zealand: Seismicity, focal mechanisms, and stress observations. Journal of Geophysical Research 106(B2), 2193-2220.

Lisle, R. J. 1985. The use of the orientation tensor for the description and statistical testing of fabrics. Journal of Structural Geology 7(1), 115-117.

Lister, G. S. 1977. Discussion: Cross-girdled c-axis fabrics in quartzites plastically deformed by plane strain and progressive simple shear. Tectonophysics $\mathbf{3 9}$, 51-54.

Lister, G. S. \& Hobbs, B. E. 1980. The simulation of fabric development during plastic deformation and its application to quartzite: the influence of deformation history. Journal of Structural Geology 2(3), 355-370.

Lister, G. S., Paterson, M. S. \& Hobbs, B. E. 1978. The simulation of fabric development in plastic deformation and its application to quartzite: The model. Tectonophysics 45, 107-158.

Lister, G. S. \& Williams, I. S. 1979. Fabric development in shear zones: theoretical controls and observed phenomena. Journal of Structural Geology 1(4), 283297.

Little, T. A. 1996. Faulting-related displacement gradients and strain adjacent to the Awatere strike-slip fault in New Zealand. Journal of Structural Geology 18(2/3), 321-340.

Little, T. A. 2004. Transpressive ductile flow and oblique ramping of lower crust in a two-sided orogen: Insight from quartz grain-shape fabrics near the Alpine Fault, New Zealand. Tectonics 23, TC2013, doi:10.1029/2002TC001456.

Little, T. A., Cox, S., Vry, J. K. \& Batt, G. E. 2005. Variation in exhumation level and uplift-rate along the oblique-slip Alpine fault, central Southern Alps, New Zealand. Bulletin of the Geological Society of America 117(4), 707-723.

Little, T. A., Holcombe, R. J. \& Ilg, B. R. 2002a. Ductile fabrics in the zone of active oblique convergence near the Alpine Fault, New Zealand: identifying the neotectonic overprint. Journal of Structural Geology 24, 193-217. 
Little, T. A., Holcombe, R. J. \& Ilg, B. R. 2002b. Kinematics of oblique collision and ramping inferred from microstructures and strain in middle crustal rocks, central Southern Alps, New Zealand. Journal of Structural Geology 24, 219239.

Llana-Fúnez, S. 2002. Quartz c-axis texture mapping of a variscan regional foliation (Malpica - Tui Unit, NW Spain). Journal of Structural Geology 24, 12991312.

Lloyd, G. E., Law, R. D., Mainprice, D. \& Wheeler, J. 1992. Microstructural and crystal fabric evolution during shear zone formation. Journal of Structural Geology 14(8/9), 1079-1100.

Lockner, D. A. 1995. Rock failure. In: Rock physics and phase relations: A handbook of physical constants (edited by Ahrens, T. J.) 3. American Geophysical Union Reference Shelf, 127-147.

MacCready, T. 1996. Misalignment of quartz c-axis fabrics and lineations due to oblique final strain increments in the Ruby Mountains core complex, Nevada. Journal of Structural Geology 18(6), 765-776.

Mainprice, D., Bouchez, J.-L., Blumenfeld, P. \& Tubia, J. M. 1986. Dominant c slip in naturally deformed quartz: Implications for dramatic plastic softening at high temperature. Geology 14, 819-822.

Mainprice, D., Lloyd, G. E. \& Casey, M. 1993. Individual orientation measurements in quartz polycrystals: advantages and limitations for texture and petrophysical property determinations. Journal of Structural Geology 15(9/10), 1169-1187.

Marshak, S. \& Mitra, G. 1988. Basic Methods of Structural Geology. Prentice Hall.

Means, W. D. 1989. Stretching Faults. Geology 17, 893-896.

Mercier, J.-C. C., Anderson, D. A. \& Carter, N. L. 1977. Stress in the lithosphere: Inferences from steady state flow of rocks. Pure and Applied Geophysics 115, 199-226.

Miller, D. M. \& Christie, J. M. 1981. Comparison of quartz microfabric with strain in recrystallized quartzite. Journal of Structural Geology 3(2), 129-141.

Morgan, S. S. \& Law, R. D. 2004. Unusual transition in quartzite dislocation creep regimes and crystal slip systems in the aureole of the Eureka Valley - Joshua Flat - Beer Creek pluton, California: a case for anhydrous conditions created by decarbonation reactions. Tectonophysics 384, 209-231.

Newman, J. 1994. The influence of grain size and grain size distribution on methods for estimating paleostress from twinning in carbonates. Journal of Structural Geology 16(12), 1589-1601.

Norris, R. J. \& Cooper, A. F. 1995. Origin of small-scale segmentation and transpressional thrusting along the Alpine Fault, New Zealand. GSA Bulletin 107(2), 231-240.

Norris, R. J. \& Cooper, A. F. 1997. Erosional control on the structural evolution of a transpressional thrust complex on the Alpine Fault, New Zealand. Journal of Structural Geology 19(10), 1323-1342. 
Norris, R. J. \& Cooper, A. F. 2001. Late Quaternary slip rates and slip partitioning on the Alpine Fault, New Zealand. Journal of Structural Geology 23, 507520 .

Norris, R. J. \& Cooper, A. F. 2003. Very high strains recorded in mylonites along the Alpine Fault, New Zealand: Implications for the deep structure of plate boundary faults. Journal of Structural Geology 25, 2141-2157.

Norris, R. J. \& Craw, D. 1987. Aspiring Terrane: an oceanic assemblage from New Zealand and its implications for terrane accretion in the southwest pacific. A.G.U. Geodynamics Series 19, 169-177.

Norris, R. J., Koons, P. O. \& Cooper, A. F. 1990. The oblique-convergent plate boundary in the South Island of New Zealand: implications for ancient collision zones. Journal of Structural Geology 12(5-6), 715-725.

Okudaira, T., Takeshita, T., Hara, I. \& Ando, J.-i. 1995. A new estimate of the conditions for transition from basal $<a>$ to prism [c] slip in naturally deforming quartz. Tectonophysics 250, 31-46.

Ord, A. \& Christie, J. M. 1984. Flow stresses from microstructures in mylonitic quartzites of the Moine Thrust zone, Assynt area, Scotland. Journal of Structural Geology 6(6), 639-654.

Passchier, C. W. 1983. The reliability of asymmetric c-axis fabrics of quartz to determine sense of vorticity. Tectonophysics 99, T9-T18.

Passchier, C. W. 1998. Monoclinic model shear zones. Journal of Structural Geology 20(8), 1121-1137.

Passchier, C. W. \& Trouw, R. A. J. 1998. Microtectonics. Springer.

Pauli, C., Schmid, S. M. \& Heibronner, R. P. 1996. Fabric domains in quartz mylonites: localised three dimensional analysis of microstructure and texture. Journal of Structural Geology 18(10), 1183-1203.

Pfiffner, O. A. \& Ramsay, J. G. 1982. Constraints on geological strain rates: Arguments from finite strain rates of naturally deformed rocks. Journal of Geophysical Research 87(B1), 311-321.

Phillips, W. R. 1971. Mineral optics: Principles and techniques. W. H. Freeman and Company, San Francisco.

Pieri, M., Burlini, L., Kunze, K., Stretton, I. \& Olgaard, D. L. 2001. Rheological and microstructural evolution of Carrara marble with high shear strain: results from high temperature torsion experiments. Journal of Structural Geology 23, 1393-1413.

Price, G. P. 1985. Preferred Orientations in Quartzites. In: Preferred orientation in deformed metals and rocks: An introduction to modern texture analysis. (edited by Wenk, H.-R.). Academic Press Inc., Sydney, 385-406.

Ramsay, J. G. 1967. Folding and fracturing of rocks. McGraw-Hill, New York.

Ramsay, J. G. \& Huber, M. I. 1983. Techniques of Modern Structural Geology, Vol 1: Strain Analysis. 
Ratschbacher, L., Wenk, H. R. \& Sintubin, M. 1991. Calcite textures: examples from nappes with strain-path partitioning. Journal of Structural Geology 13(4), 369-384.

Robin, P.-Y. F. \& Cruden, A. R. 1994. Strain and vorticity patterns in ideally ductile transposition zones. Journal of Structural Geology 16(4), 447-466.

Roedder, E. 1984. Fluid Inclusions (edited by Ribbe, P. H.). Reviews in mineralogy 12, 646.

Rowe, K. J. \& Rutter, E. H. 1990. Palaeostress estimation using calcite twinning: experimental calibration and application to nature. Journal of Structural Geology 12(1), 1-17.

Rutter, E. H. 1974. The influence of temperature, strain rate and interstitial water in the experimental deformation of calcite rocks. Tectonophysics 22, 311-334.

Rutter, E. H. 1995. Experimental study of the influence of stress, temperature, and strain on the dynamical recrystallization of Carrara Marble. Journal of Geophysical Research 100(B12), 24651-24663.

Rutter, E. H. \& Brodie, K. H. 2004a. Experimental intracrystalline plastic flow in hot-pressed synthetic quartzite prepared from Brazilian quartz crystals. Journal of Structural Geology 26, 259-270.

Rutter, E. H. \& Brodie, K. H. 2004b. Experimental grain size-sensitive flow of hotpressed Brazilian quartz aggregates. Journal of Structural Geology 26, 20112023.

Rutter, E. H., Casey, M. \& Burlini, L. 1994. Preferred crystallographic orientation development during the plastic and superplastic flow of calcite rocks. Journal of Structural Geology 16(10), 1431-1446.

Sanderson, D. J. 1982. Models of strain variation in nappes and thrust sheets: a review. Tectonophysics 88, 201-233.

Sanderson, D. J. \& Marchini, W. R. D. 1984. Transpression. Journal of Structural Geology 6(5), 449-458.

Schmid, S. M. 1982. Laboratory experiments on rheology and deformation mechanisms in calcite and their application to studies in the field. Mitt. geol. Inst. ETH Univ. Zurich 241, 1-105.

Schmid, S. M., Boland, J. N. \& Patterson, M. S. 1977. Superplastic flow in fine grained limestone. Tectonophysics 43, 257-291.

Schmid, S. M. \& Casey, M. 1986. Complete fabric analysis of some commonly observed quartz c-axis patterns. Geophysical Monograph 36, 263-285.

Schmid, S. M., Panozzo, R. \& Bauer, S. 1987. Simple shear experiments on calcite rocks: rheology and microfabric. Journal of Structural Geology 9(5/6), 747778.

Schmid, S. M., Patterson, M. S. \& Boland, J. N. 1980. High temperature flow and dynamic recrystallisation in Carrara marble. Tectonophysics 65, 245-280.

Shelley, D. 1982. Quartz and sheet-silicate preferred orientations of low symmetry, Pikikiruna Schist, New Zealand. Tectonophysics 83, 309-327. 
Shelley, D. 1989. Plagioclase and quartz preferred orientations in a low-grade schist: the roles of primary growth and plastic deformation. Journal of Structural Geology 11(8), 1029-1037.

Shi, Y., Allis, R. \& Davey, F. 1996. Thermal modeling of the Southern Alps, New Zealand. Pure and Applied Geophysics 146(3/4), 469-501.

Sibson, R. H. 2000. A brittle failure mode plot defining conditions for high-flux flow. Economic Geology 95, 41-48.

Sibson, R. H., Robert, F. \& Poulsen, K. H. 1988. High angle reverse faults, fluidpressure cycling, and mesothermal gold-quartz deposits. Geology 16, 551555.

Sibson, R. H., White, S. H. \& Atkinson, B. K. 1979. Fault rock distribution and structure within the Alpine Fault Zone: A preliminary account. Bulletin of the Royal Society of New Zealand 18, 55-65.

Sibson, R. H., White, S. H. \& Atkinson, B. K. 1981. Structure and distribution of fault rocks in the Alpine Fault Zone, New Zealand. Geological Society of London 9, 197-210.

Smith, C. S. \& Guttman, L. 1953. Measurement of internal boundaries in threedimensional structures by random sectioning. Trans. AIME 197, 81-87.

Starkey, J. \& Cutforth, C. 1978. A demonstration of the degree of quartz preferred orientation and the quartz content of deformed rocks. Canadian Journal of Earth Sciences 15, 841-847.

Stern, T., Kelffmann, S., Okaya, D., Scherwath, M. \& Bannister, S. 2001. Low seismic-wave speeds and enhanced fluid pressure beneath the Southern Alps of New Zealand. Geology 29(8), 679-682.

Stipp, M., Stunitz, H., Heilbronner, R. \& Schmid, S. M. 2002a. Dynamic recrystallization of quartz: correlation between natural and experimental conditions. In: Deformation mechanisms, Rheology and Tectonics: Current status and future perspectives. (edited by De Meer, S., Drury, M. R., De Bresser, J. H. P. \& Pennock, G. M.) 200. Geological Society, London, Special Publications, 171-190.

Stipp, M., Stünitz, H., Heilbronner, R. \& Schmid, S. M. 2002b. The eastern Tonale fault zone: a 'natural laboratory' for crystal plastic deformation of quartz over a temperature range from 250 to $700{ }^{\circ} \mathrm{C}$. Journal of Structural Geology 24, 1861-1884.

Stockhert, B., Brix, M. R., Kleinschrodt, R., Hurford, A. J. \& Wirth, R. 1999. Thermochronometry and microstructures of quartz - a comparison with experimental flow laws and predictions on the temperature of the brittleplastic transition. Journal of Structural Geology 21, 351-369.

Strine, M. \& Wojtal, S. F. 2004. Evidence for non-plane strain flattening along the Moine thrust, Lock Srath nan Aisinnin, North-West Scotland. Journal of Structural Geology 26, 1755-1772.

Sutherland, R. 1994. Displacement since the Pliocene along the southern section of the Alpine fault, New Zealand. Geology 22, 327-330. 
Sutherland, R. 1995. The Australia-Pacific boundary and Cenozoic plate motions in the SW Pacific: Some constraints from Geosat data. Tectonics 14(4), 819831.

Sutherland, R. 1999a. Cenozoic bending of New Zealand basement terranes and Alpine Fault displacement: a brief review. New Zealand Journal of Geology and Geophysics 42, 295-301.

Sutherland, R., Davey, F. \& Beavan, J. 2000. Plate boundary deformation in South Island, New Zealand, is related to inherited lithospheric structure. Earth and Planetary Science Letters 177, 141-151.

Sutherland, R., Nathan, S. \& Turnbull, I. M. 1995. Pliocene - Quaternary sedimentation and Alpine Fault related tectonics in the lower Cascade valley, South Westland, New Zealand. New Zealand Journal of Geology and Geophysics 38, 431-450.

Sutherland, R. \& Norris, R. J. 1995. Late Quaternary displacement rate, paleoseismicity, and geomorphic evolution of the Alpine Fault: evidence from Hokuri Creek, South Westland, New Zealand. New Zealand Journal of Geology and Geophysics 38, 419-430.

Tagami, M. \& Takeshita, T. 1998. c-Axis fabrics and microstructures in quartz schist from the Sambagawa metamorphic belt, central Shikoku, Japan. Journal of Structural Geology 20(11), 1549-1568.

Teagle, D. A. H., Hall, C. M., Cox, S. C. \& Craw, D. 1998. Ar / Ar dating and uplift of hydrothermal minerals in the Southern Alps, New Zealand. In: Water-Rock Interaction (edited by Arehart, G. B. \& Hulston, J. R.). Proceeding of the 9th International Symposium on Water-Rock Interaction. A. A. Balkema.

Tikoff, B. \& Fossen, H. 1999. Three-dimensional reference deformations and strain facies. Journal of Structural Geology 21, 1497-1512.

Tikoff, B. \& Greene, D. 1997. Stretching lineations in transpressional shear zones: an example from the Sierra Nevada Batholith, California. Journal of Structural Geology 19(1), 29-39.

Tikoff, B. \& Teyssier, C. 1994. Strain modelling of displacement-field partitioning in transpressional orogens. Journal of Structural Geology 16(11), 1575-1588.

Trepmann, C. A. \& Stockhert, B. 2003. Quartz microstructures developed during non-steady state plastic flow at rapidly decaying stress and strain rate. Journal of Structural Geology 25, 2035-2051.

Tullis, J. 1977. Preferred orientation of quartz produced by slip during plane strain. Tectonophysics 39, 87-102.

Tullis, J. 2002. Deformation of granitic rocks: Experimental studies and natural examples. In: Plastic Deformation of Minerals and Rocks (edited by Karato, S.-i. \& Wenk, H.-R.). Reviews in Mineralogy and Geochemistry 51, 51-95.

Turnbull, I. M., Mortimer, N. \& Craw, D. 2001. Textural zones in the Haast Schist a reappraisal. New Zealand Journal of Geology and Geophysics 44(171-183), 171-183.

Turner, F. J. \& Weiss, L. E. 1963. Structural Analysis of Metamorphic Tectonites. McGraw-Hill Book Company, Inc., United States of America. 
Twiss, R. J. 1977. Theory and applicability of a recrystallized grain size paleopiezometer. Pure and Applied Geophysics 115, 227-244.

Twiss, R. J. 1980. Static theory of size variation with stress for subgrains in dynamically recrystallized grains. In: Proceedings of the IX. conference, magnitude of deviatoric stresses in the Earth's crust and upper mantle. Open file report. (edited by USGS) 80-625, Menlo Park, California, 665-683.

Twiss, R. J. \& Moores, E. M. 1992. Structural Geology. W. H. Freeman and Company, New York.

Ullemeyer, K., Braun, G., Dahms, M., Kruhl, J. H., Olesen, N. O. \& Siegesmund, S. 2000. Texture analysis of a muscovite-bearing quartzite: a comparison of some currently used techniques. Journal of Structural Geology 22, 15411557.

Ulrich, S., Schulmann, K. \& Casey, M. 2002. Microstructural evolution and rheological behaviour of marbles deformed at different crustal levels. Journal of Structural Geology 24, 979-995.

Van der Pluijm, B. A. \& Marshak, S. 1997. Earth Structure: An introduction to structural geology and tectonics. WCB / McGraw Hill.

Vry, J. K., Baker, J. A., Maas, R., Little, T. A., Grapes, R. H. \& Dixon, M. 2004. Zoned (Cretaceous and Cenozoic) garnet and the timing of high grade metamorphism, Southern Alps, New Zealand. Journal of Metamorphic Geology 22(3), 137-157.

Walcott, R. I. 1979. Plate motion and shear strain rates in the vicinity of the Southern Alps. Bulletin of the Royal Society of New Zealand 18, 5-12.

Walcott, R. I. 1998. Modes of oblique compression: Late Cenozoic tectonics of the South Island of New Zealand. Reviews of Geophysics 36(1), 1-26.

Walker, A. N., Rutter, E. H. \& Brodie, K. H. 1990. Experimental study of grain-size sensitive flow of synthetic, hot-pressed calcite rocks. In: Deformation Mechanisms, Rheology and Tectonics (edited by Knipe, R. J. \& Rutter, E. H.) 54. Geological Society Special Publication, 259-284.

Wannamaker, P. E., Jiracek, G. R., Stodt, J. H., Caldwell, T. G., Gonzalez, V. M., McKnight, J. D. \& Porter, A. D. 2002. Fluid generation and pathways beneath an active compressional orogen, the New Zealand Southern Alps, inferred from magnetotelluric data. Journal of Geophysical Research 107(B6), ETG6 1-21.

Wellman, H. W. 1979. An uplift map for the South Island of New Zealand, and a model for uplift of the Southern Alps. Bulletin of the Royal Society of New Zealand 18, 13-20.

Wells, A., Yetton, M. D., Duncan, R. P. \& Stewart, G. H. 1999. Prehistoric dates of the most recent Alpine fault earthquakes, New Zealand. Geology 27(11), 995998.

Wenk, H.-R. 1985a. Preferred orientation in deformed metals and rocks: An introduction to modern texture analysis. Academic Press, Inc., Sydney. 
Wenk, H.-R. 1985b. Measurement of Pole Figures. In: Preferred orientation in deformed metals and rocks: An introduction to modern texture analysis. (edited by Wenk, H.-R.). Academic Press Inc., Sydney, 11-25.

Wenk, H.-R. 1985c. Carbonates. In: Preferred orientation in deformed metals and rocks: An introduction to modern texture analysis. (edited by Wenk, H.-R.). Academic Press Inc., Sydney, 361-384.

Wenk, H. R. \& Christie, J. M. 1991. Comments on the interpretation of deformation textures in rocks. Journal of Structural Geology 13(10), 1091-1110.

Wenk, H. R. \& Takeshita, T. 1987. Pure shear and simple shear calcite textures. Comparison of experimental, theoretical and natural data. Journal of Structural Geology 9(5/6), 731-745.

White, S. H., Burrows, S. E., Carreras, J., Shaw, N. D. \& Humpherys, F. J. 1980. On mylonites in ductile shear zones. Journal of Structural Geology 2(1/2), 175187.

Wightman, R. H. 2000. The fabrics and ductile microstructures in the Alpine Schist mylonite zone near Fox Glacier, New Zealand. Unpublished BSc (Hon) thesis, Victoria University of Wellington.

Wightman, R. H. 2005. Deformation and orogensis: the geodynamic significance of a brittle-ductile fault array in the Central Southern Alps, New Zealand. Unpublished $\mathrm{PhD}$ thesis, Victoria University of Wellington.

Wightman, R. H. \& Little, T. A. 2003. Life at the base of a major continental fault ramp: Stress conditions, fluid pressure and transient deep embrittlement above the Alpine Fault, New Zealand. Geological Society of New Zealand Miscellaneous Publication 116A, 160.

Woodcock, N. H. 1977. Specification of fabric shapes using an eigenvalue method. Bulletin of the Geological Society of America 88, 1231-1236.

Woodcock, N. H. \& Naylor, M. A. 1983. Randomness testing in three-dimensional orientation data. Journal of Structural Geology 5(5), 539-548.

Woodward, D. J. 1979. The crustal structure of the Southern Alps, New Zealand, as determined by gravity. Bulletin of the Royal Society of New Zealand 18, 9598.

Zulauf, G. 2001. Structural style, deformation mechanisms and paleodifferential stress along an exposed crust section: constraints on the rheology of quartzofeldspathic rocks at supra- and infrastructural levels (Bohemian Massif). Tectonophysics 332, 211-237. 


\section{Appendices}

Appendix A: Structural field data

Orientation of foliations, lineations, shear planes and other structural data collected across the Sam Peak, Chancellor Ridge, Baumann Glacier, Waiho River and Hare Mare Creek field areas.

Appendix B: Brittle-ductile shear survey data A-15

Data collected from structural surveys on Chancellor Ridge and Baumann Glacier. Finite ductile shear strain as well as the pitch of the marker vein in the shear plane is presented for each node in the survey. Graphs of ductile deformation against marker vein thickness are also plotted for this appendix.

Appendix C: Data collected from optical microscopy A-35

A list of microstructural data collected from optical microscopy of the schist, deformed veins and shear infilling veins in brittle-ductile shears sampled in this study.

Appendix D: Quartz CPO fabric plots of sheared brittle-ductile veins .... A-39 Schematic illustrations of sheared veins and the quartz crystallographic preferred orientation (CPO) fabrics measured in each of the sections in the shear zone.

Appendix E: Quartz CPO fabrics measured throughout the BDSZ ......... A-56

Database of all quartz CPO fabrics measured in this study.

Appendix F: $\quad$ Hare Mare Creek Alpine Schist mylonite ................................ A-65 Structural geology of the Hare Mare Creek mylonite zone and the quartz CPO fabric measured from a chert layer in the Alpine Schist mylonite.

Appendix G: $\quad$ CPO of euhedral quartz crystals ................................................ A-66

A sample of euhedral quartz crystals that has be analysed for the $\mathrm{CPO}$ of the crystals that have grown off the wall of the host rock.

Appendix H: Quartz and calcite CPO fabric data.................................... A-67

Fabric strength and CPO fabric plot orientation data for all the CPO fabrics measured in this study.

Appendix I: $\quad$ Calcite CPO fabric plots of sheared brittle-ductile veins..... A-72 Schematic illustrations of sheared veins and the calcite CPO fabrics measured in each of the sections in the shear zone.

Appendix J: Calcite CPO fabrics measured throughout the BDSZ A-75

Database of all calcite CPO fabrics measured in this study. 


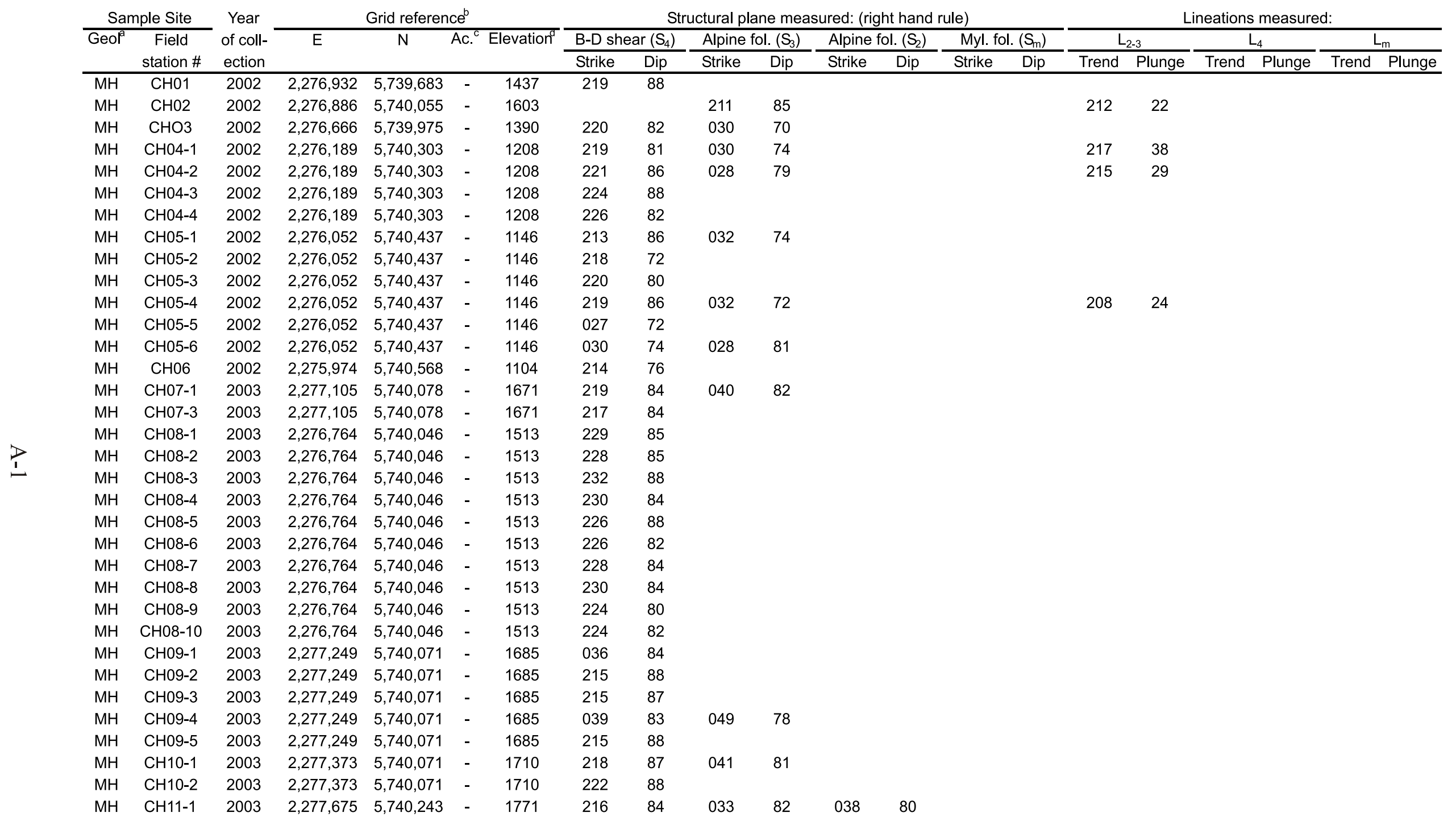




\begin{tabular}{|c|c|c|c|c|c|c|c|c|c|c|c|c|c|c|c|c|c|c|c|c|}
\hline \multicolumn{2}{|c|}{ Sample Site } & \multirow{3}{*}{$\begin{array}{l}\text { Year } \\
\text { of coll- } \\
\text { ection }\end{array}$} & \multicolumn{4}{|c|}{ Grid reference $^{b}$} & \multicolumn{8}{|c|}{ Structural plane measured: (right hand rule) } & \multicolumn{6}{|c|}{ Lineations measured: } \\
\hline \multirow[t]{2}{*}{$\mathrm{Geol}^{\mathrm{a}}$} & \multirow{2}{*}{$\begin{array}{c}\text { Field } \\
\text { station \# }\end{array}$} & & \multirow[t]{2}{*}{$E$} & \multirow[t]{2}{*}{$\mathrm{N}$} & \multirow[t]{2}{*}{ Ac. $^{\mathrm{C}}$} & \multirow[t]{2}{*}{ Elevation $^{d}$} & \multicolumn{2}{|c|}{ B-D shear $\left(S_{4}\right)$} & \multicolumn{2}{|c|}{ Alpine fol. $\left(\mathrm{S}_{3}\right)$} & \multicolumn{2}{|c|}{ Alpine fol. $\left(\mathrm{S}_{2}\right)$} & \multicolumn{2}{|c|}{ Myl. fol. $\left(S_{m}\right)$} & \multicolumn{2}{|c|}{$\mathrm{L}_{2-3}$} & \multicolumn{2}{|c|}{$\mathrm{L}_{4}$} & \multicolumn{2}{|c|}{$L_{m}$} \\
\hline & & & & & & & Strike & Dip & Strike & Dip & Strike & Dip & Strike & Dip & Trend & Plunge & Trend & Plunge & Trend & Plunge \\
\hline $\mathrm{MH}$ & $\mathrm{CH} 12$ & 2003 & $2,277,619$ & $5,740,276$ & - & 1770 & 215 & 82 & & & & & & & & & & & & \\
\hline $\mathrm{MH}$ & $\mathrm{CH} 13-1$ & 2003 & $2,277,325$ & $5,740,132$ & - & 1710 & 218 & 84 & 034 & 80 & & & & & & & 223 & 38 & & \\
\hline $\mathrm{MH}$ & $\mathrm{CH} 13-2$ & 2003 & $2,277,325$ & $5,740,132$ & - & 1710 & 038 & 89 & & & & & & & & & & & & \\
\hline $\mathrm{MH}$ & $\mathrm{CH} 14-1$ & 2003 & $2,277,286$ & $5,740,163$ & - & 1689 & 217 & 88 & 032 & 76 & & & & & & & & & & \\
\hline $\mathrm{MH}$ & $\mathrm{CH} 14-2$ & 2003 & $2,277,300$ & $5,740,178$ & - & 1689 & 215 & 87 & 032 & 75 & & & & & & & & & & \\
\hline $\mathrm{MH}$ & $\mathrm{CH} 14-3$ & 2003 & $2,277,300$ & $5,740,178$ & - & 1689 & & & 034 & 76 & 038 & 70 & & & 218 & 34 & & & & \\
\hline $\mathrm{MH}$ & $\mathrm{CH} 14-4$ & 2003 & $2,277,301$ & $5,740,163$ & - & 1695 & 217 & 86 & 042 & 70 & & & & & 220 & 40 & & & & \\
\hline $\mathrm{MH}$ & $\mathrm{CH} 14-5$ & 2003 & $2,277,301$ & $5,740,163$ & - & 1695 & 217 & 88 & & & & & & & & & & & & \\
\hline $\mathrm{MH}$ & $\mathrm{CH} 14-6$ & 2003 & $2,277,301$ & $5,740,163$ & - & 1695 & 215 & 85 & & & & & & & & & & & & \\
\hline $\mathrm{MH}$ & $\mathrm{CH} 14-7$ & 2003 & $2,277,301$ & $5,740,163$ & - & 1695 & 215 & 88 & & & & & & & & & & & & \\
\hline $\mathrm{MH}$ & $\mathrm{CH} 14-8$ & 2003 & $2,277,301$ & $5,740,163$ & - & 1695 & 216 & 86 & & & & & & & & & & & & \\
\hline $\mathrm{MH}$ & $\mathrm{CH} 14-9$ & 2003 & $2,277,301$ & $5,740,163$ & - & 1695 & 216 & 86 & & & & & & & & & & & & \\
\hline $\mathrm{MH}$ & $\mathrm{CH} 14-10$ & 2003 & $2,277,301$ & $5,740,163$ & - & 1695 & 216 & 88 & & & & & & & & & & & & \\
\hline $\mathrm{MH}$ & $\mathrm{CH} 15-1$ & 2003 & $2,277,272$ & $5,740,207$ & - & 1665 & 217 & 82 & 027 & 75 & & & & & & & & & & \\
\hline $\mathrm{MH}$ & $\mathrm{CH} 15-2$ & 2003 & $2,277,272$ & $5,740,207$ & - & 1665 & 219 & 85 & & & & & & & & & & & & \\
\hline $\mathrm{MH}$ & $\mathrm{CH} 15-3$ & 2003 & $2,277,272$ & $5,740,207$ & - & 1665 & & & & & & & & & & & & & & \\
\hline $\mathrm{MH}$ & $\mathrm{CH} 15-4$ & 2003 & $2,277,272$ & $5,740,207$ & - & 1665 & & & & & & & & & & & & & & \\
\hline $\mathrm{MH}$ & $\mathrm{CH} 16$ & 2003 & $2,277,107$ & $5,740,211$ & - & 1618 & 221 & 85 & 034 & 74 & & & & & & & & & & \\
\hline $\mathrm{MH}$ & $\mathrm{CH} 17$ & 2003 & $2,276,934$ & $5,740,285$ & - & 1551 & 218 & 86 & 035 & 78 & & & & & & & & & & \\
\hline $\mathrm{MH}$ & $\mathrm{CH} 18-1$ & 2003 & $2,275,675$ & $5,740,507$ & - & 878 & & & 039 & 71 & & & & & & & & & & \\
\hline $\mathrm{MH}$ & $\mathrm{CH} 18-2$ & 2003 & $2,275,675$ & $5,740,507$ & - & 878 & & & 025 & 78 & 036 & 60 & & & & & & & & \\
\hline $\mathrm{MH}$ & $\mathrm{CH} 19-1$ & 2003 & $2,275,814$ & $5,740,403$ & - & 920 & 223 & 76 & 035 & 63 & & & & & & & & & & \\
\hline $\mathrm{MH}$ & CH19-5 & 2003 & $2,275,814$ & $5,740,403$ & - & 920 & 220 & 82 & & & & & & & & & & & & \\
\hline $\mathrm{MH}$ & $\mathrm{CH} 2 \mathrm{O}-1$ & 2003 & $2,276,050$ & $5,740,450$ & - & 1183 & 215 & 87 & 029 & 77 & & & & & & & & & & \\
\hline $\mathrm{MH}$ & $\mathrm{CH} 2 \mathrm{O}-2$ & 2003 & $2,276,050$ & $5,740,450$ & - & 1183 & 218 & 88 & & & & & & & & & & & & \\
\hline $\mathrm{MH}$ & $\mathrm{CH} 2 \mathrm{O}-3$ & 2003 & $2,276,050$ & $5,740,450$ & - & 1183 & 208 & 81 & & & & & & & & & & & & \\
\hline $\mathrm{MH}$ & $\mathrm{CH} 21-1$ & $2003 b$ & $2,276,064$ & $5,740,293$ & - & 1156 & 221 & 86 & 035 & 76 & & & & & & & & & & \\
\hline $\mathrm{MH}$ & $\mathrm{CH} 21-2$ & $2003 b$ & $2,276,064$ & $5,740,293$ & - & 1156 & 224 & 88 & 032 & 70 & & & & & & & & & & \\
\hline $\mathrm{MH}$ & $\mathrm{CH} 21-3$ & $2003 b$ & $2,276,064$ & $5,740,293$ & - & 1156 & 220 & 88 & 032 & 70 & & & & & & & & & & \\
\hline $\mathrm{MH}$ & $\mathrm{CH} 21-4$ & $2003 b$ & $2,276,064$ & $5,740,293$ & - & 1156 & 218 & 87 & 036 & 75 & & & & & & & & & & \\
\hline $\mathrm{MH}$ & $\mathrm{CH} 22-1$ & $2003 b$ & $2,276,050$ & $5,740,450$ & - & 1183 & 040 & 82 & 028 & 82 & & & & & & & & & & \\
\hline $\mathrm{MH}$ & $\mathrm{CH} 22-2$ & $2003 b$ & $2,276,050$ & $5,740,450$ & - & 1183 & 038 & 88 & 036 & 70 & & & & & & & & & & \\
\hline $\mathrm{MH}$ & $\mathrm{CH} 23-1$ & $2003 b$ & $2,275,985$ & $5,740,544$ & - & 1123 & 221 & 87 & 035 & 72 & & & & & & & & & & \\
\hline $\mathrm{MH}$ & CH23-2 & $2003 b$ & $2,275,985$ & $5,740,544$ & - & 1123 & 216 & 78 & 028 & 70 & & & & & & & & & & \\
\hline
\end{tabular}




\begin{tabular}{|c|c|c|c|c|c|c|c|c|c|c|c|c|c|c|c|c|c|c|c|c|}
\hline \multicolumn{2}{|c|}{ Sample Site } & \multirow{3}{*}{$\begin{array}{l}\text { Year } \\
\text { of coll- } \\
\text { ection }\end{array}$} & \multicolumn{4}{|c|}{ Grid reference ${ }^{b}$} & \multicolumn{8}{|c|}{ Structural plane measured: (right hand rule) } & \multicolumn{6}{|c|}{ Lineations measured: } \\
\hline \multirow[t]{2}{*}{$\overline{G e o l^{a}}$} & \multirow{2}{*}{$\begin{array}{c}\text { Field } \\
\text { station \# }\end{array}$} & & \multirow[t]{2}{*}{$E$} & \multirow[t]{2}{*}{$\mathrm{N}$} & \multirow[t]{2}{*}{ Ac. $^{c}$} & \multirow[t]{2}{*}{ Elevation $^{d}$} & \multicolumn{2}{|c|}{ B-D shear $\left(\mathrm{S}_{4}\right)$} & \multicolumn{2}{|c|}{ Alpine fol. $\left(\mathrm{S}_{3}\right)$} & \multicolumn{2}{|c|}{ Alpine fol. $\left(S_{2}\right)$} & \multicolumn{2}{|c|}{ Myl. fol. $\left(S_{m}\right)$} & \multicolumn{2}{|c|}{$\mathrm{L}_{2-3}$} & \multicolumn{2}{|c|}{$\mathrm{L}_{4}$} & \multicolumn{2}{|c|}{$\mathrm{L}_{\mathrm{m}}$} \\
\hline & & & & & & & Strike & Dip & Strike & Dip & Strike & Dip & Strike & Dip & Trend & Plunge & Trend & Plunge & Trend & Plunge \\
\hline $\mathrm{MH}$ & $\mathrm{CH} 23-3$ & $2003 b$ & $2,275,985$ & $5,740,544$ & - & 1123 & 220 & 79 & 029 & 68 & & & & & & & & & & \\
\hline $\mathrm{MH}$ & $\mathrm{CH} 24$ & $2003 b$ & $2,276,129$ & $5,740,351$ & - & 1161 & 224 & 84 & 038 & 70 & & & & & & & & & & \\
\hline $\mathrm{MH}$ & $\mathrm{CH} 25-1$ & $2003 b$ & $2,276,338$ & $5,740,114$ & - & 1264 & 220 & 85 & 036 & 65 & & & & & & & & & & \\
\hline $\mathrm{MH}$ & $\mathrm{CH} 25-2$ & $2003 b$ & $2,276,338$ & $5,740,114$ & - & 1264 & 219 & 88 & 025 & 70 & & & & & & & & & & \\
\hline $\mathrm{MH}$ & $\mathrm{CH} 26-1$ & $2003 b$ & $2,277,280$ & $5,740,132$ & - & 1666 & 213 & 85 & 028 & 71 & & & & & & & & & & \\
\hline $\mathrm{MH}$ & $\mathrm{CH} 26-2$ & $2003 b$ & $2,277,280$ & $5,740,132$ & - & 1666 & 219 & 84 & 027 & 76 & & & & & & & & & & \\
\hline $\mathrm{MH}$ & $\mathrm{CH} 27-1$ & $2003 b$ & $2,277,348$ & $5,740,090$ & - & 1704 & 222 & 88 & 027 & 75 & & & & & & & & & & \\
\hline $\mathrm{MH}$ & $\mathrm{CH} 27-2$ & $2003 b$ & $2,277,348$ & $5,740,090$ & - & 1704 & 218 & 89 & 025 & 74 & & & & & & & & & & \\
\hline $\mathrm{MH}$ & $\mathrm{CH} 28$ & $2003 b$ & $2,277,421$ & $5,740,067$ & - & 1698 & 222 & 86 & 027 & 75 & & & & & & & 223 & 12 & & \\
\hline $\mathrm{MH}$ & $\mathrm{CH} 29-1$ & $2003 b$ & $2,277,802$ & $5,739,908$ & - & 1751 & 231 & 82 & 029 & 74 & & & & & & & & & & \\
\hline $\mathrm{MH}$ & $\mathrm{CH} 29-2$ & $2003 b$ & $2,277,802$ & $5,739,908$ & - & 1751 & 218 & 85 & 028 & 80 & & & & & & & & & & \\
\hline $\mathrm{MH}$ & $\mathrm{CH} 30$ & $2003 b$ & $2,277,114$ & $5,740,287$ & - & 1580 & 210 & 88 & 041 & 64 & & & & & & & & & & \\
\hline $\mathrm{MH}$ & $\mathrm{CH} 31-1$ & $2003 b$ & $2,277,232$ & $5,740,212$ & - & 1641 & 216 & 86 & 037 & 67 & & & & & & & & & & \\
\hline $\mathrm{MH}$ & $\mathrm{CH} 32$ & $2003 b$ & $2,276,924$ & $5,739,676$ & - & 1449 & 216 & 68 & 042 & 78 & & & & & & & & & & \\
\hline $\mathrm{MH}$ & $\mathrm{CH} 33$ & $2003 b$ & $2,276,926$ & $5,739,676$ & - & 1452 & 218 & 84 & & & & & & & & & 223 & 41 & & \\
\hline $\mathrm{MH}$ & $\mathrm{CH} 34$ & $2003 b$ & $2,276,924$ & $5,739,671$ & - & 1441 & 218 & 82 & 035 & 82 & & & & & & & & & & \\
\hline $\mathrm{MH}$ & $\mathrm{CH} 35$ & $2003 b$ & $2,276,935$ & $5,739,670$ & - & 1450 & 216 & 80 & 042 & 78 & & & & & & & & & & \\
\hline $\mathrm{MH}$ & $\mathrm{CH} 36-1$ & $2003 b$ & $2,276,962$ & $5,739,676$ & - & 1451 & 212 & 80 & & & & & & & & & & & & \\
\hline $\mathrm{MH}$ & $\mathrm{CH} 36-2$ & $2003 b$ & $2,276,962$ & $5,739,676$ & - & 1451 & 196 & 82 & & & & & & & & & & & & \\
\hline $\mathrm{MH}$ & $\mathrm{CH} 36-3$ & $2003 b$ & $2,276,962$ & $5,739,676$ & - & 1451 & 208 & 81 & & & & & & & & & & & & \\
\hline $\mathrm{MH}$ & $\mathrm{CH} 31-2$ & $2003 b$ & $2,277,232$ & $5,740,212$ & - & 1641 & 220 & 65 & & & & & & & & & 239 & 35 & & \\
\hline $\mathrm{MH}$ & $\mathrm{CH} 31-3$ & $2003 b$ & $2,277,232$ & $5,740,212$ & - & 1641 & 219 & 78 & & & & & & & & & 225 & 25 & & \\
\hline $\mathrm{MH}$ & $\mathrm{CH} 31-4$ & $2003 b$ & $2,277,232$ & $5,740,212$ & - & 1641 & 210 & 82 & & & & & & & & & 214 & 25 & & \\
\hline
\end{tabular}

Appendix A-1. Structural field data collected on Chancellor Ridge. a - geologist collecting the data: MH - Matt Hill, TL - Timothy Little, RW - Ruth Wightman. Collection year and field season ( $\mathrm{a}$ or $\mathrm{b}$ ) within that year listed. $\mathrm{b}$ - Grid reference is in New Zealand map grid coordinates (metres). $\mathrm{c}$ - Accuracy of coordinates measured using a GPS unit ( \pm in meters). d - elevation given in meters above mean sea level. Alpine Fol refers to the Alpine Schist foliation and Myl fol refers to the Alpine Schist mylonitic foliation. Lineation subscripts refer to foliations or intersections: $\mathrm{L}_{2-3}$ - intersection lineation between $\mathrm{S}_{2}$ and $\mathrm{S}_{3}, \mathrm{~L}_{4}$ - mineral fibre lineation decorating $\mathrm{S}_{4}$ fault surfaces, and $\mathrm{L}_{\mathrm{m}}$ - mineral stretching lineation on Alpine Schist mylonite foliation $\left(\mathrm{S}_{\mathrm{m}}\right)$. 


\begin{tabular}{|c|c|c|c|c|c|c|c|c|c|c|c|c|c|c|c|c|c|c|c|c|}
\hline \multicolumn{2}{|c|}{ Sample Site } & \multirow{3}{*}{$\begin{array}{l}\text { Year } \\
\text { of coll- } \\
\text { ection }\end{array}$} & \multicolumn{4}{|c|}{ Grid reference $^{b}$} & \multicolumn{8}{|c|}{ Structural plane measured: (right hand rule) } & \multicolumn{6}{|c|}{ Lineations measured: } \\
\hline \multirow[t]{2}{*}{$\overline{\mathrm{Geol}^{2}}$} & \multirow{2}{*}{$\begin{array}{c}\text { Field } \\
\text { station \# }\end{array}$} & & \multirow[t]{2}{*}{$\mathrm{E}$} & \multirow[t]{2}{*}{$\mathrm{N}$} & \multirow[t]{2}{*}{ Ac. $^{\mathrm{C}}$} & \multirow[t]{2}{*}{ Elevation $^{d}$} & \multicolumn{2}{|c|}{ B-D shear $\left(S_{4}\right)$} & \multicolumn{2}{|c|}{ Alpine fol. $\left(S_{3}\right)$} & \multicolumn{2}{|c|}{ Alpine fol. $\left(S_{2}\right)$} & \multicolumn{2}{|c|}{ Myl. fol. $\left(\mathrm{S}_{\mathrm{m}}\right)$} & \multicolumn{2}{|c|}{$\mathrm{L}_{2-3}$} & \multicolumn{2}{|c|}{$\mathrm{L}_{4}$} & \multicolumn{2}{|c|}{$\mathrm{L}_{\mathrm{m}}$} \\
\hline & & & & & & & Strike & Dip & Strike & Dip & Strike & Dip & Strike & Dip & Trend & Plunge & Trend & Plunge & Trend & Plunge \\
\hline $\mathrm{MH}$ & SP01 & 2002 & $2,273,780$ & $5,738,418$ & 16 & - & & & 042 & 74 & & & & & 212 & 38 & & & & \\
\hline $\mathrm{MH}$ & SP02 & 2002 & $2,273,686$ & $5,738,406$ & 12 & - & & & 028 & 62 & & & & & & & & & & \\
\hline $\mathrm{MH}$ & SP03 & 2002 & $2,273,513$ & $5,738,421$ & - & - & & & 030 & 74 & & & & & 218 & 32 & & & & \\
\hline $\mathrm{MH}$ & SP04 & 2002 & $2,273,385$ & $5,738,506$ & 8 & 1700 & & & 204 & 60 & & & & & 218 & 54 & & & & \\
\hline $\mathrm{MH}$ & SP05 & 2002 & $2,273,235$ & $5,738,374$ & 6 & - & & & 026 & 80 & & & & & 222 & 50 & & & & \\
\hline $\mathrm{MH}$ & SP06 & 2002 & $2,272,925$ & $5,738,335$ & 6 & 1680 & & & 039 & 60 & 182 & 62 & & & 221 & 22 & & & & \\
\hline $\mathrm{MH}$ & SP07 & 2002 & $2,274,496$ & $5,737,332$ & - & 1860 & 228 & 62 & 217 & 89 & & & & & & & & & & \\
\hline $\mathrm{MH}$ & SP08 & 2002 & $2,274,495$ & $5,737,213$ & 5 & 1865 & 034 & 62 & 026 & 82 & & & & & & & & & & \\
\hline $\mathrm{MH}$ & SP09 & 2002 & $2,274,514$ & $5,737,163$ & 5 & 1865 & 202 & 52 & 205 & 76 & & & & & & & & & & \\
\hline $\mathrm{MH}$ & SP10 & 2002 & $2,274,555$ & $5,737,213$ & 7 & 1875 & 182 & 64 & 204 & 73 & & & & & & & & & & \\
\hline $\mathrm{MH}$ & SP11 & 2002 & $2,274,762$ & $5,737,045$ & 5 & 1900 & 196 & 40 & 213 & 64 & & & & & & & & & & \\
\hline $\mathrm{MH}$ & SP12 & 2002 & $2,274,625$ & $5,737,165$ & - & - & 207 & 54 & 200 & 69 & & & & & & & & & & \\
\hline $\mathrm{MH}$ & SP13 & 2002 & $2,274,525$ & $5,737,220$ & - & - & 210 & 66 & 212 & 82 & & & & & & & & & & \\
\hline RW & RW29-1 & 2002 & $2,273,715$ & $5,738,047$ & - & - & & & & & 201 & 68 & & & & & & & & \\
\hline RW & RW29-2 & 2002 & $2,273,715$ & $5,738,047$ & - & - & & & & & 207 & 50 & & & & & & & & \\
\hline RW & RW29-3 & 2002 & $2,273,715$ & $5,738,047$ & - & - & & & & & 063 & 73 & & & & & & & & \\
\hline RW & RW29-4 & 2002 & $2,273,715$ & $5,738,047$ & - & - & & & 041 & 90 & 101 & 16 & & & & & & & & \\
\hline RW & RW30-1 & 2002 & $2,273,655$ & $5,738,044$ & - & - & & & 200 & 68 & & & & & & & & & & \\
\hline RW & RW30-2 & 2002 & $2,273,655$ & $5,738,044$ & - & - & & & 201 & 68 & & & & & & & & & & \\
\hline RW & RW31 & 2002 & $2,273,585$ & $5,738,002$ & - & - & & & 213 & 80 & 111 & 10 & & & 217 & 10 & & & & \\
\hline RW & RW32-1 & 2002 & $2,273,439$ & $5,738,035$ & - & - & & & 210 & 72 & & & & & 225 & 38 & & & & \\
\hline RW & RW32-2 & 2002 & $2,273,439$ & $5,738,035$ & - & - & & & & & & & & & & & & & & \\
\hline RW & RW33 & 2002 & $2,273,325$ & $5,737,971$ & - & - & & & 213 & 87 & & & & & & & & & & \\
\hline RW & RW34-1 & 2002 & $2,273,135$ & $5,738,015$ & - & - & & & 013 & 88 & 181 & 47 & & & & & & & & \\
\hline RW & RW34-2 & 2002 & $2,273,135$ & $5,738,015$ & - & - & & & 037 & 84 & & & & & & & & & & \\
\hline RW & RW35-1 & 2002 & $2,274,172$ & $5,737,505$ & - & - & 207 & 65 & & & 207 & 80 & & & & & & & & \\
\hline RW & RW35-2 & 2002 & $2,274,172$ & $5,737,505$ & - & - & 205 & 62 & & & 210 & 84 & & & & & & & & \\
\hline RW & RW35-3 & 2002 & $2,274,172$ & $5,737,505$ & - & - & 212 & 70 & & & 200 & 74 & & & & & & & & \\
\hline RW & RW35-4 & 2002 & $2,274,172$ & $5,737,505$ & - & - & 207 & 55 & & & & & & & & & & & & \\
\hline RW & RW35-5 & 2002 & $2,274,172$ & $5,737,505$ & - & - & 218 & 60 & & & & & & & & & & & & \\
\hline RW & RW35-6 & 2002 & $2,274,172$ & $5,737,505$ & - & - & 212 & 74 & & & & & & & & & & & & \\
\hline RW & RW35-7 & 2002 & $2,274,172$ & $5,737,505$ & - & - & 213 & 63 & & & & & & & & & & & & \\
\hline RW & RW35-8 & 2002 & $2,274,172$ & $5,737,505$ & - & - & 207 & 64 & & & & & & & & & & & & \\
\hline RW & RW35-9 & 2002 & $2,274,172$ & $5,737,505$ & - & - & 200 & 56 & & & 203 & 80 & & & & & & & & \\
\hline
\end{tabular}




\begin{tabular}{|c|c|c|c|c|c|c|c|c|c|c|c|c|c|c|c|c|c|c|c|c|}
\hline \multicolumn{2}{|c|}{ Sample Site } & \multirow{3}{*}{$\begin{array}{l}\text { Year } \\
\text { of coll- } \\
\text { ection }\end{array}$} & \multicolumn{4}{|c|}{ Grid reference $^{b}$} & \multicolumn{8}{|c|}{ Structural plane measured: (right hand rule) } & \multicolumn{6}{|c|}{ Lineations measured: } \\
\hline \multirow[t]{2}{*}{$\mathrm{Geol}^{\mathrm{a}}$} & \multirow{2}{*}{$\begin{array}{c}\text { Field } \\
\text { station \# }\end{array}$} & & \multirow[t]{2}{*}{$E$} & \multirow[t]{2}{*}{$\mathrm{N}$} & \multirow[t]{2}{*}{ Ac. $^{\mathrm{C}}$} & \multirow[t]{2}{*}{ Elevation $^{d}$} & \multicolumn{2}{|c|}{ B-D shear $\left(S_{4}\right)$} & \multicolumn{2}{|c|}{ Alpine fol. $\left(\mathrm{S}_{3}\right)$} & \multicolumn{2}{|c|}{ Alpine fol. $\left(\mathrm{S}_{2}\right)$} & \multicolumn{2}{|c|}{ Myl. fol. $\left(S_{m}\right)$} & \multicolumn{2}{|c|}{$\mathrm{L}_{2-3}$} & \multicolumn{2}{|c|}{$\mathrm{L}_{4}$} & \multicolumn{2}{|c|}{$\mathrm{L}_{\mathrm{m}}$} \\
\hline & & & & & & & Strike & Dip & Strike & Dip & Strike & Dip & Strike & Dip & Trend & Plunge & Trend & Plunge & Trend & Plunge \\
\hline RW & RW35-10 & 2002 & $2,274,172$ & $5,737,505$ & - & - & 197 & 64 & & & & & & & & & & & & \\
\hline RW & RW35-11 & 2002 & $2,274,172$ & $5,737,505$ & - & - & 191 & 58 & & & & & & & & & & & & \\
\hline RW & RW35-12 & 2002 & $2,274,172$ & $5,737,505$ & - & - & 188 & 60 & & & 211 & 72 & & & & & & & & \\
\hline RW & RW35-13 & 2002 & $2,274,172$ & $5,737,505$ & - & - & 191 & 62 & & & & & & & & & & & & \\
\hline RW & RW35-14 & 2002 & $2,274,172$ & $5,737,505$ & - & - & 206 & 64 & & & 193 & 68 & & & & & & & & \\
\hline RW & RW36 & 2002 & $2,274,383$ & $5,737,438$ & - & - & 181 & 64 & & & & & & & & & & & & \\
\hline RW & RW37 & 2002 & $2,274,302$ & $5,737,456$ & - & - & 179 & 64 & & & 202 & 78 & & & & & & & & \\
\hline RW & RW38-1 & 2002 & $2,274,188$ & $5,737,505$ & - & - & 213 & 65 & & & 204 & 83 & & & & & & & & \\
\hline RW & RW38-2 & 2002 & $2,274,188$ & $5,737,505$ & - & - & 207 & 64 & & & & & & & & & & & & \\
\hline RW & RW38-3 & 2002 & $2,274,188$ & $5,737,505$ & - & - & 213 & 56 & & & & & & & & & & & & \\
\hline $\mathrm{TL}$ & TJFA36-1 & 2002 & $2,273,840$ & $5,738,296$ & - & - & & & 043 & 78 & 132 & 55 & & & 211 & 40 & & & & \\
\hline TL & TJFA36-2 & 2002 & $2,273,840$ & $5,738,296$ & - & - & & & & & 155 & 40 & & & & & & & & \\
\hline TL & TJFA37 & 2002 & $2,273,843$ & $5,738,156$ & - & 1670 & & & 195 & 71 & 189 & 27 & & & 205 & 15 & & & & \\
\hline TL & TJFA38 & 2002 & $2,273,855$ & $5,737,949$ & - & 1700 & & & 201 & 71 & 080 & 52 & & & 226 & 20 & & & & \\
\hline TL & TJFA39 & 2002 & $2,273,928$ & $5,737,901$ & - & 1727 & & & 215 & 85 & 087 & 58 & & & 222 & 23 & & & & \\
\hline TL & TJFA40 & 2002 & $2,274,236$ & $5,737,567$ & - & 1786 & & & 201 & 72 & 081 & 40 & & & 205 & 32 & & & & \\
\hline TL & TJFA41 & 2002 & $2,274,321$ & $5,737,492$ & - & 1815 & 222 & 82 & 205 & 76 & & & & & 215 & 23 & & & & \\
\hline TL & TJFA42-1 & 2002 & $2,274,079$ & $5,737,423$ & - & 1837 & 232 & 80 & & & & & & & & & & & & \\
\hline TL & TJFA42-2 & 2002 & $2,274,079$ & $5,737,423$ & - & - & 227 & 87 & 203 & 64 & & & & & & & & & & \\
\hline TL & TJFA42-3 & 2002 & $2,274,079$ & $5,737,423$ & - & - & 222 & 84 & & & & & & & & & & & & \\
\hline TL & TJFA42-4 & 2002 & $2,274,079$ & $5,737,423$ & - & - & 218 & 70 & & & & & & & & & & & & \\
\hline $\mathrm{TL}$ & TJFA42-5 & 2002 & $2,274,079$ & $5,737,423$ & - & - & 210 & 79 & & & & & & & & & & & & \\
\hline TL & TJFA43 & 2002 & $2,274,409$ & $5,737,321$ & - & 1824 & 211 & 64 & 202 & 79 & & & & & & & & & & \\
\hline TL & TJFA44-1 & 2002 & $2,274,436$ & $5,737,312$ & - & 1837 & 215 & 75 & 208 & 82 & & & & & 210 & 21 & & & & \\
\hline TL & TJFA44-2 & 2002 & $2,274,436$ & $5,737,312$ & - & - & 210 & 68 & & & & & & & & & & & & \\
\hline TL & TJFA46-1 & 2002 & $2,274,517$ & $5,737,228$ & - & 1865 & 211 & 75 & & & & & & & & & & & & \\
\hline $\mathrm{TL}$ & TJFA46-2 & 2002 & $2,274,517$ & $5,737,228$ & - & - & 212 & 62 & & & & & & & & & & & & \\
\hline TL & TJFA47 & 2002 & $2,274,502$ & $5,737,234$ & - & 1865 & 213 & 60 & 203 & 89 & & & & & & & & & & \\
\hline TL & TJFA48 & 2002 & $2,274,461$ & $5,737,285$ & - & 1850 & 220 & 64 & & & & & & & & & 224 & 7 & & \\
\hline TL & TJFA49-1 & 2002 & $2,274,356$ & $5,737,408$ & - & 1809 & 218 & 68 & 204 & 83 & & & & & 210 & 27 & & & & \\
\hline TL & TJFA49-2 & 2002 & $2,274,356$ & $5,737,408$ & - & - & 209 & 63 & & & & & & & & & 220 & 20 & & \\
\hline TL & TJFA49-3 & 2002 & $2,274,356$ & $5,737,408$ & - & - & 220 & 70 & & & & & & & & & & & & \\
\hline TL & TJFA49-4 & 2002 & $2,274,356$ & $5,737,408$ & - & - & 210 & 70 & & & & & & & & & & & & \\
\hline TL & TJFA50-1 & 2002 & $2,274,300$ & $5,737,390$ & - & 1815 & 209 & 67 & 198 & 74 & & & & & & & & & & \\
\hline
\end{tabular}




\begin{tabular}{|c|c|c|c|c|c|c|c|c|c|c|c|c|c|c|c|c|c|c|c|c|}
\hline \multicolumn{2}{|c|}{ Sample Site } & \multirow{3}{*}{$\begin{array}{l}\text { Year } \\
\text { of coll- } \\
\text { ection }\end{array}$} & \multicolumn{4}{|c|}{ Grid reference $^{b}$} & \multicolumn{8}{|c|}{ Structural plane measured: (right hand rule) } & \multicolumn{6}{|c|}{ Lineations measured: } \\
\hline \multirow[t]{2}{*}{$\mathrm{Geol}^{\mathrm{a}}$} & \multirow{2}{*}{$\begin{array}{c}\text { Field } \\
\text { station \# }\end{array}$} & & \multirow[t]{2}{*}{$E$} & \multirow[t]{2}{*}{$\mathrm{N}$} & \multirow[t]{2}{*}{ Ac. $^{\mathrm{C}}$} & \multirow[t]{2}{*}{ Elevation $^{d}$} & \multicolumn{2}{|c|}{ B-D shear $\left(S_{4}\right)$} & \multicolumn{2}{|c|}{ Alpine fol. $\left(\mathrm{S}_{3}\right)$} & \multicolumn{2}{|c|}{ Alpine fol. $\left(S_{2}\right)$} & \multicolumn{2}{|c|}{ Myl. fol. $\left(S_{m}\right)$} & \multicolumn{2}{|c|}{$\mathrm{L}_{2-3}$} & \multicolumn{2}{|c|}{$\mathrm{L}_{4}$} & \multicolumn{2}{|c|}{$\mathrm{L}_{\mathrm{m}}$} \\
\hline & & & & & & & Strike & Dip & Strike & Dip & Strike & Dip & Strike & Dip & Trend & Plunge & Trend & Plunge & Trend & Plunge \\
\hline $\mathrm{TL}$ & TJFA50-2 & 2002 & $2,274,300$ & $5,737,390$ & - & - & 209 & 68 & & & & & & & & & & & & \\
\hline TL & TJFA51-1 & 2002 & $2,274,266$ & $5,737,416$ & - & 1795 & 226 & 65 & & & & & & & & & 253 & 44 & & \\
\hline TL & TJFA51-2 & 2002 & $2,274,266$ & $5,737,416$ & - & 1786 & 211 & 65 & & & & & & & & & & & & \\
\hline TL & TJFA51-3 & 2002 & $2,274,266$ & $5,737,416$ & - & 1788 & 210 & 63 & & & & & & & & & 216 & 12 & & \\
\hline TL & TJFA52-1 & 2002 & $2,274,288$ & $5,737,385$ & - & 1797 & 204 & 68 & & & & & & & & & & & & \\
\hline TL & TJFA52-2 & 2002 & $2,274,288$ & $5,737,385$ & - & - & 212 & 60 & & & & & & & & & & & & \\
\hline TL & TJFA52-3 & 2002 & $2,274,288$ & $5,737,385$ & - & 1787 & 215 & 65 & & & & & & & & & & & & \\
\hline TL & TJFA53 & 2002 & $2,274,248$ & $5,737,386$ & - & - & 215 & 67 & 205 & 77 & & & & & & & & & & \\
\hline TL & TJFA54 & 2002 & $2,274,210$ & $5,737,380$ & - & 1761 & 209 & 60 & 198 & 64 & & & & & 225 & 43 & & & & \\
\hline TL & TJFA56 & 2002 & $2,274,197$ & $5,737,210$ & - & 1741 & 212 & 63 & 207 & 73 & & & & & & & & & & \\
\hline TL & TJFA57 & 2002 & $2,274,246$ & $5,737,177$ & - & 1757 & 212 & 62 & & & & & & & & & & & & \\
\hline TL & TJFA59 & 2002 & $2,274,341$ & $5,737,202$ & - & 1798 & 227 & 67 & & & & & & & & & & & & \\
\hline TL & TJFA60-1 & 2002 & $2,274,352$ & $5,737,202$ & - & 1801 & 215 & 60 & & & & & & & & & & & & \\
\hline
\end{tabular}

Appendix A-2. Structural field data collected on Sam Peak. a - geologist collecting the data: MH - Matt Hill, TL - Timothy Little, RW - Ruth Wightman. Collection year and field season ( $\mathrm{a}$ or $\mathrm{b}$ ) within that year listed. $\mathrm{b}$ - Grid reference is in New Zealand map grid coordinates (metres). c - Accuracy of coordinates measured using a GPS unit ( \pm in meters). $d$ elevation given in meters above mean sea level. Alpine Fol refers to the Alpine Schist foliation and Myl fol refers to the Alpine Schist mylonitic foliation. Lineation subscripts refer to foliations or intersections: $\mathrm{L}_{2-3}$ - intersection lineation between $\mathrm{S}_{2}$ and $\mathrm{S}_{3}, \mathrm{~L}_{4}$ - mineral fibre lineation decorating $\mathrm{S}_{4}$ fault surfaces, and $\mathrm{L}_{\mathrm{m}}$ - mineral stretching lineation on Alpine Schist mylonite foliation $\left(\mathrm{S}_{\mathrm{m}}\right)$. 


\begin{tabular}{|c|c|c|c|c|c|c|c|c|c|c|c|c|c|c|c|c|c|c|c|c|}
\hline \multicolumn{2}{|c|}{ Sample Site } & \multirow{3}{*}{$\begin{array}{l}\text { Year } \\
\text { of coll- } \\
\text { ection }\end{array}$} & \multicolumn{4}{|c|}{ Grid reference $^{b}$} & \multicolumn{8}{|c|}{ Structural plane measured: (right hand rule) } & \multicolumn{6}{|c|}{ Lineations measured: } \\
\hline \multirow[t]{2}{*}{$\left.\overline{\mathrm{Geol}}\right|^{2}$} & \multirow{2}{*}{$\begin{array}{c}\text { Field } \\
\text { station \# }\end{array}$} & & \multirow[t]{2}{*}{$\bar{E}$} & \multirow[t]{2}{*}{$\mathrm{N}$} & \multirow[t]{2}{*}{ Ac. $^{\mathrm{C}}$} & \multirow[t]{2}{*}{ Elevation $^{0}$} & \multicolumn{2}{|c|}{ B-D shear $\left(S_{4}\right)$} & \multicolumn{2}{|c|}{ Alpine fol. $\left(S_{3}\right)$} & \multicolumn{2}{|c|}{ Alpine fol. $\left(S_{2}\right)$} & \multicolumn{2}{|c|}{ Myl. fol. $\left(\mathrm{S}_{\mathrm{m}}\right)$} & \multicolumn{2}{|c|}{$\mathrm{L}_{2-3}$} & \multicolumn{2}{|c|}{$\mathrm{L}_{4}$} & \multicolumn{2}{|c|}{$\mathrm{L}_{\mathrm{m}}$} \\
\hline & & & & & & & Strike & Dip & Strike & Dip & Strike & Dip & Strike & Dip & Trend & Plunge & Trend & Plunge & Trend & Plunge \\
\hline $\mathrm{MH}$ & BM01-01 & 2004 & $2,280,390$ & $5,745,031$ & 8 & 1495 & 062 & 74 & & & & & & & & & & & & \\
\hline $\mathrm{MH}$ & BM01-02 & 2004 & $2,280,390$ & $5,745,031$ & 8 & 1495 & 043 & 80 & & & & & & & & & & & & \\
\hline $\mathrm{MH}$ & BM01-03 & 2004 & $2,280,390$ & $5,745,031$ & 8 & 1495 & & & 067 & 72 & & & & & & & & & & \\
\hline $\mathrm{MH}$ & BM01-05 & 2004 & $2,280,390$ & $5,745,031$ & 8 & 1495 & 042 & 78 & & & & & & & & & & & & \\
\hline $\mathrm{MH}$ & BM02-01 & 2004 & $2,280,528$ & $5,745,097$ & 9 & 1480 & 048 & 86 & & & & & & & & & & & & \\
\hline $\mathrm{MH}$ & BM02-02 & 2004 & $2,280,528$ & $5,745,097$ & 9 & 1480 & & & & & 040 & 78 & & & & & & & & \\
\hline $\mathrm{MH}$ & BM03-01 & 2004 & $2,280,760$ & $5,745,004$ & 6 & 1531 & 052 & 60 & & & & & & & & & & & & \\
\hline $\mathrm{MH}$ & BM03-02 & 2004 & $2,280,760$ & $5,745,004$ & 6 & 1531 & 046 & 67 & & & & & & & & & & & & \\
\hline $\mathrm{MH}$ & BM03-03 & 2004 & $2,280,760$ & $5,745,004$ & 6 & 1531 & 046 & 70 & & & & & & & & & & & & \\
\hline $\mathrm{MH}$ & BM04-01 & 2004 & $2,280,815$ & $5,744,895$ & 6 & 1546 & 046 & 72 & & & & & & & & & & & & \\
\hline $\mathrm{MH}$ & BM04-02 & 2004 & $2,280,815$ & $5,744,895$ & 6 & 1546 & 036 & 72 & & & & & & & & & & & & \\
\hline $\mathrm{MH}$ & BM05-01 & 2004 & $2,280,956$ & $5,744,858$ & 9 & 1613 & 052 & 70 & & & & & & & & & & & & \\
\hline $\mathrm{MH}$ & BM05-02 & 2004 & $2,280,956$ & $5,744,858$ & 9 & 1613 & 054 & 72 & & & & & & & & & & & & \\
\hline $\mathrm{MH}$ & BM05-04 & 2004 & $2,280,956$ & $5,744,858$ & 9 & 1613 & 052 & 49 & & & & & & & & & & & & \\
\hline $\mathrm{MH}$ & BM05-05 & 2004 & $2,280,956$ & $5,744,858$ & 9 & 1613 & 049 & 68 & & & & & & & & & & & & \\
\hline $\mathrm{MH}$ & BM05-06 & 2004 & $2,280,956$ & $5,744,858$ & 9 & 1613 & 056 & 68 & & & & & & & & & & & & \\
\hline $\mathrm{MH}$ & BM05-07 & 2004 & $2,280,956$ & $5,744,858$ & 9 & 1613 & 049 & 70 & & & & & & & & & & & & \\
\hline $\mathrm{MH}$ & BM05-08 & 2004 & $2,280,956$ & $5,744,858$ & 9 & 1613 & & & & & 064 & 68 & & & & & & & & \\
\hline $\mathrm{MH}$ & BM05-10 & 2004 & $2,280,956$ & $5,744,858$ & 9 & 1613 & 235 & 88 & & & & & & & & & & & & \\
\hline $\mathrm{MH}$ & BM05-11 & 2004 & $2,280,956$ & $5,744,858$ & 9 & 1613 & 227 & 86 & & & & & & & & & & & & \\
\hline $\mathrm{MH}$ & BM05-12 & 2004 & $2,280,956$ & $5,744,858$ & 9 & 1613 & 237 & 87 & & & & & & & & & & & & \\
\hline $\mathrm{MH}$ & BM05-13 & 2004 & $2,280,956$ & $5,744,858$ & 9 & 1613 & 227 & 88 & & & & & & & & & & & & \\
\hline $\mathrm{MH}$ & BM05-14 & 2004 & $2,280,956$ & $5,744,858$ & 9 & 1613 & 233 & 84 & & & & & & & & & & & & \\
\hline $\mathrm{MH}$ & BM05-15 & 2004 & $2,280,956$ & $5,744,858$ & 9 & 1613 & 223 & 84 & 048 & 74 & & & & & & & & & & \\
\hline $\mathrm{MH}$ & BM06 & 2004 & $2,281,063$ & $5,744,840$ & 16 & 1629 & 046 & 86 & & & & & & & & & & & & \\
\hline $\mathrm{MH}$ & BM07-01 & 2004 & $2,281,277$ & $5,744,898$ & 5 & 1745 & & & & & 038 & 68 & & & & & & & & \\
\hline $\mathrm{MH}$ & BM08 & 2004 & $2,281,306$ & $5,744,853$ & 6 & 1750 & & & & & 038 & 78 & & & & & & & & \\
\hline $\mathrm{MH}$ & BM09-01 & 2004 & $2,281,304$ & $5,744,565$ & 50 & 1730 & & & & & 044 & 86 & & & 221 & 40 & & & & \\
\hline $\mathrm{MH}$ & BM09-02 & 2004 & $2,281,304$ & $5,744,565$ & 50 & 1730 & & & & & 056 & 70 & & & & & & & & \\
\hline $\mathrm{MH}$ & BM10-01 & 2004 & $2,281,178$ & $5,744,490$ & 50 & 1740 & 057 & 76 & & & & & & & & & & & & \\
\hline $\mathrm{MH}$ & BM10-02 & 2004 & $2,281,178$ & $5,744,490$ & 50 & 1740 & & & & & 074 & 54 & & & & & & & & \\
\hline $\mathrm{MH}$ & BM11-01 & 2004 & $2,281,162$ & $5,744,633$ & 8 & 1699 & 229 & 80 & & & & & & & & & & & & \\
\hline $\mathrm{MH}$ & BM11-02 & 2004 & $2,281,162$ & $5,744,633$ & 8 & 1699 & 228 & 88 & & & & & & & & & & & & \\
\hline $\mathrm{MH}$ & BM11-03 & 2004 & $2,281,162$ & $5,744,633$ & 8 & 1699 & 226 & 82 & & & & & & & & & & & & \\
\hline
\end{tabular}




\begin{tabular}{|c|c|c|c|c|c|c|c|c|c|c|c|c|c|c|c|c|c|c|c|c|}
\hline \multicolumn{2}{|c|}{ Sample Site } & \multirow{3}{*}{$\begin{array}{c}\text { Year } \\
\text { of coll- } \\
\text { ection }\end{array}$} & \multicolumn{4}{|c|}{ Grid reference $^{b}$} & \multicolumn{8}{|c|}{ Structural plane measured: (right hand rule) } & \multicolumn{6}{|c|}{ Lineations measured: } \\
\hline \multirow[t]{2}{*}{$\mathrm{GeO}^{2}$} & \multirow{2}{*}{$\begin{array}{c}\text { Field } \\
\text { station \# }\end{array}$} & & \multirow[t]{2}{*}{$E$} & \multirow[t]{2}{*}{$\mathrm{N}$} & \multirow[t]{2}{*}{ Ac. $^{\mathrm{C}}$} & \multirow[t]{2}{*}{ Elevation $^{d}$} & \multicolumn{2}{|c|}{ B-D shear $\left(S_{4}\right)$} & \multicolumn{2}{|c|}{ Alpine fol. $\left(\mathrm{S}_{3}\right)$} & \multicolumn{2}{|c|}{ Alpine fol. $\left(\mathrm{S}_{2}\right)$} & \multicolumn{2}{|c|}{ Myl. fol. $\left(S_{m}\right)$} & \multicolumn{2}{|c|}{$\mathrm{L}_{2-3}$} & \multicolumn{2}{|c|}{$\mathrm{L}_{4}$} & \multicolumn{2}{|c|}{$\mathrm{L}_{\mathrm{m}}$} \\
\hline & & & & & & & Strike & Dip & Strike & Dip & Strike & Dip & Strike & Dip & Trend & Plunge & Trend & Plunge & Trend & Plunge \\
\hline $\mathrm{MH}$ & BM12-01 & 2004 & $2,279,955$ & $5,744,609$ & 6 & 1728 & 046 & 82 & & & & & & & & & & & & \\
\hline $\mathrm{MH}$ & BM12-02 & 2004 & $2,279,955$ & $5,744,609$ & 6 & 1728 & 054 & 80 & & & & & & & & & & & & \\
\hline $\mathrm{MH}$ & BM12-03 & 2004 & $2,279,955$ & $5,744,609$ & 6 & 1728 & 044 & 78 & & & & & & & & & & & & \\
\hline $\mathrm{MH}$ & BM12-05 & 2004 & $2,279,955$ & $5,744,609$ & 6 & 1728 & 048 & 86 & & & & & & & & & & & & \\
\hline $\mathrm{MH}$ & BM13-01 & 2004 & $2,279,906$ & $5,744,559$ & 6 & 1746 & 042 & 74 & & & & & & & & & & & & \\
\hline $\mathrm{MH}$ & BM13-02 & 2004 & $2,279,906$ & $5,744,559$ & 6 & 1746 & 043 & 76 & & & & & & & & & & & & \\
\hline $\mathrm{MH}$ & BM13-04 & 2004 & $2,279,906$ & $5,744,559$ & 6 & 1746 & 039 & 78 & & & & & & & & & & & & \\
\hline $\mathrm{MH}$ & BM14-01 & 2004 & $2,279,922$ & $5,744,478$ & 7 & 1780 & 045 & 82 & & & & & & & & & & & & \\
\hline $\mathrm{MH}$ & BM14-02 & 2004 & $2,279,922$ & $5,744,478$ & 7 & 1780 & 048 & 78 & 038 & 83 & 050 & 70 & & & & & & & & \\
\hline $\mathrm{MH}$ & BM14-03 & 2004 & $2,279,922$ & $5,744,478$ & 7 & 1780 & 041 & 82 & 045 & 68 & & & & & & & & & & \\
\hline $\mathrm{MH}$ & BM14-04 & 2004 & $2,279,922$ & $5,744,478$ & 7 & 1780 & 045 & 82 & 038 & 84 & & & & & & & & & & \\
\hline $\mathrm{MH}$ & BM14-05 & 2004 & $2,279,922$ & $5,744,478$ & 7 & 1780 & 046 & 80 & 038 & 83 & & & & & & & & & & \\
\hline $\mathrm{MH}$ & BM14-06 & 2004 & $2,279,922$ & $5,744,478$ & 7 & 1780 & 234 & 84 & 038 & 83 & 045 & 68 & & & & & & & & \\
\hline $\mathrm{MH}$ & BM15-01 & 2004 & $2,279,964$ & $5,744,459$ & 5 & 1823 & 046 & 86 & & & & & & & & & & & & \\
\hline $\mathrm{MH}$ & BM15-02 & 2004 & $2,279,964$ & $5,744,459$ & 5 & 1823 & 048 & 78 & & & & & & & & & & & & \\
\hline $\mathrm{MH}$ & BM16-01 & 2004 & $2,280,054$ & $5,744,399$ & 5 & 1877 & 228 & 82 & & & & & & & & & & & & \\
\hline $\mathrm{MH}$ & BM16-02 & 2004 & $2,280,054$ & $5,744,399$ & 5 & 1877 & 045 & 77 & & & & & & & & & & & & \\
\hline $\mathrm{MH}$ & BM16-03 & 2004 & $2,280,054$ & $5,744,399$ & 5 & 1877 & 052 & 70 & & & & & & & & & & & & \\
\hline $\mathrm{MH}$ & BM16-04 & 2004 & $2,280,054$ & $5,744,399$ & 5 & 1877 & 048 & 74 & & & & & & & & & & & & \\
\hline $\mathrm{MH}$ & BM16-05 & 2004 & $2,280,054$ & $5,744,399$ & 5 & 1877 & 045 & 70 & & & & & & & & & & & & \\
\hline $\mathrm{MH}$ & BM17-01 & 2004 & $2,280,153$ & $5,744,359$ & 5 & 1940 & 046 & 73 & & & & & & & & & & & & \\
\hline $\mathrm{MH}$ & BM17-02 & 2004 & $2,280,153$ & $5,744,359$ & 5 & 1940 & 043 & 88 & & & & & & & & & & & & \\
\hline $\mathrm{MH}$ & BM17-03 & 2004 & $2,280,153$ & $5,744,359$ & 5 & 1940 & 231 & 88 & & & & & & & & & & & & \\
\hline $\mathrm{MH}$ & BM17-04 & 2004 & $2,280,153$ & $5,744,359$ & 5 & 1940 & 055 & 86 & & & & & & & & & & & & \\
\hline $\mathrm{MH}$ & BM17-05 & 2004 & $2,280,153$ & $5,744,359$ & 5 & 1940 & 040 & 72 & & & & & & & & & & & & \\
\hline $\mathrm{MH}$ & BM18-01 & 2004 & $2,279,994$ & $5,744,738$ & 6 & 1744 & 050 & 76 & & & & & & & & & & & & \\
\hline $\mathrm{MH}$ & BM18-05 & 2004 & $2,279,994$ & $5,744,738$ & 6 & 1744 & 044 & 88 & & & & & & & & & & & & \\
\hline $\mathrm{MH}$ & BM19-01 & 2004 & $2,280,084$ & $5,744,774$ & 6 & 1761 & 047 & 83 & & & & & & & & & & & & \\
\hline $\mathrm{MH}$ & BM19-02 & 2004 & $2,280,084$ & $5,744,774$ & 6 & 1761 & 058 & 78 & & & & & & & & & & & & \\
\hline $\mathrm{MH}$ & BM20-01 & 2004 & $2,280,081$ & $5,744,689$ & 5 & 1737 & 046 & 83 & 036 & 70 & & & & & & & & & & \\
\hline $\mathrm{MH}$ & BM20-02 & 2004 & $2,280,081$ & $5,744,689$ & 5 & 1737 & 046 & 80 & 221 & 89 & & & & & & & & & & \\
\hline $\mathrm{MH}$ & BM20-03 & 2004 & $2,280,100$ & $5,744,678$ & 5 & 1750 & 048 & 77 & 221 & 89 & & & & & & & & & & \\
\hline $\mathrm{MH}$ & BM20-04 & 2004 & $2,280,100$ & $5,744,678$ & 5 & 1750 & 048 & 77 & & & & & & & & & & & & \\
\hline $\mathrm{MH}$ & BM20-05 & 2004 & $2,280,100$ & $5,744,678$ & 5 & 1750 & 049 & 88 & & & & & & & & & & & & \\
\hline
\end{tabular}




\begin{tabular}{|c|c|c|c|c|c|c|c|c|c|c|c|c|c|c|c|c|c|c|c|c|}
\hline \multicolumn{2}{|c|}{ Sample Site } & \multirow{3}{*}{$\begin{array}{l}\text { Year } \\
\text { of coll- } \\
\text { ection }\end{array}$} & \multicolumn{4}{|c|}{ Grid reference $^{b}$} & \multicolumn{8}{|c|}{ Structural plane measured: (right hand rule) } & \multicolumn{6}{|c|}{ Lineations measured: } \\
\hline \multirow[t]{2}{*}{$\mathrm{Geol}^{\mathrm{a}}$} & \multirow{2}{*}{$\begin{array}{c}\text { Field } \\
\text { station \# }\end{array}$} & & \multirow[t]{2}{*}{$\bar{E}$} & \multirow[t]{2}{*}{$\mathrm{N}$} & \multirow[t]{2}{*}{ Ac. $^{c}$} & \multirow[t]{2}{*}{ Elevation $^{d}$} & \multicolumn{2}{|c|}{ B-D shear $\left(\mathrm{S}_{4}\right)$} & \multicolumn{2}{|c|}{ Alpine fol. $\left(S_{3}\right)$} & \multicolumn{2}{|c|}{ Alpine fol. $\left(S_{2}\right)$} & \multicolumn{2}{|c|}{ Myl. fol. $\left(S_{m}\right)$} & \multicolumn{2}{|c|}{$\mathrm{L}_{2-3}$} & \multicolumn{2}{|c|}{$\mathrm{L}_{4}$} & \multicolumn{2}{|c|}{$\mathrm{L}_{\mathrm{m}}$} \\
\hline & & & & & & & Strike & Dip & Strike & Dip & Strike & Dip & Strike & Dip & Trend & Plunge & Trend & Plunge & Trend & Plunge \\
\hline $\mathrm{MH}$ & BM20-06 & 2004 & $2,280,112$ & $5,744,667$ & 6 & 1759 & 048 & 76 & 221 & 89 & & & & & & & & & & \\
\hline $\mathrm{MH}$ & BM21-02 & 2004 & $2,280,123$ & $5,744,672$ & 6 & 1764 & 056 & 80 & 215 & 84 & 053 & 60 & & & & & & & & \\
\hline $\mathrm{MH}$ & BM22-01 & 2004 & $2,280,138$ & $5,744,640$ & 4 & 1773 & 051 & 73 & & & 045 & 60 & & & & & & & & \\
\hline $\mathrm{MH}$ & BM22-02 & 2004 & $2,280,138$ & $5,744,640$ & 4 & 1773 & 049 & 74 & 039 & 80 & & & & & 219 & 19 & & & & \\
\hline $\mathrm{MH}$ & BM22-03 & 2004 & $2,280,138$ & $5,744,640$ & 4 & 1773 & 045 & 85 & & & & & & & & & & & & \\
\hline $\mathrm{MH}$ & BM22-04 & 2004 & $2,280,138$ & $5,744,640$ & 4 & 1773 & 044 & 86 & & & & & & & & & & & & \\
\hline $\mathrm{MH}$ & BM22-05 & 2004 & $2,280,138$ & $5,744,640$ & 4 & 1773 & 047 & 73 & & & & & & & & & & & & \\
\hline $\mathrm{MH}$ & BM23 & 2004 & $2,280,172$ & $5,744,593$ & 5 & 1812 & 048 & 85 & 226 & 86 & 052 & 72 & & & & & & & & \\
\hline $\mathrm{MH}$ & BM24-01 & 2004 & $2,280,207$ & $5,744,569$ & 6 & 1826 & 051 & 80 & 025 & 85 & 018 & 88 & & & 218 & 33 & & & & \\
\hline $\mathrm{MH}$ & BM24-02 & 2004 & $2,280,207$ & $5,744,569$ & 6 & 1826 & 222 & 88 & & & & & & & & & & & & \\
\hline $\mathrm{MH}$ & BM25 & 2004 & $2,280,294$ & $5,744,536$ & 7 & 1887 & 053 & 82 & 045 & 80 & 202 & 72 & & & & & & & & \\
\hline $\mathrm{MH}$ & BM27-01 & 2004 & $2,280,326$ & $5,744,483$ & 5 & 1929 & 047 & 75 & 210 & 82 & 197 & 76 & & & 218 & 36 & & & & \\
\hline $\mathrm{MH}$ & BM27-02 & 2004 & $2,280,326$ & $5,744,483$ & 5 & 1929 & 050 & 85 & & & & & & & & & & & & \\
\hline $\mathrm{MH}$ & BM28-01 & 2004 & $2,280,123$ & $5,744,672$ & 6 & 1764 & 062 & 88 & & & & & & & & & & & & \\
\hline $\mathrm{MH}$ & BM28-02 & 2004 & $2,280,123$ & $5,744,672$ & 6 & 1764 & 225 & 82 & & & & & & & & & & & & \\
\hline $\mathrm{MH}$ & BM28-03 & 2004 & $2,280,123$ & $5,744,672$ & 6 & 1764 & 225 & 82 & & & & & & & & & & & & \\
\hline $\mathrm{TL}$ & BM01-01 & 2004 & $2,280,390$ & $5,745,031$ & 8 & 1537 & 226 & 83 & & & & & & & & & & & & \\
\hline TL & BM01-02 & 2004 & $2,280,390$ & $5,745,031$ & - & 1537 & 046 & 78 & & & & & & & & & & & & \\
\hline TL & BM01-03 & 2004 & $2,280,390$ & $5,745,031$ & - & 1537 & 044 & 73 & & & 045 & 61 & & & 224 & 27 & & & & \\
\hline TL & BM02 & 2004 & $2,280,516$ & $5,745,090$ & - & - & 048 & 86 & & & & & & & & & & & & \\
\hline TL & BM04-01 & 2004 & $2,280,836$ & $5,744,894$ & - & 1450 & 049 & 88 & & & & & & & & & & & & \\
\hline TL & BM04-02 & 2004 & $2,280,836$ & $5,744,894$ & - & 1450 & 225 & 87 & & & & & & & & & & & & \\
\hline TL & BM04-04 & 2004 & $2,280,836$ & $5,744,894$ & - & 1450 & & & & & 035 & 87 & & & 205 & 27 & & & & \\
\hline TL & BM05-01 & 2004 & $2,280,959$ & $5,744,858$ & - & 1540 & 055 & 78 & 041 & 83 & & & & & 217 & 18 & & & & \\
\hline TL & BM05-02 & 2004 & $2,280,959$ & $5,744,858$ & - & 1540 & 051 & 79 & & & & & & & & & & & & \\
\hline TL & BM05-03 & 2004 & $2,280,959$ & $5,744,858$ & - & 1540 & 054 & 77 & & & & & & & & & & & & \\
\hline TL & BM05-04 & 2004 & $2,280,959$ & $5,744,858$ & - & 1540 & 048 & 82 & & & & & & & & & & & & \\
\hline TL & BM05-05 & 2004 & $2,280,959$ & $5,744,858$ & - & 1540 & 238 & 83 & & & & & & & & & & & & \\
\hline TL & BM05-06 & 2004 & $2,280,959$ & $5,744,858$ & - & 1540 & 049 & 90 & & & & & & & & & & & & \\
\hline TL & BM05-07 & 2004 & $2,280,959$ & $5,744,858$ & - & 1540 & & & & & 055 & 57 & & & & & & & & \\
\hline TL & BM07 & 2004 & $2,281,277$ & $5,744,898$ & - & - & & & & & 034 & 72 & & & 216 & 13 & & & & \\
\hline TL & BM08-01 & 2004 & $2,281,236$ & $5,744,785$ & - & 1675 & & & & & 038 & 78 & & & 214 & 33 & & & & \\
\hline TL & BM08-02 & 2004 & $2,281,236$ & $5,744,785$ & - & 1675 & & & & & 043 & 69 & & & & & & & & \\
\hline TL & BM08-03 & 2004 & $2,281,236$ & $5,744,785$ & - & 1675 & & & & & 050 & 73 & & & & & & & & \\
\hline
\end{tabular}




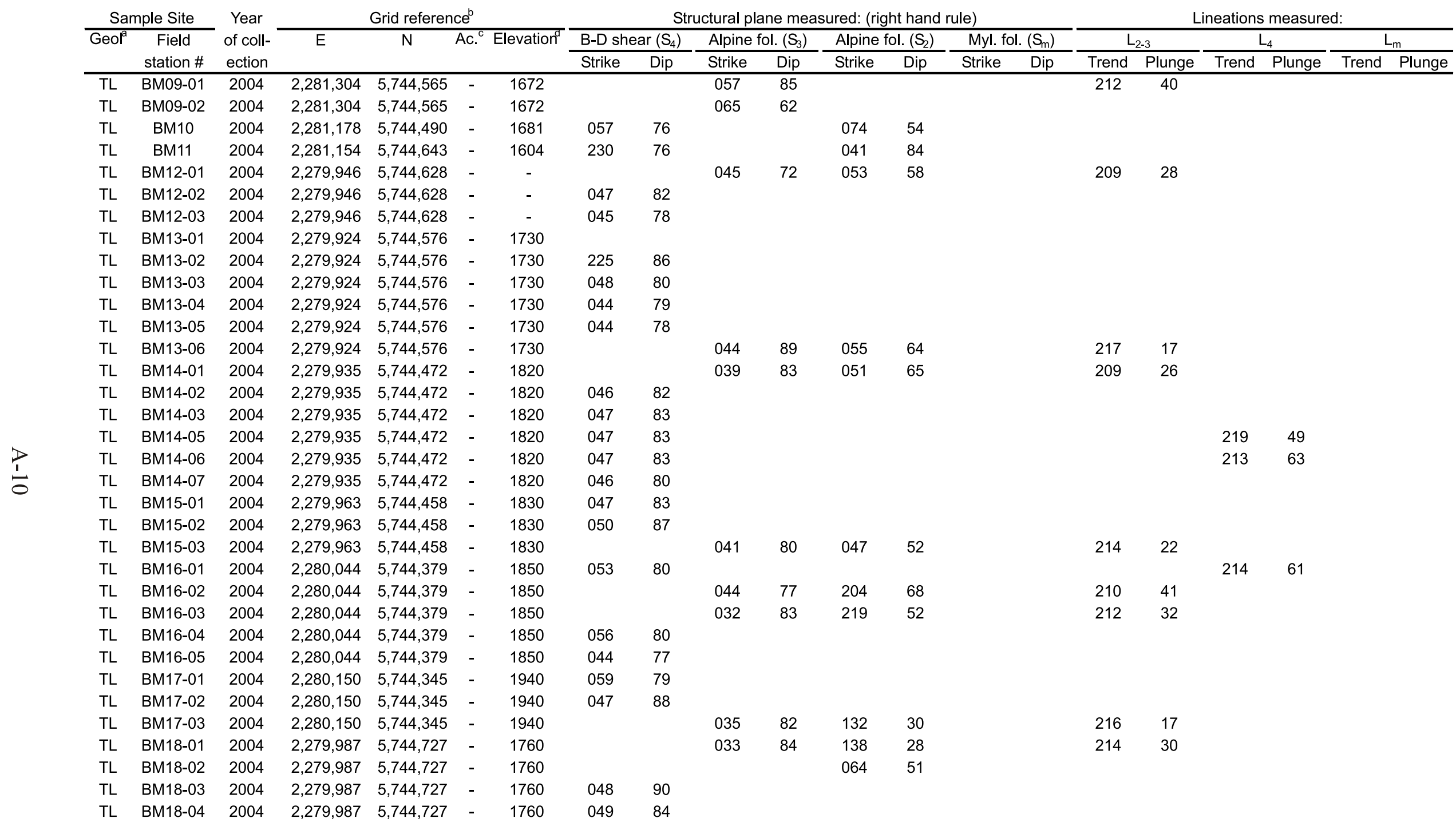




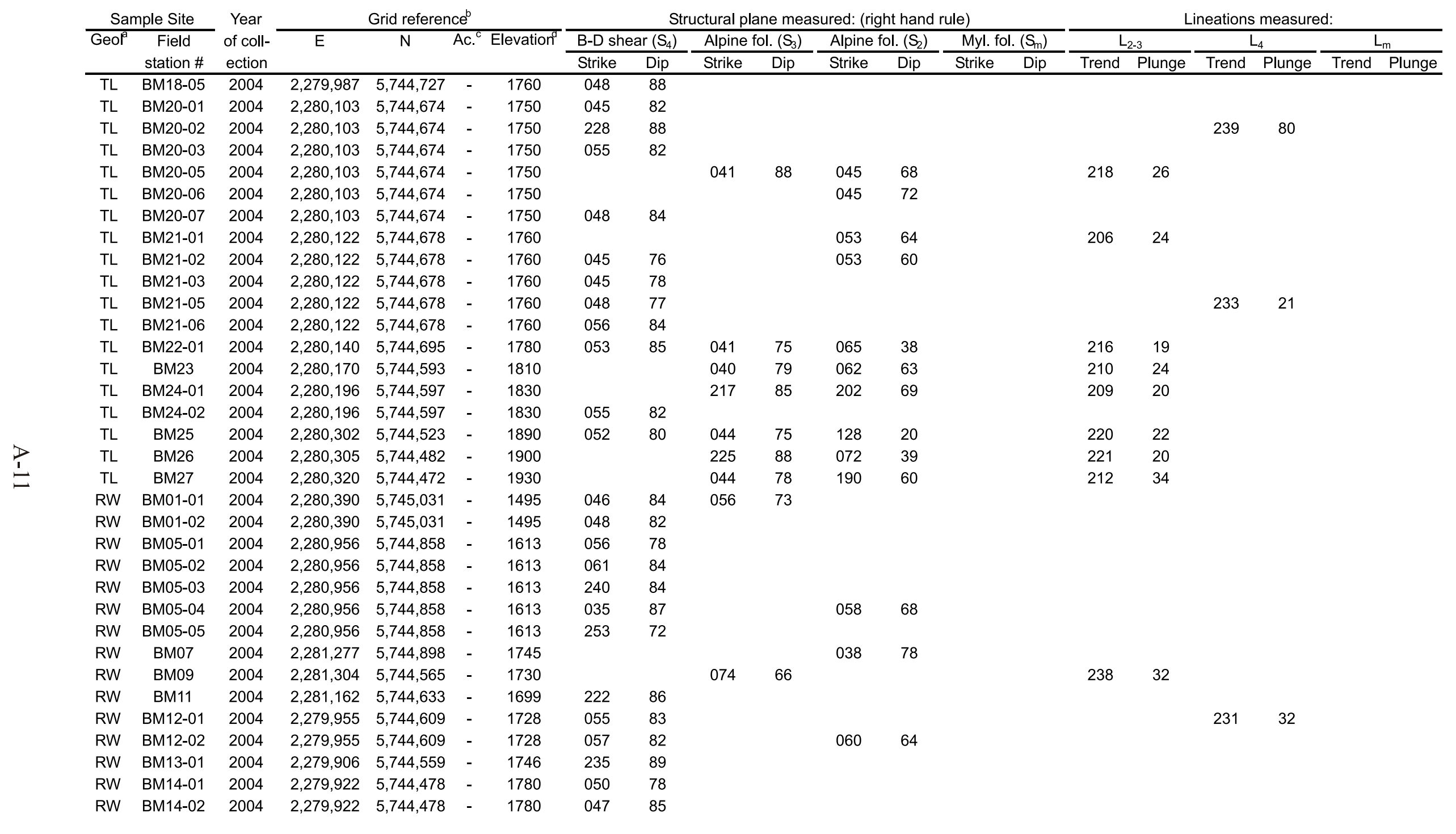




\begin{tabular}{|c|c|c|c|c|c|c|c|c|c|c|c|c|c|c|c|c|c|c|c|c|}
\hline \multicolumn{2}{|c|}{ Sample Site } & \multirow{3}{*}{$\begin{array}{l}\text { Year } \\
\text { of coll- } \\
\text { ection }\end{array}$} & \multicolumn{4}{|c|}{ Grid reference ${ }^{b}$} & \multicolumn{8}{|c|}{ Structural plane measured: (right hand rule) } & \multicolumn{6}{|c|}{ Lineations measured: } \\
\hline \multirow[t]{2}{*}{$\mathrm{Geol}^{2}$} & \multirow{2}{*}{$\begin{array}{c}\text { Field } \\
\text { station \# }\end{array}$} & & \multirow[t]{2}{*}{$E$} & \multirow[t]{2}{*}{$\mathrm{N}$} & \multirow[t]{2}{*}{ Ac. $^{\mathrm{C}}$} & \multirow[t]{2}{*}{ Elevation $^{d}$} & \multicolumn{2}{|c|}{ B-D shear $\left(S_{4}\right)$} & \multicolumn{2}{|c|}{ Alpine fol. $\left(\mathrm{S}_{3}\right)$} & \multicolumn{2}{|c|}{ Alpine fol. $\left(\mathrm{S}_{2}\right)$} & \multicolumn{2}{|c|}{ Myl. fol. $\left(S_{m}\right)$} & \multicolumn{2}{|c|}{$\mathrm{L}_{2-3}$} & \multicolumn{2}{|c|}{$\mathrm{L}_{4}$} & \multicolumn{2}{|c|}{$\mathrm{L}_{\mathrm{m}}$} \\
\hline & & & & & & & Strike & Dip & Strike & Dip & Strike & Dip & Strike & Dip & Trend & Plunge & Trend & Plunge & Trend & Plunge \\
\hline RW & BM14-03 & 2004 & $2,279,922$ & $5,744,478$ & - & 1780 & 045 & 82 & & & & & & & & & & & & \\
\hline RW & BM15-01 & 2004 & $2,279,964$ & $5,744,459$ & - & 1823 & 239 & 88 & & & & & & & & & & & & \\
\hline RW & BM15-02 & 2004 & $2,279,964$ & $5,744,459$ & - & 1823 & 050 & 82 & & & & & & & & & & & & \\
\hline RW & BM16-01 & 2004 & $2,280,054$ & $5,744,399$ & - & 1877 & 055 & 84 & & & & & & & & & & & & \\
\hline RW & BM16-02 & 2004 & $2,280,054$ & $5,744,399$ & - & 1877 & 225 & 87 & & & & & & & & & & & & \\
\hline RW & BM17 & 2004 & $2,280,153$ & $5,744,359$ & - & 1940 & 053 & 85 & & & & & & & & & & & & \\
\hline RW & BM18-01 & 2004 & $2,279,994$ & $5,744,738$ & - & 1744 & 231 & 88 & 042 & 77 & 152 & 44 & & & & & & & & \\
\hline RW & BM18-02 & 2004 & $2,279,994$ & $5,744,738$ & - & 1744 & 045 & 83 & & & & & & & & & & & & \\
\hline RW & BM18-03 & 2004 & $2,279,994$ & $5,744,738$ & - & 1744 & 209 & 84 & & & & & & & & & & & & \\
\hline RW & BM19-01 & 2004 & $2,280,084$ & $5,744,774$ & - & 1761 & 041 & 82 & & & & & & & & & & & & \\
\hline RW & BM19-02 & 2004 & $2,280,084$ & $5,744,774$ & - & 1761 & 240 & 82 & & & & & & & & & & & & \\
\hline RW & BM19-03 & 2004 & $2,280,084$ & $5,744,774$ & - & 1761 & 230 & 88 & & & & & & & & & & & & \\
\hline RW & BM20-01 & 2004 & $2,280,081$ & $5,744,689$ & - & 1737 & 233 & 82 & & & & & & & & & & & & \\
\hline RW & BM20-02 & 2004 & $2,280,081$ & $5,744,689$ & - & 1737 & 041 & 80 & & & & & & & & & & & & \\
\hline RW & BM20-03 & 2004 & $2,280,081$ & $5,744,689$ & - & 1737 & 227 & 78 & & & & & & & & & & & & \\
\hline RW & BM22-01 & 2004 & $2,280,138$ & $5,744,640$ & - & 1773 & 056 & 78 & & & 076 & 50 & & & & & & & & \\
\hline RW & BM22-02 & 2004 & $2,280,138$ & $5,744,640$ & - & 1773 & 237 & 88 & & & & & & & & & & & & \\
\hline RW & BM23 & 2004 & $2,280,172$ & $5,744,593$ & - & 1812 & 048 & 82 & 057 & 70 & 065 & 62 & & & & & & & & \\
\hline RW & BM24 & 2004 & $2,280,207$ & $5,744,569$ & - & 1826 & 057 & 90 & & & & & & & & & & & & \\
\hline RW & BM25-01 & 2004 & $2,280,294$ & $5,744,536$ & - & 1887 & 230 & 82 & 026 & 74 & & & & & & & & & & \\
\hline RW & BM25-02 & 2004 & $2,280,294$ & $5,744,536$ & - & 1887 & 229 & 87 & & & & & & & & & & & & \\
\hline
\end{tabular}

Appendix A-3. Structural field data collected on Baumann Glacier. a - geologist collecting the data: MH - Matt Hill, TL - Timothy Little, RW - Ruth Wightman. Collection year and field season ( $\mathrm{a}$ or $\mathrm{b}$ ) within that year listed. $\mathrm{b}$ - Grid reference is in New Zealand map grid coordinates (metres). $\mathrm{c}$ - Accuracy of coordinates measured using a GPS unit ( \pm in meters). d - elevation given in meters above mean sea level. Alpine Fol refers to the Alpine Schist foliation and Myl fol refers to the Alpine Schist mylonitic foliation. Lineation subscripts refer to foliations or intersections: $\mathrm{L}_{23}$ - intersection lineation between $\mathrm{S}_{2}$ and $\mathrm{S}_{3}, \mathrm{~L}_{4}$ - mineral fibre lineation decorating $\mathrm{S}_{4}$ fault surfaces, and $\mathrm{L}_{\mathrm{m}}$ - mineral stretching lineation on Alpine Schist mylonite foliation $\left(\mathrm{S}_{\mathrm{m}}\right)$. 


\begin{tabular}{|c|c|c|c|c|c|c|c|c|c|c|c|c|c|c|c|c|c|c|c|c|}
\hline \multicolumn{2}{|c|}{ Sample Site } & \multirow{3}{*}{$\begin{array}{l}\text { Year } \\
\text { of coll- } \\
\text { ection }\end{array}$} & \multicolumn{4}{|c|}{ Grid reference $^{b}$} & \multicolumn{8}{|c|}{ Structural plane measured: (right hand rule) } & \multicolumn{6}{|c|}{ Lineations measured: } \\
\hline \multirow[t]{2}{*}{$\mathrm{Geol}^{2}$} & \multirow{2}{*}{$\begin{array}{c}\text { Field } \\
\text { station \# }\end{array}$} & & \multirow[t]{2}{*}{$E$} & \multirow[t]{2}{*}{$\mathrm{N}$} & \multirow[t]{2}{*}{ Ac. $^{\mathrm{C}}$} & \multirow[t]{2}{*}{ Elevation $^{d}$} & \multicolumn{2}{|c|}{ B-D shear $\left(S_{4}\right)$} & \multicolumn{2}{|c|}{ Alpine fol. $\left(\mathrm{S}_{3}\right)$} & \multicolumn{2}{|c|}{ Alpine fol. $\left(S_{2}\right)$} & \multicolumn{2}{|c|}{ Myl. fol. $\left(S_{m}\right)$} & \multicolumn{2}{|c|}{$\mathrm{L}_{2-3}$} & \multicolumn{2}{|c|}{$\mathrm{L}_{4}$} & \multicolumn{2}{|c|}{$\mathrm{L}_{\mathrm{m}}$} \\
\hline & & & & & & & Strike & Dip & Strike & Dip & Strike & Dip & Strike & Dip & Trend & Plunge & Trend & Plunge & Trend & Plunge \\
\hline $\mathrm{MH}$ & HM02-1 & 2002 & $2,273,760$ & $5,747,622$ & - & 315 & & & & & & & 057 & 34 & & & & & & \\
\hline $\mathrm{MH}$ & HM02-2 & 2002 & $2,273,760$ & $5,747,622$ & - & 315 & & & & & & & 053 & 46 & & & & & 077 & 32 \\
\hline $\mathrm{MH}$ & HM03-1 & 2002 & $2,273,889$ & $5,747,623$ & - & 325 & & & & & & & 046 & 39 & & & & & 095 & 35 \\
\hline $\mathrm{MH}$ & HM03-2 & 2002 & $2,273,889$ & $5,747,623$ & - & 325 & & & & & & & 045 & 37 & & & & & 097 & 33 \\
\hline $\mathrm{MH}$ & HM04-1 & 2002 & $2,274,099$ & $5,747,608$ & - & 415 & & & & & & & 048 & 28 & & & & & 094 & 18 \\
\hline $\mathrm{MH}$ & HM04-2 & 2002 & $2,274,099$ & $5,747,608$ & - & 415 & & & & & & & 044 & 26 & & & & & 104 & 20 \\
\hline $\mathrm{MH}$ & HM05-1 & 2002 & $2,273,843$ & $5,747,610$ & - & 295 & & & & & & & 059 & 27 & & & & & 117 & 23 \\
\hline $\mathrm{MH}$ & HM05-2 & 2002 & $2,273,843$ & $5,747,610$ & - & 295 & & & & & & & 058 & 33 & & & & & & \\
\hline $\mathrm{MH}$ & HM06-1 & 2002 & $2,273,909$ & $5,747,537$ & - & 313 & & & & & & & 042 & 30 & & & & & 104 & 34 \\
\hline $\mathrm{MH}$ & HM06-2 & 2002 & $2,273,909$ & $5,747,537$ & - & - & & & & & & & 049 & 29 & & & & & 108 & 31 \\
\hline $\mathrm{MH}$ & HM06-3 & 2002 & $2,273,909$ & $5,747,537$ & - & - & & & & & & & & & & & & & 112 & 24 \\
\hline $\mathrm{MH}$ & HM06-4 & 2002 & $2,273,909$ & $5,747,537$ & - & - & & & & & & & & & & & & & 101 & 26 \\
\hline $\mathrm{MH}$ & HM07 & 2002 & $2,274,011$ & $5,747,467$ & - & - & & & & & & & 043 & 22 & & & & & 113 & 27 \\
\hline $\mathrm{MH}$ & HM08 & 2002 & $2,274,040$ & $5,747,448$ & - & - & & & & & & & 042 & 31 & & & & & 088 & 20 \\
\hline $\mathrm{TL}$ & $2-11$ & 2002 & $2,273,890$ & $5,747,630$ & - & - & & & & & & & 046 & 39 & & & & & 095 & 35 \\
\hline TL & $2-12-1$ & 2002 & $2,274,117$ & $5,747,616$ & - & - & & & & & & & 048 & 28 & & & & & & \\
\hline TL & $2-12-2$ & 2002 & $2,274,117$ & $5,747,616$ & - & - & & & & & & & 088 & 27 & & & & & & \\
\hline TL & $2-12-3$ & 2002 & $2,274,117$ & $5,747,616$ & - & - & & & & & & & 029 & 22 & & & & & 092 & 24 \\
\hline TL & $2-13-1$ & 2002 & $2,273,909$ & $5,747,537$ & - & - & & & & & & & 049 & 29 & & & & & 033 & 28 \\
\hline TL & $2-13-2$ & 2002 & $2,273,909$ & $5,747,537$ & - & - & & & & & & & & & & & & & 101 & 26 \\
\hline TL & $2-13-3$ & 2002 & $2,273,909$ & $5,747,537$ & - & - & & & & & & & & & & & & & 112 & 24 \\
\hline TL & $2-14$ & 2002 & $2,274,041$ & $5,747,446$ & - & - & & & & & & & 032 & 37 & & & & & 157 & 30 \\
\hline TL & $2-15$ & 2002 & $2,274,010$ & $5,747,466$ & - & - & & & & & & & 039 & 30 & & & & & 092 & 22 \\
\hline $\mathrm{MH}$ & HM01 & 2004 & $2,273,722$ & $5,747,569$ & 50 & 275 & & & & & & & 061 & 32 & & & & & & \\
\hline
\end{tabular}

Appendix A-4. Structural field data collected in Hare Mare Creek. a - geologist collecting the data: MH - Matt Hill, TL - Timothy Little. Collection year and field season (a or b) within that year listed. b - Grid reference is in New Zealand map grid coordinates (metres). c - Accuracy of coordinates measured using a GPS unit ( \pm in meters). d - elevation given in meters above mean sea level. Alpine Fol refers to the Alpine Schist foliation and Myl fol refers to the Alpine Schist mylonitic foliation. Lineation subscripts refer to foliations or intersections: $\mathrm{L}_{2-3}$ - intersection lineation between $\mathrm{S}_{2}$ and $\mathrm{S}_{3}, \mathrm{~L}_{4}$ - mineral fibre lineation decorating $\mathrm{S}_{4}$ fault surfaces, and $\mathrm{L}_{\mathrm{m}}$ - mineral stretching lineation on $\mathrm{Alpine}$ Schist mylonite foliation $\left(\mathrm{S}_{\mathrm{m}}\right)$. 


\begin{tabular}{|c|c|c|c|c|c|c|c|c|c|c|c|c|c|c|c|c|c|c|c|c|}
\hline \multicolumn{2}{|c|}{ Sample Site } & \multirow{3}{*}{$\begin{array}{c}\text { Year } \\
\text { of coll- } \\
\text { ection }\end{array}$} & \multicolumn{4}{|c|}{ Grid reference $^{b}$} & \multicolumn{8}{|c|}{ Structural plane measured: (right hand rule) } & \multicolumn{6}{|c|}{ Lineations measured: } \\
\hline \multirow[t]{2}{*}{$\mathrm{Geol}^{2}$} & \multirow{2}{*}{$\begin{array}{c}\text { Field } \\
\text { station \# }\end{array}$} & & \multirow[t]{2}{*}{$\mathrm{E}$} & \multirow[t]{2}{*}{$\mathrm{N}$} & \multirow[t]{2}{*}{ Ac. $^{\mathrm{c}}$} & \multirow[t]{2}{*}{ Elevation $^{\mathrm{d}}$} & \multicolumn{2}{|c|}{ B-D shear $\left(\mathrm{S}_{4}\right)$} & \multicolumn{2}{|c|}{ Alpine fol. $\left(\mathrm{S}_{3}\right)$} & \multicolumn{2}{|c|}{ Alpine fol. $\left(\mathrm{S}_{2}\right)$} & \multicolumn{2}{|c|}{ Myl. fol. $\left(\mathrm{S}_{\mathrm{m}}\right)$} & \multicolumn{2}{|c|}{$\mathrm{L}_{2-3}$} & \multicolumn{2}{|c|}{$\mathrm{L}_{4}$} & \multicolumn{2}{|c|}{$L_{m}$} \\
\hline & & & & & & & Strike & Dip & Strike & Dip & Strike & Dip & Strike & Dip & Trend & Plunge & Trend & Plunge & Trend & Plunge \\
\hline $\mathrm{MH}$ & FJ02 & 2002 & $2,280,850$ & $5,749,464$ & - & 231 & & & 042 & 78 & & & & & 211 & 34 & & & & \\
\hline $\mathrm{MH}$ & FJ04 & 2002 & $2,280,808$ & $5,748,981$ & - & 222 & & & 042 & 78 & & & & & & & & & & \\
\hline $\mathrm{MH}$ & FJ05 & 2002 & $2,280,954$ & $5,748,339$ & - & 209 & & & 042 & 72 & & & & & 204 & 42 & & & & \\
\hline $\mathrm{MH}$ & FJ07 & 2002 & $2,281,034$ & $5,748,112$ & - & 261 & & & 040 & 83 & & & & & & & & & & \\
\hline $\mathrm{MH}$ & FJ08-1 & 2002 & $2,281,021$ & $5,748,082$ & - & 274 & & & & & 042 & 78 & & & & & & & & \\
\hline $\mathrm{MH}$ & FJ08-2 & 2002 & $2,281,021$ & $5,748,082$ & - & 274 & & & & & & & & & & & & & & \\
\hline $\mathrm{MH}$ & FJ09 & 2002 & $2,281,016$ & $5,747,832$ & - & 252 & & & 040 & 76 & 040 & 76 & & & 199 & 55 & & & & \\
\hline TL & 02-01-01 & 2002 & $2,281,061$ & $5,748,126$ & - & - & & & 038 & 71 & & & & & 192 & 52 & & & & \\
\hline TL & 02-02 & 2002 & $2,281,039$ & $5,748,111$ & - & - & & & & & 042 & 78 & & & 212 & 38 & & & & \\
\hline TL & $02-03$ & 2002 & $2,281,021$ & $5,748,082$ & - & - & & & & & 039 & 87 & & & 216 & 48 & & & & \\
\hline TL & $02-04$ & 2002 & $2,280,954$ & $5,747,997$ & - & - & & & & & 042 & 82 & & & 207 & 62 & & & & \\
\hline TL & $02-05$ & 2002 & $2,281,045$ & $5,747,850$ & - & - & & & & & 038 & 81 & & & 204 & 56 & & & & \\
\hline TL & $02-06$ & 2002 & $2,281,024$ & $5,747,826$ & - & - & & & & & 038 & 75 & & & 195 & 56 & & & & \\
\hline TL & $02-07$ & 2002 & $2,281,065$ & $5,747,761$ & - & - & & & & & 039 & 84 & & & 212 & 51 & & & & \\
\hline TL & $02-08$ & 2002 & $2,281,103$ & $5,747,766$ & - & - & & & & & 040 & 83 & & & 212 & 48 & & & & \\
\hline TL & $02-09$ & 2002 & $2,281,124$ & $5,747,720$ & - & - & & & & & 036 & 81 & & & & & & & & \\
\hline TL & $02-10$ & 2002 & $2,281,205$ & $5,747,692$ & - & - & & & & & 037 & 84 & & & 207 & 59 & & & & \\
\hline
\end{tabular}

Appendix A-5. Structural field data collected in Waiho River Valley. a - geologist collecting the data: MH - Matt Hill, TL - Timothy Little. Collection year and field season (a or b) within that year listed. b - Grid reference is in New Zealand map grid coordinates (metres). c - Accuracy of coordinates measured using a GPS unit ( \pm in meters). d - elevation given in meters above mean sea level. Alpine Fol refers to the Alpine Schist foliation and Myl fol refers to the Alpine Schist mylonitic foliation. Lineation subscripts refer to foliations or intersections: $\mathrm{L}_{23}$ - intersection lineation between $\mathrm{S}_{2}$ and $\mathrm{S}_{3}, \mathrm{~L}_{4}$ - mineral fibre lineation decorating $\mathrm{S}_{4}$ fault surfaces, and $\mathrm{L}_{2}$ - mineral stretching lineation on Alpine Schist mylonite foliation $\left(\mathrm{S}_{\mathrm{m}}\right)$. 


\section{Appendix B. Brittle-ductile shear survey data.}

This appendix contains data collected from transects through continuous arrays of spaced brittle-ductile shears at Chancellor Ridge and Baumann Glacier. Orientation and spacing data (see Chapter 3) was collected from three survey sites at Chancellor Ridge (CH01, CH02 and $\mathrm{CH03}$ ) and from one site at Baumann Glacier (BM01). Data for these surveys was measured from well exposed glaciated Alpine Schist outcrops and every shear zone visible that intersected the shear normal transect line was measured. An additional survey (BM-f) was compiled from field data collected across the Baumann Glacier field area and combined to form a non-continuous (not along a continuous transect line) data set.

Each shear zone has been assigned a node number within the survey for use with the measured in the computer software by Little (1996) which calculated the shear displacement (net-slip) from an assigned displacement vector (net-slip pitch). This pitch was 30 as determined from field observations of mineral fibre lineations decorating the fault surfaces and piercing point net-slip pitch calculations. This net-slip data has been filtered and any nodes with a marker cutoff pitch (intersection of the marker vein with the shear plane) within 5 of the net-slip pitch is removed from the survey to avoid trigonometrically unstable net-slip calculations. From the remaining nodes the finite ductile shear strain has bee $n$ calculated.

This appendix contains:

B-1. Data collected in the field and calculated net-slip for nodes in Survey CH01.

B-2. Data collected in the field and calculated net-slip for nodes in Survey CH02.

B-3. Data collected in the field and calculated net-slip for nodes in Survey CH03.

B-4. Data collected in the field and calculated net-slip for nodes in Survey BM01.

B-5. Data collected in the field and calculated net-slip for nodes in Survey BM-f.

B-6. Finite ductile shear strains calculated for each node from the Chancellor Ridge survey sites.

B-7. Finite ductile shear strains calculated for each node from the Baumann Glacier survey sites and for the shear zone samples used for CPO analysis.

B-8. Plots of the intersection of the marker $\mathrm{v}$

B-9. Plots of the intersection of the marker veins in the shear planes for Baumann Glacier and the shear zone samples used for CPO analysis.

B-10. Plots of ductile deformation characteristics against marker vein thickness for Chancellor Ridge surveys. 


\begin{tabular}{|c|c|c|c|}
\hline Survey length: & $67.01 \mathrm{~m}$ & Average fin & ite ductile she \\
\hline Nodes: & 47 & Average shear & displacement ( \\
\hline Location & st node $e^{a}$ : & E 2,276,050 & N $5,740,450$ \\
\hline Elevatio & rst node ${ }^{b}$ : & 1132 m & \\
\hline Bearing & rvey line: & $124,14^{\circ}$ & Nodes 1-7 \\
\hline & & $102,25^{\circ}$ & Nodes 8-23 \\
\hline & & $120,18^{\circ}$ & Nodes 24-35 \\
\hline & & $122,24^{\circ}$ & Nodes $36-47$ \\
\hline
\end{tabular}

Surveyed by: $\quad$ Matt Hill (2003)

Node Shear plane Marker plane Spacing from Thickness of: Ductile Total Ductile/total Calculated

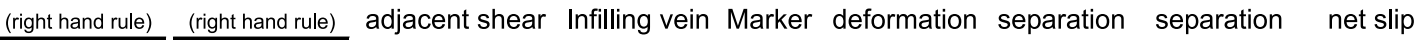

\begin{tabular}{|c|c|c|c|c|c|c|c|c|c|c|c|}
\hline & Strike & Dip & Strike & Dip & plane $(\mathrm{m})$ & $(\mathrm{mm})$ & $(\mathrm{mm})^{\mathrm{c}}$ & width $(\mathrm{cm})$ & $(\mathrm{cm})$ & ratio $^{d}$ & $(\mathrm{~cm})^{\mathrm{e}}$ \\
\hline 1 & 220 & 85 & 014 & 73 & 0.00 & 3 & 9 & 1.0 & 4.4 & 0.32 & 3.6 \\
\hline 2 & 223 & 84 & 196 & 89 & 2.73 & 3 & 8 & 0.7 & 4.2 & 0.64 & 4.3 \\
\hline 3 & 213 & 87 & 013 & 72 & 1.39 & 2 & 18 & 1.4 & 7.9 & 0.37 & 4.9 \\
\hline 4 & 215 & 88 & 179 & 76 & 1.47 & 3 & 6 & 0.4 & 3.5 & 0.14 & 5.2 \\
\hline 5 & 213 & 77 & 186 & 85 & 2.50 & 2 & 6 & 0.4 & 3.4 & 0.26 & 2.8 \\
\hline 6 & 218 & 80 & 003 & 72 & 1.66 & 3 & 14 & 1.5 & 13.2 & 0.17 & 12.0 \\
\hline 7 & 216 & 85 & 189 & 75 & 2.69 & 3 & 12 & 1.0 & 9 & 0.22 & 13.9 \\
\hline 8 & 210 & 82 & 193 & 82 & 0.97 & 1 & 9 & 0.4 & 3.5 & 0.14 & - \\
\hline 9 & 217 & 87 & - & - & 2.05 & - & - & - & - & - & - \\
\hline 10 & 217 & 87 & - & - & 2.40 & - & - & - & - & - & - \\
\hline 11 & 219 & 85 & 194 & 76 & 0.44 & 3 & 10 & 1.3 & 3.5 & 0.09 & 4.5 \\
\hline 12 & 219 & 84 & 020 & 72 & 3.45 & 2 & 2 & 0.0 & 4.4 & 0.00 & 3.7 \\
\hline 13 & 216 & 87 & 191 & 79 & 1.07 & 2 & 7 & 0.2 & 10.5 & 0.05 & 13.9 \\
\hline 14 & 220 & 82 & 203 & 89 & 0.96 & 5 & 7 & 0.4 & 4.5 & 0.11 & 4.5 \\
\hline 15 & 217 & 82 & 018 & 69 & 1.34 & 4 & 3 & 0.4 & 4.5 & 0.11 & - \\
\hline 16 & 216 & 84 & 015 & 68 & 0.51 & 3 & 5 & 0.5 & 3.2 & 0.38 & 2.3 \\
\hline 17 & 211 & 87 & 194 & 85 & 0.55 & 1 & 4 & 0.3 & 3.4 & 0.26 & - \\
\hline 18 & 212 & 80 & 022 & 68 & 0.45 & 4 & 6 & 0.5 & 7.2 & 0.10 & 2.1 \\
\hline 19 & 217 & 80 & 019 & 75 & 0.17 & 1 & 5 & 0.3 & 4.5 & 0.07 & 0.5 \\
\hline 20 & 218 & 85 & 026 & 74 & 1.33 & 1 & 3 & 0.0 & 6.6 & 0.00 & - \\
\hline 21 & 215 & 84 & 012 & 62 & 0.51 & 1 & 4 & 0.0 & 1.3 & 0.00 & - \\
\hline 22 & 222 & 85 & 012 & 78 & 0.34 & 2 & 5 & 0.8 & 2.5 & 0.60 & 2.3 \\
\hline 23 & 222 & 86 & - & - & 0.80 & - & - & - & - & - & - \\
\hline 24 & 217 & 88 & 008 & 70 & 0.79 & 1 & 13 & 1.1 & 8.5 & 0.44 & 7.5 \\
\hline 25 & 037 & 88 & - & - & 3.12 & - & - & - & - & - & - \\
\hline 26 & 035 & 82 & - & - & 0.79 & - & - & - & - & - & - \\
\hline 27 & 217 & 86 & - & - & 0.72 & - & - & - & - & - & - \\
\hline 28 & 214 & 88 & - & - & 1.85 & - & - & - & - & - & - \\
\hline 29 & 028 & 85 & - & - & 3.27 & - & - & - & - & - & - \\
\hline 30 & 212 & 84 & - & - & 0.46 & - & - & - & - & - & - \\
\hline 31 & 215 & 88 & - & - & 0.89 & - & - & - & - & - & - \\
\hline 32 & 214 & 82 & - & - & 0.68 & - & - & - & - & - & - \\
\hline 33 & 034 & 87 & - & - & 1.02 & - & - & - & - & - & - \\
\hline 34 & 039 & 75 & - & - & 0.37 & - & - & - & - & - & - \\
\hline 35 & 215 & 88 & - & - & 2.06 & - & - & - & - & - & - \\
\hline 36 & 025 & 86 & - & - & 1.05 & - & - & - & - & - & - \\
\hline 37 & 031 & 85 & - & - & 2.92 & - & - & - & - & - & - \\
\hline 38 & 032 & 83 & - & - & 1.65 & - & - & - & - & - & - \\
\hline 39 & 030 & 86 & - & - & 2.11 & - & - & - & - & - & - \\
\hline
\end{tabular}




\begin{tabular}{|c|c|c|c|c|c|c|c|c|c|c|c|}
\hline \multirow[t]{3}{*}{ Node } & \multirow{2}{*}{\multicolumn{2}{|c|}{$\begin{array}{l}\text { Shear plane } \\
\text { (right hand rule) } \\
\end{array}$}} & \multirow{2}{*}{\multicolumn{2}{|c|}{$\begin{array}{l}\text { Marker plane } \\
\text { (right hand rule) } \\
\end{array}$}} & \multirow{3}{*}{$\begin{array}{c}\text { Spacing from } \\
\text { adjacent shear } \\
\text { plane }(\mathrm{m})\end{array}$} & \multicolumn{2}{|c|}{ Thickness of: } & \multirow{3}{*}{$\begin{array}{c}\text { Ductile } \\
\text { deformation } \\
\text { width }(\mathrm{cm})\end{array}$} & \multirow{3}{*}{$\begin{array}{c}\text { Total } \\
\text { separation } \\
(\mathrm{cm}) \\
\end{array}$} & \multirow{3}{*}{$\begin{array}{c}\text { Ductile/total } \\
\text { separation } \\
\text { ratio }^{d}\end{array}$} & \multirow{3}{*}{$\begin{array}{c}\text { Calculated } \\
\text { net slip } \\
(\mathrm{cm})^{\mathrm{e}} \\
\end{array}$} \\
\hline & & & & & & \multirow{2}{*}{$\begin{array}{c}\text { Infilling vein } \\
(\mathrm{mm})\end{array}$} & \multirow{2}{*}{$\begin{array}{l}\text { Marker } \\
(\mathrm{mm})^{c}\end{array}$} & & & & \\
\hline & Strike & Dip & Strike & Dip & & & & & & & \\
\hline 40 & 212 & 87 & - & - & 1.90 & - & - & - & - & - & - \\
\hline 41 & 220 & 83 & 015 & 76 & 1.76 & 1 & 30 & 0.5 & 8.8 & 0.43 & 7.8 \\
\hline 42 & 220 & 85 & 018 & 78 & 0.62 & 4 & 16 & 0.9 & 5.9 & 0.36 & 4.7 \\
\hline 43 & 218 & 82 & - & - & 0.22 & - & - & - & - & - & - \\
\hline 44 & 216 & 80 & 010 & 70 & 0.27 & 3 & 25 & 1.3 & 3.3 & 0.58 & 2.3 \\
\hline 45 & 221 & 86 & - & - & 0.24 & - & - & - & - & - & - \\
\hline 46 & 220 & 88 & - & - & 0.44 & - & - & - & - & - & - \\
\hline 47 & 224 & 84 & - & - & 0.58 & - & - & - & - & - & - \\
\hline
\end{tabular}

Appendix B-1. Data collected for Chancellor Ridge structural survey 01(CH01) from an array of shears in the brittle-ductile shear zone (BDSZ). a - Survey location listed in New Zealand Grid coordinates (metres). b Elevation is in metres above mean sea level. c - marker thickness not listed where the Alpine Foliation was used as the displacement marker $(<1 \mathrm{~mm}$ thick). $\mathrm{d}$ - Ductile / total separation ratio was calculated from the ductile separation of the marker veins and the total measured separation of the vein across the survey (brittle-ductile separation). e - The net-slip (shear displacement) is calculated for a net-slip pitch (displacement vector) of $30^{\circ}$ in the fault plane. Net-slip has been filtered for shear zones that have a marker vein that intercepts the shear plane at a pitch that is within $5^{\circ}$ of the the net-slip pitch. Shear plane and marker vein orientations are listed in right-handrule notation. 


\begin{tabular}{|c|c|c|}
\hline Survey length: & $5.1 \mathrm{~m}$ & Average finite ductile she \\
\hline Nodes: & 100 & Average shear displacement \\
\hline Location & st node ${ }^{\text {a }}$. & E $2,277,114 N$ N 7440,287 \\
\hline Elevatio & rst node $e^{b}$ : & $1579 \mathrm{~m}$ \\
\hline Bearing & rvey line: & $120,15^{\circ}$ \\
\hline
\end{tabular}

Surveyed by: Matt Hill, Ruth Wightman and Kate Wilson (2003)

\begin{tabular}{|c|c|c|c|c|c|c|c|c|c|c|c|}
\hline \multirow[t]{3}{*}{ Node } & \multirow{2}{*}{\multicolumn{2}{|c|}{$\begin{array}{l}\text { Shear plane } \\
\text { (right hand rule) } \\
\end{array}$}} & \multirow{2}{*}{\multicolumn{2}{|c|}{$\begin{array}{l}\text { Marker plane } \\
\text { (right hand rule) } \\
\end{array}$}} & \multirow{3}{*}{$\begin{array}{l}\text { Spacing from } \\
\text { adjacent shear } \\
\text { plane }(m)\end{array}$} & \multicolumn{2}{|c|}{ Thickness of: } & \multirow{3}{*}{$\begin{array}{c}\text { Ductile } \\
\text { deformation } \\
\text { width }(\mathrm{cm})\end{array}$} & \multirow{3}{*}{$\begin{array}{c}\text { Total } \\
\text { separation } \\
(\mathrm{cm})\end{array}$} & \multirow{3}{*}{$\begin{array}{l}\text { Ductile/total } \\
\text { separation } \\
\text { ratio }^{d}\end{array}$} & \multirow{3}{*}{$\begin{array}{c}\text { Calculated } \\
\text { net slip } \\
(\mathrm{cm})^{\mathrm{e}}\end{array}$} \\
\hline & & & & & & \multirow{2}{*}{$\begin{array}{l}\text { Infilling vein } \\
(\mathrm{mm})\end{array}$} & \multirow{2}{*}{$\begin{array}{l}\text { Marker } \\
(\mathrm{mm})^{c}\end{array}$} & & & & \\
\hline & Strike & Dip & Strike & Dip & & & & & & & \\
\hline 1 & 207 & 88 & 045 & 77 & 0.000 & 1.0 & - & 0.0 & 4.5 & 0.00 & 13.4 \\
\hline 2 & 212 & 89 & 045 & 77 & 0.087 & 1.0 & - & 0.0 & 1.2 & 0.00 & 5.5 \\
\hline 3 & 212 & 86 & 045 & 77 & 0.039 & 1.0 & - & 0.0 & 0.5 & 0.00 & 3.9 \\
\hline 4 & 211 & 89 & 045 & 77 & 0.068 & 1.0 & - & 0.0 & 0.3 & 0.00 & 1.2 \\
\hline 5 & 214 & 86 & 200 & 88 & 0.020 & 1.0 & 1.0 & 0.0 & 1.0 & 0.00 & 0.8 \\
\hline 6 & 210 & 89 & 040 & 65 & 0.058 & 1.0 & 2.0 & 0.2 & 2.5 & 0.12 & 11.5 \\
\hline 7 & 214 & 85 & 040 & 75 & 0.010 & 1.0 & - & 0.0 & 1.1 & 0.00 & 3.7 \\
\hline 8 & 213 & 88 & 035 & 70 & 0.029 & 1.0 & - & 0.1 & 3.0 & 0.07 & 4.5 \\
\hline 9 & 213 & 88 & 035 & 70 & 0.088 & 1.0 & - & 0.0 & 5.2 & 0.00 & 7.9 \\
\hline 10 & 205 & 88 & 018 & 81 & 0.097 & 1.0 & 8.0 & 0.1 & 20.0 & 1.00 & - \\
\hline 11 & 208 & 89 & 032 & 72 & 0.039 & 1.0 & 3.0 & 0.2 & 2.1 & 1.00 & 4.9 \\
\hline 12 & 210 & 87 & 051 & 69 & 0.127 & 1.0 & - & 0.0 & 1.2 & 0.00 & 6.9 \\
\hline 13 & 214 & 89 & 192 & 86 & 0.184 & 2.0 & 15.0 & 0.1 & 30.0 & 0.27 & - \\
\hline 14 & 204 & 88 & 044 & 77 & 0.039 & 0.5 & - & 0.0 & 1.9 & 0.00 & 5.0 \\
\hline 15 & 209 & 87 & 044 & 77 & 0.029 & 1.0 & - & 0.0 & 6.0 & 0.00 & 26.5 \\
\hline 16 & 211 & 75 & 039 & 70 & 0.030 & 0.5 & - & 0.0 & 0.4 & 0.00 & 1.0 \\
\hline 17 & 207 & 87 & 059 & 71 & 0.117 & 0.5 & - & 0.0 & 0.4 & 0.00 & 1.0 \\
\hline 18 & 214 & 89 & 059 & 71 & 0.010 & 1.0 & - & 0.0 & 2.8 & 0.00 & 8.3 \\
\hline 19 & 218 & 88 & 059 & 71 & 0.010 & 0.5 & - & 0.0 & 0.2 & 0.00 & 0.8 \\
\hline 20 & 215 & 89 & 059 & 71 & 0.010 & 1.0 & - & 0.0 & 3.4 & 0.00 & 10.6 \\
\hline 21 & 213 & 89 & 059 & 71 & 0.010 & 0.5 & - & 0.0 & 0.7 & 0.00 & 2.0 \\
\hline 22 & 210 & 87 & 059 & 71 & 0.020 & 1.0 & - & 0.1 & 3.0 & 0.50 & 8.2 \\
\hline 23 & 209 & 89 & 145 & 52 & 0.058 & 1.0 & 4.0 & 0.3 & 1.5 & 0.60 & 4.5 \\
\hline 24 & 210 & 86 & 037 & 71 & 0.039 & 1.0 & 4.0 & 0.0 & 1.0 & 0.00 & 3.2 \\
\hline 25 & 210 & 87 & 037 & 71 & 0.049 & 0.5 & 2.0 & 0.0 & 0.8 & 0.00 & 2.7 \\
\hline 26 & 216 & 87 & 046 & 70 & 0.010 & 0.5 & - & 0.0 & 1.5 & 0.00 & 9.7 \\
\hline 27 & 212 & 88 & 046 & 70 & 0.010 & 0.5 & - & 0.0 & 0.2 & 0.00 & - \\
\hline 28 & 212 & 88 & 046 & 70 & 0.005 & 0.5 & - & 0.0 & 0.5 & 0.00 & - \\
\hline 29 & 206 & 87 & 039 & 71 & 0.034 & 0.5 & - & 0.0 & 0.8 & 0.00 & - \\
\hline 30 & 212 & 86 & 043 & 75 & 0.049 & 1.0 & - & 0.0 & 5.0 & 0.00 & - \\
\hline 31 & 209 & 89 & 041 & 66 & 0.029 & 1.0 & - & 0.0 & 0.3 & 0.00 & 2.4 \\
\hline 32 & 211 & 88 & 041 & 69 & 0.029 & 0.5 & - & 0.0 & 0.6 & 0.00 & 3.8 \\
\hline 33 & 211 & 87 & 036 & 75 & 0.020 & 0.5 & 6.0 & 0.2 & 2.0 & 0.05 & 5.8 \\
\hline 34 & 210 & 86 & 071 & 54 & 0.010 & 0.5 & 6.0 & 0.0 & 2.0 & 0.00 & 10.8 \\
\hline 35 & 212 & 87 & 102 & 67 & 0.010 & 0.5 & 6.0 & 0.0 & 0.2 & 0.00 & 0.3 \\
\hline 36 & 208 & 85 & 102 & 67 & 0.015 & 0.5 & 5.0 & 0.2 & 1.8 & 0.22 & 3.1 \\
\hline 37 & 211 & 86 & 043 & 68 & 0.025 & 0.5 & - & 0.0 & 0.5 & 0.00 & 3.8 \\
\hline 38 & 213 & 89 & 043 & 68 & 0.010 & 0.5 & - & 0.0 & 0.3 & 0.00 & 1.8 \\
\hline 39 & 218 & 88 & 045 & 69 & 0.039 & 4.0 & - & 0.0 & 19.0 & 0.00 & 58.6 \\
\hline 40 & 208 & 89 & - & - & 0.029 & 0.5 & - & - & - & - & - \\
\hline 41 & 202 & 89 & 032 & 63 & 0.010 & 0.5 & - & 0.0 & 2.2 & 0.00 & 8.4 \\
\hline 42 & 203 & 88 & 181 & 85 & 0.019 & 0.5 & 2.0 & 0.0 & 1.2 & 0.00 & 1.4 \\
\hline
\end{tabular}


Node Shear plane Marker plane Spacing from

Thickness of:

Ductile Total Ductile/total Calculated

$\frac{\text { (right hand rule) }}{\text { (right hand rule) }}$ adjacent shear Infilling vein Marker deformation separation separation net slip

\begin{tabular}{|c|c|c|c|c|c|c|c|c|c|c|c|}
\hline & Strike & Dip & Strike & Dip & plane $(\mathrm{m})$ & $(\mathrm{mm})$ & $(\mathrm{mm})^{\mathrm{c}}$ & width $(\mathrm{cm})$ & $(\mathrm{cm})$ & ratio $^{d}$ & $(\mathrm{~cm})^{\mathrm{e}}$ \\
\hline 43 & 210 & 89 & 030 & 65 & 0.107 & 1.0 & 1.0 & 0.0 & 4.8 & 0.00 & 5.1 \\
\hline 44 & 210 & 87 & 030 & 65 & 0.020 & 0.5 & 1.0 & 0.0 & 2.6 & 0.00 & 2.8 \\
\hline 45 & 208 & 89 & 041 & 66 & 0.010 & 0.5 & - & 0.0 & 0.3 & 0.00 & - \\
\hline 46 & 206 & 88 & 041 & 64 & 0.068 & 0.5 & - & 0.0 & 2.5 & 0.00 & - \\
\hline 47 & 207 & 88 & 041 & 64 & 0.019 & 1.0 & - & 0.0 & 0.3 & 0.00 & - \\
\hline 48 & 211 & 89 & 041 & 64 & 0.019 & 3.0 & - & 0.0 & 13.0 & 0.00 & 52.8 \\
\hline 49 & 209 & 89 & 061 & 66 & 0.068 & 1.0 & 3.0 & 0.2 & 6.0 & 0.08 & 18.2 \\
\hline 50 & 212 & 89 & 061 & 66 & 0.010 & 0.5 & 3.0 & 0.1 & 0.7 & 0.29 & 2.4 \\
\hline 51 & 027 & 79 & 041 & 62 & 0.081 & 1.0 & - & 0.2 & 10.5 & 0.03 & 10.7 \\
\hline 52 & 212 & 89 & 041 & 66 & 0.039 & 0.5 & - & 0.0 & 0.2 & 0.00 & 0.8 \\
\hline 53 & 210 & 89 & 039 & 64 & 0.019 & 0.5 & - & 0.0 & 1.1 & 0.00 & 3.8 \\
\hline 54 & 033 & 82 & 039 & 64 & 0.018 & 1.0 & - & 0.2 & 2.0 & 0.15 & 2.0 \\
\hline 55 & 219 & 89 & 039 & 64 & 0.019 & 0.5 & - & 0.0 & 0.8 & 0.00 & 0.8 \\
\hline 56 & 030 & 84 & 039 & 64 & 0.028 & 0.5 & - & 0.0 & 0.3 & 0.00 & 0.3 \\
\hline 57 & 212 & 87 & 042 & 69 & 0.020 & 2.0 & - & 0.0 & 1.5 & 0.00 & 8.5 \\
\hline 58 & 214 & 80 & 042 & 69 & 0.080 & 0.5 & - & 0.0 & 0.2 & 0.00 & 0.5 \\
\hline 59 & 213 & 84 & 044 & 60 & 0.030 & 5.0 & - & 0.0 & 18.0 & 0.00 & 54.3 \\
\hline 60 & 217 & 89 & 044 & 60 & 0.077 & 1.0 & - & 0.0 & 0.6 & 0.00 & 1.3 \\
\hline 61 & 209 & 88 & 186 & 81 & 0.058 & 0.5 & 10.0 & 0.5 & 3.0 & 0.33 & 4.3 \\
\hline 62 & 207 & 89 & 045 & 67 & 0.034 & 0.5 & - & 0.0 & 1.0 & 0.00 & - \\
\hline 63 & 221 & 87 & 040 & 61 & 0.053 & 0.5 & - & 0.0 & 0.2 & 0.00 & 0.2 \\
\hline 64 & 204 & 89 & 063 & 52 & 0.164 & 1.0 & 5.0 & 0.3 & 0.6 & 1.00 & 4.0 \\
\hline 65 & 207 & 82 & 265 & 80 & 0.030 & 1.0 & 5.0 & 0.3 & 1.2 & 0.83 & 0.9 \\
\hline 66 & 213 & 88 & 045 & 62 & 0.068 & 0.5 & - & 0.0 & 0.9 & 0.00 & 4.5 \\
\hline 67 & 209 & 88 & 059 & 65 & 0.078 & 1.0 & 8.0 & 0.5 & 7.5 & 0.07 & 28.4 \\
\hline 68 & 215 & 82 & 278 & 85 & 0.010 & 1.0 & 3.0 & 0.0 & 1.0 & 0.00 & 0.9 \\
\hline 69 & 208 & 85 & 236 & 78 & 0.049 & 1.0 & 12.0 & 0.0 & 1.4 & 0.00 & 0.8 \\
\hline 70 & 209 & 86 & 043 & 61 & 0.098 & 10.0 & - & 0.0 & 6.0 & 0.00 & 33.3 \\
\hline 71 & 211 & 87 & 324 & 66 & 0.098 & 0.5 & 8.0 & 0.4 & 1.2 & 1.00 & 0.6 \\
\hline 72 & 210 & 85 & 038 & 67 & 0.010 & 1.0 & 5.0 & 0.1 & 2.5 & 0.20 & 7.7 \\
\hline 73 & 206 & 89 & 057 & 78 & 0.261 & 1.0 & 12.0 & 0.3 & 0.4 & 1.00 & 0.7 \\
\hline 74 & 209 & 84 & 196 & 78 & 0.119 & 1.0 & 12.0 & 1.0 & 7.5 & 1.00 & 13.2 \\
\hline 75 & 206 & 86 & 043 & 62 & 0.029 & 1.0 & 9.0 & 0.5 & 3.0 & 1.00 & - \\
\hline 76 & 212 & 86 & 043 & 62 & 0.020 & 1.0 & 9.0 & 0.3 & 4.5 & 0.44 & 16.8 \\
\hline 77 & 210 & 88 & 041 & 65 & 0.136 & 1.0 & 8.0 & 0.2 & 2.5 & 0.04 & 13.1 \\
\hline 78 & 208 & 88 & 045 & 63 & 0.049 & 1.0 & - & 0.0 & 0.8 & 0.00 & - \\
\hline 79 & 208 & 89 & 040 & 68 & 0.053 & 0.5 & - & 0.0 & 0.4 & 0.00 & - \\
\hline 80 & 207 & 89 & 040 & 68 & 0.005 & 0.5 & - & 0.0 & 0.4 & 0.00 & - \\
\hline 81 & 205 & 88 & 040 & 68 & 0.005 & 0.5 & - & 0.0 & 0.5 & 0.00 & - \\
\hline 82 & 210 & 86 & 032 & 63 & 0.142 & 0.5 & 1.5 & 0.1 & 1.2 & 0.50 & 1.7 \\
\hline 83 & 209 & 86 & 040 & 69 & 0.010 & 1.0 & - & 0.0 & 1.3 & 0.00 & 9.0 \\
\hline 84 & 210 & 88 & 039 & 64 & 0.068 & 2.0 & - & 0.0 & 3.0 & 0.00 & 10.3 \\
\hline 85 & 214 & 84 & 031 & 68 & 0.197 & 1.0 & 3.0 & 0.2 & 1.8 & 0.06 & 1.5 \\
\hline 86 & 210 & 88 & 031 & 68 & 0.019 & 1.0 & 10.0 & 0.5 & 5.0 & 0.16 & 6.6 \\
\hline 87 & 020 & 76 & 037 & 40 & 0.052 & 0.5 & 5.0 & 0.3 & 1.1 & 0.64 & 1.2 \\
\hline 88 & 212 & 84 & 230 & 77 & 0.049 & 3.0 & 2.0 & 0.4 & 32.0 & 0.03 & 16.8 \\
\hline 89 & 209 & 89 & 020 & 58 & 0.029 & 0.5 & - & 0.0 & 2.5 & 0.00 & 1.3 \\
\hline 90 & 207 & 89 & 020 & 58 & 0.078 & 1.0 & - & 0.0 & 20.0 & 0.00 & 12.9 \\
\hline 91 & 212 & 88 & - & - & 0.078 & 30.0 & - & - & - & - & - \\
\hline 92 & 030 & 67 & 046 & 61 & 0.063 & 1.0 & - & 0.0 & 5.0 & 0.00 & 5.0 \\
\hline 93 & 208 & 89 & 038 & 67 & 0.087 & 2.0 & - & 0.0 & 32.0 & 0.00 & 181.0 \\
\hline 94 & 210 & 88 & 060 & 66 & 0.029 & 5.0 & 5.0 & 0.6 & 2.2 & 0.09 & 6.8 \\
\hline
\end{tabular}




\begin{tabular}{|c|c|c|c|c|c|c|c|c|c|c|c|}
\hline \multirow[t]{3}{*}{ Node } & \multirow{2}{*}{\multicolumn{2}{|c|}{$\begin{array}{l}\text { Shear plane } \\
\text { (right hand rule) } \\
\end{array}$}} & \multirow{2}{*}{\multicolumn{2}{|c|}{$\begin{array}{r}\text { Marker plane } \\
\text { (right hand rule) } \\
\end{array}$}} & \multirow{3}{*}{$\begin{array}{l}\text { Spacing from } \\
\text { adjacent shear } \\
\text { plane }(\mathrm{m})\end{array}$} & \multicolumn{2}{|c|}{ Thickness of: } & \multirow{3}{*}{$\begin{array}{c}\text { Ductile } \\
\text { deformation } \\
\text { width }(\mathrm{cm})\end{array}$} & \multirow{3}{*}{$\begin{array}{c}\text { Total } \\
\text { separation } \\
(\mathrm{cm}) \\
\end{array}$} & \multirow{3}{*}{$\begin{array}{c}\text { Ductile/total } \\
\text { separation } \\
\text { ratio }^{d}\end{array}$} & \multirow{3}{*}{$\begin{array}{c}\text { Calculated } \\
\text { net slip } \\
(\mathrm{cm})^{\mathrm{e}} \\
\end{array}$} \\
\hline & & & & & & \multirow{2}{*}{$\begin{array}{c}\text { Infilling vein } \\
(\mathrm{mm})\end{array}$} & \multirow{2}{*}{$\begin{array}{l}\text { Marker } \\
(\mathrm{mm})^{c}\end{array}$} & & & & \\
\hline & Strike & Dip & Strike & Dip & & & & & & & \\
\hline 95 & 209 & 87 & 002 & 75 & 0.020 & 2.0 & 3.0 & 0.0 & 3.3 & 0.00 & 2.2 \\
\hline 96 & 210 & 87 & 034 & 70 & 0.039 & 1.0 & - & 0.0 & 2.8 & 0.00 & 6.7 \\
\hline 97 & 208 & 85 & 038 & 71 & 0.039 & 10.0 & - & 0.0 & 26.0 & 0.00 & 177.2 \\
\hline 98 & 207 & 82 & 038 & 71 & 0.050 & 2.0 & - & 0.0 & 34.0 & 0.00 & 225.4 \\
\hline 99 & 212 & 88 & 034 & 65 & 0.029 & 15.0 & - & 0.0 & 22.0 & 0.00 & 38.9 \\
\hline 100 & 217 & 88 & 014 & 62 & 0.019 & 1.0 & 2.0 & 0.3 & 0.3 & 0.67 & - \\
\hline
\end{tabular}

Appendix B-2. Data collected for Chancellor Ridge structural survey 02 (CH02) from an array of shears in the brittle-ductile shear zone (BDSZ). a - Survey location listed in New Zealand Grid coordinates (metres). b Elevation is in metres above mean sea level. c - marker thickness not listed where the Alpine Foliation was used as the displacement marker $(<1 \mathrm{~mm}$ thick). d - Ductile / total separation ratio was calculated from the ductile separation of the marker veins and the total measured separation of the vein across the survey (brittle-ductile separation). e - The net-slip (shear displacement) is calculated for a net-slip pitch (displacement vector) of $30^{\circ}$ in the fault plane. Net-slip has been filtered for shear zones that have a marker vein that intercepts the shear plane at a pitch that is within $5^{\circ}$ of the the net-slip pitch. Shear plane and marker vein orientations are listed in right-handrule notation. 


\begin{tabular}{|c|c|c|}
\hline Survey length: & $27.11 \mathrm{~m}$ & Average finite ductile she \\
\hline Nodes: & 155 & Average shear displacement \\
\hline Location & st node ${ }^{a}$ : & E $2,277,232$ N $5,740,212$ \\
\hline Elevatio & rst node ${ }^{b}$ : & $1636 \mathrm{~m}$ \\
\hline Bearing & vey line: & $129,32^{\circ}$ \\
\hline
\end{tabular}

Surveyed by: Matt Hill, Ruth Wightman and Kate Wilson (2003)

Node Shear plane Marker plane Spacing from Thickness of: Ductile Total Ductile/total Calculated

\begin{tabular}{|c|c|c|c|c|c|c|c|c|c|c|c|}
\hline & \multicolumn{2}{|c|}{ (right hand rule) } & \multicolumn{2}{|c|}{ (right hand rule) } & \multirow{2}{*}{$\begin{array}{c}\text { adjacent shear } \\
\text { plane }(\mathrm{m})\end{array}$} & \multirow{2}{*}{$\begin{array}{l}\text { Infilling vein } \\
\text { (mm) }\end{array}$} & \multirow{2}{*}{$\begin{array}{l}\text { Marker } \\
(\mathrm{mm})^{c}\end{array}$} & \multirow{2}{*}{$\begin{array}{c}\text { deformation } \\
\text { width }(\mathrm{cm})\end{array}$} & \multirow{2}{*}{$\begin{array}{c}\text { separation } \\
(\mathrm{cm})\end{array}$} & \multirow{2}{*}{$\begin{array}{c}\text { separation } \\
\text { ratio }^{d}\end{array}$} & \multirow{2}{*}{$\begin{array}{l}\text { net slip } \\
(\mathrm{cm})^{\mathrm{e}}\end{array}$} \\
\hline & Strike & Dip & Strike & Dip & & & & & & & \\
\hline 1 & 212 & 89 & 235 & 80 & 0.000 & 7.0 & 9.0 & 1.2 & 16.5 & 0.42 & 10.5 \\
\hline 2 & 216 & 89 & 050 & 76 & 0.102 & 1.0 & - & 0.0 & 8.5 & 0.00 & 24.3 \\
\hline 3 & 033 & 80 & 045 & 71 & 0.052 & 5.0 & 12.0 & 2.0 & 20.0 & 0.20 & 41.2 \\
\hline 4 & 219 & 87 & 042 & 63 & 0.173 & 1.0 & - & 0.0 & 2.5 & 0.96 & 3.2 \\
\hline 5 & 220 & 87 & 042 & 63 & 0.030 & 1.0 & - & 0.0 & 0.5 & 0.00 & 0.6 \\
\hline 6 & 223 & 86 & 042 & 63 & 0.013 & 2.0 & - & 0.0 & 0.5 & 0.00 & 0.4 \\
\hline 7 & 222 & 87 & 050 & 55 & 0.068 & 3.0 & - & 0.0 & 0.5 & 0.00 & 0.9 \\
\hline 8 & 216 & 86 & 050 & 55 & 0.079 & 0.5 & - & 0.0 & 1.0 & 0.00 & 3.3 \\
\hline 9 & 217 & 80 & 050 & 55 & 0.046 & 1.0 & - & 0.3 & 4.0 & 0.05 & 10.6 \\
\hline 10 & 218 & 81 & 043 & 48 & 0.100 & 2.0 & - & 0.0 & 0.5 & 0.00 & 0.5 \\
\hline 11 & 216 & 82 & 043 & 48 & 0.064 & 2.0 & - & 0.3 & 0.5 & 0.40 & 0.6 \\
\hline 12 & 215 & 88 & 051 & 53 & 0.026 & 0.5 & - & 0.0 & 0.7 & 0.00 & 2.5 \\
\hline 13 & 220 & 84 & 062 & 54 & 0.062 & 1.0 & - & 0.0 & 2.0 & 0.00 & - \\
\hline 14 & 220 & 87 & 062 & 54 & 0.009 & 5.0 & - & 0.0 & 1.3 & 0.00 & - \\
\hline 15 & 217 & 88 & 050 & 53 & 0.052 & 2.0 & - & 0.0 & 3.0 & 0.00 & 73.5 \\
\hline 16 & 035 & 86 & 210 & 85 & 0.089 & 1.0 & 30.0 & 0.0 & 1.8 & 0.00 & - \\
\hline 17 & 037 & 86 & 210 & 85 & 0.032 & 2.0 & 26.0 & 0.4 & 0.8 & 0.25 & 4.9 \\
\hline 18 & 218 & 80 & 032 & 50 & 0.064 & 2.0 & 2.0 & 0.0 & 0.9 & 0.00 & 0.6 \\
\hline 19 & 217 & 82 & 055 & 50 & 0.054 & 2.0 & 2.0 & 0.0 & 1.5 & 0.00 & 5.1 \\
\hline 20 & 212 & 85 & 056 & 57 & 0.045 & 1.0 & 1.0 & 0.2 & 0.5 & 0.60 & - \\
\hline 21 & 216 & 84 & 052 & 58 & 0.009 & 0.5 & 2.0 & 0.3 & 2.4 & 0.38 & 11.4 \\
\hline 22 & 035 & 82 & 230 & 85 & 0.038 & 0.5 & 3.0 & 0.3 & 6.2 & 0.11 & 2.7 \\
\hline 23 & 039 & 82 & 230 & 85 & 0.008 & 1.5 & 3.0 & 0.7 & 5.0 & 0.50 & 1.7 \\
\hline 24 & 039 & 85 & 190 & 79 & 0.039 & 1.5 & 3.0 & 0.0 & 2.0 & 0.00 & 3.9 \\
\hline 25 & 220 & 83 & 222 & 80 & 0.080 & 2.0 & 30.0 & 1.5 & 22.0 & 0.41 & - \\
\hline 26 & 214 & 85 & 012 & 73 & 0.098 & 1.0 & 4.0 & 0.7 & 5.3 & 0.75 & 1.6 \\
\hline 27 & 215 & 80 & 240 & 77 & 0.139 & 2.0 & 4.0 & 0.4 & 6.7 & 0.16 & 6.0 \\
\hline 28 & 217 & 76 & 058 & 72 & 0.047 & 2.0 & 2.0 & 0.0 & 0.3 & 0.00 & - \\
\hline 29 & 222 & 82 & 058 & 72 & 0.063 & 2.0 & 3.0 & 0.0 & 0.5 & 0.00 & - \\
\hline 30 & 216 & 88 & 058 & 72 & 0.078 & 18.0 & - & - & - & - & - \\
\hline 31 & 217 & 80 & 041 & 53 & 0.064 & 2.0 & 3.0 & 0.4 & 2.6 & 0.31 & 0.0 \\
\hline 32 & 040 & 62 & 068 & 73 & 0.029 & 0.5 & 2.0 & 0.1 & 2.5 & 0.12 & 2.5 \\
\hline 33 & 034 & 66 & 068 & 73 & 0.017 & 0.5 & - & - & - & - & - \\
\hline 34 & 217 & 80 & 043 & 76 & 0.101 & 0.5 & 7.0 & 0.3 & 21.5 & 0.02 & 12.5 \\
\hline 35 & 038 & 64 & 359 & 82 & 0.110 & 2.0 & 1.0 & 0.0 & 21.5 & 0.00 & 30.0 \\
\hline 36 & 041 & 72 & 032 & 70 & 0.025 & 1.0 & 1.0 & 0.0 & 0.3 & 0.00 & 0.3 \\
\hline 37 & 215 & 82 & 039 & 72 & 0.182 & 1.0 & 6.0 & 0.5 & 6.5 & 0.38 & 1.5 \\
\hline 38 & 219 & 88 & 180 & 82 & 0.051 & 0.5 & 15.0 & 0.3 & 16.5 & 0.03 & - \\
\hline 39 & 221 & 85 & 180 & 82 & 0.070 & 2.0 & 15.0 & 1.0 & 8.0 & 0.75 & - \\
\hline 40 & 224 & 83 & 069 & 67 & 0.071 & 1.0 & 2.0 & 0.3 & 1.5 & 0.60 & 7.4 \\
\hline 41 & 219 & 81 & 230 & 82 & 0.564 & 1.0 & 5.0 & 0.0 & 1.5 & 0.00 & - \\
\hline 42 & 220 & 84 & 230 & 82 & 0.009 & 1.0 & 2.0 & 0.2 & 4.5 & 0.22 & 4.7 \\
\hline
\end{tabular}


Node Shear plane Marker plane Spacing from

Thickness of:

Ductile Total Ductile/total Calculated (right hand rule) (right hand rule) adjacent shear Infilling vein Marker deformation separation separation net slip

\begin{tabular}{|c|c|c|c|c|c|c|c|c|c|c|c|}
\hline & Strike & Dip & Strike & Dip & plane $(\mathrm{m})$ & $(\mathrm{mm})$ & $(\mathrm{mm})^{\mathrm{c}}$ & width $(\mathrm{cm})$ & $(\mathrm{cm})$ & ratio $^{d}$ & $(\mathrm{~cm})^{\mathrm{e}}$ \\
\hline 43 & 223 & 87 & 051 & 58 & 0.077 & 1.5 & 5.0 & 0.4 & 1.7 & 0.18 & 1.8 \\
\hline 44 & 041 & 67 & 018 & 63 & 0.073 & 2.0 & 1.0 & 0.0 & 1.0 & 0.00 & 1.0 \\
\hline 45 & 219 & 83 & 018 & 63 & 0.072 & 1.0 & 1.0 & 0.0 & 0.5 & 0.00 & - \\
\hline 46 & 036 & 64 & 210 & 87 & 0.184 & 2.0 & 1.5 & 0.0 & 1.2 & 0.00 & 1.1 \\
\hline 47 & 215 & 89 & 176 & 73 & 0.060 & 1.0 & 8.0 & 0.4 & 0.2 & 1.00 & 0.3 \\
\hline 48 & 220 & 86 & 211 & 75 & 0.462 & 0.5 & 2.0 & 0.0 & 0.6 & 0.00 & 3.1 \\
\hline 49 & 236 & 77 & 165 & 57 & 0.059 & 1.0 & 6.0 & 0.2 & 1.8 & 0.33 & 3.6 \\
\hline 50 & 229 & 81 & 240 & 79 & 0.219 & 1.0 & 3.0 & 0.0 & 9.0 & 0.00 & 8.8 \\
\hline 51 & 042 & 82 & 052 & 74 & 0.404 & 1.0 & 1.0 & 0.3 & 0.2 & 1.00 & 0.5 \\
\hline 52 & 222 & 89 & 231 & 76 & 0.117 & 1.0 & 7.0 & 0.6 & 10.5 & 0.14 & - \\
\hline 53 & 210 & 83 & 040 & 63 & 0.100 & 0.5 & 1.0 & 0.0 & 0.7 & 0.00 & 1.2 \\
\hline 54 & 212 & 86 & 224 & 88 & 0.053 & 0.5 & 4.0 & 0.4 & 1.4 & 0.07 & 1.8 \\
\hline 55 & 032 & 62 & 224 & 56 & 0.020 & 0.5 & 1.0 & 0.2 & 1.6 & 0.19 & 0.1 \\
\hline 56 & 040 & 72 & 085 & 70 & 0.013 & 1.0 & - & 0.2 & 0.3 & 1.00 & 0.4 \\
\hline 57 & 031 & 71 & 085 & 70 & 0.019 & 0.5 & 5.0 & 0.0 & 1.0 & 0.00 & 1.3 \\
\hline 58 & 214 & 84 & 240 & 83 & 0.009 & 0.5 & 3.0 & 0.0 & 2.0 & 0.00 & 2.2 \\
\hline 59 & 215 & 82 & 106 & 55 & 0.009 & 1.0 & 3.0 & 0.3 & 2.7 & 0.26 & 5.9 \\
\hline 60 & 214 & 88 & 332 & 78 & 0.242 & 1.0 & 16.0 & 0.7 & 13.0 & 0.35 & 12.9 \\
\hline 61 & 218 & 85 & 222 & 88 & 0.185 & 5.0 & 4.0 & 0.0 & 3.0 & 0.00 & 6.5 \\
\hline 62 & 220 & 83 & 241 & 87 & 0.268 & 1.0 & 2.0 & 0.4 & 0.5 & 1.00 & 0.6 \\
\hline 63 & 242 & 87 & 154 & 82 & 0.067 & 1.0 & 3.0 & 0.3 & 0.6 & 0.50 & 0.8 \\
\hline 64 & 212 & 84 & 040 & 51 & 0.045 & 0.5 & 1.0 & 0.0 & 0.6 & 0.00 & 0.7 \\
\hline 65 & 215 & 80 & 045 & 68 & 0.111 & 3.0 & 4.0 & 0.6 & 0.3 & 1.00 & 0.7 \\
\hline 66 & 212 & 82 & 052 & 67 & 0.100 & 15.0 & 10.0 & 1.8 & 18.5 & 0.57 & - \\
\hline 67 & 214 & 84 & 043 & 64 & 0.072 & 1.0 & 2.0 & 0.4 & 0.2 & 1.00 & 0.1 \\
\hline 68 & 213 & 82 & 043 & 64 & 0.009 & 0.5 & 2.0 & 0.3 & 0.1 & 1.00 & 0.1 \\
\hline 69 & 210 & 86 & 198 & 88 & 0.009 & 4.0 & 1.0 & 0.0 & 0.5 & 0.00 & 0.5 \\
\hline 70 & 221 & 85 & 011 & 52 & 0.035 & 10.0 & 5.0 & 1.2 & 3.0 & 0.33 & - \\
\hline 71 & 224 & 88 & 059 & 74 & 0.059 & 1.0 & 8.0 & 0.0 & 0.2 & 0.00 & 0.8 \\
\hline 72 & 041 & 64 & 206 & 79 & 0.046 & 0.5 & 7.0 & 0.5 & 4.0 & 0.18 & 9.9 \\
\hline 73 & 214 & 88 & 206 & 79 & 0.017 & 0.5 & 10.0 & 0.0 & 0.5 & 0.00 & 1.5 \\
\hline 74 & 213 & 87 & 206 & 79 & 0.017 & 1.0 & 10.0 & 0.0 & 2.3 & 0.00 & 7.2 \\
\hline 75 & 213 & 83 & 230 & 80 & 0.136 & 1.0 & 3.0 & 0.0 & 1.1 & 0.00 & 1.2 \\
\hline 76 & 215 & 85 & 232 & 82 & 0.213 & 2.0 & 1.0 & 0.3 & 0.7 & 0.14 & 0.7 \\
\hline 77 & 040 & 65 & 234 & 78 & 0.011 & 1.0 & 3.0 & 0.0 & 3.8 & 0.00 & 2.7 \\
\hline 78 & 218 & 88 & 010 & 45 & 0.257 & 2.0 & 2.0 & 0.0 & 2.0 & 0.00 & 1.8 \\
\hline 79 & 215 & 80 & 226 & 87 & 0.166 & 4.0 & 3.0 & 1.0 & 13.5 & 0.22 & 25.1 \\
\hline 80 & 217 & 76 & 232 & 82 & 0.482 & 15.0 & 7.0 & 2.0 & 23.0 & 0.15 & 36.1 \\
\hline 81 & 216 & 82 & 346 & 68 & 0.200 & 1.0 & 10.0 & 1.5 & 7.0 & 1.00 & 4.7 \\
\hline 82 & 212 & 82 & 254 & 80 & 0.420 & 0.5 & 7.0 & 0.5 & 6.8 & 0.35 & 6.6 \\
\hline 83 & 217 & 85 & 260 & 77 & 0.451 & 6.0 & 4.0 & 0.7 & 10.5 & 0.10 & 8.0 \\
\hline 84 & 214 & 81 & 050 & 63 & 0.312 & 1.0 & - & 0.0 & 1.7 & 0.00 & 8.0 \\
\hline 85 & 216 & 78 & 223 & 80 & 0.355 & 3.0 & 4.0 & 0.4 & 4.5 & 0.11 & 6.3 \\
\hline 86 & 216 & 79 & 339 & 63 & 0.195 & 1.0 & 17.0 & 0.7 & 5.7 & 1.00 & 5.0 \\
\hline 87 & 214 & 83 & 228 & 80 & 0.045 & 1.0 & 5.0 & 0.6 & 6.0 & 0.75 & 6.2 \\
\hline 88 & 213 & 85 & 224 & 84 & 0.027 & 1.0 & 1.0 & 0.0 & 5.0 & 0.00 & 5.5 \\
\hline 89 & 214 & 88 & 043 & 55 & 0.069 & 2.0 & 24.0 & 1.5 & 11.0 & 0.18 & 21.1 \\
\hline 90 & 215 & 88 & 043 & 55 & 0.190 & 0.5 & 13.0 & 1.2 & 2.5 & 0.12 & 3.7 \\
\hline 91 & 212 & 83 & 225 & 75 & 0.208 & 0.5 & 7.0 & 0.5 & 3.0 & 0.60 & 2.6 \\
\hline 92 & 215 & 80 & 225 & 75 & 0.046 & 11.0 & 10.0 & 1.3 & 5.5 & 0.27 & 5.0 \\
\hline 93 & 032 & 68 & 352 & 62 & 0.082 & 1.0 & 7.0 & 0.4 & 0.4 & 1.00 & 0.4 \\
\hline 94 & 032 & 82 & 352 & 62 & 0.011 & 1.0 & 5.0 & 0.3 & 0.3 & 1.00 & 0.3 \\
\hline
\end{tabular}


Node Shear plane Marker plane Spacing from

Thickness of:

Ductile Total Ductile/total Calculated (right hand rule) (right hand rule) adjacent shear Infilling vein Marker deformation separation separation net slip

\begin{tabular}{|c|c|c|c|c|c|c|c|c|c|c|c|}
\hline & Strike & Dip & Strike & Dip & plane $(\mathrm{m})$ & $(\mathrm{mm})$ & $(\mathrm{mm})^{\mathrm{c}}$ & width $(\mathrm{cm})$ & $(\mathrm{cm})$ & ratio $^{d}$ & $(\mathrm{~cm})^{\mathrm{e}}$ \\
\hline 95 & 212 & 80 & 322 & 71 & 0.246 & 0.5 & 6.0 & 0.0 & 0.3 & 0.00 & 0.3 \\
\hline 96 & 218 & 84 & 263 & 84 & 0.151 & 3.0 & 3.0 & 0.0 & 8.0 & 0.00 & 8.3 \\
\hline 97 & 217 & 78 & 133 & 78 & 0.056 & 0.5 & 6.0 & 0.2 & 0.8 & 0.50 & 0.8 \\
\hline 98 & 214 & 82 & 133 & 78 & 0.046 & 0.5 & 6.0 & 0.3 & 1.7 & 0.82 & 1.9 \\
\hline 99 & 220 & 86 & 028 & 68 & 0.122 & 1.0 & 3.0 & 0.2 & 0.4 & 0.50 & 0.1 \\
\hline 100 & 218 & 84 & 255 & 60 & 0.027 & 1.0 & 6.0 & 0.6 & 2.4 & 0.63 & 1.7 \\
\hline 101 & 217 & 82 & 018 & 72 & 0.318 & 2.0 & 6.0 & 1.1 & 32 & 0.44 & 17.1 \\
\hline 102 & 210 & 86 & 231 & 76 & 0.009 & 0.5 & 1.0 & 0.0 & 2.5 & 0.00 & 2.1 \\
\hline 103 & 213 & 80 & 223 & 80 & 0.009 & 2.0 & 4.0 & 0.0 & 6 & 0.00 & 6.8 \\
\hline 104 & 219 & 78 & 230 & 78 & 0.014 & 0.5 & 13.0 & 0.6 & 11 & 0.35 & 12.5 \\
\hline 105 & 212 & 82 & 222 & 78 & 0.123 & 2.0 & 12.0 & 1.5 & 15.5 & 0.68 & 13.5 \\
\hline 106 & 214 & 82 & 347 & 52 & 0.155 & 0.5 & 5.0 & 0.4 & 11.2 & 0.12 & 8.4 \\
\hline 107 & 214 & 85 & 038 & 60 & 0.142 & 1.0 & - & 0.0 & 8.5 & 0.00 & 10.2 \\
\hline 108 & 212 & 78 & 038 & 60 & 0.009 & 0.5 & - & 0.0 & 0.9 & 0.00 & 1.4 \\
\hline 109 & 208 & 87 & 038 & 60 & 0.009 & 1.0 & - & 0.0 & 1.9 & 0.00 & 5.1 \\
\hline 110 & 210 & 88 & 038 & 60 & 0.104 & 2.0 & 1.0 & 0.5 & 13 & 0.08 & 28.7 \\
\hline 111 & 212 & 82 & 332 & 61 & 0.091 & 8.0 & 6.0 & 1.0 & 4 & 0.25 & 0.0 \\
\hline 112 & 213 & 84 & 054 & 55 & 0.018 & 1.0 & - & 0.0 & 5.5 & 0.00 & 45.4 \\
\hline 113 & 216 & 87 & 355 & 69 & 0.052 & 1.0 & 13.0 & 0.7 & 14.5 & 0.14 & 12.2 \\
\hline 114 & 215 & 84 & 011 & 64 & 0.251 & 1.0 & 6.0 & 1.2 & 9 & 0.78 & - \\
\hline 115 & 218 & 83 & 056 & 57 & 0.799 & 0.5 & - & 0.0 & 0.8 & 0.00 & 2.8 \\
\hline 116 & 210 & 87 & 338 & 64 & 0.087 & 1.0 & 7.0 & 3.0 & 1.5 & 0.67 & 1.1 \\
\hline 117 & 219 & 84 & 210 & 85 & 0.302 & 2.0 & 5.0 & 0.0 & 7.4 & 0.00 & 8.1 \\
\hline 118 & 223 & 82 & 021 & 88 & 0.161 & 2.0 & 2.0 & 0.0 & 0.4 & 0.00 & 0.4 \\
\hline 119 & 227 & 85 & 230 & 63 & 0.043 & 1.0 & 6.0 & 0.6 & 1.2 & 1.00 & 1.0 \\
\hline 120 & 040 & 65 & 059 & 60 & 0.442 & 2.0 & 4.0 & 0.4 & 8 & 0.38 & 12.4 \\
\hline 121 & 213 & 89 & 229 & 84 & 0.094 & 0.5 & 2.0 & 0.3 & 0.7 & 1.00 & 0.7 \\
\hline 122 & 214 & 80 & 048 & 79 & 0.111 & 1.0 & 2.0 & 0.0 & 9.6 & 0.00 & - \\
\hline 123 & 210 & 79 & 039 & 70 & 0.252 & 0.5 & 3.0 & 0.0 & 1.5 & 0.00 & 5.2 \\
\hline 124 & 036 & 74 & 053 & 58 & 0.392 & 1.0 & - & 0.0 & 24 & 0.00 & 97.6 \\
\hline 125 & 223 & 82 & 056 & 65 & 0.419 & 1.0 & 3.0 & 0.0 & 13 & 0.00 & 41.6 \\
\hline 126 & 216 & 81 & 079 & 59 & 0.284 & 2.0 & 1.0 & 4.0 & 35 & 0.09 & 100.8 \\
\hline 127 & 211 & 86 & 125 & 64 & 0.309 & 1.0 & 6.0 & 0.0 & 1 & 0.00 & 1.8 \\
\hline 128 & 212 & 88 & 052 & 64 & 0.069 & 1.0 & 12.0 & 0.0 & 2.8 & 0.00 & - \\
\hline 129 & 213 & 81 & 222 & 89 & 0.110 & 1.0 & 2.0 & 0.4 & 1.8 & 0.83 & 4.1 \\
\hline 130 & 217 & 82 & 205 & 71 & 0.245 & 0.5 & 2.0 & 0.3 & 6 & 0.22 & 14.9 \\
\hline 131 & 218 & 85 & 016 & 71 & 0.110 & 1.0 & 7.0 & 0.5 & 8.5 & 0.65 & 6.4 \\
\hline 132 & 220 & 85 & 163 & 69 & 0.022 & 1.0 & 15.0 & 0.4 & 3.8 & 0.53 & 5.5 \\
\hline 133 & 036 & 85 & 059 & 70 & 0.238 & 0.5 & 22.0 & 0.4 & 0.2 & 1.00 & 0.3 \\
\hline 134 & 217 & 76 & 196 & 68 & 0.558 & 1.0 & 11.0 & 0.8 & 1.5 & 0.47 & 1.4 \\
\hline 135 & 202 & 75 & 120 & 52 & 0.266 & 0.5 & 17.0 & 0.0 & 1.5 & 0.00 & 3.0 \\
\hline 136 & 212 & 81 & 296 & 54 & 0.405 & 3.0 & 14.0 & 1.2 & 2 & 1.00 & 2.0 \\
\hline 137 & 204 & 88 & 250 & 79 & 0.284 & 1.0 & 4.0 & 0.0 & 0.8 & 0.00 & 0.8 \\
\hline 138 & 216 & 81 & 186 & 76 & 0.092 & 1.0 & 3.0 & 5.0 & 4 & 1.00 & 5.4 \\
\hline 139 & 219 & 79 & 152 & 83 & 0.314 & 2.0 & 3.0 & 0.0 & 2 & 0.00 & 2.2 \\
\hline 140 & 208 & 89 & 328 & 67 & 0.540 & 1.0 & 20.0 & 1.5 & 13 & 0.62 & 11.6 \\
\hline 141 & 210 & 82 & 062 & 67 & 0.658 & 1.0 & 10.0 & 0.6 & 26 & 0.33 & 66.1 \\
\hline 142 & 215 & 87 & 053 & 66 & 0.366 & 3.0 & 7.0 & 1.0 & 14.5 & 0.34 & - \\
\hline 143 & 209 & 84 & 098 & 45 & 0.306 & 1.0 & 4.0 & 0.0 & 3 & 0.33 & 5.4 \\
\hline 144 & 217 & 85 & 098 & 45 & 0.283 & 50.0 & - & - & - & - & - \\
\hline 145 & 212 & 83 & 189 & 83 & 0.172 & 2.0 & 5.0 & 0.5 & 8.5 & 0.12 & 9.9 \\
\hline 146 & 210 & 79 & 192 & 72 & 0.084 & 2.0 & 13.0 & 1.0 & 8.5 & 0.24 & 13.2 \\
\hline
\end{tabular}




\begin{tabular}{|c|c|c|c|c|c|c|c|c|c|c|c|}
\hline \multirow[t]{3}{*}{ Node } & \multirow{2}{*}{\multicolumn{2}{|c|}{$\begin{array}{l}\text { Shear plane } \\
\text { (right hand rule) }\end{array}$}} & \multirow{2}{*}{\multicolumn{2}{|c|}{$\begin{array}{l}\text { Marker plane } \\
\text { (right hand rule) }\end{array}$}} & \multirow{3}{*}{$\begin{array}{l}\text { Spacing from } \\
\text { adjacent shear } \\
\text { plane }(m)\end{array}$} & \multicolumn{2}{|c|}{ Thickness of: } & \multirow{3}{*}{$\begin{array}{c}\text { Ductile } \\
\text { deformation } \\
\text { width }(\mathrm{cm})\end{array}$} & \multirow{3}{*}{$\begin{array}{c}\text { Total } \\
\text { separation } \\
(\mathrm{cm})\end{array}$} & \multirow{3}{*}{$\begin{array}{c}\text { Ductile/total } \\
\text { separation } \\
\text { ratio }^{d}\end{array}$} & \multirow{3}{*}{$\begin{array}{l}\text { Calculatec } \\
\text { net slip } \\
(\mathrm{cm})^{\mathrm{e}}\end{array}$} \\
\hline & & & & & & Infilling vein & $\overline{\text { Marker }}$ & & & & \\
\hline & Strike & $\overline{\text { Dip }}$ & Strike & Dip & & $(\mathrm{mm})$ & $(\mathrm{mm})^{c}$ & & & & \\
\hline 147 & 215 & 85 & 344 & 77 & 0.160 & 0.5 & 10.0 & 0.6 & 4.5 & 0.62 & 4.5 \\
\hline 148 & 210 & 82 & 249 & 46 & 0.375 & 1.0 & 12.0 & 0.9 & 15 & 0.27 & 14.7 \\
\hline 149 & 211 & 77 & 181 & 83 & 0.425 & 1.0 & 4.0 & 0.0 & 11.4 & 0.00 & 11.5 \\
\hline 150 & 206 & 85 & 181 & 83 & 0.027 & 1.0 & 4.0 & 0.0 & 23 & 0.00 & 25.7 \\
\hline 151 & 205 & 82 & 202 & 79 & 0.036 & 2.0 & 3.0 & 0.6 & 4.8 & 1.00 & 8.2 \\
\hline 152 & 208 & 77 & 329 & 58 & 0.019 & 1.0 & 3.0 & 0.5 & 7.6 & 0.07 & 7.5 \\
\hline 153 & 205 & 76 & 329 & 58 & 0.645 & 3.0 & - & - & - & - & - \\
\hline 154 & 212 & 78 & 329 & 58 & 0.244 & 30.0 & - & - & - & - & - \\
\hline 155 & 222 & 85 & 245 & 88 & 0.524 & 2.0 & 8.0 & 1.1 & 3.2 & 0.88 & - \\
\hline
\end{tabular}

Appendix B-3. Data collected for Chancellor Ridge structural survey 03 (CH03) from an array of shears in the brittle-ductile shear zone (BDSZ). a - Survey location listed in New Zealand Grid coordinates (metres). b Elevation is in metres above mean sea level. c - marker thickness not listed where the Alpine Foliation was used as the displacement marker $(<1 \mathrm{~mm}$ thick). d - Ductile / total separation ratio was calculated from the ductile separation of the marker veins and the total measured separation of the vein across the survey (brittle-ductile separation). e - The net-slip (shear displacement) is calculated for a net-slip pitch (displacement vector) of $30^{\circ}$ in the fault plane. Net-slip has been filtered for shear zones that have a marker vein that intercepts the shear plane at a pitch that is within $5^{\circ}$ of the the net-slip pitch. Shear plane and marker vein orientations are listed in right-handrule notation. 


\begin{tabular}{|c|c|c|}
\hline Survey length: & Average fir & nite ductile she \\
\hline Nodes: & Average shear & displacement ( \\
\hline Location of first node ${ }^{a}$ : & E $2,280,123$ & N $5,744,672$ \\
\hline Elevation of first node ${ }^{b}$ : & $1740 \mathrm{~m}$ & \\
\hline Bearing of survey line: & $312,23^{\circ}$ & Nodes 1-34 \\
\hline & $330,26^{\circ}$ & Nodes $35-56$ \\
\hline & $320,17^{\circ}$ & Nodes $57-86$ \\
\hline & $324,68^{\circ}$ & Nodes 87-109 \\
\hline
\end{tabular}

Surveyed by: $\quad$ Tim Little, Julie Vry, Ruth Wightman and Matt Hill (2004)

Node Shear plane Marker plane Spacing from Thickness of: Ductile Total Ductile/total Calculated

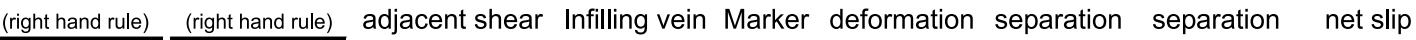

\begin{tabular}{|c|c|c|c|c|c|c|c|c|c|c|c|}
\hline & Strike & Dip & Strike & Dip & plane $(\mathrm{m})$ & $(\mathrm{mm})$ & $(\mathrm{mm})^{\mathrm{c}}$ & width $(\mathrm{cm})$ & $(\mathrm{cm})$ & ratio $^{d}$ & $(\mathrm{~cm})^{\mathrm{e}}$ \\
\hline 0 & 044 & 73 & 063 & 62 & 0.000 & - & 5.0 & 0.0 & 3.0 & 0.00 & 6.2 \\
\hline 1 & 046 & 80 & 345 & 80 & 0.389 & - & 17.0 & 0.6 & 4.0 & 0.35 & 4.3 \\
\hline 2 & 229 & 88 & 018 & 66 & 0.081 & - & 12.0 & 3.0 & 8.3 & 0.34 & 6.1 \\
\hline 3 & 039 & 70 & 175 & 69 & 0.170 & - & 15.0 & 0.3 & 2.7 & 0.78 & 6.9 \\
\hline 4 & 047 & 66 & 175 & 69 & 0.040 & - & 15.0 & 0.3 & 2.0 & 0.50 & 4.3 \\
\hline 5 & 052 & 69 & 175 & 69 & 0.039 & - & 10.0 & 0.2 & 2.7 & 0.07 & 5.0 \\
\hline 6 & 049 & 70 & 182 & 81 & 0.317 & - & 4.0 & 0.2 & 7.2 & 0.03 & 12.1 \\
\hline 7 & 048 & 78 & 175 & 80 & 0.176 & - & 20.0 & 0.5 & 46.5 & 0.16 & - \\
\hline 8 & 042 & 80 & 175 & 80 & 0.117 & 1.0 & 25.0 & 1.8 & 7.5 & 1.00 & 11.6 \\
\hline 9 & 049 & 80 & 071 & 60 & 0.261 & - & 5.0 & 0.3 & 1.2 & 0.67 & 3.8 \\
\hline 10 & 046 & 74 & 023 & 79 & 0.040 & 2.0 & 4.0 & 0.4 & 18.5 & 0.03 & - \\
\hline 11 & 049 & 78 & 195 & 84 & 0.117 & - & 2.0 & 0.0 & 1.0 & 0.00 & 1.6 \\
\hline 12 & 045 & 84 & 014 & 77 & 0.115 & - & 5.0 & 1.0 & 72.0 & 0.04 & 70.3 \\
\hline 13 & 050 & 80 & 024 & 80 & 0.251 & - & 15.0 & 2.0 & 6.0 & 0.33 & 6.5 \\
\hline 14 & 050 & 82 & 338 & 88 & 0.057 & 5.0 & 10.0 & 1.0 & 5.0 & 1.00 & 5.4 \\
\hline 15 & 050 & 80 & 027 & 83 & 0.174 & - & 15.0 & 0.8 & 4.5 & 1.00 & - \\
\hline 16 & 054 & 77 & 018 & 80 & 0.222 & - & 5.0 & 1.0 & 2.5 & 1.00 & 2.7 \\
\hline 17 & 049 & 79 & 017 & 75 & 0.408 & - & 2.0 & 0.2 & 1.5 & 0.67 & 1.6 \\
\hline 18 & 045 & 78 & 062 & 66 & 0.373 & 0.5 & 4.0 & 0.0 & 5.4 & 0.00 & 9.2 \\
\hline 19 & 049 & 73 & 198 & 81 & 0.030 & 1.0 & 6.0 & 1.0 & 9.0 & 0.28 & 13.9 \\
\hline 20 & 045 & 79 & 007 & 74 & 0.117 & 0.5 & 12.0 & 0.2 & 6.5 & 0.08 & 6.8 \\
\hline 21 & 047 & 78 & 204 & 89 & 0.166 & 5.0 & 4.0 & 0.3 & 49.0 & 0.01 & 66.9 \\
\hline 22 & 045 & 80 & 197 & 80 & 0.039 & - & 8.0 & 0.5 & 13.0 & 0.27 & 20.1 \\
\hline 23 & 042 & 79 & 312 & 77 & 0.049 & 1.0 & 15.0 & 1.5 & 18.0 & 0.39 & 18.8 \\
\hline 24 & 050 & 79 & 066 & 62 & 0.194 & 4.0 & 2.0 & 0.0 & 23.5 & 0.02 & 50.7 \\
\hline 25 & 047 & 74 & 150 & 82 & 0.673 & 0.5 & 13.0 & 0.9 & 2.5 & 1.00 & 3.0 \\
\hline 27 & 053 & 77 & 334 & 80 & 0.339 & - & 2.0 & 0.4 & 4.8 & 1.00 & 5.0 \\
\hline 28 & 048 & 70 & 170 & 80 & 0.020 & - & 7.0 & 0.7 & 3.5 & 1.00 & 4.5 \\
\hline 29 & 051 & 76 & 345 & 71 & 0.039 & - & 15.0 & 0.6 & 10.0 & 0.40 & 10.3 \\
\hline 30 & 048 & 77 & 335 & 76 & 0.020 & - & 20.0 & 1.5 & 17 & 0.09 & 17.9 \\
\hline 32 & 050 & 79 & 335 & 76 & 0.087 & 0.5 & 17.5 & 3.8 & 14.0 & 0.25 & 14.6 \\
\hline 33 & 051 & 82 & 176 & 80 & 0.038 & 0.5 & 10.0 & 1.0 & 6.0 & 0.58 & 6.9 \\
\hline 34 & 045 & 72 & 087 & 62 & 0.040 & 1.0 & 20.0 & 2.0 & 25 & 0.12 & 33.6 \\
\hline 35 & 233 & 87 & 102 & 71 & 0.026 & 0.5 & 4.0 & 1.0 & 3.0 & 0.67 & 5.0 \\
\hline 36 & 055 & 79 & 020 & 64 & 0.067 & 1.0 & 7.0 & 0.6 & 3.3 & 0.94 & 2.8 \\
\hline 37 & 051 & 72 & 014 & 74 & 0.118 & - & 8.0 & 0.0 & 3.3 & 0.00 & 3.7 \\
\hline 38 & 231 & 72 & 200 & 71 & 0.071 & 0.5 & 25.0 & 1.5 & 16.5 & 0.21 & - \\
\hline 39 & 055 & 75 & 215 & 70 & 0.078 & 0.5 & 4.0 & 1.3 & 8.0 & 0.20 & - \\
\hline 40 & 233 & 87 & 195 & 63 & 0.017 & 0.5 & 9.0 & 0.5 & 8.5 & 0.29 & 18.3 \\
\hline
\end{tabular}


Node Shear plane Marker plane Spacing from Thickness of: Ductile Total Ductile/total Calculated

\begin{tabular}{|c|c|c|c|c|c|c|c|c|c|c|c|}
\hline & \multicolumn{2}{|c|}{ (right hand rule) } & \multicolumn{2}{|c|}{ (right hand rule) } & \multirow{2}{*}{$\begin{array}{c}\text { adjacent shear } \\
\text { plane }(m)\end{array}$} & \multirow{2}{*}{$\begin{array}{l}\text { Infilling vein } \\
(\mathrm{mm})\end{array}$} & \multirow{2}{*}{$\begin{array}{l}\text { Marker } \\
(\mathrm{mm})^{c}\end{array}$} & \multirow{2}{*}{$\begin{array}{l}\text { deformation } \\
\text { width }(\mathrm{cm})\end{array}$} & \multirow{2}{*}{$\begin{array}{c}\text { separation } \\
(\mathrm{cm})\end{array}$} & \multirow{2}{*}{$\begin{array}{c}\text { separation } \\
\text { ratio }^{d}\end{array}$} & \multirow{2}{*}{$\begin{array}{l}\text { net slip } \\
(\mathrm{cm})^{\mathrm{e}}\end{array}$} \\
\hline & Strike & Dip & Strike & Dip & & & & & & & \\
\hline 41 & 042 & 74 & 207 & 78 & 0.688 & 0.5 & 13.0 & 1.8 & 9.0 & 0.44 & - \\
\hline 42 & 055 & 72 & 190 & 82 & 0.059 & 1.0 & 6.0 & 0.8 & 6.0 & 0.33 & 9.9 \\
\hline 43 & 232 & 81 & 167 & 66 & 0.130 & - & 8.0 & 0.6 & 3.8 & 0.47 & 5.9 \\
\hline 44 & 231 & 86 & - & - & 0.026 & - & - & - & - & - & - \\
\hline 45 & 230 & 84 & - & - & 0.292 & - & - & - & - & - & - \\
\hline 46 & 231 & 70 & 206 & 70 & 0.089 & 1.0 & 8.0 & 1.2 & 9.5 & 0.53 & - \\
\hline 47 & 228 & 77 & 190 & 70 & 0.364 & - & 2.0 & 0.1 & 5.6 & 0.05 & 7.8 \\
\hline 48 & 234 & 84 & 210 & 74 & 0.295 & 1.0 & 4.0 & 0.8 & 2.0 & 1.00 & 3.1 \\
\hline 49 & 229 & 78 & 210 & 74 & 0.046 & 1.0 & 3.0 & 1.5 & 5.0 & 1.00 & 6.8 \\
\hline 50 & 229 & 86 & - & - & 0.076 & - & - & - & - & - & - \\
\hline 51 & 223 & 89 & 202 & 81 & 0.102 & 2.0 & 2.0 & 0.4 & 4.0 & 0.38 & 6.1 \\
\hline 52 & 051 & 76 & 196 & 64 & 0.803 & 0.5 & 14.0 & 1.5 & 16.7 & 0.10 & 62.2 \\
\hline 53 & 051 & 79 & - & - & 0.124 & 3.0 & - & - & - & - & - \\
\hline 54 & 231 & 64 & 355 & 56 & 0.012 & 0.5 & 5.0 & 0.3 & 3.5 & 0.29 & 3.2 \\
\hline 55 & 231 & 68 & 344 & 60 & 0.138 & 0.5 & 5.0 & 0.7 & 2.5 & 1.00 & 2.4 \\
\hline 56 & 225 & 69 & 344 & 60 & 0.013 & 1.0 & 5.0 & 0.4 & 1.3 & 1.00 & 1.2 \\
\hline 57 & 042 & 83 & - & - & 0.302 & - & - & - & - & - & - \\
\hline 58 & 039 & 81 & 301 & 71 & 0.156 & - & 10.0 & 0.8 & 5.0 & 0.40 & 4.3 \\
\hline 59 & 042 & 82 & 192 & 83 & 0.039 & - & 6.0 & 1.0 & 6.0 & 1.00 & 10.4 \\
\hline 60 & 053 & 71 & 007 & 68 & 0.020 & - & 7.0 & 0.0 & 3.0 & 0.00 & 2.9 \\
\hline 61 & 048 & 80 & 012 & 62 & 0.149 & - & 8.0 & 0.8 & 5.0 & 0.40 & 3.6 \\
\hline 62 & 043 & 79 & 012 & 62 & 0.030 & - & 20.0 & 0.0 & 10.0 & 0.00 & 6.9 \\
\hline 63 & 046 & 70 & 358 & 68 & 0.379 & - & 5.0 & 0.0 & 2.0 & 0.00 & 1.9 \\
\hline 64 & 044 & 76 & 358 & 68 & 0.010 & - & 3.0 & 0.2 & 1.0 & 1.00 & 0.9 \\
\hline 65 & 229 & 84 & 166 & 62 & 0.405 & - & 6.0 & 0.8 & 7.0 & 0.29 & 12.8 \\
\hline 66 & 042 & 73 & 181 & 80 & 0.020 & - & 10.0 & 1.0 & 2.5 & 1.00 & 4.8 \\
\hline 67 & 043 & 76 & 181 & 80 & 0.030 & - & 10.0 & 0.3 & 3.5 & 0.80 & 6.3 \\
\hline 68 & 044 & 78 & 181 & 80 & 0.010 & - & 5.0 & 0.0 & 0.7 & 0.00 & 1.2 \\
\hline 69 & 233 & 83 & 178 & 74 & 0.055 & 1.0 & 10.0 & 0.6 & 1.5 & 1.00 & 2.1 \\
\hline 70 & 047 & 75 & 198 & 80 & 0.459 & 0.5 & 13.0 & 0.0 & 10.5 & 0.00 & 26.2 \\
\hline 71 & 046 & 88 & 032 & 88 & 0.125 & 1.5 & 20.0 & 3.0 & 8.5 & 0.76 & 9.6 \\
\hline 72 & 049 & 74 & - & - & 0.270 & - & - & - & - & - & - \\
\hline 73 & 052 & 74 & 297 & 61 & 0.380 & 1.0 & 20.0 & 2.3 & 9.5 & 0.68 & 6.7 \\
\hline 74 & 043 & 80 & - & - & 0.374 & 5.0 & - & - & - & - & - \\
\hline $75 a$ & 232 & 85 & 303 & 89 & 0.213 & - & 14.0 & 1.2 & 9.0 & 1.00 & 10.3 \\
\hline $75 b$ & 047 & 77 & 350 & 68 & 0.219 & 5.0 & 17.0 & 0.0 & 40.0 & 0.00 & 35.8 \\
\hline 76 & 044 & 70 & 305 & 84 & 0.030 & 0.5 & 14.0 & 0.5 & 9.0 & 0.22 & 9.1 \\
\hline 77 & 233 & 87 & 343 & 78 & 0.056 & 1.0 & 3.0 & 0.4 & 7.8 & 0.38 & 7.5 \\
\hline 78 & 222 & 77 & - & - & 0.103 & - & - & - & - & - & - \\
\hline 79 & 048 & 69 & 312 & 88 & 0.309 & 1.0 & 7.0 & 0.4 & 9.8 & 0.18 & 10.6 \\
\hline 80 & 045 & 68 & 058 & 70 & 0.109 & 7.0 & 6.0 & 0.0 & 33.5 & 0.00 & 34.6 \\
\hline 83 & 050 & 74 & 187 & 80 & 0.050 & 1.0 & 2.0 & 0.0 & 3.7 & 0.00 & 6.7 \\
\hline 84 & 043 & 77 & - & - & 0.050 & - & - & - & - & - & - \\
\hline 85 & 051 & 73 & - & - & 0.230 & 10.0 & - & - & - & - & - \\
\hline 86 & 051 & 70 & 282 & 78 & 0.180 & - & 15.0 & 0.6 & 3.0 & 1.00 & 2.4 \\
\hline 87 & 048 & 83 & 339 & 80 & 0.082 & 5.0 & 12.0 & 1.1 & 7.7 & 0.48 & 7.6 \\
\hline 88 & 049 & 82 & 332 & 72 & 0.030 & 2.0 & 10.0 & 0.6 & 3.5 & 1.00 & 3.6 \\
\hline 89 & 048 & 87 & 081 & 78 & 0.172 & 4.0 & 25.0 & 3.0 & 7.4 & 1.00 & 10.3 \\
\hline 90 & 046 & 88 & 059 & 76 & 0.153 & - & 15.0 & 1.3 & 7.5 & 0.53 & 26.7 \\
\hline 91 & 054 & 88 & 290 & 85 & 0.207 & 0.5 & 13.0 & 5.0 & 11.0 & 0.05 & 11.9 \\
\hline 92 & 225 & 81 & 082 & 80 & 0.046 & 1.0 & 8.0 & 7.0 & 13.0 & 1.00 & 20.9 \\
\hline 93 & 055 & 78 & 122 & 70 & 0.095 & 2.0 & 10.0 & 1.4 & 6.0 & 1.00 & 8.3 \\
\hline
\end{tabular}




\begin{tabular}{|c|c|c|c|c|c|c|c|c|c|c|c|}
\hline \multirow[t]{3}{*}{ Node } & \multirow{2}{*}{\multicolumn{2}{|c|}{$\begin{array}{l}\text { Shear plane } \\
\text { (right hand rule) }\end{array}$}} & \multirow{2}{*}{\multicolumn{2}{|c|}{$\begin{array}{l}\text { Marker plane } \\
\text { (right hand rule) }\end{array}$}} & \multirow{3}{*}{$\begin{array}{l}\text { Spacing from } \\
\text { adjacent shear } \\
\text { plane }(\mathrm{m})\end{array}$} & \multicolumn{2}{|c|}{ Thickness of: } & \multirow{3}{*}{$\begin{array}{c}\text { Ductile } \\
\text { deformation } \\
\text { width }(\mathrm{cm}) \\
\end{array}$} & \multirow{3}{*}{$\begin{array}{c}\text { Total } \\
\text { separation } \\
(\mathrm{cm}) \\
\end{array}$} & \multirow{3}{*}{$\begin{array}{c}\text { Ductile/total } \\
\text { separation } \\
\text { ratio }^{d} \\
\end{array}$} & \multirow{3}{*}{$\begin{array}{c}\text { Calculated } \\
\text { net slip } \\
(\mathrm{cm})^{\mathrm{e}} \\
\end{array}$} \\
\hline & & & & & & Infilling vein & Marker & & & & \\
\hline & Strike & Dip & Strike & Dip & & $(\mathrm{mm})$ & $(\mathrm{mm})^{\mathrm{c}}$ & & & & \\
\hline 94 & 047 & 81 & 090 & 82 & 0.072 & 0.5 & 10.0 & 1.0 & 13.0 & 0.08 & - \\
\hline 95 & 051 & 84 & 055 & 72 & 0.117 & - & 8.0 & 1.3 & 4.3 & 1.00 & 15.0 \\
\hline 96 & 052 & 86 & 074 & 69 & 0.123 & 0.5 & 10.0 & 1.0 & 5.0 & 0.60 & 11.2 \\
\hline 97 & 045 & 78 & 001 & 87 & 0.244 & 3.0 & 5.0 & 1.5 & 32.5 & 0.09 & - \\
\hline 98 & 049 & 79 & 167 & 45 & 0.212 & - & 13.0 & 1.5 & 6.0 & 1.00 & 23.2 \\
\hline $99 b$ & 048 & 78 & 173 & 82 & 0.006 & - & 20.0 & 0.4 & 3.5 & 0.14 & 5.1 \\
\hline $99 a$ & 053 & 84 & 332 & 78 & 0.028 & 1.0 & 10.0 & 0.8 & 5.0 & 0.60 & 4.8 \\
\hline 100 & 050 & 79 & 332 & 78 & 0.016 & - & 20.0 & 0.2 & 11.0 & 0.05 & 10.7 \\
\hline $101 a$ & 050 & 79 & 129 & 48 & 0.076 & 1.0 & 20.0 & 0.5 & 2.5 & 1.00 & 6.8 \\
\hline $101 b$ & 042 & 76 & 108 & 60 & 0.035 & - & 20.0 & 0.6 & 7.5 & 0.20 & 13.5 \\
\hline $102 a$ & 049 & 75 & 154 & 61 & 0.096 & - & 8.0 & 0.0 & 2 & 0.00 & 4.1 \\
\hline $102 b$ & 045 & 82 & 005 & 81 & 0.005 & 2.0 & 25.0 & 2.4 & 8 & 1.00 & 7.5 \\
\hline 103 & 044 & 80 & 005 & 81 & 0.147 & 1.0 & 35.0 & 1.0 & 6 & 1.00 & 5.9 \\
\hline 104 & 050 & 55 & 193 & 80 & 0.042 & 0.5 & 7.0 & 0.5 & 6 & 1.00 & 15.0 \\
\hline 105 & 051 & 85 & 022 & 79 & 0.082 & 0.5 & 5.0 & 0.4 & 3 & 1.00 & 2.2 \\
\hline $106 a$ & 044 & 87 & 192 & 79 & 0.042 & 1.0 & 13 & 0.7 & 2.5 & 1.00 & 3.9 \\
\hline $106 \mathrm{~b}$ & 047 & 86 & 192 & 79 & 0.013 & 0.5 & 13 & 0.7 & 3 & 0.67 & 4.7 \\
\hline 107 & 048 & 72 & 062 & 67 & 0.096 & 0.5 & 5 & 0.0 & 2 & 0.00 & 2.3 \\
\hline 108 & 050 & 89 & 065 & 78 & 0.062 & 2.0 & 10.0 & 0.0 & 5.5 & 0.00 & 14.1 \\
\hline 109 & 050 & 85 & 183 & 89 & 0.145 & 2.0 & 3.0 & 0.4 & 4.7 & 1.00 & - \\
\hline
\end{tabular}

Appendix B-4. Data collected for Baumann Glacier structural survey 01 (BM01) from an array of shears in the brittle-ductile shear zone (BDSZ). a - Survey location listed in New Zealand Grid coordinates (metres). b Elevation is in metres above mean sea level. $\mathrm{c}$ - marker thickness not listed where the Alpine Foliation was used as the displacement marker $(<1 \mathrm{~mm}$ thick). $\mathrm{d}$ - Ductile / total separation ratio was calculated from the ductile separation of the marker veins and the total measured separation of the vein across the survey (brittle-ductile separation). e - The net-slip (shear displacement) is calculated for a net-slip pitch (displacement vector) of $30^{\circ}$ in the fault plane. Net-slip has been filtered for shear zones that have a marker vein that intercepts the shear plane at a pitch that is within $5^{\circ}$ of the the net-slip pitch. Shear plane and marker vein orientations are listed in right-handrule notation. 
Survey length: $\quad$ -

Nodes: $\quad 22$

Location of first node ${ }^{a}$ :

Elevation of first node ${ }^{b}$ :

Bearing of survey line:

Surveyed by: $\quad$ Matt Hill (2004)

$\begin{array}{rcc}\text { Average finite ductile shear strain: } & 4.9 & 2 \sigma=1.4 \\ \text { Average shear displacement (net-slip): } & 13.5 & 2 \sigma=4.4\end{array}$

Varied shear locations where node $=$ field station number from Appendix 1.

This data was collected from individual and small arrays of brittle-ductile shears found in the Baumann Glacier brittle-ductile shear zone.

\begin{tabular}{|c|c|c|c|c|c|c|c|c|c|c|c|}
\hline \multirow[t]{3}{*}{ Node } & \multirow{2}{*}{\multicolumn{2}{|c|}{$\begin{array}{l}\text { Shear plane } \\
\text { (right hand rule) }\end{array}$}} & \multirow{2}{*}{\multicolumn{2}{|c|}{$\begin{array}{l}\text { Marker plane } \\
\text { (right hand rule) }\end{array}$}} & \multirow{3}{*}{$\begin{array}{c}\text { Spacing from } \\
\text { adjacent shear } \\
\text { plane }(\mathrm{m})\end{array}$} & \multicolumn{2}{|c|}{ Thickness of: } & \multirow{3}{*}{$\begin{array}{c}\text { Ductile } \\
\text { deformation } \\
\text { width }(\mathrm{cm})\end{array}$} & \multirow{3}{*}{$\begin{array}{c}\text { Total } \\
\text { separation } \\
(\mathrm{cm}) \\
\end{array}$} & \multirow{3}{*}{$\begin{array}{c}\text { Ductile/total } \\
\text { separation } \\
\text { ratio }^{d} \\
\end{array}$} & \multirow{3}{*}{$\begin{array}{l}\text { Calculated } \\
\text { net slip } \\
(\mathrm{cm})^{\mathrm{e}} \\
\end{array}$} \\
\hline & & & & & & \multirow{2}{*}{$\begin{array}{c}\text { Infilling vein } \\
(\mathrm{mm})\end{array}$} & \multirow{2}{*}{$\begin{array}{l}\text { Marker } \\
(\mathrm{mm})^{\mathrm{c}}\end{array}$} & & & & \\
\hline & Strike & Dip & Strike & Dip & & & & & & & \\
\hline BM03 & 046 & 70 & 192 & 82 & - & - & 8.0 & 1.0 & 4.5 & 0.22 & 9.1 \\
\hline BM04 & 036 & 72 & 102 & 86 & - & - & 10.0 & 1.0 & 12.0 & 0.08 & 7.2 \\
\hline BM12a & 044 & 74 & 027 & 84 & - & 4.0 & 12.0 & 1.4 & 13.0 & 0.58 & 22.7 \\
\hline BM12b & 048 & 86 & 201 & 71 & - & 1.0 & 11.0 & 1.8 & 10.0 & 0.60 & 24.4 \\
\hline BM13 & 043 & 76 & 195 & 75 & - & - & 6.0 & 1.0 & 12.0 & 0.25 & 20.2 \\
\hline BM15 & 049 & 78 & 180 & 64 & - & - & 10.0 & 1.5 & 4.0 & 1.00 & 8.6 \\
\hline BM17a & 046 & 73 & 004 & 62 & - & - & 18.0 & 1.2 & 4.2 & 0.76 & 3.7 \\
\hline BM17b & 231 & 88 & 198 & 74 & - & - & 14.0 & 1.6 & 6.2 & 1.00 & 10.8 \\
\hline BM17c & 053 & 86 & 198 & 74 & 0.088 & - & 5.0 & 0.5 & 3.3 & 1.00 & 6.6 \\
\hline BM18a & 050 & 76 & 198 & 70 & - & 1.0 & 7.0 & 1.0 & 20.5 & 0.14 & 26.7 \\
\hline BM18b & 050 & 76 & 210 & 74 & - & 1.0 & 5.0 & 0.8 & 7.5 & 0.40 & - \\
\hline BM18c & 050 & 76 & 202 & 84 & - & 1.0 & 3.0 & 0.5 & 9.5 & 0.11 & 10.9 \\
\hline BM19 & 058 & 78 & 196 & 88 & - & - & 9.0 & 1.0 & 6.5 & 0.51 & 4.0 \\
\hline BM20a & 048 & 70 & 025 & 83 & - & - & 9.0 & 1.6 & 8.0 & 1.00 & 14.7 \\
\hline BM20b & 049 & 88 & 025 & 83 & 0.085 & - & 9.0 & 1.4 & 2.0 & 1.00 & 1.7 \\
\hline
\end{tabular}

Appendix B-5. Data collected for Baumann Glacier structural survey 2 (BM-f) from shear zones in the brittleductile shear zone (BDSZ). a - Survey location listed in New Zealand Grid coordinates (metres). b - Elevation is in metres above mean sea level. c - marker thickness not listed where the Alpine Foliation was used as the displacement marker ( $<1 \mathrm{~mm}$ thick). d - Ductile / total separation ratio was calculated from the ductile separation of the marker veins and the total measured separation of the vein across the survey (brittle-ductile separation). e The net-slip (shear displacement) is calculated for a net-slip pitch (displacement vector) of $30^{\circ}$ in the fault plane. Net-slip has been filtered for shear zones that have a marker vein that intercepts the shear plane at a pitch that is within $5^{\circ}$ of the th e net-slip pitch. Shear plane and marker vein orientations are listed in right-hand-rule notation. This data is an augmented data set created from individual shear zone measurements across the Baunmann Glacier field area and not from a continuous transect line. Node number refer to field sites in Appendix A. 

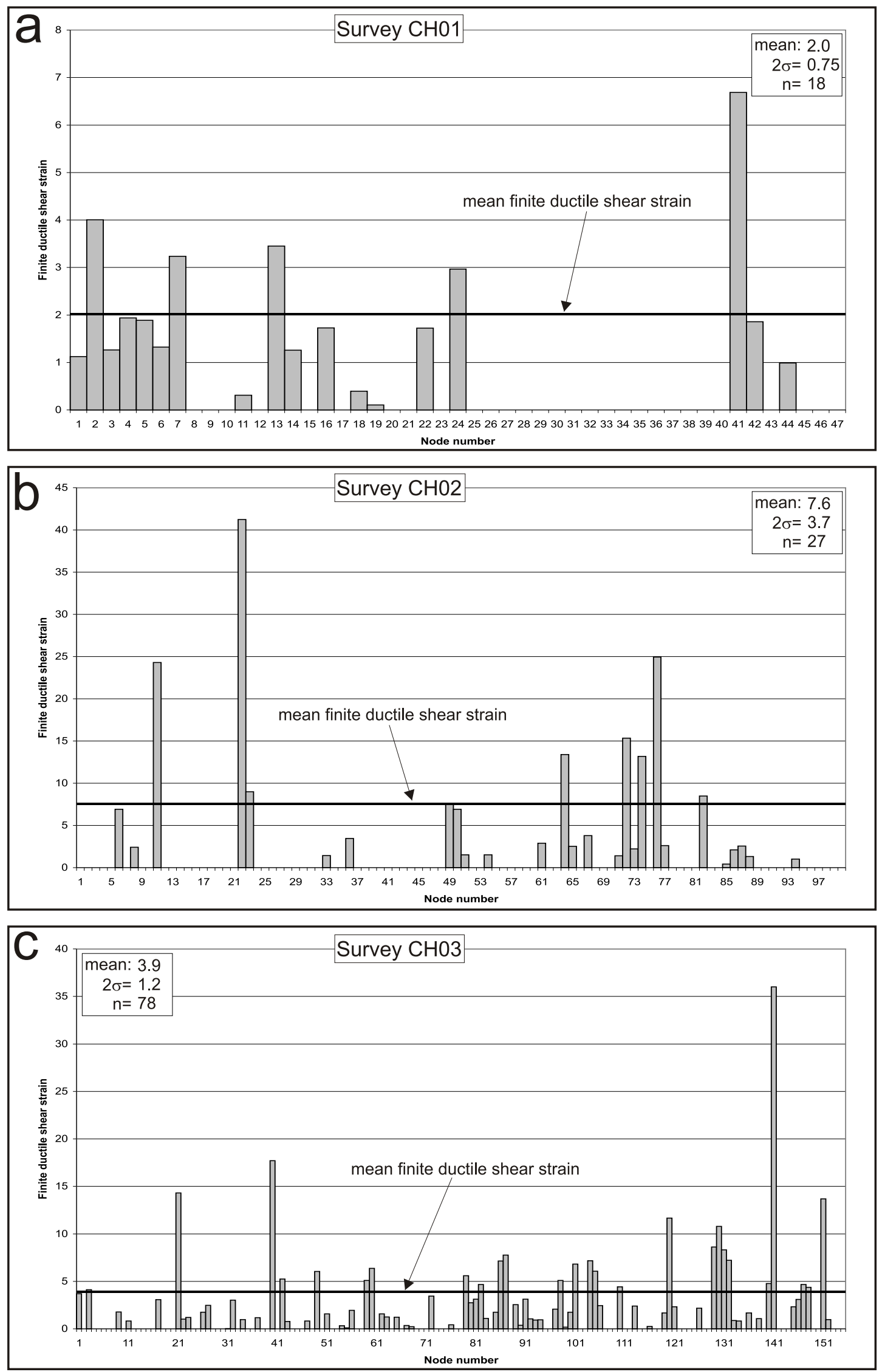

Appendix B-6. Histogram plots of finite ductile shear strain calculated from transect survey data at Chancellor Ridge. Shear strains are calculated from a shear displacement with a net-slip pitch of $30^{\circ}$ from the southwest. Where not data is present, the node may have been brittlely offset, a marker may not have been present, or the data may have been filtered from the survey (filtering of any nodes which had an intersection of the shear and marker planes $\pm 5^{\circ}$ of the net-slip pitch was made). 

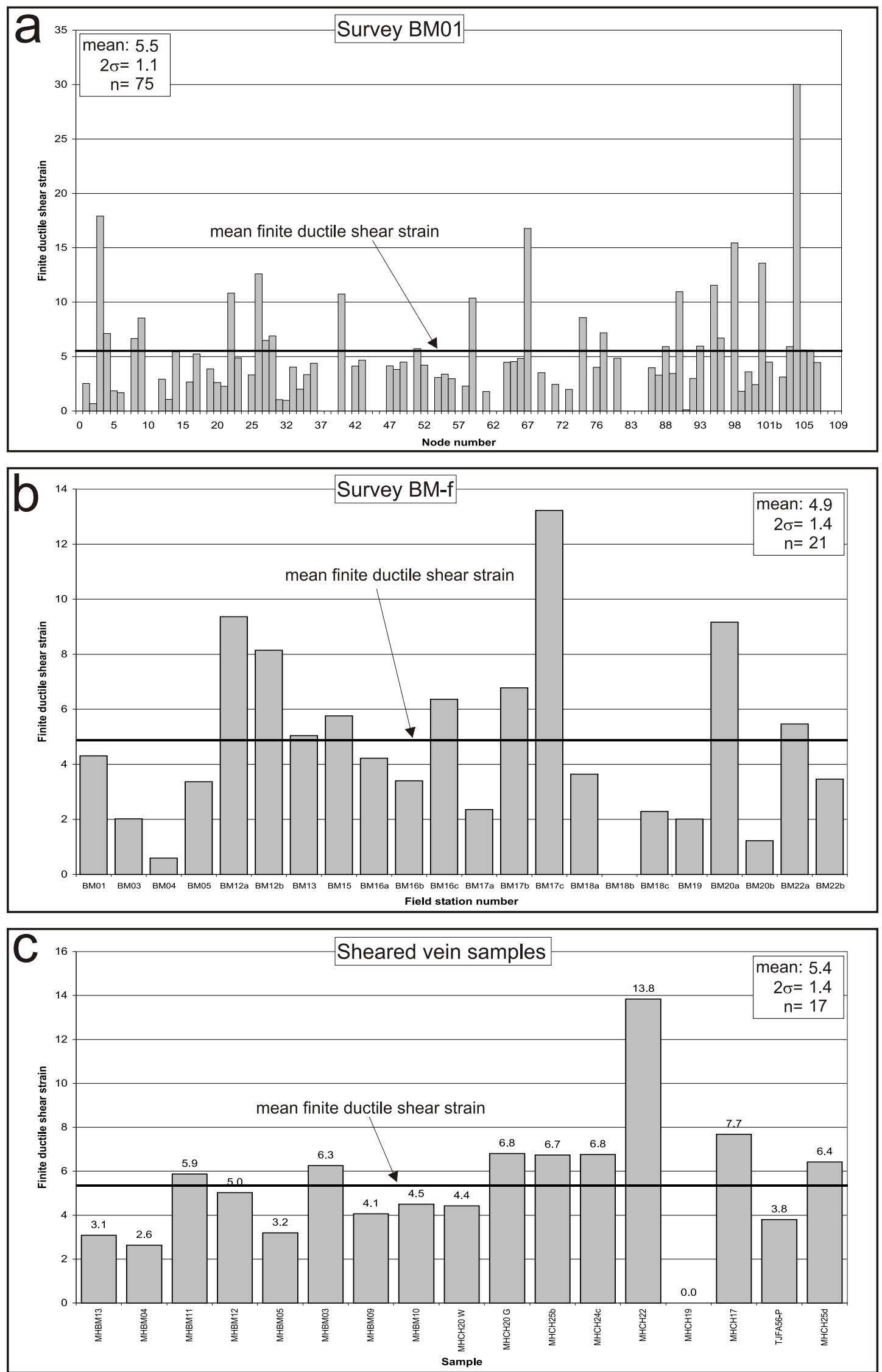

Appendix B-7. Histogram plots of finite ductile shear strain calculated from transect survey data at Baumann Glacier ( $\mathrm{a} \& \mathrm{~b}$ ) and for the sheared vein samples used for CPO analysis (c). Shear strains are calculated from a shear displacement with a net-slip pitch of $30^{\circ}$ from the southwest. Where not data is present, the node may have been brittlely offset, a marker may not have been present, or the data may have been filtered from the survey (filtering of any nodes which had an intersection of the shear and marker planes $\pm 5^{\circ}$ of the net-slip pitch was made). 

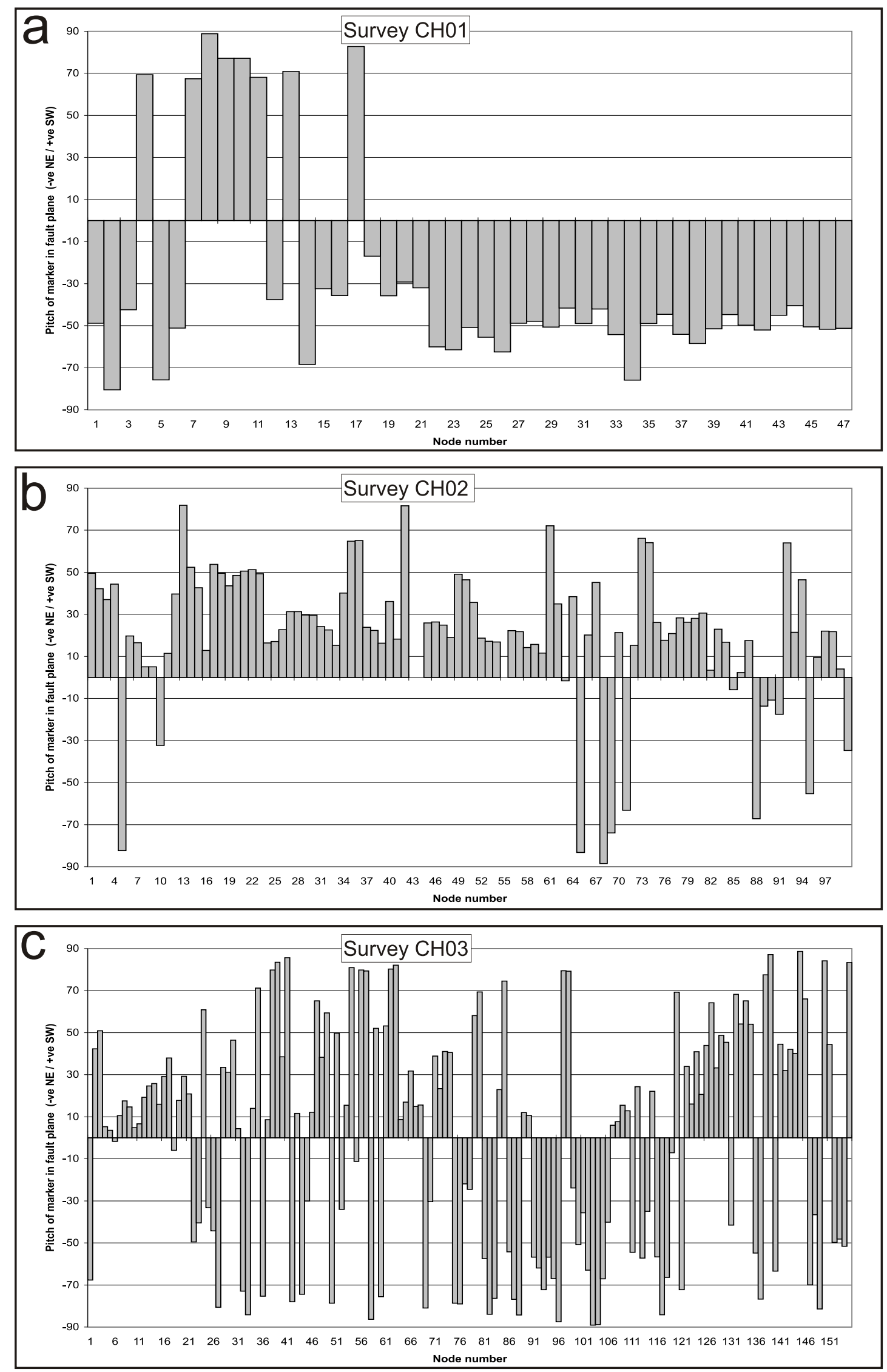

Appendix B-8. Pitches of the intersection of the marker (qtz-cal vein or bedding) in the shear plane. Positive values are pitching from the SW and negative values are pitching from the NE. a. Pitches of markers in shear planes for survey $\mathrm{CH} 01$. b. Pitches of markers in shear planes for survey $\mathrm{CH02}$. c. Pitches of markers in shear planes for survey $\mathrm{CH} 03$. 

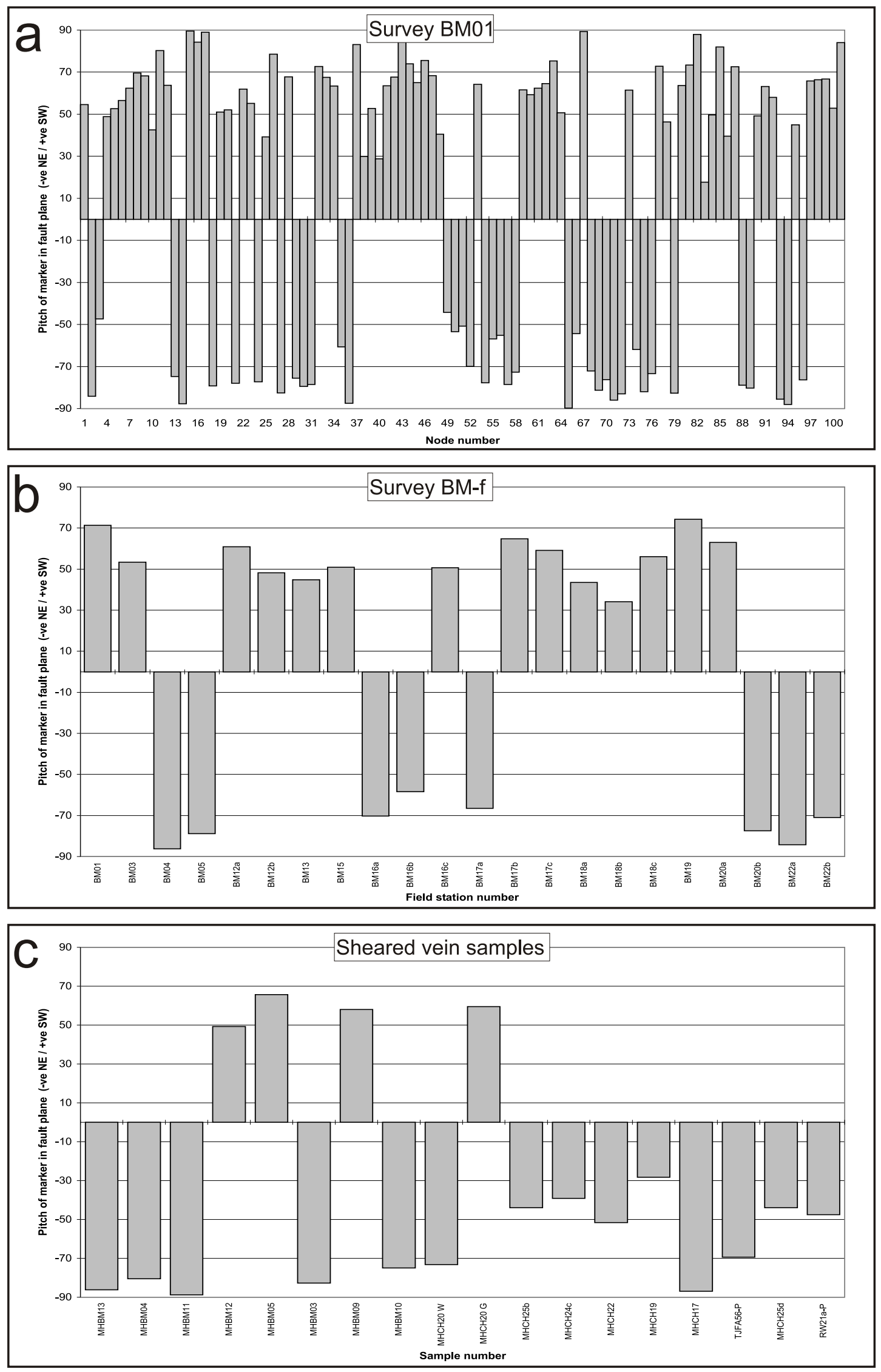

Appendix B-9. Pitches of the intersection of the marker (qtz-cal vein or bedding) in the shear plane. Positive values are pitching from the SW and negative values are pitching from the NE. a. Pitches of markers in shear planes for survey BM01. b. Pitches of markers in shear planes for survey BM-f. c. Pitches of markers in shear planes for shears that have undergone CPO analysis. 

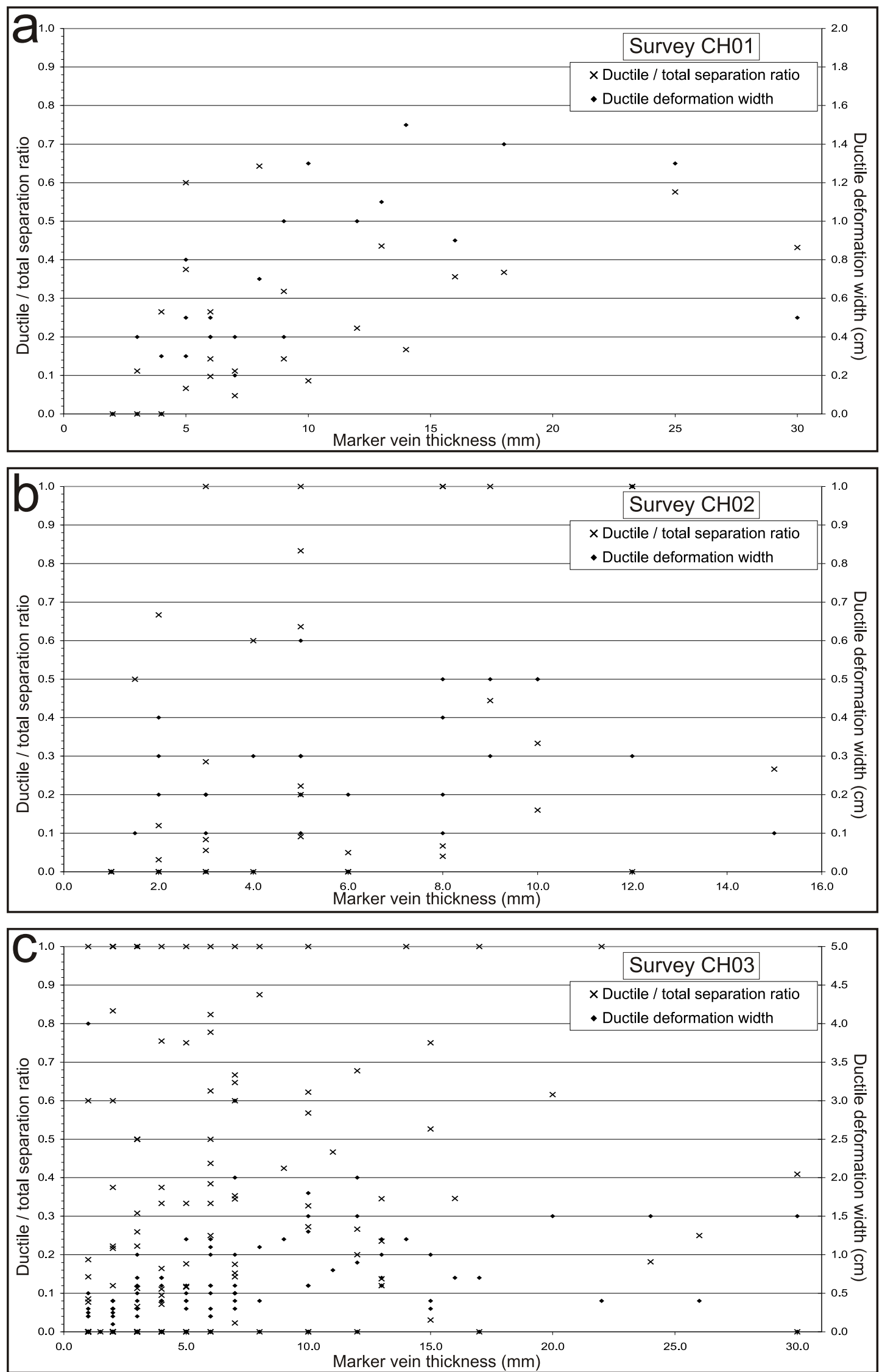

Appendix B-10. Ductile deformation width and ductile / total ratio separation ratio against marker vein thickness for Chancellor Ridge surveys. 

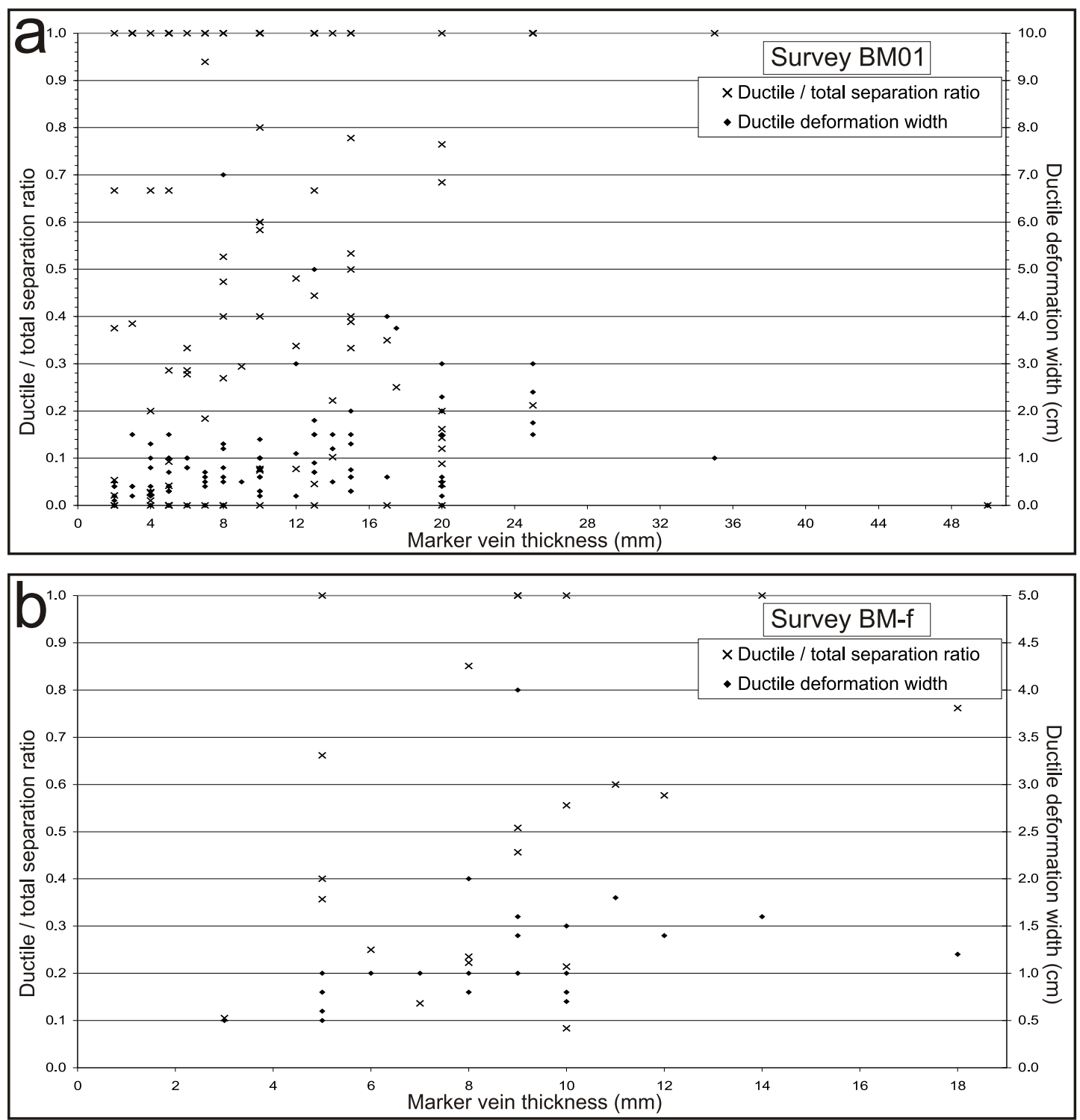

Appendix B-11. Ductile deformation width and ductile / total ratio separation ratio against marker vein thickness for Baumann Glacier surveys. 


\section{Appendix C. Data collected from optical microscopy of sheared veins and Alpine} Schist in brittle-ductile shears in the brittle-ductile shear zone (BDSZ).

Optical microscopy has been used to identify the main mode percent of minerals in the sheared vein and the Alpine Schist as well as identify microstructures related to deformation of the rock (dynamic or static recrystallisation). Samples are listed in the follow appendix with their sample numbers from the field (a) and Victoria University Collection (VUW) numbers (b). The sample area (c) refers to either the Alpine Schist, the internal most highly deformed vein section of sheared quartz-calcite veins, the sections external to the shear deformation in these veins, and the shear infilling veins.

Grain sizes (d) were calculated using the intercept method (see Chapter 4) and are listed for each of the shear zone sections. Minerals are listed using the abbreviations of Kretz (1983). Grain boundary migration (GBM) and subgrain rotation (SGR) are estimated as the approximate percent of quartz grains with these features and given a fabric strength ranking (e). A ranking of 5 is the highest with 0 the lowest with no grains showing any of these microstructures. See Chapter 4 for microphotographs and examples of these rankings. The grain shape fabric is also give the same fabric strength ranking, one that defines the overall strength appearance of the fabric (f). The angle of the grain shape fabric (Obl. GSF ) from the shear zone is also listed and has been used for minimum strain estimates (see Chapter 4). Data has been collected in different thin-section cuts; where all cuts are perpendicular to the shear zone and either parallel to the mineral $\mathrm{f}$ 


\begin{tabular}{|c|c|c|c|c|c|c|c|c|c|c|c|c|c|c|c|}
\hline \multicolumn{2}{|c|}{ Sample number } & \multirow{2}{*}{\multicolumn{2}{|c|}{ Sample area ${ }^{c}$}} & \multirow{2}{*}{$\begin{array}{c}\text { Grain } \\
\left.D^{d} \mu \mathrm{m}\right)\end{array}$} & \multicolumn{2}{|c|}{ Minerals in the: (abbreviations as in Kretz, 1983) } & \multicolumn{3}{|c|}{ Estimated content } & \multicolumn{3}{|c|}{ Fabric strengh ranking ${ }^{\mathrm{e}}$} & \multicolumn{2}{|c|}{ Obl. GSF $\angle^{f}$} & \multirow{2}{*}{$\begin{array}{c}R^{i} \\
-p \text { cut }\end{array}$} \\
\hline Field $^{\mathrm{a}}$ & $\mathrm{VUW}^{\mathrm{b}}$ & & & & Alpine Schist & Sheared veins & $\%$ Qtz & $\% \mathrm{Cal}$ & $\%$ Mica & GBM & SGR & GSF & $-p$ cut $^{g}$ & - st cut $^{\mathrm{h}}$ & \\
\hline $\mathrm{MHCH01}$ & 39380 & - & Schist & 95 & Qtz, Bt, Ms, Chl, Ep, PI, Ilm, Ttn, opaques & Qtz, Bt, Ms, Chl & 98 & 0 & 2 & 1 & 1 & 0 & - & - & - \\
\hline $\mathrm{MHCHO} 2$ & 39381 & - & Infilling & 116 & Qtz, Cal, Bt, Chl, Ms, Ep, opaques & Qtz, Cal, Chl, Ms & 98 & 1 & 1 & 1 & 2 & 2 & - & 0 & - \\
\hline $\mathrm{MHCHO} 3$ & 39382 & - & Schist & 118 & Qtz, Bt, Cal, Ep, Ms, Chl, opaques & Qtz, Cal & 60 & 38 & 2 & 2 & 1 & 1 & - & 0 & - \\
\hline $\mathrm{MHCHO} 4$ & 39383 & - & Infilling & 126 & $\mathrm{Qtz}, \mathrm{Bt}, \mathrm{Ms}, \mathrm{Cal}, \mathrm{Chl}, \mathrm{Pl}, \mathrm{Ep}$, opaques & Qtz, Ms, Cal, Chl & 95 & 4 & 1 & 3 & 2 & 1 & - & 45 & - \\
\hline $\mathrm{MHCH} 05$ & 39384 & - & Schist & - & Qtz, Bt, Ms, Chl, Ttn, Ep, Pl & - & - & - & - & - & - & - & - & - & - \\
\hline $\mathrm{MHCHO6}$ & 39385 & - & Infilling & 140 & Qtz, Cal, Ms, Cal, Bt, Pl, Chl, opaques & Qtz, Cal, Ms & 95 & 4 & 1 & 1 & 2 & 3 & 25 & 30 & 2.08 \\
\hline $\mathrm{MHCH} 07$ & 39386 & - & Infilling & 138 & Qtz, Cal, Chl, Ms & Qtz, Cal, Chl, Ms & 90 & 7 & 3 & 2 & 2 & 3 & 32 & 45 & 2.70 \\
\hline $\mathrm{MHCHO}$ & 39387 & - & Infilling & 400 & Qtz, Cal, Bt, Ms, Pl, Chl & Qtz, Cal, Ms & 60 & 39 & 1 & 1 & 1 & 2 & - & 0 & - \\
\hline $\mathrm{MHCHO9}$ & 39388 & - & Schist & - & Qtz, Cal, Ms, Bt, Pl, Ep, Chl, opaques & Qtz, Cal, Ms & 50 & 49 & 1 & - & - & 2 & - & 0 & - \\
\hline $\mathrm{MHCH} 10$ & 39389 & - & Infilling & 157 & Qtz, Cal, Ms, Chl, Bt & Qtz, Cal, Ms, Chl & 95 & 3 & 2 & 3 & 2 & 2 & 36 & 37 & 2.27 \\
\hline $\mathrm{MHCH} 11$ & 39390 & - & External & 90 & Qtz, Cal, Bt, Ep, Pl & Qtz, Cal & - & - & - & 1 & 1 & 2 & - & 0 & - \\
\hline $\mathrm{MHCH} 12$ & 39391 & A & Infilling & 143 & Qtz, Cal, Ms, Chl, Bt & Qtz, Cal, Ms, Chl & 93 & 5 & 2 & 3 & 2 & 3 & 25 & 30 & 2.13 \\
\hline $\mathrm{MHCH} 12$ & - & B & Infilling & - & Qtz, Cal, Ms, Chl, Bt & Qtz, Cal, Ms, Chl, Bt & - & - & - & 3 & 2 & 2 & - & 25 & - \\
\hline $\mathrm{MHCH} 13$ & 39392 & - & Schist & - & Bt, Ms, Qtz, Cal, Chl, Pl & - & - & - & - & - & - & - & - & - & - \\
\hline $\mathrm{MHCH} 14$ & 39394 & - & Infilling & 155 & Qtz, Chl, Cal, Bt, Ms & Qtz, Chl, Cal, Ms & 79 & 20 & 1 & 2 & 2 & 2 & 20 & 20 & 2.08 \\
\hline $\mathrm{MHCH} 15$ & 39395 & - & Infilling & 170 & Cal, Qtz, Ms, Bt, opaques & Qtz, Cal, Ms & 70 & 28 & 2 & 2 & 2 & 2 & - & 36 & - \\
\hline $\mathrm{MHCH} 16$ & 39396 & - & Schist & - & Qtz, Cal, PI, Ms, Bt, Chl, IIm, Po, Ep & - & - & - & - & - & - & - & - & - & - \\
\hline $\mathrm{MHCH} 17$ & 39397 & B & Internal & 178 & - & Qtz, Cal, Ms & 90 & 8 & 2 & 1 & 1 & 0 & - & - & - \\
\hline $\mathrm{MHCH} 17$ & - & C & Infilling & 150 & - & Qtz, Cal, Ms & 58 & 40 & 2 & 3 & 1 & 1 & - & 0 & - \\
\hline $\mathrm{MHCH} 17$ & - & A & External & 208 & Qtz, Cal, Bt, PI, Ms & Qtz, Cal, Ms & 90 & 8 & 2 & 1 & 1 & 0 & - & - & - \\
\hline $\mathrm{MHCH} 18$ & 39398 & - & Infilling & 139 & Qtz, Cal, Bt, Ms, Pl, Ep, Chl, opaques & Qtz, Cal & 90 & 7 & 3 & 3 & 1 & 2 & - & 0 & - \\
\hline $\mathrm{MHCH} 19$ & 39399 & B & Internal & 111 & - & Qtz, Cal, Ms, Chl & 94 & 5 & 1 & 2 & 2 & 2 & - & Fol & - \\
\hline $\mathrm{MHCH} 19$ & - & C & Infilling & 125 & - & Qtz, Cal, Ms, Chl & - & - & - & 1 & 1 & 0 & - & 0 & - \\
\hline $\mathrm{MHCH} 19$ & - & A & External & 111 & Qtz, Cal, Ms, Ep, Chl & Qtz, Cal, Ms, Chl & - & - & - & 2 & 2 & 2 & - & Fol & - \\
\hline $\mathrm{MHCH} 20$ & 39400 & A & External & 118 & Qtz, Cal, Bt, Ms, Ep, Chl, Ttn, Pl, Po, opaques & Qtz, Cal, Chl & - & - & - & 1 & 1 & 3 & - & Fol & - \\
\hline $\mathrm{MHCH} 2 \mathrm{O}$ & - & B & Internal & - & - & $\mathrm{Qtz}, \mathrm{Cal}, \mathrm{Chl}$ & - & - & - & - & - & - & - & - & - \\
\hline $\mathrm{MHCH} 20$ & - & C & Internal & 149 & - & Qtz, Cal, Chl & - & - & - & 1 & 2 & 2 & - & 0 & - \\
\hline $\mathrm{MHCH} 20$ & - & $\mathrm{E}$ & External & 116 & - & $\mathrm{Qtz}, \mathrm{Cal}, \mathrm{Chl}$ & - & - & - & 2 & 3 & 3 & - & Fol & - \\
\hline $\mathrm{MHCH} 20$ & - & $\mathrm{F}$ & Internal & - & - & Qtz, Cal, Chl & - & - & - & - & - & - & - & - & - \\
\hline $\mathrm{MHCH} 20$ & - & G & Internal & 76 & - & Qtz, Cal, Chl & - & - & - & - & - & - & - & - & - \\
\hline $\mathrm{MHCH} 20$ & - & $\mathrm{H}$ & External & 90 & - & Qtz, Cal, Chl & - & - & - & - & - & - & - & - & - \\
\hline $\mathrm{MHCH} 20$ & - & I & Internal & 135 & - & Qtz, Cal, Chl & - & - & - & 2 & 2 & 2 & - & 0 & - \\
\hline $\mathrm{MHCH} 20$ & - & $\mathrm{J}$ & Internal & 122 & - & Qtz, Cal, Chl & - & - & - & 2 & 2 & 2 & - & 0 & - \\
\hline $\mathrm{MHCH} 20$ & - & $\mathrm{K}$ & Internal & 142 & - & $\mathrm{Qtz}, \mathrm{Cal}, \mathrm{Chl}$ & - & - & - & - & - & - & - & Fol & - \\
\hline $\mathrm{MHCH} 20$ & - & L & External & 142 & - & Qtz, Cal, Chl & - & - & - & 3 & 3 & 3 & - & Fol & - \\
\hline $\mathrm{MHCH} 20$ & - & 0 & Internal & 52 & - & Qtz, Cal, Chl & 50 & 50 & 0 & - & - & - & - & - & - \\
\hline
\end{tabular}




\begin{tabular}{|c|c|c|c|c|c|c|c|c|c|c|c|c|c|c|c|}
\hline \multicolumn{2}{|c|}{ Sample number } & \multirow{2}{*}{\multicolumn{2}{|c|}{ Sample area ${ }^{c}$}} & \multirow{2}{*}{$\begin{array}{c}\text { Grain } \\
\left.D^{d} \mu \mathrm{m}\right)\end{array}$} & \multicolumn{2}{|c|}{ Minerals in the: (abbreviations as in Kretz, 1983) } & \multicolumn{3}{|c|}{ Estimated content } & \multicolumn{3}{|c|}{ Fabric strengh ranking $^{\mathrm{e}}$} & \multicolumn{2}{|c|}{ Obl. GSF $\angle^{f}$} & \multirow{2}{*}{$\begin{array}{c}R^{i} \\
-p \text { cut }\end{array}$} \\
\hline Field $^{a}$ & VUW $^{b}$ & & & & Alpine Schist & Sheared veins & $\%$ Qtz & $\% \mathrm{Cal}$ & $\%$ Mica & GBM & SGR & GSF & $-p$ cut $^{g}$ & - st cut $^{\mathrm{h}}$ & \\
\hline $\mathrm{MHCH} 21$ & 39401 & $\bar{A}$ & Infilling & 145 & Qtz, Cal, Ms, Bt, Ttn, opaques & Qtz, Cal, Ms & 60 & 38 & 2 & 1 & 3 & 1 & - & 0 & - \\
\hline $\mathrm{MHCH} 21$ & - & B & External & 149 & - & Qtz, Cal, Ms & - & - & - & 2 & 2 & 1 & - & Fol & - \\
\hline $\mathrm{MHCH} 22$ & 39402 & B & Internal & 113 & Qtz, Bt, Chl, Ms, Ep, Ttn, Pl & Qtz, Cal, Chl & - & - & - & 2 & 1 & 3 & - & 25 & 1.85 \\
\hline $\mathrm{MHCH} 22$ & - & $\mathrm{C}$ & Infilling & 38 & - & Qtz, Chl & 75 & 0 & 25 & 0 & 1 & 3 & - & 0 & 1.67 \\
\hline $\mathrm{MHCH} 22$ & - & A & External & 92 & - & Qtz, Cal, Chl & - & - & - & 3 & 3 & 2 & - & Fol & - \\
\hline $\mathrm{MHCH} 23$ & 39403 & - & Infilling & 167 & Chl, Qtz, Cal, Bt, Ms, Pl, opaques & Qtz, Cal, Chl & 90 & 9 & 1 & 2 & 2 & 2 & - & 30 & - \\
\hline $\mathrm{MHCH} 24 \mathrm{a}$ & 39404 & - & Infilling & 151 & Chl, Qtz, Cal, Ms, Bt, Pl, Chl & Qtz, Chl, Cal, Ms & 90 & 8 & 2 & 1 & 1 & 1 & - & 0 & - \\
\hline $\mathrm{MHCH} 24 \mathrm{~b}$ & - & - & Infilling & 123 & Qtz, Cal, Chl, Ms, Bt, Pl, Ep, Ttn, opaques & Qtz, Chl, Cal, Ms & 90 & 7 & 3 & 1 & 1 & 1 & - & 0 & _ \\
\hline $\mathrm{MHCH} 24 \mathrm{c}$ & - & B & Internal & - & Qtz, Cal, Ms, Chl, Pl, Bt, Ep, Ttn & Qtz, Chl, Cal, Ms & 90 & 9 & 1 & 1 & 2 & 2 & - & Fol & - \\
\hline $\mathrm{MHCH} 24 \mathrm{c}$ & - & C & Internal & 108 & 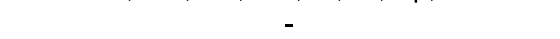 & Qtz, Chl, Cal, Ms & & - & - & 1 & 2 & 0 & - & - & - \\
\hline $\mathrm{MHCH} 24 \mathrm{c}$ & - & D & Infilling & 134 & - & Qtz, Chl, Cal, Ms & 70 & 28 & 2 & 0 & 2 & 1 & - & 0 & - \\
\hline $\mathrm{MHCH} 24 \mathrm{c}$ & - & A & External & 133 & - & Qtz, Chl, Cal, Ms & - & - & - & 2 & 3 & 2 & - & Fol & - \\
\hline $\mathrm{MHCH} 25$ & 39405 & D & Internal & 144 & Qtz, Cal, Bt, Ms, Chl, Ep, Ttn, PI, sulphides & Qtz, Cal, Ms & 90 & 8 & 2 & 0 & 1 & 2 & - & 0 & - \\
\hline $\mathrm{MHCH} 25$ & - & B & Internal & 120 & 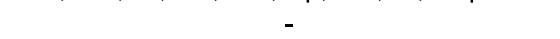 & Qtz, Cal, Ms & - & - & - & 0 & 1 & 2 & - & 0 & - \\
\hline $\mathrm{MHCH} 25$ & - & C & External & 124 & - & Qtz, Cal, Ms & - & - & - & 3 & 2 & 0 & - & - & - \\
\hline $\mathrm{MHCH} 25$ & - & A & External & 130 & - & Qtz, Cal, Ms & - & - & - & 3 & 2 & 0 & - & - & - \\
\hline MHFJ01a & 39406 & - & Chert & 189 & Qtz, Cal, Ms, Bt & - & 94 & 5 & 1 & 2 & 2 & 3 & - & 10 & - \\
\hline MHFJ01b & - & - & Chert & - & $\mathrm{Qtz}, \mathrm{Cal}, \mathrm{Ms}, \mathrm{Bt}$ & - & - & - & - & - & - & - & - & - & - \\
\hline MHFJ02a & 39407 & - & Chert & 159 & Grt, Qtz, Ms, Bt, Cal & - & - & - & - & 1 & 2 & 3 & - & 0 & - \\
\hline MHFJ02b & - & - & Chert & 113 & Qtz, Cal, Ms, Bt & - & 93 & 1 & 6 & 2 & 2 & 2 & - & 0 & - \\
\hline MHFJ03 & 39408 & - & Chert & 110 & Grt, Qtz, Bt, Ms, Cal, opaques, Chl & - & 90 & 5 & 5 & 3 & 1 & 2 & - & 0 & - \\
\hline MHHM01a & 39409 & & Ionitic Chert & 76 & Grt, Bt, Hbl, Pl, Qtz, Ms & - & 85 & 0 & - & 2 & 3 & 3 & - & 0 & - \\
\hline MHHM01b & - & & Ionitic Chert & 86 & Qtz, Grt, Bt, Ms, Pl, Hbl & - & 85 & 0 & - & 2 & 3 & 3 & - & 0 & - \\
\hline MHSP04 & 39410 & - & Schist & - & Qtz, Ms, Bt, Chl, Gr, IIl, Ttn, Grt, Ep & - & - & - & - & - & - & - & - & - & - \\
\hline MHSP06 & 39411 & - & Schist & - & Bt, Chl, Ms, Grt, Qtz, opaques, Ttn, III & - & - & - & - & - & - & - & - & - & - \\
\hline MHSP07 & 39412 & - & Schist & - & Qtz, Cal, Chl, Bt, Ms, Pl & - & - & - & - & - & - & - & - & - & - \\
\hline MHSP08 & 39413 & - & Schist & - & Bt, Gr, Ms, Qtz, Cal, Chl, Ttn, opaques & - & - & - & - & - & - & - & - & - & - \\
\hline MHSP09 & 39414 & - & Infilling & 138 & - & Qtz, Cal, Chl, Ms & 60 & 30 & 10 & 1 & 2 & 0 & - & - & - \\
\hline MHSP10 & 39415 & - & Schist & - & Qtz, opaques, sulphides, Bt, Ms, Chl, Gr & - & - & - & - & - & - & - & - & - & - \\
\hline MHSP11 & 39416 & - & Infilling & 138 & Qtz, Bt, Ms, Chl, Ttn, Ep & Qtz, Ms, Chl & 90 & 0 & 10 & 2 & 2 & 2 & - & 40 & - \\
\hline RW35b & 39431 & - & Infilling & 133 & - & Qtz, Ms & 95 & 0 & 5 & 1 & 1 & 2 & - & 0 & - \\
\hline TJFA43 & 39432 & - & Infilling & 143 & Qtz, Cal, Ms, Chl, Bt, Ep, Ttn & Qtz, Cal, Ms, Chl & 50 & 45 & 5 & 2 & 1 & 2 & - & 0 & - \\
\hline TJFA47 & 39433 & - & Infilling & 127 & Qtz, Cal, Ms, Chl, Bt, Ep & Qtz, Cal, Ms, Chl & 50 & 45 & 5 & 2 & 2 & 1 & - & 0 & - \\
\hline TJFA50 & 39434 & A & External & - & Qtz, Cal, Ms, Bt, sulphides, Ttn, Ep, PI & Qtz, Cal, Ms & 94 & 5 & 1 & - & - & - & - & - & - \\
\hline TJFA50 & - & B & External & - & - & Qtz, Cal, Ms & - & - & - & - & - & - & - & - & - \\
\hline TJFA52 & 39435 & - & Infilling & 145 & - & Qtz, Ms, Cal & 97 & 1 & 2 & 1 & 2 & 2 & - & 0 & - \\
\hline
\end{tabular}




\begin{tabular}{|c|c|c|c|c|c|c|c|c|c|c|c|c|c|c|c|}
\hline \multicolumn{2}{|c|}{ Sample number } & \multicolumn{2}{|c|}{ Sample area ${ }^{c}$} & \multirow{2}{*}{$\begin{array}{c}\text { Grain } \\
\left.D^{d} \mu \mathrm{m}\right)\end{array}$} & \multicolumn{2}{|c|}{ Minerals in the: (abbreviations as in Kretz, 1983) } & \multicolumn{3}{|c|}{ Estimated content } & \multicolumn{3}{|c|}{ Fabric strengh ranking ${ }^{\mathrm{e}}$} & \multicolumn{2}{|c|}{ Obl. GSF $\angle^{f}$} & \multirow{2}{*}{$\begin{array}{c}R^{i} \\
-p \text { cut }\end{array}$} \\
\hline Field $^{a}$ & VUW $^{\mathrm{b}}$ & & & & Alpine Schist & Sheared veins & $\%$ Qtz & $\% \mathrm{Cal}$ & $\%$ Mica & GBM & SGR & GSF & $-p$ cut $^{g}$ & - st cut $^{\mathrm{h}}$ & \\
\hline TJFA56 & 39436 & $\mathrm{~B}$ & Internal & 200 & Qtz, Ms, Chl, Pl, Bt, Ttn & Qtz, Ms, Chl & 98 & 0 & 2 & 1 & 2 & 0 & - & - & - \\
\hline TJFA56 & - & A & External & 194 & - & Qtz, Ms, Chl & 98 & 0 & 2 & 3 & 1 & 1 & - & Fol & - \\
\hline MHBM01 & 39417 & - & Infilling & 75 & Qtz, Cal, Ms, Chl, Ttn, Ep, Pl, Bt, opaques & Qtz, Cal, Ms, Chl & 60 & 35 & 5 & 3 & 1 & 2 & - & 0 & - \\
\hline MHBM02 & 39418 & - & Infilling & 1015 & Qtz, Cal, Ms, Chl, Bt, Ep, PI, Ttn, opaques & Qtz, Cal, Ms, Chl & 70 & 28 & 2 & 3 & 3 & 2 & - & 38 & - \\
\hline MHBM03 & 39419 & B & Internal & - & Qtz, Cal, Ms, Chl, Pl, Bt, Ep, Ttn & Qtz, Cal, Ms & - & - & - & - & - & - & - & - & - \\
\hline MHBM03 & - & $\mathrm{C}$ & Internal & 157 & - & Qtz, Cal, Ms & 60 & 35 & 5 & 1 & 1 & 1 & - & 0 & - \\
\hline MHBM03 & - & D & Infilling & 149 & - & Qtz, Cal, Ms & 60 & 36 & 4 & 1 & 2 & 2 & - & 0 & - \\
\hline MHBM03 & - & A & External & 176 & - & Qtz, Cal, Ms & 90 & 8 & 2 & 1 & 1 & 2 & - & Fol & - \\
\hline MHBM04 & 39420 & B & Internal & 113 & Qtz, Cal, Ms, Bt, opaques, PI & Qtz, Cal, Ms & 98 & 1 & 1 & 0 & 1 & 0 & - & - & - \\
\hline MHBM04 & - & A & External & 138 & 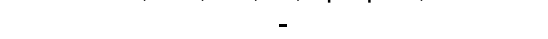 & Qtz, Cal, Ms & & - & - & 0 & 1 & 2 & - & Fol & - \\
\hline MHBM05 & 39421 & C & Internal & 130 & Cal, Qtz, Ms, Bt, Ttn, Ep, Pl & Qtz, Cal, Ms & 88 & 10 & 2 & 1 & 1 & 0 & - & - & - \\
\hline MHBM05 & - & B & External & - & - & Qtz, Cal, Ms & - & - & - & - & - & - & - & - & - \\
\hline MHBM05 & - & A & External & 156 & - & Qtz, Cal, Ms & 88 & 10 & 2 & 1 & 2 & 1 & - & Fol & - \\
\hline MHBM06 & 39422 & - & Infilling & 155 & Qtz, Cal, Ms, Bt, Pl, opaques & Qtz, Cal, Ms & 85 & 10 & 5 & 3 & 3 & 2 & 30 & 35 & 2.33 \\
\hline MHBM07 & 39423 & - & Infilling & 137 & - & Qtz, Cal, Ms & 97 & 2 & 1 & 2 & 2 & 2 & 22 & 30 & 1.85 \\
\hline MHBM08 & 39424 & - & Infilling & 1440 & - & Qtz, Cal, Ms & 60 & 35 & 5 & 2 & 2 & 1 & - & 0 & - \\
\hline MHBM09 & 39425 & B & Internal & 117 & Qtz, Ms, Cal, Bt, Ep, Ttn, Pl & Qtz, Cal, Ms & 99 & 1 & 0 & 1 & 1 & 1 & - & 0 & - \\
\hline MHBM09 & - & A & External & 160 & - & Qtz, Cal, Ms & 97 & 1 & 2 & 2 & 2 & 2 & - & Fol & - \\
\hline MHBM10 & 39426 & B & Internal & 166 & Qtz, Cal, Ms, Bt, Chl, Ep, Pl, Ttn & Qtz, Cal, Ms, Bt, Chl & 90 & 7 & 3 & 1 & 0 & 0 & - & - & - \\
\hline MHBM10 & - & A & External & 149 & - & Qtz, Cal, Ms, Bt, Chl & 95 & 4 & 1 & 3 & 3 & 2 & - & Fol & - \\
\hline MHBM10 & - & C & External & 149 & - & Qtz, Cal, Ms, Bt, Chl & - & - & - & 3 & 3 & 2 & - & Fol & - \\
\hline MHBM11 & 39427 & B & Internal & 173 & Bt, Chl, Ttn, Ep, PI, Qtz, Cal, Ms & Qtz, Cal, Ms & 90 & 8 & 2 & 2 & 1 & 0 & - & - & - \\
\hline MHBM11 & - & A & External & 170 & - & Qtz, Cal, Ms & 90 & 9 & 1 & 2 & 2 & 2 & - & Fol & - \\
\hline MHBM12 & 39428 & B & Internal & 60 & Qtz, Cal, Ms, Chl, Bt, Ep, Ttn, Pl & Qtz, Cal, Ms, Chl & 80 & 10 & 10 & 2 & 1 & 2 & - & 0 & - \\
\hline MHBM12 & - & c & Infilling & 82 & - & Qtz, Cal, Ms, Chl & 60 & 35 & 5 & 2 & 1 & 2 & - & 0 & - \\
\hline MHBM12 & - & A & External & 176 & - & Qtz, Cal, Ms, Chl & 70 & 28 & 2 & 1 & 1 & 2 & - & Fol & - \\
\hline MHBM13 & 39429 & B & Internal & 106 & Qtz, Cal, Ms, Bt, Ep, PI, Ttn, Chl & Qtz, Cal, Ms & 95 & 5 & 0 & 2 & 1 & 1 & - & 0 & - \\
\hline MHBM13 & - & A & External & 208 & - & Qtz, Cal, Ms & 95 & 3 & 2 & 2 & 2 & 0 & - & - & - \\
\hline MHBM13 & - & c & Internal & 109 & - & Qtz, Cal, Ms & 95 & 5 & 0 & 1 & 0 & 2 & - & 0 & - \\
\hline MHBM13 & - & $\mathrm{D}$ & External & 145 & - & Qtz, Cal, Ms & 95 & 3 & 2 & 2 & 1 & 0 & - & - & - \\
\hline MHBM14b & 39430 & A & Infilling & 1504 & - & Qtz, Cal, Ms, Chl & 70 & 26 & 4 & 2 & 1 & 2 & - & 0 & - \\
\hline MHBM14b & - & B & Infilling & 95 & - & Qtz, Cal, Ms, Chl & 70 & 26 & 4 & 1 & 2 & 1 & - & 0 & - \\
\hline
\end{tabular}




\section{Appendix D. Quartz CPO fabrics measured from sheared quartz-carbonate veins collected in the brittle-ductile shear zone (BDSZ).}

Crystallographic orientations of quartz c-axes have been measured using a universalstage microscope in various locations throughout individual shear zones. This appendix combines schematic illustrations of the sheared veins that have been sampled for this crystallographic research with the crystallographic preferred orientation (CPO) fabric plots and CPO patterns as well as fabric strength data. Sample locations can be found by cross-referencing the sample numbers with data in Appendix C. All structural orientations and the finite ductile shear strain for the deformation are listed with each sample in this appendix. Sixteen veins were sampled and are illustrated in Appendixes D-1 to D-16. Some of these figures have been reproduced in Figs. 5.6 and 6.2 although samples have been re-labelled in those figures. Field sample numbers are presented for each cartoon in these two figures and are able to be cross-referenced with this appendix.

Shear zone schematic illustrations include the sheared vein, the Alpine Schist host rock and shear infilling vein material where present. They are scale drawings of the actual samples collected and stored in the Victoria University of Wellington rock collection (see Appendix $\mathrm{C}$ for collection numbers). The drawings are made from rock surface cuts perpendicular to the shear zone and either parallel to the strike or the mineral fibre lineation measured on the shear plane (as noted on the cartoon). Each drawing is also labelled with the top side of the sample and the north or down-dip end of the section. The Alpine Schist foliation is drawn as an intersection lineation on the surface of the rock cut. Locations of crystallographic analyses are noted by letters in the location where the measurements were made (in an area of $\sim 10 \mathrm{~mm}^{2}$ ). Orientations of all the planes (and the $[\mathrm{x}]$ direction of the most highly deformed CPO fabric plots) are shown on a stereogram for each sample.

CPO fabric plots are shown in a rotated reference frame $(x-y-z)$. This reference frame and the rotation process are outlined in Chapter 5. CPO fabrics are presented in both scatter pole figures and contour plots of pole density with the Alpine Schist annotated onto samples external to the ductile shear deformation. CPO patterns (see Chapter 5) are plotted onto scatter plots to illustrate the inferred skeletal outlines. All CPO fabric plots are on equal area, lower hemisphere, stereographic projections.

Data for each of the CPO fabric is listed in a table which includes: the orientation of the shear plane (x-y plane) in the plot, the pitch of $[\mathrm{x}]$ from the southwest and eigenvector ratios. 

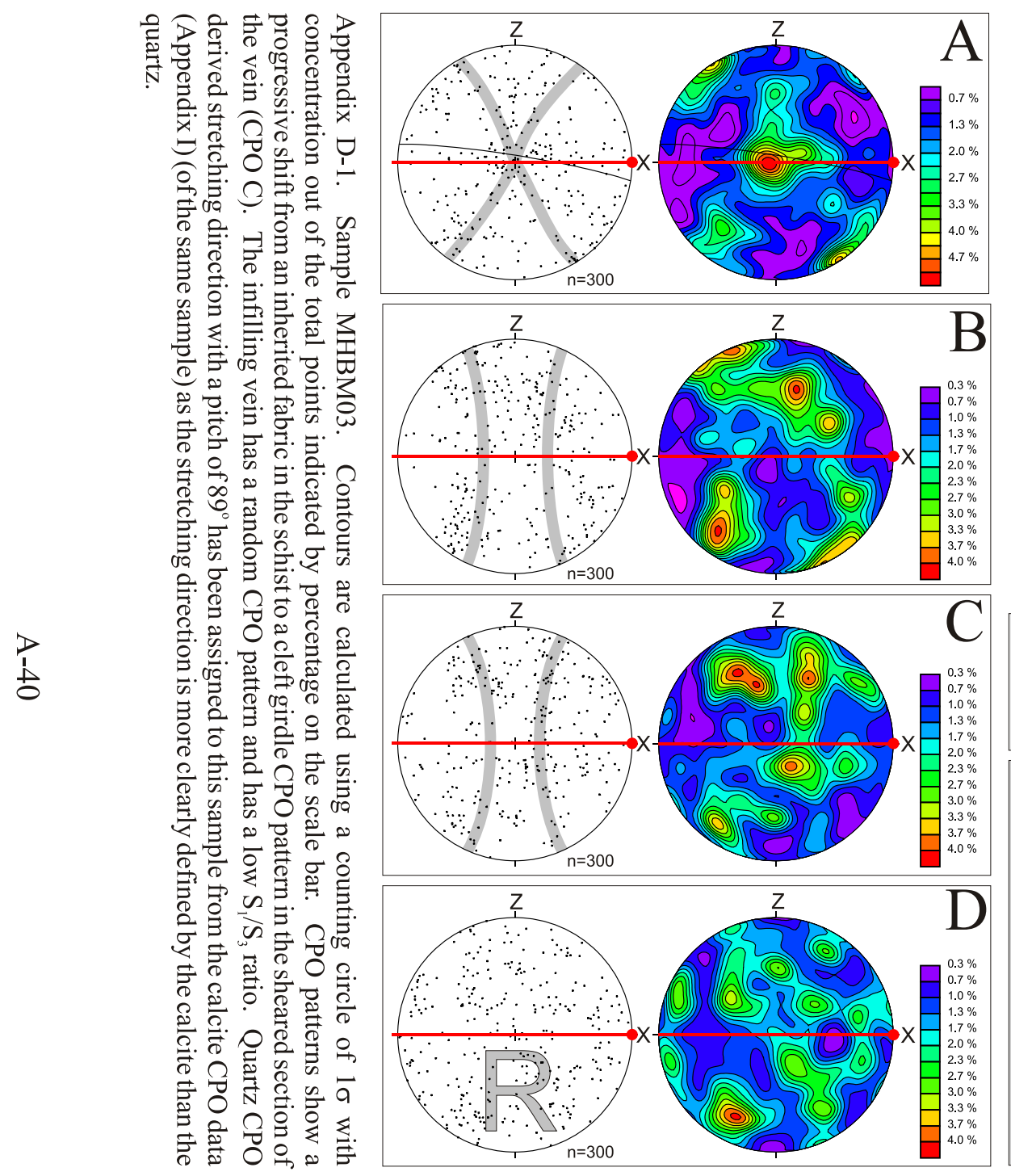

c-axis CPO

A

B

C

D

X-Y Plane

048@78E

048@78E

048@78E

048@78E

$\mathrm{X}$ (Pitch from $\mathrm{S}$ )

$55^{\circ}$
1.56

$68^{\circ}$
1.51

$80^{\circ}$

$90^{\circ}$

$\mathrm{S} 1 / \mathrm{S} 2$

1.22

1.26

1.60

1.09

$\mathrm{S} 2 / \mathrm{S} 3$

1.28

1.20

1.25

1.02

Finite ductile shear strain Shear plane (S)

Vein orientation (V)

Alpine foliation (F)

$>6.3$

Thin section plane $(\mathrm{T})$

048@78 SE

020@76 SE

038@83 SE

228@12 NW

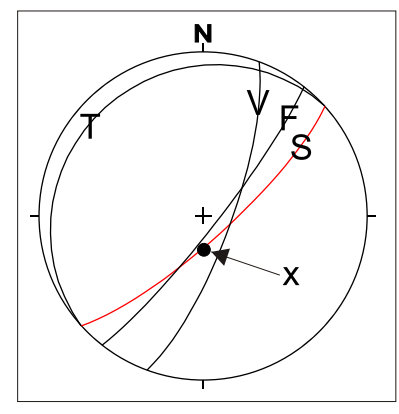

\section{\begin{tabular}{|l|}
\hline Brittle fracture \\
Shear Infilling Vein \\
Sheared Vein
\end{tabular} \\ Alpine Schist}

Sample cut parallel to strike and perpendicular to the shear plane

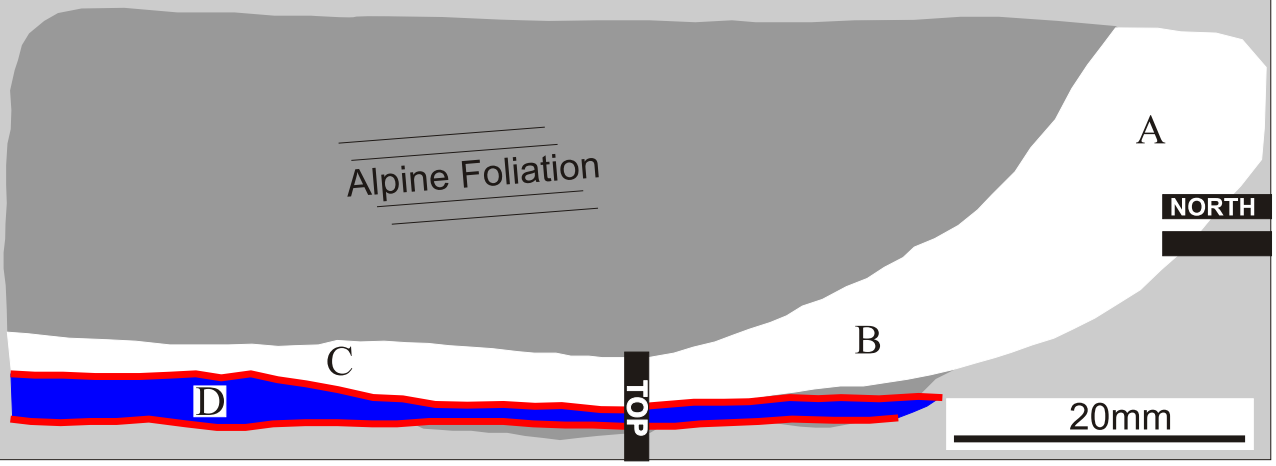



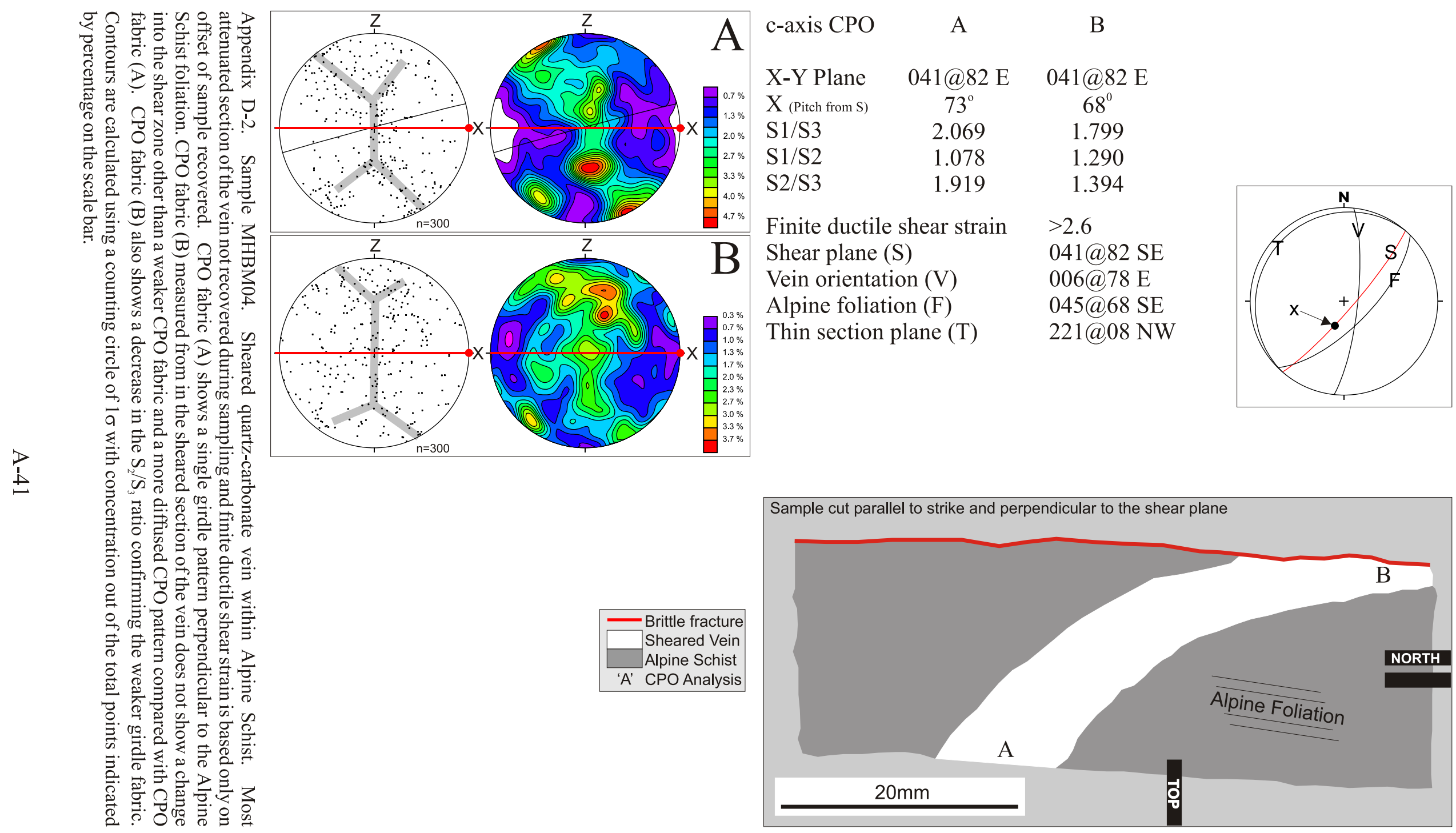


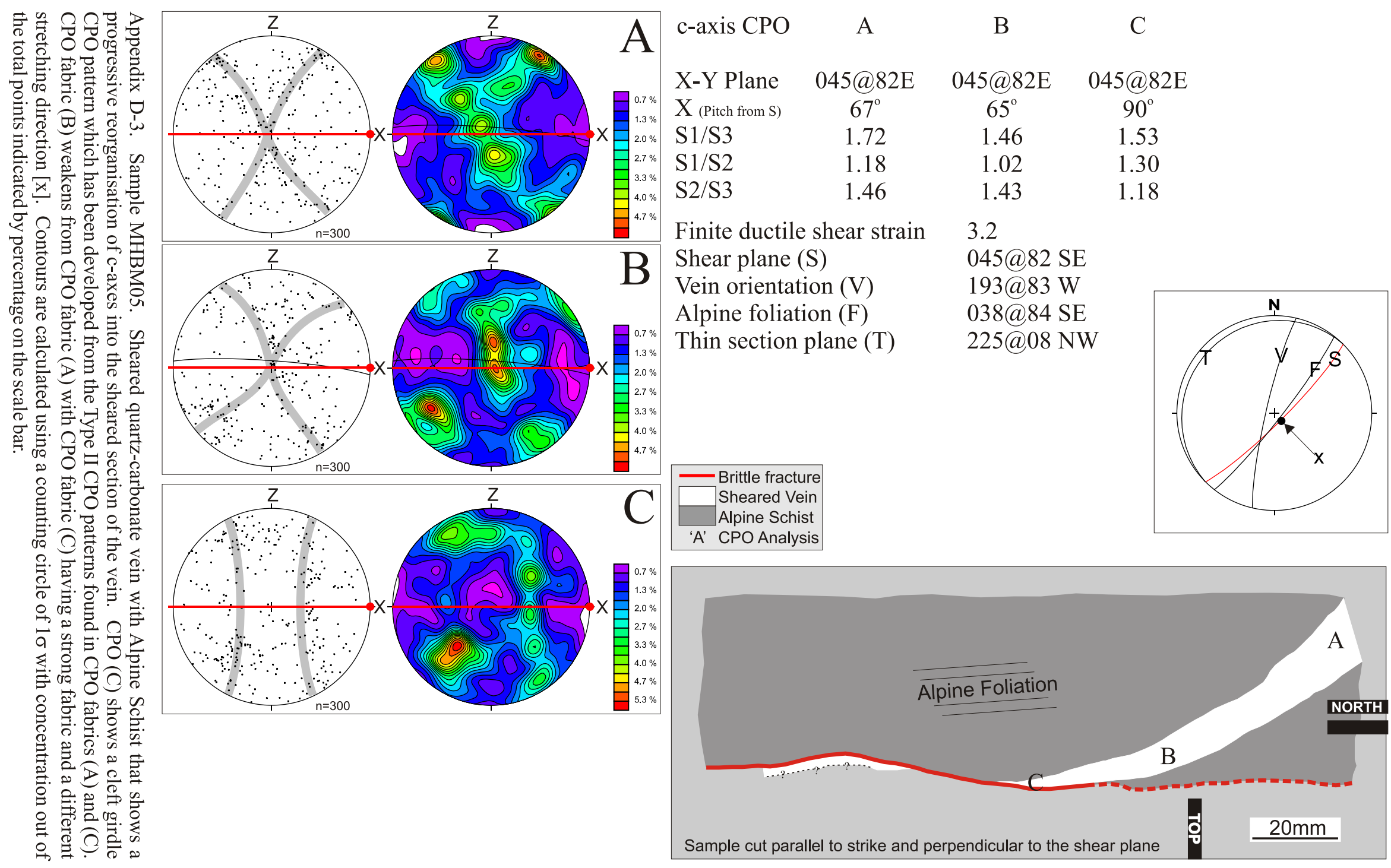



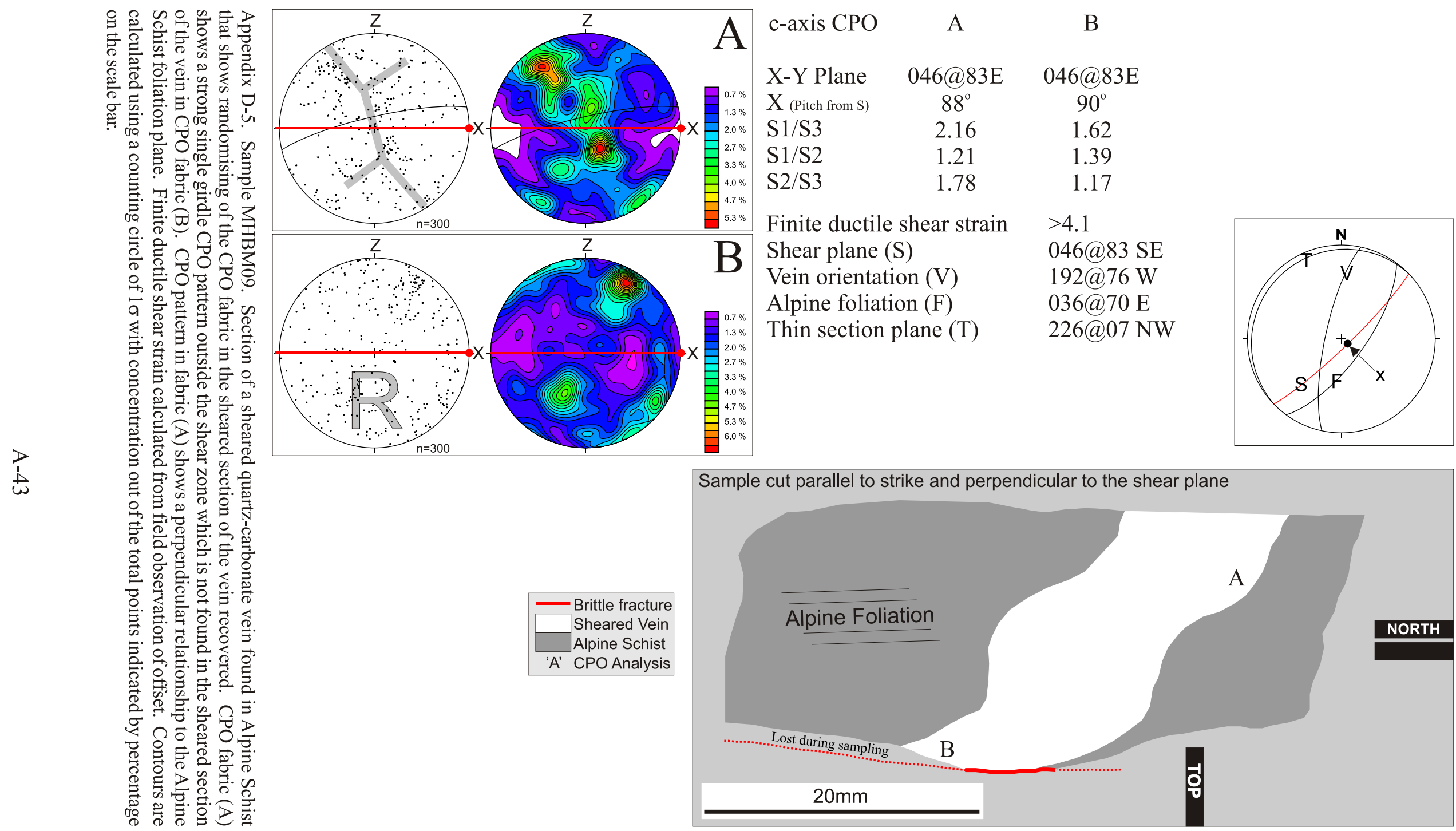

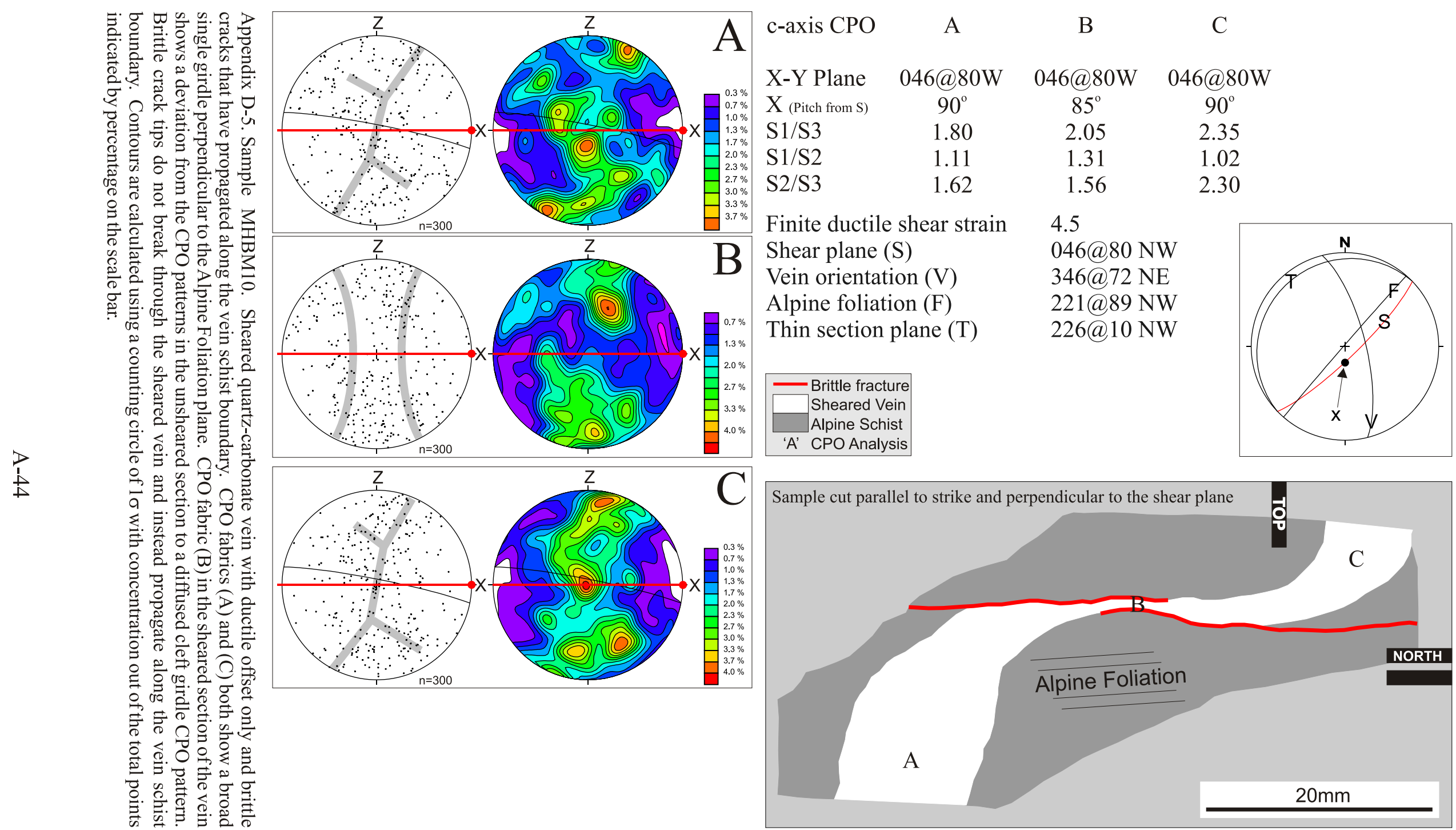


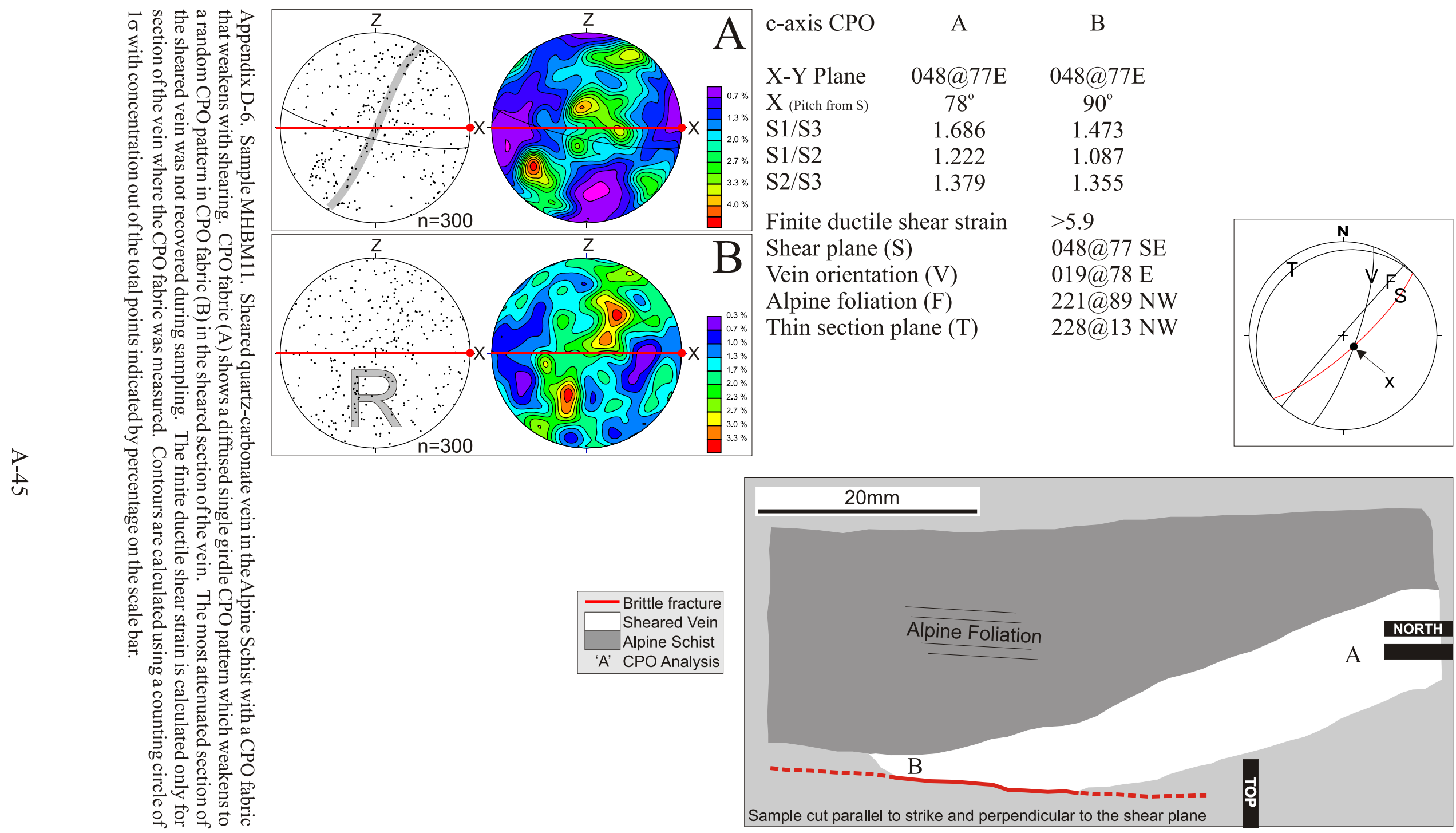




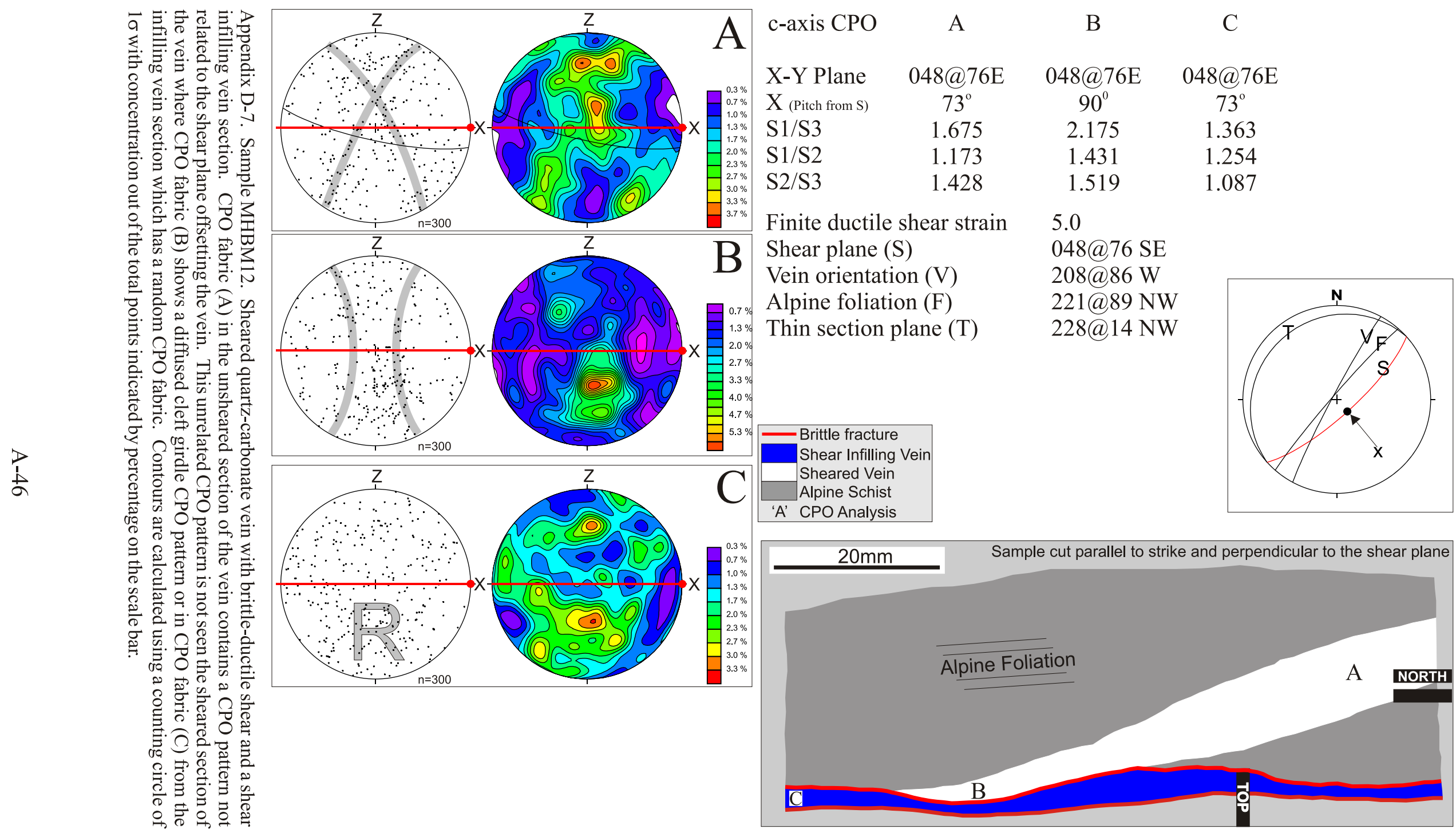



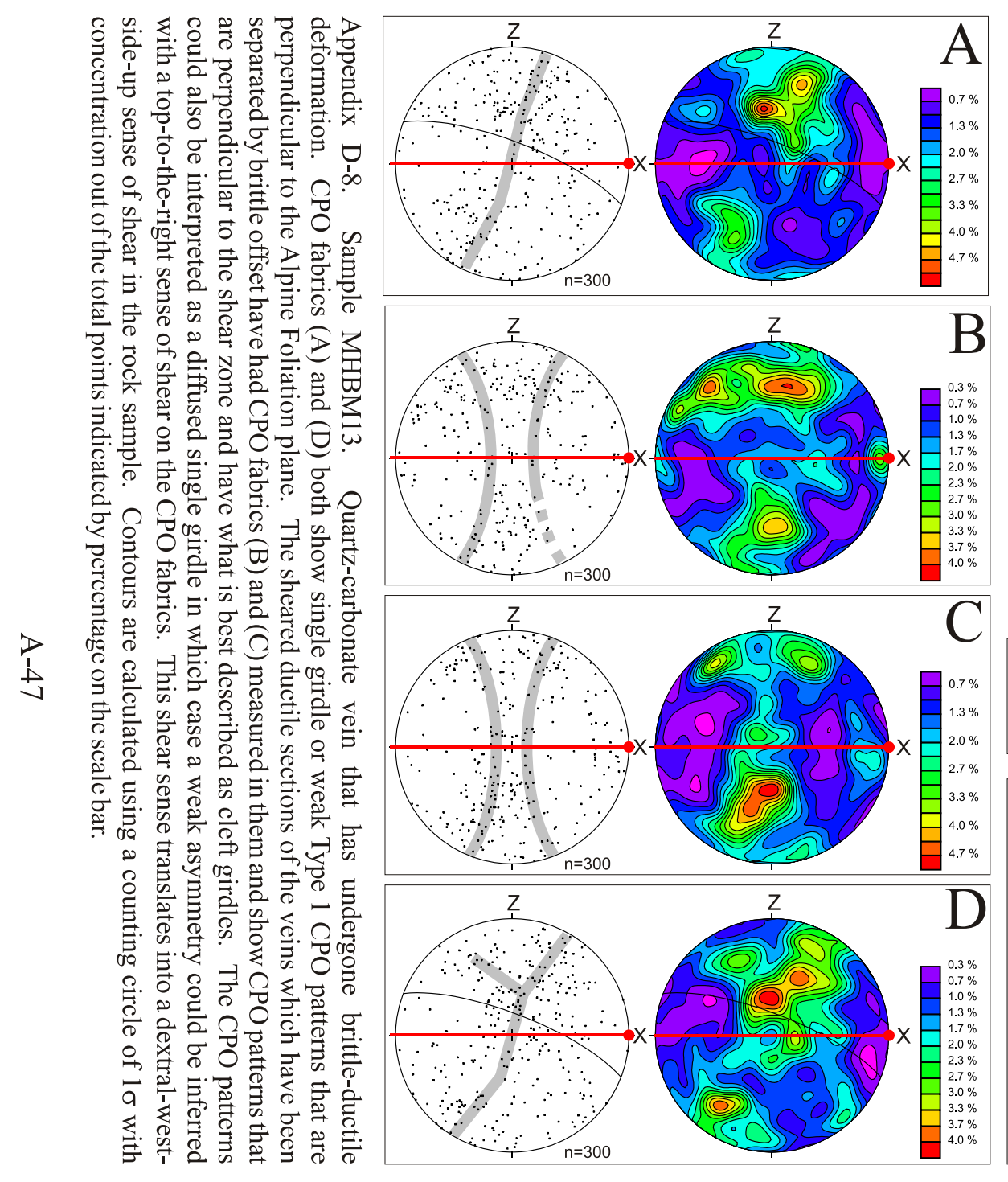

c-axis $\mathrm{CPO}$

A

B

C

D

$\begin{array}{lcccc}\text { X-Y Plane } & 056 @ 80 \mathrm{E} & 056 @ 80 \mathrm{E} & 056 @ 80 \mathrm{E} & 056 @ 80 \mathrm{E} \\ \mathrm{X} \text { (Pitch from S) } & 73^{\circ} & 80^{\circ} & 86^{\circ} & 68^{\circ} \\ \text { S1/S3 } & 2.12 & 1.66 & 2.03 & 2.08 \\ \mathrm{~S} 1 / \mathrm{S} 2 & 1.44 & 1.35 & 1.34 & 1.32 \\ \text { S2 } 33 & 1.47 & 1.23 & 1.51 & 1.57\end{array}$

Finite ductile shear strain $\quad 3.1$

Shear plane (S)

Vein orientation $(\mathrm{V})$

Alpine foliation $(\mathrm{F})$

056@80 SE

014@80 E

215@84 NW

Thin section plane $(\mathrm{T})$

236@10NW

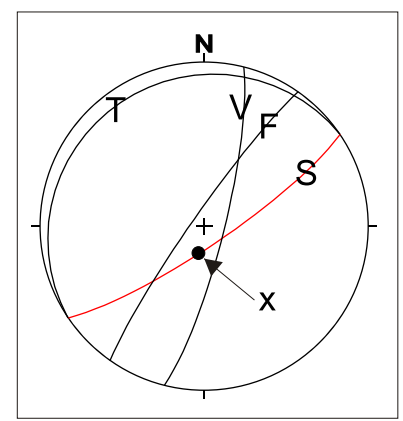

\section{Brittle fracture \\ Sheared Vein \\ CPO Analysis}

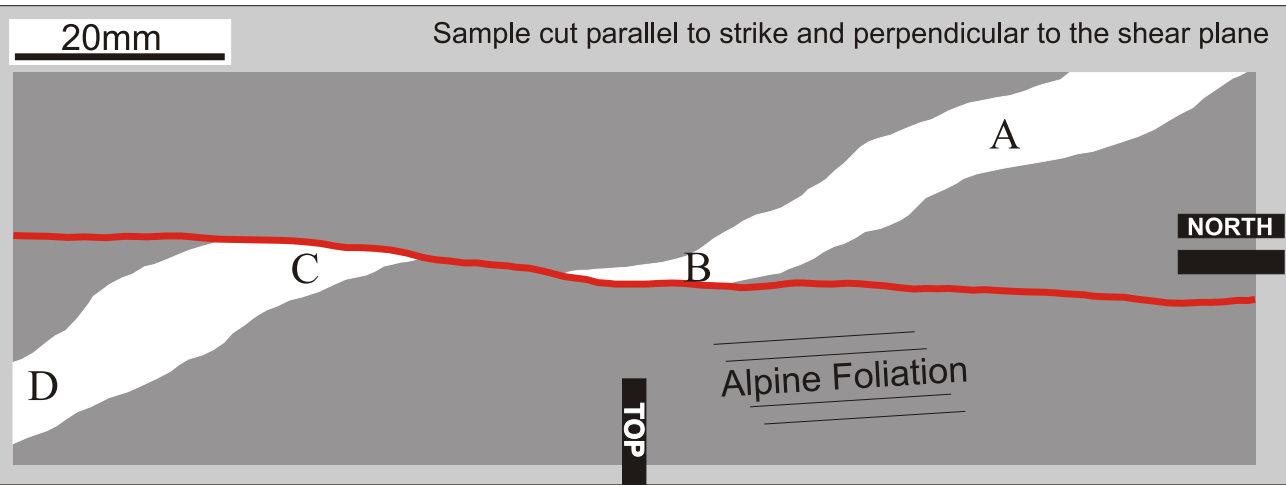




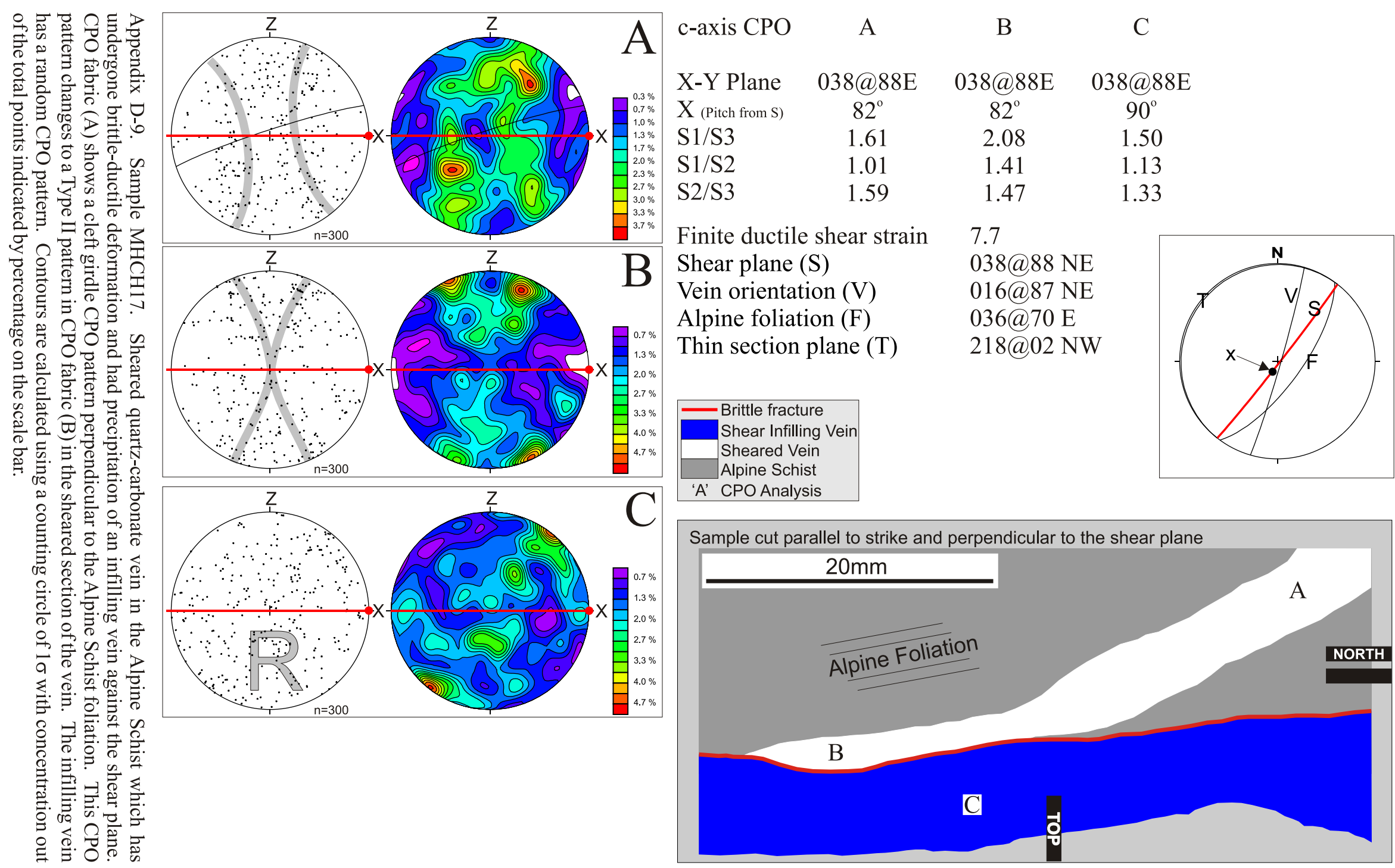



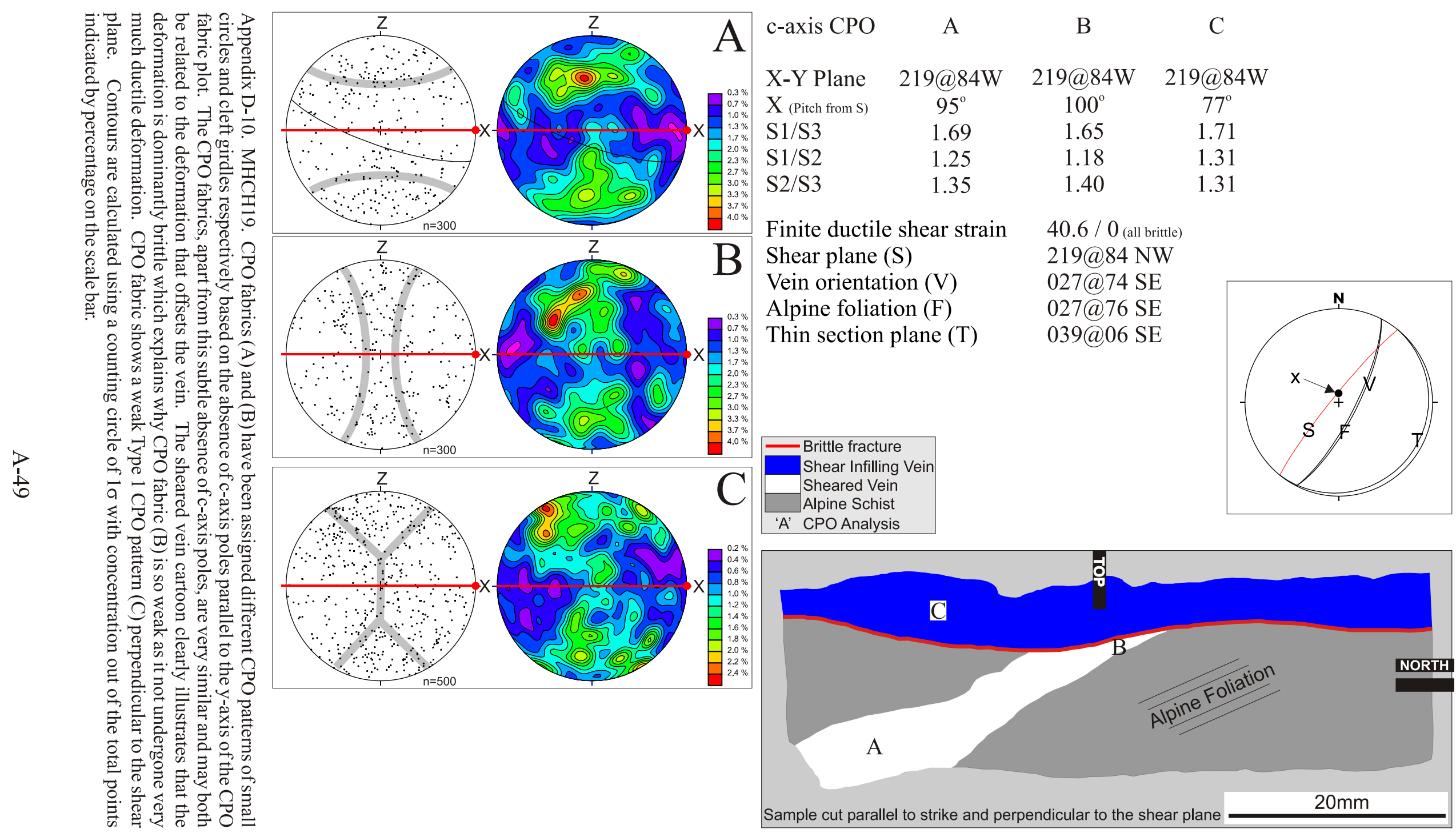

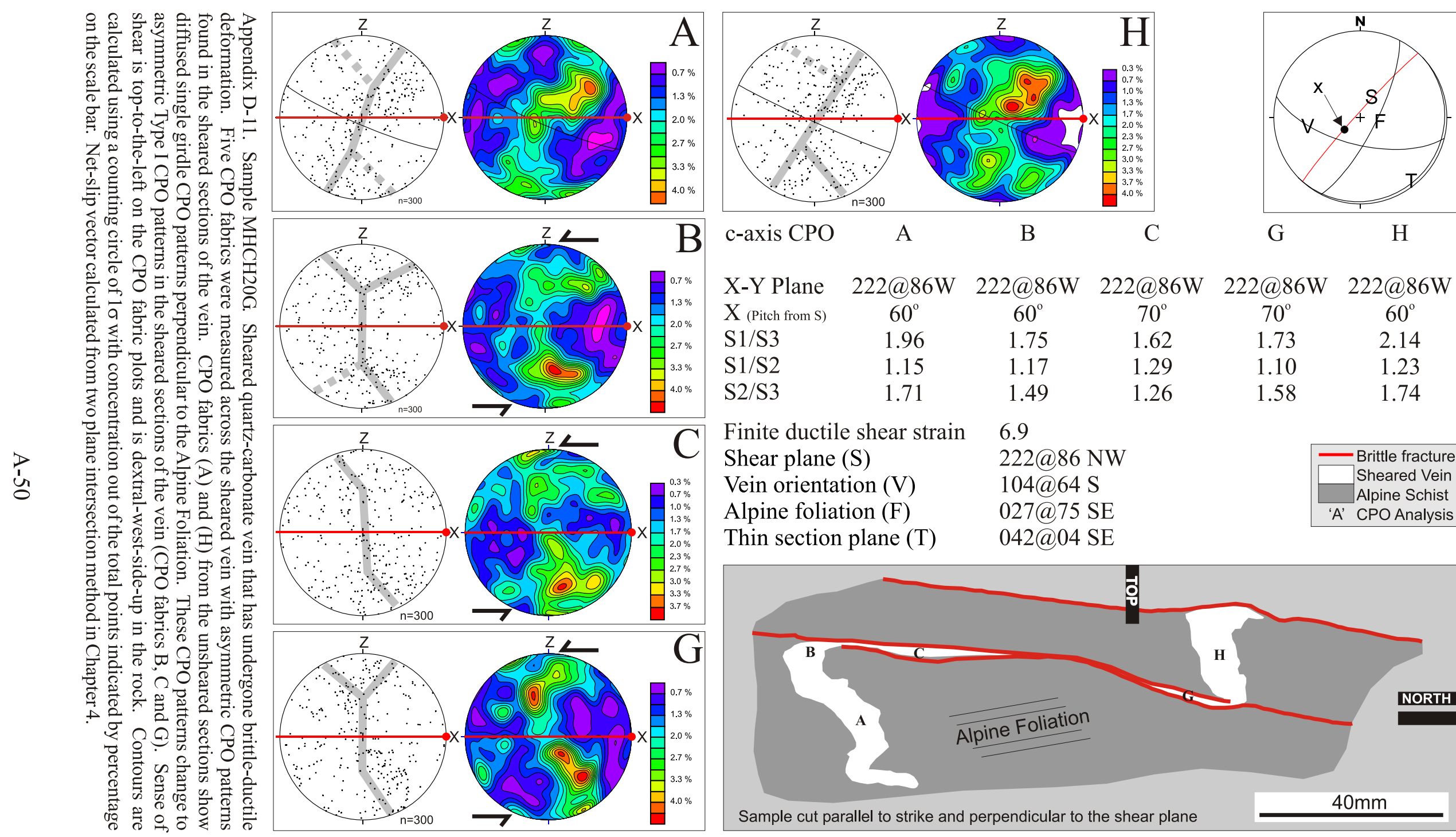

$\mathrm{X}-\mathrm{Y}$ Plane

$222 @ 86 \mathrm{~W}$

222@86W

$222 @ 86 \mathrm{~W}$

222@86W222@86W

$\begin{array}{llllll}\mathrm{X} \text { (Pitch from } \mathrm{S}) & 60^{\circ} & 60^{\circ} & 70^{\circ} & 70^{\circ} & 60^{\circ}\end{array}$

$\mathrm{S} 1 / \mathrm{S} 3$

1.96

1.75

1.62

1.29

1.73

2.14

$\mathrm{S} 1 / \mathrm{S} 2$

1.71

1.49

1.26

1.10

1.23

Finite ductile shear strain $\quad 6.9$

Shear plane (S)

Vein orientation $(\mathrm{V})$

222@86 NW

Alpine foliation (F)

104@64 S

027@75 SE

Thin section plane $(\mathrm{T})$

042@04 SE

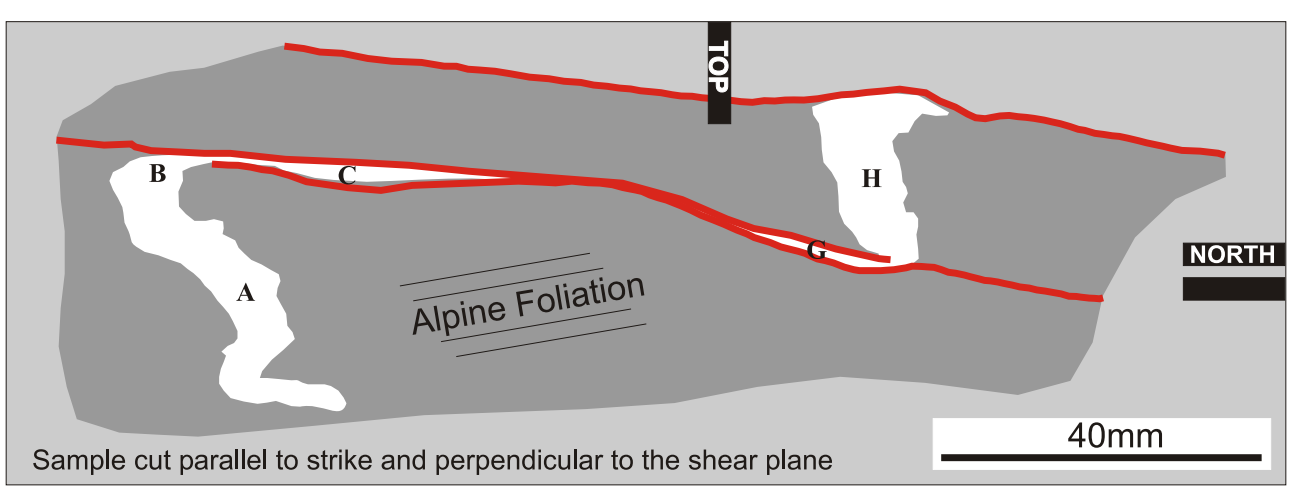




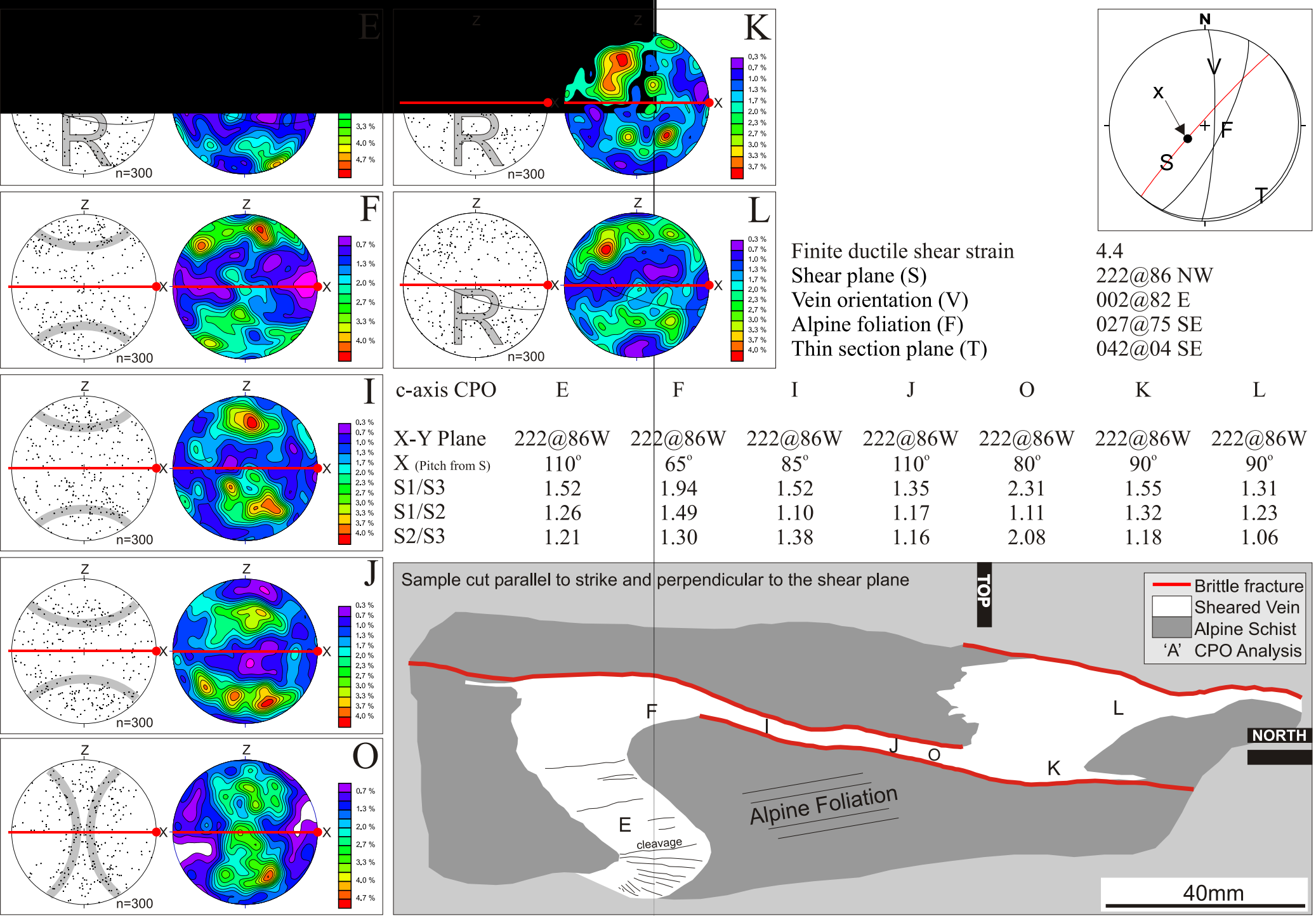



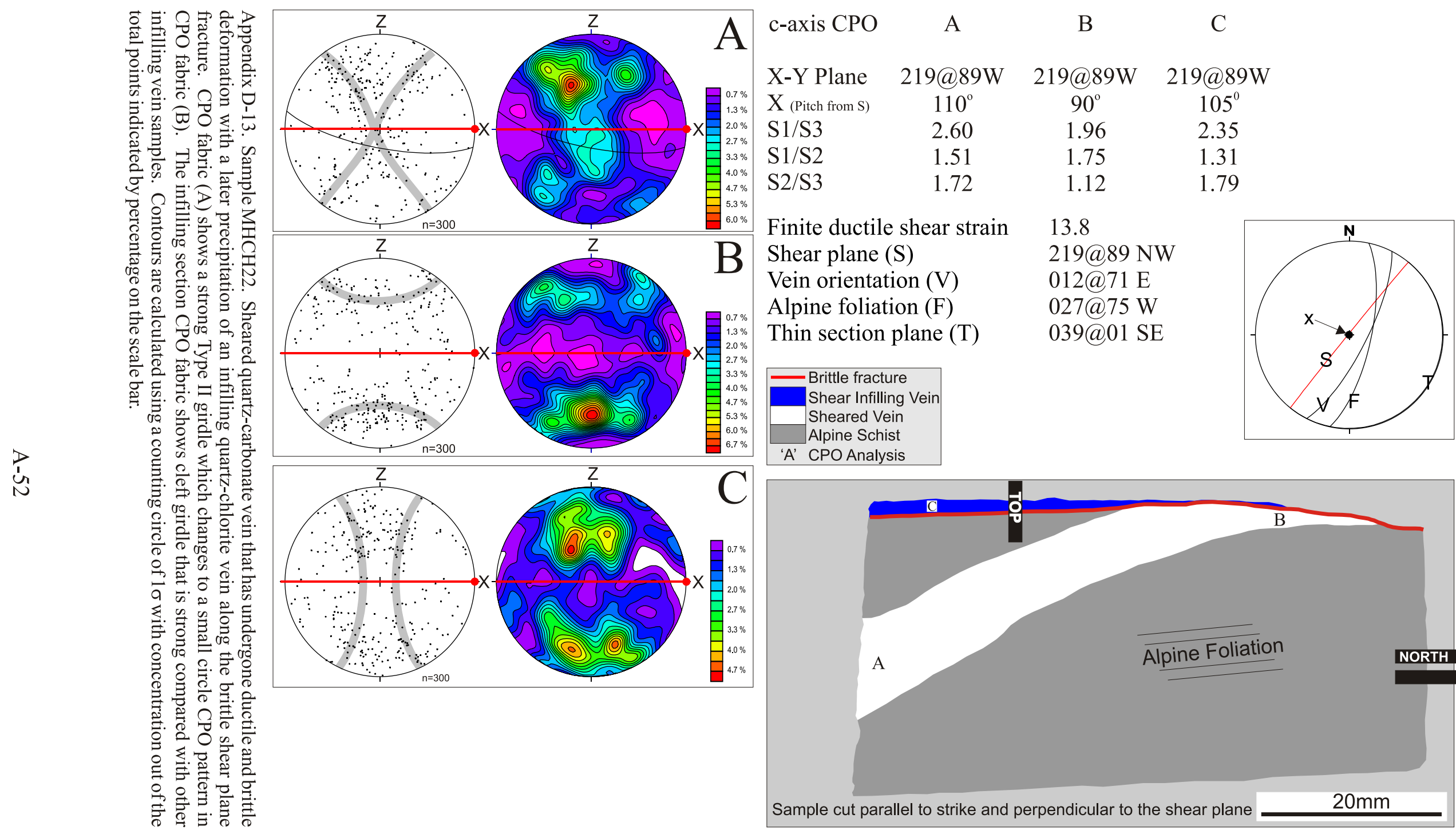

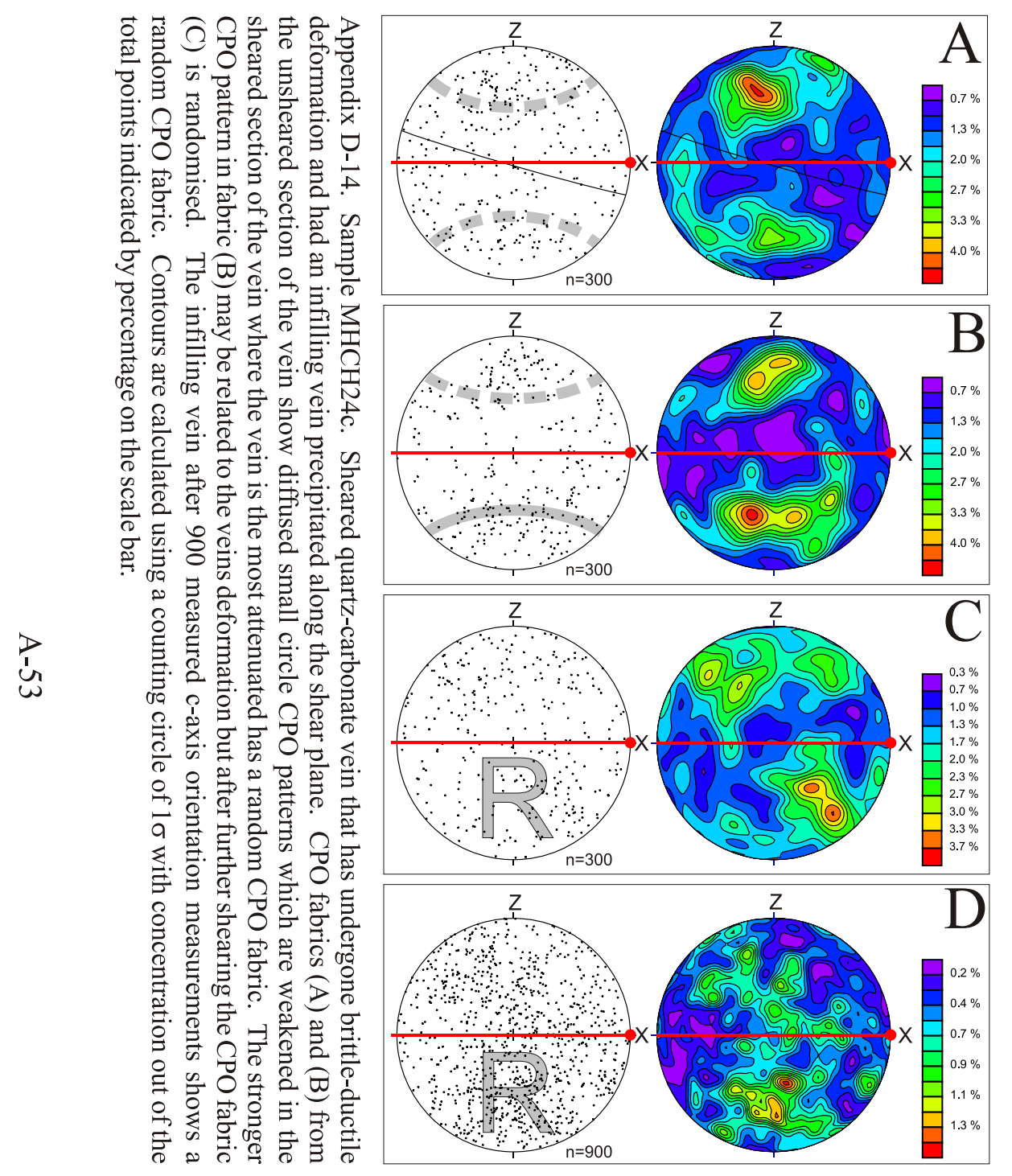

c-axis CPO

A

B

C

D

\section{X-Y Plane}

218@82W

$\mathrm{X}$ (Pitch from S)

$\mathrm{S} 1 / \mathrm{S} 3$

$85^{\circ}$

1.52

$\mathrm{S} 1 / \mathrm{S} 2$

1.20

$\mathrm{S} 2 / \mathrm{S} 3$

1.27

218@82W

$70^{\circ}$

218@82W

$90^{\circ}$

1.44

1.23

1.40

1.17

1.23
1.17

$90^{\circ}$

Finite ductile shear strain

6.8

Shear plane (S)

Vein orientation (V)

Alpine foliation (F)

218@82 NW

020@76E

Thin section plane (T)

035@82 SE

038@08 SE

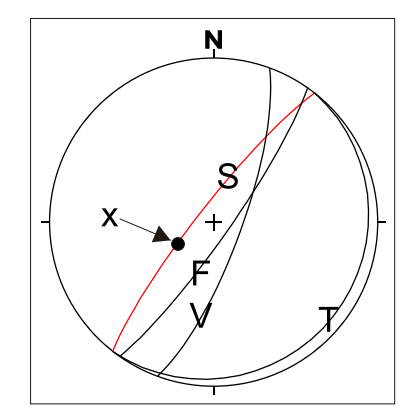

Shear Infilling Vein

Sheared Vein

Alpine Schist

A' CPO Analysis

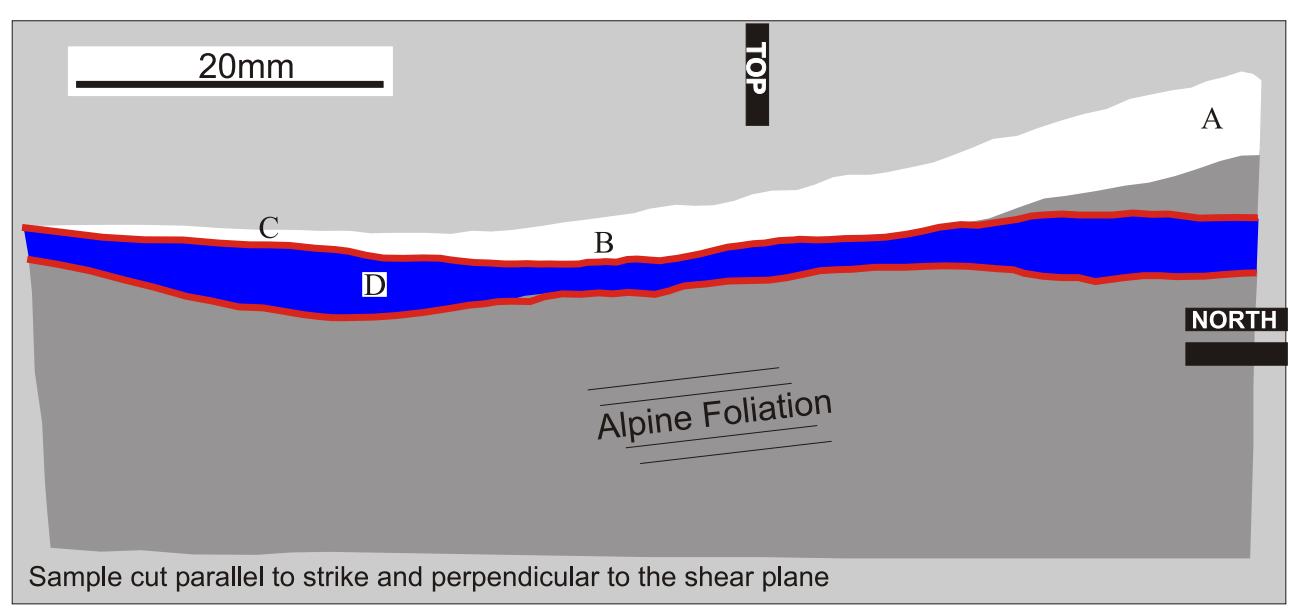




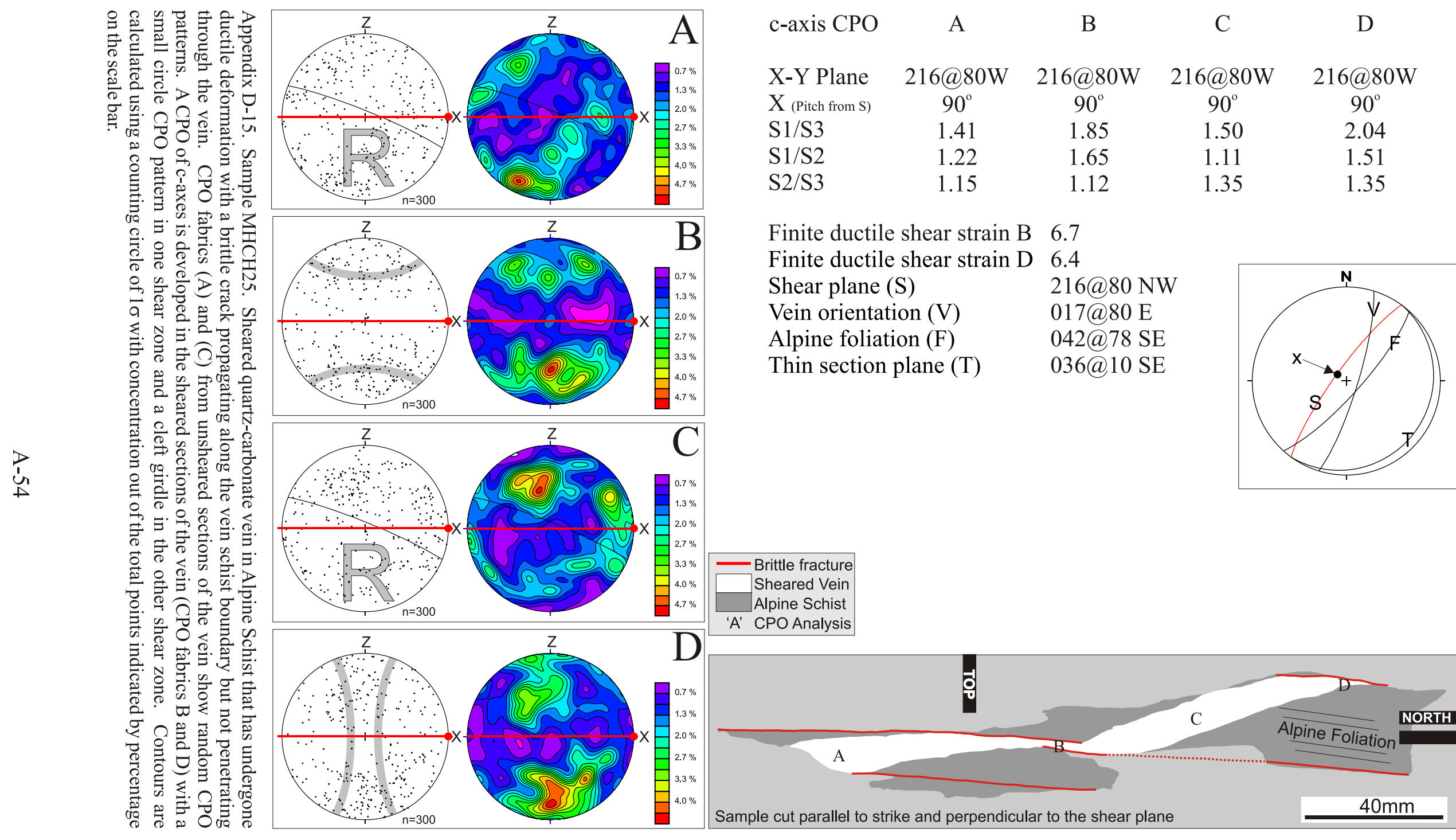



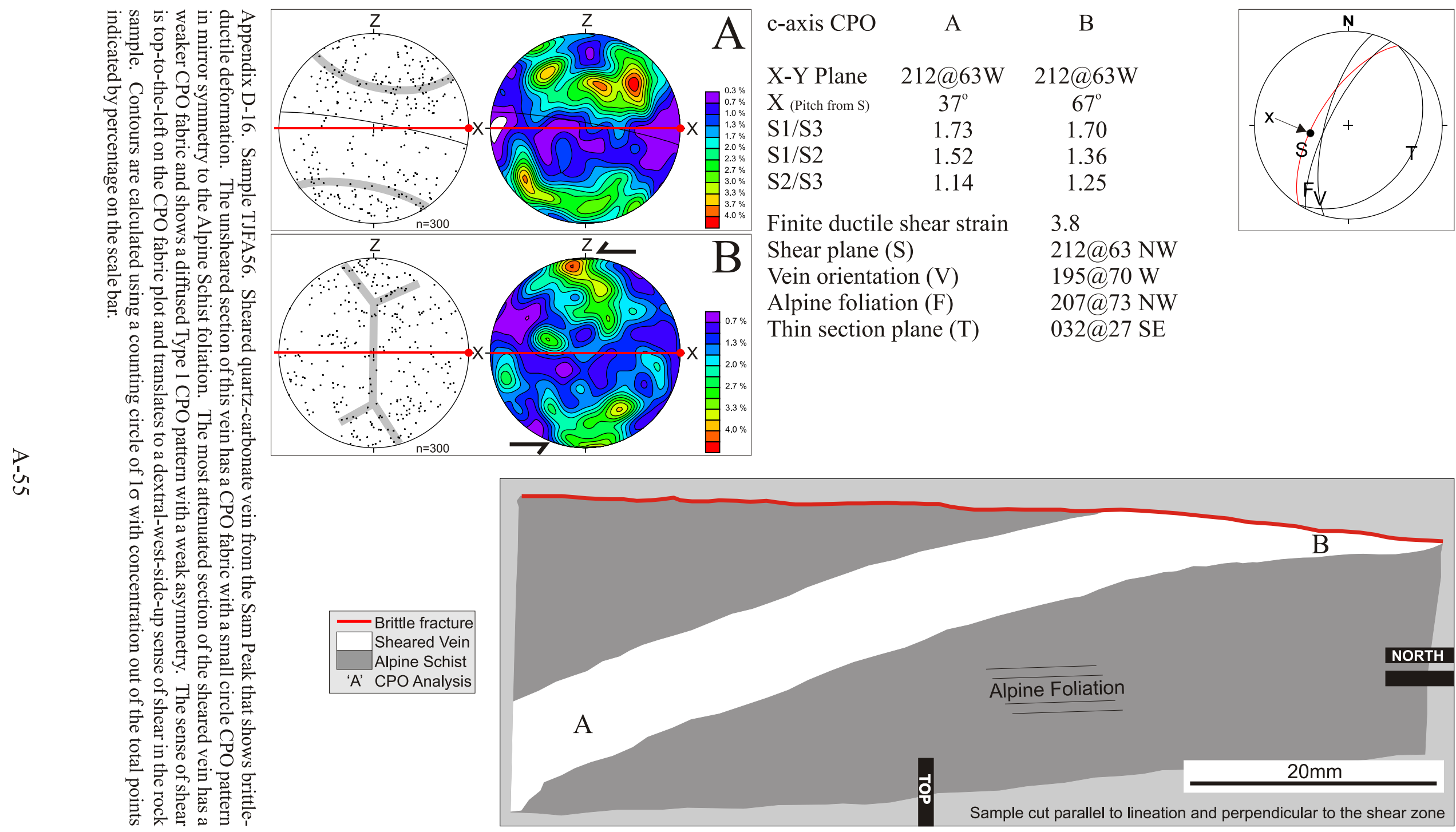

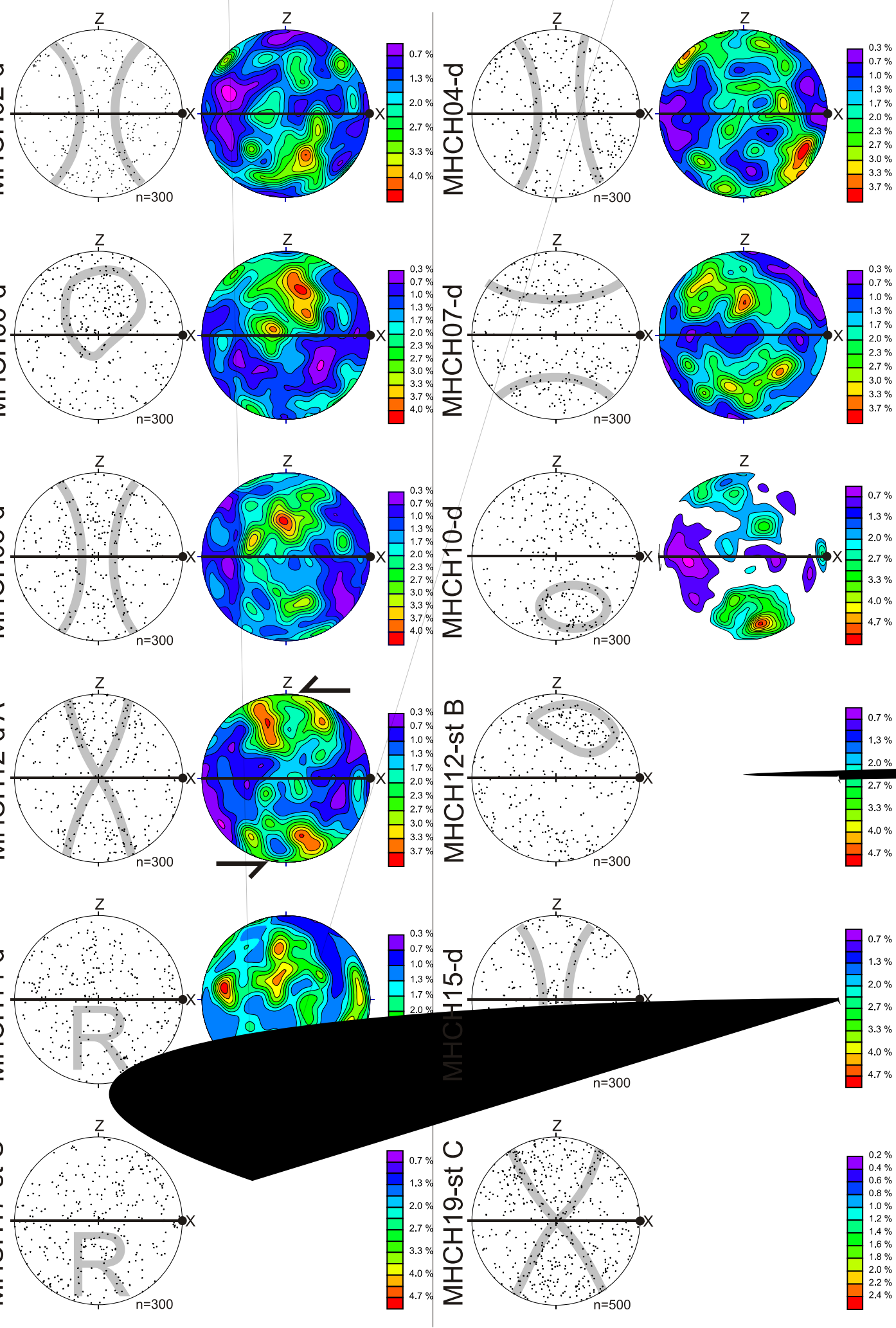

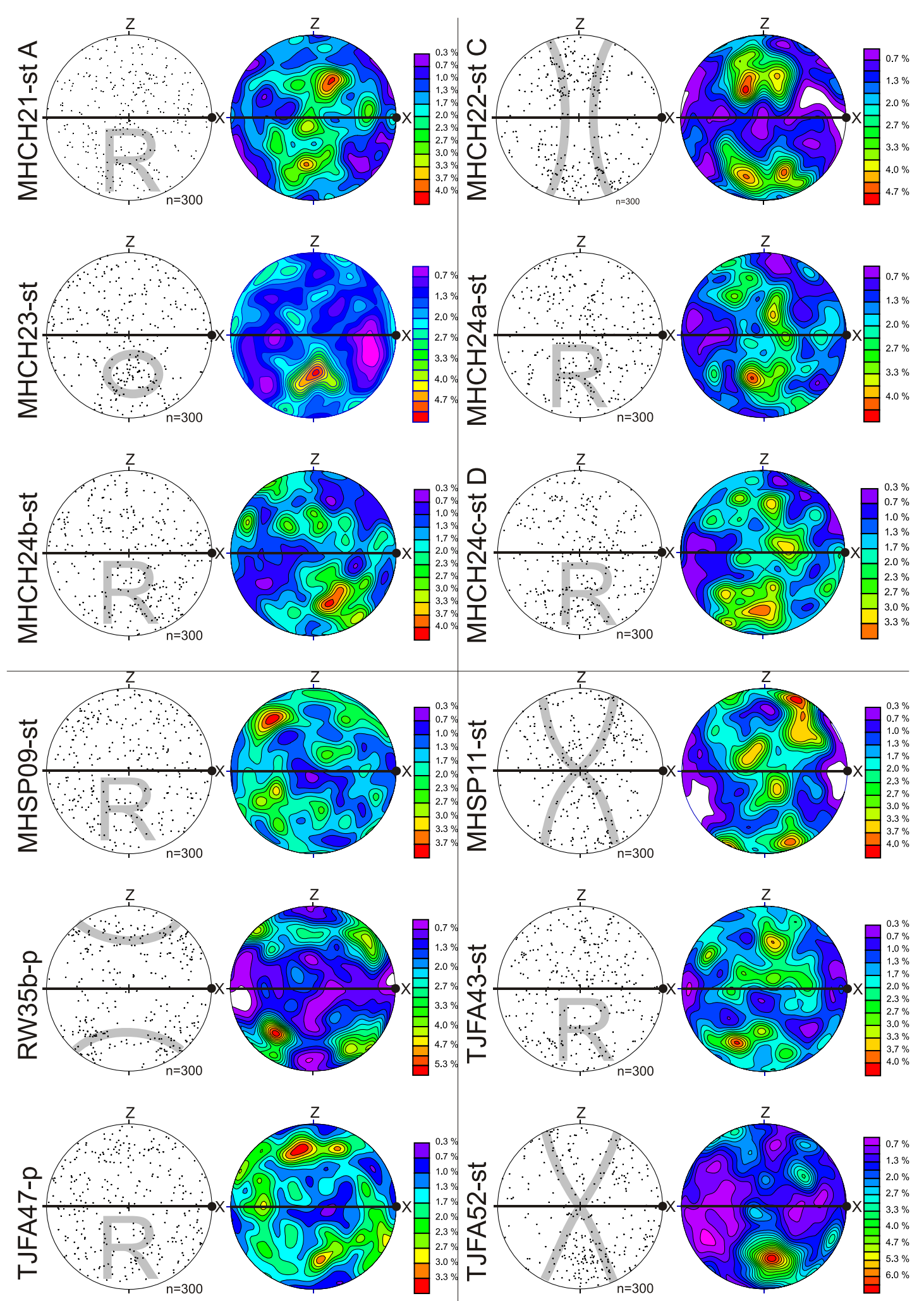

Appendix E-2. Crystallographic preferred orientations of quartz c-axes in the shear infilling vein samples on Chancellor Ridge and Sam Peak (6 fabric plots below horizontal division). Scatter and contour plots are on equal area, lower hemisphere, stereographic projections in the $x-y-z$ reference frame (see Chapter 5). Contours were calculated using a $1 \sigma$ counting circle and are plotted as lines of equal point concentration. Eigenvector ratios and fabric plot orientations can be found in Appendix H. CPO fabric plots are labelled by their field sample numbers and annotated with the thin-section orientation they were measured from (e.g. -st or -d; see Chapter 4). A second annotation to the sample number (e.g. A, B. C etc.) is the location of the sample in the sheared vein schematic illustrations in Appendix D. Where identified, internal asymmetries are illustrated on fabrics and the Alpine Schist folitation plane is plotted on fabrics external to the most deformed part of the vein. 


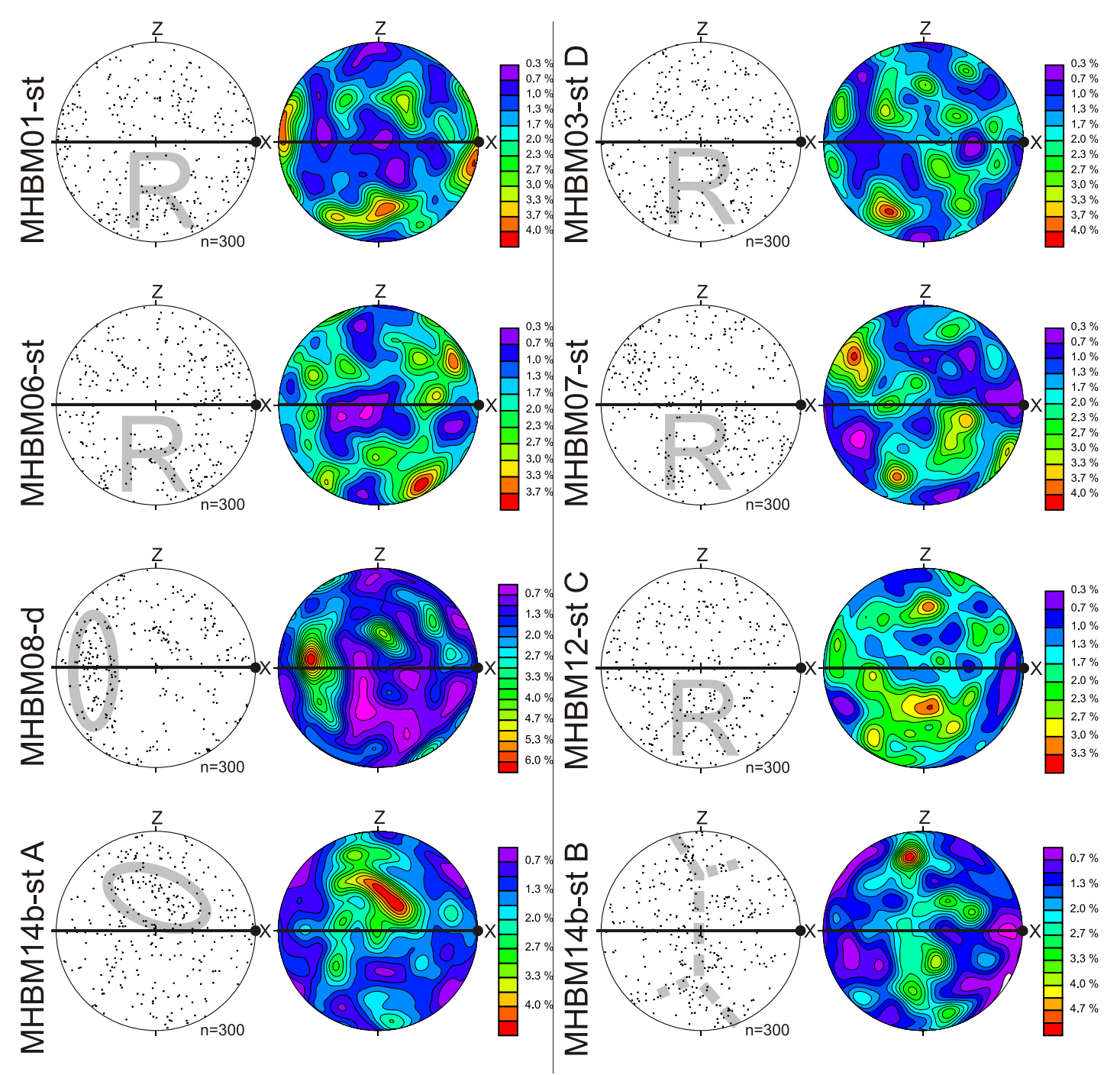

Appendix E-3. Crystallographic preferred orientations of quartz c-axes in the shear infilling vein samples at Baumann Glacier. Scatter and contour plots are on equal area, lower hemisphere, stereographic projections in the $x-y-z$ reference frame (see Chapter 5). Contours were calculated using a $1 \sigma$ counting circle and are plotted as lines of equal point concentration. Eigenvector ratios and fabric plot orientations can be found in Appendix H. CPO fabric plots are labelled by their field sample numbers and annotated with the thin-section orientation they were measured from (e.g. -st or -d; see Chapter 4). A second annotation to the sample number (e.g. A, B. C etc.) is the location of the sample in the sheared vein schematic illustrations in Appendix D. Where identified, internal asymmetries are illustrated on fabrics and the Alpine Schist folitation plane is plotted on fabrics external to the most deformed part of the vein. 

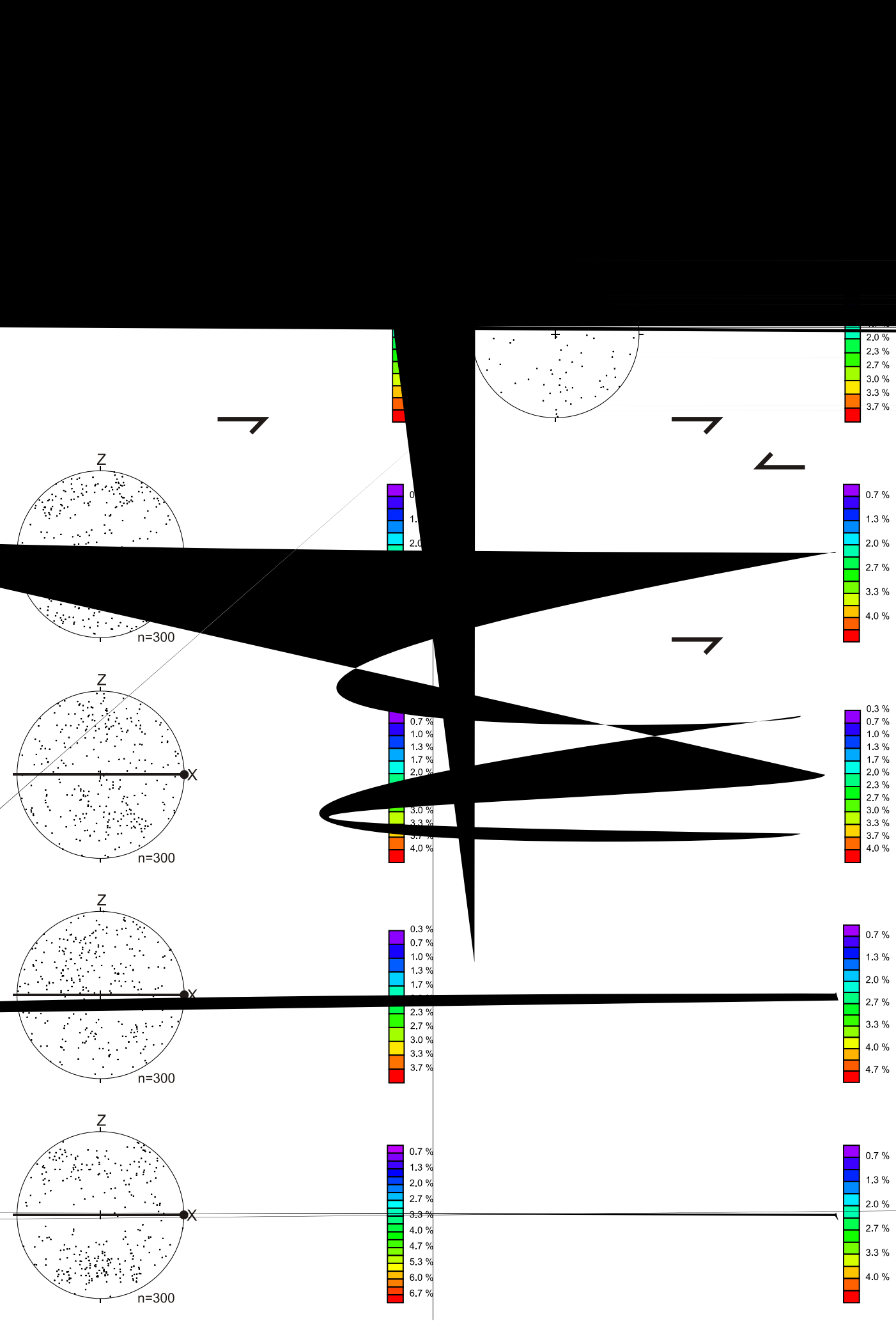

Appendix E-4. Crystallographic preferred orientations of quartz c-axes from the highly deformed internal sections of the sheared veins on Chancellor Ridge. Scatter and contour plots are on equal area, lower hemisphere, stereographic projections in the $\mathrm{x}-\mathrm{y}-\mathrm{z}$ reference frame (see Chapter 5). Contours were calculated using a $1 \sigma$ counting circle and are plotted as lines of equal point concentration. Eigenvector ratios and fabric plot orientations can be found in Appendix H. CPO fabric plots are labelled by their field sample numbers and annotated with the thin-section orientation they were measured from (e.g. -st or -d; see Chapter 4). A second annotation to the sample number (e.g. A, B. C etc.) is the location of the sample in the sheared vein schematic illustrations in Appendix D. Where identified, internal asymmetries are illustrated on fabrics and the Alpine Schist folitation plane is plotted on fabrics external to the most deformed part of the vein. 

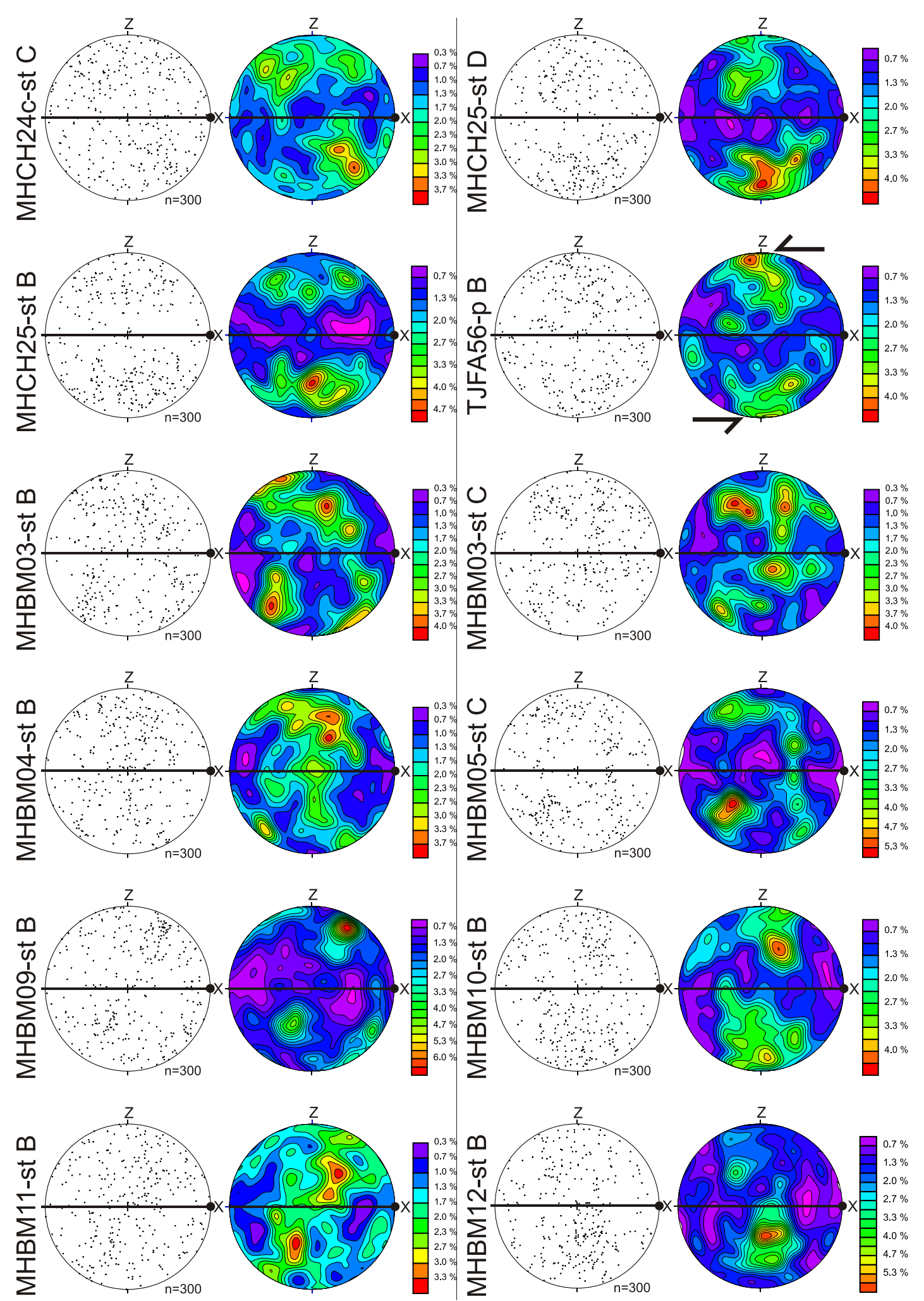

Appendix E-5. Crystallographic preferred orientations of quartz c-axes from the highly deformed internal sections of the sheared veins on Chancellor Ridge, Sam Peak and at Baumann Glacier. Scatter and contour plots are on equal area, lower hemisphere, stereographic projections in the $x-y-z$ reference frame (see Chapter 5). Contours were calculated using a $1 \sigma$ counting circle and are plotted as lines of equal point concentration. Eigenvector ratios and fabric plot orientations can be found in Appendix $\mathrm{H}$. CPO fabric plots are labelled by their field sample numbers and annotated with the thin-section orientation they were measured from (e.g. -st or -d; see Chapter 4). A second annotation to the sample number (e.g. A, B. C etc.) is the location of the sample in the sheared vein schematic illustrations in Appendix D. Where identified, internal asymmetries are illustrated on fabrics and the Alpine Schist folitation plane is plotted on fabrics external to the most deformed part of the vein. 


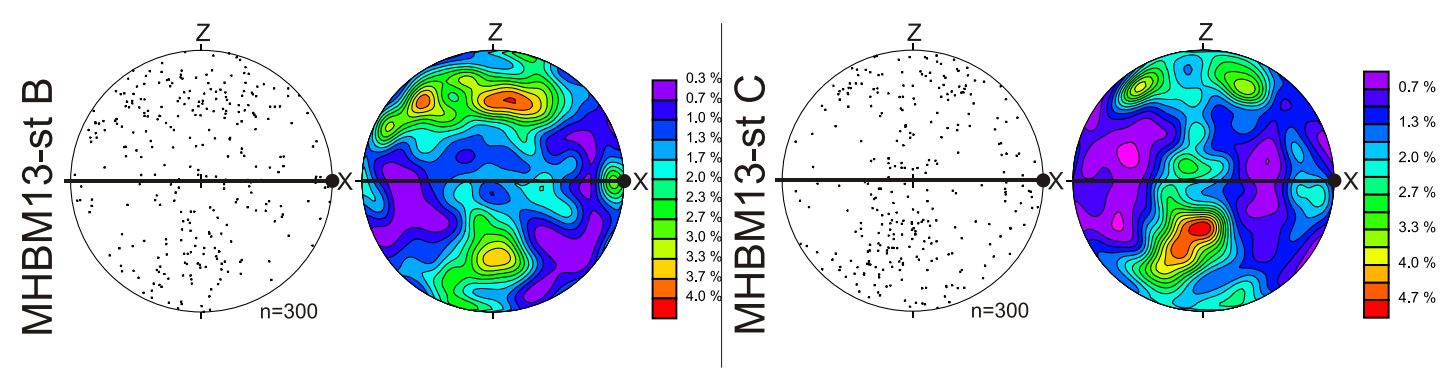

Appendix E-6. Crystallographic preferred orientations of quartz c-axes from the highly deformed internal sections of the sheared veins at Baumann Glacier. Scatter and contour plots are on equal area, lower hemisphere, stereographic projections in the $\mathrm{x}-\mathrm{y}-\mathrm{z}$ reference frame (see Chapter 5). Contours were calculated using a $1 \sigma$ counting circle and are plotted as lines of equal point concentration. Eigenvector ratios and fabric plot orientations can be found in Appendix H. CPO fabric plots are labelled by their field sample numbers and annotated with the thin-section orientation they were measured from (e.g. -st or -d; see Chapter 4). A second annotation to the sample number (e.g. A, B. C etc.) is the location of the sample in the sheared vein schematic illustrations in Appendix D. Where identified, internal asymmetries are illustrated on fabrics and the Alpine Schist folitation plane is plotted on fabrics external to the most deformed part of the vein.

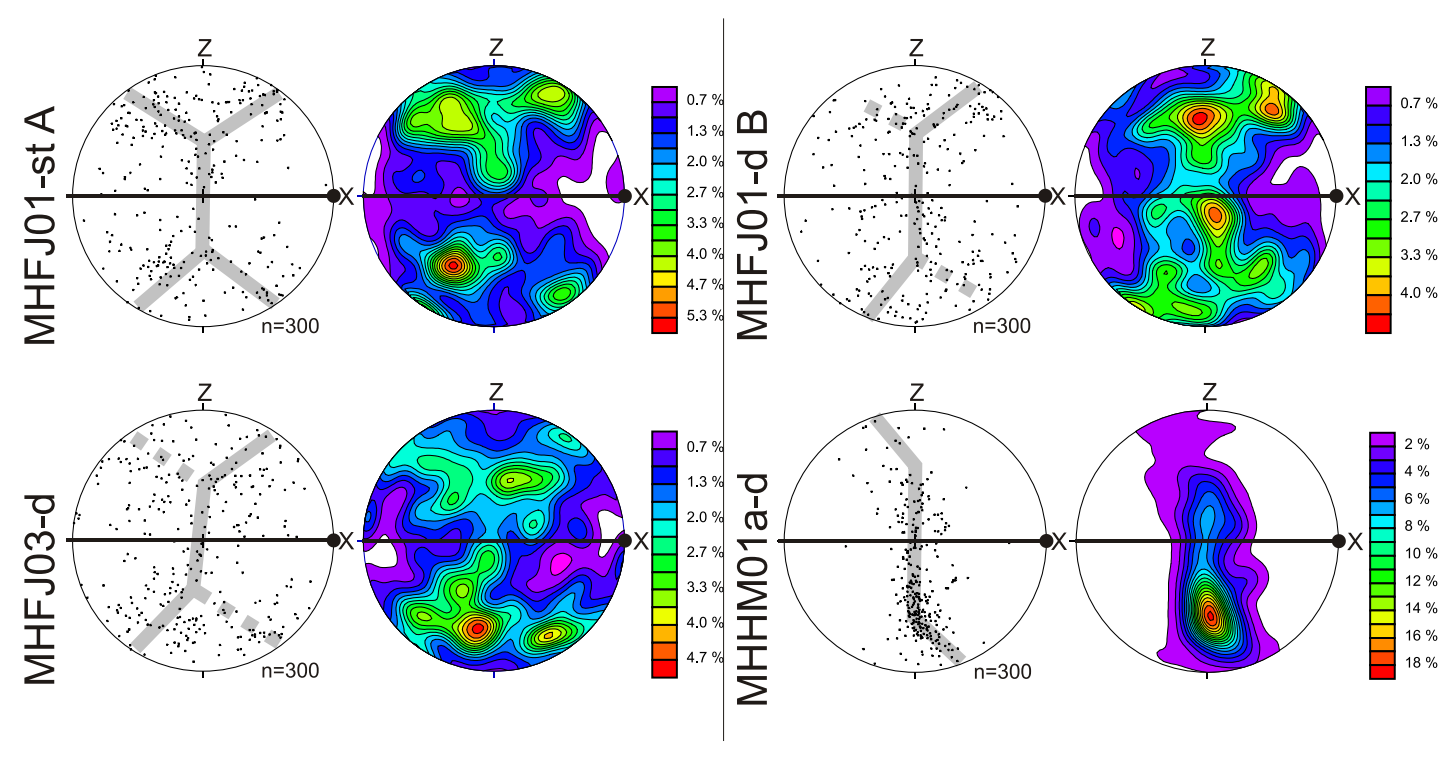

Appendix E-7. Crystallographic preferred orientations of quartz c-axes of chert samples from the nonmylonitic Alpine Schist and the Alpine Schist mylonite. Scatter and contour plots are on equal area, lower hemisphere, stereographic projections in the $x-y-z$ reference frame (see Chapter 5). Contours were calculated using a $1 \sigma$ counting circle and (except MHHM01a-d which was calculated using a $3 \sigma$ counting circle) are plotted as lines of equal point concentration. Eigenvector ratios and fabric plot orientations can be found in Appendix H. CPO fabric plots are labelled by their field sample numbers and annotated with the thin-section orientation they were measured from (e.g. -st or -d; see Chapter 4). A second annotation to the sample number (e.g. A, B. C etc.) is the location of the sample in the sheared vein schematic illustrations in Appendix D. Where identified, internal asymmetries are illustrated on fabrics and the Alpine Schist folitation plane is plotted on fabrics external to the most deformed part of the vein. 
Appendix E-8. Crystallographic preferred orientations of quartz c-axes from the less deformed external sections of the sheared veins on Chancellor Ridge. Scatter and contour plots are on equal area, lower hemisphere, stereographic projections in the $x-y-z$ reference frame (see Chapter 5). Contours were calculated using a 1 counting circle and are plotted as lines

Eigenvector ratios and fabric plot orientations can be found in Appendix H. CPO fabric plots are labelled by their field sample numbers and annotated with the thin-section orientation they were measured from (e.g. -st or -d; see Chapter 4). A second annotation to the sample number (e.g. A, B. C etc.) is the location of the sample in the sheared vein schematic illustrations in Appendix D. W nternal asymmetries are illustrated on fabrics and the Alpine Schist folitation plane is plotted on fabrics external to the most deformed part of the vein. 

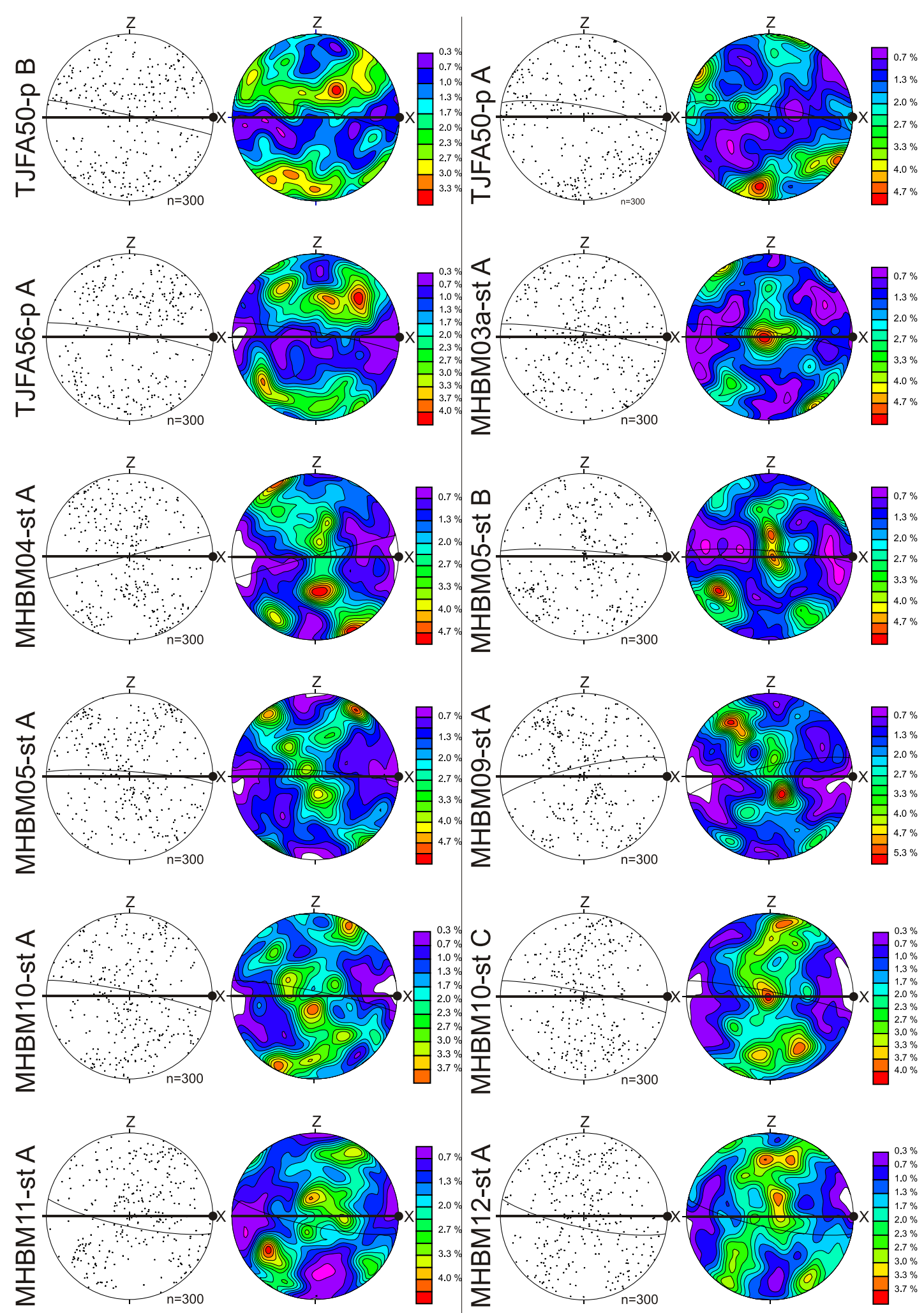

Appendix E-9. Crystallographic preferred orientations of quartz c-axes from the less deformed external sections of the sheared veins on Chancellor Ridge, Sam Peak and at Baumann Glacier. Scatter and contour plots are on equal area, lower hemisphere, stereographic projections in the $x-y-z$ reference frame (see Chapter 5). Contours were calculated using a $1 \sigma$ counting circle and are plotted as lines of equal point concentration. Eigenvector ratios and fabric plot orientations can be found in Appendix H. CPO fabric plots are labelled by their field sample numbers and annotated with the thin-section orientation they were measured from (e.g. -st or -d; see Chapter 4). A second annotation to the sample number (e.g. A, B. C etc.) is the location of the sample in the sheared vein schematic illustrations in Appendix D. Where identified, internal asymmetries are illustrated on fabrics and the Alpine Schist folitation plane is plotted on fabrics external to the most deformed part of the vein. 


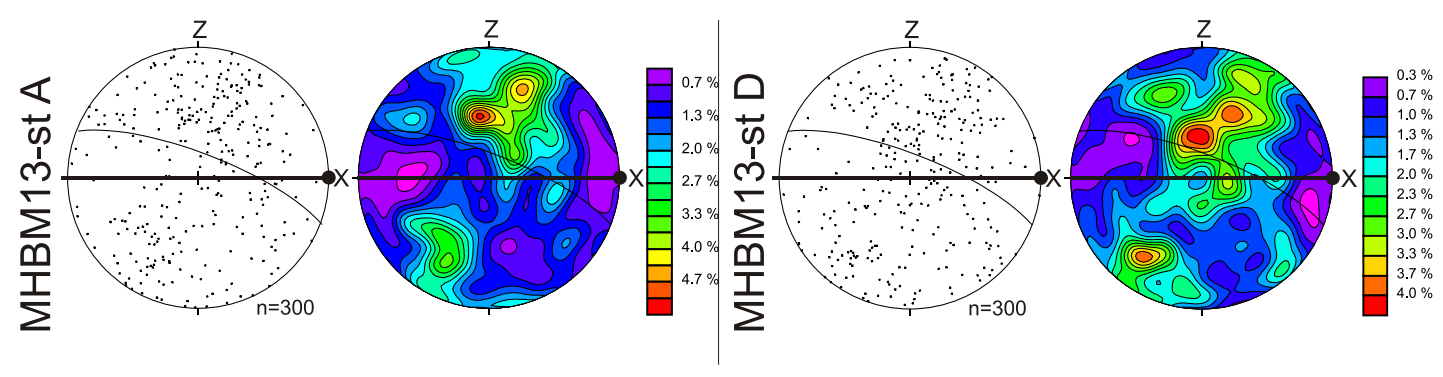

Appendix E-10. Crystallographic preferred orientations of quartz c-axes from the less deformed external sections of the sheared veins at Baumann Glacier. Scatter and contour plots are on equal area, lower hemisphere, stereographic projections in the $x-y-z$ reference frame (see Chapter 5). Contours were calculated using a $1 \sigma$ counting circle and are plotted as lines of equal point concentration. Eigenvector ratios and fabric plot orientations can be found in Appendix H. CPO fabric plots are labelled by their field sample numbers and annotated with the thin-section orientation they were measured from (e.g. -st or -d; see Chapter 4). A second annotation to the sample number (e.g. A, B. C etc.) is the location of the sample in the sheared vein schematic illustrations in Appendix D. Where identified, internal asymmetries are illustrated on fabrics and the Alpine Schist folitation plane is plotted on fabrics external to the most deformed part of the vein. 

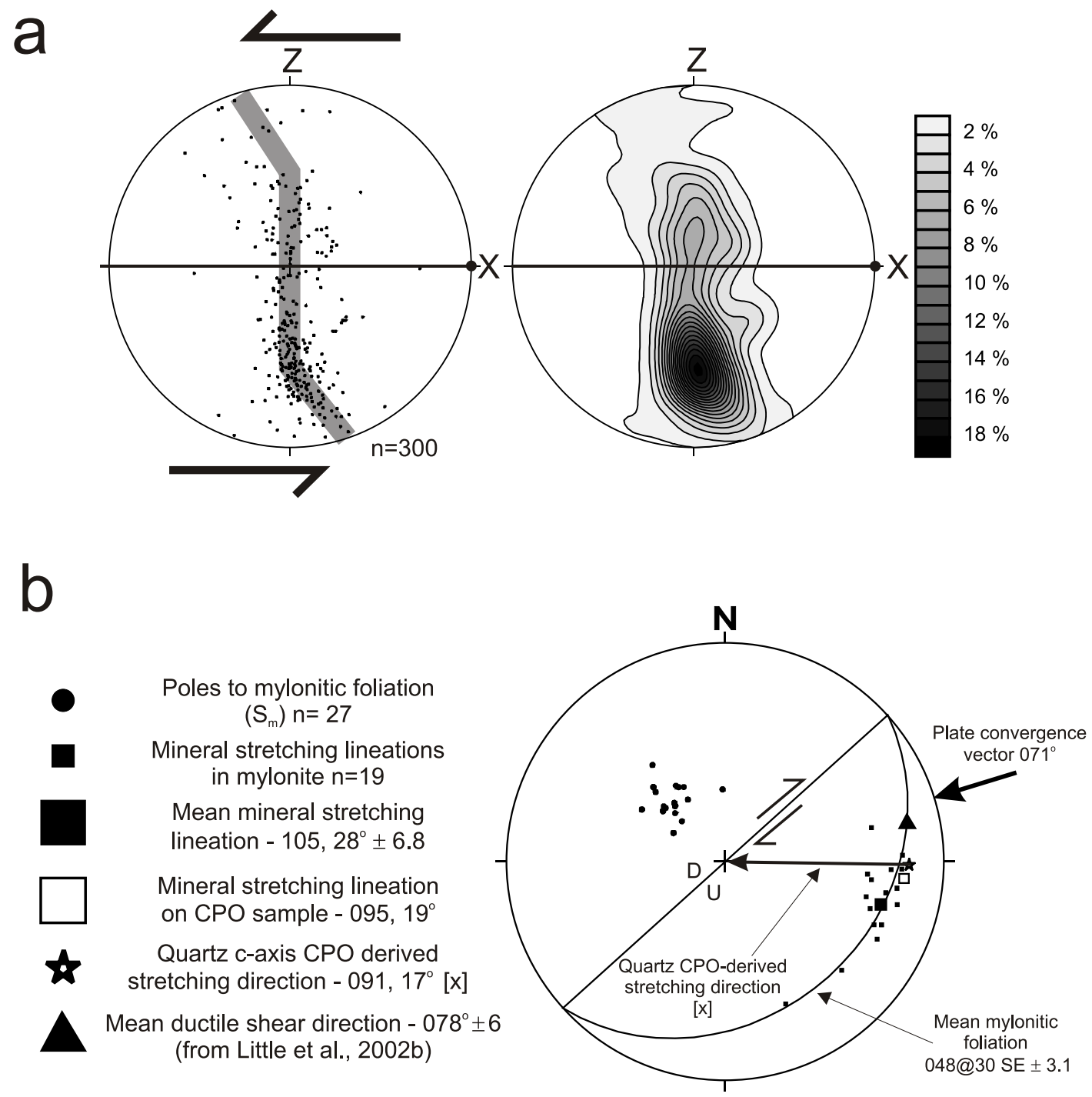

Appendix F. Hare Mare Creek Alpine Fault mylonite quartz c-axis CPO, microstructural and field measurements.

a. Quartz c-axis poles plotted on an equal area, lower hemisphere, stereographic projection. Contours were calculated using a counting circle of $3 \sigma$ and are plotted as lines of equal concentration percentage. Light shades represent low concentration and dark shades represent high concentrations of c-axes. Percent measurements are shown on the graduated scale bar. Contour and scatter plots are paired for complete and objective fabric interpretations. $[\mathrm{x}]$ has been determined from rotation in the $\mathrm{x}$-y plane from down $\operatorname{dip}(\mathrm{P}=90 \mathrm{NE})$ to the best fit extension direction $[\mathrm{x}](\mathrm{P}=34 \mathrm{NE})$. Shear sense has been interpreted from a single girdle CPO pattern with an internal asymmetry. Fabric data can be found in Table 5.1 and rotation methods in Fig. 5.4. Crystallographic measurements were made using a universal stage and were from a chert band parallel to the dominant mylonitic foliation.

b. Stereographic projection of Alpine Fault mylonite planes, poles and shear directions from Hare Mare Creek in this study. Plate convergence vector from NUVEL-1A (DeMets et al., 1994). Mean ductile shear direction from Little et al. (2002b). CPO shear direction (star) and shear sense from CPO pattern (this Appendix a) with mineral stretching lineation on that sample (empty square) plotted for comparison. Uncertainties are for a $95 \%$ confidence ellipse about the mean line or pole to the mean plane. Quartz caxis CPO-derived stretching direction is coincident with the mineral stretching lineation on the Alpine Fault mylonite sample measured. Mineral lineations and foliation collected in this study are plotted. Sample locations can be found in Appendix B. Spread of mineral stretching lineations is consistent with

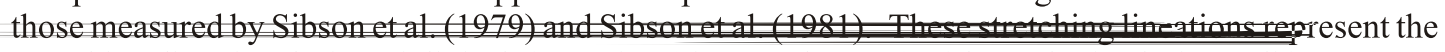
stretching direction during triclinic deformation (Jiang et al., 2001) of the mylonite during uplift. 
a

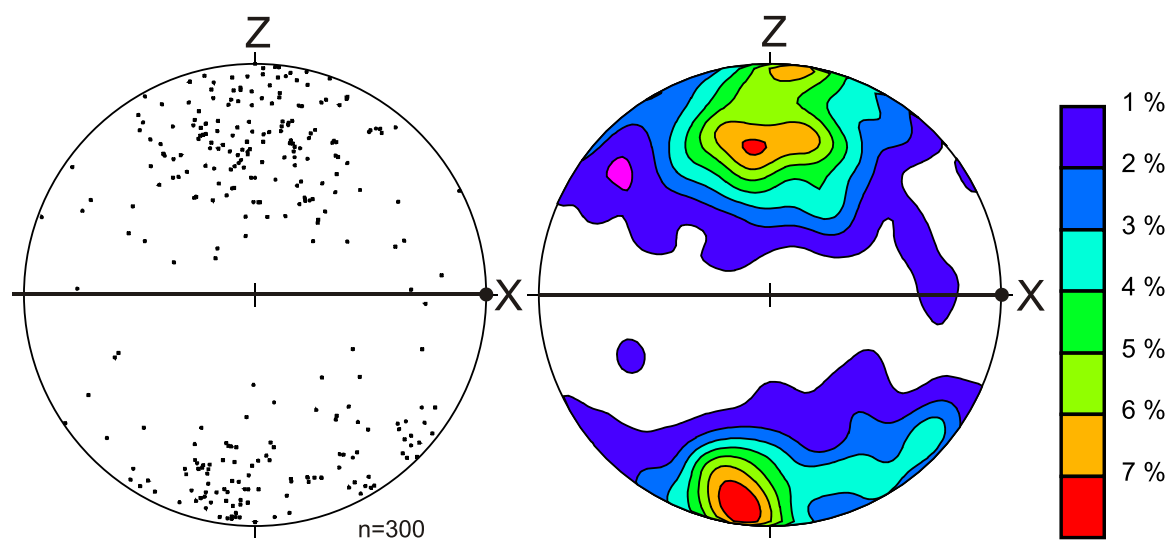

b

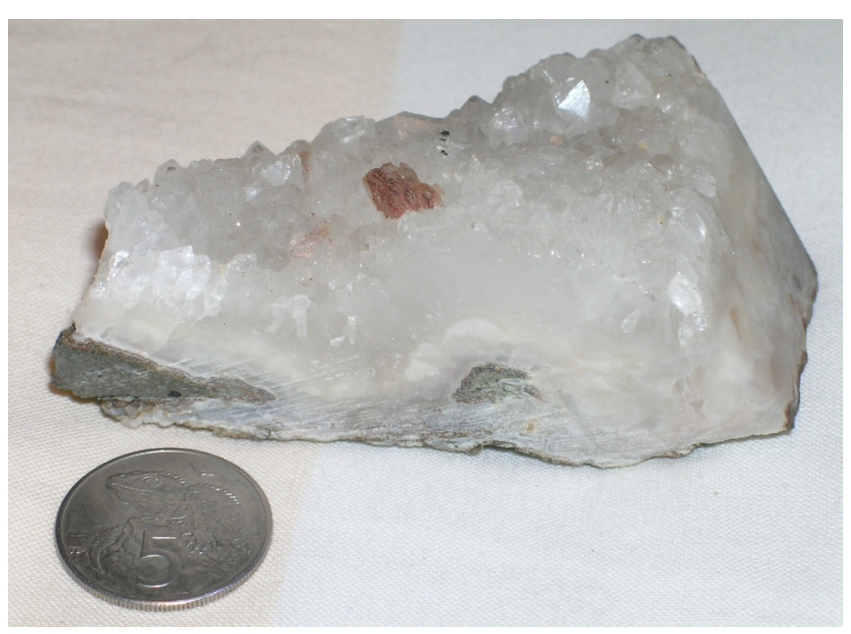

C

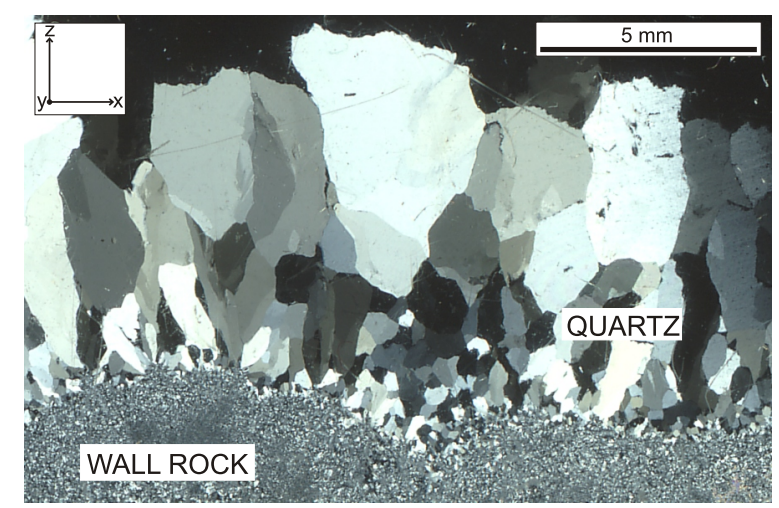

Appendix G. a. Crystallographic preferred orientation of quartz c-axes from euhedral quartz grains in photographs (b) and (c). Contours plotted for equal percent of total points and calculated using the Kamb contouring method and a $3 \sigma$ counting circle. Reference system for $\mathrm{CPO}$ fabric plot has the z-pole normal to the vein wall with the $\mathrm{x}$ - and $\mathrm{y}$-poles perpendicular in the vein wall plane. $\mathrm{x}$-pole direction is unspecified as sample was not orientated in a geographic reference frame. b. Photograph of the unorientated sample used, and euhedral quartz crystals that have growth out from the vein wall are clearly visible. Photograph courtesy Mr. D. P. M. Mason with New Zealand 5 cent piece for scale. c. Microphotograph of thin section made for quartz c-axis orientation measurement from sample in (b) in an orientation where the thin section is normal to the wall rock. Orientation axes shown are the same as those for the CPO fabric plot in (a) and wall rock and quartz crystals are labeled for reference. 


\section{Appendix H. Data for quartz and calcite CPO fabrics measured across the brittle- ductile shear zone (BDSZ).}

The appendix contains the data related to the location, orientation and fabric strength of the c-axis CPO fabric plots in Appendices E, F, G, I and J. Samples are identified by both their field number (a) and their Victoria University of Wellington Collection number (c) for cross-referencing with other data in this thesis and are also identified by the section of the shear zone the CPO fabric was measured from (vein section; $b$ ). The finite ductile shear strain $(\gamma)$ is listed where known for a samples shear zone (d). The orientation of the quartz or calcite CPO-derived [x] direction (e) is presented and all values are for pitches in the shear plane orientation given for each sample.

CPO fabric have been assigned CPO patterns (f) and these are listed according to the pattern codes and methods in Chapter 5. Fabric strength data is also listed in this Appendix in the form of eigenvalues, fabric strength rankings (g), and fabric intensities (I). The calculation methods and use of the eigenvalue ratios can be found in Chapter 5. 


\begin{tabular}{|c|c|c|c|c|c|c|c|c|c|c|c|c|c|c|c|c|c|}
\hline \multicolumn{3}{|c|}{ Sample number } & \multirow{3}{*}{$\begin{array}{c}\text { Section of } \\
\text { shear zone } \\
\text { analysed }\end{array}$} & \multirow[t]{3}{*}{$\gamma$} & \multirow{2}{*}{\multicolumn{2}{|c|}{$\begin{array}{c}\text { Shear plane } \\
\text { oriention }\end{array}$}} & \multirow{3}{*}{$\begin{array}{c}\text { Pitch of } \\
{[x]} \\
\text { from } S W^{e}\end{array}$} & \multirow{3}{*}{$\begin{array}{c}\text { CPO } \\
\text { pattern }^{f}\end{array}$} & \multirow{3}{*}{$\begin{array}{c}\text { Fabric } \\
\text { strength } \\
\text { ranking }^{g}\end{array}$} & \multirow{3}{*}{$\begin{array}{c}\text { Count of } \\
\text { c-axes }\end{array}$} & \multicolumn{3}{|c|}{ Eigenvalues } & \multicolumn{3}{|c|}{ Eigenvalue ratios } & \multirow{3}{*}{$\begin{array}{l}\text { Fabric } \\
\text { inten- } \\
\text { sity }(I)\end{array}$} \\
\hline \multirow[t]{2}{*}{ Field $^{\mathrm{a}}$} & \multirow{2}{*}{$\begin{array}{l}\text { Vein } \\
\text { sctn }^{\mathrm{b}}\end{array}$} & \multirow[t]{2}{*}{$\mathrm{VUW}^{\mathrm{c}}$} & & & & & & & & & $\mathrm{S}_{1}$ & $\mathrm{~S}_{2}$ & $\mathrm{~S}_{3}$ & $\mathrm{~S}_{1} / \mathrm{S}_{3}$ & $\mathrm{~S}_{1} / \mathrm{S}_{2}$ & $\overline{S_{2} / S_{3}}$ & \\
\hline & & & & & Strike & Dip & & & & & & & & & & & \\
\hline $\mathrm{MHCH} 01$ & & 39380 & Schist & & 219 & 84 & - & - & - & - & - & - & - & - & - & - & - \\
\hline $\mathrm{MHCHO} 2$ & & 39381 & Infilling & & 215 & 88 & 60 & CG & 1 & 300 & 0.42 & 0.32 & 0.26 & 1.66 & 1.32 & 1.25 & 0.11 \\
\hline $\mathrm{MHCH} 03$ & & 39382 & Schist & & 218 & 87 & - & - & - & - & - & - & - & - & - & - & - \\
\hline $\mathrm{MHCHO4}$ & & 39383 & Infilling & & 039 & 88 & 4 & CG & 2 & 300 & 0.39 & 0.35 & 0.26 & 1.54 & 1.13 & 1.36 & 0.08 \\
\hline $\mathrm{MHCHO5}$ & & 39384 & Schist & & 216 & 84 & - & - & - & - & - & - & - & - & - & - & - \\
\hline MHCH06 & & 39385 & Infilling & & 218 & 84 & 7 & $C$ & 4 & 300 & 0.47 & 0.28 & 0.26 & 1.82 & 1.67 & 1.09 & 0.20 \\
\hline $\mathrm{MHCH} 07$ & & 39386 & Infilling & & 217 & 88 & 90 & SC & 1 & 300 & 0.38 & 0.35 & 0.26 & 1.46 & 1.09 & 1.34 & 0.06 \\
\hline MHCH08 & & 39387 & Infilling & & 215 & 87 & 5 & CG & 2 & 300 & 0.42 & 0.34 & 0.24 & 1.73 & 1.25 & 1.38 & 0.12 \\
\hline МHCHO9 & & 39388 & Schist & & - & - & - & - & - & - & - & - & - & - & - & - & - \\
\hline $\mathrm{MHCH} 10$ & & 39389 & Infilling & & 217 & 86 & 8 & $\mathrm{C}$ & 3 & 300 & 0.44 & 0.32 & 0.23 & 1.92 & 1.37 & 1.40 & 0.17 \\
\hline $\mathrm{MHCH} 11$ & & 39390 & External & & 217 & 82 & 80 & $\mathrm{~T} 1$ & 4 & 300 & 0.49 & 0.31 & 0.20 & 2.43 & 1.60 & 1.52 & 0.32 \\
\hline $\mathrm{MHCH} 12$ & $A$ & 39391 & Infilling & & 221 & 85 & 18 & $\mathrm{~T} 2$ & 3 & 300 & 0.45 & 0.32 & 0.23 & 1.97 & 1.44 & 1.37 & 0.19 \\
\hline $\mathrm{MHCH} 12$ & $B$ & & Infilling & & 221 & 85 & 18 & $C$ & 3 & 300 & 0.47 & 0.28 & 0.25 & 1.90 & 1.66 & 1.15 & 0.21 \\
\hline $\mathrm{MHCH} 13$ & & 39392 & Schist & & - & - & - & - & - & - & - & - & - & - & - & - & - \\
\hline $\mathrm{MHCH} 14$ & & 39394 & Infilling & & 218 & 88 & 7 & $\mathrm{R}$ & 0 & 300 & 0.38 & 0.34 & 0.28 & 1.35 & 1.09 & 1.23 & 0.04 \\
\hline $\mathrm{MHCH} 16$ & & 39396 & Schist & & - & - & 90 & - & - & - & - & - & - & - & - & - & - \\
\hline $\mathrm{MHCH} 17$ & $B$ & 39397 & Internal & 7.7 & 038 & 88 & 82 & $\mathrm{~T} 2$ & 3 & 300 & 0.46 & 0.32 & 0.22 & 2.08 & 1.41 & 1.47 & 0.21 \\
\hline $\mathrm{MHCH} 17$ & $\mathrm{C}$ & & Infilling & & 038 & 88 & 90 & $\mathrm{R}$ & 0 & 300 & 0.39 & 0.35 & 0.26 & 1.50 & 1.13 & 1.33 & 0.07 \\
\hline $\mathrm{MHCH} 17$ & $A$ & & External & & 038 & 88 & 82 & CG & 3 & 300 & 0.38 & 0.38 & 0.24 & 1.61 & 1.01 & 1.59 & 0.10 \\
\hline $\mathrm{MHCH} 18$ & & 39398 & Infilling & & - & - & - & - & - & - & - & - & - & - & - & - & - \\
\hline $\mathrm{MHCH} 19$ & B & 39399 & Internal & 0 & 219 & 84 & 100 & CG & 3 & 300 & 0.41 & 0.35 & 0.25 & 1.65 & 1.18 & 1.40 & 0.10 \\
\hline $\mathrm{MHCH} 19$ & $C$ & & Infilling & & 219 & 84 & 77 & $\mathrm{~T} 1$ & 2 & 500 & 0.43 & 0.33 & 0.25 & 1.71 & 1.31 & 1.31 & 0.12 \\
\hline $\mathrm{MHCH} 19$ & $A$ & & External & & 219 & 84 & 95 & SC & 3 & 300 & 0.42 & 0.33 & 0.25 & 1.69 & 1.25 & 1.35 & 0.11 \\
\hline $\mathrm{MHCH} 20$ & $A$ & 39400 & External & & 222 & 86 & 60 & SG-2 & 4 & 300 & 0.42 & 0.37 & 0.21 & 1.96 & 1.15 & 1.71 & 0.17 \\
\hline $\mathrm{MHCH} 20$ & B & & Internal & 6.9 & 222 & 86 & 60 & SG-2 & 3 & 300 & 0.41 & 0.35 & 0.24 & 1.75 & 1.17 & 1.49 & 0.12 \\
\hline $\mathrm{MHCH} 20$ & $C$ & & Internal & 6.9 & 222 & 86 & 70 & SG-2 & 3 & 300 & 0.42 & 0.32 & 0.26 & 1.62 & 1.29 & 1.26 & 0.10 \\
\hline $\mathrm{MHCH} 20$ & $E$ & & External & & 222 & 86 & 110 & $\mathrm{R}$ & 0 & 300 & 0.41 & 0.32 & 0.27 & 1.52 & 1.26 & 1.21 & 0.07 \\
\hline $\mathrm{MHCH} 20$ & $\mathrm{~F}$ & & Internal & 6.9 & 222 & 86 & 65 & SC & 3 & 300 & 0.46 & 0.31 & 0.24 & 1.94 & 1.49 & 1.30 & 0.19 \\
\hline $\mathrm{MHCH} 20$ & $\mathrm{G}$ & & Internal & 6.9 & 222 & 86 & 70 & SG-2 & 4 & 300 & 0.40 & 0.37 & 0.23 & 1.73 & 1.10 & 1.58 & 0.12 \\
\hline $\mathrm{MHCH} 20$ & $\mathrm{H}$ & & External & & 222 & 86 & 60 & SG-2 & 4 & 300 & 0.44 & 0.36 & 0.21 & 2.14 & 1.23 & 1.74 & 0.21 \\
\hline
\end{tabular}




\begin{tabular}{|c|c|c|c|c|c|c|c|c|c|c|c|c|c|c|c|c|c|}
\hline \multicolumn{3}{|c|}{ Sample number } & \multirow{3}{*}{$\begin{array}{l}\text { Section of } \\
\text { shear zone } \\
\text { analysed }\end{array}$} & \multirow[t]{3}{*}{$\gamma$} & \multirow{2}{*}{\multicolumn{2}{|c|}{$\begin{array}{c}\text { Shear plane } \\
\text { oriention }\end{array}$}} & \multirow{3}{*}{$\begin{array}{c}\text { Pitch of } \\
{[x]} \\
\text { from } S_{W}{ }^{e} \\
\end{array}$} & \multirow{3}{*}{$\begin{array}{c}\text { CPO } \\
\text { pattern }^{f}\end{array}$} & \multirow{3}{*}{$\begin{array}{c}\text { Fabric } \\
\text { strength } \\
\text { ranking }^{\text {g }} \\
\end{array}$} & \multirow{3}{*}{$\begin{array}{c}\text { Count of } \\
\text { c-axes }\end{array}$} & \multicolumn{3}{|c|}{ Eigenvalues } & \multicolumn{3}{|c|}{ Eigenvalue ratios } & \multirow{3}{*}{$\begin{array}{l}\text { Fabric } \\
\text { inten- } \\
\text { sity }(I)\end{array}$} \\
\hline \multirow{2}{*}{ Field $^{a}$} & \multirow{2}{*}{$\begin{array}{l}\text { Vein } \\
\text { sctn }^{b} \\
\end{array}$} & \multirow{2}{*}{ VUW $^{c}$} & & & & & & & & & \multirow[t]{2}{*}{$S_{1}$} & \multirow[t]{2}{*}{$\mathrm{S}_{2}$} & \multirow[t]{2}{*}{$\mathrm{S}_{3}$} & \multirow{2}{*}{$\mathrm{S}_{1} / \mathrm{S}_{3}$} & \multirow{2}{*}{$\mathrm{S}_{1} / \mathrm{S}_{2}$} & \multirow[t]{2}{*}{$\mathrm{S}_{2} / \mathrm{S}_{3}$} & \\
\hline & & & & & Strike & Dip & & & & & & & & & & & \\
\hline $\mathrm{MHCH} 20$ & 1 & & Internal & 4.4 & 222 & 86 & 85 & SC & 3 & 300 & 0.39 & 0.35 & 0.26 & 1.52 & 1.10 & 1.38 & 0.07 \\
\hline $\mathrm{MHCH} 20$ & $J$ & & Internal & 4.4 & 222 & 86 & 110 & $\mathrm{SC}$ & 4 & 300 & 0.38 & 0.33 & 0.28 & 1.35 & 1.17 & 1.16 & 0.04 \\
\hline $\mathrm{MHCH} 20$ & $\mathrm{~K}$ & & Internal & 4.4 & 222 & 86 & 90 & $\mathrm{R}$ & 0 & 300 & 0.42 & 0.32 & 0.27 & 1.55 & 1.32 & 1.18 & 0.09 \\
\hline $\mathrm{MHCH} 20$ & L & & External & & 222 & 86 & 90 & $\mathrm{R}$ & 1 & 300 & 0.39 & 0.32 & 0.30 & 1.31 & 1.23 & 1.06 & 0.03 \\
\hline $\mathrm{MHCH} 20$ & $\mathrm{O}$ & & Internal & 4.4 & 222 & 86 & 80 & CG & 4 & 300 & 0.43 & 0.39 & 0.19 & 2.31 & 1.11 & 2.08 & 0.25 \\
\hline $\mathrm{MHCH} 21$ & $A$ & 39401 & Infilling & & 218 & 89 & 100 & $\mathrm{R}$ & 1 & 300 & 0.41 & 0.34 & 0.25 & 1.60 & 1.21 & 1.32 & 0.09 \\
\hline $\mathrm{MHCH} 21$ & B & & External & & 218 & 89 & 80 & SG-2 & 2 & 300 & 0.39 & 0.36 & 0.25 & 1.60 & 1.09 & 1.47 & 0.09 \\
\hline $\mathrm{MHCH} 22$ & B & 39402 & Internal & 13.8 & 219 & 89 & 90 & SC & 4 & 300 & 0.48 & 0.27 & 0.25 & 1.96 & 1.75 & 1.12 & 0.25 \\
\hline $\mathrm{MHCH} 22$ & C & & Infilling & & 219 & 89 & 105 & CG & 4 & 300 & 0.46 & 0.35 & 0.19 & 2.35 & 1.31 & 1.79 & 0.26 \\
\hline $\mathrm{MHCH} 22$ & $A$ & & External & & 219 & 89 & 110 & $\mathrm{~T} 2$ & 3 & 300 & 0.49 & 0.32 & 0.19 & 2.60 & 1.51 & 1.72 & 0.34 \\
\hline $\mathrm{MHCH} 23$ & & 39403 & Infilling & & 218 & 84 & 40 & $\mathrm{C}$ & 1 & 300 & 0.42 & 0.32 & 0.26 & 1.61 & 1.32 & 1.22 & 0.10 \\
\hline $\mathrm{MHCH} 24$ All & I Al| & 39404 & Infilling & & 218 & 82 & 90 & SG-2 & 1 & 900 & 0.41 & 0.33 & 0.26 & 1.55 & 1.22 & 1.27 & 0.08 \\
\hline $\mathrm{MHCH} 24 a$ & & & Infilling & & 218 & 82 & 105 & $\mathrm{R}$ & 1 & 300 & 0.41 & 0.34 & 0.26 & 1.59 & 1.22 & 1.31 & 0.09 \\
\hline $\mathrm{MHCH} 24 \mathrm{~b}$ & & & Infilling & & 218 & 82 & 90 & $\mathrm{R}$ & 0 & 300 & 0.42 & 0.32 & 0.26 & 1.59 & 1.28 & 1.25 & 0.09 \\
\hline $\mathrm{MHCH} 24 \mathrm{c}$ & B & & Internal & 6.8 & 218 & 82 & 70 & SC & 4 & 300 & 0.43 & 0.31 & 0.26 & 1.64 & 1.40 & 1.17 & 0.11 \\
\hline $\mathrm{MHCH} 24 \mathrm{c}$ & D & & Infilling & & 218 & 82 & 120 & $\mathrm{R}$ & 0 & 300 & 0.40 & 0.34 & 0.25 & 1.61 & 1.17 & 1.37 & 0.09 \\
\hline $\mathrm{MHCH} 24 \mathrm{c}$ & $A$ & & External & & 218 & 82 & 85 & $\mathrm{SC}$ & 2 & 300 & 0.40 & 0.34 & 0.26 & 1.52 & 1.20 & 1.27 & 0.07 \\
\hline $\mathrm{MHCH} 25$ & $D$ & 39405 & Internal & 6.4 & 216 & 80 & 90 & CG & 3 & 300 & 0.46 & 0.31 & 0.23 & 2.04 & 1.51 & 1.35 & 0.22 \\
\hline $\mathrm{MHCH} 25$ & B & & Internal & 6.7 & 216 & 80 & 90 & SC & 4 & 300 & 0.47 & 0.28 & 0.25 & 1.85 & 1.65 & 1.12 & 0.20 \\
\hline $\mathrm{MHCH} 25$ & $C$ & & External & & 216 & 80 & 90 & $\mathrm{R}$ & 0 & 300 & 0.39 & 0.35 & 0.26 & 1.50 & 1.11 & 1.35 & 0.07 \\
\hline $\mathrm{MHCH} 25$ & A & & External & & 216 & 80 & 90 & $\mathrm{R}$ & 1 & 300 & 0.40 & 0.32 & 0.28 & 1.41 & 1.22 & 1.15 & 0.05 \\
\hline MHFJ01a & & 39406 & Chert & & 048 & 75 & 25 & T2 & 4 & 300 & 0.46 & 0.34 & 0.20 & 2.36 & 1.37 & 1.73 & 0.27 \\
\hline MHFJ01b & & & Chert & & 048 & 75 & 40 & SG-2 & 3 & 300 & 0.43 & 0.39 & 0.18 & 2.35 & 1.11 & 2.11 & 0.26 \\
\hline MHFJ02a & & 39407 & Chert & & - & - & - & - & - & - & - & - & - & - & - & - & - \\
\hline MHFJ02b & & & Chert & & - & - & - & - & - & - & - & - & - & - & - & - & - \\
\hline MHFJ03 & & 39408 & Chert & & 035 & 75 & 60 & $\mathrm{~T} 2$ & 3 & 300 & 0.41 & 0.36 & 0.23 & 1.79 & 1.13 & 1.59 & 0.13 \\
\hline MHHM01a & & 39409 & Mylonitic Chert & & 061 & 32 & 146 & SG-3 & 5 & 300 & 0.69 & 0.28 & 0.03 & 21.09 & 2.48 & 8.50 & 1.65 \\
\hline MHHM01b & & & Mylonitic Chert & & 061 & 32 & - & - & - & - & - & - & - & - & - & - & - \\
\hline MHSP04 & & 39410 & Schist & & - & - & - & - & - & - & - & - & - & - & - & - & - \\
\hline MHSP06 & & 39411 & Schist & & - & - & - & - & - & - & - & - & - & - & - & - & - \\
\hline
\end{tabular}




\begin{tabular}{|c|c|c|c|c|c|c|c|c|c|c|c|c|c|c|c|c|c|}
\hline \multicolumn{3}{|c|}{ Sample number } & \multirow{3}{*}{$\begin{array}{c}\text { Section of } \\
\text { shear zone } \\
\text { analysed }\end{array}$} & \multirow[t]{3}{*}{$\gamma$} & \multirow{2}{*}{\multicolumn{2}{|c|}{$\begin{array}{c}\text { Shear plane } \\
\text { oriention }\end{array}$}} & \multirow{3}{*}{$\begin{array}{c}\text { Pitch of } \\
{[x]} \\
\text { from } S W^{e}\end{array}$} & \multirow{3}{*}{$\begin{array}{c}\text { CPO } \\
\text { pattern }^{f}\end{array}$} & \multirow{3}{*}{$\begin{array}{c}\text { Fabric } \\
\text { strength } \\
\text { ranking }^{g}\end{array}$} & \multirow{3}{*}{$\begin{array}{c}\text { Count of } \\
\text { c-axes }\end{array}$} & \multicolumn{3}{|c|}{ Eigenvalues } & \multicolumn{3}{|c|}{ Eigenvalue ratios } & \multirow{3}{*}{$\begin{array}{l}\text { Fabric } \\
\text { inten- } \\
\text { sity }(I)\end{array}$} \\
\hline \multirow[t]{2}{*}{ Field $^{a}$} & \multirow{2}{*}{$\begin{array}{l}\text { Vein } \\
\text { sctn }^{\mathrm{b}}\end{array}$} & \multirow[t]{2}{*}{$\mathrm{VUW}^{\mathrm{c}}$} & & & & & & & & & \multirow[t]{2}{*}{$\mathrm{S}_{1}$} & \multirow[t]{2}{*}{$\mathrm{S}_{2}$} & \multirow[t]{2}{*}{$\mathrm{S}_{3}$} & \multirow[t]{2}{*}{$\mathrm{S}_{1} / \mathrm{S}_{3}$} & \multirow[t]{2}{*}{$\mathrm{S}_{1} / \mathrm{S}_{2}$} & \multirow[t]{2}{*}{$\mathrm{S}_{2} / \mathrm{S}_{3}$} & \\
\hline & & & & & Strike & Dip & & & & & & & & & & & \\
\hline MHSP07 & & 39412 & Schist & & - & - & - & - & - & - & - & - & - & - & - & - & - \\
\hline MHSP08 & & 39413 & Schist & & - & - & - & - & - & - & - & - & - & - & - & - & - \\
\hline MHSPO9 & & 39414 & Infilling & & 202 & 52 & 90 & $\mathrm{R}$ & 0 & 300 & 0.36 & 0.35 & 0.29 & 1.23 & 1.02 & 1.21 & 0.02 \\
\hline MHSP10 & & 39415 & Schist & & - & - & - & - & - & - & - & - & - & - & - & - & - \\
\hline MHSP11 & & 39416 & Infilling & & 206 & 48 & 105 & $\mathrm{~T} 2$ & 3 & 300 & 0.43 & 0.36 & 0.21 & 2.00 & 1.19 & 1.68 & 0.18 \\
\hline RW35b & & 39431 & Infilling & & 206 & 64 & 30 & SC & 3 & 300 & 0.42 & 0.31 & 0.26 & 1.59 & 1.34 & 1.19 & 0.10 \\
\hline TJFA43 & & 39432 & Infilling & & 211 & 64 & 45 & $\mathrm{R}$ & 0 & 300 & 0.38 & 0.35 & 0.26 & 1.46 & 1.09 & 1.33 & 0.06 \\
\hline TJFA47 & & 39433 & Infilling & & 213 & 60 & 43 & $\mathrm{R}$ & 0 & 300 & 0.38 & 0.32 & 0.30 & 1.26 & 1.16 & 1.09 & 0.02 \\
\hline TJFA50 & $A$ & 39434 & External & & 206 & 65 & 47 & SC & 3 & 300 & 0.43 & 0.30 & 0.26 & 1.64 & 1.45 & 1.14 & 0.12 \\
\hline TJFA50 & $B$ & & External & & 206 & 65 & 37 & SC & 3 & 300 & 0.39 & 0.31 & 0.30 & 1.32 & 1.27 & 1.03 & 0.04 \\
\hline TJFA52 & & 39435 & Infilling & & 200 & 65 & 110 & T2 & 2 & 300 & 0.49 & 0.30 & 0.22 & 2.21 & 1.64 & 1.35 & 0.28 \\
\hline TJFA56 & B & 39436 & Internal & 3.8 & 212 & 63 & 67 & SG-2 & 2 & 300 & 0.43 & 0.32 & 0.25 & 1.70 & 1.36 & 1.25 & 0.12 \\
\hline TJFA56 & A & & External & & 212 & 63 & 37 & SC & 3 & 300 & 0.45 & 0.29 & 0.26 & 1.73 & 1.52 & 1.14 & 0.15 \\
\hline MHBM01 & & 39417 & Infilling & & 223 & 84 & 90 & $\mathrm{R}$ & 0 & 300 & 0.38 & 0.35 & 0.27 & 1.40 & 1.08 & 1.29 & 0.05 \\
\hline MHBM02 & & 39418 & Infilling & & - & - & - & - & - & - & - & - & - & - & - & - & - \\
\hline MHBM03 & $\mathrm{C}$ & & Internal & 6.3 & 048 & 78 & 80 & CG & 3 & 300 & 0.41 & 0.33 & 0.26 & 1.60 & 1.25 & 1.27 & 0.09 \\
\hline MHBM03 & $D$ & & Infilling & & 048 & 78 & 90 & $\mathrm{R}$ & 0 & 300 & 0.35 & 0.34 & 0.32 & 1.09 & 1.02 & 1.07 & 0.00 \\
\hline MHBM03 & $A$ & & External & & 048 & 78 & 55 & $\mathrm{~T} 2$ & 2 & 300 & 0.41 & 0.33 & 0.26 & 1.56 & 1.22 & 1.28 & 0.08 \\
\hline MHBM04 & B & 39420 & Internal & 2.6 & 041 & 82 & 68 & SG-2 & 2 & 300 & 0.43 & 0.33 & 0.24 & 1.80 & 1.29 & 1.39 & 0.14 \\
\hline MHBMO4 & $A$ & & External & & 041 & 82 & 73 & SG-2 & 3 & 300 & 0.41 & 0.38 & 0.20 & 2.07 & 1.08 & 1.92 & 0.20 \\
\hline MHBM05 & $\mathrm{C}$ & 39421 & Internal & 3.2 & 045 & 82 & 90 & CG & 3 & 300 & 0.41 & 0.32 & 0.27 & 1.53 & 1.30 & 1.18 & 0.08 \\
\hline MHBM05 & $B$ & & External & & 045 & 82 & 65 & $\mathrm{~T} 2$ & 2 & 300 & 0.38 & 0.37 & 0.26 & 1.46 & 1.02 & 1.43 & 0.07 \\
\hline MHBM05 & $A$ & & External & & 045 & 82 & 67 & $\mathrm{~T} 2$ & 3 & 300 & 0.41 & 0.35 & 0.24 & 1.72 & 1.18 & 1.46 & 0.11 \\
\hline MHBM06 & & 39422 & Infilling & & 046 & 80 & 90 & $\mathrm{R}$ & 0 & 300 & 0.36 & 0.36 & 0.28 & 1.30 & 1.02 & 1.28 & 0.03 \\
\hline MHBM07 & & 39423 & Infilling & & 040 & 72 & 45 & $\mathrm{R}$ & 0 & 300 & 0.39 & 0.35 & 0.26 & 1.48 & 1.12 & 1.32 & 0.06 \\
\hline MHBM08 & & 39424 & Infilling & & 044 & 88 & 90 & $C$ & 2 & 300 & 0.44 & 0.33 & 0.23 & 1.95 & 1.34 & 1.45 & 0.18 \\
\hline MHBM09 & B & 39425 & Internal & 4.1 & 046 & 83 & 90 & $\mathrm{R}$ & 0 & 300 & 0.43 & 0.31 & 0.26 & 1.62 & 1.39 & 1.17 & 0.11 \\
\hline MHBM09 & $A$ & & External & & 046 & 83 & 88 & SG & 2 & 300 & 0.44 & 0.36 & 0.20 & 2.16 & 1.21 & 1.78 & 0.22 \\
\hline MHBM10 & $B$ & 39426 & Internal & 4.5 & 046 & 80 & 85 & SG & 3 & 300 & 0.44 & 0.34 & 0.22 & 2.05 & 1.31 & 1.56 & 0.19 \\
\hline MHBM10 & A & & External & & 046 & 80 & 90 & SG & 3 & 300 & 0.41 & 0.37 & 0.23 & 1.80 & 1.11 & 1.62 & 0.14 \\
\hline
\end{tabular}




\begin{tabular}{|c|c|c|c|c|c|c|c|c|c|c|c|c|c|c|c|c|c|}
\hline \multicolumn{3}{|c|}{ Sample number } & \multirow{3}{*}{$\begin{array}{l}\text { Section of } \\
\text { shear zone } \\
\text { analysed }\end{array}$} & \multirow[t]{3}{*}{$\gamma$} & \multirow{2}{*}{\multicolumn{2}{|c|}{$\begin{array}{c}\text { Shear plane } \\
\text { oriention } \\
\end{array}$}} & \multirow{3}{*}{$\begin{array}{c}\text { Pitch of } \\
{[\mathrm{x}]} \\
\text { from } \mathrm{SW}^{\mathrm{e}}\end{array}$} & \multirow{3}{*}{$\begin{array}{c}\text { CPO } \\
\text { pattern }^{f}\end{array}$} & \multirow{3}{*}{$\begin{array}{c}\text { Fabric } \\
\text { strength } \\
\text { ranking }^{\text {g }}\end{array}$} & \multirow{3}{*}{$\begin{array}{c}\text { Count of } \\
\text { c-axes }\end{array}$} & \multicolumn{3}{|c|}{ Eigenvalues } & \multicolumn{3}{|c|}{ Eigenvalue ratios } & \multirow{3}{*}{$\begin{array}{l}\text { Fabric } \\
\text { inten- } \\
\text { sity }(I) \\
\end{array}$} \\
\hline \multirow[t]{2}{*}{ Field $^{a}$} & \multirow{2}{*}{$\begin{array}{l}\text { Vein } \\
\operatorname{sctn}^{b} \\
\end{array}$} & \multirow[t]{2}{*}{$\mathrm{VUW}^{\mathrm{c}}$} & & & & & & & & & \multirow[t]{2}{*}{$\mathrm{S}_{1}$} & \multirow[t]{2}{*}{$\mathrm{S}_{2}$} & \multirow[t]{2}{*}{$\mathrm{S}_{3}$} & \multirow[t]{2}{*}{$\mathrm{S}_{1} / \mathrm{S}_{3}$} & \multirow[t]{2}{*}{$\mathrm{S}_{1} / \mathrm{S}_{2}$} & \multirow[t]{2}{*}{$\mathrm{S}_{2} / \mathrm{S}_{3}$} & \\
\hline & & & & & Strike & Dip & & & & & & & & & & & \\
\hline MHBM10 & $\mathrm{C}$ & & External & & 046 & 80 & 90 & SG & 3 & 300 & 0.42 & 0.41 & 0.18 & 2.35 & 1.02 & 2.30 & 0.28 \\
\hline MHBM11 & B & 39427 & Internal & 5.9 & 048 & 77 & 90 & $\mathrm{R}$ & 1 & 300 & 0.38 & 0.35 & 0.26 & 1.47 & 1.09 & 1.36 & 0.06 \\
\hline MHBM11 & A & & External & & 048 & 77 & 78 & SG-3 & 3 & 300 & 0.41 & 0.34 & 0.25 & 1.69 & 1.22 & 1.38 & 0.11 \\
\hline MHBM12 & B & 39428 & Internal & 5 & 048 & 76 & 90 & CG & 3 & 300 & 0.46 & 0.32 & 0.21 & 2.18 & 1.43 & 1.52 & 0.24 \\
\hline MHBM12 & $\mathrm{C}$ & & Infilling & & 048 & 76 & 73 & $\mathrm{R}$ & 0 & 300 & 0.40 & 0.32 & 0.29 & 1.36 & 1.25 & 1.09 & 0.05 \\
\hline MHBM12 & $A$ & & External & & 048 & 76 & 73 & $\mathrm{~T} 2$ & 3 & 300 & 0.41 & 0.35 & 0.24 & 1.68 & 1.17 & 1.43 & 0.10 \\
\hline MHBM13 & B & 39429 & Internal & 3.1 & 056 & 80 & 80 & CG & 3 & 300 & 0.43 & 0.32 & 0.26 & 1.66 & 1.35 & 1.23 & 0.11 \\
\hline MHBM13 & A & & External & & 056 & 80 & 73 & SG-3 & 3 & 300 & 0.46 & 0.32 & 0.22 & 2.12 & 1.44 & 1.47 & 0.22 \\
\hline MHBM13 & $\mathrm{C}$ & & Internal & 3.1 & 056 & 80 & 86 & CG & 4 & 300 & 0.45 & 0.33 & 0.22 & 2.03 & 1.34 & 1.51 & 0.19 \\
\hline MHBM13 & $\mathrm{D}$ & & External & & 056 & 80 & 68 & SG-3 & 3 & 300 & 0.45 & 0.34 & 0.22 & 2.08 & 1.32 & 1.57 & 0.20 \\
\hline MHBM14b & $A$ & 39430 & Infilling & & 225 & 82 & 92 & C & 3 & 300 & 0.46 & 0.29 & 0.25 & 1.79 & 1.57 & 1.14 & 0.17 \\
\hline MHBM14b & $\mathrm{B}$ & & Infilling & & 225 & 82 & 105 & SG & 2 & 300 & 0.40 & 0.36 & 0.23 & 1.74 & 1.11 & 1.57 & 0.12 \\
\hline $\mathrm{MHCH} 17$ & $\mathrm{C}$ & as above & Calcite Infilling & & 038 & 88 & 86 & $\mathrm{C}$ & 5 & 300 & 0.65 & 0.29 & 0.06 & 10.96 & 2.26 & 4.85 & 1.34 \\
\hline $\mathrm{MHCH} 17$ & B & as above & Calcite Sheared & 7.7 & 038 & 88 & 82 & CG & 5 & 300 & 0.65 & 0.29 & 0.06 & 10.17 & 2.26 & 4.51 & 1.31 \\
\hline $\mathrm{MHCH} 17$ & A & as above & Calcite Unsheared & & 038 & 88 & - & CG & 5 & 300 & 0.57 & 0.34 & 0.09 & 6.45 & 1.67 & 3.87 & 0.87 \\
\hline $\mathrm{MHCH} 20$ & $A$ & as above & Calcite Unsheared & & 222 & 86 & - & $\mathrm{C}$ & 5 & 300 & 0.64 & 0.29 & 0.07 & 9.18 & 2.24 & 4.10 & 1.25 \\
\hline $\mathrm{MHCH} 20$ & $\mathrm{~J}$ & as above & Calcite Sheared & 4.4 & 222 & 86 & 82 & CG & 5 & 300 & 0.63 & 0.30 & 0.07 & 8.88 & 2.13 & 4.17 & 1.20 \\
\hline $\mathrm{MHCH} 12 \mathrm{~b}$ & $A$ & as above & Calcite Infilling & & 221 & 85 & - & $\mathrm{C}$ & 5 & 300 & 0.63 & 0.24 & 0.14 & 4.52 & 2.67 & 1.70 & 1.00 \\
\hline $\mathrm{MHCH} 12 \mathrm{~b}$ & B & as above & Calcite Infilling & & 221 & 85 & - & CG & 5 & 300 & 0.63 & 0.27 & 0.10 & 6.45 & 2.30 & 2.80 & 1.10 \\
\hline $\mathrm{MHCH} 14$ & & as above & Calcite Infilling & & 218 & 88 & - & $\mathrm{C}$ & 5 & 300 & 0.63 & 0.23 & 0.14 & 4.40 & 2.74 & 1.61 & 1.00 \\
\hline TJFA47 & & as above & Calcite Infilling & & 213 & 60 & - & C & 5 & 300 & 0.65 & 0.24 & 0.11 & 6.02 & 2.77 & 2.17 & 1.22 \\
\hline MHSP09 & & as above & Calcite Infilling & & 216 & 46 & - & $\mathrm{C}$ & 5 & 300 & 0.77 & 0.16 & 0.07 & 11.25 & 4.87 & 2.31 & 2.20 \\
\hline MHBM03 & B & as above & Calcite Infilling & & 048 & 78 & - & $\mathrm{C}$ & 5 & 300 & 0.73 & 0.15 & 0.11 & 6.62 & 4.76 & 1.39 & 1.82 \\
\hline MHBM03 & $\mathrm{A}$ & as above & Calcite Sheared & 6.3 & 048 & 78 & 89 & CG & 5 & 300 & 0.65 & 0.27 & 0.08 & 8.18 & 2.36 & 3.47 & 1.25 \\
\hline MH-EHD & & 39453 & Euhedral Qtz & - & - & - & - & $\mathrm{C}$ & 5 & 300 & 0.65 & 0.20 & 0.15 & 4.46 & 3.26 & 1.37 & 1.16 \\
\hline
\end{tabular}




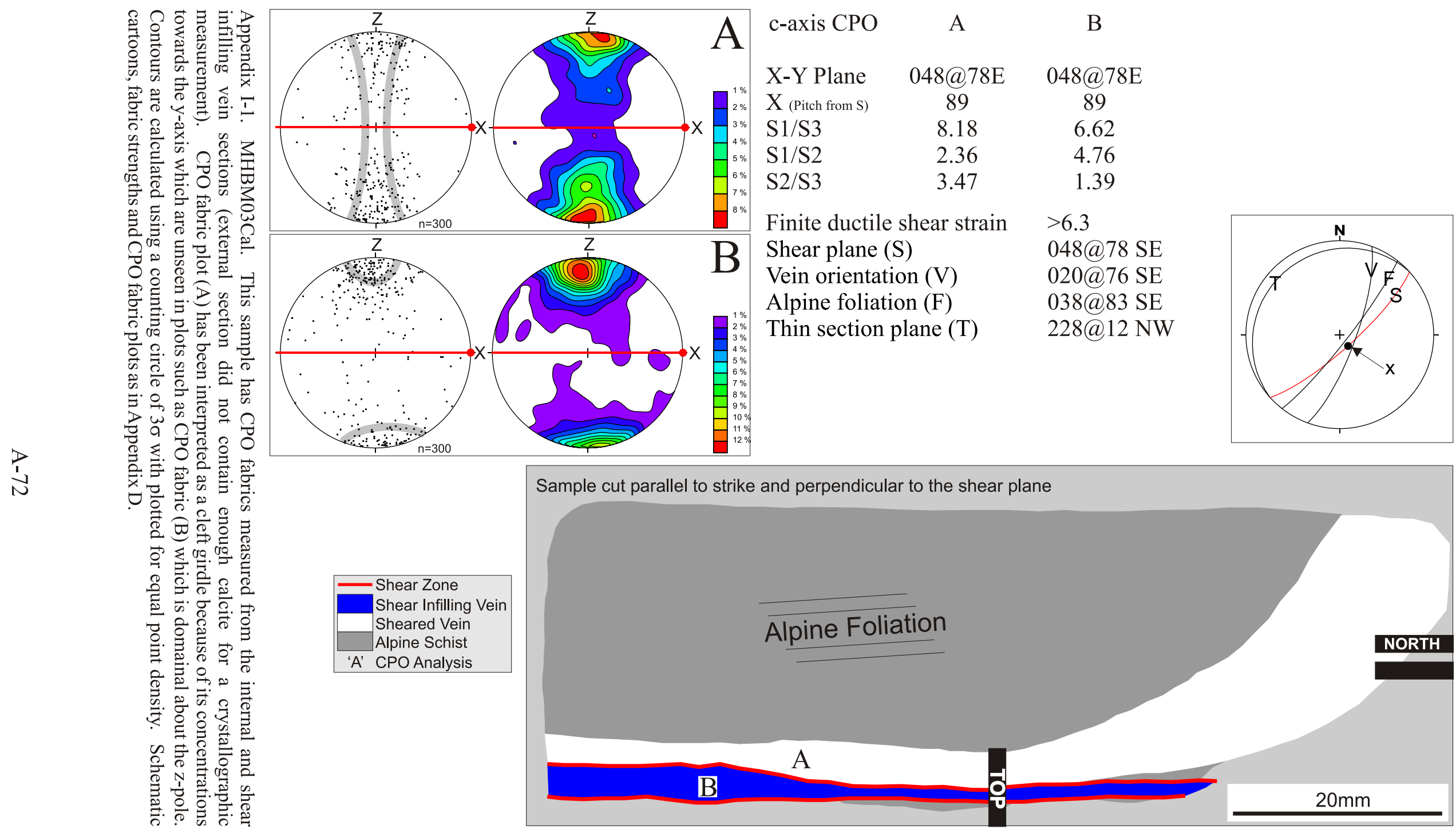



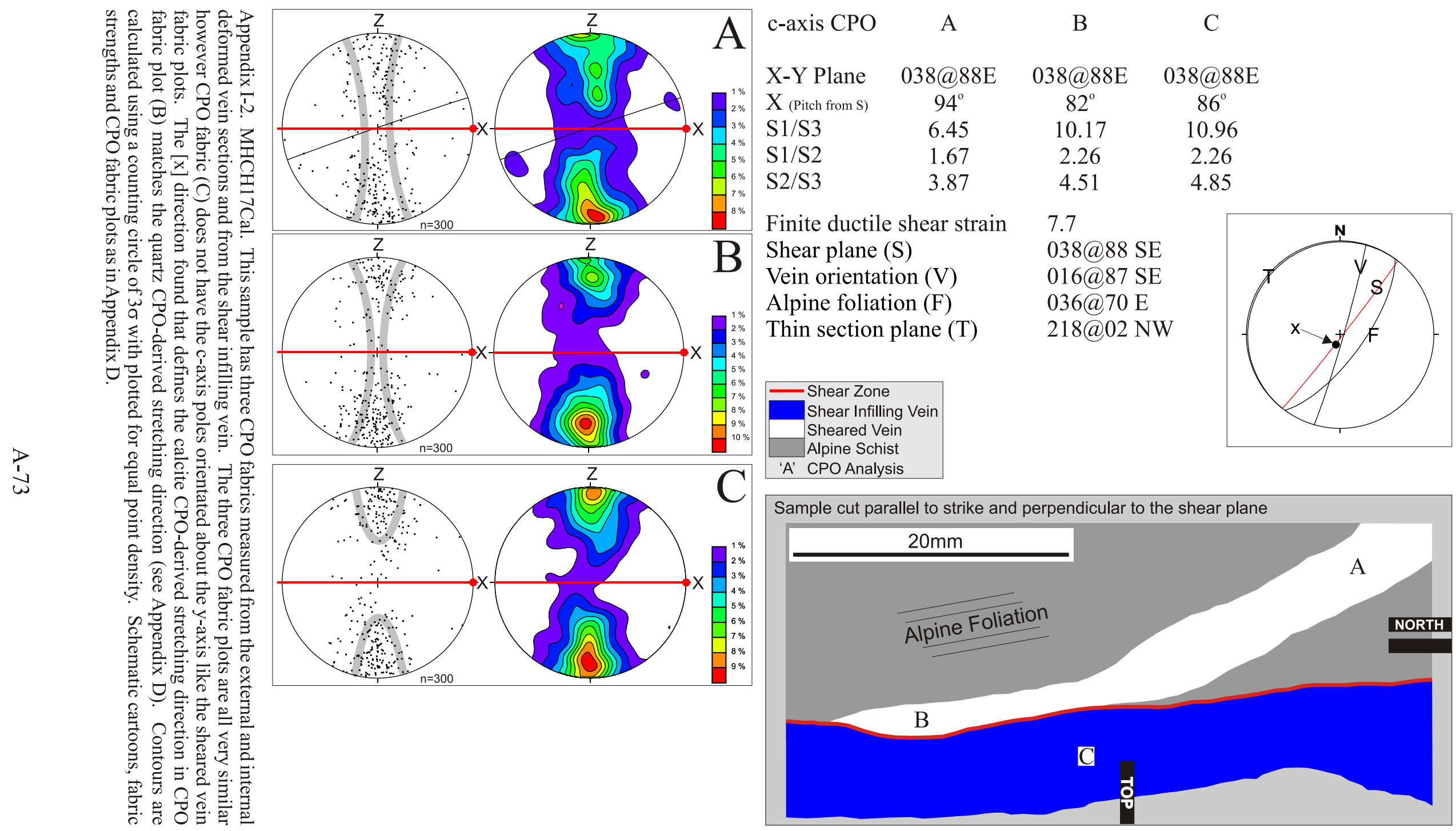


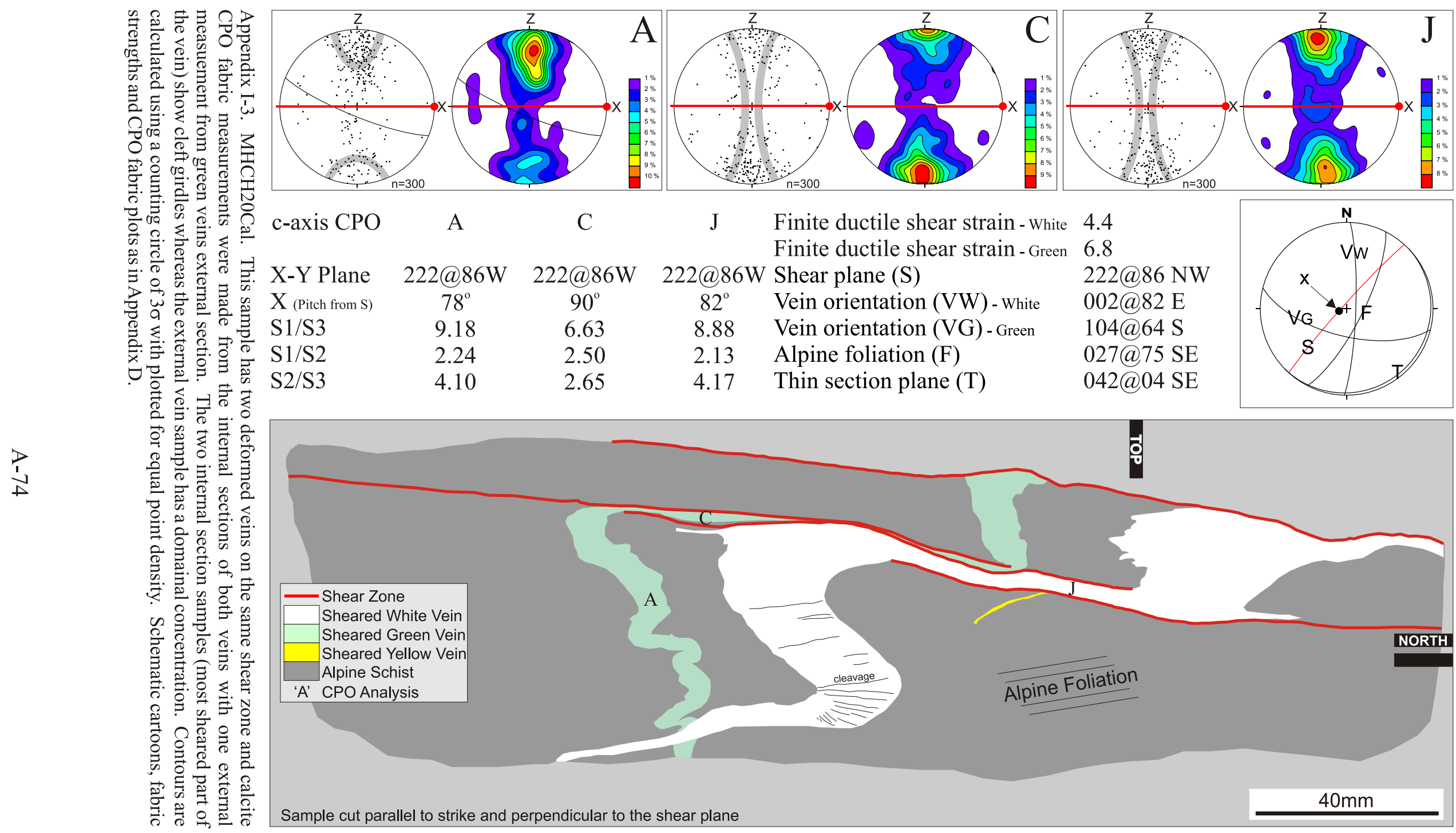




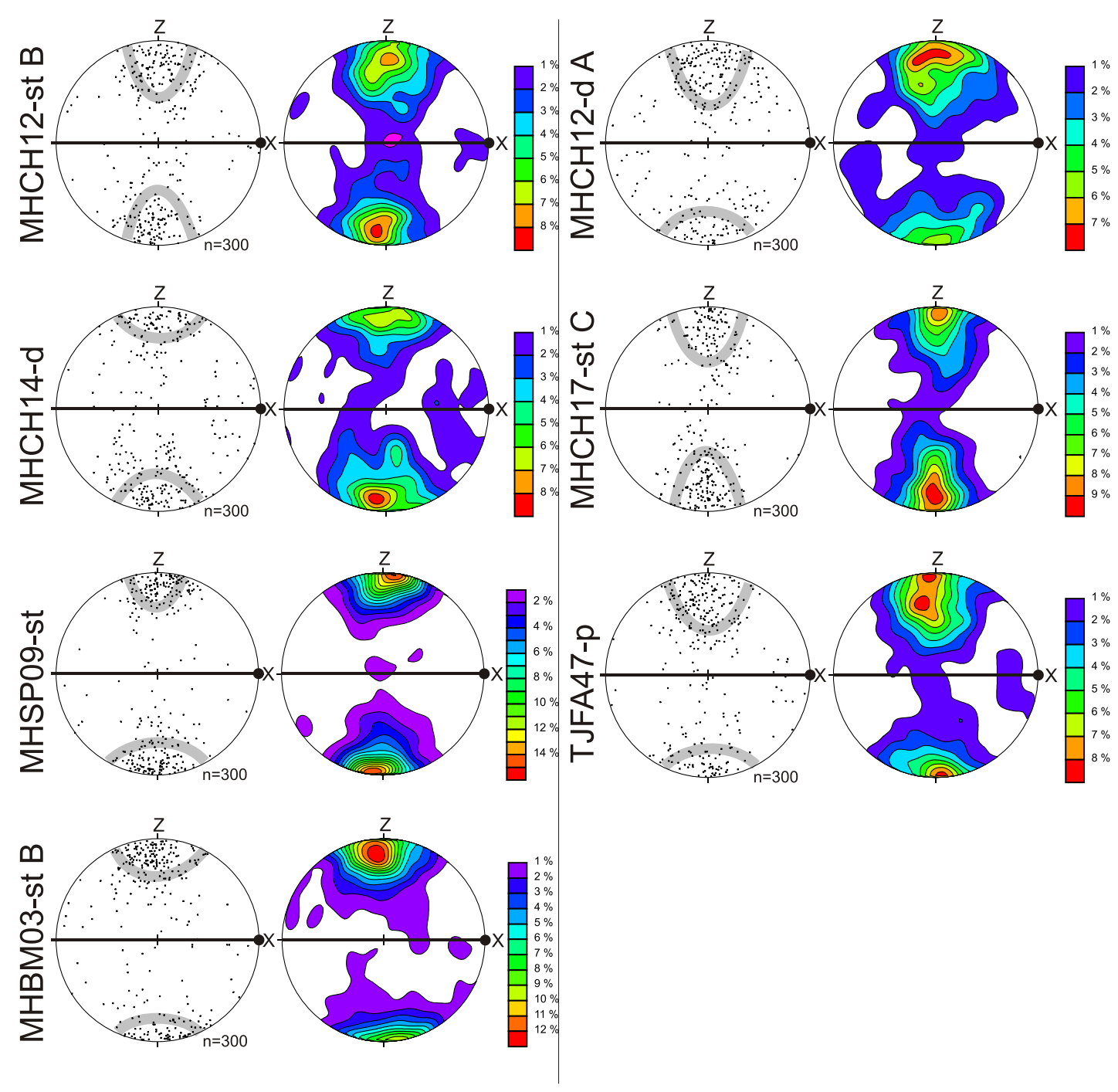

Appendix J-1. Crystallographic preferred orientations of calcite c-axes in the shear infilling vein samples on Chancellor Ridge, Sam Peak and at Baumann Glacier. Scatter and contour plots are on equal area, lower hemisphere, stereographic projections in the $\mathrm{x}-\mathrm{y}-\mathrm{z}$ reference frame (see Chapter 5). Contours were calculated using a $3 \sigma$ counting circle and are plotted as lines of equal point concentration. Eigenvector ratios and fabric plot orientations can be found in Appendix H. CPO fabric plots are labelled by their field sample numbers and annotated with the thin-section orientation they were measured from (e.g. -st or -d; see Chapter 4). A second annotation to the sample number (e.g. A, B. C etc.) is the location of the sample in the sheared vein schematic illustrations in Appendix I. Where identified, internal asymmetries are illustrated on fabrics and the Alpine Schist folitation plane is plotted on fabrics external to the most 

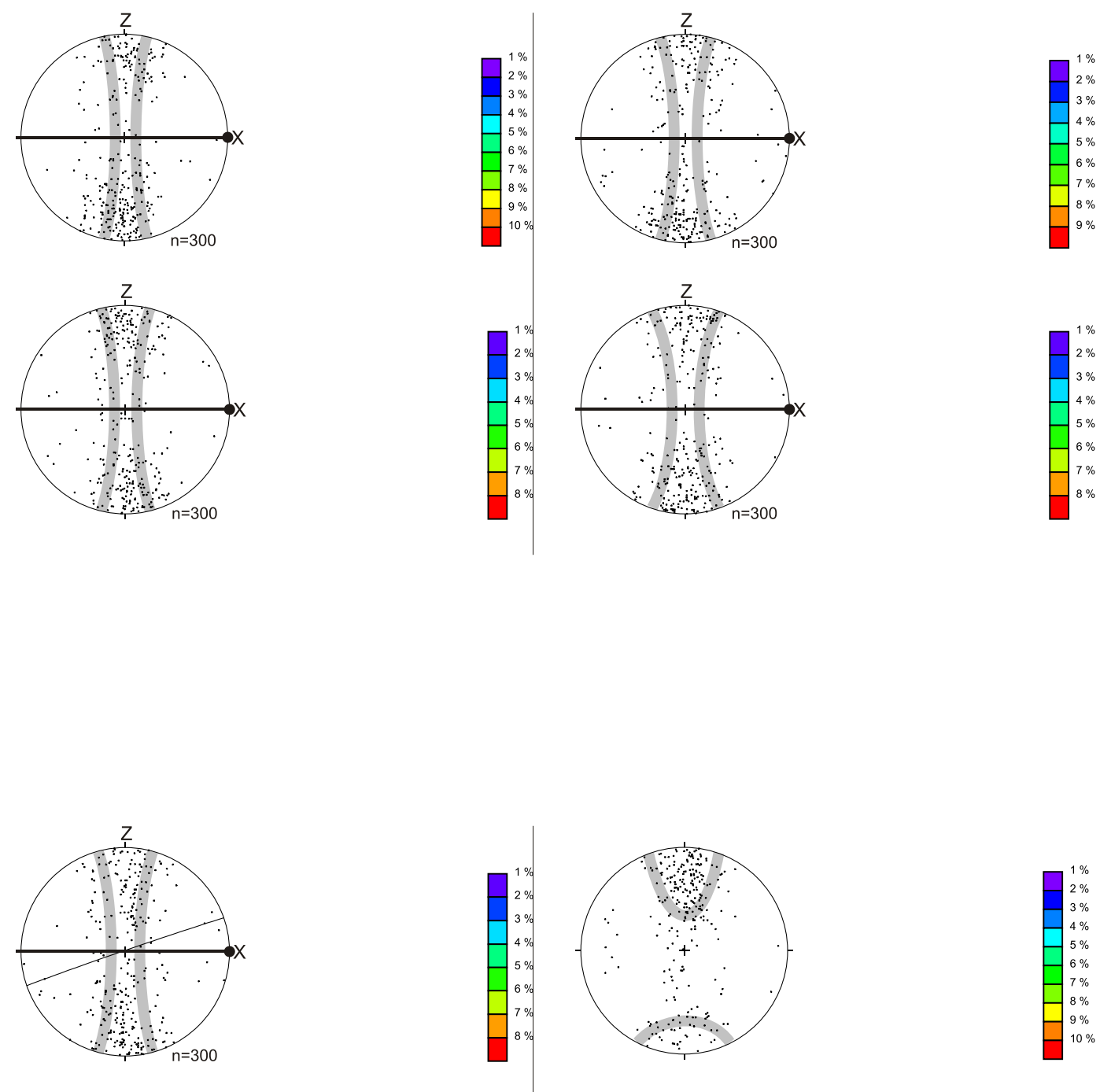


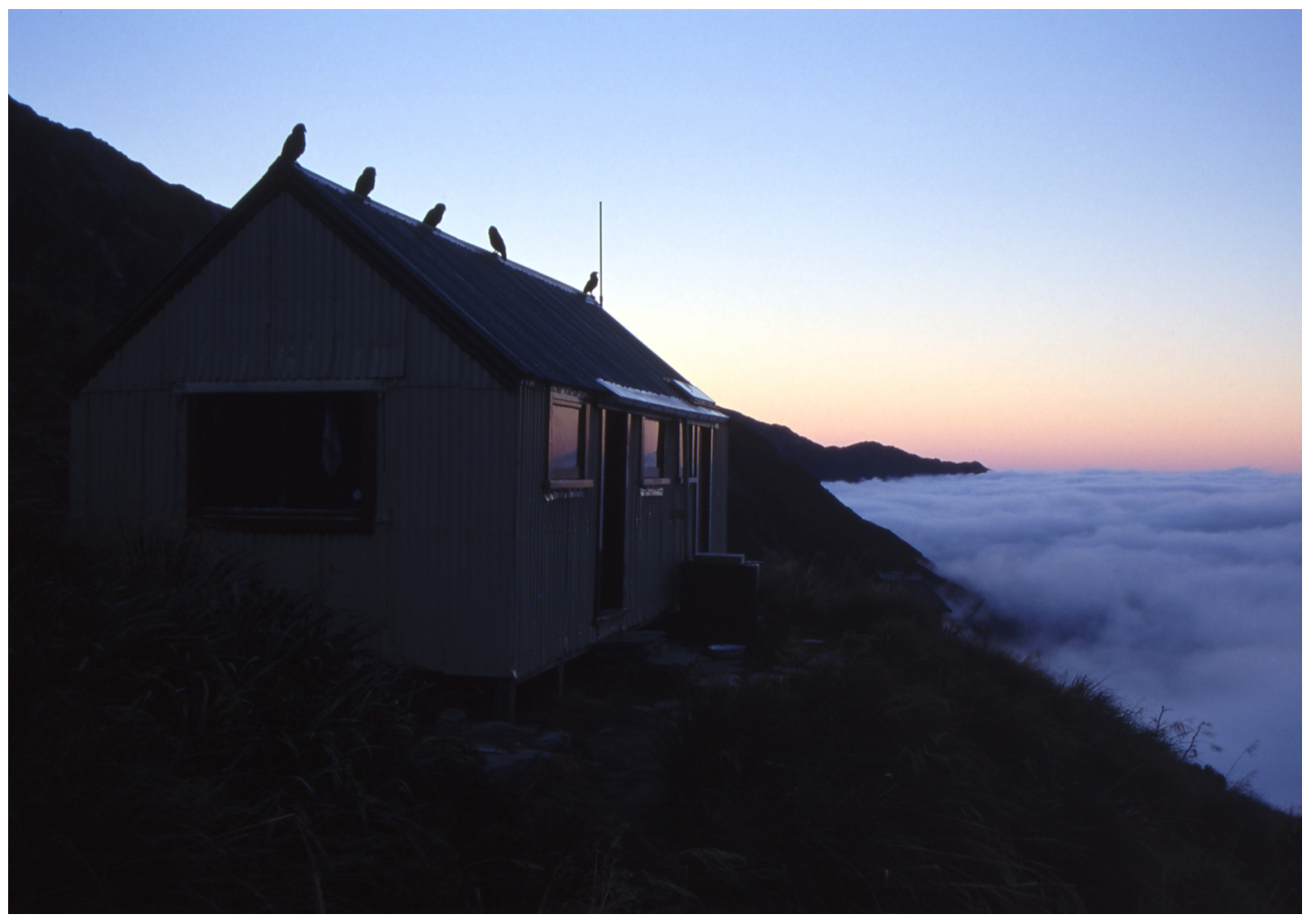

Cloud at sunset infilling the Fox Glacier valley behind the historic Chancellor Hut - an evening roost for the local Kea (New Zealand Mountain Parrot). 